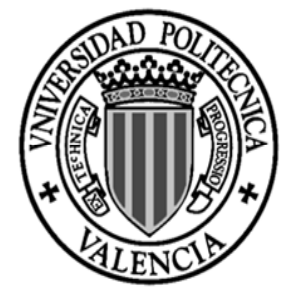

UNIVERSIDAD POLITÉCNICA DE VALENCIA

DEPARTAMENTO DE INGENIERÍA HIDRÁULICA Y MEDIO AMBIENTE

\title{
ESTUDIO DE LA INFLUENCIA DE LAS VENTOSAS EN TRANSITORIOS HIDRÁULICOS CON AIRE ATRAPADO
}

TESIS DOCTORAL

Presentada por:

Mar Carlos Alberola

Dirigida por:

Dr. Francisco Arregui de la Cruz

Dr. Enrique Cabrera Marcet

Valencia, Noviembre de 2007 



Aprendre

que res no acaba si dintre meu abans no acaba, que el sol no es pon sense tornada si en el teu cor esclata l'alba. Aprendre que l'esperança és mentida si no hi ha cada dia un esforç pel nou demà. Aprendre a estimar-se la vida quan la vida fa mal.

(Aprendre, Lluís Llach) 



\section{AGRAÏMENTS}

La realització d'aquesta tesi doctoral ha segut un camí llarg i de vegades dificultós. Aquest procés no hauria estat possible sense l'ajuda i consells dels meus directors de tesi, Francisco Arregui de la Cruz i Enrique Cabrera Marcet. A Francisco li vull agrair la seua plena dedicació i el temps compartit en discussions i intercanvi d'opinions. Enrique per la seua banda, m'ha aportat consells de la seua dilatada experiència.

En aquest camí, com en totes les situacions importants de la meua vida, sempre han estat al meu costat els meus pares, Sofia i Octavio. Ells, més que ningú, tenien ganes de veure fet realitat aquest projecte, m'han animat dia a dia, han confiat en mi i m'han recolzat en els moments de grans dubtes. Ells m'han ensenyat a ser constant en el treball $\mathrm{i}$ en la vida. També han esta al meu costat la resta de la família, les meues germanes, Auxi i Sofi, i tímidament Damian, sense oblidar a Carleta i a Eugeni per la seua alegria setmanal.

Gràcies, a les meus amigues i amics incondicionals, Núria, Isabel, Pau, Juanvi, i Juanfra que des de lluny però sempre ben a prop, m'han fet arribar la seua estima i m'han animat.

Un record des d'aquestes línies als meus companys de treballs diversos, Laura, $M^{a}$ Jesús, Mario, Paco Valero, José Vicente, Virginia, Meléndez, Enrique i Amparo. I un altre per a les famílies Peris-Mendoza i Muñoz-Mendoza pel seu interès constant.

Una abraçada ben especial a Miguel Muñoz Veiga, gran professional de l'enginyeria industrial i millor persona, per haver-me sabut escoltar i aconsellar i per dipositar confiança cega en mi en moments de dubtes i de canvis personals.

Finalment, però no per això menys important gràcies en majúscules a Manolet Peris, per la seua estima, optimisme $\mathrm{i}$ alegria. Ell ha segut una persona clau en aquest procés i espere que tots dos junts continuem compartint complicitats i portem endavant molts nous projectes. Per aquests i altres motius: 



\section{RESUM}

Les operacions que consisteixen a omplir i buidar d'aigua una instal·lació comporten el desplaçament de grans quantitats d'aigua i d'aire. Aquest tipus d'operacions, així com les possibles alteracions de la pressió del fluid durant el funcionament normal de la instal·lació, són algunes de les possibles causes que poden fer que apareguen bosses d'aire atrapat.

L'aire atrapat en un sistema de distribució d'aigua redueix la capacitat de transport, al mateix temps que pot produir desperfectes en la instal·lació i en els diferents elements i accessoris, com poden ser, comptadors d'aigua, vàlvules etc. A més a més, en els transitoris hidraùlics amb aire atrapat es poden arribar a generar sobrepressions superiors a la sobrepressió d'Allievi. També és ben cert que, en ocasions i sota determinades circumstàncies, les bosses d'aire atrapat poden actuar com un matalàs i atenuar la sobrepressió que s'assoleix en un transitori hidràulic.

Els dispositius que s'utilitzen generalment en les instal·lacions de distribució d'aigua per a eliminar o admetre aire en les conduccions són les ventoses. Les ventoses convencionals obren i tanquen automàticament de manera que no es pot actuar externament per a modificar el seu funcionament.

Actualment existeixen manuals com el que proposa I'American Water Works Association (AWWA) o els catàlegs d'alguns fabricants, basats en I'experiència acumulada al Ilarg del temps, que serveixen a mode de guia sobre com seleccionar el diàmetre adequat de la ventosa i la seua ubicació òptima en la instal·lació. Tanmateix, no existeix cap normativa 
en ferm al respecte, per la qual cosa, és finalment l'usuari de la instal-lació qui ha de prendre la decisió que considere més oportuna.

D'aquesta manera, els paràmetres determinants a l'hora de seleccionar la ventosa més adient per a un ús concret en una instal-lació són el diàmetre nominal de la ventosa i el seu coeficient de descàrrega i admissió d'aire. Sovint els fabricants proporcionen valors del coeficient de descàrrega que no es corresponen amb el coeficient de descàrrega real de la ventosa. A més, existeix poca informació relativa al comportament de les ventoses en condicions de flux no permanent i encara menys dels efectes que la instal·lació pot tindre durant un transitori hidràulic. Precisament, el treball portat a terme tracta de pal-liar les Ilacunes existents en aquest àmbit mitjançant la realització d'assajos, en una instal·lació de grans dimensions, en els quals es va analitzar la influència de les ventoses sobre les pressions enregistrades durant els transitoris que es generaven de manera controlada.

En concret, es van portar a terme assajos dinàmics d'expulsió i admissió d'aire de ventoses de diàmetre nominal $50 \mathrm{~mm}$ i $100 \mathrm{~mm}$ situades sobre unes conduccions de $200 \mathrm{~mm}$ i $500 \mathrm{~mm}$ de diàmetre respectivament. Complementàriament s'han realitzat assajos per a determinar la capacitat de descàrrega i admissió d'aire d'aquestes ventoses. Amb els resultats de les mesures obtingudes als assajos de laboratori es poden establir comparacions, en quant a l'impacte que introdueixen en el transitori, entre dues ventoses del mateix diàmetre nominal assajades en condicions semblants.

Amb l'objectiu d'afinar en el estudi del comportament dinàmic de les ventoses i de la seua influència en els resultats finals de pressió i cabdal, s'ha desenvolupat un model teòric. Mitjançant aquest model teòric, s'estudia el transitori hidràulic que es produeix quan es procedeix a l'expulsió d'aire mentre s'omple d'aigua una instal·lació, a través d'una ventosa situada a l'extrem final de la instal-lació. El model permet, a més a més, realitzar una anàlisi se sensibilitat amb tots els paràmetres que intervenen en el procés amb la finalitat de determinar el grau d'influència de cadascun d'ells sobre el resultat final del transitori.

Finalment, el treball es completa amb una recopilació dels programes informàtics que ofereixen alguns fabricants de ventoses i que serveixen d'ajuda bé per a determinar la selecció i ubicació de les ventoses en la instal·lació o bé per a analitzar el transitori hidràulic que hi té lloc. 


\section{RESUMEN}

Las operaciones de llenado y vaciado de agua de una instalación conllevan el desplazamiento de grandes cantidades tanto de agua como de aire. Este tipo de operaciones, así como las posibles alteraciones de la presión del fluido durante el funcionamiento normal de la instalación, son algunas de las posibles causas por las cuales pueden aparecer bolsas de aire atrapado en la misma.

El aire atrapado en un sistema de distribución de agua reduce la capacidad de trasporte de la misma al tiempo que puede ocasionar desperfectos en la instalación y en los diferentes elementos y accesorios, tales como, contadores de agua, válvulas, etc. Además, en los transitorios hidráulicos con aire atrapado se pueden llegar a generar sobrepresiones superiores a la sobrepresión de Allievi. También es cierto que, en ocasiones y bajo determinadas circunstancias, las bolsas de aire atrapado pueden actuar como colchón y atenuar la sobrepresión que se alcanza en un transitorio hidráulico.

Los dispositivos que se utiliza generalmente en las instalaciones de distribución de agua para eliminar o admitir aire en las conducciones son las ventosas. Las ventosas convencionales abren y cierran automáticamente, de modo que no se puede actuar externamente para modificar su funcionamiento.

Actualmente existen manuales como el de la American Water Works Association (AWWA) o los catálogos de algunos fabricantes basados en la experiencia acumulada a lo largo del tiempo que son una especie de guía sobre como seleccionar el diámetro adecuado de la ventosa y su ubicación óptima en la instalación. Sin embargo, no existe 
ninguna normativa firme al respecto, por lo que el finalmente el usuario es la persona que debe tomar la decisión que considere más oportuna.

De este modo, los parámetros determinantes a la hora de seleccionar la ventosa más adecuada para un uso concreto en una instalación son el diámetro nominal de la ventosa y su coeficiente de descarga y admisión. A menudo, los fabricantes proporcionan valores del coeficiente de descarga que no se corresponde con el real de la ventosa tal y como ha sido comprobado en algunos estudios científicos. Además, existe escasa información relativa al comportamiento de las ventosas en condiciones de flujo no permanente y menos aún de los efectos que la instalación puede llegar a tener durante un transitorio hidráulico. Precisamente el trabajo desarrollado trata de paliar las lagunas existentes en este ámbito mediante la realización, en una instalación de gran tamaño, de ensayos en los que se analizó la influencia de las ventosas en las presiones registradas durante transitorios generados de manera controlada.

En concreto se llevaron a cabo ensayos dinámicos de expulsión y admisión de aire de ventosas de diámetro nominal $50 \mathrm{~mm}$ y $100 \mathrm{~mm}$ situadas sobre unas conducciones de $200 \mathrm{~mm}$ y $500 \mathrm{~mm}$ de diámetro respectivamente. Complementariamente se han realizado ensayos en régimen permanente para determinar la capacidad de descarga y admisión de aire de estas ventosas. Con los resultados de las mediciones de los ensayos de laboratorio se pueden establecer comparaciones entre dos ventosas del mismo diámetro nominal ensayadas en condiciones semejantes, en cuanto al impacto que introducen en el transitorio,.

Con el objetivo de afinar en el estudio del comportamiento dinámico de las ventosas y de su influencia en los resultados finales de presión y caudal, se ha desarrollado un modelo teórico. Mediante dicho modelo teórico, se estudia el transitorio hidráulico que se produce cuando se procede a la expulsión de aire durante el llenado de una instalación, a través de una ventosa situada en el extremo final de una conducción. El modelo permite además realizar un análisis de sensibilidad con todos los parámetros que intervienen en el proceso con el fin de determinar el grado de influencia de cada uno de ellos sobre el resultado final del transitorio.

Finalmente, el trabajo se completa con una recopilación de los programas informáticos que ofrecen los fabricantes de ventosas y que sirven de ayuda bien para determinar la selección y ubicación de las ventosas en la instalación o bien para analizar el transitorio hidráulico que tiene lugar en la misma. 


\section{SUMMARY}

The operations consisting of filling and emptying pipe systems involve the movement of big quantities of water and air. This kind of operations, together with the possible fluid pressure alterations during the normal operation of the installation are some of the possible causes that may provoke the presence of trapped air.

The trapped air pockets in a pipes system reduce the transport capacity of the pipes, at the same time they can produce damage in the pipe and in the different elements and accessories of the pipes system, like water-metres, valves etc. Moreover, in the hydraulic transients with trapped air pressures bigger than the Allievi pressure can be generated. It is also true that in some occasions and in certain circumstances, the air pockets may mitigate the waterhammer produced in a hydraulic transient acting as a cushion.

The elements used usually in the pipe systems to eliminate or to admit air in the pipes are the air valves. The conventional air valves open and close automatically, so its behaviour can't be modified externally.

Actually, there are user's manuals like the one proposed by the American Water Works Association (AWWA) or manufacturers catalogues, based in the experience obtained through the years, that serve like a guide for selecting the adequate air valve diameter and the its optimum place in the pipe system. On the other hand, there is no a norm or an accepted standard related to this question, so, the pipe system user is the person who must take the final decision. 
In this way, the nominal air valve diameter and the discharge or admission coefficient are the determinants parameters to select the adequate air valve for a specific use in a pipe system. Quite often, the manufacturers offer discharge coefficient numbers that are not correct. Moreover, there is little information about the air valves behaviour in no steady flow conditions, and even less information about the effects and damage on the system during a hydraulic transient. In fact, this work tries to provide more information about this item by carrying out laboratory tests, in a large installation. In these tests, the influence of the air valves on the registered pressures during the transient generated under controlled conditions has been analysed.

Dynamic discharge and admission tests of air valves were realized. The air valves diameter were $50 \mathrm{~mm}$ and $100 \mathrm{~mm}$, and the pipe diameters were $200 \mathrm{~mm}$ and $500 \mathrm{~mm}$ respectively. Complementarily, tests for determining the air valves discharge or admission capacity have been done. With the results obtained in the laboratory tests comparisons, related to the impact introduced in the transient, between a pair of air valves that have the same nominal diameter and that have been tested under similar conditions can be established.

With the aim of performing a deeper study of the dynamic behaviour of the air valves and its influence in the pressure and velocity final results a mathematical model has been developed. With the aid of this mathematical model, the hydraulic transient produced during the discharge of air through an air valve situated at the extreme of a pipe while this pipe is being filled of water, is studied. Moreover, the model allows performing a sensitivity analysis of all the parameters taking part in the process with the objective of determining the degree of influence of every one of them on the transient final result.

Finally, this work is completed with a software compilation that some air valves manufacturers offer and that aid in the determination, selection and positioning of the air valves into the pipe system or a hydraulic transient analysis. 




\section{ÍNDICE}

CAPÍTULO 1. PROBLEMÁtiCA DEL AIRE ATRAPADO EN TUBERÍAS

PAGINA

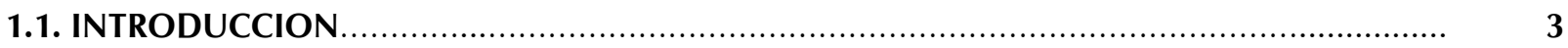

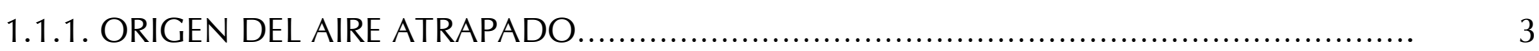

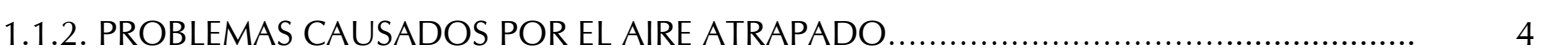

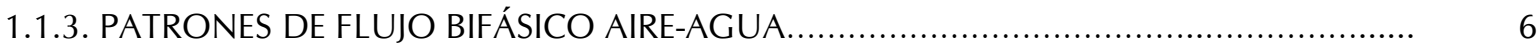

1.1.4. SOLUCIONES ACTUALES FRENTE A LA PROBLEMÀTICA DEL AIRE

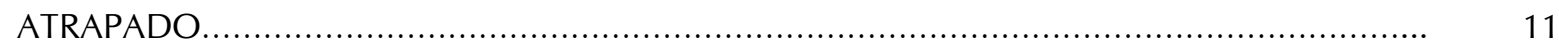

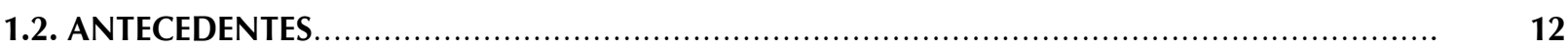

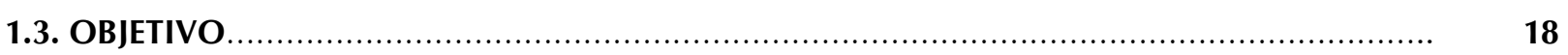

CAPÍTULO 2. TIPOLOGÍA DE VENTOSAS Y SUS FUNCIONES

PAGINA

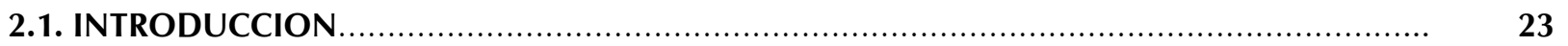

2.2. TIPOS DE VENTOSAS SEGÚN LA FUNCIÓN QUE DESEMPEÑEN ................................. 25

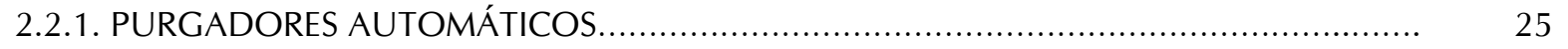

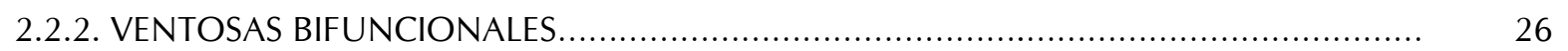

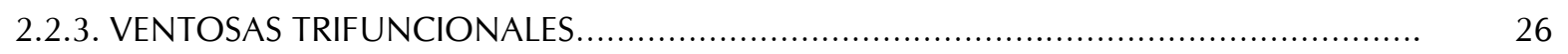

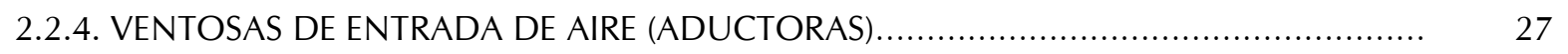

2.3. VENTOSAS DE GRAN ORIFICIO: VENTOSAS NO CINÉTICAS Y VENTOSAS 28 CINÉTICAS.

2.3.1. BALANCE DE FUERZAS EN EL FLOTADOR DE UNA VENOSA DE GRAN 28

ORIFICIO

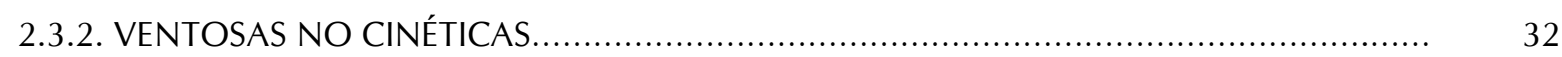

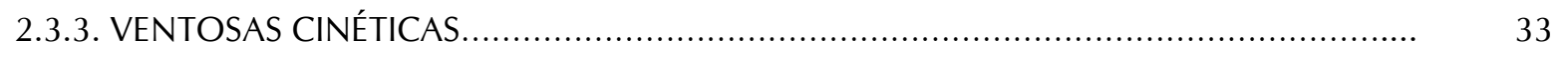

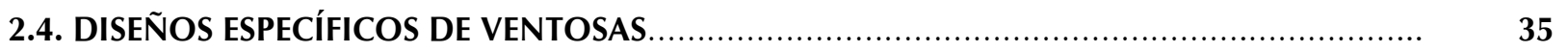

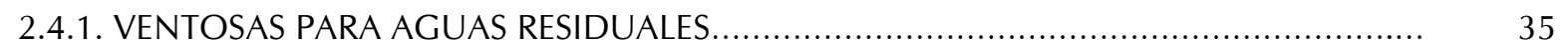

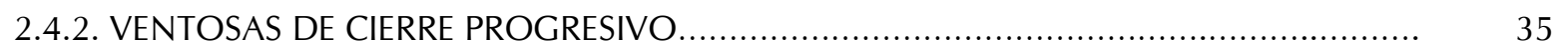

2.4.3. VENTOSA COMBINADA PARA CONTADORES DE AGUA.......................................... 39

2.4.4. MECANISMOS ADICIONALES PARA DE PROTECCIÓN PARA EVITAR

2.5. SELECCIÓN Y DIMENSIONAMIENTO DE VENTOSAS ................................................. 48

2.6. UBICACIÓN DE LAS VENTOSAS EN UNA INSTALACIÓN ................................................ 49

2.7. RECOMENDACIONES GENERALES SOBRE LA UBICACIÓN DE VENTOSAS DE LA

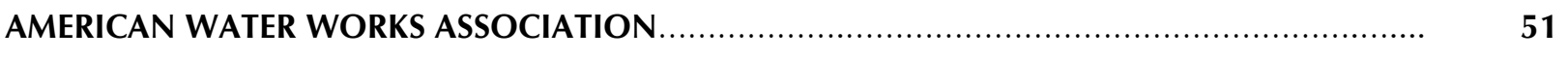

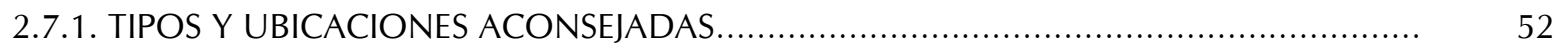


2.7.2. DISEÑO DE LA CAPACIDAD DE DESCARGA DE LAS VENTOSAS

55

2.7.2.1. DIMENSIONADO DE UNA VENTOSA EN CASO DE EXPULSIÓN DE AIRE EN UN SISTEMA A PRESIÓN. PURGADOR.

2.7.2.2. DIMENSIONADO DEL DIÁMETRO DEL ORIFICO DE LA VENTOSA EN CASO DE LLENADO DE UNA TUBERÍA.

2.7.2.3. DIMENSIONADO DEL DIÁMETRO DEL ORIFICO DE LA VENTOSA EN CASO DE DRENAJE DE UNA TUBERÍA.

2.7.2.4. DIMENSIONADO DEL DIÁMETRO DEL ORIFICO DE LA VENTOSA EN CASO DE

FLUJO POR GRAVEDAD.

2.7.2.5. DIMENSIONADO DEL DIÁMETRO DEL ORIFICO DE LA VENTOSA EN CASOS ESPECIALES

CAPÍTULO 3. PROGRAMA DE ENSAYOS PARA LA CARACTERIZACIÓN ESTÁTICA Y DINÁMICA DE VENTOSAS

\subsection{INTRODUCCIÓN}

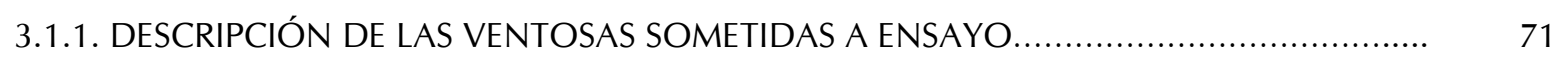

3.2. INSTRUMENTACIÓN.

3.3. DESCRIPCIÓN DE LA INSTALACIÓN

3.3.1. INSTALACIÓN PARA LA DETERMINACIÓN DE LA CAPACIDAD DE DESCARGA Y

ADMISIÓN DE LAS VENTOSAS.

3.3.2. INSTALACIÓN PARA LA DETERMINACIÓN DEL COMPORTAMIENTO DINÁMICO DE

LAS VENTOSAS.

3.3.3. INSTALACIÓN PARA EL ESTUDIO DE LA ADMISIÓN DE AIRE EN SITUACIONES DE

SEPARACIÓN DE LA COLUMNA DE AGUA.

3.4. DESCRIPCIÓN DEL PROCEDIMIENTO DE ENSAYO.

85

3.4.1. PROCEDIMIENTO DE LOS ENSAYOS PARA LA DETERMINACIÓN DE LA CAPACIDAD

DE DESCARGA Y ADMISIÓN DE LAS VENTOSAS.

3.4.2. PROCEDIMIENTO DE LOS ENSAYOS DINÁMICOS DE EXPULSIÓN DE AIRE.

3.4.3. PROCEDIMIENTO DE LOS ENSAYOS DINÁMICOS DE ADMISIÓN DE AIRE.

3.4.3.1. VACIADO DE UNA TUBERÍA.....

3.4.3.2. SEPARACIÓN DE LA COLUMNA DE AGUA.

\section{CAPÍTULO 4. ANÁLISIS DE LOS DATOS EXPERIMENTALES}

4.1. ENSAYOS PARA LA DETERMINACIÓN DE LA CAPACIDAD DE EXPULSIÓN Y ADMISIÓN

4.1.1. DETERMINACIÓN DEL COEFICIENTE DE EXPULSIÓN DE LAS VENTOSAS.

4.1.2.1. DETERMINACIÓN GRÁFICA DE C $V$ Y XT.....

4.1.2.2. DETERMINACIÓN DEL FLUJO MEDIANTE UNA ECUACIÓN PROPORCIONADA

POR LA NORMA ISA S75.02 
4.2. ENSAYOS DINÁMICOS DE EXPULSIÓN DE AIRE.

114

4.2.1. EXPULSION DE AIRE AL FINAL DE UNA CONDUCCIÓN. VENTOSAS DN100...

4.2.1.1 COMPARATIVA PRELIMINAR DEL COMPORTAMIENTO DE DOS VENTOSAS.

4.2.1.2. ESTUDIO DE LAS RELACIONES ENTRE LAS PRINCIPALES VARIABLES DEL

TRANSITORIO

4.2.2. EXPULSIÓN DE AIRE EN UN PUNTO INTERMEDIO DE LA CONDUCCIÓN.

VENTOSAS DN100.

4.2.2.1. VARIABLES CARACTERÍSTICAS.

4.2.2.2. CASUÍSTICAS DETECTADAS.

4.2.3. EXPULSIÓN DE AIRE AL FINAL DE UNA CONDUCCIÓN. VENTOSAS DN50.

4.2.3.1. VENTOSA SOBRE LA CONDUCCIÓN.

4.2.3.2. VENTOSA SOBRE CARRETE VERTICAL DE LONGITUD $1,185 \mathrm{~m}$.

4.2.3.3. VENTOSA SOBRE CARRETE VERTICAL DE LONGITUD 2,185 m.

4.2.4. ENSAYOS DE EXPULSIÓN DE AIRE EN UN PUNTO INTERMEDIO DE LA

CONDUCCIÓN. VENTOSAS DN50.

4.2.4.1. VENTOSA SOBRE LA CONDUCCIÓN.

4.2.4.2. VENTOSA SOBRE UN CARRETE VERTICAL DE LONGITUD 1,185 m.

4.2.5. COMPARACIÓN DEL COMPORTAMIENTO DE VENTOSAS, DN100 Y DN50, EN

ENSAYOS DE EXPULSIÓN DE AIRE AL FINAL DE LA CONDUCCIÓN.

4.3. ENSAYOS DINÁMICOS DE ADMISIÓN DE AIRE.

4.3.1. ADMISIÓN DE AIRE CON SEPARACIÓN DE LA COLUMNA DE AGUA.

4.3.1.1. SEPARACIÓN DE LA COLUMNA DE AIRE EN LA CONDUCCIÓN DE D $=500 \mathrm{~mm}$..

4.3.1.2. SEPARACIÓN DE LA COLUMNA DE AIRE EN LA CONDUCCIÓN DE D $=200 \mathrm{~mm}$..

4.3.2. ADMISIÓN DE AIRE DURANTE EL VACIADO DE UNA CONDUCCIÓN.

4.3.2.1 ANÁLISIS DE LA PRESIÓN Y EL CAUDAL EN LOS ENSAYOS DE ADMISIÓN DE AIRE.

CAPÍTULO 5. MODELACIÓN MATEMÁTICA DEL TRANSITORIO AGUA-AIRE

5.1. INTRODUCCIÓN

5.2. MODELO NUMÉRICO PARA SIMULAR LA EXPULSIÓN DE AIRE AL FINAL DE UNA TUBERÍA

5.1.1. ECUACIONES DEL MODELO.

5.1.1.1. BALANCE DIFERENCIAL DE MASA: ECUACIÓN DE CONTINUIDAD.

5.1.1.2. BALANCE DIFERENCIAL DE FUERZAS: ECUACIÓN DE LA CANTIDAD DE MOVIMIENTO.

5.1.1.3. ECUACIONES DE LA BOLSA DE AIRE.

5.1.2. RESOLUCIÓN DE LAS ECUACIONES MEDIANTE EL MÉTODO DE LAS

CARACTERÍSTICAS.

5.1.3. CONDICIONES INICIALES Y CONDICIONES DE CONTORN.....

PAGINA

195

197

198

198

201

204

206

210

216

217

227

235 
5.4. PROGRAMAS COMERCIALES DE DIMENSIONADO E INSTALACIÓN DE VENTOSAS.

5.4.1. ARI VALVES.......

5.4.2. VENT-O-MAT

5.4.3. APCO VALVES

5.4.4. HAMMER.

5.4.5. WANDA.

256

CAPÍTULO 6. CONCLUSIONES. 


\section{CAPÍTULO 1. PROBLEMÁTICA DEL AIRE ATRAPADO EN TUBERÍAS}

\section{PAGINA}

Figura 1.1. Medida de caudal en contador ultrasonidos.

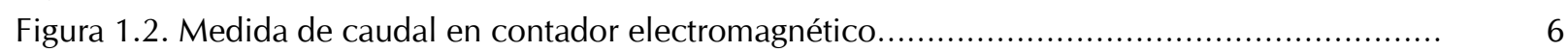

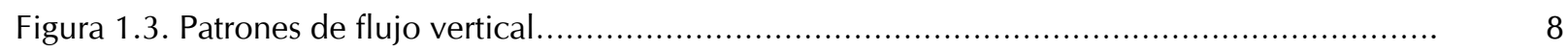

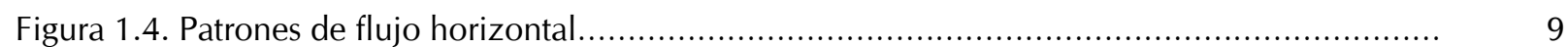

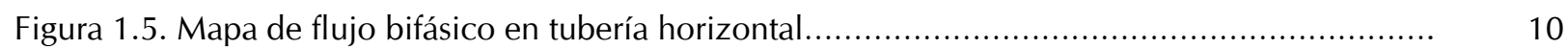

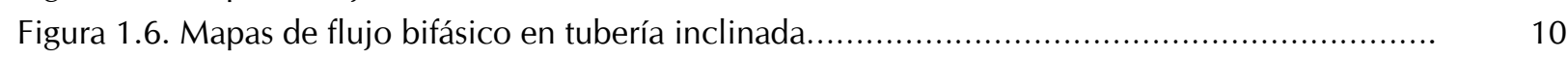

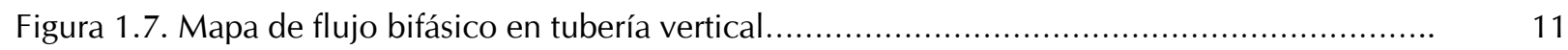

\section{CAPÍTULO 2. TIPOLOGÍA DE VENTOSAS Y SUS FUNCIONES}

\section{PAGINA}

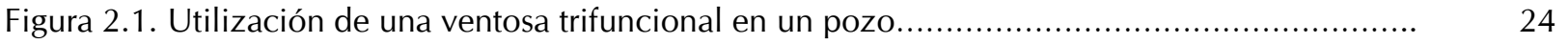

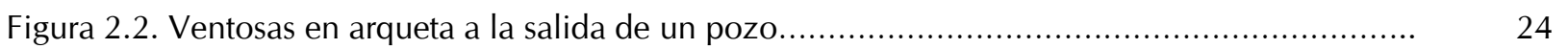

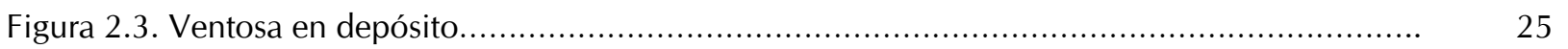

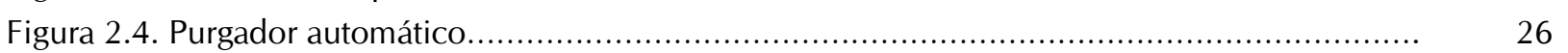

Figura 2.5. Esquema del interior de una ventosa trifuncional de doble cuerpo.............................. 27

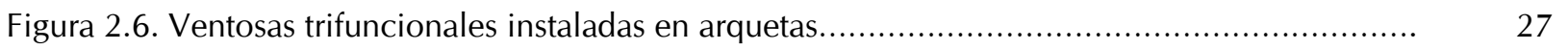

Figura 2.7. Balance de fuerzas sobre el flotador durante la admisión de aire................................

Figura 2.8. Balance de fuerzas sobre el flotador durante la expulsión de aire................................ 31

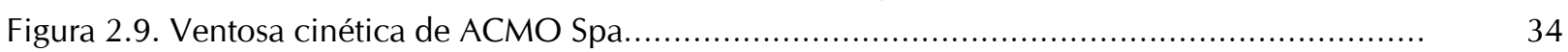

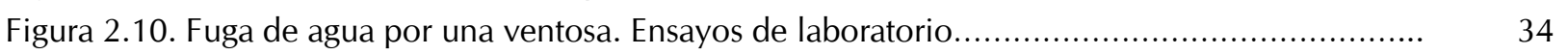

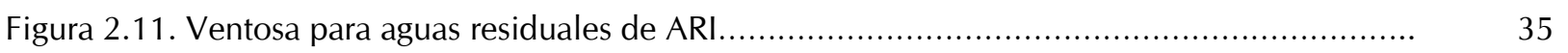

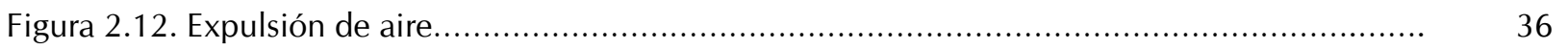

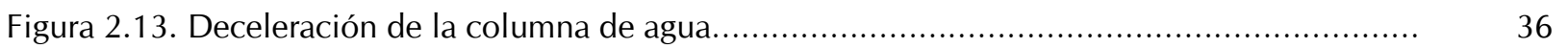

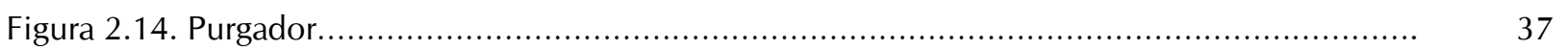

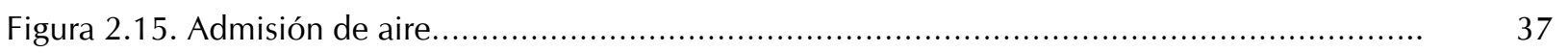

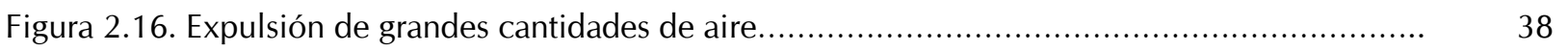

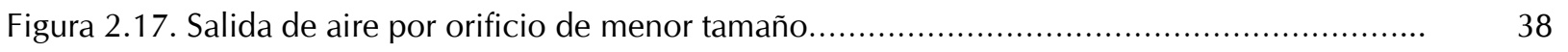

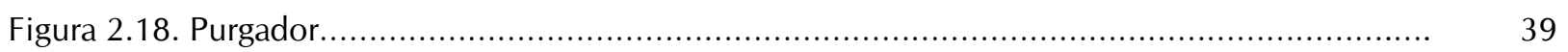

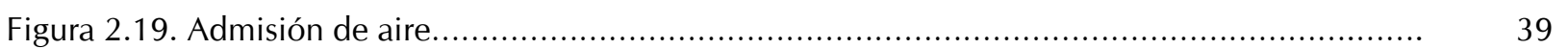

Figura 2.20. Ventosa para contador Metair modelo M-40......................................................... 40

Figura 2.21. Esquema de los componentes de la ventosa combinada....................................... 40

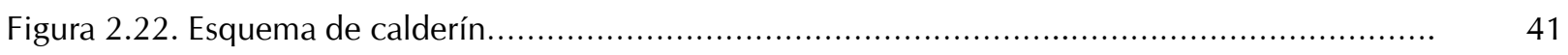

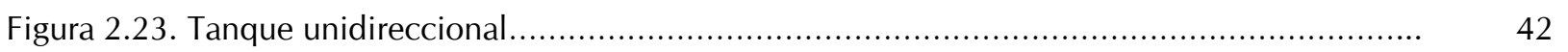

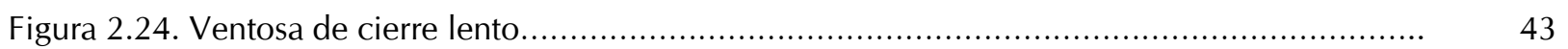

Figura 2.25. Apco Valves. Funcionamiento del cierre lento........................................................

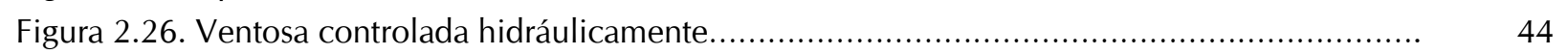

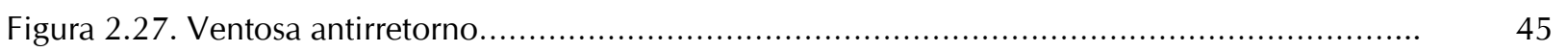

Figura 2.28. Disposición de las ventosas y otros elementos.................................................. 45 
Figura 2.29. Puesta en marcha de la bomba....

Figura 2.30. Parada de la bomba

Figura 2.31. Ventosas en puntos elevados de una instalación..........................................

Figura 2.32. Ventosas en cambio de pendiente creciente............................................. 52

Figura 2.33. Ventosa en cambio de pendiente creciente.............................................. 53

Figura 2.34. Ventosas en tramos largos de tuberías descendentes....................................... 53

Figura 2.35. Ventosas en tramos largos de tuberías ascendentes.......................................... 53

Figura 2.36. Ventosa en la tubería de impulsión de una bomba........................................... 54

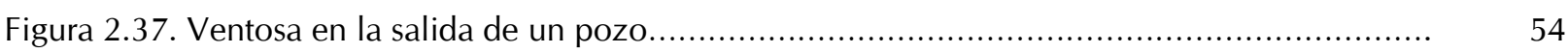

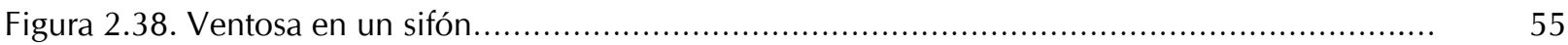

Figura 2.39. Tabla para determinar el tamaño del orificio del purgador de una ventosa.................. 57

Figura 2.40. Diagrama para determinar el tamaño del orificio del purgador.............................. 57

Figura 2.41. Tabla para determinar el diámetro de una ventosa en caso de llenado de tubería.......... 58

Figura 2.42. Gráfico para determinar el diámetro de una ventosa en caso de llenado de tubería...... 59

Figura 2.43. Tabla para determinar el diámetro de una ventosa en caso de rotura de tubería por gravedad.

Figura 2.44. Gráfico para determinar el diámetro de una ventosa en caso de rotura de tubería por gravedad.

Figura 2.45. Gráfico para determinar el diámetro del orificio de gran tamaño en entrada de aire

Figura 2.46. Arqueta para ventosa.

Figura 2.47. Ventosas en arqueta.

\section{CAPÍTULO 3. PROGRAMA DE ENSAYOS PARA LA CARACTERIZACIÓN ESTÁTICA Y DINÁMICA DE VENTOSAS}

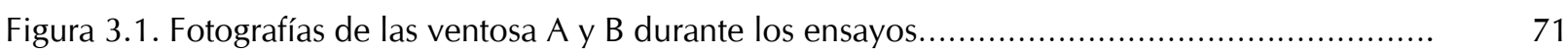

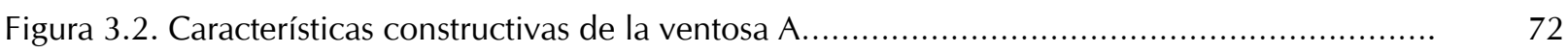

Figura 3.3. Características constructivas de la ventosa B......................................... 72

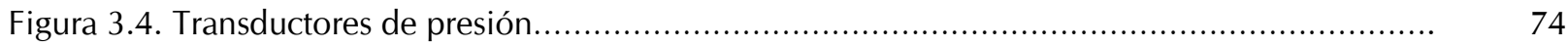

Figura 3.5. Esquema componentes transductor de presión marca Kistler................................. 74

Figura 3.6. Transductor de presión instalado sobre la tubería......................................... 75

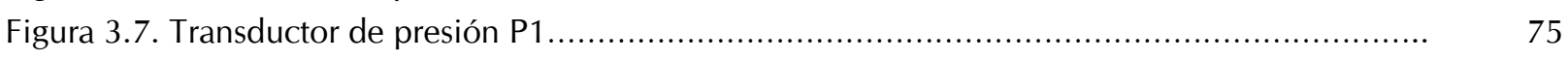

Figura 3.8. Caudalímetro electromagnético DN500 y DN200................................... 75

Figura 3.9. Caudalímetro tipo vórtex DN25 en by-pass................................................. 76

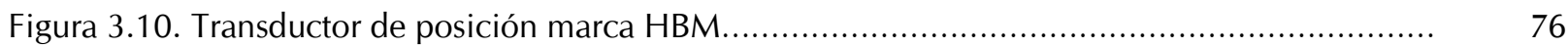

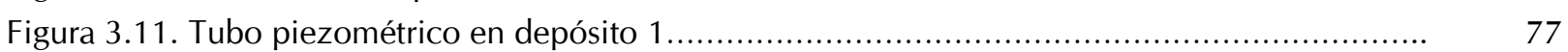

Figura 3.12. Válvula de mariposa BV1 junto a la ventosa............................................... 77

Figura 3.13. Depósito de agua con válvula de mariposa BV2 en la parte superior....................... 78

Figura 3.14. Instalación para la determinación de la capacidad de descarga/admisión de aire.......... 80

Figura 3.15. Instalación para los ensayos en flujo permanente. Detalle del By-pass....................... 80

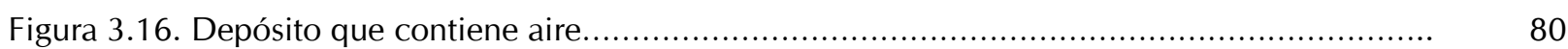

Figura 3.17. Esquema de la ubicación de la instrumentación sobre la instalación.......................... 81

Figura 3.18. Montaje de la ventosa en el punto más elevado de la conducción.......................... 81 
Figura 3.19. Dimensiones de la instalación para la determinación del comportamiento dinámico de las ventosas.

Figura 3.20. Instalación con ventosa y válvula de retención............................................ 84

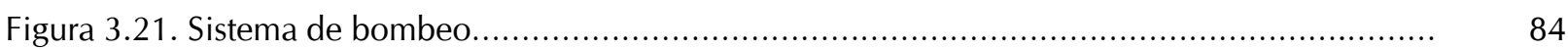

Figura 3.22. Medidas generales de la instalación para el estudio de la admisión de aire................. 85

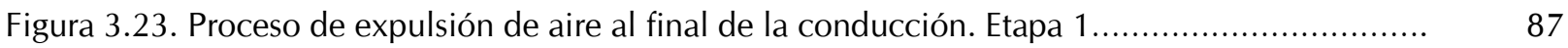

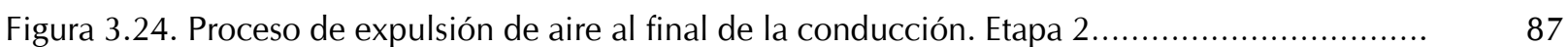

Figura 3.25. Proceso de expulsión de aire al final de la conducción. Etapa 3............................ 88

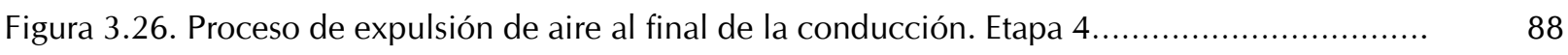

Figura 3.27. Proceso de expulsión de aire en un punto intermedio de la conducción. Etapa 1......... 89

Figura 28. Proceso de expulsión de aire en un punto intermedio de la conducción. Etapa 2............ 89

Figura 3.29. Proceso de expulsión de aire en un punto intermedio de la conducción. Etapa 3.......... 90

Figura 3.30. Proceso de expulsión de aire en un punto intermedio de la conducción. Etapa 4.......... 90

Figura 3.31. Proceso de expulsión de aire en un punto intermedio de la conducción. Etapa 5.......... 91

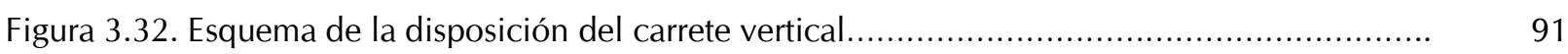

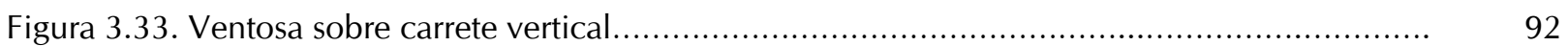

Figura 3.34. Expulsión de aire con la ventosa sobre un carrete vertical.................................. 92

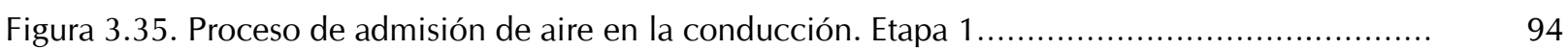

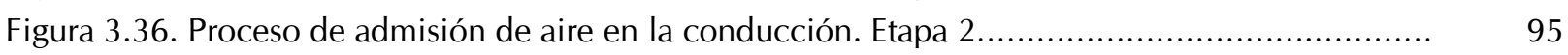

Figura 3.37. Proceso de admisión de aire en la conducción. Etapa 3..................................... 95

Figura 3.38. Esquema instalación para el estudio de la separación de la columna de agua.............. 96

Figura 3.39. Depósito de agua..................................................................... 96

Figura 3.40. Proceso para el estudio de la separación de la columna de agua. Etapa 1...................... 97

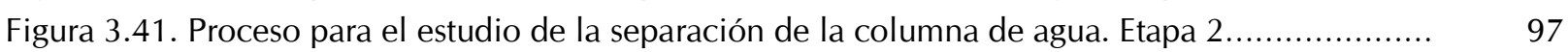

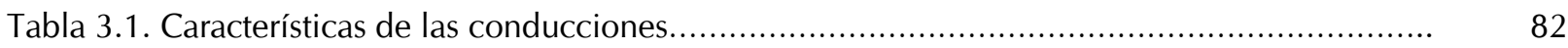

Tabla 3.2. Características metrológicas de la instalación............................................... 82

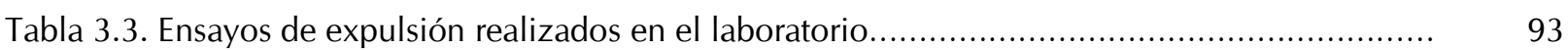

\section{CAPÍTULO 4. ANÁLISIS DE LOS DATOS EXPERIMENTALES}

Figura 4.1. Factor de calibración del caudalímetro vórtex de 200 mm de diámetro.

Figura 4.2. Caudal nominal en ensayos para la determinación de la capacidad de expulsión de aire de las ventosas.

Figura 4.3. Caudal nominal en ensayos para la determinación de la capacidad de admisión de aire de las ventosas.

Figura 4.4. Caudal nominal en ensayos para la determinación del coeficiente de expulsión de aire de las ventosas.

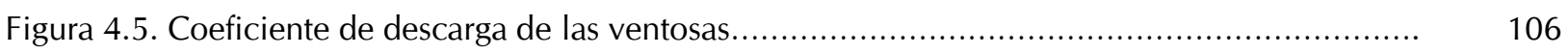

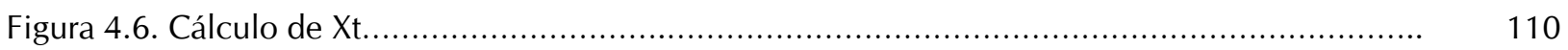

Figura 4.7. Cálculo de Xt para diferentes aperturas de la ventosa........................................ 111

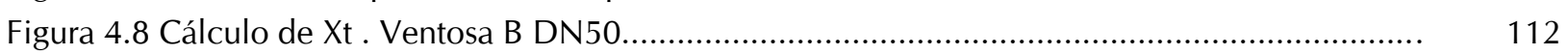

Figura 4.9. Comparación entre caudales calculados y caudales medidos................................... 113

Figura 4.10. Comparación gráfica de dos ensayos de expulsión de aire similares con ventosas DN100. Ensayos A17 y B28. 
Figura 4.11. Comparación gráfica de dos ensayos de expulsión de aire similares con ventosas DN100. Ensayos A18 y B30.

Figura 4.12. Comparación gráfica de dos ensayos de expulsión de aire similares con ventosas DN100. Ensayos A19 y B33.

Figura 4.13. Comparación gráfica de dos ensayos de expulsión de aire similares con ventosas DN100. Ensayos A20 y B31....

Figura 4.14. Comparación gráfica de dos ensayos de expulsión de aire similares con ventosas DN100. Ensayos A21 y B32......

Figura 4.15. Comparación gráfica del cierre del flotador en dos ensayos similares de ventosas DN10

Figura 4.16. Variables principales en un ensayo de expulsión de aire.....

Figura 4.17. Definición de la velocidad del flujo en cada instante de tiempo

Figura 4.18. Medida de las alturas iniciales de la columna de agua: L1, L2.

Figura 4.19. Presión máxima en ensayos similares de dos ventosas diferentes.

Figura 4.20. Variación de la velocidad del flujo en ensayos similares de dos ventosas diferentes......

Figura 4.21. Variación de la velocidad del flujo en ensayos similares de dos ventosas diferentes......

Figura 4.22. Volumen de agua circulado en ensayos similares de ventosas diferentes.

Figura 4.23. Relaciones de velocidades

Figura 4.24. Duración del cierre.

Figura 4.25. Relaciones entre dos instantes de tiempo.

Figura 4.26. Evolución dv/dt cz con la presión máxima.....

Figura 4.27. Evolución dv/dt_cz con $\Delta p$.....

Figura 4.28. Velocidad de llegada de la columna de agua frente a $\Delta \mathrm{p}$.

Figura 4.29. Evolución de la deceleración dv/dt_cz con la anchura del pico.

Figura 4.30. Evolución dv/dt_cz con la duración del cierre de la ventosa.....

Figura 4.31. Evolución de la anchura del pico de presión con la sobrepresión aplicada.

Figura 4.32. Evolución de la anchura del pico de presión con la duración del cierre de la ventosa.

Figura 4.33. Evolución de la presión máxima con la anchura del pico de presión.......

Figura 4.34. Evolución de la anchura del pico de presión con la suma de caudales.

Figura 4.35. Evolución de la presión máxima con la sobrepresión aplicada....

Figura 4.36. Evolución de la suma de caudales con la sobrepresión aplicada.....

Figura 4.37. Evolución de la suma de caudales con Vmin/Vo.....

Figura 4.38. Evolución de la presión máxima con la suma de caudales.

Figura 4.39. Presión máxima según velocidad de llegada a la ventosa.....

Figura 4.40. Evolución de la presión máxima con la sobrepresión aplicada.

Figura 4.41. Evolución de la velocidad mínima con la sobrepresión aplicada............

Figura 4.42. Evolución de la presión máxima con la velocidad mínima......

Figura 4.43. Presión máxima según la velocidad de llegada a la ventosa................................. 144

Figura 4.44. Fuga de agua a través de la ventosa.

Figura 4.45. Ensayo de la ventosa a. oscilaciones en el pico de presión.

Figura 4.46. Oscilaciones en la curva de presión y desplazamiento del flotador.

Figura 4.47. Ensayo de la ventosa a. rebote del flotador y oscilaciones en la presión...................... 146

Figura 4.48. Evolución general de un ensayo de la ventosa b. presión máxima............................ 147

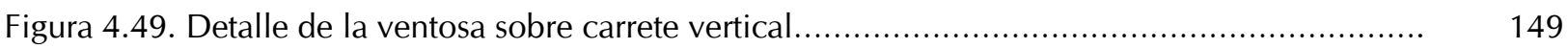

Figura 4.50. Presiones máximas según la sobrepresión inicial......................................... 150

Figura 4.51. Relación entre la presión máxima y la anchura del pico de presión máxima............... 151 
Figura 4.52. Presión máxima cuando la ventosa está sobre la conducción.

Figura 4.53. Secuencia de cierres de la ventosa.

Figura 4.54. Presión máxima en segundo cierre.

Figura 4.55. Oscilaciones de la presión en múltiples cierres.....

Figura 4.56. Presión máxima en ventosa A, DN50

Figura 4.57. Evolución del ensayo.

Figura 4.58. Evolución general del ensayo.

Figura 4.59. Presión máxima en ensayos de la ventosa B en el punto más elevado de la conducción.

Figura 4.60. Sucesión de cierres de la ventosa y presión máxima.

Figura 61. Oscilaciones de presión y cierres de la ventosa DN50 con valores de sobrepresión intermedios.

Figura 4.62. Presión máxima en el segundo cierre de la ventosa....................................... 157

Figura 4.63. Presión máxima. Ventosa B.

Figura 4.64. Relación entre la frecuencia de cierres y la oscilación de la presión en ensayos con ventosa DN50.

Figura 4.65. Relación entre la frecuencia de cierres y la oscilación de la presión.

Figura 4.66. Presión máxima en ensayos con ventosa sobre carrete vertical corto.

Figura 4.67. Presión máxima y anchura del pico de presión en ensayos con ventosa sobre carrete vertical corto.

Figura 4.68. Evolución general de un ensayo con ventosa A DN50 sobre carrete vertical corto........

Figura 4.69. Evolución general de un ensayo con ventosa A DN50 sobre carrete vertical corto con una velocidad de llegada menor.

Figura 4.70. Evolución general de un ensayo con ventosa B sobre carrete vertical corto....

Figura 4.71. Ensayo con la ventosa B sobre carrete vertical corto con sobrepresión inicial menor de 2 m.c.a.

Figura 4.72. Ensayo con la ventosa B sobre carrete vertical corto con sobrepresión inicial mayor de

2 m.c.a.

Figura 4.73. Presión máxima en ensayos con ventosas sobre carrete vertical largo.

Figura 4.74. Comparación de resultados entre los tres tipos de ensayos de expulsión de aire al final de la conducción con ventosa DN50.

Figura 4.75. Presión máxima frente a la anchura del pico de presión en ventosas sobre carrete vertical largo.

Figura 4.76. Evolución general de un ensayo con la ventosa A montada sobre un carrete vertical largo. Sobrepresion inicial =1,9 m.c.a.

Figura 4.77. Evolución de un ensayo con la ventosa A montada sobre un carrete vertical largo. Sobrepresion inicial $=2,6$ m.c.a.

Figura 4.78. Evolución de un ensayo con la ventosa A montada sobre un carrete vertical largo. Sobrepresion inicial $=3,03$ m.c.a..

Figura 4.79. Evolución de un ensayo con la ventosa A montada sobre un carrete vertical largo. Sobrepresion inicial $=2,22$ m.c.a..

Figura 4.80. Evolución de un ensayo con la ventosa A montada sobre un carrete vertical largo. Sobrepresion inicial $=1,65$ m.c.a..

Figura 4.81. Evolución de un ensayo con la ventosa A montada sobre un carrete vertical largo. Sobrepresion inicial $=1,87$ m.c.a..

Figura 4.82. Evolución de un ensayo con la ventosa B montada sobre un carrete vertical largo. Sobrepresion inicial $=2,99$ m.c.a.. 
Figura 4.83. Evolución de un ensayo con la ventosa B montada sobre un carrete vertical largo. Sobrepresion inicial $=3,07$ m.c.a.

Figura 4.84. Presión máxima en ensayos de expulsión de aire un punto intermedio instalación. Ventosas DN50....

Figura 4.85. Presión máxima frente a la anchura del pico de presión en ensayos de expulsión de aire en un punto intermedio instalación. Ventosas DN50.

Figura 4.86. Evolución general de un ensayo de la ventosa A sobre conducción y en punto intermedio de la instalación. Sobrepresión inicial =2,23 m.c.a.

Figura 4.87. Evolución general de un ensayo de la ventosa B sobre conducción y en punto intermedio de la instalación. Sobrepresión inicial=2,51 m.c.a..

Figura 4.88. Relación entre la presión máxima y la sobrepresión aplicada......

Figura 4.89. Comparación entre las presiones máximas obtenidas en ensayos de expulsión de aire a través de una ventosa situada sobre la t o al final de un carrete vertical corto.....

Figura 4.90. Relación entre la presión máxima y la anchura del pico de presión en expulsión de aire en un punto intermedio de la instalación con ventosa sobre carrete vertical corto.

Figura 4.91. Cierre parcial de la ventosa y pico de presión.

Figura 4.92. Movimiento del flotador de la ventosa A DN50 y presión medida.

Figura 4.93. Movimiento del flotador de la ventosa A DN50 y presión medida............................... 178

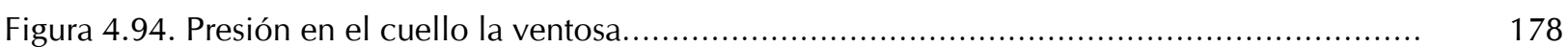

Figura 4.95. Ondulaciones en el perfil de la onda de presión...................................... 179

Figura 4.96. Presión máxima frente a la velocidad en el instante que aumenta la presión................ 180

Figura 4.97. Velocidad cuando aumenta la presión frente a la sobrepresión inicial......................... 181

Figura 4.98. Presión máxima frente a la sobrepresión inicial.

Figura 4.99. Variación de la velocidad de la columna de agua en ensayo de admisión de aire a través de una ventosa debido al cierre de una válvula..

Figura 4.100. Separación columna de agua. Ensayo sin y con ventosa.

Figura 4.101. Presiones máximas y deceleración del flujo en ensayos de cierre de válvula de retención por inversión del flujo.

Figura 4.102. Velocidad mínima y presión máxima en ensayos de cierre de válvula de retención por inversión del flujo.

Figura 4.103. Velocidad mínima y presión máxima en ensayos de cierre de válvula de retención por inversión del flujo.....

Figura 4.104. Relación entre la presión máxima y la duración de la depresión.

Figura 4.105. Relación entre la velocidad mínima, la duración de la depresión y la sobrepresión inicial aplicada en ensayos con y sin ventosa.

Figura 4.106. Presión aguas arriba y aguas abajo de la válvula de retención...............................

Figura 4.107. Medida de la presión en el lado de las bajas presiones.

Figura 4.108. Duración de la depresión frente a la sobrepresión que invierte el flujo....

Figura 4.109. Evolución de un ensayo de admisión de aire a través de una ventosa......

Figura 4.110. Presión mínima medida junto a la ventosa.

Figura 4.111. Caudales mínimos registrados durante los ensayos..........

Figura 4.112. Evolución general de un ensayo de admisión de aire.

Tabla 4.1. Coeficientes de descarga promedio según el grado de apertura de la ventosa.......

Tabla 4.3. Comparación de los resultados numéricos de algunas variables en ensayos similares de dos ventosas diferentes. 


\section{CAPÍTULO 5. MODELACIÓN MATEMÁTICA DEL TRANSITORIO AGUA-AIRE}

PAGINA

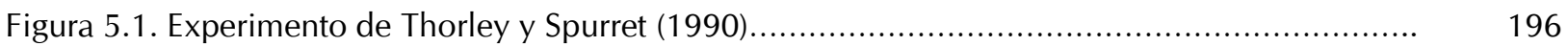

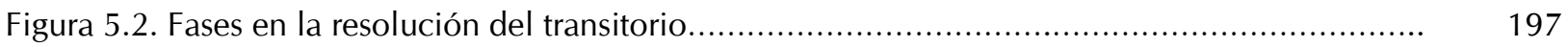

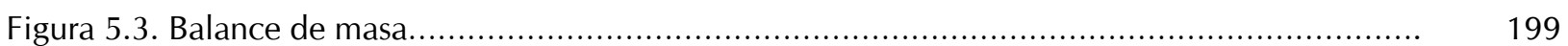

Figura 5.4. Celeridad del fluido según la proporción de gas y líquido........................................ 201

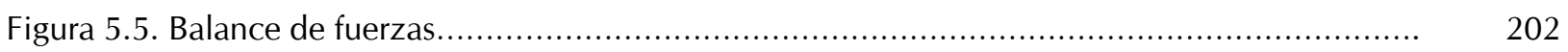

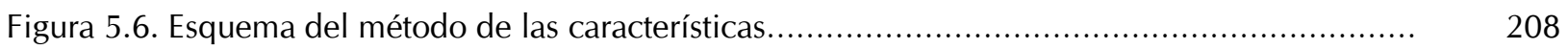

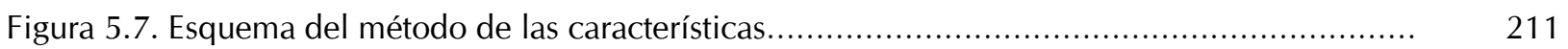

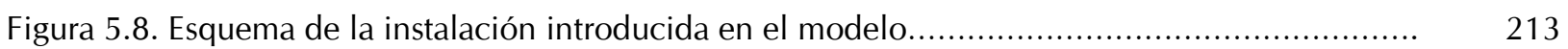

Figura 5.9. Expulsión de aire con ventosa A DN100, deltap = 3,31 ......................................... 223

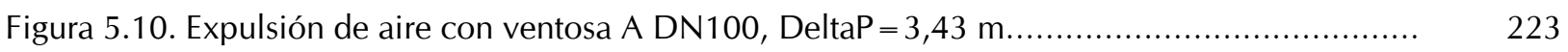

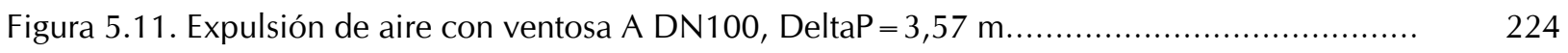

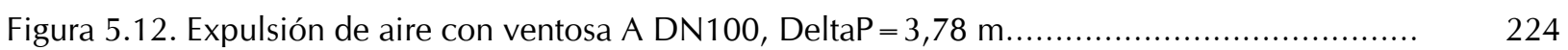

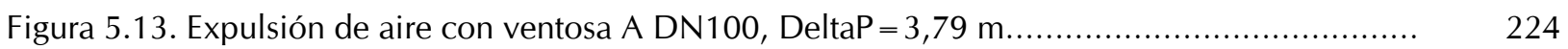

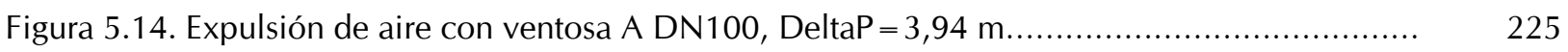

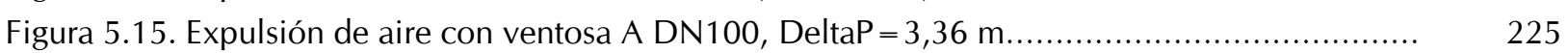

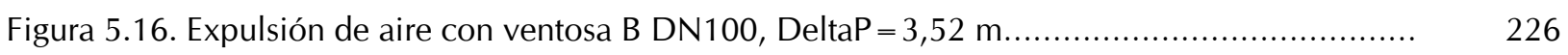

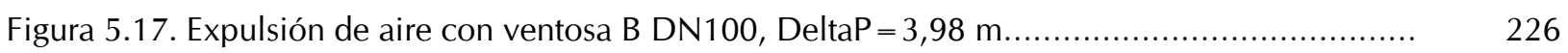

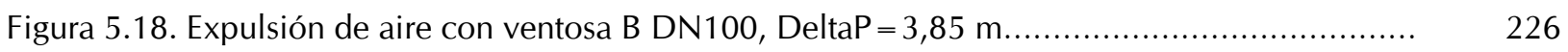

Figura 5.19. Expulsión de aire con ventosa $B$ DN100, DeltaP =3,91 m......................................... 227

Figura 5.20. Expulsión de aire con ventosa A DN100. datos de partida...................................... 228

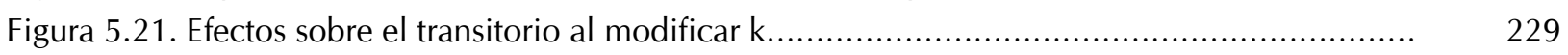

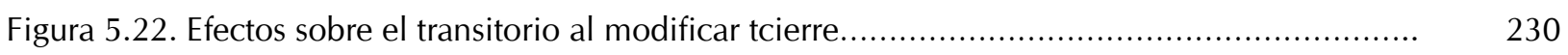

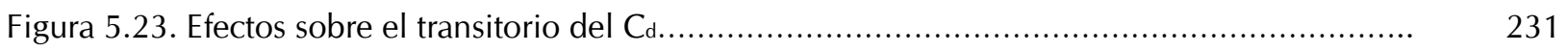

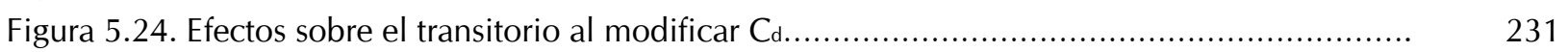

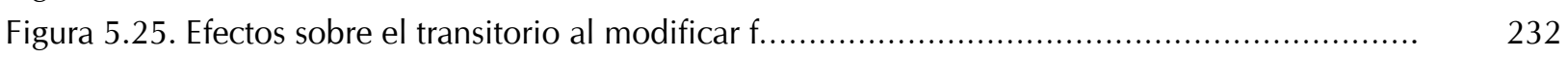

Figura 5.26. Efectos sobre el transitorio al modificar la longitud del tubo.................................... 233

Figura 5.27. Efectos sobre el transitorio al modificar el volumen de aire..................................... 234

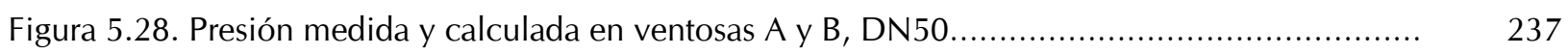

Figura 5.29 Coeficiente de Hazen Williams según el material de la tubería..................................... 239

Figura 5.30. Entrada de datos del perfil de la instalación.......................................................... 240

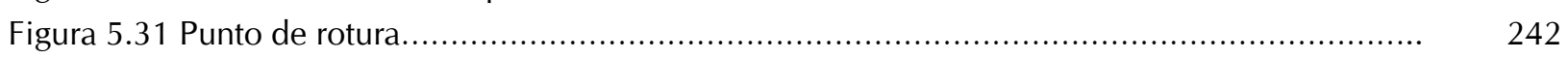

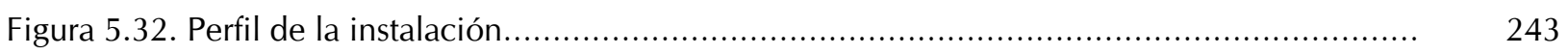

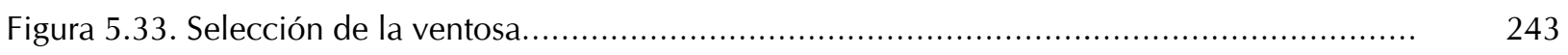

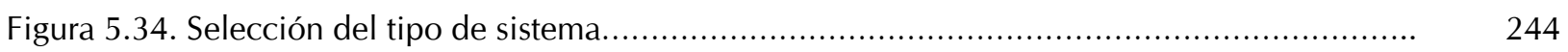

Figura 5.35. Análisis que efectúa el programa VENTOMAT ...................................................... 247

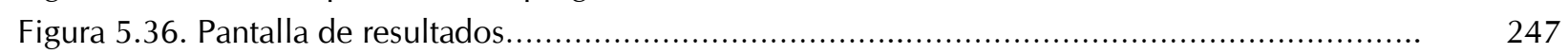

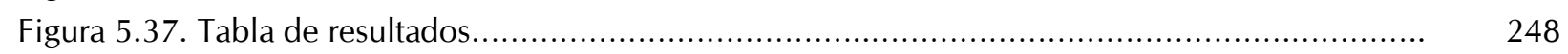

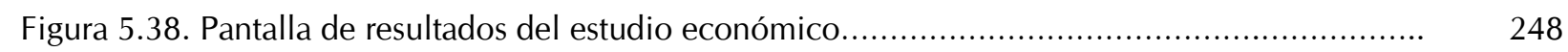

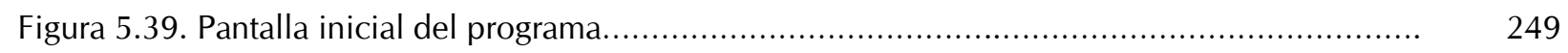

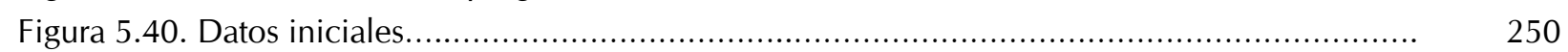

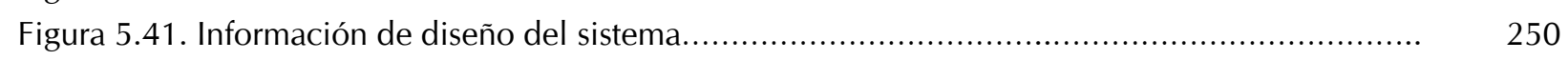

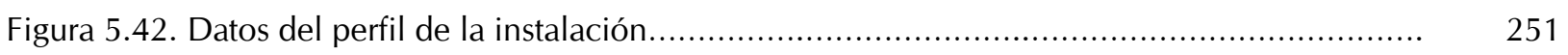

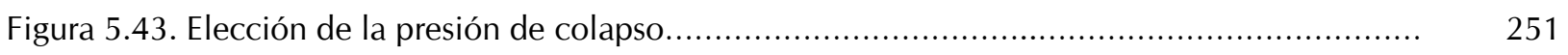


Figura 5.44. Elección del orificio de salida de la ventosa....

Figura 5.45. Elección del tamaño del orificio de entrada de aire......................................... 252

Figura 5.46. Tabla de las ventosas disponibles en el catálogo de APCO................................ 253

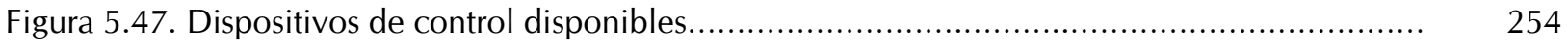

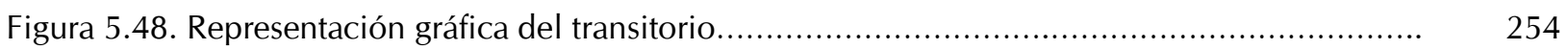

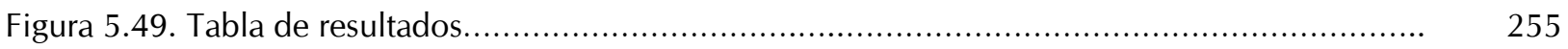

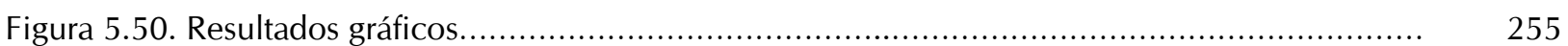

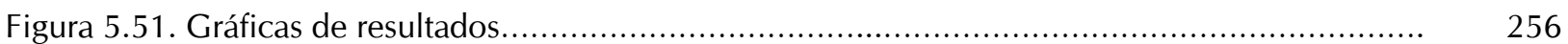

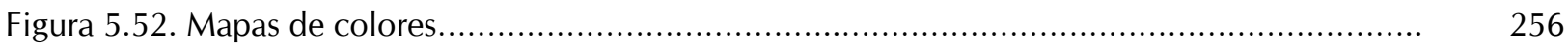

Figura 5.53. Módulos de los que consta el programa.................................................. 257

Figura 5.54. Curvas de la bomba..................................................................... 258

Figura 5.55. Salida de datos en diferentes idiomas..................................................... 258

Tabla 5.1. Tabla de rugosidades del material............................................................ 245 


\section{LISTADO DE SÍMBOLOS}

A Sección trasversal de la tubería $\left(\mathrm{m}^{2}\right)$

$A_{v}$ Sección del orificio de la ventosa $\left(\mathrm{m}^{2}\right)$

BV1 Válvula de mariposa 1

BV2 Válvula de mariposa 2

$\mathrm{C}_{\mathrm{d}}$ Coeficiente de descarga de una ventosa

Cexp Coeficiente de expulsión de la ventosa

$\mathrm{C}_{\mathrm{v}}$ Coeficiente de flujo de una válvula

dv/dt_cz deceleración de la columna de agua entre los instantes tc y tz

IntQ_ti_tz Suma de caudales circulados a través del caudalímetro entre el instante inicial y tz

IntQ_tc_to Suma de caudales circulados a través del caudalímetro entre el instante tc y to f frecuencia del caudalímetro tipo vórtex

Gg Gravedad específica de un vapor relativa al aire

K constante de calibración del caudalímetro tipo vórtex

K1 medida del transductor de presión Kristler en la posición 1

K2 medida del transductor de presión Kristler en la posición 2

K3 medida del transductor de presión Kristler en la posición 3

Lo Longitud inicial de la columna de agua

$\mathrm{P}^{*}{ }_{\text {atm }}$ Presión atmosférica en valores absolutos

Pmax Presión máxima medida en el sistema

$\mathrm{P}{ }^{*}$ Presión absoluta en el interior de la tubería

P1 medida del transductor de presión de alta precisión P1

Q Caudal $\left(\mathrm{m}^{3} / \mathrm{s}\right)$

Qi Caudal inicial

Qm Caudal másico $(\mathrm{Kg} / \mathrm{s})$

Qmin Caudal mínimo

Q Caudal normalizado $\left(\mathrm{Nm}^{3} / \mathrm{h}\right)$

Qv Caudal volumétrico $\left(\mathrm{m}^{3} / \mathrm{s}\right)$ 
T temperatura

$\mathrm{tc}_{c}$ Instante de cierre de la ventosa

$t_{i}$ Instante inicial

tm Instante en el que se produce la presión máxima en la instalación

to Instante en el que empieza a cerrar la ventosa

$t_{p}$ Instante en el que empieza a cambiar la presión de la columna de agua

tpo Instante de presión nula después del cierre de la ventosa

toini Instante inicial

tQmin Instante en el cual e caudal medido es mínimo

$\mathrm{t}_{z}$ instante de velocidad nula del flujo

$V_{c}$, Velocidad de la columna de agua en el instante $t_{c}$, o velocidad cuando la ventosa cierra por completo

$V_{i}$, Velocidad en el instante $t_{i}$, velocidad inicial de la columna de agua

$V_{m}$ Velocidad en el instante $t_{m}$, cuando se alcanza la presión máxima en el interior del sistema

$V_{\text {min }}$ Velocidad mínima de retorno

$V_{o}$, Velocidad en el instante to, velocidad de la columna de agua cuando empieza a cerrar la ventosa

$V_{z}$, Velocidad en el instante $t_{z}$ o velocidad nula.

$\mathrm{X}$ relación de presiones

$\mathrm{X}_{\mathrm{T}}$ Factor de presión crítico

Y Factor de expansión

$\rho$ Densidad

$\Delta \mathrm{P}$ Diferencia de presión 


CAPÍTULO 1. PROBLEMÁTICA DEL AIRE ATRAPADO EN TUBERÍAS 



\subsection{INTRODUCCIÓN}

\subsubsection{ORIGEN DEL AIRE ATRAPADO}

El estudio detallado de la evolución del aire atrapado en una tubería así como el modo más eficiente de expulsarlo o admitirlo en la misma son fundamentales tanto para poder predecir los efectos indeseables que dicho aire puede tener sobre el conjunto de la instalación, como para limitar o anular los mismos.

El agua contiene en condiciones normales cierta cantidad de aire disuelto (el nivel de saturación del aire disuelto en el agua es aproximadamente de un $2 \%$, a presión atmosférica y a temperatura ambiente). Cuando se produce una caída de presión en el sistema, la cantidad de aire disuelto puede superar el valor de saturación de la disolución a dicha presión y temperatura por lo que se libera cierta cantidad del mismo. Los aumentos de temperatura también son una causa de descarga de aire ya que la presión de vapor del agua aumenta con la temperatura (a $15{ }^{\circ} \mathrm{C}$ esta presión es de $1,70 \mathrm{KN} / \mathrm{m}^{2}$ mientras que a $30^{\circ} \mathrm{C}$ es de $4,24 \mathrm{KN} / \mathrm{m}^{2}$ ). Esto significa que el volumen potencial de aire que puede ser desprendido es 2,5 veces mayor a $30^{\circ} \mathrm{C}$ que a $15{ }^{\circ} \mathrm{C}$, Lauchan et al. (2005). Estas consideraciones pueden ser importantes a la hora de diseñar sistemas de tuberías en climas con altas temperaturas o sujetos a variaciones térmicas importantes.

La presencia de aire en las tuberías puede tener además otros orígenes muy diferentes. Uno de ellos es el resultado de que la instalación se encuentre incorrectamente diseñada o no haya sido convenientemente llenada y purgada, en cuyo caso pueden Ilegar a existir grandes masas de aire atrapado en su interior. Por otro lado, el aire puede entrar en la conducción en el transcurso de su funcionamiento normal atendiendo a otros motivos tales como, eventuales vórtices en la aspiración de las bombas, operación de ventosas 
admitiendo aire, roturas de las tuberías o pequeñas fisuras en regiones de presión negativa.

Muchas veces las conducciones deben salvar desniveles importantes del terreno siendo su perfil claramente irregular, lo cual facilita la concentración de bolsas de aire en los puntos altos de las mismas. Es el caso de gran parte de los sistemas de abastecimiento de agua en los cuales existe un desnivel considerable entre las fuentes de suministro hasta los depósitos de distribución situados en la cabecera de las redes. Además de los perfiles perjudiciales de las instalaciones hay que añadir, en muchas ocasiones, el corte de suministro con la consecuente puesta en marcha de la instalación. Estas situaciones son completamente habituales en las impulsiones para riego en las cuales las interrupciones en el suministro son inevitables. Es también frecuente en poblaciones en las cuales la escasez de agua hace necesario establecer cortes de suministro. El posterior arranque de la instalación, después que la instalación haya permanecido fuera servicio, contempla a menudo la presencia de aire atrapado en las tuberías.

\subsubsection{PROBLEMAS CAUSADOS POR EL AIRE ATRAPADO}

La presencia del aire atrapado en tuberías es un fenómeno bastante común que puede agravar los efectos perjudiciales originados por los transitorios hidráulicos, acentuando los picos de presión. Las altas presiones pueden provocar rupturas en la instalación y en sus accesorios, lo cual tiene una importante repercusión económica. Además, las bolsas de aire pueden causar otra serie de efectos negativos en las instalaciones tales como la reducción de la capacidad de transporte de la instalación, disminución del rendimiento de las bombas, dificultad en el funcionamiento de los filtros, vibraciones en tuberías, corrosión de las conducciones, desgaste de las partes móviles de los accesorios, errores en la medida de caudal etc.

Entre los posibles problemas asociados a la presencia de aire en una conducción cabe destacar lo siguiente:

- Reduce la sección transversal efectiva de la tubería, lo cual implica una disminución de la capacidad de transporte de la tubería

- Las propiedades del fluido cambian al estar constituido por una mezcla de aire y agua, la densidad del fluido disminuye mientras que la elasticidad del mismo aumenta.

- Cambia la estructura de la turbulencia del flujo y modifica la fricción con la pared de la tubería.

- Las burbujas de aire se desplazan debido a su flotación lo cual puede modificar el campo de velocidades del flujo.

- En transitorios hidráulicos, la presencia de grandes bolsas de aire influye en las ondas de presión, acentuándolas en algunos casos y deformándolas. También se 
ha encontrado que las pequeñas acumulaciones de aire pueden presentar efectos adversos en los transitorios de presiones.

- La acumulación de aire en un sistema puede ocasionar vibraciones y daños estructurales y causar inestabilidades en el flujo.

- El aire puede causar dificultades en las operaciones de filtrado. Los picos producidos por variaciones en la presión del aire hacen difícil mantener buenas operaciones de filtrado. Además las burbujas de aire pueden quedar atrapadas en los filtros de arena reduciendo de esta forma su eficiencia.

- La presencia de aire puede reducir la eficiencia de bombas y turbinas. Cuando el aire se mezcla con el agua que alimenta una turbina, se produce una caída de presión en la salida.

- En tuberías de hierro la presencia de aire acelera la corrosión de las mismas.

- El aire puede producir errores en dispositivos de lectura o de medición tales como contadores de agua y caudalímetros. En casos extremos puede incluso inutilizar el equipo de medida.

Los contadores mecánicos, bien sean de chorro único, chorro múltiple, Woltmann o tangencial disponen de elementos móviles. Como el aire no tiene propiedades lubricantes ni refrigera estos elementos móviles, es decir los engranajes o la turbina, se ven sometidos a elevadas velocidades. El aire provoca el desgaste de los puntos de apoyo de dichos elementos. Al mismo tiempo, en este tipo de contadores, se producen errores de medición ya que se contabiliza el paso de aire como si fuera agua.

En los contadores de agua por ultrasonidos, las bolsas de aire interfieren el paso de la señal entre los transductores. De este modo los tiempos de llegada de la señal de un transductor a otro se ven alterados. En este tipo de contadores, el caudal se considera proporcional a dichos tiempos y por tanto con bolsas de aire, el cómputo del caudal es erróneo.

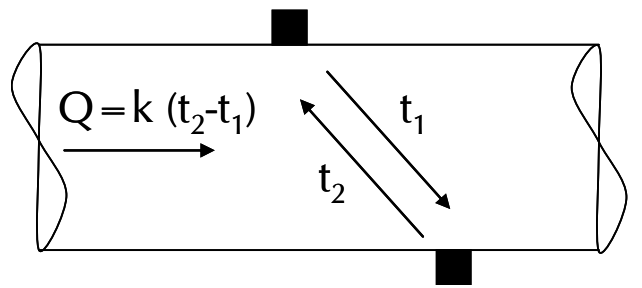

Figura 1.1. Medida de caudal en contador ultrasonidos

Finalmente, los contadores de agua electromagnéticos también aportan medidas erráticas de caudal cuando aparece aire en la instalación. En la figura siguiente se muestran tres supuestos en los cuales el contador o bien estaría dando una medida incorrecta o bien no mediría. En el caso (a) el contador registraría un caudal proporcional al diámetro de la conducción como si toda el área transversal de la tubería estuviera llena de agua cuando realmente no es cierto. En el caso (b) el contador directamente no aportaría medida de 
caudal de agua ya que no detecta al fluido. Finalmente, cuando aparecen burbujas de aire en la instalación, como en el primer caso el contador aportaría una medida de caudal de agua errática, como si toda el área de la tubería estuviera Ilena de agua.

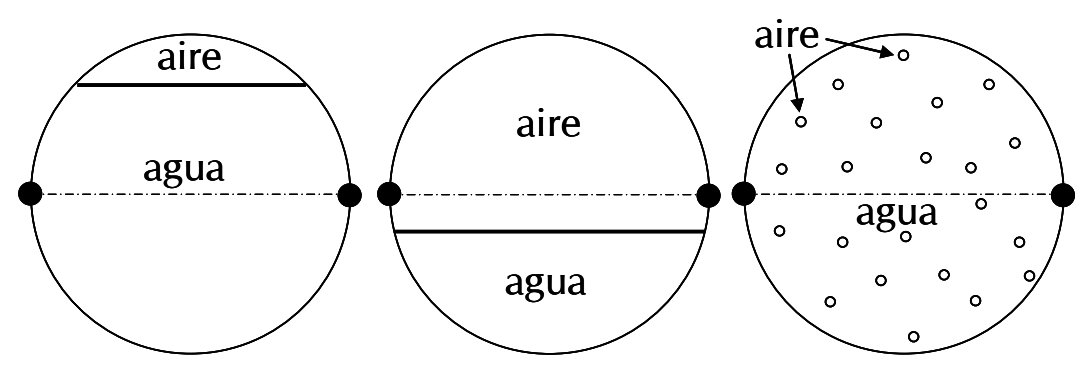

(a)

(b)

(c)

Figura 1.2. Medida de caudal en contador electromagnético

La reducción del rendimiento de la instalación como consecuencia del aire atrapado además de incrementar las pérdidas de carga, aumenta los ciclos de bombeo y aumenta, por tanto, el consumo de energía. Algunos estudios realizados por fabricantes de ventosas apuntan que en redes de distribución de agua el aire atrapado puede reducir la eficiencia de la tubería hasta incluso un $30 \%$ y que la mayoría de sistemas de distribución de agua funcionan con bolsas de aire que ocupan entre el $15 \%$ y el $20 \%$ del volumen total de la instalación. Las bolsas de aire comprimido representan un verdadero obstáculo a la hora de bombear el fluido ya que la acumulación de aire hace que las bombas tengan que suministrar más altura y trabajar durante más horas, lo cual supone un claro aumento en el consumo de energía eléctrica.

Según Thomas (1998), la pérdida de eficiencia de la instalación debido al aire atrapado puede a veces ser incluso mayor que las pérdidas por fricción y las pérdidas debidas a fugas. Thomas coincide con los fabricantes de ventosas en que bajo determinadas circunstancias, la presencia de bolsas de aire atrapado puede representar un elevado porcentaje del coste operacional de una instalación correspondiente al coste de bombeo del fluido. Matiza finalmente que la presencia de aire atrapado aumenta el coste operacional de la instalación.

\subsubsection{PATRONES DE FLUJO BIFÁSICO AIRE-AGUA}

La aparición de un flujo bifásico agua-aire hace que se modifique la capacidad de transporte de la tubería así como la elasticidad del fluido en cuestión. La aparición de aire hace que se deforme el perfil de velocidades que se tendría si en un sistema presurizado solo existiera agua. A la hora de analizar un transitorio en el cual intervengan los dos fluidos es importante conocer la proporción y distribución de ambos fluidos en la tubería. En la actualidad se dispone una serie de patrones de flujo en una tubería, lo cual no sería extrapolable a un sistema de tuberías interconectadas. 
Estos patrones dependen además de la proporción de agua y aire y de la velocidad de los fluidos, de la pendiente de la tubería. Algunos autores como Falvey (1980) y Rouhani y Sohal (1983) proporcionan en sus trabajos revisiones de posibles patrones de flujo. Seguidamente se muestra simplemente una pequeña representación de los patrones propuestos ya que en la literatura se pueden encontrar según Rouhani y Sohal (1983), hasta 84 denominaciones de tipos de flujo diferentes.

En caso de flujo vertical se puede tener según la proporción y velocidad del flujo de aire en el agua los siguientes tipos de flujo:

- Flujo en burbujas (Bubble flow): El aire se encuentra distribuido en el agua en forma de burbujas esféricas las cuales son más pequeñas que el diámetro de la tubería.

- Flujo en tapones (Plug flow): Ocurre cuando aumenta el flujo de aire. La transición del flujo de burbuja a flujo en tapones se produce cuando el diámetro de la burbuja es aproximadamente la mitad del diámetro de la tubería.

- Flujo en balas o tramos (Slug flow): Cuando se incrementa aún más el flujo de aire se unen varias burbujas de forma regular. Toda la sección transversal del tubo queda prácticamente ocupada por cada uno de estos conjuntos de burbujas de aire, que adoptan forma de bala o cohete, excepto una fina capa de líquido que se sitúa cerca de la pared y su longitud es de varias veces el diámetro del tubo.

- Flujo batido (Churn flow): Si continúa aumentando la velocidad del flujo, los grupos de burbujas se rompen formando un flujo desordenado de aire y agua.

- Flujo anular (Annular flow): Se produce cuando existe un flujo de aire relativamente elevado y poca agua. El agua aparece como una fina capa que se mueve paralela a la pared del tubo y el flujo de aire fluye por la parte central de la tubería.

- Flujo disperso (Dispersed flow): Cuando el flujo de aire crece, se rompe la fina capa de agua que fluye cercana a la pared en el flujo anular y se mezcla en forma de pequeñas gotas con el aire. 


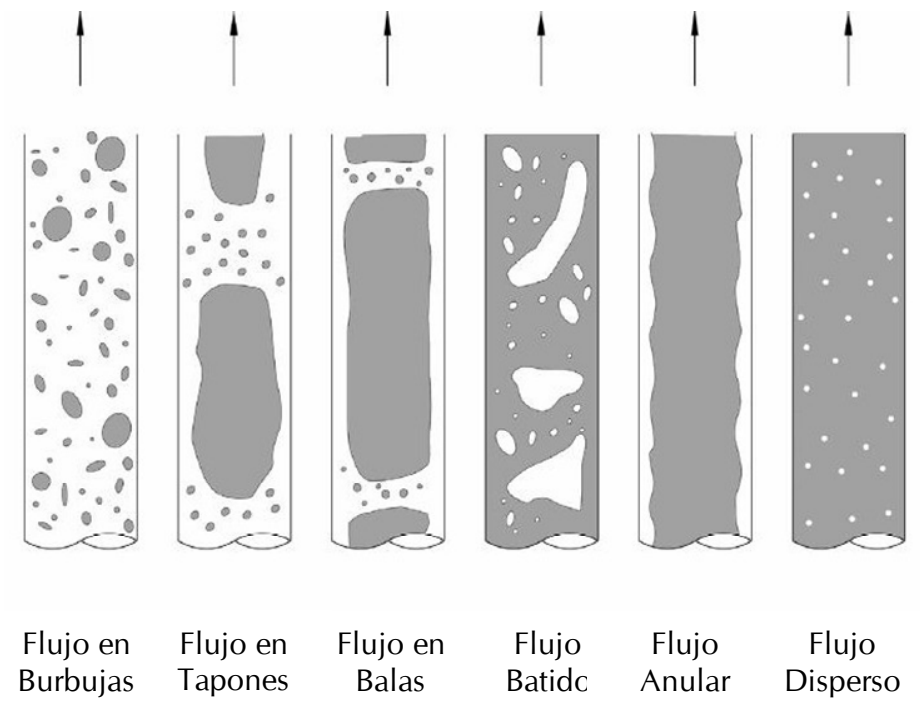

Figura 1.3. Patrones de flujo vertical

En el caso de flujos horizontales, aparecen generalmente patrones no simétricos debido a la influencia de la gravedad en estos dos fluidos de diferente densidad. Se genera una tendencia a la estratificación en dirección vertical con el líquido, que es el fluido de mayor densidad, en la posición inferior. Una posible clasificación del flujo bifásico en este caso sería:

- Flujo en burbujas (Bubble flow): El aire forma burbujas en la superficie superior de la tubería. Las velocidades de las burbujas de aire y del agua son similares. Este flujo tiene lugar generalmente cuando la velocidad del líquido es relativamente elevada y existe poco flujo de aire

- Flujo en tapones (Plug flow): Para velocidades del aire mayores las burbujas de aire se unen formando bolsas de aire. Estas bolsas o tapones se encuentran dispersas en el flujo de agua y son transportadas con el agua hacia el punto más elevado de la tubería.

- Flujo estratificado horizontal (Stratified Horizontal flow): Una interfaz horizontal separa el flujo de aire del flujo de agua. Este tipo de flujo se observa normalmente a velocidades elevadas tanto del aire como del agua.

- Flujo estratificado ondulado (Stratified Wavy flow): Si sigue aumentando la velocidad del aire, aparecen ondas superficiales en la interfaz del flujo estratificado. Dicha interfaz pasa de ser completamente horizontal a ser ondulada.

- Flujo en balas (Slug flow): Las amplitudes de las ondas son demasiado grandes para sellar el conducto. Las ondas forman un batido espumoso que toca el techo del conducto. El conjunto viaja a una velocidad mayor que la velocidad media del líquido.

- Flujo anular (Annular flow): Para velocidades elevadas del flujo de aire el agua fluye formando una fina capa sobre la pared de la tubería mientras el aire fluye a gran velocidad por la parte central. 
- Flujo disperso (Dispersed flow): Para velocidades muy elevadas del aire se rompe la capa de agua en forma de anillo quedando finas gotas de agua dispersas en el aire.

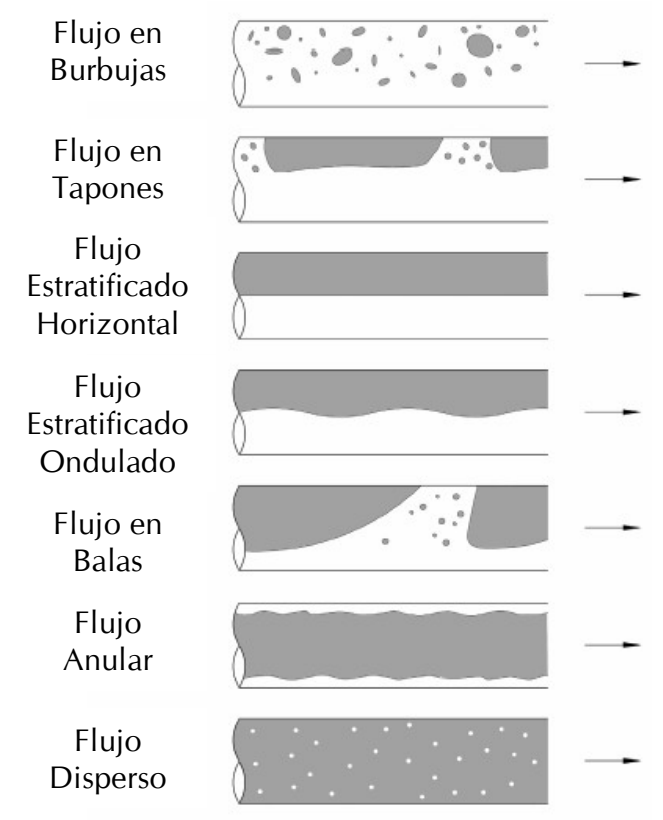

Figura 1.4. Patrones de flujo horizontal

En 1986 Hansen llevó a cabo un estudio de los regímenes de flujo bifásico aire-agua tanto en tuberías horizontales como en tuberías verticales. Gracias a dicho estudio encontró que en las tuberías horizontales o prácticamente horizontales el flujo es más complejo debido a la asimetría que introduce la fuerza gravitatoria. Actualmente es posible encontrar en la bibliografía técnica los trabajos de numerosos autores que proporcionan mapas de patrones de flujo. La transición de un tipo de flujo a otro es función de un determinado número de variables entre las cuales se encuentran:

- El caudal másico de aire y de agua.

- Las propiedades de ambos fluidos.

- El diámetro y ángulo de inclinación de la tubería sobre la horizontal.

Taitel y Duckler (1976) desarrollaron un modelo para determinar las transiciones del flujo bifásico gas-líquido. El modelo se basa en conceptos físicos y se puede usar para proporcionar un mapa generalizado de patrones de flujos bifásicos que circulen por tuberías horizontales o prácticamente horizontales. El modelo considera cinco tipos de flujo tal y como muestra la Figura 1.5, que se corresponde con los flujos definidos anteriormente. 


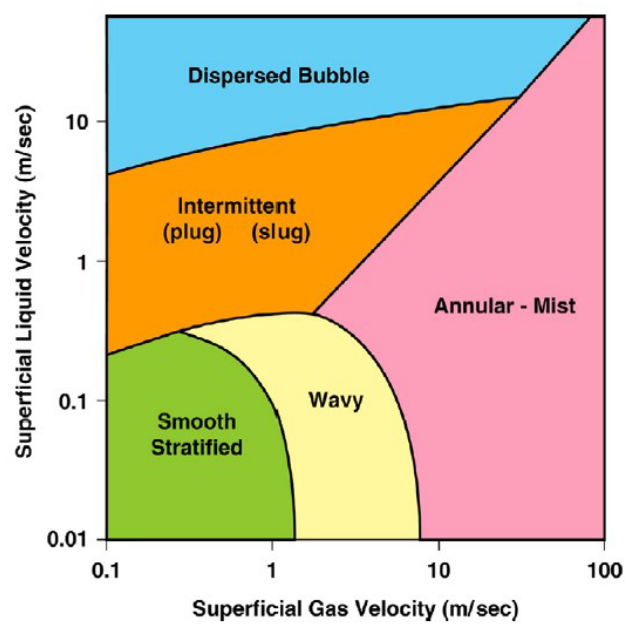

Figura 1.5. Mapa de flujo bifásico en tubería horizontal

Estos autores estudiaron asimismo el efecto producido en las transiciones del flujo debido a pequeñas inclinaciones de la tubería. En pendientes decrecientes se requieren mayores velocidades del gas y del líquido para que se produzca la transición de flujo estratificado a flujo intermitente (en tapones y en balas) tal como se muestra en la Figura 1.5 y la región del flujo intermitente se ve considerablemente reducida.

Más tarde, en 1980, Barnea describió estudios experimentales de patrones de transiciones de flujo en tuberías inclinadas y comparó los resultados con los de Tailtel y Duckler. De la comparación de los resultados experimentales con los del modelo teórico se desprende que el modelo proporciona resultados satisfactorios en tuberías horizontales y en tuberías inclinadas $\pm 10^{\circ}$. En los siguientes diagramas se muestran los mapas de flujo en tuberías inclinadas basados en los estudios de Barnea. En ellos se aprecia en primer lugar el mapa de patrones de flujo en tubería inclinada con flujo circulando hacia cotas decrecientes y en segundo lugar el mapa de patrones de flujo en tubería inclinada con flujo circulando hacia cotas crecientes:

Flujo descendente

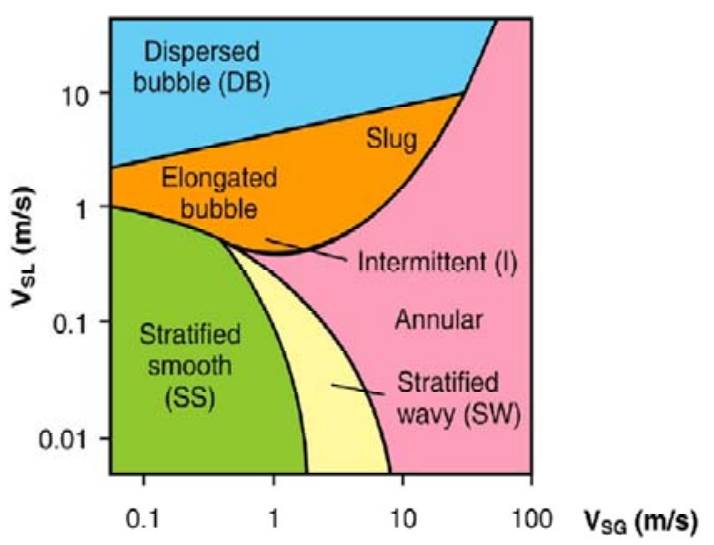

Flujo ascendente

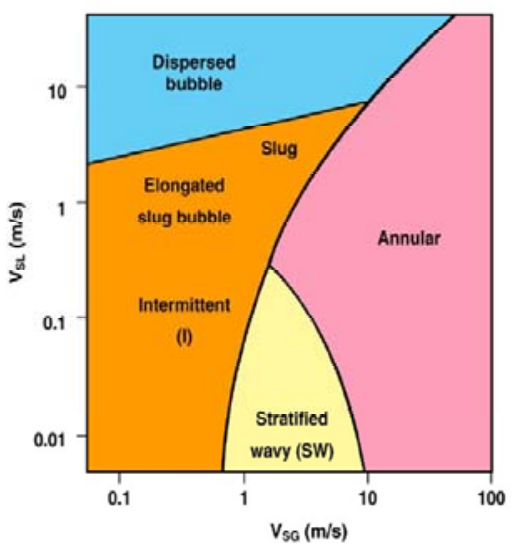

Figura 1.6. Mapas de flujo bifásico en tubería inclinada 
No existen modelos de este estilo para tuberías con inclinaciones mayores o tuberías verticales. Sin embargo existen diversos mapas de flujo para tuberías verticales producidos por diversos autores. Por ejemplo, en la Figura 1.7, se comparan los patrones de flujo vertical de Ishii y Mishima (1980) con los de Duckler y Taitel (1977)
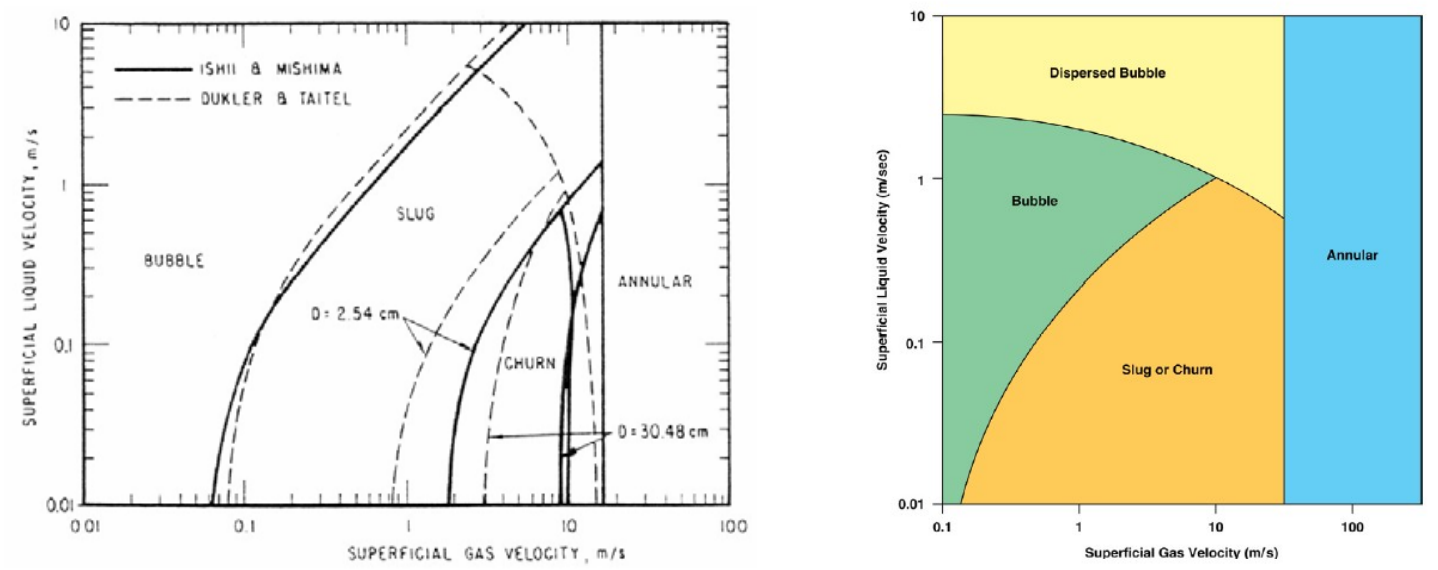

Figura 1.7. Mapa de flujo bifásico en tubería vertical

\subsubsection{SOLUCIONES ACTUALES FRENTE A LA PROBLEMÁTICA DEL AIRE ATRAPADO}

Una posible solución para evitar los picos elevados de presión en redes de distribución de agua consecuencia de la compresión del aire atrapado durante los transitorios hidráulicos y las condiciones de vacío en las instalaciones es la utilización de ventosas. Las funciones básicas de las ventosas son, a grandes rasgos, admitir aire para eliminar las presiones subatmosféricas de una forma rápida, expulsar grandes cantidades de aire de la instalación cuando se procede a su llenado así como expulsar pequeñas cantidades de aire durante la operación normal del sistema.

En la práctica, la utilización de ventosas presenta dificultades a la hora de realizar un adecuado dimensionado y selección de las mismas para cada instalación. Tan perjudicial como la no utilización de estos elementos de protección puede llegar a ser la elección de una ventosa cuyo tamaño no sea el apropiado para llevar a cabo correctamente sus funciones.

Otro problema importante que presenta el uso de ventosas es la falta de documentación acerca de su comportamiento tanto en condiciones estáticas como dinámicas. Sobre todo en cuanto a la caracterización dinámica de ventosas se refiere, los técnicos disponen de datos y se desconocen los tiempos de respuesta de las ventosas actualmente en el mercado desde que la columna de agua llega al flotador hasta que ésta cierra, la capacidad de expulsión o admisión de aire en régimen permanente, el caudal de aire que puede provocar un cierre anticipado de la venosa etc. 
El cierre brusco de una ventosa tras la expulsión de aire de una instalación puede ocasionar elevados picos de presión. Es por ello que a menudo se utilizan una serie de dispositivos que ralentizan el cierre de la ventosa y hacen que la expulsión de aire se lleve a cabo de modo controlado. Los problemas que presenta la utilización de dichos dispositivos es el requerimiento de un espacio mayor así como el incremento del coste de los mismos.

\subsection{ANTECEDENTES}

Los efectos del aire atrapado en las presiones del sistema han sido estudiados por un gran número de investigadores. La presencia de burbujas de aire inmersas en el líquido, o la acumulación de bolsas de aire complican el análisis de los transitorios hidráulicos y hacen difícil predecir los verdaderos efectos sobre las presiones tal y como explican Wylie y Streeter (1978), fuente de referencia más notable sobre transitorios hidráulicos y golpe de ariete, y en muchas otras contribuciones científicas.

Numerosos libros de texto proporcionan una revisión elemental muy útil de la teoría básica, es el caso de Nalluri y Featherstone (2001), para no especialistas en el tema. Los trabajos de Thorley $(1979,1991)$ proporcionan guías de formación para formulaciones computacionales y una amplia descriptiva con casos de estudio prácticos. Anderson (2000) facilita una revisión histórica del tema en cuestión.

Del trabajo de Burrows y Qiu (1995) se desprende que la presencia de aire atrapado puede ser perjudicial en instalaciones sujetas a transitorios en los cuales aparezcan depresiones y cavitación lo cual se puede traducir en una subestimación substancial de los picos de presión.

En contrapartida con los efectos adversos del aire mencionados, el valor máximo de la onda de presión en un transitorio puede verse ampliamente reducido si las burbujas de gas se distribuyen en el líquido (Wylie y Streeter, 1978) ya que la presencia de aire libre incrementa la elasticidad del fluido. En este sentido hay que tener en cuenta que el gas solo se dispersa si la velocidad del líquido es moderada. Además si al disminuir la celeridad del líquido la velocidad no permanece constante o moderada, se forman bolsas de aire. Adicionalmente, el aire se puede acumular en columnas intermitentes de gas y líquido cuando el líquido fluye más rápidamente, así lo explica Martin (1976) y bajo estas circunstancias es necesario un análisis en condiciones de fluido multifase detallado. Esto sucede sobre todo con fracciones elevadas del gas, por ejemplo en líneas de fuel oil y en algunas instalaciones industriales, Falk y Gudmundsson (2000) y Fujii y Akagawa (2000)

En cuanto a la revisión de modelos matemáticos que simulen este tipo de transitorios hidráulicos generalmente se realiza un análisis unidimensional, donde las ecuaciones de 
movimiento (continuidad y momento) se expresan en términos de variaciones en intervalos finitos en el espacio $(\Delta \mathrm{x})$ a lo largo de la tubería y en el tiempo $(\Delta \mathrm{t})$. Las ecuaciones en diferencias finitas resultantes se pueden luego configurar para obtener una solución mediante el Método de las Caracaterísticas (MOC), Wylie y Streeter (1978), Thorley (1979, 1991), Nalluri y Featherstone (2001)

Esta aproximación es aceptable para realizar diseños predictivos con un fluido simple pero se pueden introducir mejoras que realicen una simulación de las observaciones más afinada en cuanto a la forma de los picos de presión, la frecuencia de las oscilaciones y la atenuación del transitorio. Todo esto se traduce en: mejorar el modelo de disipación (fricción variable) en una formulación matemática, Abreu y Almeida (2000), Prado et al. (2002), comportamiento no elástico Borga et al (2004), Covas et al. (2003) y celeridad variable Lee (1994, 2003), Bora et al. (2004). Otras mejoras hacen referencia explícitamente al proceso de cavitación ya que la fracción de vapor crece y colapsa cuando cambia la presión. El método general tratado por Streeter y Wiley (1978) es ampliamente utilizado pero han aparecido recientemente nuevos artículos como el de Bergant et al (2004), Borga et al.(2004) y Dudlik (2000).

Cuando la cantidad de aire atrapado es significativa y existe un doble movimiento del agua y del aire, es necesario muchas veces utilizar modelos multifásicos. Esto se puede introducir en diversos niveles, Falk y Gudmundson (2000), Fujii y Akagawa (2000), Huygens et al. (1998) y Lee et al. (2003) tomando desde un modelo de dos fluidos (dos componentes) el cual satisface las ecuaciones del movimiento y de conservación en cada fluido, hasta un modelo de flujo homogéneo, el cual asume las mismas velocidades en cada fase, requiriendo los datos de los principales parámetros (por ejemplo densidad y celeridad) en el modelo. Falk y Huygens apuntan que el MOC modificado da una buena aproximación de las ondas de presión para predecir las magnitudes de las presiones que se pueden producir.

Algunas veces el MOC predice picos de presión menores que los obtenidos experimentalmente. El trabajo de Lee (1994) intenta explicarlo utilizando la teoría del golpe de ariete estándar estableciendo un modelo numérico con la celeridad variable basándose en la absorción y descarga de aire que se produce cuando aparecen cambios de presión.

Lee en principio citó el trabajo de otros investigadores, las observaciones de Whiteman y Pearsall (1959 y 1962) en los cuales el primer pico de presión producido debido a la parada de una bomba excedió las predicciones del modelo. Dawson y Fox (1983) razonaron que la acumulación de cambios menores en el flujo durante el período transitorio tenía un efecto significativo sobre los picos de presión haciendo que éstos fueran mayores. Por otra parte, Jonsson L. (1985) atribuye los resultados a la compresión de un colchón de aire aislado cerca de la válvula de retención. Jonsson lo justifica aplicando un modelo estándar (celeridad constante y teoría de la elasticidad) y concluye 
que debería existir un volumen mínimo de aire para el cual aplicar el término "colchón de aire" fuera válido. Burrows R. y Qiu D.Q. (1995) utilizaron las investigaciones de Jonsson del uso de bolsas de aire como una validación independiente para mejorar las explicaciones las discrepancias entre las observaciones del transitorio y los resultados del modelo. Estos autores sugirieron que debería ser necesaria una combinación entre celeridad variable y la consideración de una bolsa de aire discreta para obtener un modelo más riguroso pero que serían necesarios unos ensayos de laboratorio de alta calidad para mejorar la verificación de resultados. Ensayos de laboratorio más recientes y estudios piloto a escala Kapelan Z. et al. (2003), Covas et al. (2003) también han identificado picos de presión elevados y distorsión del transitorio debido a bolsas de aire. El trabajo de Leow L.C. y Lee T.S. (1998) y el de Low H.T. y Lee T.S.(1998), con el desarrollo de modelos numéricos que consideran una celeridad variable concluyen que hay una evidencia significativa que el aire atrapado en sistemas presurizados puede aumentar considerablemente los picos de presión.

Brunone (1999) y Baker y Ramos (2000) aportan a través de estudios esponsorizados por la UE un estándar europeo de software de análisis de transitorios, con la intención de servir de guía a los usuarios con un cierto nivel de complejidad en los modelos que aporte resultados consistentes. Algunos investigadores han intentado con cierto éxito utilizar una metodología formal, Stewardson et al. (2000) para caracterizar el comportamiento y proporcionar modelos predictivos sobre la base de la multiregresión en simulaciones de un problema transitorio específico. Sin embargo, estos modelos fallan al hacer un modelo predictivo general en sistemas complejos.

Campbell presenta en 1983 el trabajo "The effect of air valves on surges in pipelines" en la "International conference on pressure surges" celebrada en la Universidad de Bath en Inglaterra. El objetivo perseguido era demostrar los riesgos de utilizar ventosas de doble orificio convencionales de manera indiscriminada en todos los puntos elevados de un sistema de distribución de agua o en sistemas de saneamiento. El cierre de estas ventosas en procesos de descarga de aire produce presiones elevadas que pueden dañar las ventosas o incluso las tuberías. Para evitar estos flujos elevados, el autor propone llenar las líneas lentamente y limitar las presiones negativas de manera que se mantengan alturas positivas en todos los puntos de la instalación para evitar la entrada de aire. Sin embargo cumplir todas estas limitaciones es a menudo imposible por diversos motivos entre los que se pueden encontrar razones económicas. Según el autor reemplazar las ventosas críticas con válvulas antiretorno sirve para evitar los picos elevados de presión y la descarga gradual del aire atrapado en un sistema presurizado absorbe energía y amortigua las oscilaciones de la columna de agua. El autor afirma que se pueden diseñar combinaciones de ventosas que permitan una expulsión de aire eficiente al mismo tiempo que protejan la línea de los picos de presión y describe dichos diseños.

En Octubre de 1996 se publica en el "Journal of Hydraulic Engineering", el estudio "Filling of pipelines with ondulating elevation profiles" de Liou et al. Los autores formulan 
un modelo para describir el movimiento no estacionario de una columna de agua de longitud variable y rígida la cual llena una conducción de perfil ondulado y que se encuentra inicialmente vacía. El modelo aporta históricos de tiempo de la longitud de la columna de agua, de la velocidad y de la presión en diferentes puntos. Establecen además, unos criterios que permiten decidir la aplicabilidad del modelo en términos de intrusión de aire y del avance del frente de agua. Analizan la fase de llenado de la tubería experimentalmente, la cual tiene un diámetro interior de 22,9 $\mathrm{mm}$. Mediante un ejemplo los autores demuestran las aplicaciones del modelo a la hora de determinar la evolución de la velocidad y la aparición de la separación de la columna de agua en la instalación de perfil ondulado. El modelo que presentan es válido únicamente si no hay intrusión de aire.

Álvaro Acosta presenta en el "Grupo de Trabajo sobre Hidromecánica" en Montevideo (Uruguay, 1999) el documento "Aire atrapado en tuberías. Consideraciones sobre el volumen crítico", en el cual estudia la compresión dinámica de una bolsa de aire atrapada en el extremo de una tubería. La compresión la provoca la aceleración de una columna de agua que avanza desde un tanque hacia la bolsa de aire. El objetivo de este trabajo es determinar las sobrepresiones máximas que se alcanzan al comprimirse la bolsa de aire dinámicamente, ya que estas son mucho mayores que si la compresión se realiza de forma cuasi-estática. En este último caso la presión máxima que alcanza la bolsa de aire es igual a la diferencia de cotas. El autor supone la columna de agua incompresible y la evolución de la bolsa de aire politrópica. El principal problema que encuentra al hacer estas suposiciones es que para volúmenes de aire pequeños las sobrepresiones que estima son mucho mayores que las observadas experimentalmente debido a que al suponer la columna líquida incompresible la única manera de transferir la energía es comprimiendo la bolsa de aire. Esto implica que para volúmenes pequeños de aire las sobrepresiones resultan extremadamente elevadas. Por ello, finalmente se tiene en cuenta la compresibilidad de la columna líquida. Los ensayos de laboratorio se llevaron a acabo en una conducción de 14 mm de diámetro.

En el artículo "Experimental setup for entrapped air pockets model validation" presentado por Fuertes V.S. et al. (2000), los autores aportan un modelo matemático capaz de analizar el comportamiento de diferentes bolsas de aire atrapadas en una conducción de perfil irregular. Los autores validaron el modelo con ensayos prácticos. La conducción utilizada en los ensayos tenía una longitud total de 6,90 m y un diámetro interior de $18,8 \mathrm{~mm}$. Los autores concluyen que en transitorios rápidos el comportamiento de las bolsas de aire se puede considerar como una evolución adiabática con $\mathrm{k}=1,4$.

Una de las publicaciones recientes más interesantes que incluye el tratamiento de los transitorios hidráulicos con aire atrapado, es el efectuado por Zhou et al. (2002) "Transient flow in a rapidly filling horizontal pipe containing trapped air". Los autores destacan el evento ocurrido en Julio de 1995 en el área de Bonnie Doon de Edmonton, Alberta, en Canadá, en donde una gran tormenta de un período de retorno de 300 años sobrecargó la 
instalación de saneamiento en poco tiempo. De este modo, el sistema entró en carga en un corto período de tiempo. Como consecuencia del aire atrapado se experimentó un flujo inverso que provocó presiones muy altas las cuales fueron las causantes de que se saltaran las tapas de alcantarillado, con el consecuente peligro para los viandantes. En este trabajo se investiga tanto experimental como analíticamente la presión en una bolsa de aire atrapado en un Ilenado rápido de una tubería horizontal. Los autores ensayan tres tamaños diferentes de orificios por los que escapa el aire. El modelo matemático utilizado asume ciertas hipótesis, por ejemplo, considerar que la columna de agua es rígida, la tubería es horizontal, el aire ocupa completamente la sección transversal de la tubería, la interfaz aire-agua es vertical, el aire evoluciona politrópicamente, el factor de fricción utilizado es el correspondiente a flujo estático, la bolsa de aire presenta una resistencia despreciable y la presión de cabecera (condición de contorno aguas arriba) se considera constante.

Los mismos autores presentan en 2002 "Observations of air-water interaction in a rapidly filling horizontal pipe" en el cual aparecen los resultados de un estudio de observación relacionado con el comportamiento de sistemas de alcantarillado bajo condiciones de sobrecarga hidráulica. La investigación se centra en la interacción del agua y el aire atrapado en sistemas de alcantarillado sobrecargados y sistemas de tuberías presurizados, estudiando el comportamiento del flujo aire-agua en el Ilenado de una tubería horizontal. Se documentan fotográficamente los patrones de la interfaz aire-agua, entrada de aire y descarga de aire a través de un orificio al final de una tubería. También presentan las trazas de presión registradas sincrónicamente para ilustrar la relación entre la evolución de la fase aire-agua y los patrones de la oscilación de la presión. Más tarde, en 2004, publican el documento "Analysis of effects of air pocket on hydraulic failure of urban drainage infrastructure" en el cual estudian los efectos del aire atrapado sobre las oscilaciones del flujo y sobre la presión en un sistema de alcantarillado que se ve sometido a un Ilenado rápido. El estudio revela los impactos perjudiciales debidos a la existencia de aire atrapado durante varias tormentas bajo las cuales las conducciones se sobrecargaron. Los resultados de esta investigación revelaron la aparición de picos de presión elevados y oscilaciones de presión severas dentro del sistema.

El artículo "Transient flow in a rapidly filling horizontal pipe containing trapped air" fue discutido en 2002 por Arregui et al. En la discusión se cuestiona el modelo analítico propuesto por Zhou et al., así como las hipótesis establecidas. Zhou optó por la utilización del modelo rígido basándose en un estudio previo de Cabrera et al. En el estudio de Cabrera et al. (1992) se concluye que en un llenado rápido de una tubería en la cual quedan bolsas de aire atrapado, los resultados aportados por el modelo rígido y el modelo elástico no difieren más de un $2 \%$, lo cual solo es válida en sistemas en los cuales no haya descarga de aire al exterior. Según Cabrera et al. esta diferencia del $2 \%$ depende además de las presiones generadas y de dos parámetros adimensionales $\sigma$ y $\rho^{*}$. La utilización del modelo rígido solo sería válida para valores del producto $\sigma \cdot \rho^{*}>10$. A medida que este producto decrece, las diferencias entre el modelo rígido y elástico 
aumentan. Por tanto Arregui et al. concluyen que en el sistema estudiado por Zhou et al. no sería válida la consideración del modelo rígido

En el XII Congreso latino americano de hidráulica, el profesor Hugo Saturno Bello presentó el artículo "Nuevo método para la selección de válvulas de admisión de aire para tuberías" en el cual se analiza el proceso no permanente de vaciado de un tramo de tubería de diámetro, longitud y pendiente conocidos. La descarga del agua a la atmósfera se realiza por el extremo inferior de la tubería la cual tiene en su extremo superior una válvula de admisión de aire. Trata el agua como incompresible y toma en consideración la expansión del aire que entra a la tubería. El autor presenta unas tablas que permiten estimar la mínima presión que se produce dentro de la tubería durante el proceso de vaciado o escoger la válvula apropiada para proteger la tubería contra el colapso.

Kruinsbrick et al. en su trabajo "Dynamic performance characterisation of air valves" (2004) presentan las primeras ideas de la caracterización dinámica de ventosas. Los autores de este documento desarrollan parámetros característicos adimensionales para describir el comportamiento dinámico de las ventosas. Estos parámetros se obtienen a partir de un análisis dimensional del comportamiento de la bolsa de aire atrapado, de las ecuaciones del movimiento del flotador de la ventosa y de las ecuaciones de la columna del movimiento de la columna de agua. Pendiente queda por otro lado en este trabajo, la validación experimental de los métodos propuestos para estimar los picos de presión producidos tras el cierre de la ventosa.

Paralelamente al trabajo de Kruinsbricjk, aparece "Air valve dynamic behaviour" de Arregui et al., en el cual se hace especial hincapié en las pocas referencias y conocimientos disponibles acerca del comportamiento dinámico de las ventosas. Los autores detallan una serie de ensayos para determinar el comportamiento dinámico de ventosas en situaciones de admisión y de expulsión de aire. Además destacan la importancia de ciertos parámetros sobre la magnitud del pico de presión alcanzado tales como la velocidad de la columna de agua a la cual llega al flotador de la ventosa, el volumen de aire atrapado y la inercia de la columna de agua.

Todos estos trabajos ponen de manifiesto que en los últimos años ha aparecido una clara preocupación por el estudio de los efectos del aire atrapado en una instalación. En la actualidad existen muchos trabajos que estudian la caracterización dinámica de las válvulas. Por el contrario, el comportamiento dinámico de las ventosas es un tema del cual se dispone de poca bibliografía respecto a ensayos en laboratorio. Existen algunos estudios recientes del comportamiento de ventosas bajo condiciones de flujo cuasiestático pero solamente a escalas muy inferiores a las utilizadas en instalaciones reales. La falta de datos experimentales a escala real, el carácter dinámico del fenómeno y la complejidad en la caracterización del flujo bifásico son algunas de las principales causas del lento progreso efectuado en este campo. 


\subsection{OBJETIVO}

El principal objetivo del presente trabajo es profundizar en el estudio de los transitorios hidráulicos producidos en conducciones de agua las cuales contienen aire atrapado. Además se pretende analizar como pueden afectar al transitorio los elementos de protección de las conducciones utilizados en estos casos, concretamente las ventosas. En general se prevé estudiar el grado en que estos dispositivos evitan o reducen el impacto negativo que puede tener tanto el aire atrapado como la aparición de bajas presiones en una instalación.

Uno de los puntos más novedosos que se desea introducir en este trabajo es el estudio del transitorio ocurrido en una instalación a gran escala en la cual se ensayan varios tipos de ventosas comerciales. Los requerimientos de espacio que esto supone hacen que se piense en unas instalaciones como las de W.L.|Delft Hydraulics (Holanda). Gracias a la aprobación del proyecto "Dynamic behaviour of air valves" dentro del programa "Transnational Access to Major Research Infraestructure (MRI)" de la Comisión Europea, ha sido posible disponer de este tipo específico de instalaciones para la realización de ensayos. También como consecuencia de este proyecto europeo ha sido posible colaborar en la programación y realización de estos ensayos con investigadores pertenecientes a cinco grandes grupos de investigación europeos.

El trabajo práctico se ha estructurado de manera que los ensayos se llevaron a cabo de manera ordenada y eficiente. El primer paso del estudio de las ventosas comerciales consiste en conocer la capacidad de descarga y admisión de aire de las mismas. De este modo, se pretende comparar los datos reales con los aportados por el fabricante de las ventosas. Para el estudio de la capacidad de descarga y admisión de las ventosas se propone una serie de ensayos en los cuales se hace circular un caudal de aire en régimen permanente en la instalación.

Conocida la capacidad de descarga de las ventosas, el segundo paso consiste en analizar los transitorios con aire atrapado que simulan el llenado y el vaciado de la instalación. Se requiere así pues ensayos en los cuales se obtengan mediciones de presiones en varios puntos de la conducción, el caudal de agua circulado y el desplazamiento del flotador de la ventosa instalada en cada instante.

Finalmente, se considera interesante el estudio de la capacidad de respuesta de una ventosa situada junto a una válvula de retención frente a las depresiones producidas por el cierre brusco de dicha válvula.

Los datos de los ensayos deben estar perfectamente organizados, seleccionados, clasificados y tratados para poder extraer conclusiones de los mismos. A partir de las mediciones obtenidas en los ensayos como pueden ser la presión máxima medida en el sistema, el caudal de agua etc se propone establecer relaciones entre las variables 
características de los mismos. Además con las mediciones se pueden extraer otro tipo de variables tales como la deceleración de la columna de agua, la duración de los procesos de expansión y compresión de la bolsa de aire atrapado, la duración del cierre de la ventosa etc. La visualización de resultados de manera que se pueda establecer una comparación entre los diferentes ensayos debe ser clara. La cantidad de datos numéricos en el estudio de transitorios hidráulicos es tal que se propone la representación gráfica de los mismos.

El tratamiento y análisis de resultados prácticos se debe ser útil principalmente a la hora de realizar un análisis de sensibilidad de los parámetros que intervienen en el proceso. Los parámetros del transitorio que en un principio no se conocen son la celeridad, el coeficiente de fricción, el coeficiente politrópico así como el volumen de aire atrapado en la instalación. Dicho análisis de sensibilidad, debería predecir cuales son los parámetros que más afectan al resultado final del transitorio hidráulico. La elaboración del análisis de sensibilidad requiere de un modelo teórico que sea capaz de simular el fenómeno transitorio.

Debido a la dificultad que supone el tratamiento y estudio de los transitorios hidráulicos con aire atrapado en una instalación es importante centrar el análisis de sensibilidad en un solo tipo de ensayos. Es decir, se debe plantear un modelo teórico que simule el caso que aporte los resultados más homogéneos y sea más simple de definir. En principio cabe pensar que los ensayos que cumplen con esta premisa son los ensayos de expulsión de aire al final de una conducción, los cuales presentan la configuración más sencilla de la instalación.

El modelo teórico que se proponga debe incluir tanto las ecuaciones de la columna de agua como las de la bolsa de aire. El modelo debe ser flexible para poder cambiar en cada caso las condiciones iniciales del ensayo a representar así como el valor de los parámetros. Dadas las facilidades de cómputo que ofrecen hoy en día los ordenadores, cabría plantear en un principio las ecuaciones modelo elástico y realizar la resolución de dicho modelo matemático mediante el método de las características.

Con todo ello, este trabajo pretende ser una modesta aportación al estudio de los transitorios hidráulicos con aire atrapado en una instalación que cuenta con la presencia de una ventosa. 

CAPÍTULO 2. TIPOLOGÍA DE VENTOSAS Y SUS FUNCIONES 



\subsection{INTRODUCCIÓN}

El informe CIRIA (Reader et al 1997) define una ventosa como "una válvula ubicada en un punto estratégico de un sistema con la finalidad de expulsar aire cuando la instalación se está llenando de agua o bien admitir aire cuando se vacía".

En los sistemas de distribución de agua, las ventosas realizan una o varias de las siguientes funciones:

- Descarga de grandes cantidades de aire durante el llenado de agua de un sistema parcial o completamente vacío.

- Admisión de grandes cantidades de aire en la instalación que se desea vaciar de agua con el fin de evitar depresiones que puedan dañar el sistema.

- Descarga de aire residual que se ha quedado atrapado después del Ilenado de agua o que se ha desprendido de la misma durante el funcionamiento normal en una instalación presurizada.

Así pues, la función de las ventosas en líneas generales es expulsar y/o introducir aire en una conducción. La expulsión de aire se produce como se ha indicado anteriormente cuando se procede a llenar de agua una conducción que inicialmente se encontraba parcial o totalmente llena de aire. Estos casos pueden ocurrir cuando se pone en funcionamiento una instalación nueva, en el arranque de bombas que captan agua subterránea o cuando se llenan de agua las conducciones después de haberse producido un corte de suministro. 
La admisión de aire mediante ventosas se realiza con la finalidad de proteger la instalación frente al colapso debido a la caída de presión por debajo de la atmosférica. Esto se puede dar por ejemplo en los casos en los que se procede a un vaciado de la instalación, durante un transitorio hidráulico, en zonas elevadas debido a un aumento de consumo o en sistemas con desniveles.
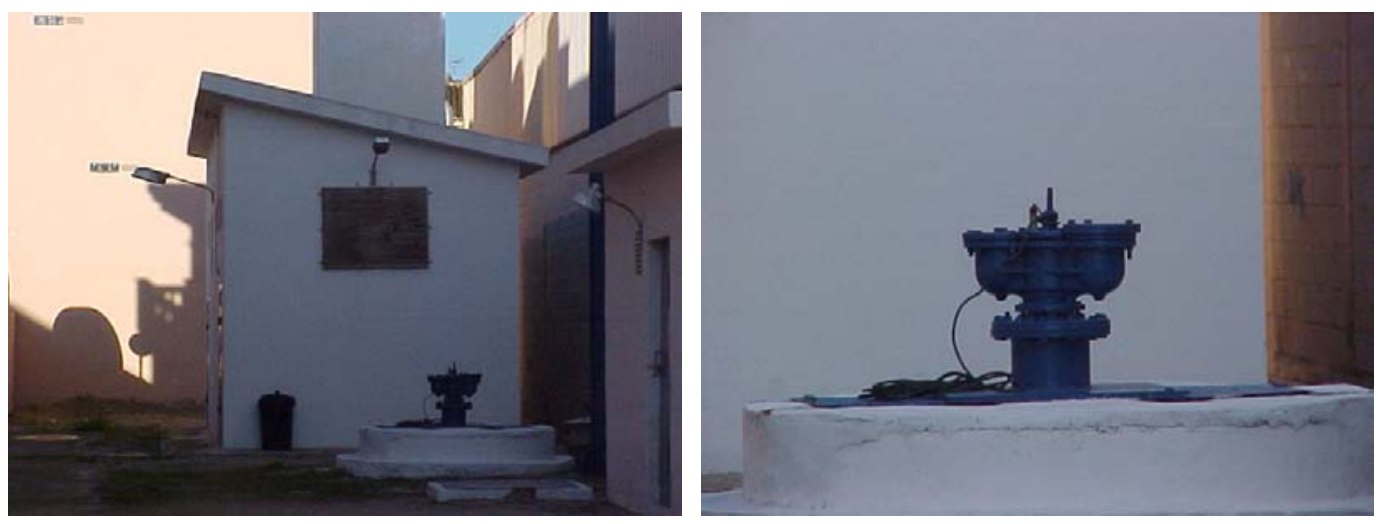

Figura 2.1. Utilización de una ventosa trifuncional en un pozo

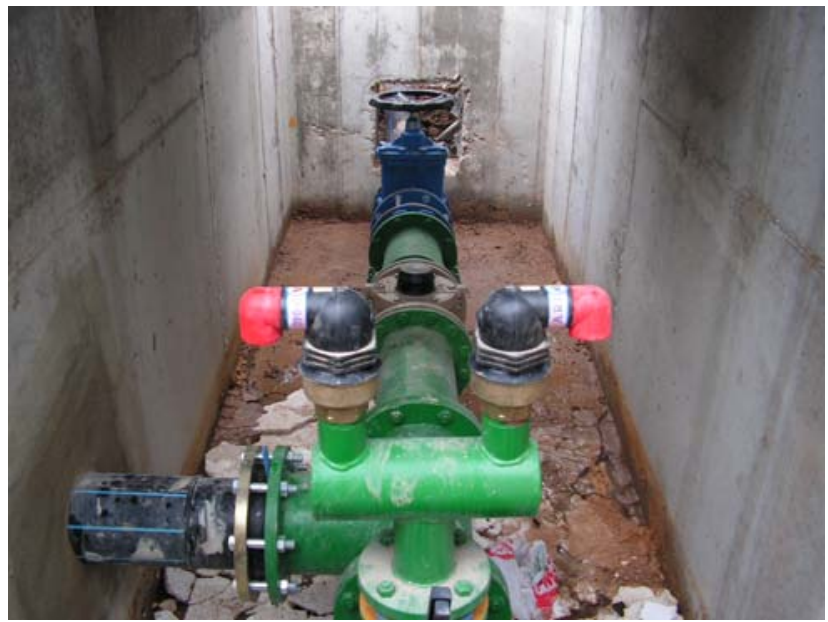

Figura 2.2. Ventosas en arqueta a la salida de un pozo 


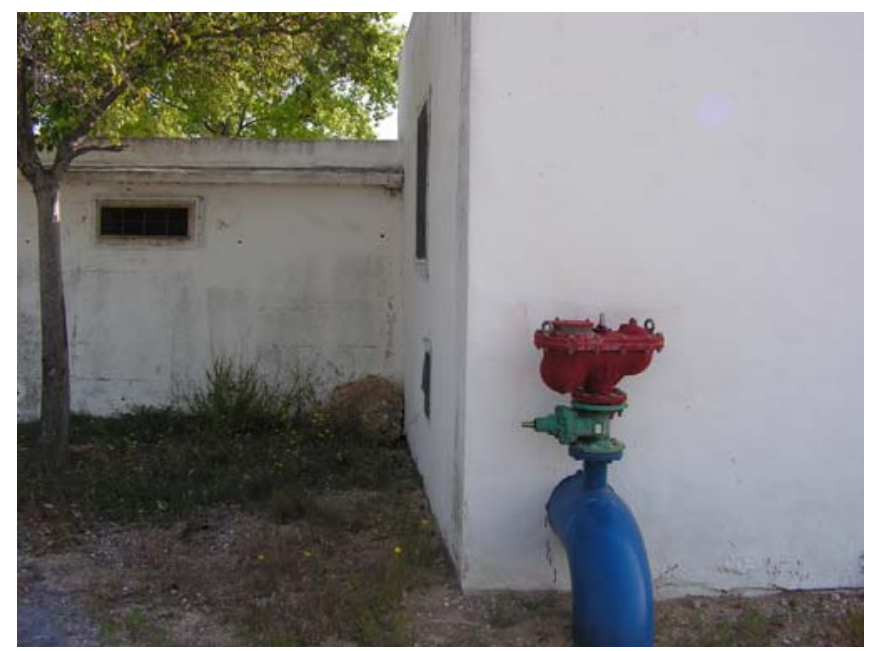

Figura 2.3. Ventosa en depósito

\subsection{TIPOS DE VENTOSAS SEGÚN LA FUNCIÓN QUE DESEMPEÑEN.}

El proyectista de una instalación debe escoger el tipo de ventosa que más se adecue a cada problema concreto atendiendo a la función que se desee que desempeñe, a su tamaño etc. Generalmente, la estructura básica de una ventosa consiste en un cuerpo en forma de copa, cuya parte superior posee una tapa con un orificio y en la parte inferior una brida o rosca que conecta con la tubería. En el interior del cuerpo se aloja el mecanismo de obturación que consiste en un flotador, que suele ser esférico o cilíndrico, el cual obstruye el orificio de la tapa. Aunque el cierre de la ventosa se realiza en muchos casos directamente mediante el flotador, existen diseños en los cuales el flotador mueve una palanca que a su vez posee en su extremo final un obturador el cual es el encargado final de cerrar la ventosa. Como diseño especial cabe citar las ventosas de cierre progresivo o cierre lento las cuales disponen de un mecanismo que ralentiza el movimiento del obturador.

\subsubsection{PURGADORES AUTOMÁTICOS}

Los purgadores son válvulas de aireación de pequeño orificio cuya función es expulsar pequeñas cantidades del aire desprendido que pueda circular por la tubería presurizada. Este aire disuelto aparece como consecuencia de los cambios de presión y temperatura que puede sufrir el agua en el interior de la instalación. El diámetro del orifico de salida de los purgadores se dimensiona en relación con la presión de trabajo en la instalación. Generalmente el orificio de salida del aire no suele ser superior a $12 \mathrm{~mm}^{2}$. Los purgadores automáticos se suelen ubicar cerca de bombas centrífugas, las cuales durante su funcionamiento habitual suelen introducir pequeñas cantidades de aire. 


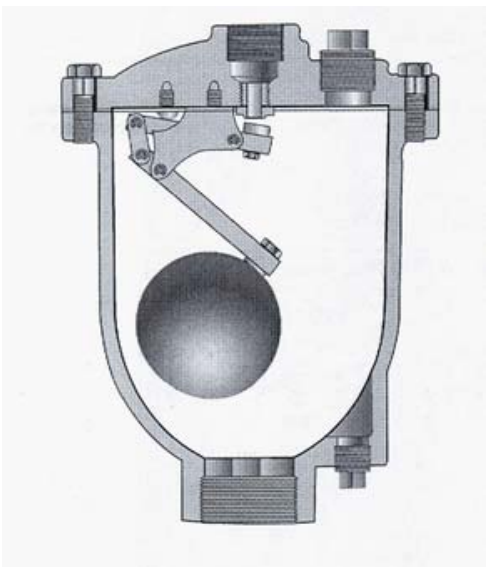

Figura 2.4. Purgador automático

\subsubsection{VENTOSAS BIFUNCIONALES}

Este tipo de ventosas están provistas de un orificio de gran tamaño el cual es capaz de realizar dos funciones, evacuar grandes cantidades de aire durante el proceso de llenado de la conducción y admitir aire, también en grandes cantidades, durante el proceso de vaciado de la misma o cuando se produce cualquier fenómeno capaz de generar una depresión en el sistema.

\subsubsection{VENTOSAS TRIFUNCIONALES}

Las ventosas trifuncionales son una combinación de las dos ventosas expuestas anteriormente, es decir, constan de un purgador y de una ventosa bifuncional. De este modo, dichas ventosas pueden expulsar pequeñas o grandes cantidades de aire durante el funcionamiento normal y el llenado de la instalación respectivamente, al mismo tiempo que son capaces de admitir grandes cantidades de aire en los procesos de vaciado de la instalación.

Las ventosas trifuncionales se fabrican generalmente en un solo cuerpo, es decir, el flotador grande y el flotador pequeño del purgador se encuentran alojados en un mismo cuerpo compacto como muestra la Figura 2.6. También es posible encontrar ventosas trifuncionales en las cuales los dos flotadores se encuentran en cuerpos separados, son las denominadas ventosas de doble cuerpo como la que aparece en la Figura 2.5. 


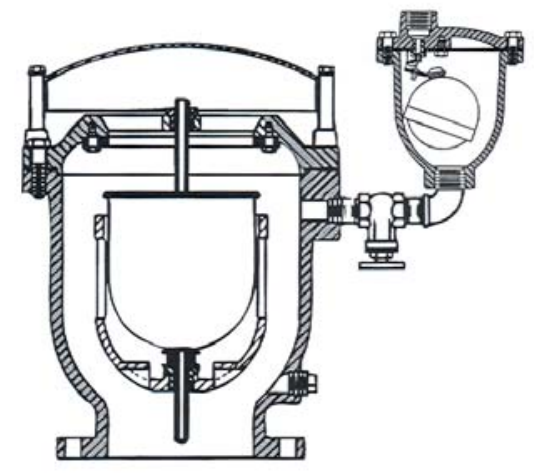

Figura 2.5. Esquema del interior de una ventosa trifuncional de doble cuerpo
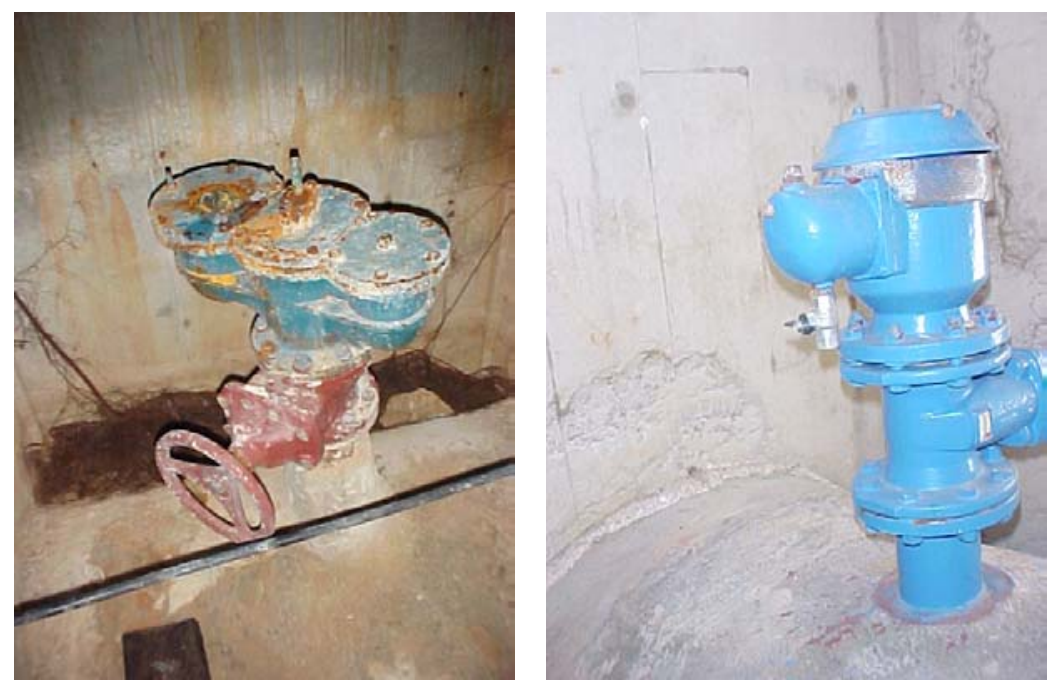

Figura 2.6. Ventosas trifuncionales instaladas en arquetas

\subsubsection{VENTOSAS DE ENTRADA DE AIRE (ADUCTORAS)}

Las ventosas de entrada de aire disponen de un orificio grande cuya única función es la admisión de aire en grandes cantidades durante cualquier proceso que implique una depresión en el interior de la tubería. Estas ventosas están provistas en algunos casos de un purgador adicional. 


\subsection{VENTOSAS DE GRAN ORIFICIO: VENTOSAS NO CINÉTICAS Y VENTOSAS CINÉTICAS}

Las ventosas de gran orificio se utilizan generalmente para permitir la descarga de aire durante el llenado de una conducción. Se considera "orificio grande" a un orificio de diámetro mayor de $25 \mathrm{~mm}$. Estas ventosas están diseñadas para permanecer cerradas una vez que la tubería esté completamente llena, presurizada y en funcionamiento normal. No permiten la descarga de pequeñas cantidades de aire que se puedan acumular durante la operación del sistema. Algunos autores proponen que las velocidades de descarga a través de una ventosa no deben exceder los $30 \mathrm{~m} / \mathrm{s}$ para evitar que la ventosa cierre prematuramente, fenómeno conocido como "cierre dinámico". Cabe destacar que la velocidad de descarga de aire depende en gran medida del diseño de la estructura interior de la ventosa. Existe una amplia variedad de ventosas de gran orifico entre las cuales se incluyen los diseños de ventosas no-cinéticas y ventosas cinéticas.

Para comprender el fenómeno del cierre dinámico, se han analizado las fuerzas que actúan en cada momento sobre el flotador de la ventosa.

\subsubsection{BALANCE DE FUERZAS EN EL FLOTADOR DE UNA VENTOSA DE GRAN ORIFICIO.}

El flotador de la ventosa se ve sometido a una serie de fuerzas mientras se producen los fenómenos de expulsión o admisión de aire en el sistema e incluso cuando la ventosa se encuentra cerrada. El balance de fuerzas para cada uno de estos eventos se describe de manera reducida a continuación.

\section{Balance de fuerzas en la entrada de aire a través de la ventosa.}

En el supuesto en el cual la ventosa se encuentre admitiendo aire en la instalación las fuerzas que actúan sobre el flotador de la misma son: el peso del flotador (W), el empuje (E) debido al aire que desaloja y las fuerzas de arrastre $\left(\mathrm{F}_{\mathrm{a}}\right)$ del aire sobre el flotador. 


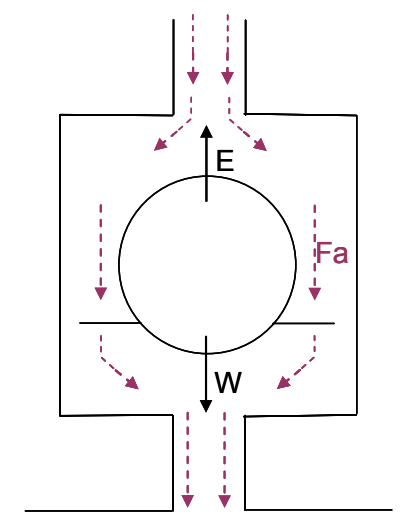

Figura 2.7. Balance de fuerzas sobre el flotador durante la admisión de aire

El balance de fuerzas correspondiente a la admisión de aire a través de una ventosa es el siguiente:

$$
\sum F=m \cdot \frac{d v}{d t}
$$

Siendo

$$
\sum F=E-W-F_{a}
$$

La fórmula general de la fuerza de arrastre viene dada por la siguiente expresión:

$$
F_{a}=\frac{1}{2} \cdot C_{a} \cdot \rho_{f} \cdot A \cdot v^{2}
$$

Donde:

$\mathrm{C}_{\mathrm{a}}$ es el coeficiente de arrastre.

$\rho_{f}$ es la densidad del fluido, en este caso aire.

$A$ es la sección transversal al movimiento. En el caso de una esfera o un flotador cilíndrico se tomará $\left(\pi \cdot r^{2}\right)$

$\checkmark$ es la velocidad del fluido.

El coeficiente de arrastre $C_{a}$, depende tanto de las características del flotador como de la geometría interna de la cámara de la ventosa. Por tanto, se deben tener en cuenta ambas piezas ya que existen interacciones entre éstas y el fluido circulante. Por este motivo, no existe una fórmula general para expresar el valor del coeficiente de arrastre. El modo más correcto para determinar su valor es mediante ensayos experimentales o bien mediante métodos numéricos. En general, el valor del coeficiente $C_{a}$ es menor cuanto menor sea la resistencia al paso del aire del conjunto. 
Existen cálculos detallados del coeficiente $C_{a}$ en el caso concreto de que el flotador de la ventosa sea una esfera sumergida en un fluido sin fronteras, llevando dicho fluido una velocidad v. En este caso, el coeficiente de arrastre es función del número de Reynolds, Re. Este parámetro es importante para definir el comportamiento de un fluido y la transición del flujo laminar a turbulento y se define como:

$\operatorname{Re}=\frac{\rho_{f} \cdot L \cdot v}{\eta}$

Donde:

L, representa la longitud característica del objeto.

$\eta$ es la viscosidad dinámica del fluido.

La viscosidad dinámica se calcula teniendo en cuenta que el valor de la viscosidad cinemática del aire a una temperatura de $20{ }^{\circ} \mathrm{C}$ es de $1,5 \cdot 10^{-5} \mathrm{Kg} /(\mathrm{m} \cdot \mathrm{s})$

En el supuesto en el cual no hubiese distorsión en el fluido alrededor del flotador, la fórmula del coeficiente de arrastre se podría expresar como:

$C_{a} \approx \frac{24}{\operatorname{Re}}+\frac{6}{1+\sqrt{\operatorname{Re}}}+0,4$

Cuando el número de Reynolds es muy pequeño, menor que la unidad, el primer término de la expresión anterior es mucho mayor que el resto. De este modo, a Reynolds bajos, la fuerza de arrastre sobre un cuerpo de forma esférica de radio $r$ se puede escribir como:

$F_{a}=\frac{1}{2} \cdot \frac{24}{\operatorname{Re}} \cdot \rho_{f} \cdot\left(\pi \cdot r^{2}\right) \cdot v^{2}=6 \cdot \pi \cdot \eta \cdot r \cdot v \quad \operatorname{Re}<1$

Si la turbulencia del fluido aumenta, encontrándose el número de Reynolds entre 1000 y 200000, el coeficiente de arrastre $C_{a}$ es aproximadamente constante y de valor $C_{a} \approx 0,4$. En consecuencia, la fuerza de arrastre sobre una esfera de radio $r$, cuando no hay distorsión en el fluido alrededor de la misma es:

$F_{a}=0,2 \cdot \rho_{f} \cdot \pi \cdot r^{2} \cdot v^{2}$

Retomando el balance de fuerzas se puede decir que cuando se produce admisión de aire a través de la ventosa la ecuación general (Ec. 1.2) queda del siguiente modo:

$m \cdot \frac{d v}{d t}=\rho_{f} \cdot \frac{4}{3} \cdot \pi \cdot r^{3} \cdot g-\rho_{e} \frac{4}{3} \cdot \pi \cdot r^{3} \cdot g-\frac{1}{2} \cdot C_{a} \cdot \rho_{f} \cdot A \cdot v^{2}$ 
Donde

$\rho_{e}$ es la densidad del elemento móvil, en este caso, del flotador de la ventosa.

En principio se supone que el flotador se encuentra asentado sobre el soporte inferior de la cámara de la ventosa lo cual implica que el flotador no está en movimiento. Por tanto, el primer término de la ecuación anterior es nulo, y el balance de fuerzas final sobre el flotador cuando se produce entrada de aire en el sistema es:

$0=\rho_{f} \cdot \frac{4}{3} \cdot \pi \cdot r^{3} \cdot g-\rho_{e} \frac{4}{3} \cdot \pi \cdot r^{3} \cdot g-\frac{1}{2} \cdot C_{a} \cdot \rho_{f} \cdot A \cdot v^{2}$

$0=\left(\rho_{f}-\rho_{e}\right) \cdot \frac{4}{3} \cdot \pi \cdot r^{3} \cdot g-\frac{1}{2} \cdot C_{a} \cdot \rho_{f} \cdot A \cdot v^{2}$

Como la densidad del fluido es mucho menor que la densidad del flotador de la ventosa, todas las fuerzas actúan en la misma dirección.

\section{Salida de aire a través de la ventosa}

El otro supuesto al que puede verse sometido el flotador de la ventosa es la expulsión de aire a través del orificio de salida. Las fuerzas actuantes sobre el flotador cuando se produce una descarga de aire a través de la ventosa son las mismas que en el caso anterior, en el cual se consideraba la admisión de aire, pero variando los sentidos de alguna de ellas. El balance de fuerzas, se muestra gráficamente en la figura siguiente:

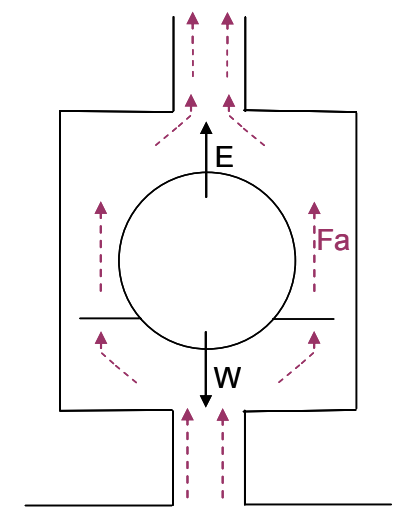

Figura 2.8. Balance de fuerzas sobre el flotador durante la expulsión de aire

La fuerza de arrastre, en este caso, toma un sentido ascendente, ya que el aire se dirige desde la instalación hacia el exterior a través de la ventosa. El balance de fuerzas se expresa en este supuesto en los siguientes términos: 
$\sum F=E-W+F_{a}$

Este balance de fuerzas se puede escribir como.

$m \cdot \frac{d v}{d t}=\rho_{f} \cdot \frac{4}{3} \cdot \pi \cdot r^{3} \cdot g-\rho_{e} \frac{4}{3} \cdot \pi \cdot r^{3} \cdot g+\frac{1}{2} \cdot C_{a} \cdot \rho_{f} \cdot A \cdot v^{2}$

Al igual que en el caso anterior, si se tiene en cuenta que el flotador se encuentra inmóvil en el asiento interior de la ventosa, el balance de fuerzas sobre el flotador durante la expulsión de aire queda del siguiente modo:

$0=\rho_{f} \cdot \frac{4}{3} \cdot \pi \cdot r^{3} \cdot g-\rho_{e} \frac{4}{3} \cdot \pi \cdot r^{3} \cdot g+\frac{1}{2} \cdot C_{a} \cdot \rho_{f} \cdot A \cdot v^{2}$

El coeficiente de arrastre límite para que el flotador se mueva y cierre la ventosa se obtiene despejando $C_{a}$ de la ecuación anterior:

$C_{a}=\frac{8 \cdot \pi \cdot r^{3} \cdot g}{3 \cdot A \cdot v^{2}} \cdot\left(\frac{\rho_{e}}{\rho_{f}}-1\right)$

Si el coeficiente de arrastre real es mayor que el coeficiente de arrastre límite obtenido mediante la ecuación (Ec 1.14) entonces se dice que la ventosa cierra prematuramente y se produce el cierre dinámico.

\subsubsection{VENTOSAS NO CINÉTICAS.}

Las ventosas no cinéticas que generalmente poseen un flotador esférico y hueco, se caracterizan porque tienen tendencia a cerrar prematuramente. Este cierre prematuro se debe fundamentalmente a que la densidad del flotador es similar o menor a la densidad del fluido.

Como consecuencia de este cierre prematuro, producido antes de que el agua alcance la ventosa, se retienen grandes cantidades de aire en el interior de las conducciones. A este efecto en el cual la ventosa cierra debido a las fuerzas aerodinámicas que genera el flujo de aire se le conoce como "cierre dinámico".

Las ventosas no cinéticas mantienen básicamente, hoy en día, el mismo diseño con el que fueron introducidas en el mercado. Por ello, quizá éste sea el tipo de ventosa que se puede encontrar en la mayoría de las instalaciones. 
El uso de flotadores esféricos y que además no presenten una densidad adecuada incluye problemas adicionales:

- Sellado pobre a presiones de trabajo relativamente bajas. Para producir un buen sellado contra el asiento de la circunferencia del orificio, el flotador debe ser perfectamente esférico. Si además el flotador es hueco, las altas presiones pueden hacer que se deforme con cierta facilidad. Estos problemas causados debido a la falta de uniformidad de la superficie del flotador se intentan corregir a menudo utilizando elementos de sellado excesivamente blandos. Dichos elementos de sellado blandos se adhieren al material del flotador dificultando su correcto funcionamiento.

- Deformación y atascamiento. Cuando la ventosa está sometida a altas presiones, el flotador esférico puede verse sometido a distorsiones y deformaciones permanentemente. Si el flotador no es perfectamente esférico debido a irregularidades en su superficie, no se produce un cierre estanco

- Cierre dinámico. Se refiere a la tendencia de la ventosa con flotador en forma de bola a cerrar con presiones diferenciales entre el exterior y el interior de la conducción relativamente bajas (3-5kPa). La ventosa cierra antes de que se haya expulsado todo el aire de la instalación, lo cual hace que, después del cierre de la ventosa, queden bolsas de aire atrapadas en la instalación.

- Limitación del tamaño del orificio y su efecto en el funcionamiento. La descarga y admisión de aire en las ventosas se ve afectada indudablemente por el tamaño del orificio. Algunos fabricantes opinan que el diámetro de la esfera no debería ser inferior a tres veces el diámetro del orificio más grande porque de no ser así el flotador podría encastrarse en el orificio y deformarse. A la hora del diseño, esto implica, por razones económicas, escoger un orificio de menor tamaño con lo cual se ve afectada de manera adversa la descarga de aire, puesto que se reduce la capacidad de expulsión del mismo.

\subsubsection{VENTOSAS CINÉTICAS.}

Las ventosas cinéticas se desarrollaron principalmente para solucionar el problema del cierre dinámico que experimentan las ventosas no cinéticas bajo ciertas condiciones, ya que tienen la capacidad de descargar aire sin que se desplace el obturador a causa del flujo de aire. Debido a su estructura interior y a las características del flotador, estas ventosas únicamente cierran una vez el agua entra en contacto con el flotador. La conservación de la apertura ante cualquier régimen de caudal de aire se logra alterando la configuración interna de la ventosa y su característica aerodinámica. Como se ha descrito anteriormente, para que no se produzca el cierre dinámico, el coeficiente de arrastre debe cumplir las condiciones del balance de fuerzas propuesto. 


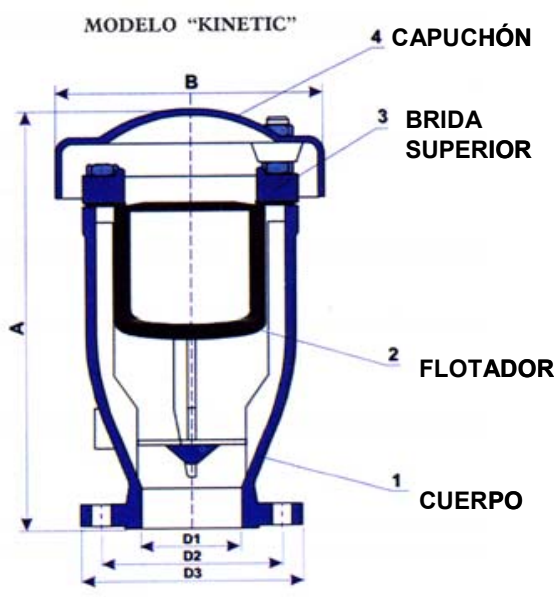

Figura 2.9. Ventosa cinética de ACMO Spa

Este tipo de ventosas permiten la expulsión de aire a grandes velocidades, lo cual puede causar ciertos problemas durante el funcionamiento normal de la instalación, por ejemplo:

- Si la velocidad de llegada de la columna de agua a la ventosa es elevada, se pueden producir transitorios hidráulicos con presiones asociadas elevadas en el momento en el cual se produce el cierre de la ventosa.

- Si el flotador del orificio de gran tamaño no reacciona a tiempo cuando entra una gran cantidad de agua en la cámara de la ventosa, dicha ventosa puede permanecer abierta. De este modo se pueden producir fugas de agua considerables que pueden dañar la instrumentación que se encuentre cerca de la ventosa si no se toman las medidas adecuadas.

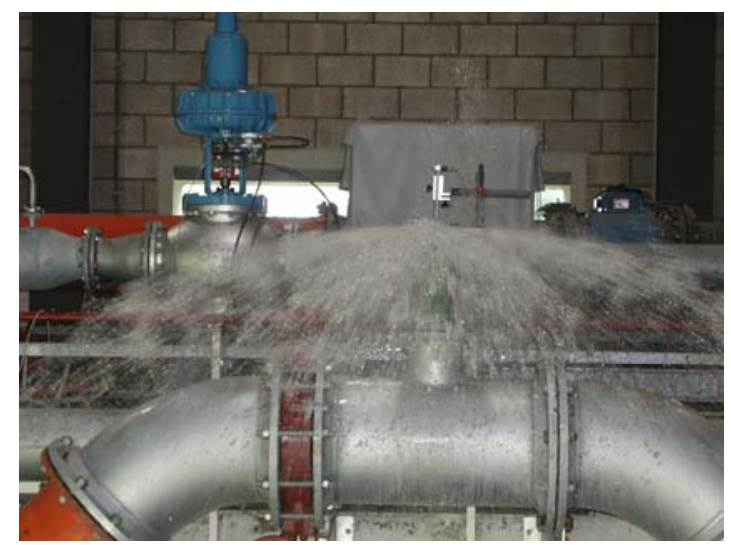

Figura 2.10. Fuga de agua por una ventosa. Ensayos de laboratorio 


\subsection{DISEÑOS ESPECÍFICOS DE VENTOSAS}

\subsubsection{VENTOSAS PARA AGUAS RESIDUALES}

Cuando el agua que circula por la instalación es agua residual, cuya característica principal es que trasporta sólidos en suspensión, se requiere un diseño específico de ventosa. Las ventosas para aguas residuales tienen una estructura particular aunque realizan las mismas tres funciones básicas que las ventosas convencionales. Los modelos de ventosas para aguas residuales presentan una mayor distancia vertical entre el flotador y el obturador para impedir que la suciedad llegue al mecanismo de palancas y al propio obturador. Uno de los principales problemas a los que se ven sometidas este tipo de ventosas es la acumulación de suciedad en la parte inferior de la misma. De este modo, dichas ventosas requieren de un mantenimiento más frecuente ya que en caso de no eliminar dicha suciedad convenientemente, la ventosa se ve sometida a un funcionamiento para incorrecto. Además de una estructura particular, las ventosas para aguas residuales deben ser fabricadas con materiales resistentes a la corrosión que les permita alargar su ciclo de vida útil.

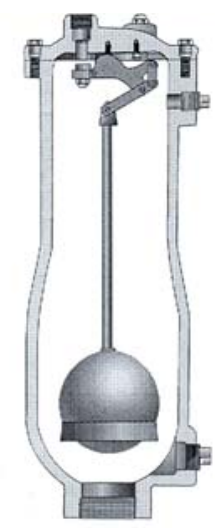

Figura 2.11. Ventosa para aguas residuales de ARI

\subsubsection{VENTOSAS DE CIERRE PROGRESIVO}

La finalidad de las ventosas de cierre progresivo es ralentizar el cierre de manera que se minimice el efecto negativo de las elevadas presiones producidas por cambios bruscos y rápidos en la velocidad del agua en el momento de cierre de la ventosa. De entre todos los catálogos consultados de modelos, que se encuentran disponibles en el mercado, cabe destacar un par de modelos específicos de ventosas diseñadas con la finalidad de establecer cierres más lentos. Es el caso de las ventosas que proponen VENT-O-MAT y ARI Valves. 


\section{Diseño de la empresa VENT-O-MAT}

La empresa VENT-O-MAT propone un diseño característico de sus ventosas introduciendo hasta tres flotadores cilíndricos superpuestos en un mismo cuerpo. Con este peculiar diseño se pretende evitar el golpe de ariete producido por el cierre de la ventosa haciendo que dicho cierre sea más lento.

El aire atrapado en el interior de la conducción entra en la ventosa a través del orificio 3. Pasa entre el espacio disponible entre los flotadores cilíndricos (4), (5) y (6) y el cuerpo de la ventosa (2). Finalmente sale a la atmósfera por el orificio de mayor tamaño (1) tal y como se puede apreciar en la Figura 2.12

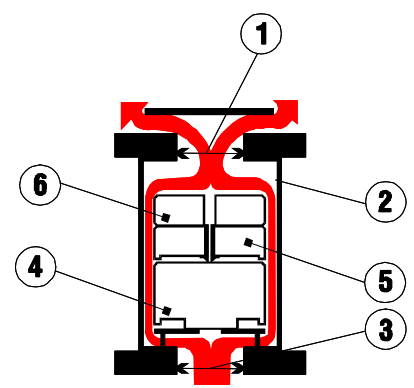

Figura 2.12. Expulsión de aire

Al aumentar el flujo de aire el flotador (6) asciende y cierra parcialmente el orificio de gran tamaño de la ventosa (1). De este modo, se obliga al aire a circular por el orificio anti-golpe (8) obteniendo como resultado la deceleración de la columna de agua debido a la resistencia que supone el aumento de la presión de aire en la ventosa.

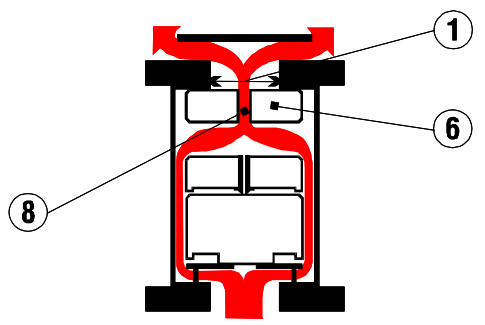

Figura 2.13. Deceleración de la columna de agua

Como consecuencia del llenado de la tubería, el líquido entra en la cámara de la ventosa (2). Al ponerse en contacto con el agua, los flotadores (4), (5) y (6) ascienden de manera que el flotador (6) tapona el orificio (1) de tal forma que la ventosa queda internamente bajo presión. Una ligera presión deja a los flotadores (5) y (6) en posición de cierre sobre el orificio (1). El aire disuelto en el agua se acumula poco a poco en la cámara de la ventosa de manera que cuando el volumen de aire es suficiente para desplazar el líquido, el flotador (4) descenderá ligeramente. Así pues, el orificio (7) quedará abierto permitiendo que escape el aire acumulado a modo de purgador convencional. Una vez 
eliminado todo el aire, el líquido llegará al flotador (4) el cual cerrará por completo de nuevo el orificio (7)

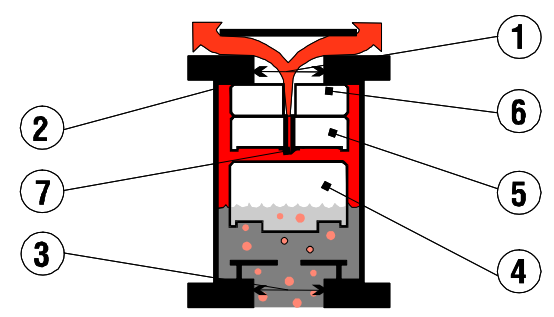

Figura 14. Purgador

En el caso que la ventosa se utilice en operaciones de drenaje de la tubería el funcionamiento de esta ventosa seguiría el proceso inverso, es decir, de apertura del orificio de entrada. El drenaje del líquido situado en la cámara (2) de la ventosa hace que los flotadores (4), (5) y (6) bajen y se sitúen sobre la plataforma (9) de manera que se permita la entrada de aire desde la atmósfera a la ventosa. La entrada de aire desplaza el líquido hacia la tubería evitando de este modo los daños intermedios que podrían producirse debido a las presiones negativas.

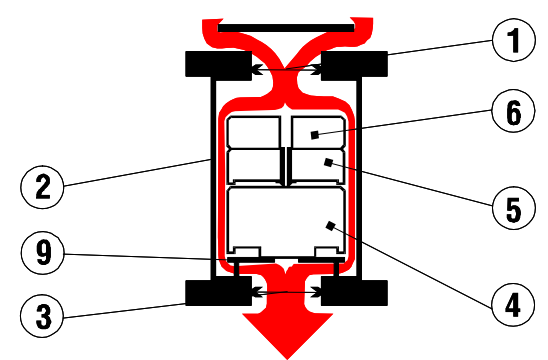

Figura 2.15. Admisión de aire

\section{Diseño de la empresa ARI Valves}

El cierre de estas ventosas se lleva a cabo en dos fases, de manera que se frena la extracción de aire en la segunda. Así pues en la fase final se elimina la bolsa de aire lentamente. El esquema de funcionamiento de dicha ventosa se explica en las siguientes figuras:

Cuando se pone en marcha la bomba, el agua desaloja el aire de la tubería con gran rapidez. El aire es expulsando por el orificio de gran tamaño (2) que posee la ventosa. Se elimina de este modo grandes cantidades de aire. 


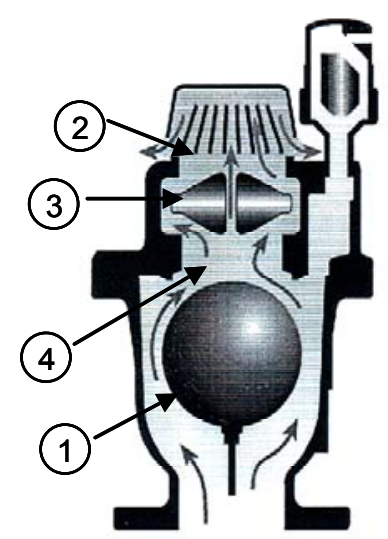

Figura 2.16. Expulsión de grandes cantidades de aire

Si la presión que ejerce el aire alcanza un determinado valor puede ser capaz de mover el flotador de menor tamaño (3) de manera que se cierra parcialmente el orificio (2). El aire sigue saliendo por el orificio pequeño que atraviesa el flotador hasta que es expulsado por completo.

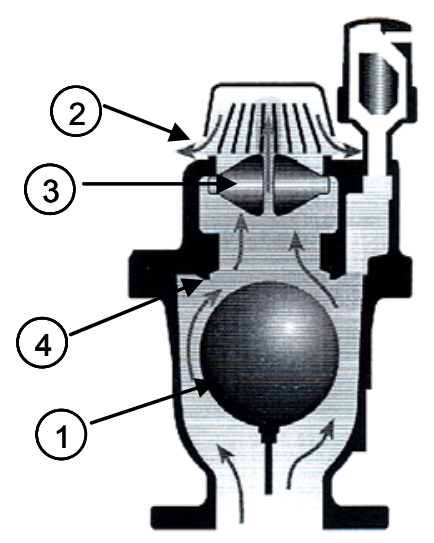

Figura 2.17. Salida de aire por orificio de menor tamaño

Cuando el agua alcanza la cámara de la ventosa, mueve el flotador (1) hacia la parte superior de la misma taponando el orificio (4). El flotador (3) vuelve a la posición abierta. El aire disuelto que se acumula en la ventosa puede ser eliminado a través del purgador (5). 


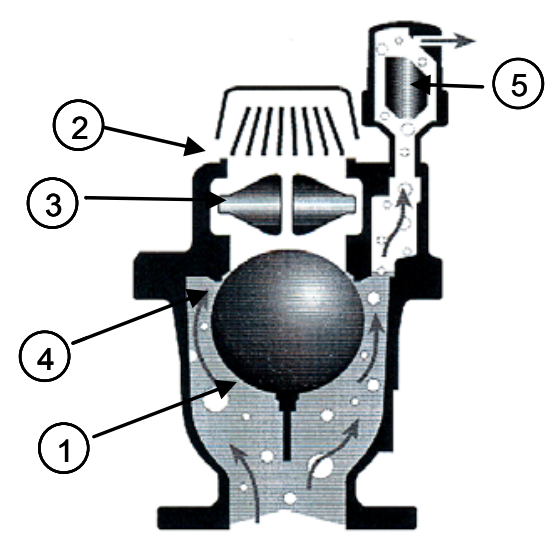

Figura 2.18. Purgador

Por el contrario, cuando se requiere drenar la tubería, la disminución de la presión que se crea desde la tubería da lugar a un descenso del flotador (1), de modo que el orificio de gran tamaño queda totalmente abierto. Con la ventosa abierta, y bajo estas circunstancias, se admiten grandes cantidades de aire en la tubería.

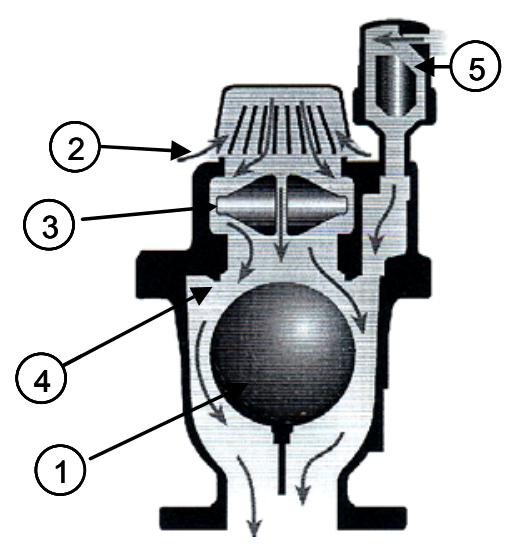

Figura 2.19. Admisión de aire

\subsubsection{VENTOSA COMBINADA PARA CONTADORES DE AGUA}

La empresa fabricante de ventosas ARI propone el diseño de una ventosa combinada cuya función es evitar que el aire que procede de la instalación circule a través del contador. El objetivo perseguido por los fabricantes es que el contador proporcione una correcta medición así como evitar el deterioro de los componentes del contador.

La ventosa combinada está constituida fundamentalmente por una ventosa, una válvula de retención y un contador de agua

Para abrir la válvula de retención se necesita una presión mínima. Si la ventosa tiene suficiente capacidad de descarga, la presión en la conducción se mantiene baja, de manera que el aire atrapado en la instalación no tiene la suficiente presión para abrir la 
válvula de retención. De este modo el aire escapa a través de la ventosa que se encuentra abierta. Cuando el agua alcanza al flotador de la ventosa ésta se cierra. En esta situación, la presión del agua es capaz de abrir la válvula de retención y de este modo, con la válvula de retención abierta, el agua puede circular a través del contador.

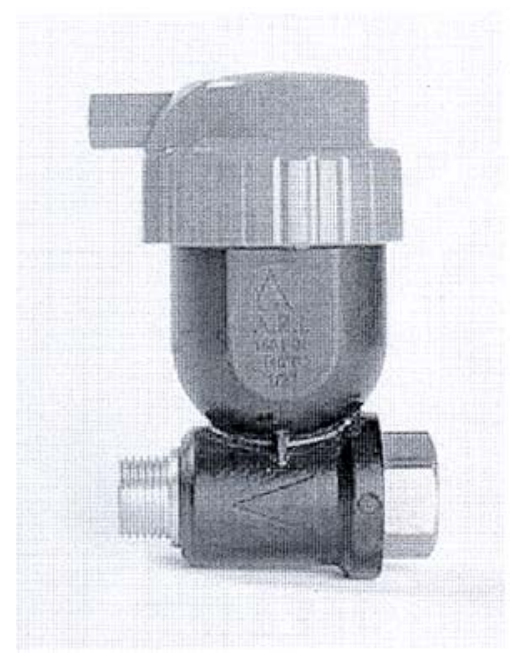

Figura 2.20. Ventosa para contador Metair modelo M-40

El esquema interior de la ventosa combinada para contador de agua se representa en la siguiente figura:

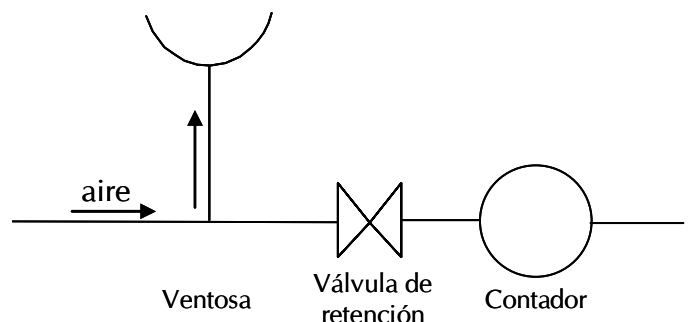

Figura 2.21. Esquema de los componentes de la ventosa combinada

\subsubsection{MECANISMOS ADICIONALES DE PROTECCIÓN PARA EVITAR SOBREPRESIONES}

Debido al peligro que supone para las instalaciones la aparición de sobrepresiones existen en el mercado una serie de mecanismos convencionales de protección los cuales actúan muchas veces conjuntamente con las ventosas. Dichos mecanismos se clasifican en mecanismos de acción directa y mecanismos de acción indirecta. Los llamados mecanismos de acción directa tratan de disminuir el efecto del transitorio actuando tal y como indica su nombre sobre la causa directa que lo provoca y se instalan en serie con la conducción a proteger. Entre los mecanismos de acción directa destacan los volantes de inercia, las válvulas de retención y las válvulas de cierre programado. Por otra parte, los mecanismos de acción indirecta actúan una vez se ha producido la perturbación sobre el 
sistema y tratan de minimizar sus efectos. Los mecanismos de acción indirecta son por ejemplo las chimeneas de equilibrio, los tanques unidireccionales, los calderines de aire comprimido, los By-pass en bombeos, los By-pass intermedios, las ventosas, las válvulas de alivio y las válvulas reguladoras de presión. Estos dispositivos se instalan en paralelo con la conducción a proteger y actúan en el momento adecuado. La elección final del dispositivo a utilizar se realiza en función de la causa que origina el transitorio.

Uno de los dispositivos más utilizados para evitar el golpe de ariete es el calderín. La habilidad de reacción del calderín ante situaciones de vacío en la instalación depende del tipo de válvulas de retención utilizadas. El vacío se produce en escasos milisegundos, lo cual a menudo es un tiempo muy pequeño para que la válvula reaccione de manera correcta y para que el agua llene suficientemente la cavidad.

En ocasiones no se instala una válvula de retención como en la Figura 2.22. El objetivo del calderín sin la válvula de retención es, de hecho, convertir un transitorio rápido (golpe de ariete) en una oscilación en masa controlada. Este fenómeno también puede ser perjudicial para la instalación en el caso de que se prolongara en el tiempo.

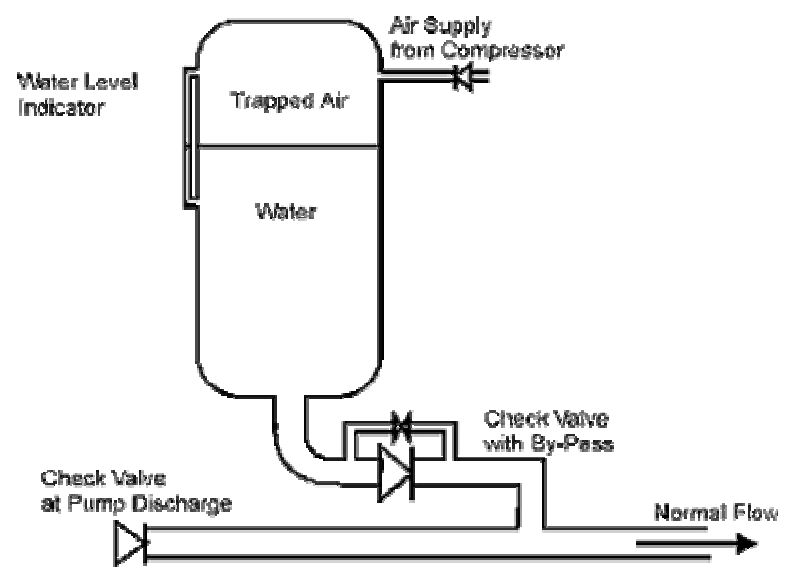

Figura 2.22. Esquema de calderín

Los tanques unidireccionales se ubican generalmente en reducciones de pendientes ascendentes o en puntos elevados de una instalación para eliminar las presiones subatmosféricas que se puedan producir. Al igual que los calderines convencionales también su respuesta está condicionada al tipo de válvula de retención instalada. 


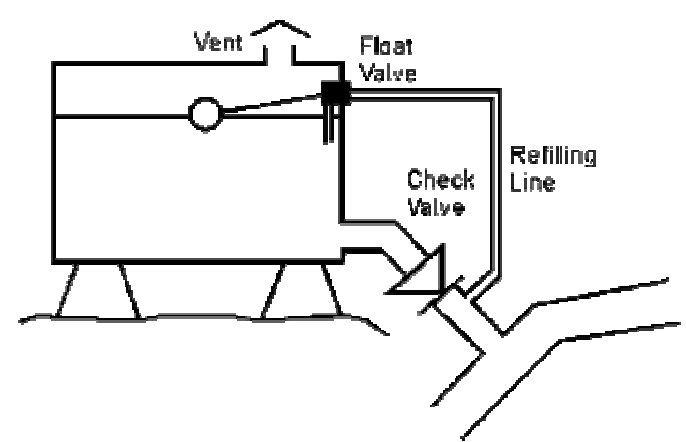

Figura 2.23. Tanque unidireccional

Por otro lado, es inherente al funcionamiento de las ventosas convencionales que se produzcan sobrepresiones debido al cierre del flotador. De hecho en la actualidad hay bastantes estudiosos de los transitorios que no tienen una opinión favorable respecto a la instalación de ventosas. Uno de los motivos de esta poca conformidad se basa en que en la práctica, las empresas de abastecimiento de agua realizan muy poco mantenimiento de las ventosas y que incluso en bastantes casos no se conoce ni siquiera la localización física de las mismas en la red de tuberías.

A lo largo del tiempo, los fabricantes han intentado aportar soluciones que protejan tanto a las ventosas como a las instalaciones del daño que provocan las sobrepresiones y el golpe de ariete realizando una serie de combinaciones que incluyen dispositivos adicionales junto a las ventosas convencionales los cuales se detallan a continuación.

\section{Ventosas de cierre lento con válvula de retención.}

Esta opción consiste en una ventosa cinética convencional la cual incorpora una válvula de retención tal y como se muestra en la Figura 2.24. El aire pasa a través de la válvula sin ninguna restricción hasta que el agua atraviesa la válvula de retención, en este instante debido a la mayor densidad del agua la válvula cierra. Con la válvula de retención cerrada se deja pasar menor flujo de agua. El flujo de agua en el interior de la cámara de la ventosa hace que el cierre la ventosa no sea instantáneo produciéndose a una velocidad menor. El principal problema que ofrece este dispositivo es que no evita que el efecto del golpe de ariete producido cuando cierra la válvula de retención afecte a la instalación. Además estos dispositivos son más caros y voluminosos que una simple ventosa. 


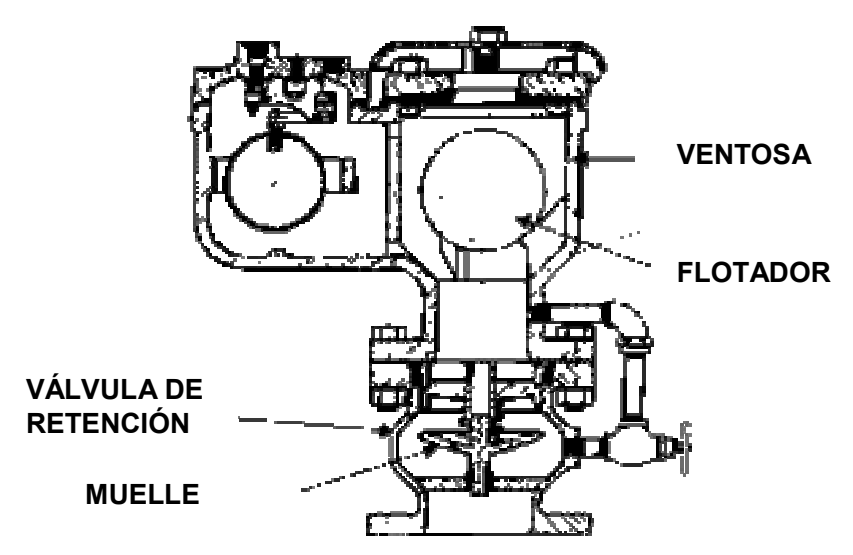

Figura 2.24. Ventosa de cierre lento

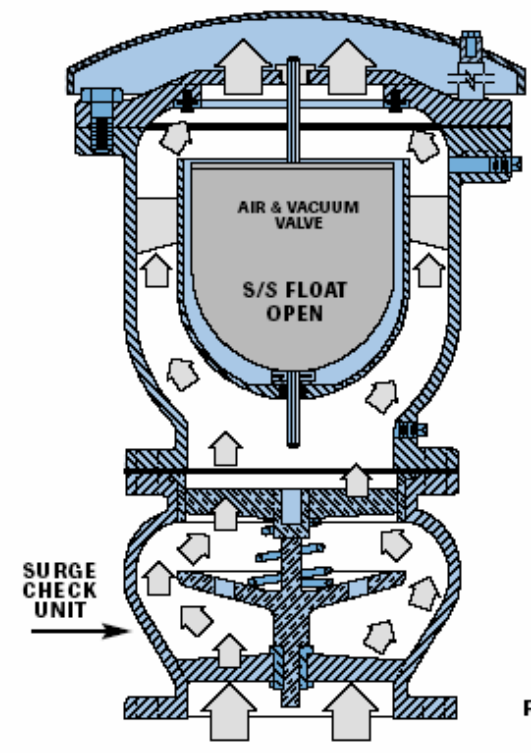

\section{See Bulletin 613}
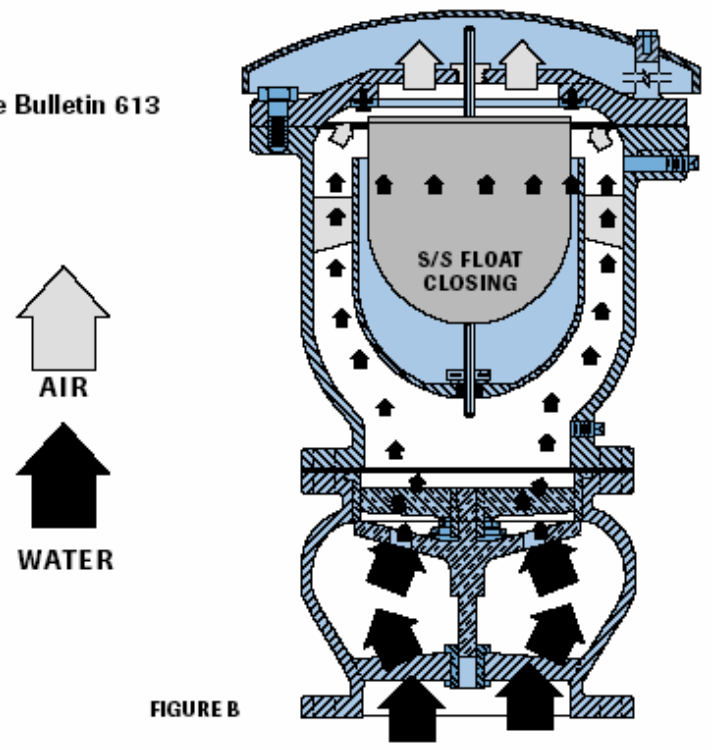

Figura 2.25. APCO Valves. Funcionamiento del cierre lento

\section{Ventosas controladas hidráulicamente.}

Estos dispositivos funcionan de la misma manera que una ventosa bifuncional convencional con la particularidad de que incorporan un mecanismo hidráulico en la parte exterior de la ventosa que controla la velocidad de cierre de la ventosa. Gracias a estos dispositivos se realiza una descarga regulada de agua a un tiempo de cierre preseleccionado, de tal forma que se eviten los cierres rápidos y la onda se disipe en la ventosa. El dispositivo de control consiste en un pistón que se mueve en el interior de un cilindro Ileno de aceite, el cual sirve como elemento de control del movimiento.

En el modelo concreto de la Figura 2.26, el cilindro dispone de dos etapas de control en el proceso de cierre. La primera etapa de control se coloca en la parte externa de la instalación y representa el $90 \%$ del desplazamiento del flotador. La segunda etapa de control localizada en el mismo cilindro, que puede ser ajustada a cualquier velocidad de cierre, se realiza en el $10 \%$ restante del desplazamiento del flotador. Los elementos de control primario y secundario deben estar completamente ajustados. Asimismo, deben 
estar situados en un lugar fácilmente accesible para que se puedan realizar los ajustes sin tener que desmontar ningún componente de la válvula y sin tener que parar la instalación. Este tipo de ventosas son también muy voluminosas y caras y además requieren de una persona que realice el ajuste del dispositivo de control hidráulico.

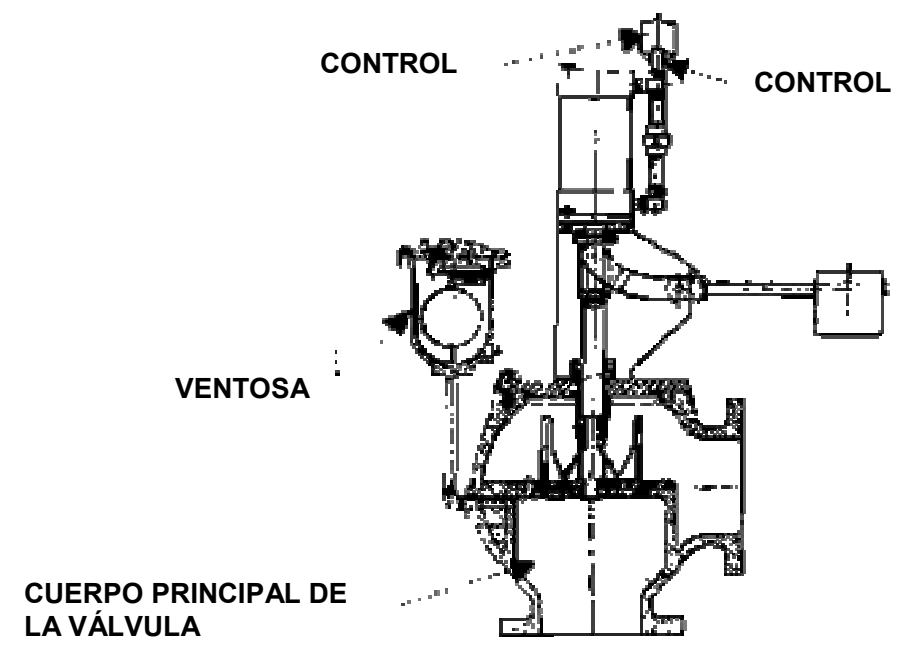

Figura 2.26. Ventosa controlada hidráulicamente

\section{Ventosas antiretorno.}

Se trata de la combinación de una válvula convencional antiretorno junto a una ventosa de pequeño orificio. Estas válvulas permiten la entrada de aire sin ninguna restricción durante la separación de la columna de agua pero controlan la descarga de aire, eliminando de esta manera la posibilidad de que tenga lugar el golpe de ariete.

Debido al pequeño tamaño del orificio, en los procesos de expulsión de aire de la instalación se acumula mucho aire en el interior de la instalación. La columna de agua comprime el aire más rápidamente de lo que éste puede ser expulsado por el orifico de salida de tal forma que provoca la aparición de oscilaciones. La gran bolsa de aire acumulada actúa en este caso como un muelle, y es la causante de las oscilaciones de la columna de agua. Con este tipo de ventosas se aumentan los tiempos de los procesos de llenado. 


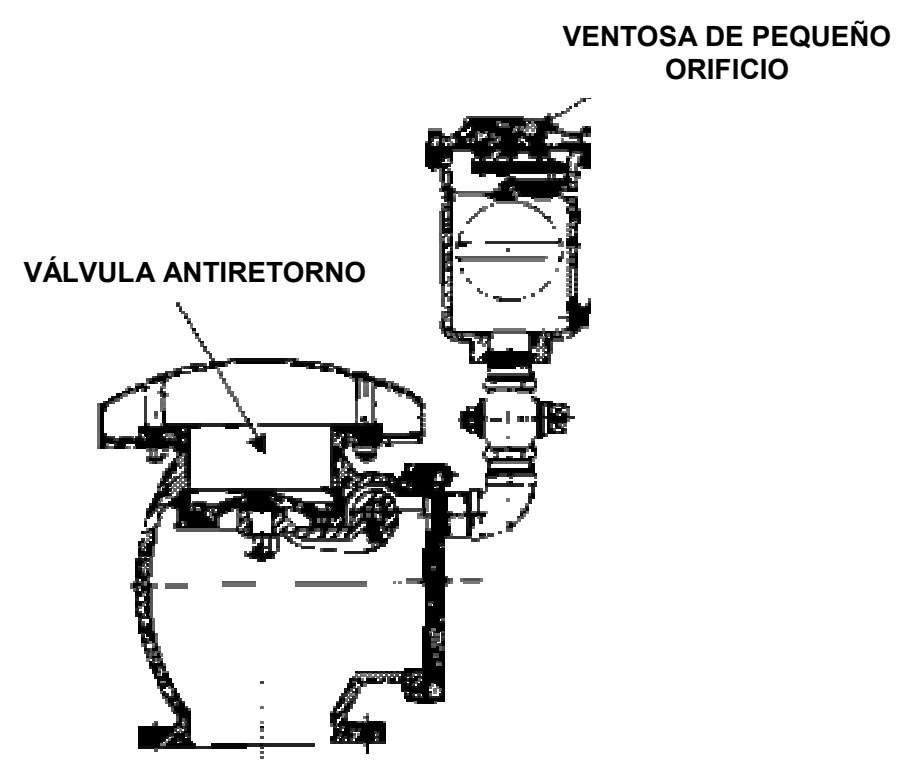

Figura 2.27. Ventosa antirretorno

Algunos experimentos realizados por A. Campbell (1983) muestran que estos dispositivos funcionan de manera efectiva como mecanismos de protección frente a sobrepresiones y golpe de ariete si se utilizan junto a ventosas no cinéticas convencionales. La ventosa no cinética convencional situada aguas arriba de la ventosa antiretorno descarga un gran volumen de aire antes del cierre y la sobrepresión creada por el cierre es absorbida por el aire que queda atrapado en el sistema. La ventosa antirretorno expulsa el aire retenido de forma controlada

Este tipo de válvulas son realmente efectivas a la hora de eliminar sobrepresiones y el golpe de ariete, pero como contrapartida son caras y requieren ser instaladas junto a ventosas no cinéticas para que el trabajo realizado sea verdaderamente eficiente, lo cual implica un mayor coste que debe ser evaluado por los usuarios finales.

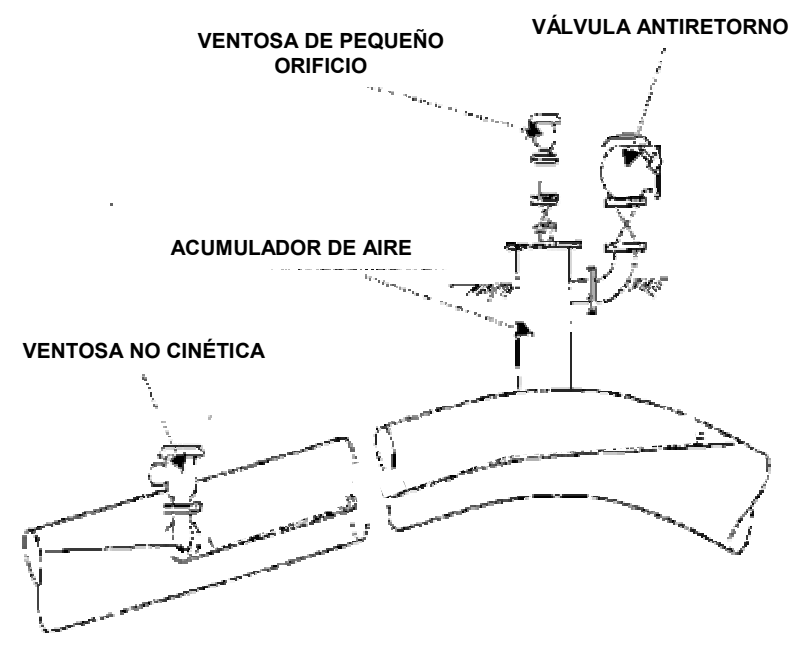

Figura 2.28. Disposición de las ventosas y otros elementos 


\section{Calderín con ventosa.}

El calderín simple, es decir sin ventosa, es uno de los dispositivos más utilizados en la industria para eliminar el golpe de ariete, sobre todo, en los casos en los que se impulsa la columna de agua mediante un bombeo. Cuando ocurre un fallo en el suministro eléctrico el calderín se convierte en una fuente de energía que tiende a mantener el movimiento del fluido en la conducción. El aire en el interior del calderín se expande de tal forma que la presión disminuye progresivamente, lo cual hace que el caudal en la tubería se reduzca de una forma controlada, más lenta de lo que ocurriría sin la presencia del mismo. Es importante colocar una válvula de retención entre el calderín y el grupo de bombeo para evitar el posible flujo inverso.

Algunos fabricantes proponen el uso de un calderín vertical, conectado a la red principal mediante una tubería situada en la parte inferior del mismo. En la parte superior del calderín existe una cámara de compresión limitada por un tubo de ventilación que se cierra mediante una ventosa. Este calderín realiza tres operaciones diferentes:

- Actúa como depósito de compresión a medida que la cámara de compresión atrapa el aire.

- Actúa como una chimenea cuando la ventosa se encuentra abierta, es decir, el flotador está en el tubo de ventilación.

- Finalmente, actúa como ventosa cuando toda el agua ha pasado a la conducción.

Una ventaja importante a la hora de utilizar este tipo de dispositivos es que la tubería de conexión se encuentra completamente abierta, con lo cual no hay riesgo de obstrucción si se quiere usar con aguas residuales.

El funcionamiento del calderín con ventosa en los casos de puesta en marcha y parada de una bomba se detalla paso a paso a continuación:

Puesta en marcha de la bomba en la instalación:

- (a) La tubería principal empieza a llenarse y aumenta el nivel de agua en el depósito, el aire escapa al exterior ya que la ventosa está abierta.

- (b) Superficie libre en la chimenea a la presión atmosférica. El depósito continúa Ilenándose de agua y sigue expulsándose aire al exterior del sistema ya que la ventosa se encuentra todavía abierta. El nivel del líquido aumenta con la bomba en funcionamiento, hasta llegar a la parte inferior del tubo central del interior del depósito.

- (c) Cierre del flotador. El volumen de aire situado sobre el nivel del agua en la cámara de compresión queda atrapado. El nivel del líquido en el tubo central aumenta ya que la ventosa continúa abierta. Por otra parte, el aire que ha quedado atrapado entre el tubo y la carcasa del calderín se va comprimiendo. El nivel del 
líquido en el tubo central aumenta hasta que llega a la altura del flotador, instante en el cual lo empuja hasta que la ventosa queda completamente cerrada.

- (d) Compresión del aire. A medida que aumenta la presión en el sistema el aire atrapado se va comprimiendo cada vez más hasta que se llega a un estado de equilibrio y no hay movimiento en el sistema.

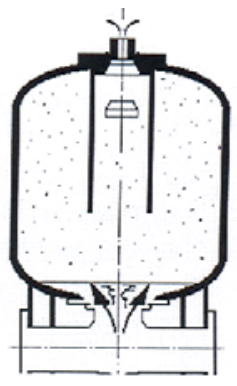

(a)

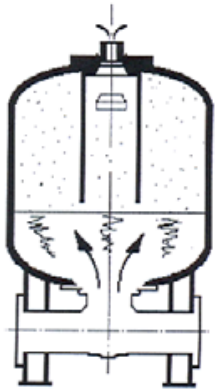

(b)

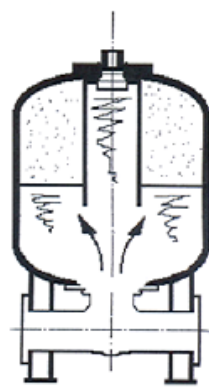

(c)

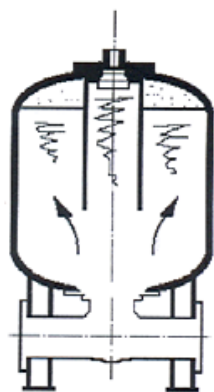

(d)

Figura 2.29. Puesta en marcha de la bomba

Parada de la bomba:

- (a) Sobrepresiones en el calderín. Inmediatamente después de la parada de la bomba, la presión en la tubería empieza a descender y la energía elástica almacenada en el gas hace que se mueva el líquido desde el calderín hacia la tubería principal. De este modo se limita la caída de presión en el sistema. Cuando el agua por debajo del tubo central del calderín ha sido descargada a la tubería principal, dicho tubo empezará a vaciarse, lo cual obligará a que la ventosa empiece a abrir.

- (b) Chimenea. El calderín se encuentra abierto a la atmósfera y el agua va Ilenando la tubería principal a una presión constante igual a la atmosférica. El nivel de agua continúa bajando hasta que el flujo de retorno procedente de la tubería principal alcanza el calderín.

- (c) Oscilaciones. El proceso oscila, se va repitiendo de manera que disminuye cada vez la amplitud de dichas oscilaciones debido a las pérdidas por fricción en la instalación. Después de varios ciclos se llega a un nivel estático por encima de la parte inferior del tubo central del depósito, o no, dependiendo de la altura geométrica en cabecera de la instalación y de la localización del calderín.

- (d) Comienzo de nuevos bombeos. La bolsa de aire en el calderín estará comprimida cuando se empiece a bombear de nuevo y oscilará antes de llegar a unas condiciones de estado estacionario. La energía elástica almacenada será capaz de afrontar un posible corte de suministro eléctrico. 


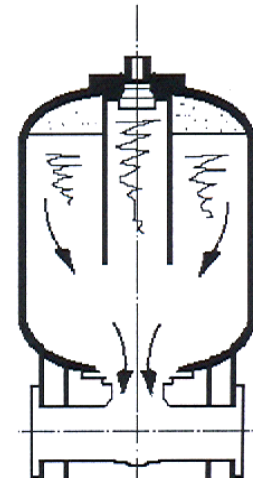

(a)

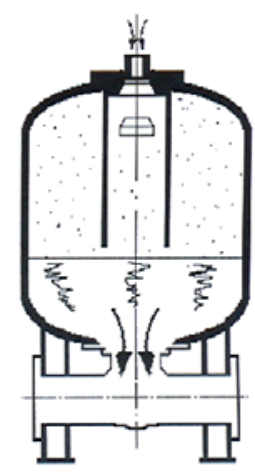

(b)

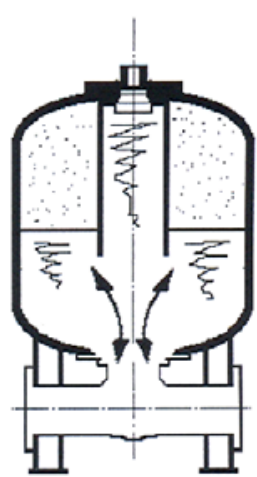

(c)

Figura 2.30. Parada de la bomba

\subsection{SELECCIÓN Y DIMENSIONAMIENTO DE VENTOSAS}

El diámetro del orificio de gran tamaño de una ventosa de expulsión de aire no se debe confundir con el diámetro nominal de dicha ventosa. El diámetro nominal de la ventosa hace referencia al diámetro de conexión de la ventosa con la tubería sobre la cual se instala mientras que el orificio de gran tamaño condiciona la forma en la que el aire escapa directamente a la atmósfera o entra en la instalación. Estas dos dimensiones no son necesariamente iguales. El área del orificio de gran tamaño y las características dinámicas de la ventosa son, en principio, las variables que determinan la capacidad de descarga y/o admisión de aire. Por tanto puede ser que dos ventosas con el mismo diámetro nominal no presenten un mismo comportamiento actuando bajo las mismas condiciones.

En 2001, la American Water Works Association (AWWA) propuso una serie de recomendaciones generales en cuanto al diseño y selección de ventosas. Asimismo, algunos fabricantes de ventosas ofrecen programas informáticos para seleccionar y ubicar las ventosas de manera eficiente en una instalación determinada.

Las fuentes citadas aportan recomendaciones para conseguir un mejor funcionamiento de la instalación pero es el usuario final, el cual conoce la disposición y funcionamiento de todos los elementos de la instalación, el que debe decidir el tamaño óptimo de las ventosas en cuestión así como su ubicación. Actualmente existen, en general, pocos trabajos experimentales en los cuales basarse para seleccionar y ubicar ventosas en una instalación. Tampoco los fabricantes suelen presentar suficientes datos sobre sus ventosas que faciliten la selección y ubicación de las ventosas, como por ejemplo la evolución del coeficiente de descarga y/o admisión de la ventosa con la presión máxima producida en la instalación. 


\subsection{UBICACIÓN DE LAS VENTOSAS EN UNA INSTALACIÓN}

La mayor parte de la bibliografía existente establece que el mejor método para determinar el posicionamiento de una ventosa en una instalación es el análisis de las cotas de los puntos de la tubería con respecto a la línea de alturas piezométricas. Por ello, se deben identificar todos los puntos a lo largo del perfil de la tubería cuya altura esté por encima de la línea de alturas piezométricas.

J. Willis (1990) estableció que las ubicaciones idóneas de las ventosas cuya función principal es la de admitir de aire son:

- Puntos elevados en los cuales la línea de alturas piezométricas pueda descender por debajo de la cota.

- Puntos situados entre 3 y $4 \mathrm{~m}$ por debajo de los puntos formados por la intersección de la línea de alturas piezométricas y el perfil de la tubería.

- Puntos del perfil de la tubería donde existe un cambio de pendiente.

- Puntos situados entre 3 y 4 m por debajo de los puntos con cambio de pendiente formado por la intersección del perfil de la tubería con la línea de alturas piezométricas.

Las ventosas cuya función principal es la de expulsar aire se sitúan en los mismos puntos comentados anteriormente pero se requieren además en secciones situadas en pendientes decrecientes. Por otro lado, es difícil determinar el tamaño necesario de las ventosas en estas circunstancias. Una actitud común entre los ingenieros proyectistas es colocar en las pendientes decrecientes ventosas del diámetro nominal estándar directamente por debajo del tamaño de la ventosa situada en el punto más alto de este tramo, suponiendo que se conoce el diámetro de dicha ventosa.

Los estudios experimentales del profesor Van Vuuren (Universidad de Pretoria) sugieren que los intervalos entre ventosas cuya función principal es la de descarga de aire se debería calcular como:

$$
L_{c}=85 \frac{D}{150}
$$

$L_{c}$ es la distancia entre ventosas en metros

D es el diámetro de la tubería en milímetros.

En dicha fórmula, cabe destacar que no se contempla el coeficiente de descarga de la ventosa.

Por otro lado, Willis (1990) incluye otras situaciones en las cuales se debe considerar el uso de ventosas, por ejemplo: 
- Colocar una ventosa de doble orificio cuya función principal sea la descarga de aire, aguas abajo de una válvula antiretorno ayuda a amortiguar el efecto del golpe de ariete cuando cesa el funcionamiento de la bomba.

- Se debe instalar una ventosa de doble orificio cuya función principal sea la descarga de aire cuando una tubería acaba con un brida ciega, válvula cerrada o similar.

- Se debe instalar una ventosa de pequeño orificio inmediatamente después de cambios bruscos de cota y en el punto más alto del cuerpo de una bomba centrífuga.

Algunos fabricantes recomiendan instalar ventosas cada $600 \mathrm{~m}$ en tramos de tuberías ascendentes de longitud considerable para asegurar una buena descarga de aire durante el Ilenado de la tubería y una buena aireación en caso de drenaje de la misma. Esta recomendación es también aplicable, según los mismos fabricantes en caso de tuberías descendentes o tuberías horizontales largas.

Asimismo, el profesor Van Vuuren proporciona la siguiente información referente a la colocación de ventosas de orificio grande y pequeño respectivamente en sistemas de tuberías:

\section{Ventosas de gran orificio:}

- Cuando las ventosas de gran orificio se usan como alternativa a los tanques unidireccionales se deben instalar lo más cerca posible y justo aguas abajo de la válvula de retención de la bomba.

- Las ventosas de gran orificio se deben instalar atendiendo al perfil longitudinal y a la posición de las válvulas de cierre o antiretorno de la línea para evitar las presiones subatmosféricas que se producen durante el drenaje. Para asegurar la efectividad y flexibilidad de las líneas, las válvulas de corte se instalan generalmente cada $1500 \mathrm{~m}$ o $3000 \mathrm{~m}$. El resultado es que el espaciado entre las ventosas de gran orificio viene a ser el mismo que el de las válvulas de corte para poder realizar un correcto drenaje.

- Los resultados de los análisis de transitorios hidráulicos indican que pueden aparecer en la instalación presiones subatmosféricas. Se sugiere la instalación de ventosas de gran orificio en los casos en los cuales la presión disminuya 6 mca en términos absolutos. 


\section{Ventosas de pequeño orificio.}

Las ventosas de pequeño orificio sirven para expulsar pequeñas cantidades de aire de la instalación durante su funcionamiento normal. Por esta razón, a menudo se suele poner un especial énfasis en el diseño de una cámara debajo de la ventosa en la cual se recoja el aire temporalmente para ser posteriormente expulsado a la atmósfera. Antes decidir la ubicación de este tipo de ventosas se deben determinar las secciones de la tubería hacia las cuales se transporta el aire. De este modo, como es lógico, los puntos elevados son ubicaciones idóneas para situar las ventosas de pequeño orificio.

Si la distancia resultante entre ventosas de pequeño orificio es corta (unos $250 \mathrm{~m}$ ) no hace falta instalar ventosas en todos los puntos identificados ya que la tubería estaría efectivamente llena y la ventosa de pequeño orificio situada aguas arriba expulsaría suficientemente el aire acumulado.

\subsection{RECOMENDACIONES GENERALES SOBRE LA UBICACIÓN DE VENTOSAS DE LA AMERICAN WATER WORKS ASSOCIATION}

La American Water Works Association (AWWA), propone una guía, manual M51 de la AWWA, 2001, "Air release, air/vacuum, and combination air valves" para seleccionar, dimensionar e instalar ventosas en instalaciones hidráulicas. El manual es una especie de revisión de prácticas recomendadas y no un estándar de uso, es decir, que la decisión última recae en el usuario de la instalación. La AWWA, en su manual, proporciona una amplia información sobre los métodos generales disponibles. Destaca que existen muchas aplicaciones de redes de tuberías especiales, las cuales escapan del alcance de la metodología de su manual y que requieren herramientas especiales como programas informáticos que analicen el transitorio hidráulico previamente. La información de la capacidad de la ventosa, que aparece en dicho manual, es una información genérica utilizada a modo de ejemplo práctico. Se hace especial hincapié en que se deben consultar los diagramas de capacidad de admisión y descarga de aire que presentan los diferentes fabricantes de ventosas antes de realizar la selección final de las mismas. El manual solamente proporciona información de los tipos de ventosas que se recogen en la última edición de la AWWA Standard C512, la cual contiene:

- Ventosas para la expulsión de aire.

- Ventosas para la admisión de aire.

- Ventosas bifuncionales.

Este manual solo introduce a modo de comentario las ventosas de aguas residuales, los dispositivos adicionales para la eliminación de vacío, las ventosas de cierre lento y los dispositivos de estrangulamiento del flujo. 
La ubicación óptima de una ventosa, cualquiera que sea la función que realice, es tan importante como determinar la capacidad de admisión y descarga de aire de la misma. Una ubicación no adecuada puede hacer que la ventosa sea ineficiente. Generalmente las ventosas se instalan bien en las tuberías que transportan el agua bruta a la planta de tratamiento de agua, o bien en tuberías que llevan el agua tratada hasta los sistemas de distribución o en aplicaciones similares. Según la AWWA, normalmente no se necesitan ventosas en tuberías pequeñas de redes de distribución malladas en las cuales los hidrantes y las conexiones de servicio sirven como medios para eliminar el aire atrapado.

\subsubsection{TIPOS Y UBICACIONES ACONSEJADAS}

El manual M51 de la AWWA, 2001, "Air release, air/vacuum, and combination air valves" sugiere que las ventosas debe instalarse en los siguientes puntos:

- Puntos elevados. Es necesario instalar ventosas en los puntos más elevados con la finalidad de expulsar aire mientras la instalación se está Ilenando, también para expulsar aire durante el funcionamiento normal de la instalación y para admitir aire durante el drenado de la misma. Un punto elevado se define mediante la línea de alturas piezométricas y se considera como el extremo final aguas arriba de cualquier tramo de tubería con pendiente descendente hacia la línea de alturas piezométricas o paralelo al mismo.

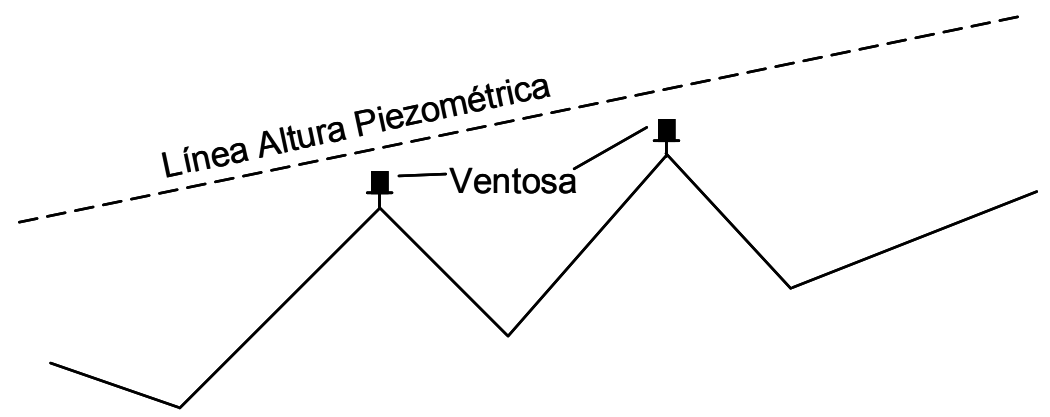

Figura 2.31. Ventosas en puntos elevados de una instalación

- Reducción de pendientes ascendentes: Se debe instalar una ventosa cuando se producen descensos bruscos de pendientes crecientes.

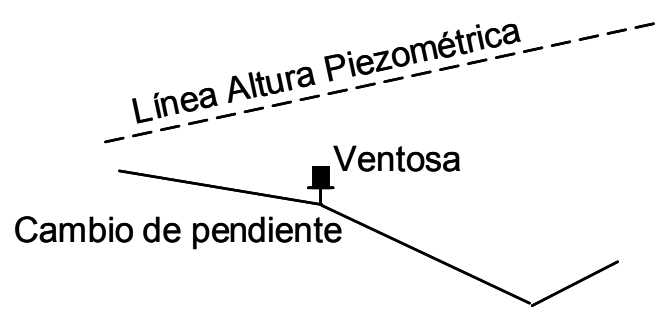

Figura 2.32. Ventosas en cambio de pendiente creciente 
- Aumento de pendientes descendentes: Cuando aparecen aumentos bruscos en una pendiente descendente es aconsejable instalar una bifuncional o trifuncional.

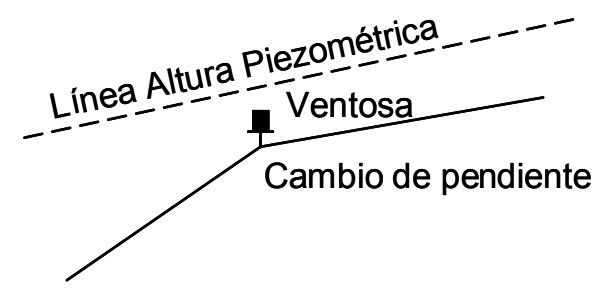

Figura 2.33. Ventosa en cambio de pendiente creciente

- Tramos de tuberías largos descendentes: Se recomienda instalar ventosas de gran orificio bifuncionales o ventosas trifuncionales en intervalos de $400 \mathrm{~m}$ y $800 \mathrm{~m}$ a lo largo de las secciones descendentes de la tubería.

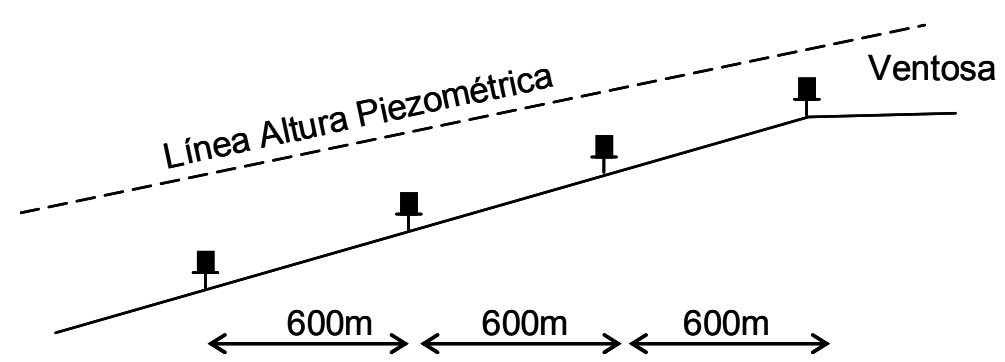

Figura 2.34. Ventosas en tramos largos de tuberías descendentes

- Tramos de tuberías largos ascendentes: Del mismo modo se recomienda instalar ventosas de gran orificio bifuncionales o ventosas trifuncionales en intervalos de $400 \mathrm{~m}$ y $800 \mathrm{~m}$ a lo largo de las secciones ascendentes de la tubería.

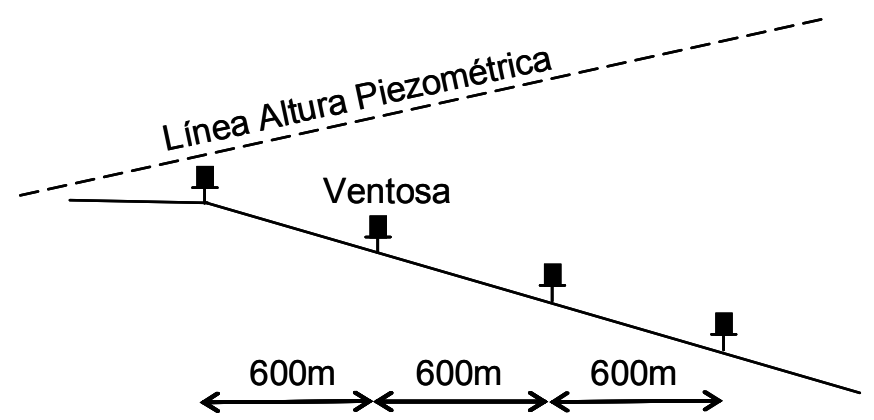

Figura 2.35. Ventosas en tramos largos de tuberías ascendentes

- Tramos horizontales: Es aconsejable colocar una ventosa bifuncional o trifuncional al principio y al final de la instalación en intervalos de $400 \mathrm{~m}$ a $800 \mathrm{~m}$ a lo largo del tramo. Es difícil expulsar aire de un tramo de tubería horizontal cuando las velocidades del flujo son reducidas.

- Medidor Venturi: Asimismo es conveniente ubicar una ventosa para la expulsión de aire aguas arriba de un medidor Venturi para evitar medidas incorrectas de caudal ocasionadas por el aire atrapado. 
- En la descarga de una bomba: Se deben instalar ventosas para la admisión y expulsión de aire en la tubería de impulsión de las bombas. De este modo se elimina el aire que se introduce en la instalación durante la puesta en marcha de la bomba y se permita la entrada de aire en la línea después de una parada de la misma.

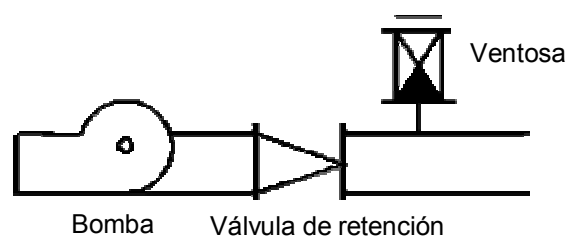

Figura 2.36. Ventosa en la tubería de impulsión de una bomba

- Aguas arriba de una válvula de retención en instalaciones con bombas sumergidas, pozos profundos y bombas verticales. De este modo se evita la entrada de grandes cantidades de aire cada vez que la bomba se ponga en funcionamiento y se admite aire cuando se produce la parada la bomba. Las ventosas montadas en este tipo de bombas requieren una consideración especial en su selección como consecuencia de los cambios violentos del flujo que se producen durante el ciclo de bombeo. Se usan a menudo ventosas de expulsión de aire conjuntamente con válvulas de retención de cierre progresivo y de accionamiento electrónico. De este modo la expulsión el aire durante el funcionamiento normal de la instalación se realiza lentamente.

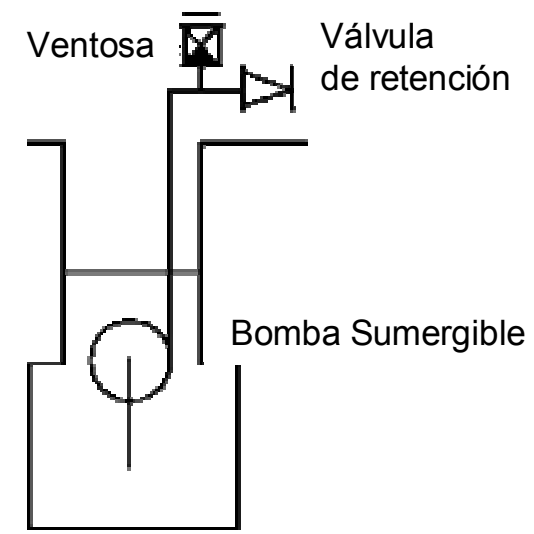

Figura 2.37. Ventosa en la salida de un pozo.

- Sifones: Es recomendable instalar una ventosa para la expulsión de aire en el punto más elevado de un sifón. La ventosa para la expulsión de aire debe ir equipada con un dispositivo de comprobación de vacío en el desagüe que impida la admisión de aire en la tubería. Cuando no se desea tener un flujo inverso después de la parada de una bomba, se puede utilizar una ventosa antisifón. Las válvulas antisifón están diseñadas para eliminar el aire durante la puesta en 
marcha de una bomba, cierra en condiciones de flujo normal y abre para romper el sifón en condiciones de flujo inverso

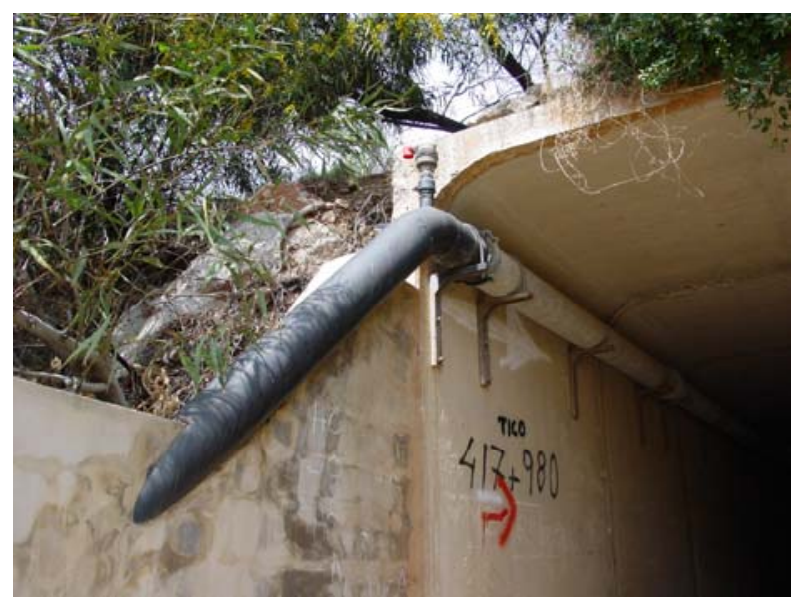

Figura 2.38. Ventosa en un sifón.

- Válvulas principales. Las ventosas se pueden utilizar junto a las válvulas principales de la instalación para facilitar el vaciado de la tubería.

\subsubsection{DISEÑO DE LA CAPACIDAD DE DESCARGA DE LAS VENTOSAS}

Al igual que la decisión de la ubicación óptima de una ventosa en una instalación es también importante decidir el diámetro del orifico de la ventosa adecuado para que la ventosa realice correctamente la función para la cual ha sido seleccionada. El mencionado manual de la AWWA proporciona una metodología común utilizada en la industria del agua basada en fórmulas y datos extraídos de una serie de tablas. En cualquier caso, se hace especial hincapié en todo el documento en que es fundamental a la hora de realizar un dimensionamiento específico de ventosas acudir a las fórmulas, gráficos y diagramas que ofrecen los fabricantes de ventosas. En dicho manual se abordan algunos ejemplos prácticos en los cuales se muestran gráficos y tablas que ofrecen ciertos fabricantes.

\subsubsection{DIMENSIONADO DE UNA VENTOSA EN CASO DE EXPULSIÓN DE AIRE EN UN SISTEMA A PRESIÓN. PURGADOR}

En primer lugar, hay que tener en cuenta que el diámetro del orificio de la ventosa por el cual se expulsa o admite aire en la instalación es distinto del diámetro del orificio interior de conexión de la ventosa con la tubería. Mientras que el diámetro del orificio de salida de aire oscila generalmente entre $1,6 \mathrm{~mm}$ y $25 \mathrm{~mm}$, el diámetro del orificio interior de conexión con la tubería oscila entre $13 \mathrm{~mm}$ y $150 \mathrm{~mm}$. En realidad, no existe un método definitivo para determinar la cantidad de aire que sería necesario expulsar de una tubería dada, debido a la dificultad de predecir la cantidad de aire que o bien puede entrar en un sistema desde el exterior o bien se desprende del agua cuando disminuye 
significativamente la presión en el interior de la tubería. Según Lescovich (1972) la solubilidad del aire en agua en condiciones estándar es de un $2 \%$. Por este motivo se debería diseñar un purgador de manera que fuera capaz de expulsar al exterior dicha cantidad de aire.

Debido a la existencia de presiones elevadas la ecuación de flujo de aire a través de un orificio se basa en la compresión adiabática del flujo en la cual no hay transferencia de calor al aire. El flujo sónico se produce cuando se descarga aire a una presión que es 1,9 veces mayor que la presión exterior. Asumiendo que la presión exterior es la atmosférica (101 kPa, en valores absolutos), cualquier presión en el interior de la tubería que exceda 1,9 veces este valor producirá flujo sónico.

Cuando se produce flujo sónico la velocidad del aire se limita a la velocidad del sonido, causando una limitación de la descarga de aire a altas presiones. Las tablas y gráficos que presenta la AWWA se han realizado tomando un coeficiente de descarga $C_{d}=0,7$. De todos modos, se advierte que para cada caso concreto hay que seguir las indicaciones del fabricante de ventosas.

Bajo este supuesto, se calcula la presión de trabajo de una ventosa para la expulsión de aire teniendo en función de la línea de alturas piezómetricas y no en el punto de descarga de la bomba. La presión diferencial de trabajo en la ubicación del purgador de aire se calcula como la diferencia entre la cota de la ventosa y el valor máximo de la línea de alturas piezométricas en la ventosa.

Para calcular de manera aproximada el tamaño necesario del orifico de salida de la ventosa teniendo en cuenta que la cantidad de aire existente en el interior de la instalación se debe simplemente al aire que deja de estar disuelto en el agua, en el manual de la AWWA se propone el siguiente método:

- Paso 1. En primer lugar, hay que transformar las unidades del flujo a pies cúbicos por minuto que en unidades del sistema internacional se miden en metros cúbicos por segundo. Este primer paso se realiza ya que en las tablas que se toman en el manual de la AWWA la presión viene expresada generalmente en libras/ pulgada ${ }^{2}$ (psi), el caudal en pies cúbicos por minuto cfm y el diámetro del orificio en pulgadas (in).

- Paso 2. Multiplicar el flujo resultante del Paso 1 por 0,02. de este modo se determina el volumen de aire que hay que expulsar como un $2 \%$ del flujo de agua existente en la tubería.

- Paso 3. Determinar la presión de trabajo en la ventosa restando a la línea de alturas piezométricas, la cota a la cual se encuentra la misma.

- Paso 4. Conocidos el caudal de aire que hay que expulsar y la presión en el orificio de salida se puede determinar el tamaño del orifico de la figura siguiente. 
Air capacity table of air-release valve orifices $\left(C_{d}=0.7\right)$

\begin{tabular}{|c|c|c|c|c|c|c|c|c|c|c|}
\hline $\begin{array}{c}\text { Pressure } \\
\text { (psi) }\end{array}$ & & & & & tifice D & ter, $I n$ & & & & \\
\hline & $1 / 16$ & $3 / 32$ & $1 / 8$ & $3 / 16$ & $1 / 4$ & $5 / 16$ & $3 / 8$ & $7 / 16$ & $1 / 2$ & 1 \\
\hline 25 & 1.6 & 3.5 & 6.3 & 14.2 & 25.2 & 39.4 & 56.7 & 77.1 & 100 & 400 \\
\hline 50 & 2.6 & 5.8 & 10.3 & 23.1 & 41.0 & 64.1 & 92.3 & 126 & 164 & 656 \\
\hline 75 & 3.6 & 8.0 & 14.2 & 32.0 & 56.9 & 88.9 & 128 & 174 & 228 & 910 \\
\hline 100 & 4.5 & 102 & 18.2 & 40.9 & 72.8 & 114 & 164 & 223 & 291 & 1,160 \\
\hline 125 & 5.5 & 12.5 & 22.2 & 49.8 & 88.6 & 138 & 199 & 271 & 354 & 1,420 \\
\hline 150 & 6.5 & 147 & 26.1 & 588 & 104 & 163 & 235 & 320 & 418 & 1,610 \\
\hline 175 & 7.5 & 16.9 & 30.1 & 67.7 & 120 & 188 & 271 & 369 & 481 & 1,920 \\
\hline 200 & 8.5 & 19.2 & 34.1 & 76.6 & 136 & 213 & 306 & 417 & 545 & 2,180 \\
\hline 225 & 9.5 & 21.4 & 38.0 & 85.5 & 152 & 238 & 342 & 466 & 608 & 2,430 \\
\hline 250 & 10.5 & 23.6 & 420 & 945 & 168 & 262 & 378 & 514 & 672 & 2,690 \\
\hline 275 & 115 & 25.8 & 45.9 & 103 & 184 & 287 & 414 & 563 & 735 & 2,940 \\
\hline 300 & 12.5 & 28.1 & 49.9 & 112 & 200 & 312 & 449 & 611 & 799 & 3,200 \\
\hline
\end{tabular}

Notz: Metric conversions-in $\times 25.4=\mathrm{mm}$, $\mathrm{cfm} \times 04719=\mathrm{L} / \mathrm{sec}, \mathrm{psi} \times 6.89476=\mathrm{kPa}$

Figura 2.39. Tabla para determinar el tamaño del orificio del purgador de una ventosa

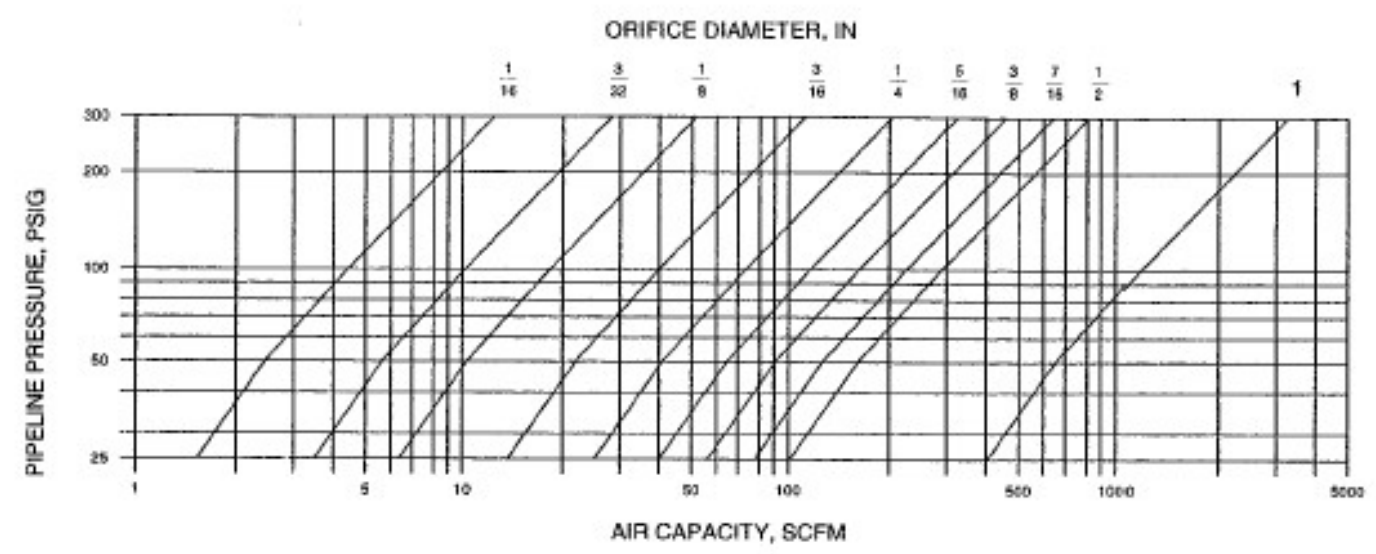

Figura 2.40. Diagrama para determinar el tamaño del orificio del purgador

\subsubsection{DIMENSIONADO DEL DIÁMETRO DEL ORIFICO DE LA VENTOSA EN CASO DE LLENADO DE UNA TUBERÍA}

Cuando se procede al Ilenado inicial de una tubería, el aire debe ser expulsado al exterior en la misma proporción en que se Ilena de agua la tubería. En este caso la ventosa debe expulsar grandes cantidades de aire al exterior. El procedimiento recomendado por la AWWA consiste en Ilenar la tubería a una velocidad gradual de manera que se eviten picos de presión no deseados. En el manual se propone como velocidad estimada una velocidad del orden de $0,3 \mathrm{~m} / \mathrm{s}$. El caudal volumétrico de aire, en el Ilenado inicial, escapa a la atmósfera a una presión diferencial de 13,8 KPa. Las válvulas equipadas con dispositivos que protejan la instalación del golpe de ariete o con dispositivos de cierre lento se pueden dimensionar, según la AWWA, considerando una presión diferencial máxima de 34,5 $\mathrm{KPa}$. 
La ecuación del flujo aplicable en este caso, se basa en las ecuaciones de un flujo compresible adiabático a través de una tobera o de un tubo corto donde no hay transferencia de calor al aire. Además se considera que la ventosa está a nivel del mar y a una temperatura de $15,5^{\circ} \mathrm{C}$. En el manual se señala que en otras condiciones, es decir, en altitudes elevadas o temperaturas extremas se deben usar otro tipo de ecuaciones. En las tablas propuestas se considera un coeficiente de descarga de la ventosa aproximado de 0,7 . El procedimiento de cálculo para la selección del tamaño de orificio adecuado sería en este caso:

Paso 1. Calcular, al igual que en el caso anterior, el flujo volumétrico de aire a la salida como:

$Q=q \cdot \frac{\left(\Delta P+P_{\text {atmosferica }}\right)}{P_{\text {atmosferica }}}$

Donde:

Q es el caudal de aire de salida q es el caudal de agua de llenado de la tubería $\Delta \mathrm{P}$ es la presión diferencial, igual a $2 \mathrm{psi}$ (libra/pulgada $\left.{ }^{2}\right)$, lo cual equivales a 0,1379 bar

Paso 2. Buscar en la tabla y/o gráfico siguientes el tamaño del orificio que proporciona el flujo requerido a una determinada presión diferencial conocida, en el orificio de salida:

Air discharge table of large orifices $\left(C_{d}=0.7, T=60^{\circ} \mathrm{F}\right.$, sea level)

\begin{tabular}{|c|c|c|c|c|c|c|c|c|c|c|c|c|}
\hline \multirow{2}{*}{$\begin{array}{l}\text { Differential } \\
\text { Pressure } \\
(p s i)\end{array}$} & \multicolumn{12}{|c|}{ Orifice Diameter, In. } \\
\hline & 1 & 2 & 3 & 4 & 6 & 8 & 10 & 12 & 14 & 16 & 18 & 20 \\
\hline 1.0 & 79 & 317 & 712 & 1,270 & 2,850 & 5,070 & 7,910 & 11,400 & 15,500 & 20,200 & 25,600 & 31,700 \\
\hline 1.5 & 97 & 387 & 870 & 1,550 & 3,480 & 6,190 & 9,670 & 14,000 & 18,900 & 24,700 & 31,300 & 38,600 \\
\hline 2.0 & 111 & 445 & 1,000 & 1,780 & 4,010 & 7,120 & 11,100 & 16,000 & 21,800 & 28,500 & 36,100 & 44,500 \\
\hline 2.5 & 124 & 497 & 1,120 & 1,990 & 4,470 & 7,950 & 12,400 & 17,900 & 24,300 & 31,800 & 40,200 & 49,600 \\
\hline 3.0 & 136 & 543 & 1,220 & 2,170 & 4,890 & 8,690 & 13,600 & 19,500 & 26,600 & 34,700 & 44,000 & 54,300 \\
\hline 3.5 & 146 & 585 & 1,320 & 2,340 & 5,270 & 9,370 & 14,600 & 21,100 & 28,700 & 37,500 & 47,400 & 58,500 \\
\hline 4.0 & 156 & 625 & 1,410 & 2,500 & 5,620 & 10,000 & 15,600 & 22,500 & 30,600 & 40,000 & 50,600 & 62,500 \\
\hline 4.5 & 165 & 662 & 1,490 & 2,650 & 5,960 & 10,600 & 16,500 & 23,800 & 32,400 & 42,300 & 53,600 & 66,200 \\
\hline 5.0 & 174 & 697 & 1,570 & 2,790 & 6,270 & 11,100 & 17,400 & 25,100 & 34,100 & 44,600 & 56,400 & 69,700 \\
\hline
\end{tabular}

NoTE: Metric conversions-in. $\times 25.4=\mathrm{mm}, \mathrm{cfm} \times 0.4719=\mathrm{L} / \mathrm{sec}, \mathrm{psi} \times 6.89476=\mathbf{k P a}$

Figura 2.41. Tabla para determinar el diámetro de una ventosa en caso de llenado de tubería 


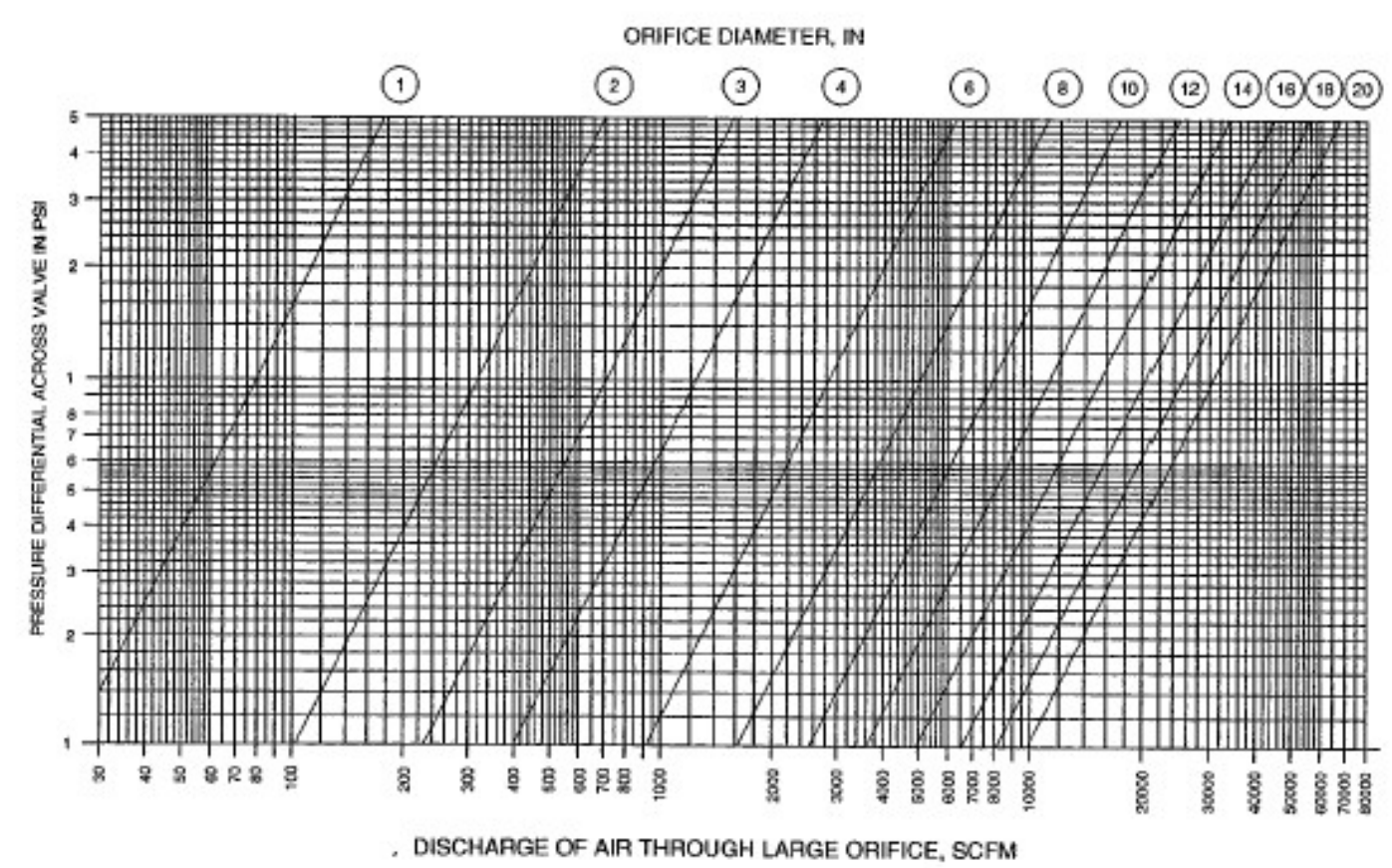

Figura 2.42. Gráfico para determinar el diámetro de una ventosa en caso de llenado de tubería

\subsubsection{DIMENSIONADO DEL DIÁMETRO DEL ORIFICO DE LA VENTOSA EN CASO DE DRENAJE DE UNA TUBERÍA}

A menudo en las instalaciones, es necesario realizar el drenaje de una tubería para proceder a su reparación. El vaciado de la conducción se debe llevar a cabo de manera controlada, es decir, a una velocidad del flujo de entre $0,3 \mathrm{~m} / \mathrm{s}$ y $0,6 \mathrm{~m} / \mathrm{s}$, para intentar minimizar las presiones que pueden aparecer en el transitorio. El objetivo es determinar el dimensionado correcto de una ventosa que debe estar situada en un punto elevado junto al punto de drenaje de la tubería de manera que sea capaz de admitir el mismo caudal volumétrico de aire que agua esté saliendo de la instalación.

\subsubsection{DIMENSIONADO DEL DIÁMETRO DEL ORIFICO DE LA VENTOSA EN CASO DE FLUJO POR GRAVEDAD}

Un corte de suministro eléctrico o una rotura de la tubería pueden dar lugar a un cambio en la velocidad del flujo debido a la separación de la columna de agua y al flujo de agua que escapa por la rotura. Ambos fenómenos pueden dar lugar a situaciones de vacío en los puntos adyacentes. En ocasiones, las tuberías de pequeño y mediano calibre utilizadas en la industria del agua pueden ser capaces de soportar dichas situaciones de vacío mientras que las tuberías de gran calibre debido a su rigidez, tienden al colapso cuando se producen presiones negativas en su interior. Consecuentemente, el dimensionado de ventosas cuando se producen flujos por gravedad es importante para garantizar la integridad de la tubería en caso de rotura. Las ventosas situadas en los puntos elevados de 
la instalación, diseñadas para permitir la entrada de aire que minimice las presiones negativas en el interior de la tubería, deben ser capaces de admitir la cantidad de aire necesaria de tal modo que se puedan prevenir posibles daños al sistema de bombeo, a los diferentes accesorios o incluso a la misma tubería. Cuando se dimensiona el diámetro del orificio de una ventosa en estas condiciones, la pendiente de la tubería es fundamental a la hora de determinar el volumen de aire de entrada necesario para evitar el vacío.

El dimensionado del tamaño del orificio de una ventosa para la admisión de aire se basa en la presión negativa más baja que es capaz de soportar la tubería, aplicando un factor de seguridad apropiado de manera que se evite un posible colapso. El flujo sónico se produce cuando la relación entre la presión de salida y la presión de entrada es menor de 0,53 . Sabiendo que la presión de entrada es aproximadamente igual a la atmosférica (101 KPa) cualquier presión negativa por debajo de $54 \mathrm{KPa}$ en términos absolutos dará lugar al flujo sónico.

Si se produce flujo por gravedad en una tubería que posee un cambio de pendiente donde las secciones inferiores de la tubería tienen una pendiente más pronunciada que las secciones superiores, entonces se debe ubicar una ventosa con función de admisión de aire en el punto en el cual cambia la pendiente de la tubería. El flujo por gravedad será mayor en la sección de la tubería que tenga una pendiente más pronunciada.

La ecuación aplicable del flujo que se propone en el manual de la AWWA supone, como en los casos anteriores, que el flujo es compresible y adiabático, y considera un factor de descarga de 0,7 .

Air inflow table of large orifices $\left(C_{d}=0.7\right)$

\begin{tabular}{|c|c|c|c|c|c|c|c|c|c|c|c|c|}
\hline \multirow[t]{2}{*}{$\begin{array}{c}\text { Differential } \\
\text { Pressure } \\
\text { (psig) }\end{array}$} & \multicolumn{5}{|c|}{ " } & \multicolumn{4}{|c|}{ Orifice Diameter, In. } & \multirow[b]{2}{*}{16} & \multirow[b]{2}{*}{18} & \multirow[b]{2}{*}{20} \\
\hline & 1 & 2 & 3 & 4 & 6 & 8 & 10 & 12 & 14 & & & \\
\hline 1.0 & 76 & 306 & 688 & 1,220 & 2,750 & 4,890 & 7,650 & 11,000 & 15,000 & 19,600 & 24,800 & 30,600 \\
\hline 1.5 & 92 & 366 & 824 & 1,470 & 3,300 & 5,860 & 9,160 & 13,200 & 17,900 & 23,500 & 29,700 & 36,700 \\
\hline 2.0 & 103 & 414 & 931 & 1,660 & 3,720 & 6,620 & 10,300 & 14,900 & 20,300 & 26,500 & 33,500 & 41,400 \\
\hline 2.5 & 113 & 452 & 1,020 & 1,810 & 4,070 & 7,230 & 11,300 & 16,300 & 22,100 & 28,900 & 36,600 & 45,200 \\
\hline 3.0 & 121 & 484 & 1,090 & 1,930 & 4,350 & 7,740 & 12,100 & 17,400 & 23,700 & 31,000 & 39,200 & 48,300 \\
\hline 3.5 & 127 & 510 & 1,150 & 2,040 & 4,590 & 8,160 & 12,700 & 18,400 & 25,000 & 32,600 & 41,300 & 51,000 \\
\hline 4.0 & 133 & 532 & 1,200 & 2,130 & 4,780 & 8,510 & 13,300 & 19,100 & 26,100 & 34,000 & 43,000 & 53,200 \\
\hline 4.5 & 137 & 550 & 1,240 & 2,200 & 4,950 & 8,800 & 13,700 & 19,800 & 26,900 & 35,200 & 44,500 & 55,000 \\
\hline 5.0 & 141 & 565 & 1,270 & 2,260 & 5,080 & 9,030 & 14,100 & 20,300 & 27,700 & 36,100 & 45,700 & 56,500 \\
\hline
\end{tabular}

Figura 2.43. Tabla para determinar el diámetro de una ventosa en caso de rotura de tubería por gravedad 


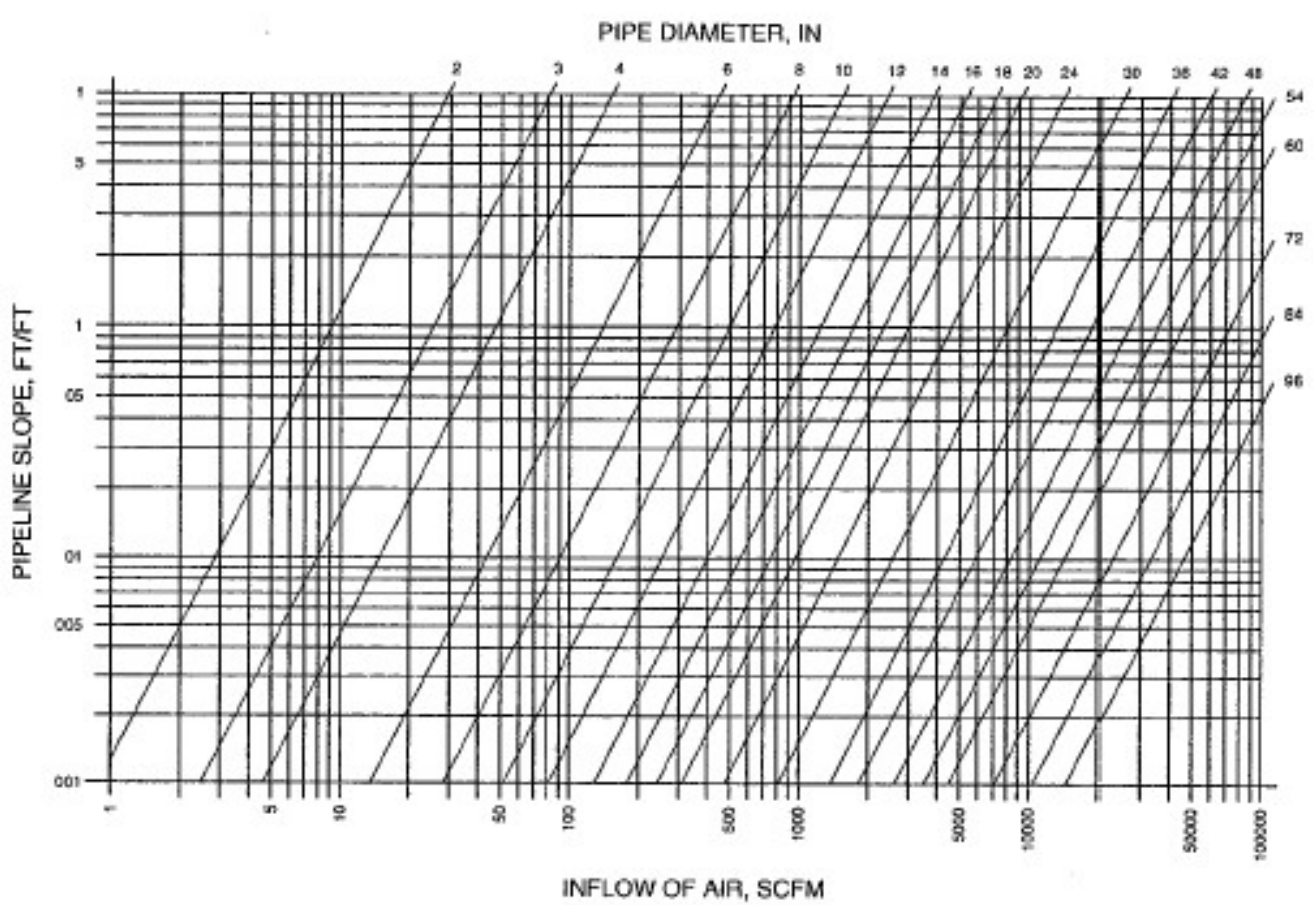

Figura 2.44. Gráfico para determinar el diámetro de una ventosa en caso de rotura de tubería por gravedad

El método de diseño propuesto en este caso es el siguiente:

Paso 1. Determinar la presión negativa que es capaz de soportar la tubería considerando un factor de seguridad razonable. Para ello, hay que consultar las recomendaciones aportadas por el fabricante de la tubería sobre las presiones negativas mínimas admisibles por la misma. En las tuberías de gran diámetro de acero de baja rigidez, la presión de colapso se puede estimar con la fórmula general del colapso de los cilindros de acero de paredes delgadas (AWWA M11, 1.989). La fórmula es aplicable en los casos en los cuales la tubería se encuentre sumergida o se trabaje en un medio subterráneo. Las tuberías enterradas con una buena compactación del suelo no son propensas a sufrir colapso por vacío.

$$
P_{c}=1676400 \cdot\left(\frac{t}{d}\right)^{3}
$$

Donde:

$\mathrm{P}_{\mathrm{c}}$ es la presión de colapso en metros de columna de agua

t es el espesor de la pared del tubo en metros

$\mathrm{d}$ es el diámetro medio del tubo en metros

La presión diferencial permitida para el dimensionado se calcula como: 
$\Delta P=\frac{P_{c}}{F S}$

Donde:

$\Delta \mathrm{P}$ es la presión diferencial en metros de columna de agua.

FS es el factor de seguridad, adimensional.

La elección del valor del factor de seguridad (por ejemplo $\mathrm{FS}=3$ o $\mathrm{FS}=4$ ) se deja a criterio del diseñador. Cuando la tubería no es susceptible de sufrir colapso se suele utilizar directamente una presión diferencial de $34 \mathrm{KPa}$.

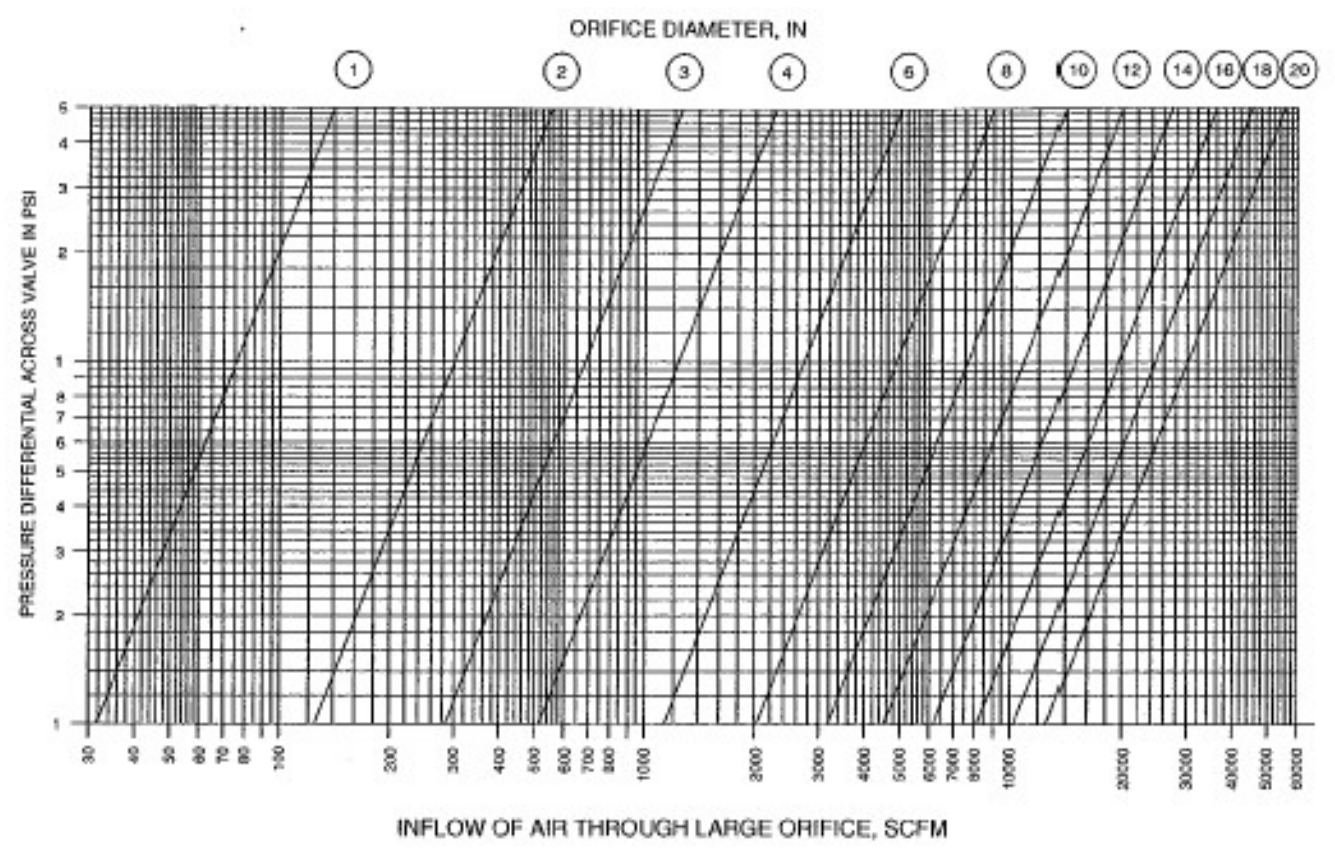

Figura 2.45. Gráfico para determinar el diámetro del orificio de gran tamaño en entrada de aire

Paso 2. Calcular la pendiente de la tubería en $\mathrm{m} / \mathrm{m}$.

Paso 3. Determinar la cantidad de aire de entrada que se requiere relacionando la pendiente de la tubería con el diámetro de la misma. Se puede calcular el caudal utilizando fórmulas comunes como la de Hazen-Williams, Manning o la siguiente fórmula:

$Q=2,23 \cdot 10^{-5} \cdot C \cdot \sqrt{s \cdot D^{5}}$

Donde:

Q es el caudal de entrada en $\mathrm{m}^{3} / \mathrm{s}$

C es el coficiente de Chezy, que toma diferentes valores según el material de la tubería: 110 (hierro), 120 (hormigón), 130 (acero) 
$\mathrm{S}$ es la pendiente de la tubería en $\mathrm{m} / \mathrm{m}$.

$\mathrm{D}$ es el diámetro interior de la tubería en $\mathrm{m}$.

Paso 4. Seleccionar el diámetro adecuado de las tablas anteriores conociendo el flujo y la presión diferencial permitida.

\subsubsection{DIMENSIONADO DEL DIÁMETRO DEL ORIFICO DE LA VENTOSA EN CASOS ESPECIALES}

Existen situaciones especiales que también requieren el uso de ventosas como el control de la separación de la columna de agua y la minimización de las presiones que se producen en los transitorios. El dimensionado de estas ventosas se incluye generalmente en el estudio del transitorio que se produce en la tubería mediante programas de cálculo, lo cual está fuera del alcance del manual que propone la AWWA.

En algunos casos como por ejemplo en tuberías de gran calibre susceptibles de sufrir colapso, el diámetro calculado como se indica en la sección anterior puede ser excesivo y estar fuera del tamaño estándar que ofrecen los fabricantes. Se recomienda en estos casos instalar grupos de ventosas. Otra alternativa es utilizar dispositivos adicionales junto a la ventosa que sean capaces de eliminar el vacío. El dimensionado de ventosas para bombas de eje vertical en pozos depende en gran medida de las características específicas de la ventosa y en ocasiones de la bomba. Estas aplicaciones se deben basar en las recomendaciones publicadas por los suministradores de ventosas.

Es práctica común entre los diseñadores de instalaciones situar las ventosas directamente sobre la tubería en un punto elevado de la misma. Pero algunos fabricantes recomiendan la instalación de un acumulador de aire en la ventosa para facilitar su operación. Otra cuestión importante es realizar un diseño adecuado de la arqueta en la que se instala la ventosa lo cual implica, entre otras cosas, un buen acceso a la misma para facilitar tanto la instalación como su posterior mantenimiento.

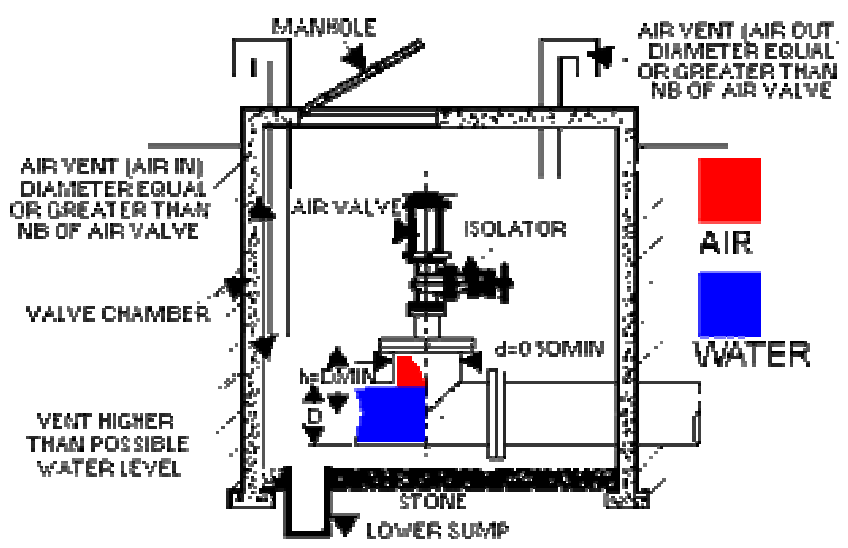

Figura 2.46. Arqueta para ventosa 


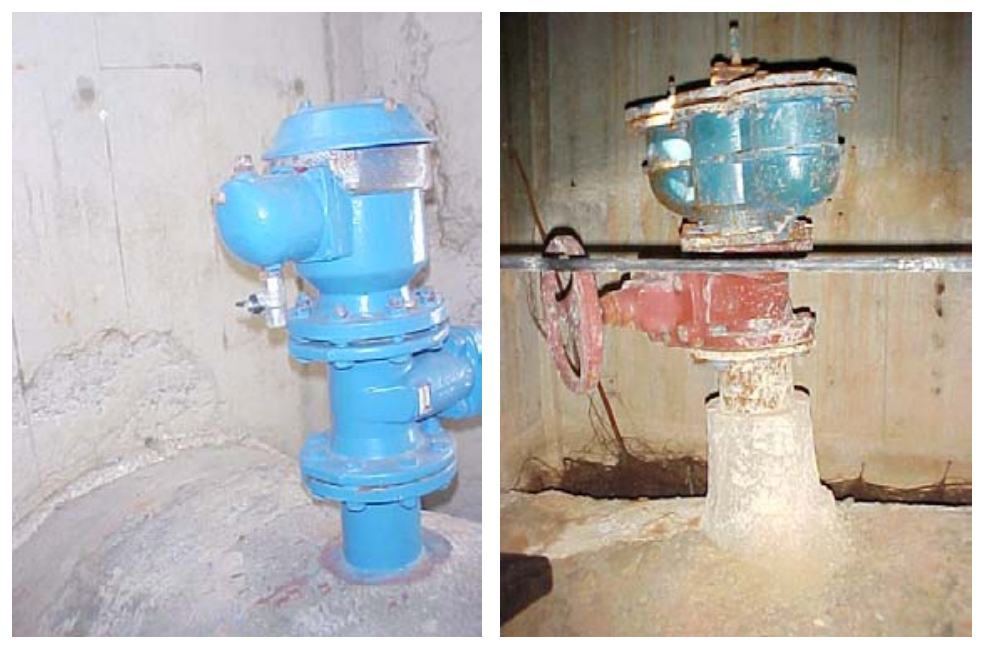

Figura 2.47 .Ventosas en arqueta 


CAPÍTULO 3. PROGRAMA DE ENSAYOS PARA LA CARACTERIZACIÓN ESTÁTICA Y DINÁMICA DE VENTOSAS 



\subsection{INTRODUCCIÓN}

La ejecución de un programa de ensayos de laboratorio para la determinación de la capacidad de descarga de las ventosas y para el estudio del comportamiento dinámico de las mismas y su correspondiente análisis representan una parte esencial del presente trabajo. La finalidad primordial de este capítulo es presentar cada tipo de ensayo llevado a cabo en el laboratorio así como las características de la instalación y de las ventosas utilizadas en cada uno de ellos.

La principal novedad que introduce este trabajo práctico es sin lugar a dudas, el estudio del comportamiento dinámico de ventosas comerciales tanto en situaciones en las que se procede a la expulsión de aire de la instalación como en situaciones en las cuales se requiere la admisión de aire en el sistema.

Otra característica importante de estos ensayos de laboratorio es que se han realizado en una instalación de tamaño real. Las dimensiones de la conducción y de las ventosas, así como de los depósitos de agua y aire y el sistema de bombeo que se necesita para poner en funcionamiento la instalación hacen que los requerimientos de espacio de este tipo de ensayos sean considerables. Tanto la necesidad de espacios amplios como el coste de las instalaciones necesarias para llevar a cabo ensayos en condiciones de régimen transitorio a ventosas comerciales podrían ser algunas de las causas de la escasez de estudios realizados sobre este tema. Los ensayos dinámicos de las ventosas se completan con ensayos para la determinación de la capacidad de descarga de las mismas los cuales se realizan previamente manteniendo diferentes grados de obturación del flotador.

Mediante este trabajo de laboratorio se observa por un lado el fenómeno físico producido en una instalación al originarse un transitorio en el cual interviene un flujo bifásico y por 
otro lado, la influencia que sobre diferentes magnitudes del mismo ejerce la dinámica de ventosas de tamaño real. Se puede considerar que este trabajo de laboratorio es pionero en este campo, lo cual es altamente positivo ya que puede servir de guía a posteriores investigaciones que se quieran seguir en esta línea.

Los ensayos de las ventosas en cuestión se realizaron en las instalaciones facilitadas por W.L.| Delft Hydraulics en Holanda como resultado de la concesión del proyecto Dynamic Behaviour of Air Valves dentro del programa Transnational Access to Major Research Infraestructure (MRI) de la Comisión Europea.

El trabajo experimental se concretó en los siguientes tipos de ensayos con las diferentes ventosas:

- Ensayos de flujo estático de expulsión y admisión de aire manteniendo varios grados de apertura del obturador para la determinación de la capacidad de expulsión y admisión de aire de las ventosas.

- Ensayos dinámicos con expulsión de aire

- Ensayos dinámicos con admisión de aire

En todos los experimentos se obtuvieron datos referentes a presiones medidas en varios puntos de la conducción, caudales y temperatura así como la posición del flotador de la ventosa en cada instante de tiempo. Los ensayos se ejecutaron en tres fases. La primera fase se llevó a cabo en Abril de 2002, la siguiente tuvo lugar tres meses más tarde, es decir, en Julio de 2002 y la tercera en Septiembre del mismo año. Se ensayaron ventosas comerciales de $50 \mathrm{~mm}$ y $100 \mathrm{~mm}$ de diámetro nominal las cuales se instalaron en tuberías de $200 \mathrm{~mm}$ y $500 \mathrm{~mm}$ de diámetro respectivamente. De cada tamaño se ensayaron dos ventosas de dos casas comerciales diferentes, en adelante ventosa A y ventosa B, cuyas características constructivas eran muy distintas tanto por la configuración de las ventosas como por las características y materiales del flotador.

En total se dispone de 392 ensayos, entre ensayos dinámicos y de determinación de la capacidad de descarga de ventosas, realizados en las instalaciones de Delft Hydraulics de los cuales:

- 127 ensayos corresponden a ensayos con la ventosa A, DN50

- 154 ensayos se efectúan con la ventosa B, DN50

- 61 ensayos realizados sobre la ventosa A, DN100

- 50 ensayos se realizaron con la ventosa B, DN100 


\subsubsection{DESCRIPCIÓN DE LAS VENTOSAS SOMETIDAS A ENSAYO}

Como se ha comentado anteriormente, las ventosas ensayadas pertenecen a dos casas comerciales diferentes, ventosa A y ventosa B. De cada marca comercial se ensayaron dos diámetros nominales, $100 \mathrm{~mm}$ y $50 \mathrm{~mm}$ respectivamente. Luego en total se ensayaron cuatro ventosas, por separado, en condiciones de flujo estáticas y dinámicas para reproducir la expulsión y la admisión de aire en una instalación.
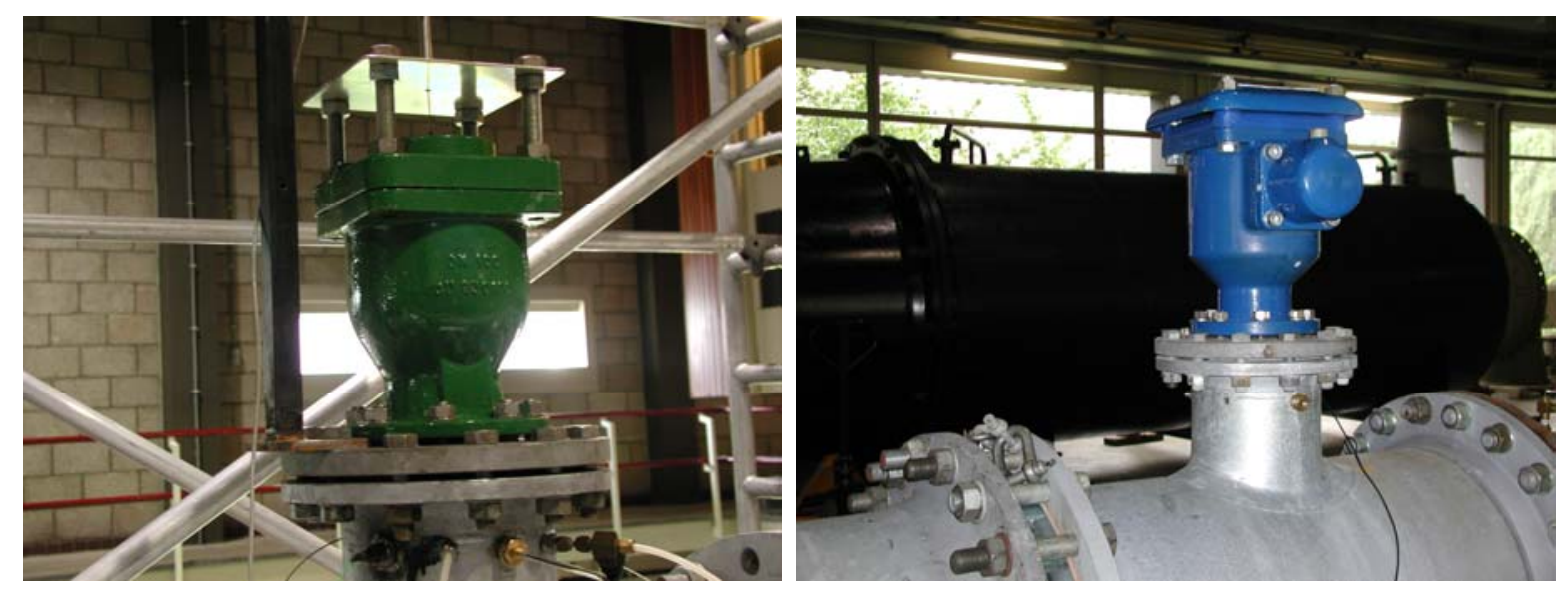

Figura 3.1. Fotografías de las ventosa A y B durante los ensayos

La ventosa A es una ventosa automática bifuncional, la cual puede evacuar grandes cantidades de aire durante el llenado de la conducción o admitir grandes cantidades de aire durante las operaciones de vaciado o cuando existan presiones negativas. Los materiales de construcción son para este tipo de ventosas y según las especificaciones del fabricante fundición nodular para cuerpo y tapa, la boya-flotador es de acero inoxidable y el asiento del cierre de elastómero. El cuerpo y tapa tienen un recubrimiento interno y externo mínimo de 150 micras de epoxi atóxico. Según datos del fabricante, esta ventosa está en conformidad con la Norma AWWA C512. 


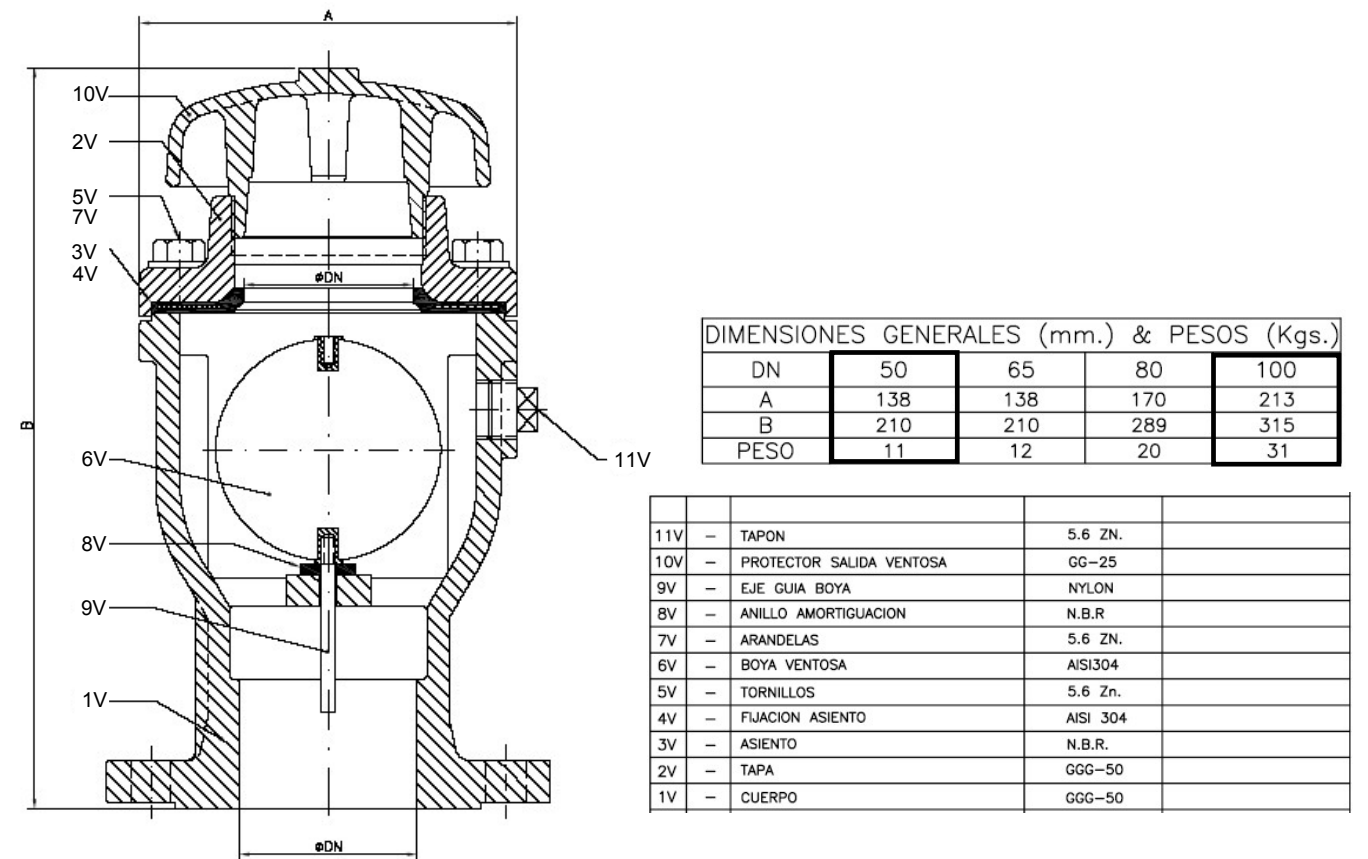

Figura 3.2. Características constructivas de la ventosa A

La ventosa $B$, por su parte, es una ventosa combinada, que posee un flotador cilíndrico de plástico de gran tamaño. $\mathrm{Al}$ igual que la ventosa $\mathrm{A}$, está pensada para descargar grandes cantidades de aire a la atmósfera durante el llenado de la instalación y permite la entrada de grandes cantidades de aire a la instalación cuando se procede a su vaciado. Además es capaz de expulsar aire mientras el sistema se encuentra a presión, aunque esta función se bloqueó durante la ejecución de estos ensayos. El cuerpo de la ventosa está recubierto por una capa de epoxi. Estas ventosas han sido diseñadas para instalaciones de agua potable a una temperatura máxima de $70{ }^{\circ} \mathrm{C}$

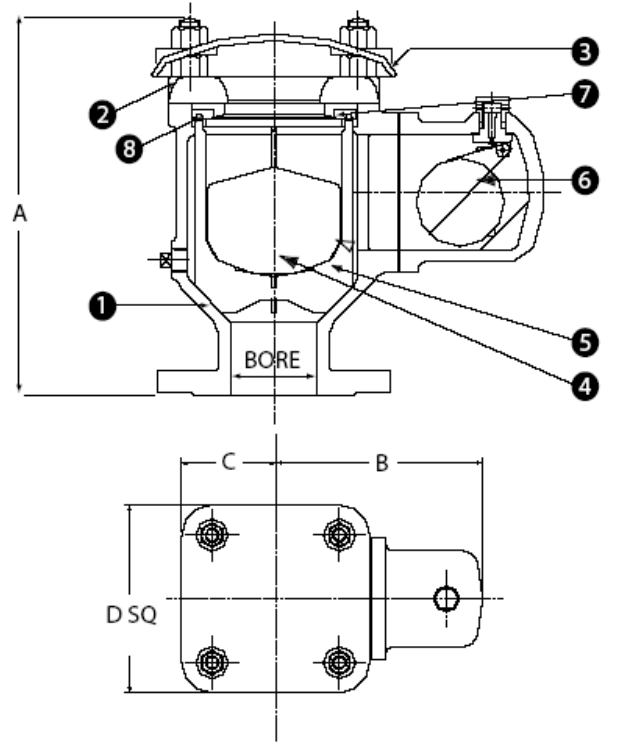

\begin{tabular}{|l|l|l|}
\hline \multicolumn{3}{|c|}{ Materiales de Construcción } \\
\hline$N^{\circ}$ & Descripción & Material \\
\hline $\mathbf{1}$ & Cuerpo & Acero fundido BS EN 1561 EN-GJL-250 \\
\hline $\mathbf{2}$ & Cobertura & Acero fundido BS EN 1561 EN-GJL-250 \\
\hline $\mathbf{3}$ & Protector salida ventosa & Acero fundido BS EN 1561 EN-GJL-250 \\
\hline $\mathbf{4}$ & Flotador (gran orificio) & Plástico ABS \\
\hline $\mathbf{5}$ & Guías del flotador & Plástico ABS \\
\hline $\mathbf{6}$ & Flotador y palanca & Plástico ABS \\
\hline $\mathbf{7}$ & Asiento & Plástico ABS \\
\hline
\end{tabular}

\begin{tabular}{|c|c|c|c|c|c|c|}
\hline \multicolumn{7}{|c|}{ Dimensiones (mm) } \\
\hline $\begin{array}{c}\text { Diámetro } \\
\text { tubería }\end{array}$ & DN & A & B & C & D & $\begin{array}{c}\text { Peso } \\
\text { aproximado } \\
\text { (Kg) }\end{array}$ \\
\hline 400 & 50 & 256 & 212 & 81 & 162 & 20.4 \\
\hline 400 & 80 & 256 & 212 & 81 & 162 & 20.4 \\
\hline 600 & 80 & 327 & 239 & 111 & 222 & 31.7 \\
\hline 900 & 100 & 410 & 259 & 146 & 292 & 51.7 \\
\hline 1000 & 150 & 410 & 259 & 146 & 292 & 72.7 \\
\hline
\end{tabular}

Figura 3.3. Características constructivas de la ventosa $B$ 


\subsection{INSTRUMENTACIÓN}

En el estudio de cualquier transitorio hidráulico el objetivo fundamental es calcular las presiones y caudales a lo largo del tiempo en los puntos críticos de la instalación. Por esta razón, en todos los ensayos se realizan mediciones de estas dos magnitudes, tomando datos de presión en varios puntos de la instalación. Como en los transitorios estudiados interviene un flujo bifásico, agua y aire, se consideró oportuno realizar mediciones de temperatura, aunque finalmente la respuesta en frecuencia de la sonda de temperatura no fue lo suficientemente elevada para detectar las variaciones de temperatura y presentaba valores constantes. Finalmente se introdujo la medición de la posición del flotador en cada instante de tiempo del transitorio.

Los puntos marcados como K1, K2 y K3 en los esquemas de la instalación general de la Figura 3.17 corresponden a tres transductores de presión de la marca Kristler. El valor de la presión registrada por dichos transductores viene dado, según el ensayo, en unidades relativas (bar) o absolutas (bar absoluto). El punto marcado como P1 en la Figura 3.17 corresponde también a un transductor de presión, cuya información se utilizó para determinar la altura del nivel del agua en el depósito de agua de alta presión. Se dispuso, además, de un caudalímetro electromagnético, identificado en los esquemas de las instalaciones que se presentan más adelante como EMF (Electromagnetic flowmeter), el cual registró los valores de caudal en cada instante de tiempo. Finalmente, se instalaron un sensor de temperatura, el cual suministró los datos de la misma en ${ }^{\circ} \mathrm{C}$ y un transductor de desplazamiento solidario con el flotador de la ventosa el cual facilitó datos de la posición del mismo en cada momento.

Resumiendo, los dispositivos de medición utilizados durante los ensayos que aportan los datos necesarios para realizar el análisis del transitorio son:

- Tres transductores de presión diferencial de $50 \mathrm{KHz}$ de respuesta en frecuencia (K1, K2 y K3): 


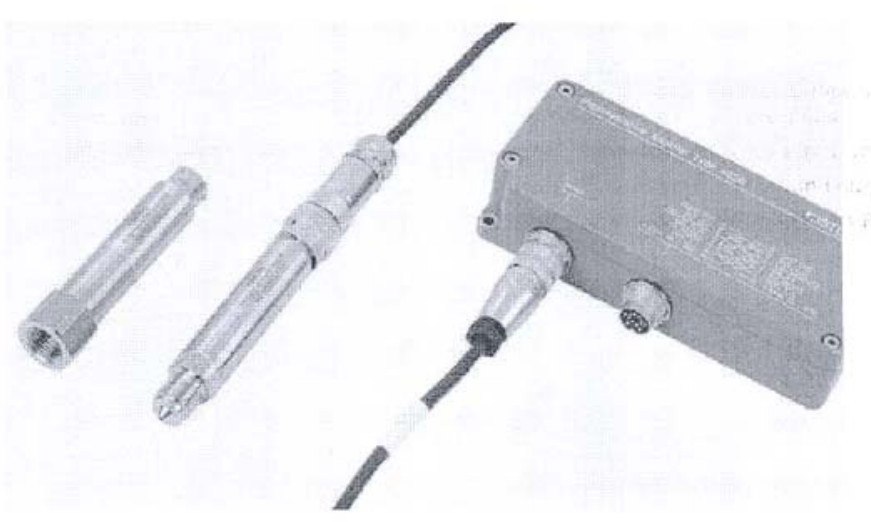

Figura 3.4. Transductores de presión

- El transductor de presión K1 mide la presión al inicio de la tubería, junto al caudalímetro.

- El transductor de presión K2 mide la presión en un punto intermedio de la tubería que comunica el depósito de agua con la ventosa.

- El transductor de presión K3 mide la presión justo a la entrada de la ventosa, en la $\mathrm{T}$.

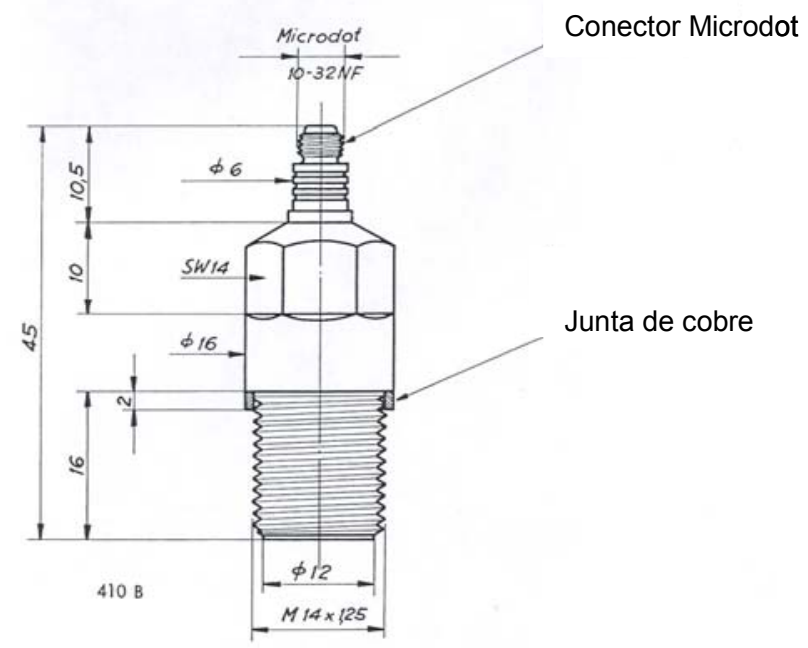

Figura 3.5. Esquema componentes transductor de presión marca Kistler 


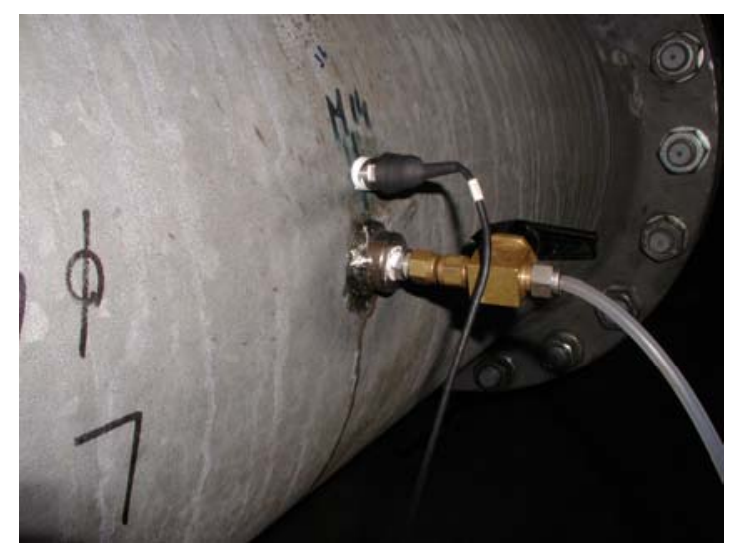

Figura 3.6. Transductor de presión instalado sobre la tubería

- Transductor de presión absoluta de gran exactiud (P1), con un error máximo de $0,1 \%$ sobre el fondo de escala (0-10 bar absolutos)

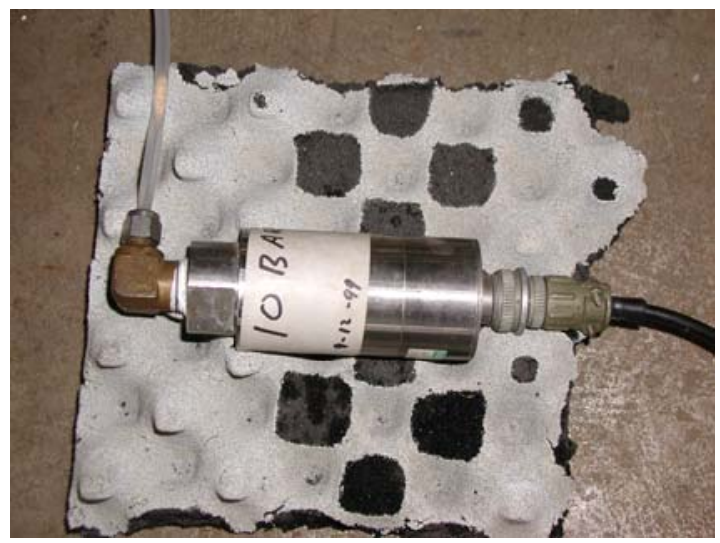

Figura 3.7. Transductor de presión P1

- Caudalímetro electromagnético con una respuesta en frecuencia alta de hasta $40 \mathrm{~Hz}$.
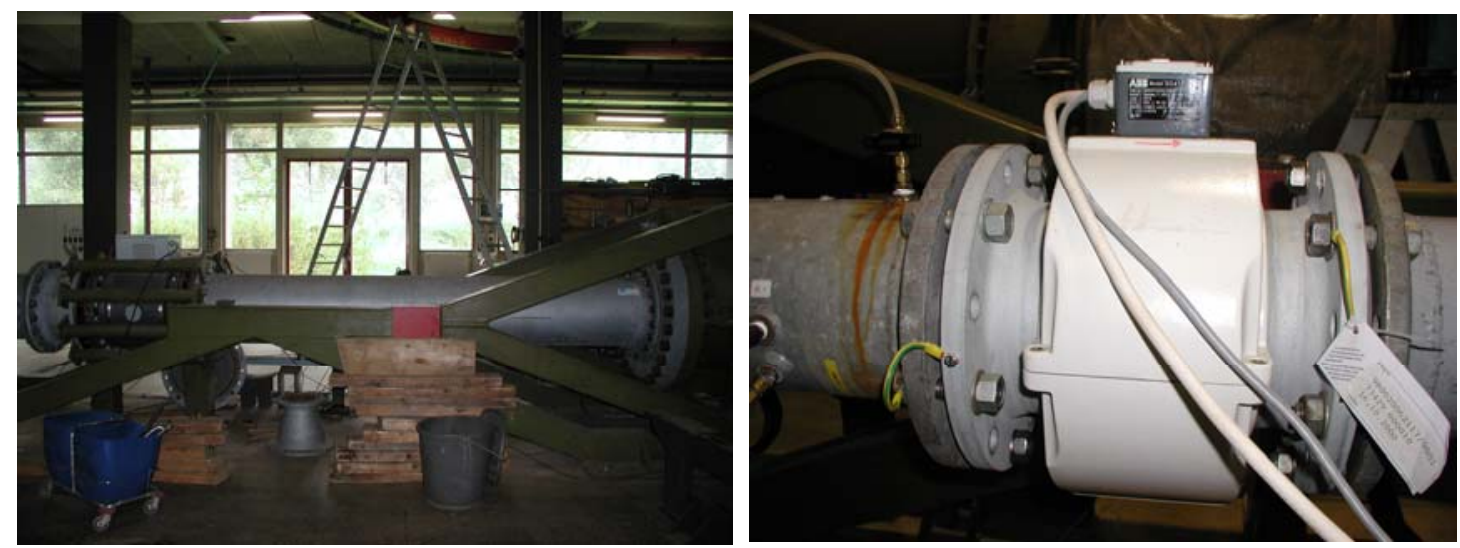

Figura 3.8. Caudalímetro electromagnético DN500 y DN200

- Caudalímetro tipo vórtex DN25. Este caudalímetro se utilizó para determinar la capacidad de descarga de las ventosas en régimen permanente de aire. También se contó con un caudalímetro vórtex de las mismas características de DN200. 


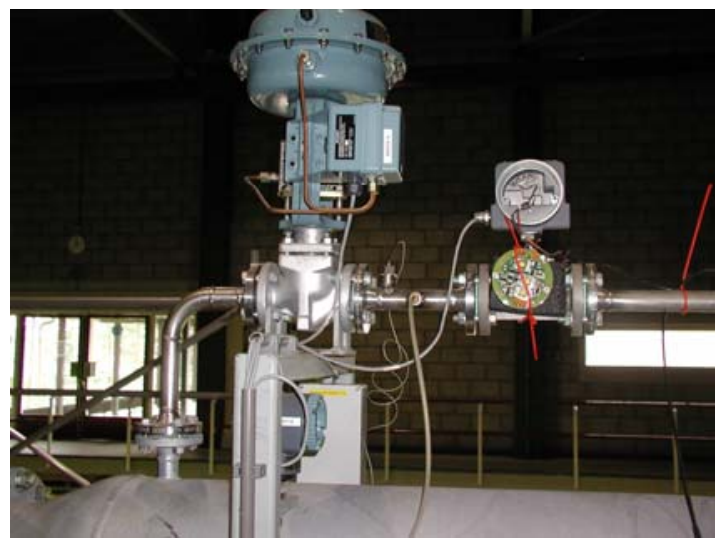

Figura 3.9. Caudalímetro tipo Vórtex DN25 en By-Pass

- Transductor de temperatura instalado en la sección de la ventosa.

- Transductor de posición situado en el flotador de la ventosa y que da información sobre la situación vertical del mismo.
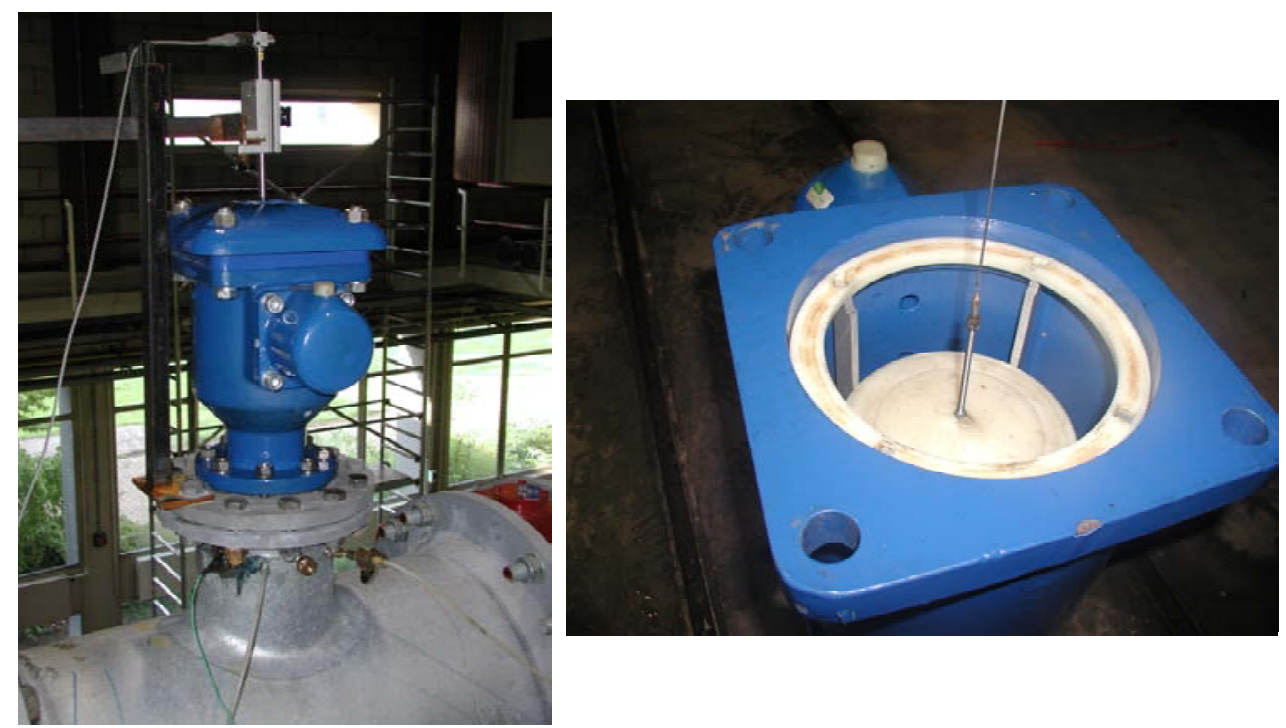

Figura 3.10. Transductor de posición marca HBM

- Tubo piezómetrico en el depósito de agua para medir el nivel inicial del agua. 


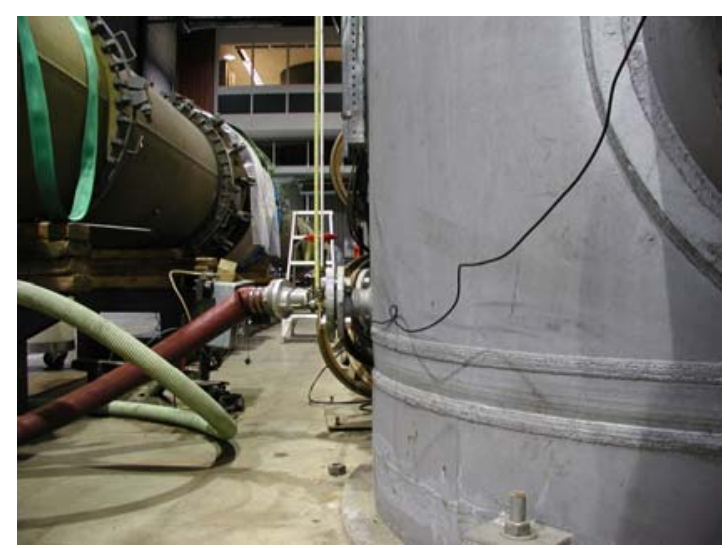

Figura 3.11. Tubo piezométrico en depósito 1

Además de estos elementos de medición se instalaron en la conducción representada en la Figura 3.17 otra serie de elementos, los cuales permitieron fijar las condiciones en las que se realizó cada ensayo así como la configuración de la instalación. Se trata por ejemplo de las válvulas de mariposa BV1 y BV2 las cuales se caracterizan por la rapidez de apertura o cierre.

La válvula, BV1, se usó para establecer el bloqueo de la columna de agua en movimiento justo cuando ésta alcanza el punto más elevado de la instalación. Con la válvula de mariposa BV1 cerrada la ventosa queda al final de la conducción, con lo que se simula la expulsión o admisión de aire al final de una conducción. Si por el contrario la válvula de mariposa BV1 se encuentra abierta, la columna de agua puede pasar al otro lado de la instalación con lo cual el bloqueo lo produce una columna de agua inmóvil situada en este otro lado. Se simula de este modo el comportamiento de una ventosa situada en un punto intermedio de la instalación que a su vez es el punto más elevado, como se muestra en la siguiente fotografía:

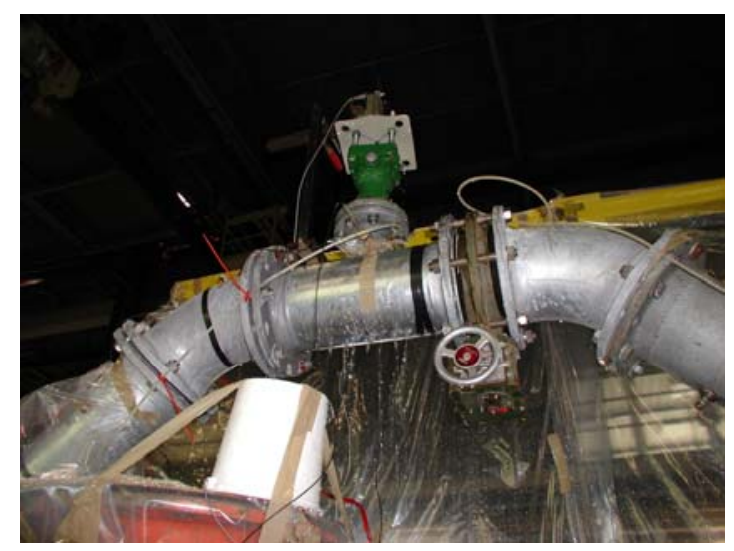

Figura 3.12. Válvula de mariposa BV1 junto a la ventosa

La segunda válvula de mariposa mencionada, la BV2, se usó para comunicar el depósito de agua con el depósito de aire de gran capacidad desde el cual se generaba el transitorio. De este modo, en los ensayos con expulsión de aire, al abrir la válvula de mariposa BV2 se permite la entrada de aire a una presión controlada que, gracias a la rapidez de 
apertura de la válvula, se comunica de manera casi instantánea al depósito de agua contiguo desde el cual se impulsa la columna de agua de la tubería. En los ensayos dinámicos con admisión de aire se crea desde el depósito de aire una depresión que se transmite de igual forma al depósito de agua, lo cual hace que la columna de agua se mueva en sentido contrario al establecido en los ensayos de expulsión de aire, es decir, desde la tubería hacia el depósito. En cualquier caso, el procedimiento se detallará más adelante.

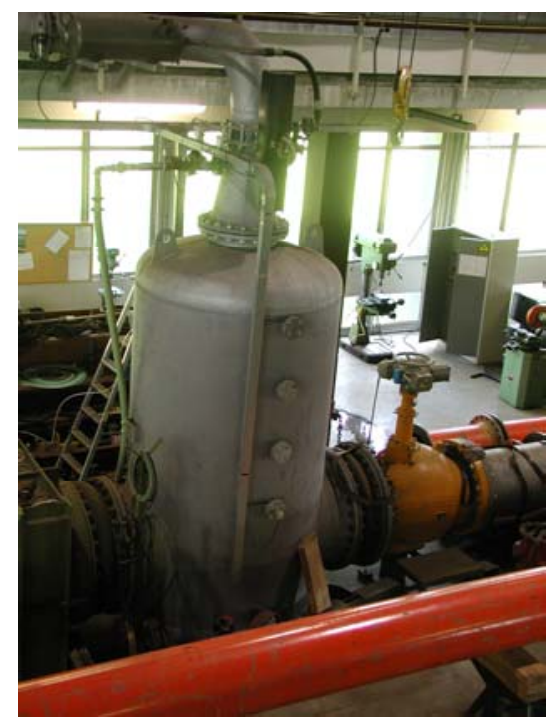

Figura 3.13. Depósito de agua con válvula de mariposa BV2 en la parte superior

Otro dispositivo presente en la instalación es la válvula de bola que comunica el depósito de alta presión con la atmósfera. Dicha válvula permitía ajustar las condiciones iniciales del ensayo.

\subsection{DESCRIPCIÓN DE LA INSTALACIÓN}

Según el tipo de ensayo que se desee llevar a cabo con una determinada ventosa, la instalación adopta la configuración más adecuada con la ayuda de los elementos descritos anteriormente. Se mantienen tres tipos de configuración básicos, es decir, la instalación para la determinación de la capacidad de descarga y admisión de aire de las ventosas, la instalación para la determinación del comportamiento dinámico de las ventosas ya sea para la expulsión como para la admisión de aire y la instalación para el estudio de la admisión de aire en un sistema cuando se produce la separación de la columna de agua.

Para cada una de estas configuraciones, se realizan ajustes y modificaciones sobre todo en la instalación para la determinación del comportamiento dinámico de las ventosas cuando se utilizan para expulsar aire. En esta instalación se ensayan tanto las ventosas de $50 \mathrm{~mm}$ como las de 100 mm de diámetro nominal. 


\subsubsection{INSTALACIÓN PARA LA DETERMINACIÓN DE LA CAPACIDAD DE DESCARGA Y ADMISIÓN DE LAS VENTOSAS}

La capacidad de descarga y admisión de aire de las ventosas se obtiene del ensayo realizado en una instalación de diámetro $200 \mathrm{~mm}$ como la mostrada en el esquema de la Figura 3.14.

Con este tipo de ensayos se pretende medir el caudal de aire y las presiones en distintos puntos de la instalación, manteniendo el flotador de la ventosa en una posición fija durante el ensayo. Se registraron medidas de presión aguas arriba de la ventosa, la diferencia de presión entre la entrada y la salida de la ventosa y la presión aguas abajo del caudalímetro vórtex DN25.

El grado de apertura de la ventosa se fijó mediante un vástago unido al flotador, el cual lo mantenía a un $25 \%$ o a un $50 \%$ de su recorrido total o bien al $100 \%$, es decir, con la ventosa completamente abierta.

Entre los elementos característicos de esta instalación cabe destacar el depósito de aire, depósito 1 de la Figura 3.14, de $70 \mathrm{~m}^{3}$ de capacidad, el cual podía ser presurizado hasta 22,5 bar pero que generalmente se mantenía a unos 6 bar o 7 bar en todos los ensayos.

Otro elemento fundamental a la hora de ejecutar estos ensayos fue la válvula de regulación del circuito que se podía controlar desde un ordenador. Mediante dicha válvula se regulaba el caudal de aire circulante por la instalación en cada caso.

En la preparación de los ensayos para determinar la capacidad de expulsión de aire de las ventosas se sometía el depósito de aire a una presión controlada, entre 6 bar y 7 bar. El By-Pass con tubería de diámetro DN25 se utilizó en el estudio de la capacidad de descarga de las ventosas de menor calibre, es decir en las de DN50, y en el estudio de las ventosas DN100 con caudales pequeños.

La presión en el depósito de aire no se modificaba externamente durante el ensayo. Por otro lado, el control del caudal se realizó mediante la válvula de regulación situada aguas arriba de la ventosa. En el instante inicial del ensayo, se fijaba una posición de apertura de dicha válvula y se mantenía fija durante el ensayo. La presencia de dicha válvula generaba perturbaciones de tal modo que al estar situada junto al caudalímetro vórtex DN200, dichas perturbaciones afectaban a la medida del caudal proporcionada por el mismo a caudales bajos de aire.

Debido a la incapacidad de generar presiones negativas en la instalación para proceder al estudio de la capacidad de admisión de aire de las ventosas en cuestión, se habilitó la salida de la ventosa de aire como entrada y se procedía a realizar el ensayo del mismo modo que en el caso anterior. 
La disposición de los elementos que intervienen en ese tipo de ensayos se muestra en la Figura 3.14:

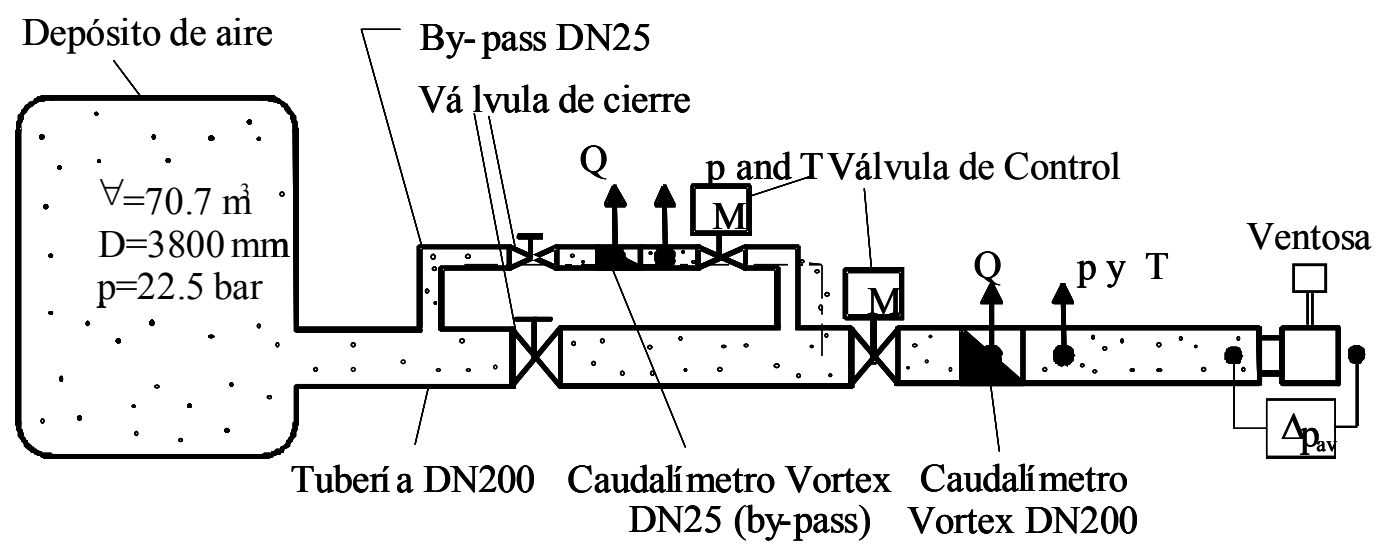

Figura 3.14. Instalación para la determinación de la capacidad de descarga/admisión de aire
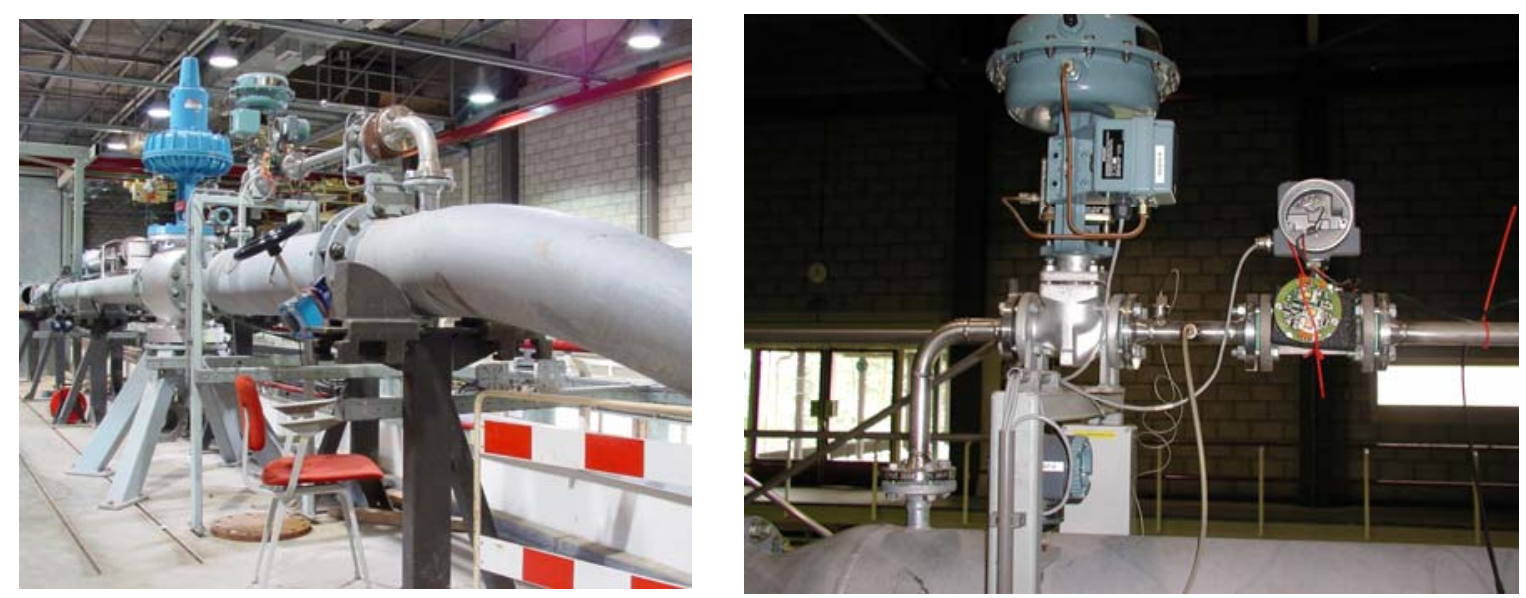

Figura 3.15. Instalación para los ensayos en flujo permanente. Detalle del By-Pass

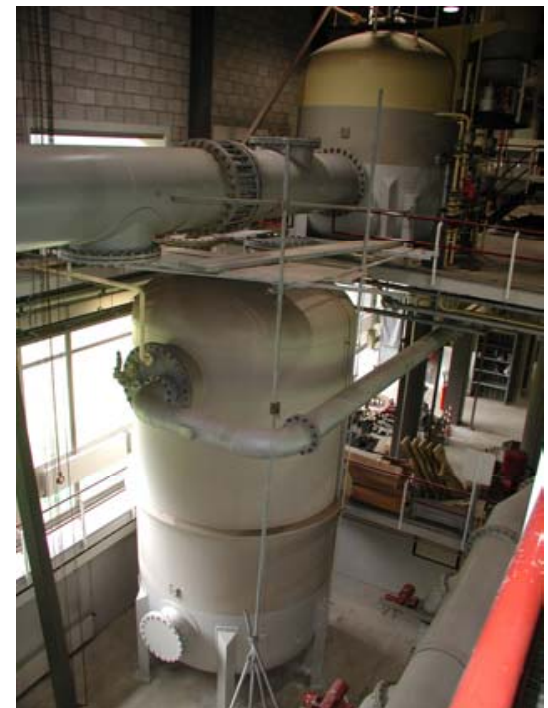

Figura 3.16. Depósito que contiene aire 


\subsubsection{INSTALACIÓN PARA LA DETERMINACIÓN DEL COMPORTAMIENTO DINÁMICO DE LAS VENTOSAS}

El esquema general del montaje utilizado para la realización de los ensayos en régimen transitorio bifásico en las instalaciones de WL| Delft Hydraulics (Holanda), consta principalmente de un depósito de aire a presión, el mismo que el utilizado en los ensayos comentados en el apartado anterior, el cual se encuentra comunicado con un depósito que contiene agua (D1). Desde dicho depósito sale una tubería que en su tramo medio presenta una pendiente de $45^{\circ}$ con respecto a la horizontal. Al final de esta conducción, sobre una unión en $\mathrm{T}$ se instala la ventosa. Junto a la ventosa, aguas abajo de la $\mathrm{T}$, existe una válvula de mariposa (BV1) que comunica la conducción con otra tubería de las mismas características y simétrica a la primera. Según el estado de la válvula de mariposa BV1 se consigue que la ventosa quede al final de la conducción (BV1 cerrada) o bien que la ventosa quede situada en un punto intermedio y a la vez más elevado de la instalación (BV1 abierta). Según estas indicaciones, el esquema general de la instalación se corresponde con el esquema mostrado en la Figura 3.17, y en la fotografía de la Figura 3.18, en las cuales aparecen cada uno de los dispositivos de medida utilizados.

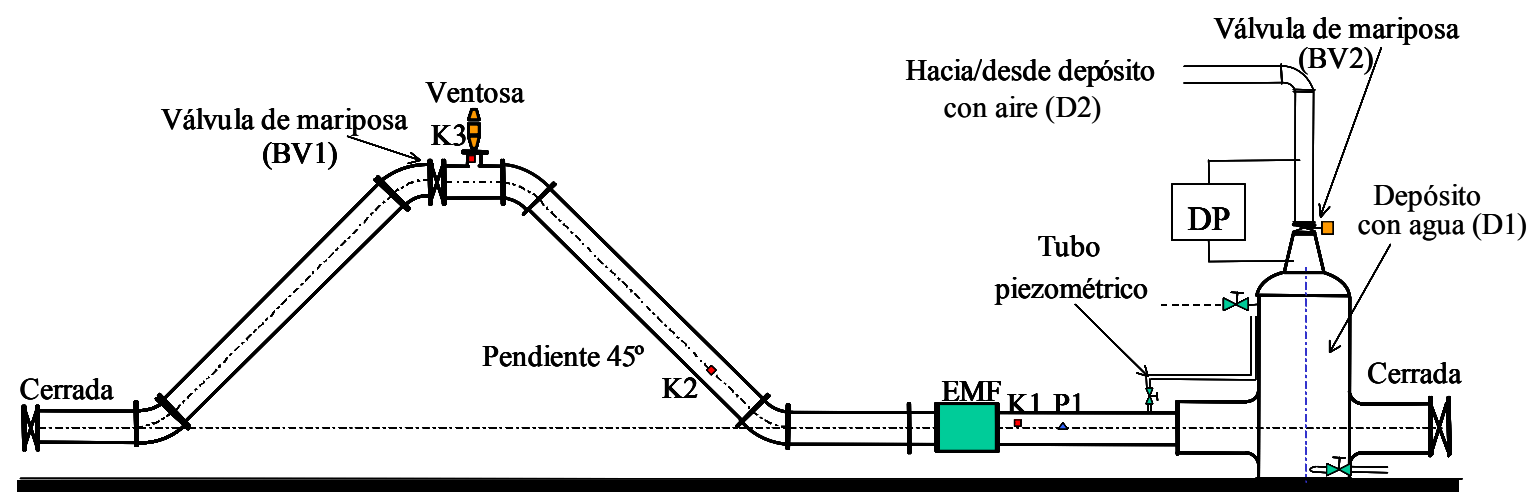

Figura 3.17. Esquema de la ubicación de la instrumentación sobre la instalación

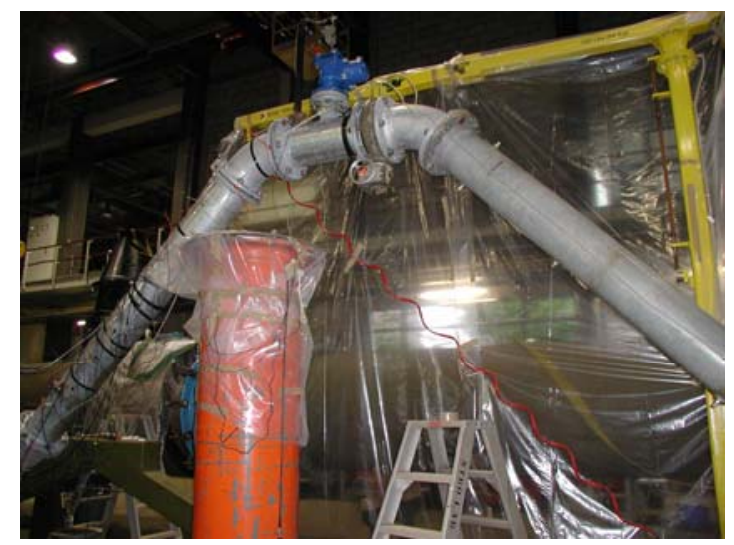

Figura 3.18. Montaje de la ventosa en el punto más elevado de la conducción 
Las ventosas de DN100 se ensayaron en una instalación cuyo diámetro de tubería es de $500 \mathrm{~mm}$ mientras que las ventosas DN50 se ensayaron en una instalación de $200 \mathrm{~mm}$ de diámetro.

Las dimensiones generales y características de la instalación de DN500 y la de DN200 (material de la tubería, espesor de la pared del tubo etc.) utilizadas para efectuar los ensayos dinámicos de las ventosas de DN100 y DN50 respectivamente se exponen en la siguiente tabla:

Tabla 3.1 Características de las conducciones

\begin{tabular}{lcc}
\hline & Tubería DN500 & Tubería DN200 \\
\hline Diámetro Interior $D(\mathrm{~mm})$ & 489 & 206 \\
\hline Espesor del tubo e $(\mathrm{mm})$ & 9.5 & 5.9 \\
\hline Material & acero & acero \\
\hline
\end{tabular}

Se investiga además la repetibilidad de los experimentos idénticos realizados en las secciones de $500 \mathrm{~mm}$ y de $200 \mathrm{~mm}$ con y sin ventosa. El objetivo de los ensayos de repetibilidad es estimar la dispersión de los datos debido a la incapacidad de llevar el sistema en la práctica a idénticas condiciones iniciales.

Las dimensiones de cada sección se definen en las tablas 3.1 y 3.2 y en la Figura 3.19. Se mantuvo el mismo factor de escala en ambas secciones para cada elemento de la instalación.

Tabla 3.2. Características metrológicas de la instalación

\begin{tabular}{ll}
\hline & Incertidumbre \\
\hline Diámetro Interior $(D)$ & $\pm 0.1 \mathrm{~mm}$ \\
\hline Espesor del tubo $(e)$ & $\pm 0.05 \mathrm{~mm}$ \\
\hline Longitud $(L)$ & $\pm 0.01 \mathrm{~m}$ \\
\hline Transductor de presión piezoelectrico $(p)$ & $\pm 0.7 \%$ Fondo Escala \\
\hline Caudalímetro electromagnético DN500 $(Q)$ & $\pm 4 \%$ de flujo \\
\hline Caudalímetro electromagnético DN $200(Q)$ & $\pm 2 \%$ de flujo \\
\hline Temperatura del agua $(T)$ & $\pm 0.5{ }^{\circ} \mathrm{C}$ \\
\hline Posición del flotador de la ventosa $\left(S_{a v}\right)$ & $\pm 0.5 \%$ Fondo Escala \\
\hline Presión barométrica $\left(p_{B}\right)$ & $\pm 0.1 \mathrm{kPa}$ \\
\hline
\end{tabular}




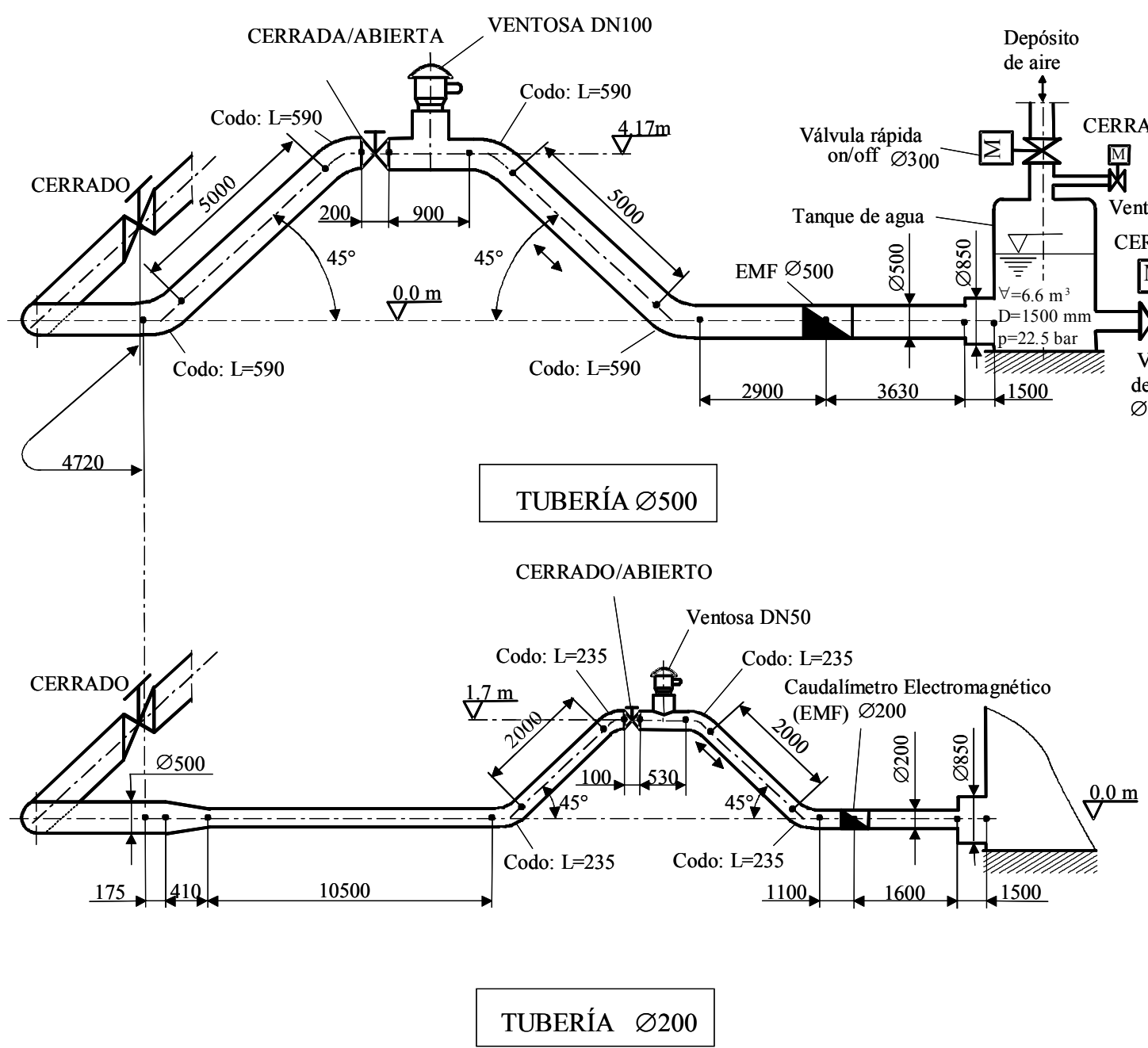

Figura 3.19. Dimensiones de la instalación para la determinación del comportamiento dinámico de las ventosas

\subsubsection{INSTALACIÓN PARA EL ESTUDIO DE LA ADMISIÓN DE AIRE EN SITUACIONES DE SEPARACIÓN DE LA COLUMNA DE AGUA}

Cuando en una determinada instalación en la cual existe una válvula de retención, se invierte el sentido habitual del flujo que circula por la misma dicha válvula se cierra. De este modo, en un lado de dicha válvula se producen sobrepresiones mientras que en el otro lado aparecen bajas presiones. Debido a estas bajas presiones se puede producir el fenómeno conocido como separación de la columna de agua que puede ser perjudicial para la instalación. El objetivo de estos ensayos es analizar si la presencia de una ventosa es capaz de eliminar estas bajas presiones. La configuración de la instalación utilizada en este caso es diferente a la de los ensayos del apartado anterior, tal y como muestran las siguientes fotografías: 

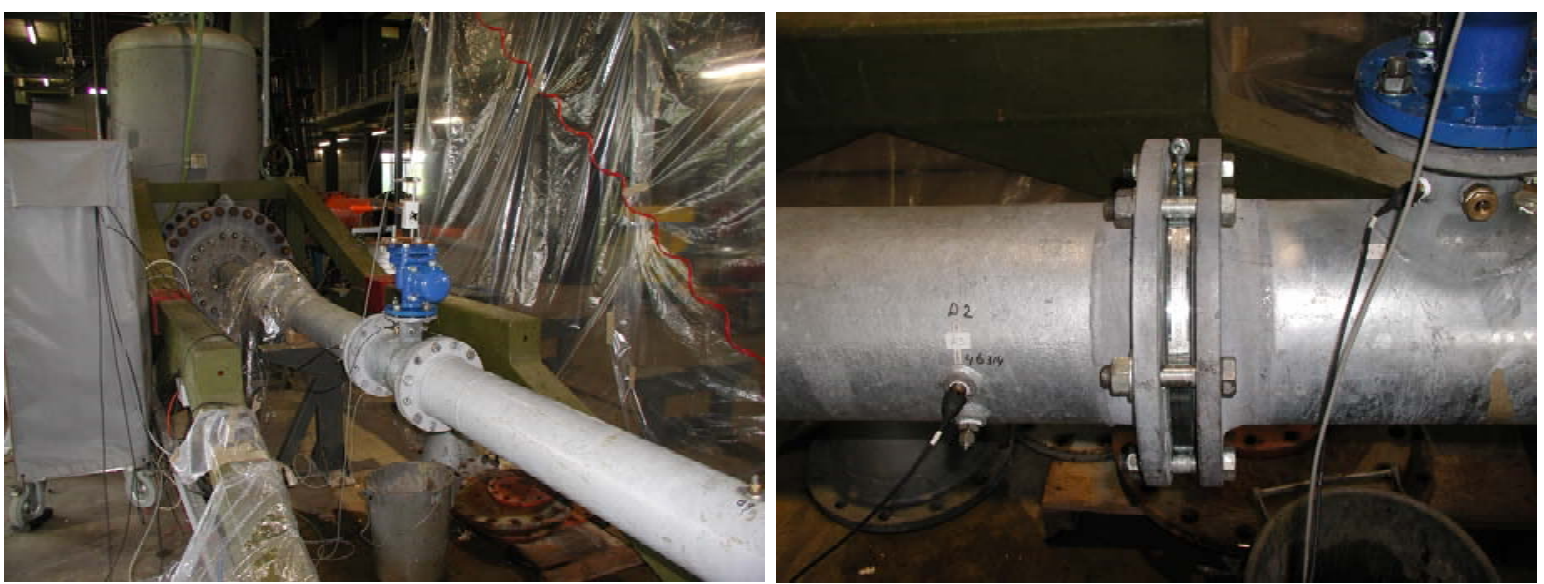

Figura 3.20. Instalación con ventosa y válvula de retención.

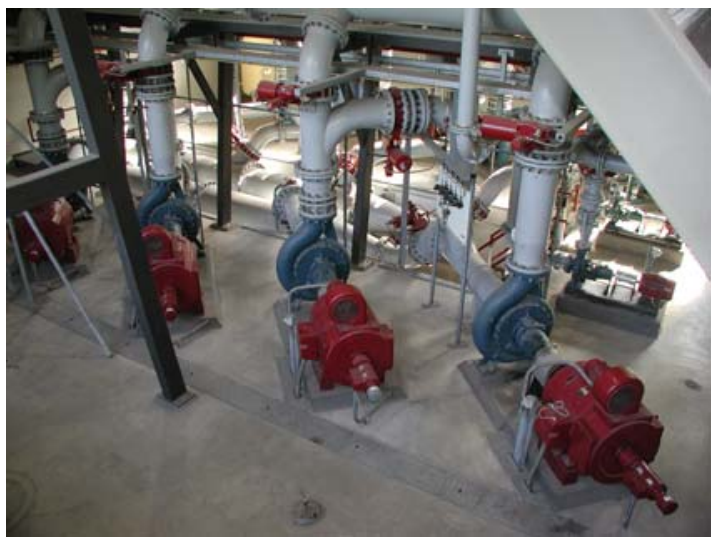

Figura 3.21. Sistema de bombeo

Como ha sido habitual en cualquier ensayo de laboratorio, las ventosas DN100 se ensayan en una instalación de $500 \mathrm{~mm}$ de diámetro y las ventosas de DN50 se ensayan en la instalación de $200 \mathrm{~mm}$ de diámetro. A continuación se muestra el esquema de la instalación en ese tipo de ensayos así como las dimensiones y ubicación de la instrumentación en cada caso: 


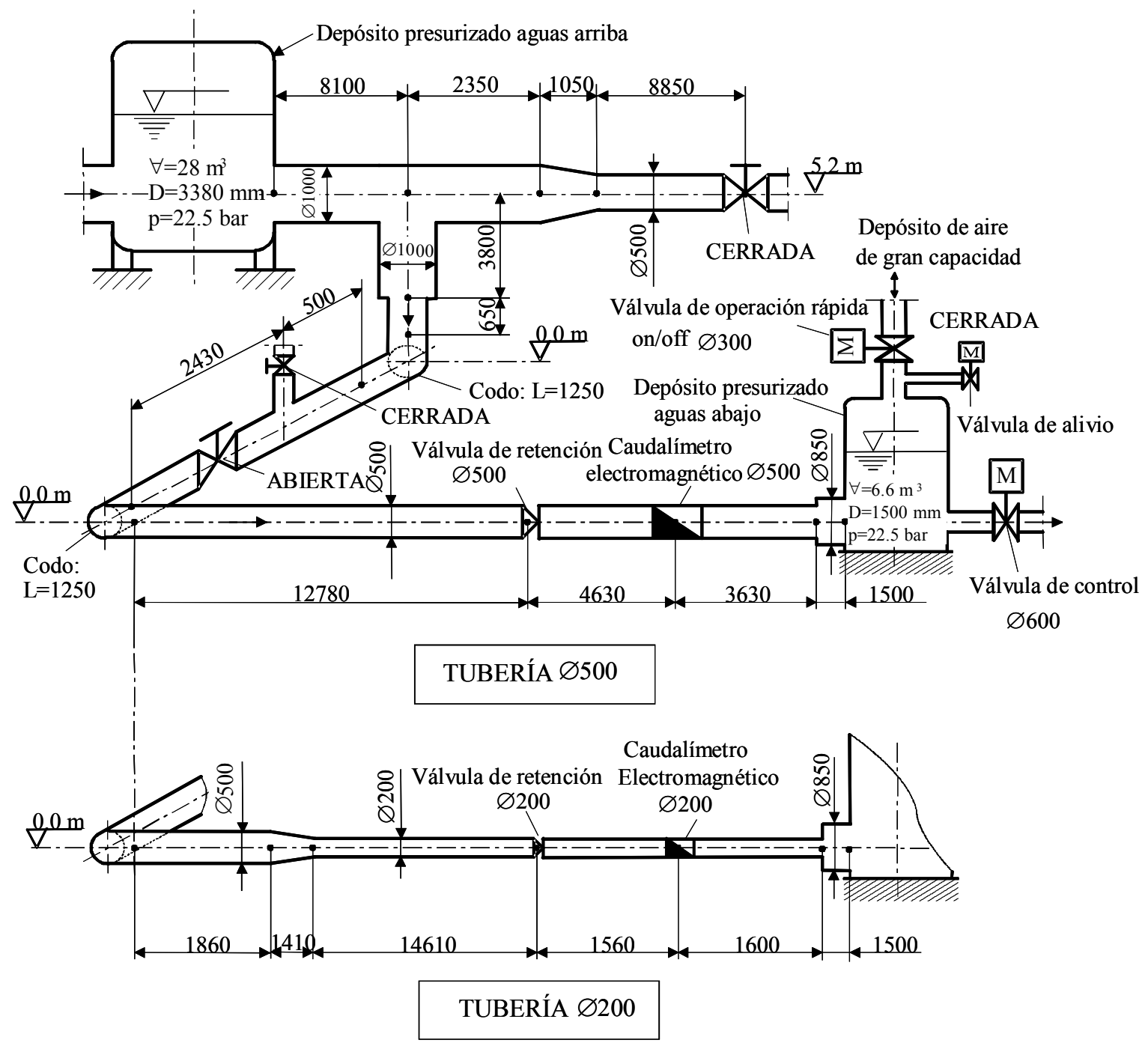

Figura 3.22. Medidas generales de la instalación para el estudio de la admisión de aire

\subsection{DESCRIPCIÓN DEL PROCEDIMIENTO DE ENSAYO}

\subsubsection{PROCEDIMIENTO DE LOS ENSAYOS PARA LA DETERMINACIÓN DE LA CAPACIDAD DE DESCARGA Y ADMISIÓN DE LAS VENTOSAS}

En los ensayos para la determinación de la capacidad de descarga o de admisión de aire de las ventosas se mantuvo tres grados de apertura fijos de la ventosa. Tanto en los casos de expulsión como en los casos de admisión de aire la ventosa se ensayó fijando un grado de apertura del $25 \%$ del total de la carrera que puede recorrer el flotador, del $50 \%$ y del $100 \%$.

En el instante inicial de estos ensayos, el depósito de aire se presurizaba de forma controlada de manera que la presión en su interior era entre 6 bar y 7 bar. El ensayo consistía fundamentalmente en hacer circular aire por la instalación y expulsarlo 
posteriormente a través de la ventosa. Para ello, la presión en el depósito de aire se mantenía fija durante todo el ensayo y el caudal de aire se regulaba según las necesidades de cada caso.

\subsubsection{PROCEDIMIENTO DE LOS ENSAYOS DINÁMICOS DE EXPULSIÓN DE AIRE}

Antes del inicio de cada ensayo, la presión en el tanque de aire de gran capacidad (D2) se ajustaba utilizando una válvula reguladora de admisión. Al alcanzar la presión deseada se dejaba un tiempo de estabilización antes de abrir la válvula de mariposa de operación rápida (BV2) situada en la parte superior del tanque de alta presión tal y como se muestra en Figura 3.17. Mediante la apertura de la válvula de alivio, conectada al depósito con agua D1, se permitía mantener dicho depósito a presión atmosférica. Al inicial el ensayo, esta válvula se cerraba.

La apertura de la válvula de mariposa BV2 comunicaba los depósitos D1 y D2 de modo que la presión del depósito D1 se igualaba a la del depósito D2. El aumento controlado de la presión en el depósito D1 ponía en movimiento la columna de agua existente en la instalación.

Durante el transitorio, un caudalímetro electromagnético especial de respuesta rápida situado en el tramo horizontal inicial junto al depósito de agua, medía el flujo de agua a través de la tubería.

Para producir transitorios de diferente magnitud en los ensayos de expulsión de aire se modificaron los siguientes factores:

- La presión inicial de aire en el depósito D1. Este es el parámetro principal utilizado para controlar la magnitud del transitorio Esta variación de la presión en el depósito D1 se obtiene comunicando el depósito D1 con el D2, el cual se presuriza previamente.

- La configuración de la instalación. Como se ha comentado en párrafos anteriores esto se consiguió cerrando y abriendo la válvula de mariposa situada junto a la ventosa (BV1). En algunos ensayos se añadieron carretes verticales entre la ventosa y la conexión en $\mathrm{T}$.

- El nivel inicial de la columna de agua en el interior de la instalación. Este parámetro sirvió para ajustar la distancia inicial entre el extremo de la columna de agua y la ventosa.

La secuencia seguida en los ensayos dinámicos de ventosas durante la expulsión de aire de una instalación la cual en el instante inicial se encuentra parcialmente llena de agua se refleja en las siguientes figuras. Cuando la ventosa se encuentra en el punto final de la 
instalación, es decir la válvula de mariposa BV1 está cerrada, el proceso de expulsión de aire se lleva a cabo en cuatro etapas diferenciadas:

- ETAPA 1: Tanto la válvula de mariposa BV1 como la válvula de mariposa BV2 están inicialmente cerradas. En esta etapa se fija la longitud inicial de la columna de agua que se pone en movimiento Ilenando o vaciando de agua la instalación. La ventosa está abierta, así como también lo está la válvula del depósito de agua que lo comunica con el exterior, de manera que tanto la superficie libre de la columna de agua como la de la masa de agua que se encuentra en el depósito están a presión atmosférica y a la misma altura del suelo.

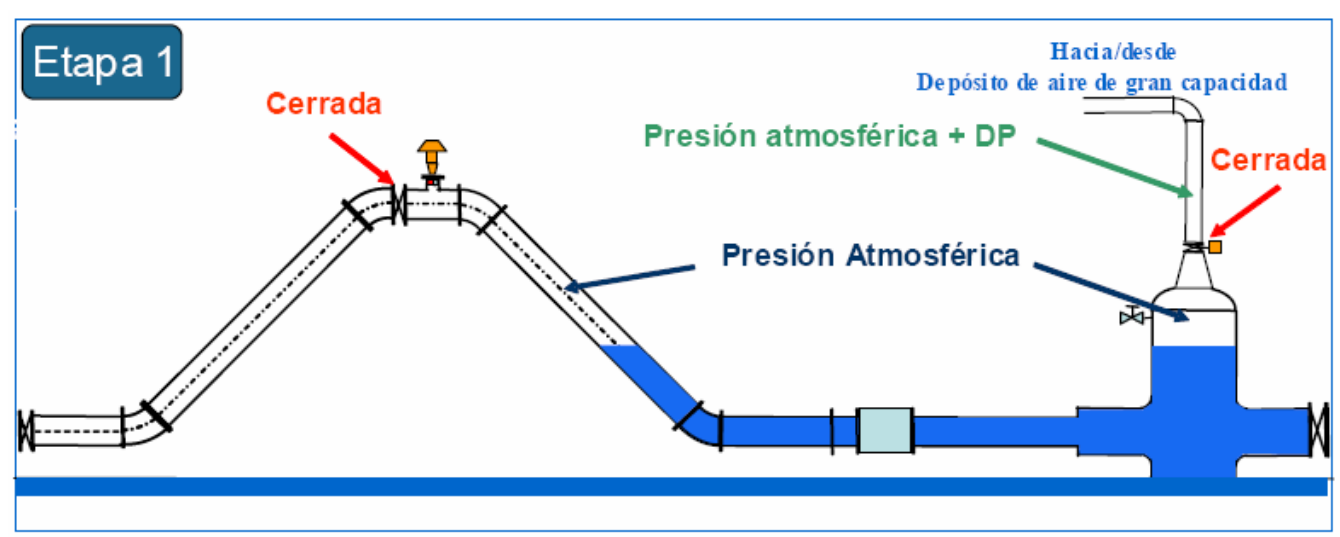

Figura 3.23. Proceso de expulsión de aire al final de la conducción. Etapa 1

- ETAPA 2: Se asegura en primer lugar que la válvula de aireación que comunica el depósito D1 con el exterior (Figura 3.19) se encuentre cerrada. Además, se presuriza el depósito D2 de manera controlada. Seguidamente, abre la válvula de mariposa BV2 de modo que se igualan las presiones de ambos depósitos. La presión adquirida por el fluido existente en el depósito D2 se transmite a la columna de agua la cual inicia en consecuencia su movimiento.

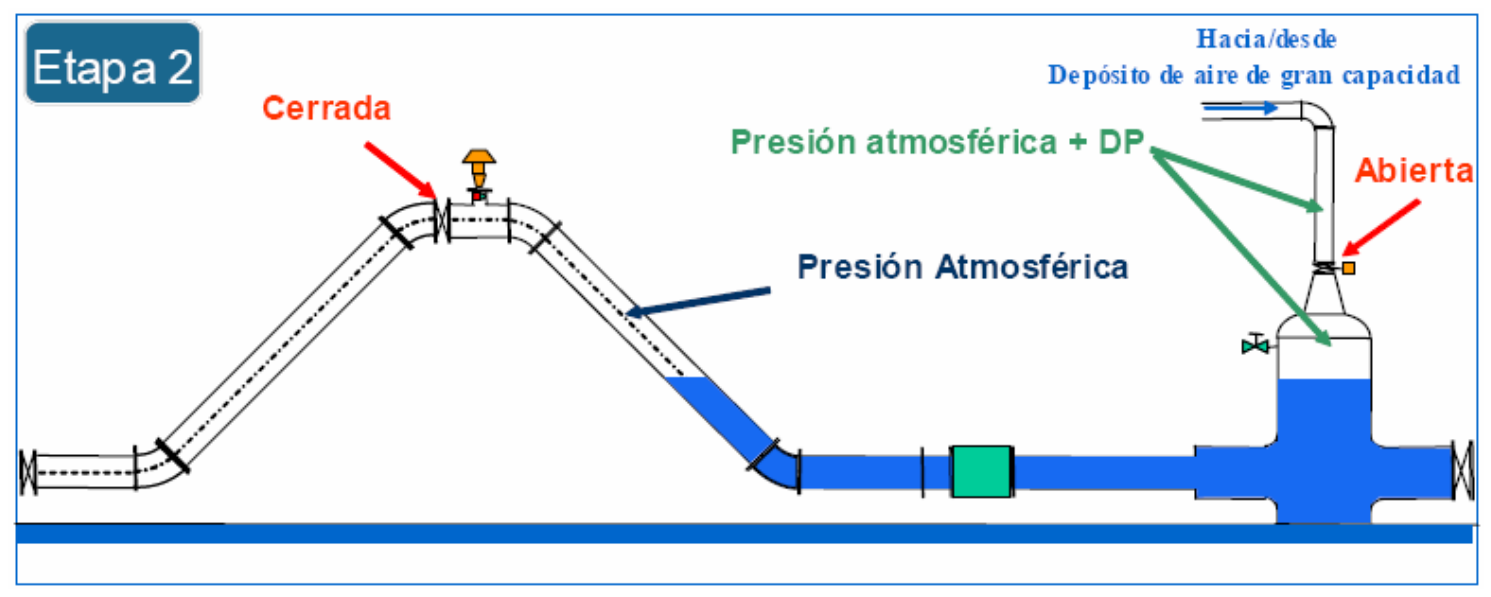

Figura 3.24. Proceso de expulsión de aire al final de la conducción. Etapa 2 
- ETAPA 3: La columna de agua al recibir la presión se mueve hacia el punto más alto de la instalación empujando de esta forma la bolsa de aire situada en su extremo final aguas abajo. La bolsa de aire existente en la tubería se expulsa hacia el exterior a través del orificio de salida de la ventosa.

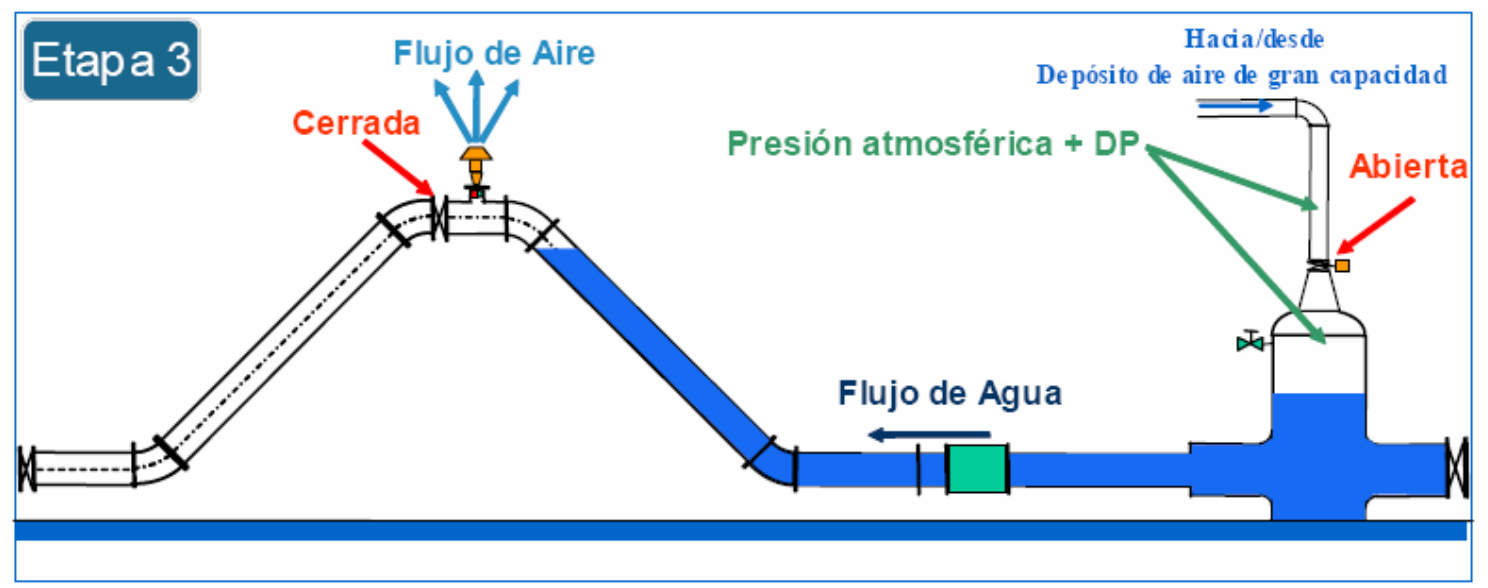

Figura 3.25. Proceso de expulsión de aire al final de la conducción. Etapa 3

- ETAPA 4: El final del ensayo se produce cuando la columna de agua alcanza el flotador y cierra la ventosa, con la consiguiente compresión de la bolsa de aire que queda atrapada en el interior de la instalación.

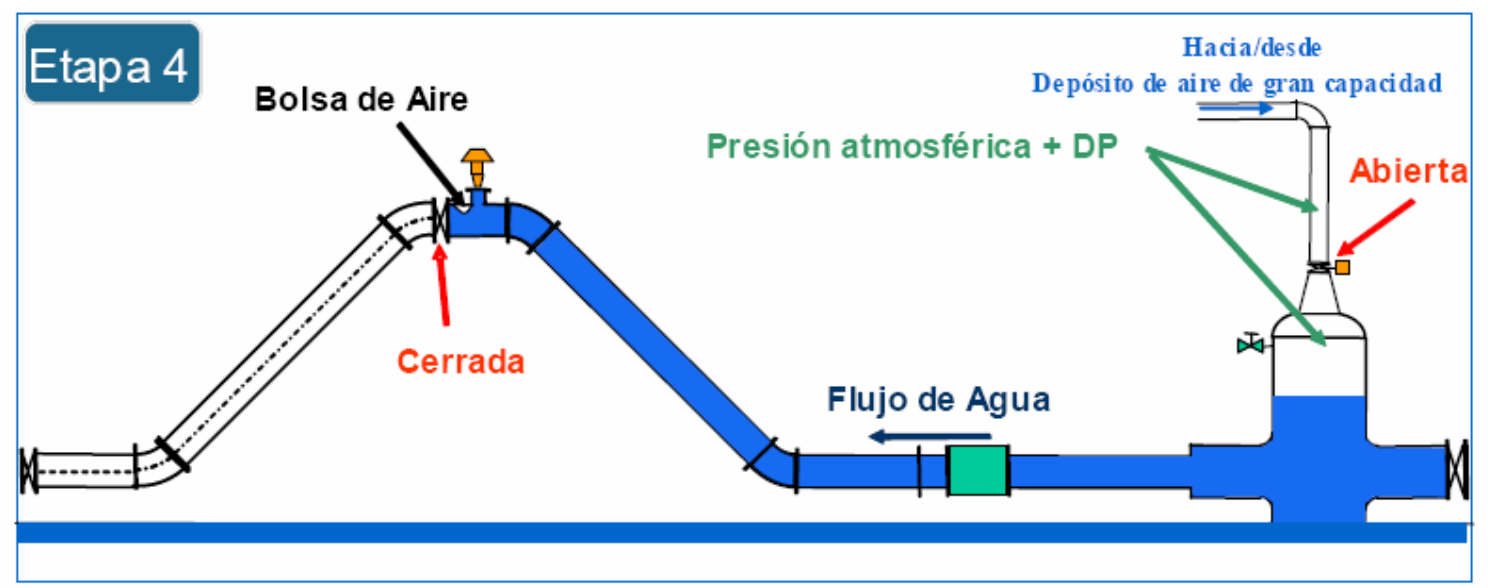

Figura 3.26. Proceso de expulsión de aire al final de la conducción. Etapa 4

El otro caso de ensayo dinámico de expulsión de aire estudiado, es decir cuando la válvula de mariposa BV1 se encuentra abierta, se ha dividido en 5 fases o etapas. La ventosa se halla en este caso, en el punto intermedio de la instalación que a su vez es el más alto.

- ETAPA 1: En un principio la válvula de mariposa BV2 se encuentra cerrada, la ventosa está abierta así como también está abierta la válvula que comunica el depósito D2 con el exterior. De esta manera la columna de agua se encuentra a presión atmosférica, se fija la longitud inicial de la misma y el volumen de la bolsa 
de aire entre la ventosa y la columna de agua. También se determina la longitud de la columna de agua en la parte opuesta de la instalación que sirve de bloqueo a la columna de agua en movimiento.

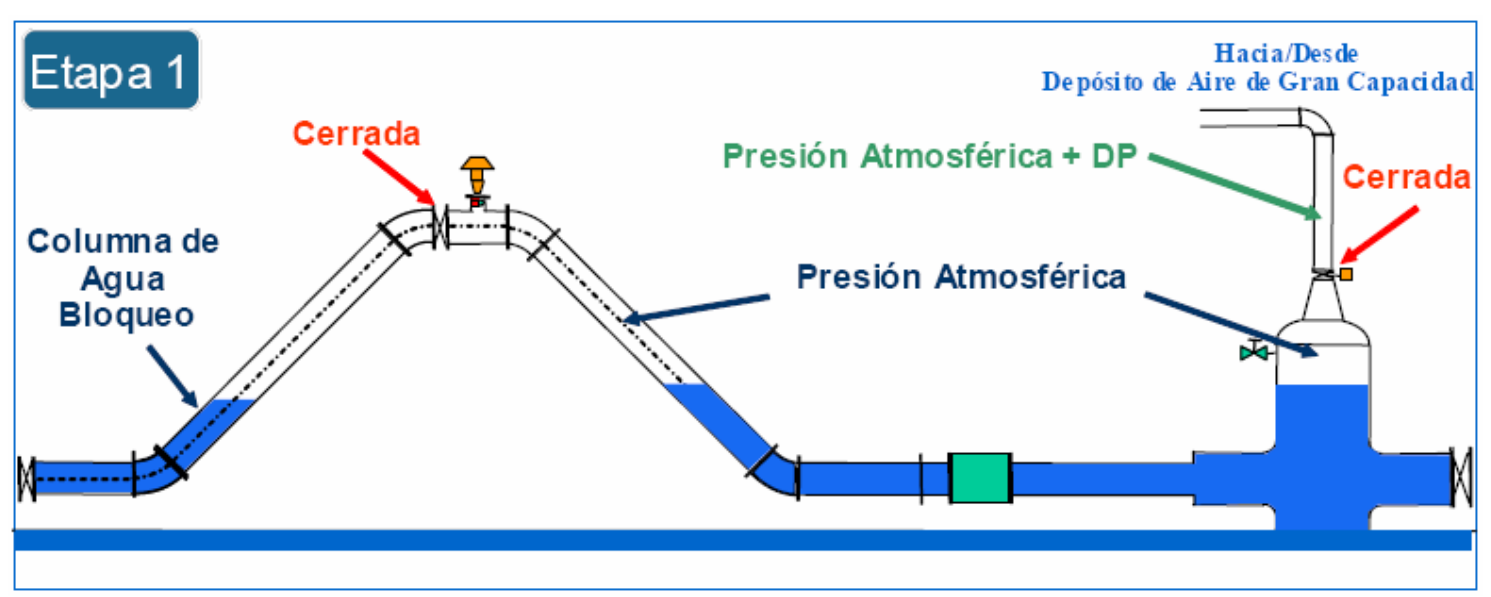

Figura 3.27. Proceso de expulsión de aire en un punto intermedio de la conducción. Etapa 1

- ETAPA 2: Se fija una presión determinada en el depósito D2 como en el caso anterior mientras permanecen las válvulas en el mismo estado que en la etapa previa.

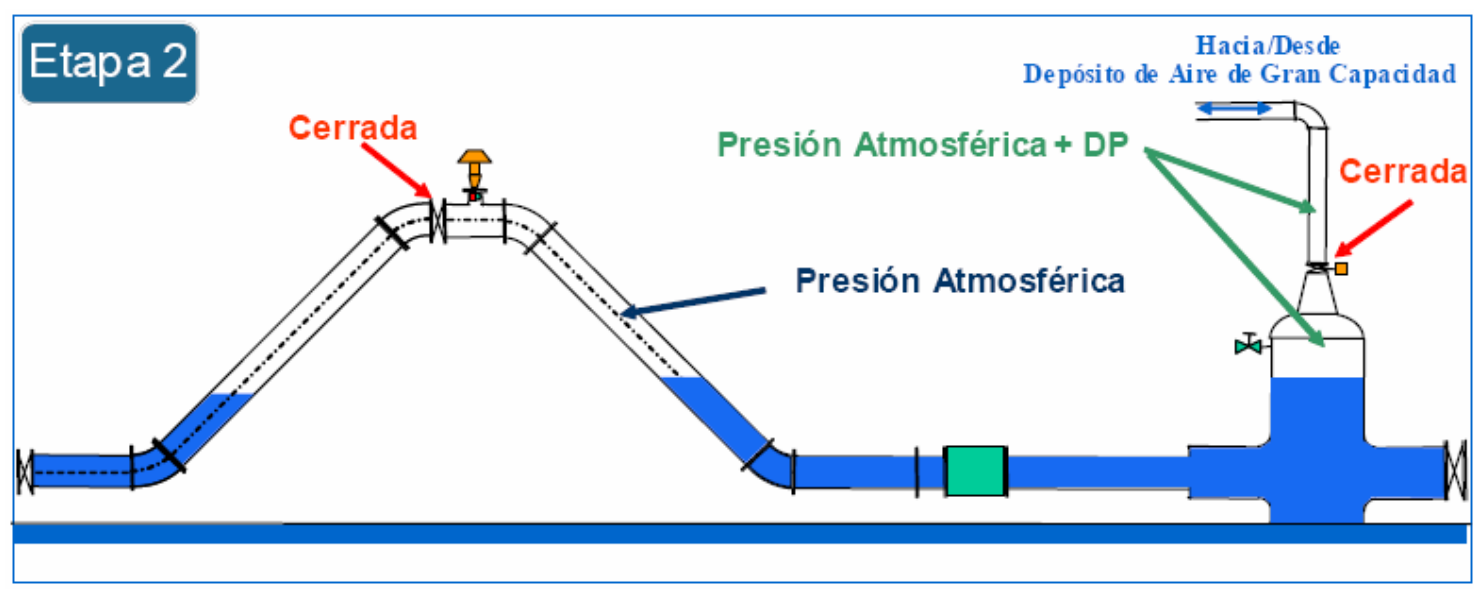

Figura 3.28. Proceso de expulsión de aire en un punto intermedio de la conducción. Etapa 2

- ETAPA 3: Abre la válvula de mariposa BV2 de manera que el agua del depósito admite rápidamente la presión procedente del tanque de aire. Con este aumento de presión la columna de agua empieza su movimiento ascendente hacia la parte superior de la instalación arrastrando consigo a la bolsa de aire que se encuentra al final de la columna de agua. 


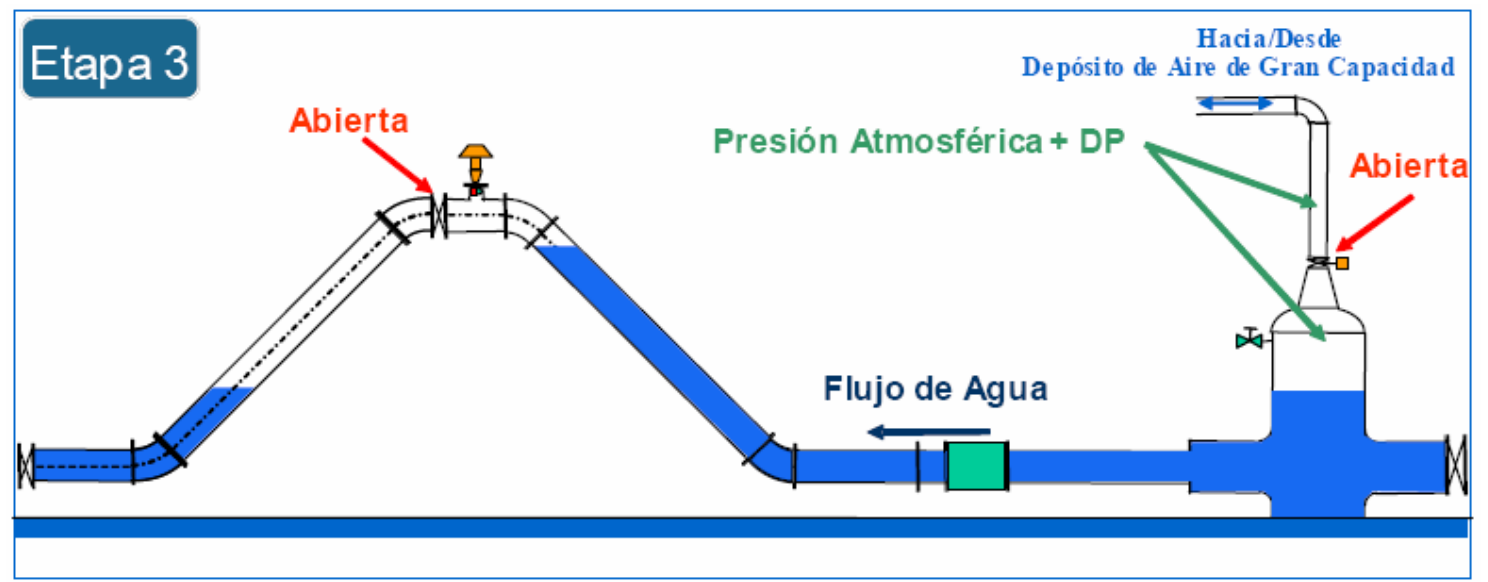

Figura 3.29. Proceso de expulsión de aire en un punto intermedio de la conducción. Etapa 3

- ETAPA 4: Una vez la columna de agua llega a la parte superior de la ventosa se encuentra con la válvula de mariposa BV1 abierta con lo cual el agua puede seguir su camino hacia el otro lado de la instalación arrastrando con su movimiento la bolsa de aire que no ha sido expulsado por la ventosa.

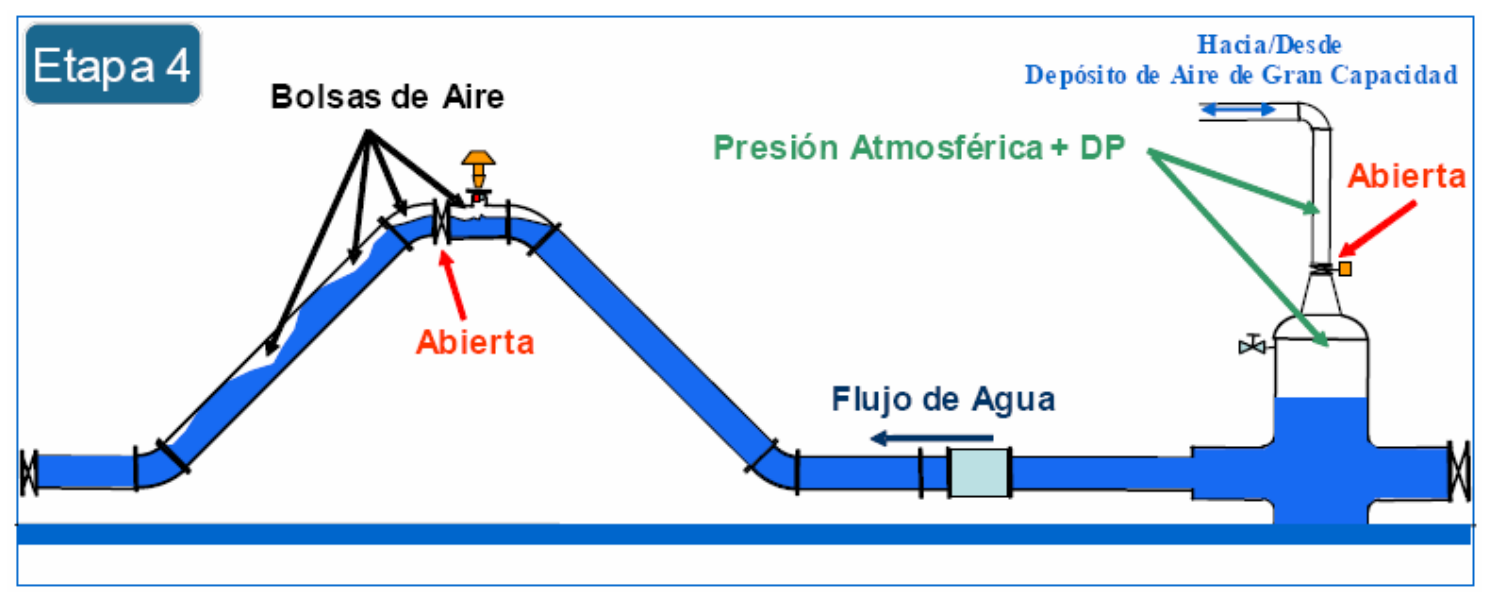

Figura 3.30. Proceso de expulsión de aire en un punto intermedio de la conducción. Etapa 4

- ETAPA 5: Al llegar la columna de agua al flotador de la ventosa es capaz de cerrarla. La instalación queda llena de agua pero con una cantidad considerable de bolsas de aire. 


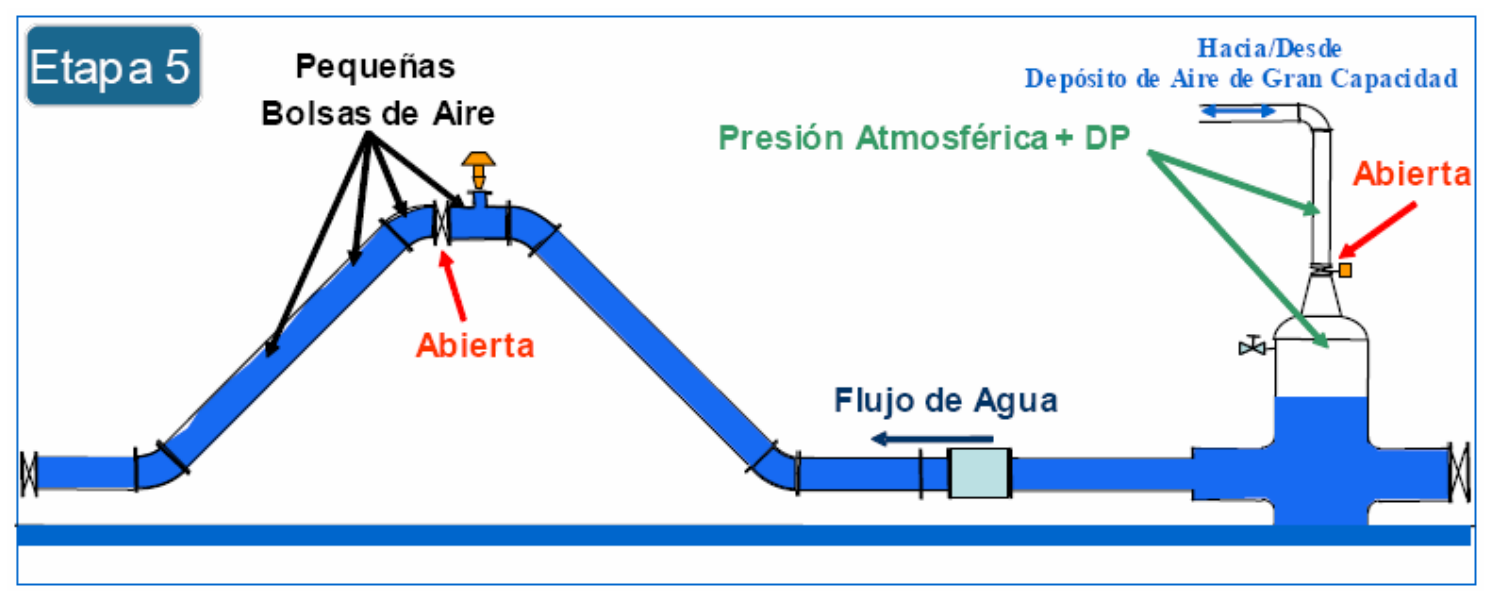

Figura 3.31. Proceso de expulsión de aire en un punto intermedio de la conducción. Etapa 5

En la sección de menor diámetro, es decir $200 \mathrm{~mm}$, se ensayan dos configuraciones adicionales. En dichas configuraciones se instala un carrete vertical entre la unión en T y la ventosa manteniendo la válvula de mariposa BV1 cerrada o abierta como en los casos anteriores. La longitud de dicho carrete vertical fue en unos casos de 1,185 $\mathrm{m}$ y en otros casos de 2,185 m. En la Figura 3.32, se muestra la parte superior estas dos nuevas configuraciones indicando la disposición de cada uno de los elementos y las nuevas dimensiones. Los procedimientos de ensayo para los tests de expulsión en estos casos fueron exactamente los mismos que los descritos anteriormente con la válvula de mariposa BV1 cerrada.
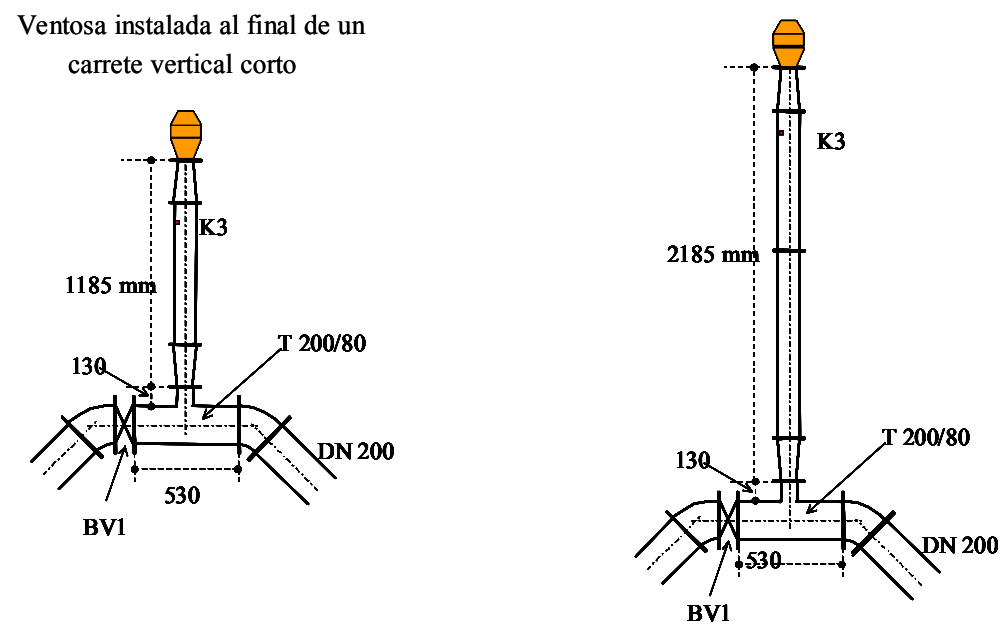

Figura 3.32. Esquema de la disposición del carrete vertical 


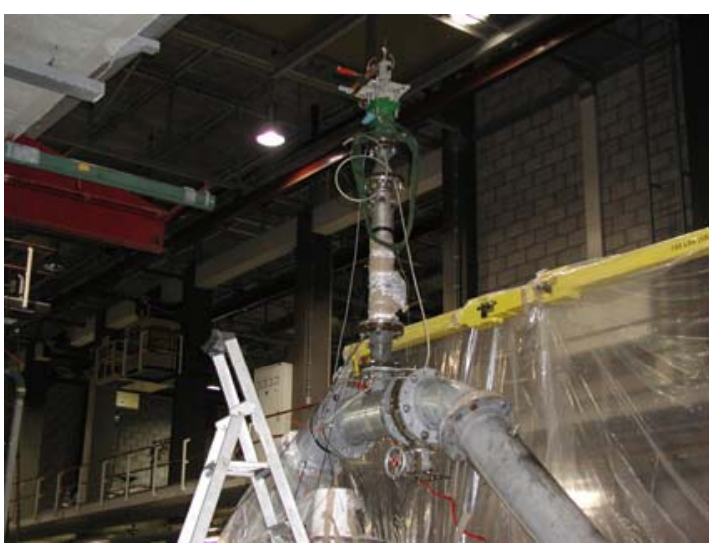

Figura 3.33. Ventosa sobre carrete vertical

La disposición general de toda la instalación con esta nueva configuración se muestra en la Figura 3.34. En ella se puede apreciar el instante inicial del ensayo.

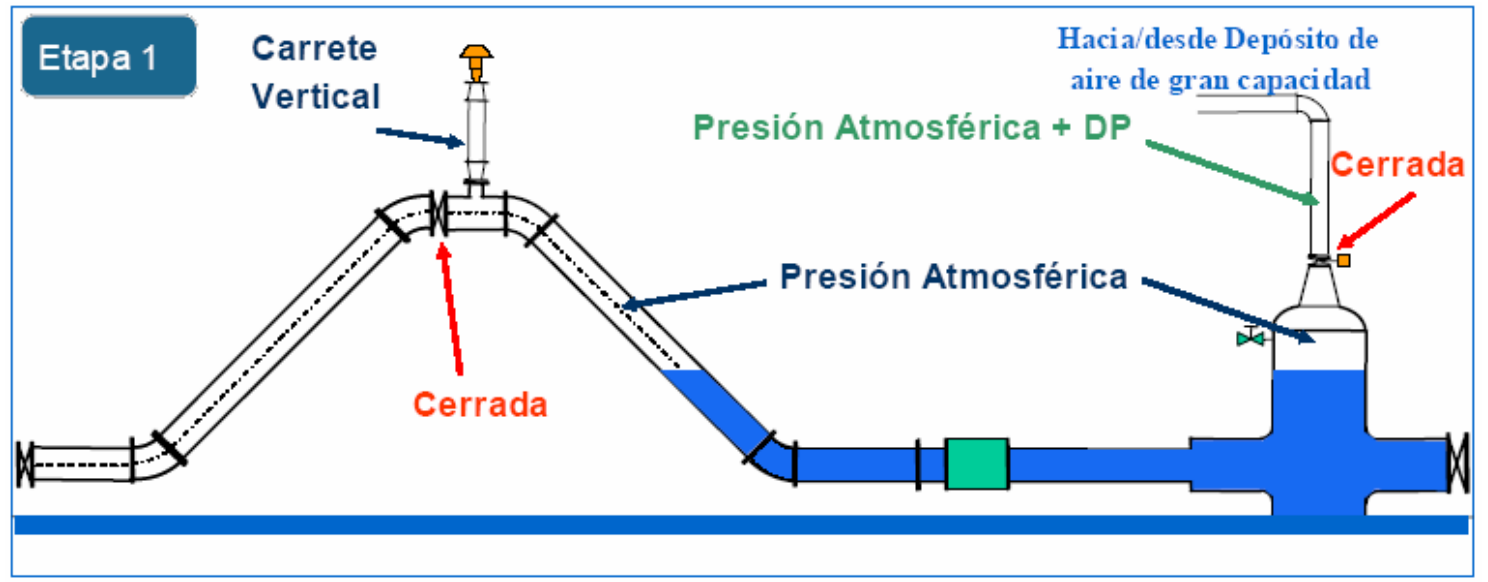

Figura 3.34. Expulsión de aire con la ventosa sobre un carrete vertical

En general, para cada configuración de la instalación, y para cada ventosa, se realizaron diferentes ensayos cambiando cada vez las condiciones iniciales. Es decir, con cada configuración se establecieron una serie de longitudes iniciales de la columna de agua móvil. Además la misma longitud inicial de agua se impulsó repetidas veces hacia el punto más alto de la instalación con diferentes presiones iniciales controladas desde el depósito de aire.

En la siguiente tabla se muestra un resumen de todos los ensayos dinámicos de ventosas en los que se representa la expulsión de aire de una conducción: 
Tabla 3.3. Ensayos de expulsión realizados en el laboratorio

\begin{tabular}{llc}
\hline \multicolumn{1}{c}{$\begin{array}{c}\text { Ensayos dinámicos de } \\
\text { expulsión de aire con: }\end{array}$} & \multicolumn{1}{c}{$\begin{array}{c}\text { Válvula BV1 } \\
\text { Cerrada }\end{array}$} & $\begin{array}{c}\text { Válvula BV1 } \\
\text { Abierta }\end{array}$ \\
\hline Ventosa A DN100 & $\mathrm{h}=1,238 \mathrm{~m}$ Tipo 1 & $\mathrm{~h}=2,86 \mathrm{~m}$ Tipo 6 \\
& $\mathrm{~h}=1,988 \mathrm{~m}$ Tipo 3 & $\mathrm{~h}=3,78 \mathrm{~m}$ Tipo 6 \\
\hline Ventosa B DN100 & $\mathrm{h}=1,238 \mathrm{~m}$ Tipo 8 & $\mathrm{~h}=2,73 \mathrm{~m}$ Tipo 12 \\
& $\mathrm{~h}=1,988 \mathrm{~m}$ Tipo 9 & $\mathrm{~h}=3,78 \mathrm{~m}$ Tipo 12 \\
\hline Ventosa A DN50 & $\mathrm{h}=0,805 \mathrm{~m}$ Tipo 1 & $\mathrm{~h}=0,2 \mathrm{~m}$ Tipo 7 \\
& $\mathrm{~h}=1,38 \mathrm{~m}$ Tipo 2 & $\mathrm{~h}=1,33 \mathrm{~m}$ Tipo 8 \\
\hline Ventosa B DN50 & $\mathrm{h}=0,805 \mathrm{~m}$ Tipo 1 & $\mathrm{~h}=0,2 \mathrm{~m}$ Tipo 7 \\
& $\mathrm{~h}=1,38 \mathrm{~m}$ Tipo 2 & $\mathrm{~h}=1,33 \mathrm{~m}$ Tipo 8 \\
\hline Ventosa A DN50 & $\mathrm{h}=1,38 \mathrm{~m}$ Tipo5 & $\mathrm{h}=0,2 \mathrm{~m}$ Tipo 9 \\
(Carrete L=1,185m) & $\mathrm{h}=0,81 \mathrm{~m}$ Tipo 6 & $\mathrm{~h}=1,33 \mathrm{~m}$ Tipo 10 \\
\hline Ventosa B DN50 & $\mathrm{h}=0,81 \mathrm{~m}$ Tipo 5 & $\mathrm{~h}=0,2 \mathrm{~m}$ Tipo 9 \\
(Carrete $\mathbf{L}=\mathbf{1 , 1 8 5 m})$ & $\mathrm{h}=1,38 \mathrm{~m}$ Tipo6 & $\mathrm{h}=1,33 \mathrm{~m}$ Tipo 10 \\
\hline Ventosa A DN50 & $\mathrm{h}=1,38 \mathrm{~m}$ Tipo 3 & - \\
(Carrete $\mathbf{L}=\mathbf{2 , 1 8 5 m})$ & $\mathrm{h}=1,85 \mathrm{~m}$ Tipo 4 & \\
\hline Ventosa B DN50 & $\mathrm{h}=1,85 \mathrm{~m}$ Tipo 4 & - \\
(Carrete L= 2,185m) & & \\
\hline
\end{tabular}

En la tabla anterior la variable $h$, hace referencia a la altura de la columna de agua medida sobre el eje longitudinal de la conducción horizontal situada junto al depósito D1.

\subsubsection{PROCEDIMIENTO DE LOS ENSAYOS DINÁMICOS DE ADMISIÓN DE AIRE}

En los ensayos dinámicos de ventosas que intentan simular el comportamiento de la ventosa en los procesos de admisión de aire en una instalación se plantea el estudio de dos casos diferentes.

- Estudiar la admisión de grandes cantidades de aire en una instalación con una ventosa situada en el extremo final de la misma, en el punto más elevado.

- Analizar el comportamiento de una ventosa ante el fenómeno de la separación de la columna de agua producido debido al cierre de una válvula de retención.

\subsubsection{VACIADO DE UNA TUBERÍA}

Los ensayos dinámicos de admisión de grandes cantidades de aire en una tubería se realizaron al igual que los de expulsión de aire con ventosas de diámetros DN100 y DN50. En este apartado solamente se realizan ensayos con la ventosa en el punto final de 
la instalación, es decir con la válvula de mariposa BV1 cerrada. La configuración y dimensiones de la instalación son las mismas que las expuestas para los ensayos dinámicos de expulsión de aire.

La variable que se modifica en estos ensayos para establecer el transitorio una vez llenada por completo la tubería de agua es, como ha sido habitual en los ensayos dinámicos de expulsión de aire, la presión inicial aplicada desde el desde el depósito de aire que en este caso es inferior a la del depósito de agua presurizado.

La dinámica seguida en estos ensayos se puede resumir en tres etapas:

- ETAPA 1: La válvula de mariposa BV1 permanece cerrada durante el transcurso del ensayo de admisión de aire. La válvula de mariposa BV2 se cierra una vez se ha presurizado el sistema. La válvula que comunica el depósito que contiene agua con el exterior está también cerrada, con lo cual, el depósito D1 se encuentra en esta primera etapa presurizado de modo que la presión de la columna de agua sobre la ventosa la mantenga cerrada.

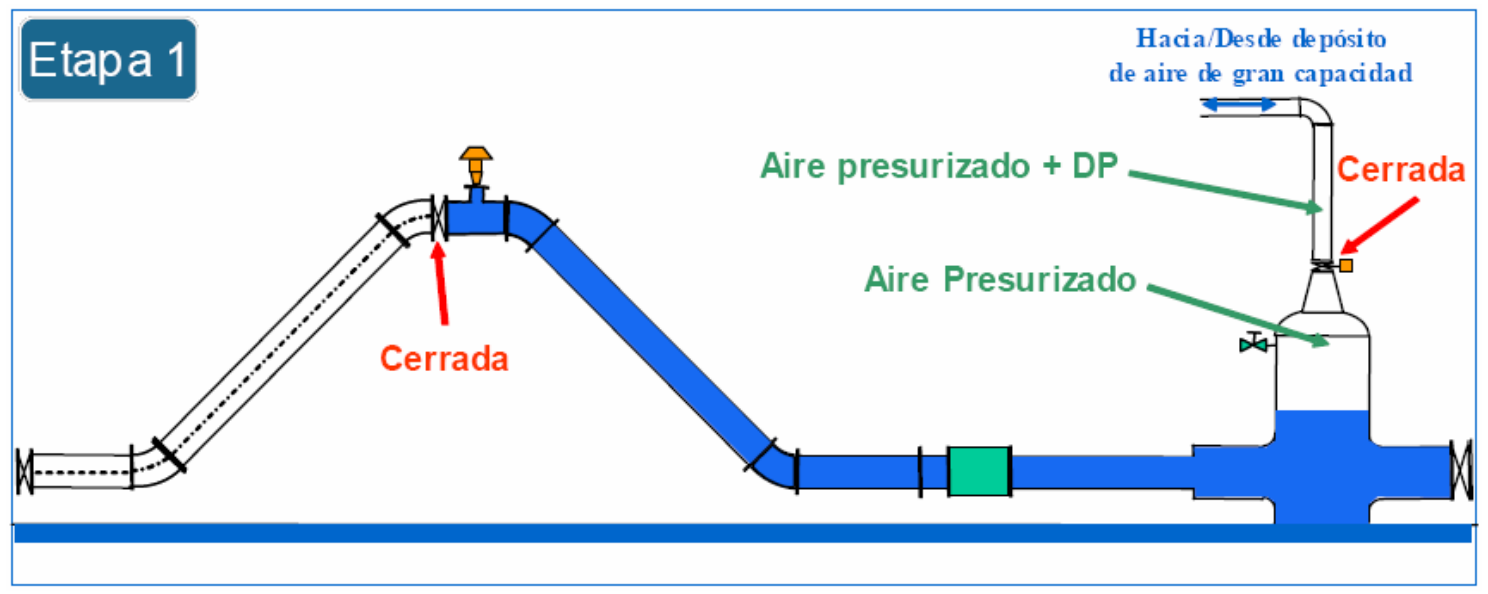

Figura 3.35. Proceso de admisión de aire en la conducción. Etapa 1

- ETAPA 2: En la segunda etapa abre la válvula de mariposa BV2 que comunica ambos depósitos, el depósito D1 con el D2 que se encuentra a una presión menor. La diferencia de presiones hace que la columna de agua se mueva desde la tubería hacia el depósito de agua, es decir, en sentido inverso al establecido en los ensayos de expulsión de aire. 


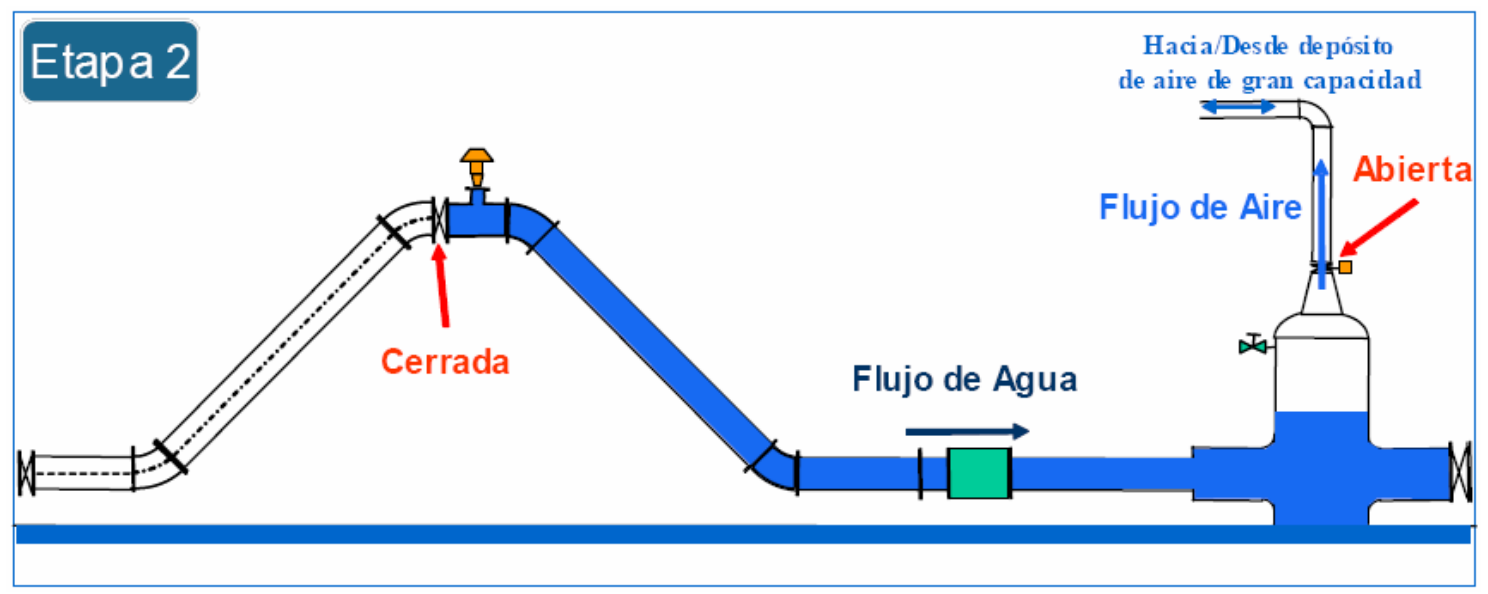

Figura 3.36. Proceso de admisión de aire en la conducción. Etapa 2

- ETAPA 3: El nivel de agua en la instalación baja de modo que en un instante dado el agua deja de estar en contacto con el flotador de la ventosa. En dicho instante de tiempo la ventosa abre con lo cual se produce la admisión de aire a través de la misma.

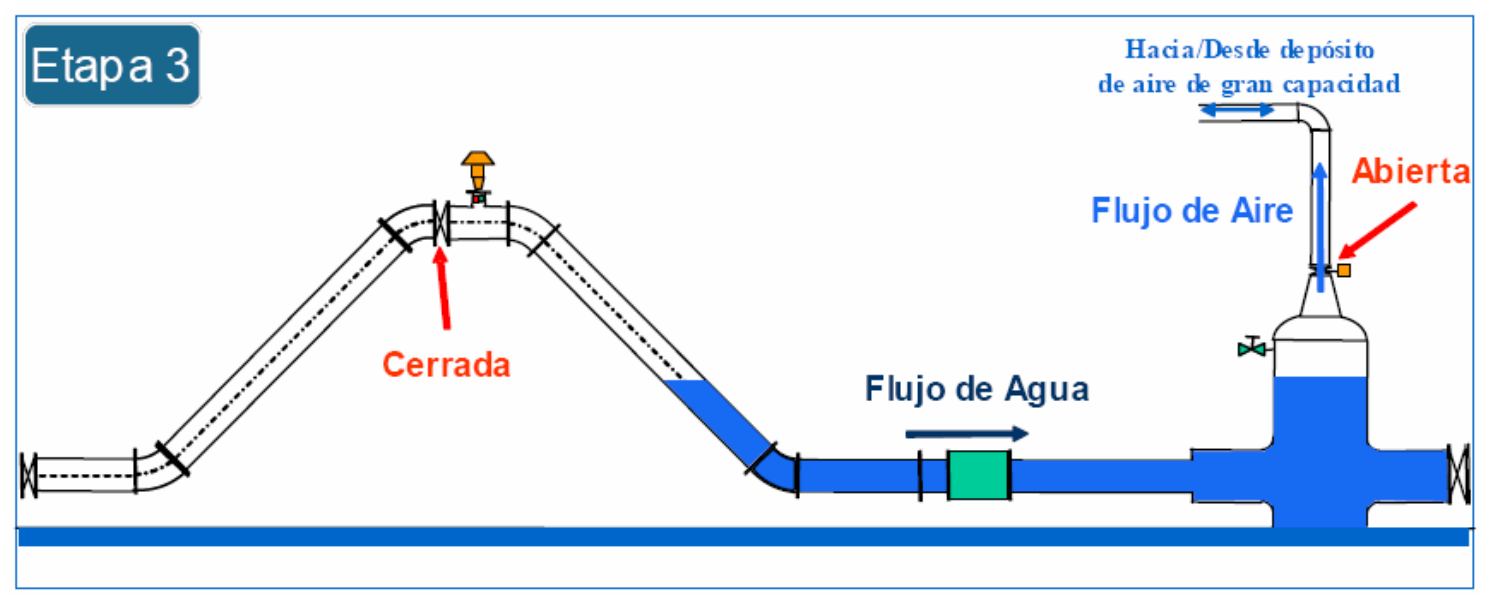

Figura 3.37. Proceso de admisión de aire en la conducción. Etapa 3

Las dimensiones de la instalación en este tipo de ensayos son las mismas que las de los ensayos dinámicos de expulsión de aire presentada anteriormente.

\subsubsection{SEPARACIÓN DE LA COLUMNA DE AGUA}

El objetivo perseguido con este tipo de ensayos es determinar si las ventosas, A y B, tanto de DN100 como de DN50 son capaces de mitigar las depresiones producidas en una instalación debidas al cierre repentino de una válvula de retención. Es decir, si dichas ventosas son capaces de eliminar la separación de la columna de agua que se produce debido al cierre de una válvula. En este tipo de ensayos se creyó conveniente realizar ensayos con ventosa y ensayos sin ventosa para establecer comparaciones entre estas dos 
configuraciones. De este modo, el objetivo principal de estos ensayos es determinar si la ventosa es capaz de evitar el fenómeno indeseado de las bajas presiones.

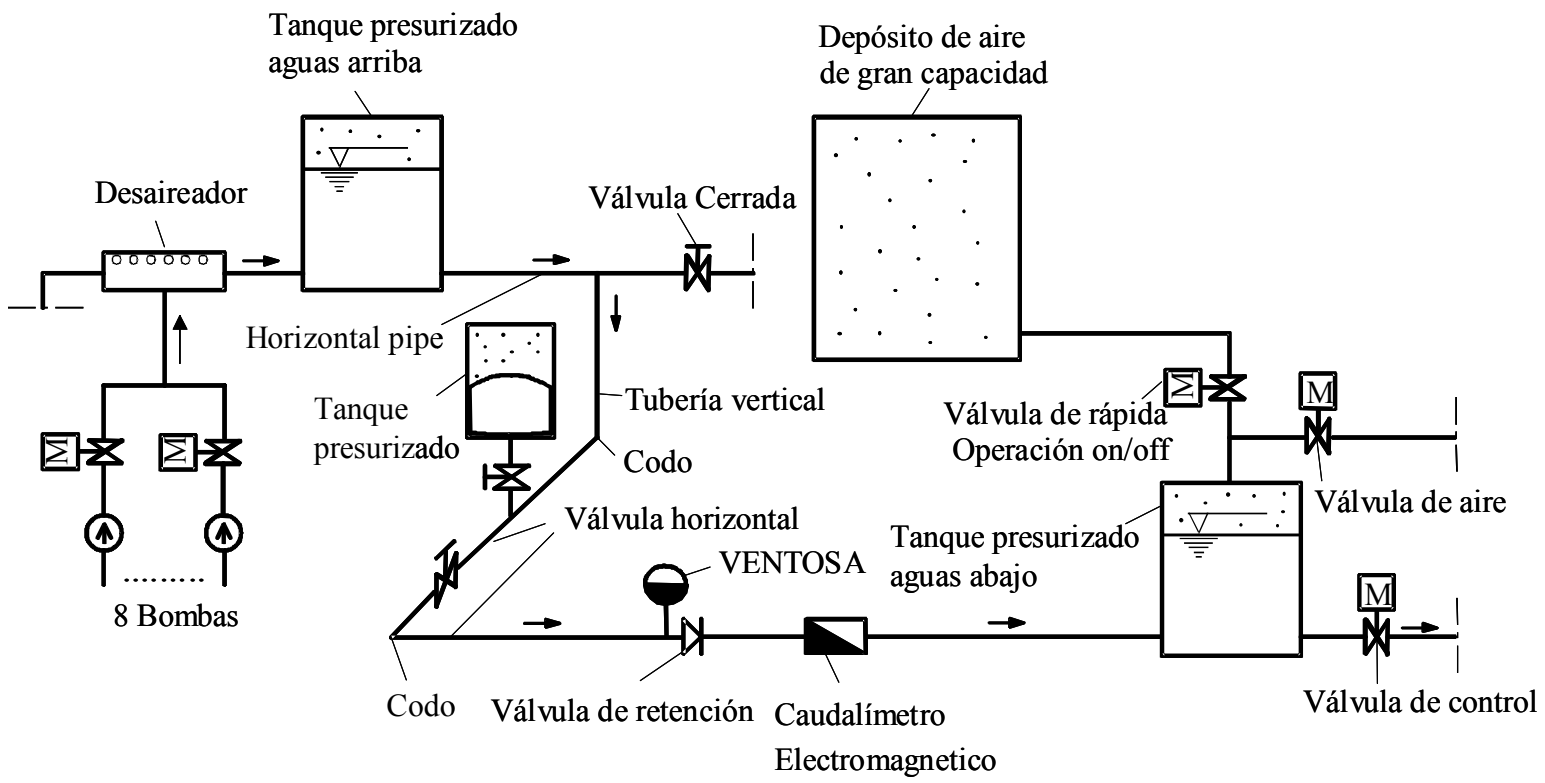

Figura 3.38. Esquema instalación para el estudio de la separación de la columna de agua

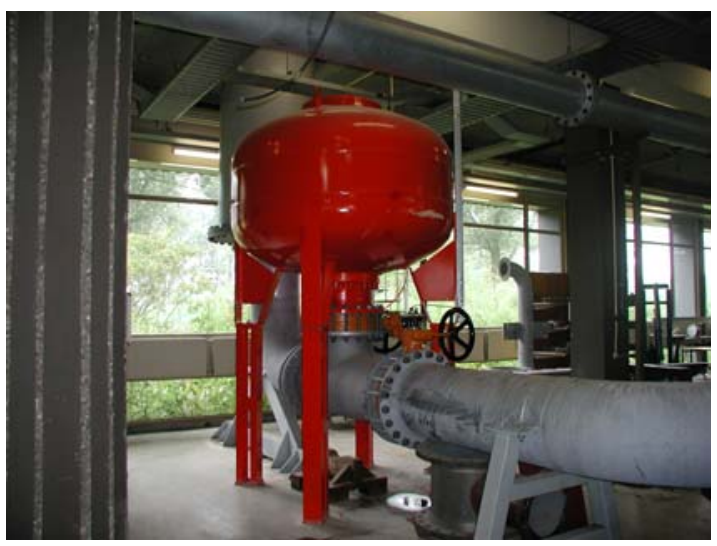

Figura 3.39. Depósito de agua

El procedimiento seguido en este tipo de ensayos se ha divido principalmente en tres etapas:

- ETAPA 1: La tubería se encuentra en el instante inicial completamente llena de agua y en condiciones de flujo en régimen permanente. Se hace circular un flujo aplicando una presión a la columna de agua desde la estación de bombeo. La válvula de retención situada junto a la ventosa se encuentra completamente abierta y la ventosa (en caso de que se haya instalado) cerrada. 


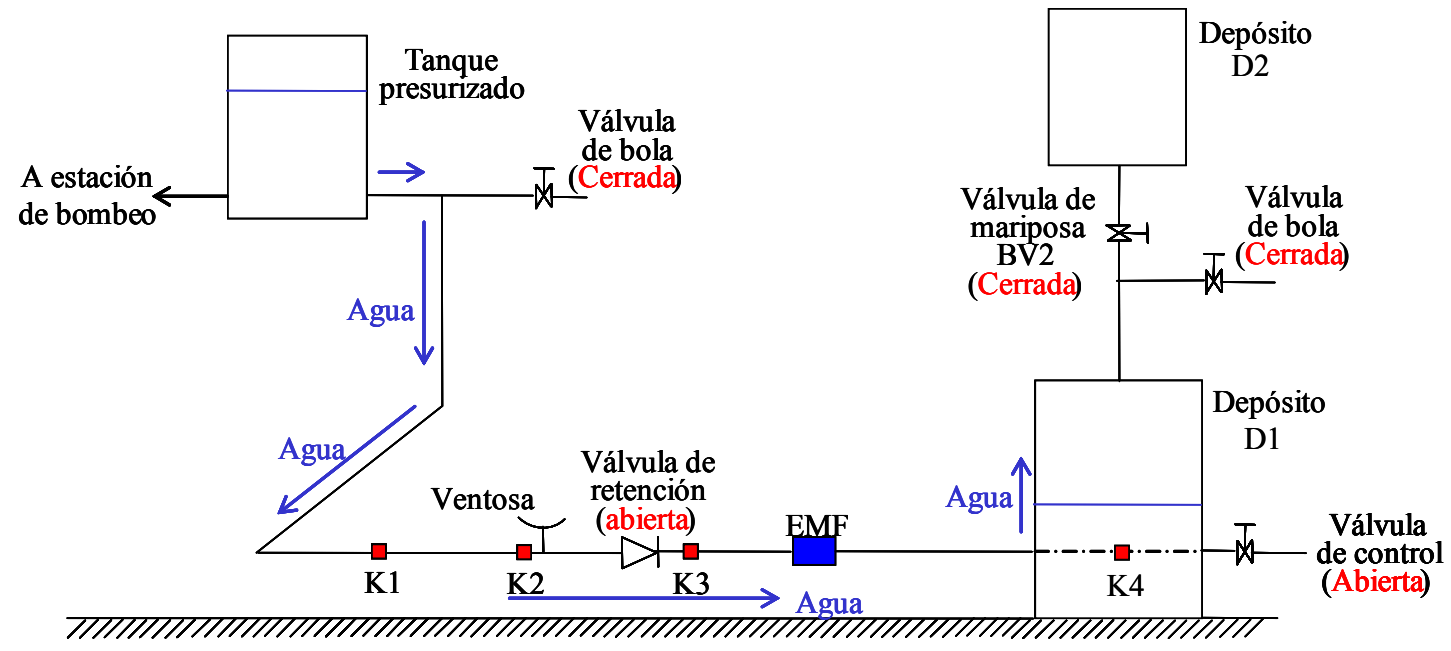

Figura 3.40. Proceso para el estudio de la separación de la columna de agua. Etapa 1

- ETAPA 2: Se invierte el sentido del flujo de agua aumentando la presión desde el depósito de aire de gran capacidad D2. Con la inversión del sentido de circulación de la columna de agua, la válvula de retención cierra produciéndose bajas presiones junto a la misma.

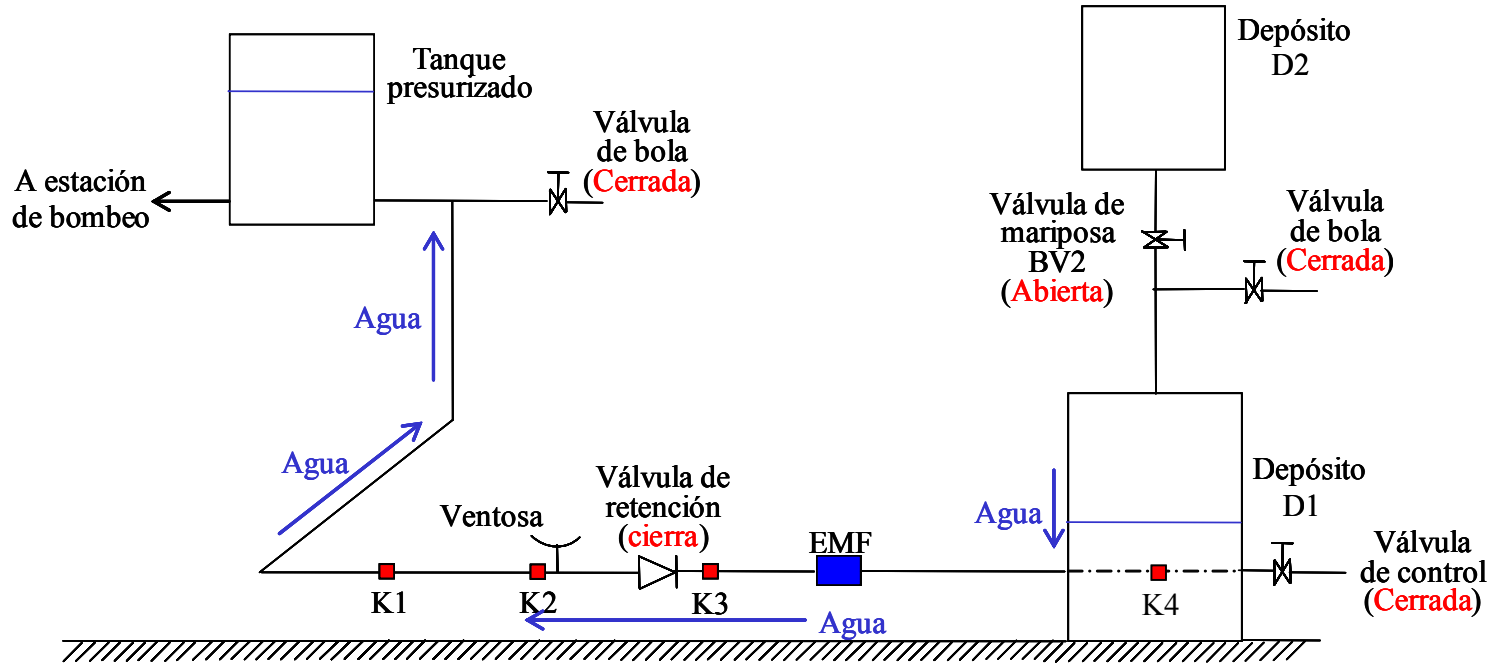

Figura 3.41. Proceso para el estudio de la separación de la columna de agua. Etapa 2

- ETAPA 3: La válvula de retención cierra con la inversión del sentido de circulación del flujo: Debido al cierre se producen bajas presiones junto a la válvula de retención, en el lado donde se instala la ventosa, dicha ventosa abre y admite el aire en el interior del sistema. 

CAPÍTULO 4. ANÁLISIS DE LOS DATOS

EXPERIMENTALES 

Una de las aportaciones más importantes del presente trabajo es, sin duda, el análisis de los datos recogidos durante la etapa práctica. La fase práctica del presente trabajo, se ha orientado a la realización de ensayos para el estudio del comportamiento dinámico de ventosas así como el transitorio hidráulico que tiene lugar en la instalación durante los procesos de expulsión y admisión de aire en una instalación determinada. Los ensayos se han llevado a cabo en tuberías de gran diámetro sobre las cuales se han podido ensayar ventosas comerciales. Actualmente existen pocos trabajos prácticos que introduzcan ventosas reales en instalaciones de gran tamaño, debido sobretodo a las necesidades de un espacio e instrumentación adecuados. El uso de instalaciones de gran tamaño, la numerosa cantidad de equipos de medida necesarios para la obtención de datos representativos así como la gran cantidad de datos recogidos, hacen que el trabajo de laboratorio haya sido enormemente laborioso.

En este capítulo se recogen los resultados de los ensayos de las ventosas que se llevan a cabo en las instalaciones de W.L.|Delft Hydraulics en Holanda. Los datos registrados durante la fase práctica del presente trabajo de investigación se han sometido a un elaborado proceso de tratamiento. De este modo, a partir de una serie de datos como el caudal, la presión y el desplazamiento del flotador, se puedan extraer conclusiones del transitorio hidráulico con aire atrapado que tiene lugar en la instalación así como del comportamiento de las ventosas ensayadas. 


\subsection{ENSAYOS PARA LA DETERMINACIÓN DE LA CAPACIDAD DE EXPULSIÓN Y ADMISIÓN DE AIRE DE UNA VENTOSA.}

Con estos ensayos se pretende determinar la capacidad de expulsión y admisión de grandes cantidades de aire de las ventosas elegidas. Para ello se mantiene una posición fija de apertura de la ventosa en condiciones de régimen permanente, en tres puntos diferentes. Así pues se dispone de datos de presiones y caudal de:

- Ensayos para la determinación de la capacidad de expulsión y de admisión de aire a través de la ventosa A y de la ventosa B de DN50 en la instalación de diámetro $200 \mathrm{~mm}$ con diferentes grados de apertura: $25 \%, 50 \%$ y $100 \%$

- Ensayos para la determinación de la capacidad de expulsión y de admisión de aire a través de la ventosa A y de la ventosa B de DN100 en la instalación de diámetro $200 \mathrm{~mm}$ con diferentes grados de apertura: $25 \%, 50 \%$ y $100 \%$

La determinación de la capacidad de expulsión de aire será útil, como se verá en el capítulo siguiente, para completar la entrada de datos referentes a las características de la ventosa en un modelo numérico el cual simule la evolución de las presiones durante el transitorio hidráulico. Al mismo tiempo, conocido el valor del coeficiente de descarga obtenido a partir de ensayos experimentales, se podrá comprobar si dicho valor coincide con los datos facilitados por los fabricantes.

\subsubsection{DETERMINACIÓN DEL COEFICIENTE DE EXPULSIÓN DE LAS VENTOSAS}

El caudalímetro utilizado para determinar el flujo de aire circulante por la instalación en este tipo de ensayos es un caudalímetro tipo vórtex el cual se calibra antes de proceder al análisis de los datos registrados. El principio de funcionamiento de un caudalímetro de vórtices se basa en el efecto de Von Karman por el cual se generan alternativamente vórtices aguas abajo de un objeto que presenta un cierto impedimento al paso del flujo. Cuando el fluido incide contra el elemento perturbador, a números de Reynolds elevados, se produce una separación del flujo, es decir, se generan pequeños remolinos o vórtices los cuales se distribuyen aleatoriamente a ambos lados del objeto. Debido a la formación de dichos vórtices se establecen áreas en las cuales la presión fluctúa según se haya formado o no un vórtice.

Mediante un sensor piezoeléctrico situado aguas abajo del objeto generador de vórtices, se puede obtener una señal eléctrica pulsátil de frecuencia igual a la frecuencia de generación de los remolinos. La frecuencia de generación de vórtices es además proporcional a la velocidad del fluido e inversamente proporcional a la anchura del objeto generador de vórtices. 


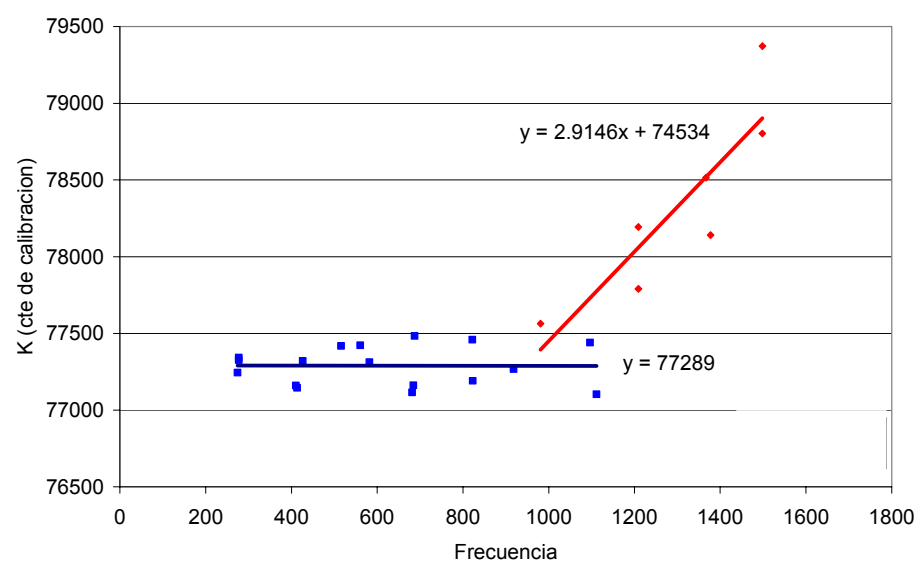

Figura 4.1. Factor de calibración del caudalímetro vórtex de 200 mm de diámetro.

A partir de los datos obtenidos en la calibración del caudalímetro, es decir a partir de la frecuencia, f, y la constante de calibración, $K$, se pueden calcular el valor del caudal volumétrico de aire $Q_{v}$ en $\mathrm{m}^{3} / \mathrm{s}$.

$Q_{v}\left(m^{3} / s\right)=\frac{f}{K}$

Una vez el caudalímetro se encuentra correctamente calibrado, y con los datos de presión medidos se calcula el coeficiente de expulsión de la ventosa a partir de la siguiente expresión:

$Q\left(m^{3} / s\right)=C_{\exp } \sqrt{\Delta P \cdot p_{t}^{*}}$

siendo

Q, caudal en $\mathrm{m}^{3} / \mathrm{s}$

$\Delta P$, la diferencia de presión entre el interior de la tubería y la atmósfera en Pascales $P{ }{ }_{t}$, la presión absoluta en el interior de la tubería en Pascales

El caudal másico Qm en $\mathrm{Kg} / \mathrm{s}$ se puede calcular a partir del caudal volumétrico y de la densidad del fluido en $\mathrm{Kg} / \mathrm{m}^{3}$ :

$Q_{m}(\mathrm{Kg} / \mathrm{s})=\rho \cdot Q_{v}$

Finalmente se calcula el caudal normalizado $Q_{n}$ en $\mathrm{Nm}^{3} / \mathrm{h}$ (a una temperatura $\mathrm{T}=20^{\circ} \mathrm{C}$ y presión $\mathrm{P}=1 \mathrm{~atm})$. A partir de este caudal normalizado se obtiene el valor del coeficiente de expulsión del aire para cada ventosa según el grado de apertura. 
$Q_{n}\left(\mathrm{Nm}^{3} / \mathrm{h}\right)=\frac{Q_{m}(\mathrm{Kg} / \mathrm{s})}{1,2256} \cdot 3600(\mathrm{~s} / \mathrm{h})$

En la Figura 4.2 se muestra la evolución de los caudales respecto a la sobrepresión aplicada en el instante inicial, en cada uno de los ensayos para determinar la capacidad de expulsión de las ventosas A y B. En el primer gráfico aparecen los resultados obtenidos con las ventosas DN50 y en el segundo los referentes a las ventosas DN100:
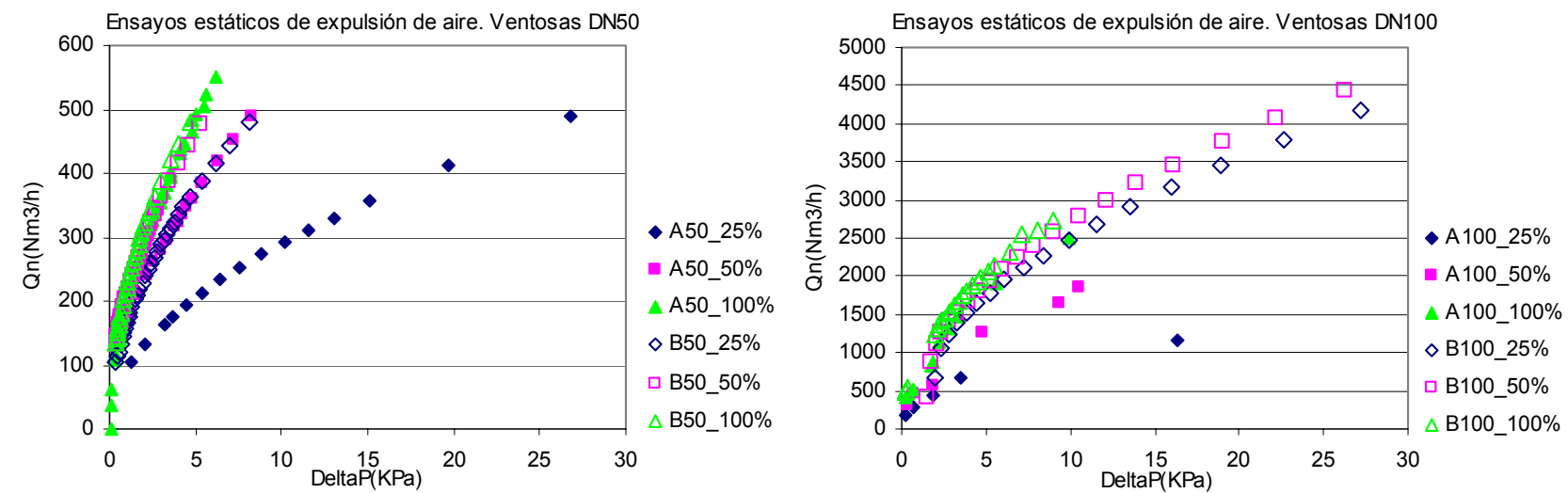

Figura 4.2. Caudal nominal en ensayos para la determinación de la capacidad de expulsión de aire de las ventosas

El mismo procedimiento de cálculo se lleva a cabo con los datos registrados en los ensayos de admisión de aire de cada ventosa en régimen permanente obteniendo los resultados que aparecen en la Figura 4.3:
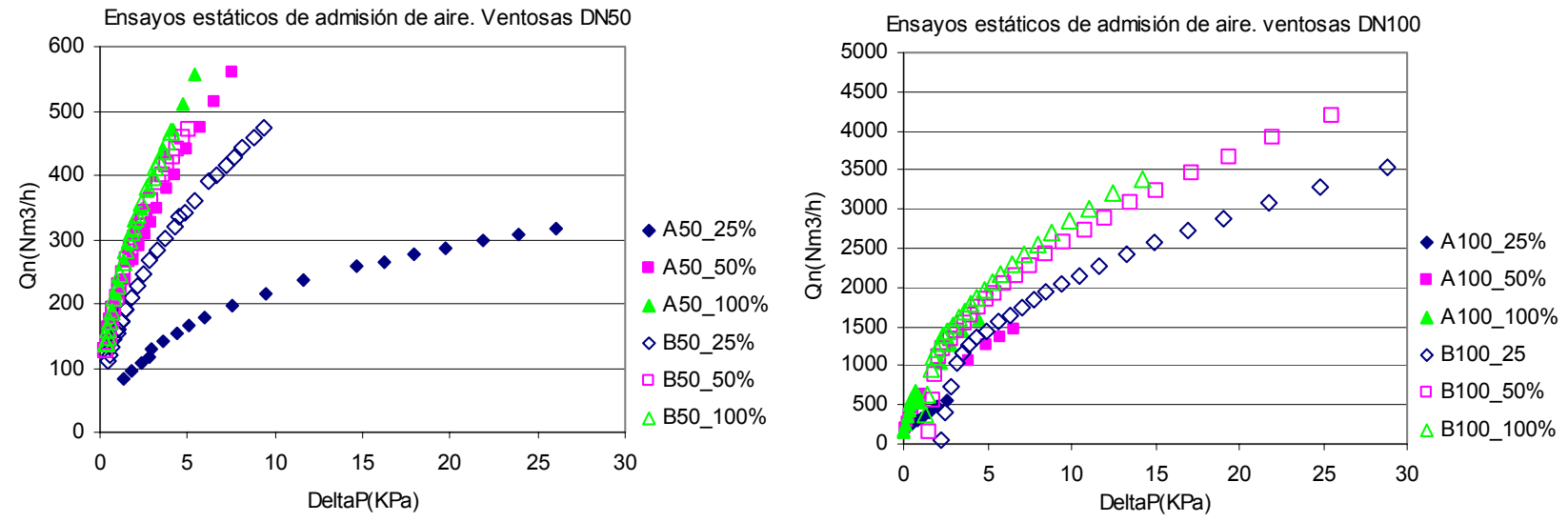

Figura 4.3. Caudal nominal en ensayos para la determinación de la capacidad de admisión de aire de las ventosas.

Tanto en los ensayos para la determinación de la capacidad de expulsión como en los de admisión de aire la diferencia de resultados entre las distintas aperturas de la ventosa son más acusadas en las ventosas de DN50 que en las de DN100. La capacidad de descarga de las ventosas no se ve prácticamente afectada cuando los grados de apertura son 
elevados $(100 \%$ o $50 \%$ ). Dicha capacidad de descarga se ve afectada de modo considerable cuando la apertura de la ventosa es de un $25 \%$.

En la Figura 4.4 se representan los coeficientes de expulsión de aire de las ventosas A y B de DN50 y de DN100. La capacidad de expulsión calculada de la manera propuesta es ligeramente mayor en la ventosa B para cualquiera de los dos tamaños de ventosa analizados.
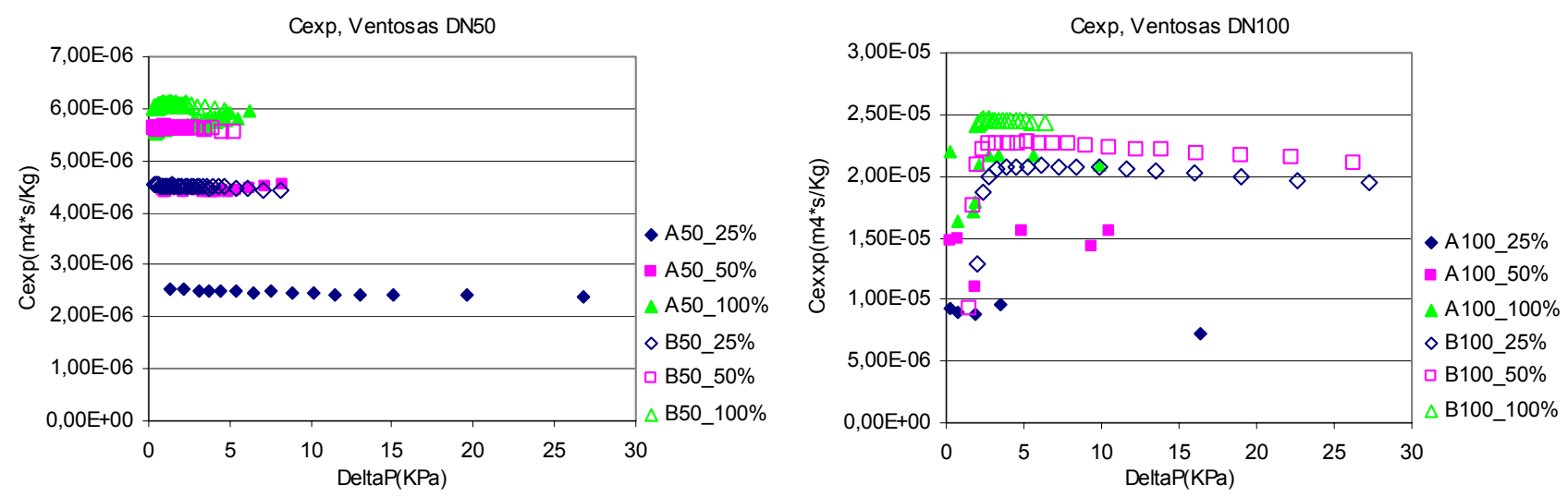

Figura 4.4. Caudal nominal en ensayos para la determinación del coeficiente de expulsión de aire de las ventosas.

En la gráfica de la derecha de la figura anterior, aparece cierta dispersión de datos cuando la presión diferencial es menor de $5 \mathrm{KPa}$. Esta dispersión de puntos se debe a errores en la instrumentación, sobretodo a errores de lectura del caudalímetro a caudales bajos. Dichos puntos erróneos no se han tenido en cuenta a la hora de realizar los diferentes cálculos.

Habitualmente al trabajar con sistemas de ecuaciones, el coeficiente de descarga utilizado es adimensional. Por ello se ha realizado también el cálculo numérico del coeficiente de descarga $C_{d}$ de cada ventosa con los datos recogidos en los diferentes ensayos. El coeficiente de descarga $C_{d}$ adimensional se calcula a partir de los valores de presión, caudal y temperatura en régimen permanente tal y como se indica en la siguiente ecuación:

$$
C_{d}=\frac{Q_{m}}{A_{v} \cdot P_{t} \cdot \sqrt{\frac{7}{287 \cdot T} \cdot\left(\frac{P_{a t m}^{*}}{P_{t}^{*}}\right)^{1,43} \cdot\left(1-\left(\frac{P_{a t m}^{*}}{P_{t}^{*}}\right)^{0,286}\right)}}
$$


Donde:

$Q_{m}$ : Caudal másico en $\mathrm{Kg} / \mathrm{s}$

$\mathrm{A}_{v}$ Sección del orificio de la ventosa, en $\mathrm{m}^{2}$

$\mathrm{T}$ : Temperatura en el interior de la tubería, en ${ }^{\circ} \mathrm{K}$

$\mathrm{P}_{\mathrm{t}}{ }^{*}$ : Presión absoluta en el interior de la tubería, en Pa.

$\mathrm{Patm}^{*}$ : Presión atmosférica en valores absolutos, en Pa

Al igual que ocurre con el coeficiente de expulsión, Cexp, se observa una mayor capacidad de expulsión de aire de cualquiera de las dos ventosas, como es lógico, cuando están completamente abiertas. La menor capacidad de descarga la presenta la ventosa A, tanto de DN50 como de DN100 cuando se encuentra un 25\% abierta.

De los gráficos y la tabla siguientes se desprende que la capacidad de descarga suele ser mayor en la ventosa B para un diámetro nominal de ventosa dado. Se comprueba además que los valores calculados del factor de descarga $C_{d}$ cuando la ventosa se encuentra completamente abierta son en general superiores al valor recomendado por la American Gas Association (1978) para flujo compresible a través de orificios y toberas, es decir, $\mathrm{C}_{\mathrm{d}}=0,65$.

Coeficiente de descarga Cd, Ventosas DN50mm

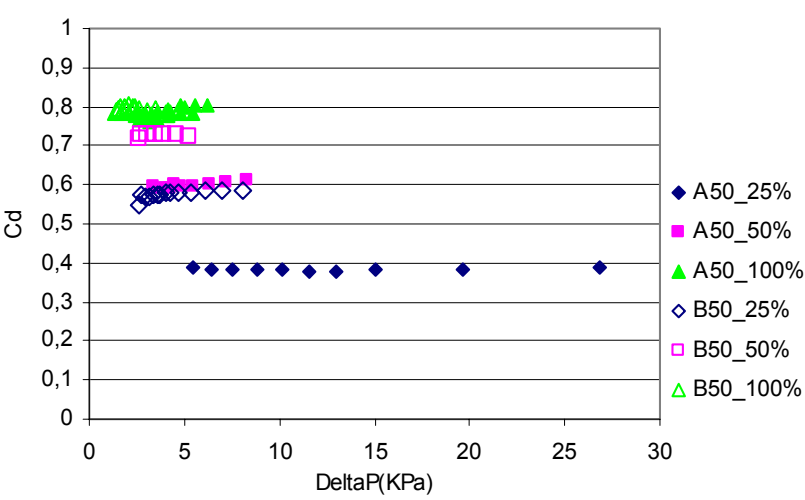

Coeficiente de descarga Cd, Ventosas DN100

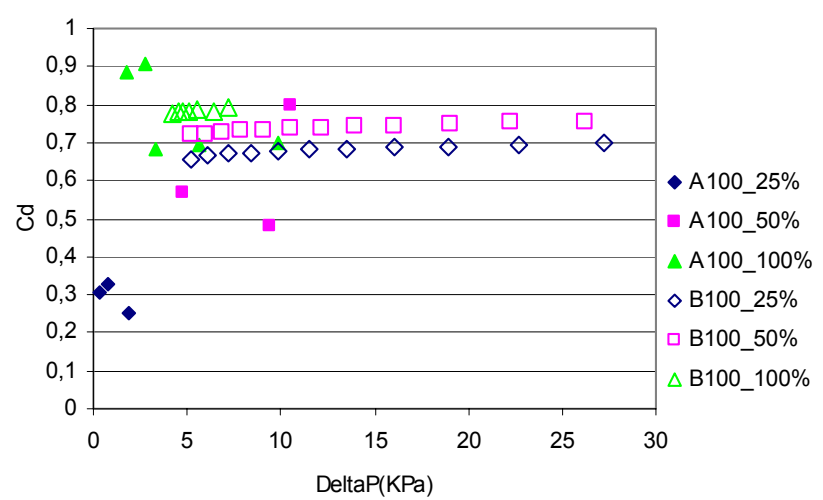

Figura 4.5. Coeficiente de descarga de las ventosas

Tabla 4.1. Coeficientes de descarga promedio según el grado de apertura de la ventosa

\begin{tabular}{c|cccc} 
GRADO APERTURA & Cd, A50 & Cd, A100 & Cd, B50 & Cd, B100 \\
\hline $\mathbf{2 5 \%}$ & 0,38 & 0,31 & 0,58 & 0,68 \\
$\mathbf{5 0} \%$ & 0,60 & 0,62 & 0,73 & 0,74 \\
$\mathbf{1 0 0} \%$ & 0,80 & 0,81 & 0,79 & 0,79
\end{tabular}




\subsubsection{DETERMINACIÓN DE LA CAPACIDAD DE EXPULSIÓN DE UNA VENTOSA A PARTIR DE LA NORMA DE VÁLVULAS INDUSTRIALES ISA S75.01}

La Norma ISA S75.01 "Flow Equations for Sizing Control Valves", proporciona excelentes ecuaciones para determinar el tamaño de las válvulas industriales tanto en flujos compresibles como en flujos incompresibles. Como dicha norma proporciona un método de cálculo ordenado y conciso aplicable a cualquier tipo de válvula se propone seguir este método para determinar el factor de expulsión de aire en el caso de las ventosas.

La práctica más comúnmente utilizada en la industria para determinar la caída de presión o la capacidad de flujo de una válvula es tomar el coeficiente de flujo de la válvula $C_{v}$ que proporciona el fabricante de la válvula y aplicarlo con la fórmula apropiada. Hoy en día, muchos fabricantes publican coeficientes de flujo así como las ecuaciones para predecir el flujo frente a la caída de presión. Muchas de estas ecuaciones para flujo incompresible son correctas, sin embargo, es sorprendente la gran cantidad de fórmulas diferentes utilizadas en el caso de flujo compresible y que no siempre dan los mismos resultados.

En un principio los fabricantes de válvulas evitaban el uso de fórmulas matemáticas y presentaban gráficas para el agua, el aire o el vapor, para cada tamaño de válvula. Esta forma de actuar prevaleció hasta mitades de 1942, año en el cual se introdujo el actual coeficiente de flujo $C_{v}$. Dicho coeficiente se usa en los cálculos tanto para flujo compresible como para incompresible. Desde 1950 a 1960 hubo una amplia discusión entre los fabricantes de válvulas sobre cual era la ecuación de flujo correcta a utilizar en el caso de flujos compresibles. El problema radicaba en que las válvulas con el mismo $\mathrm{C}_{v}$ y diferentes formas podrían tener distintas características del flujo gaseoso. Se hizo evidente que un único coeficiente de flujo $C_{v}$ de una válvula, determinado experimentalmente, era insuficiente para describir el paso de líquido y de gas a través de la válvula en todo el rango de caídas de presión.

La fórmula del flujo compresible propuesta por la norma ISA S75.01 apareció en el trabajo de Les Driskell (1969). A este trabajo le siguió un artículo publicado en ISA Transactions,(1970). Driskell reconoció que el flujo a través de las válvulas era similar al flujo a través de orificios.

La caída de presión a través de un orifico o válvula, causa una reducción en la densidad dado que el gas reacciona frente a la caída de presión expandiéndose. Esto no sucede con los líquidos ya que su densidad apenas cambia con las variaciones de presión. El flujo másico no cambia en un tramo de una conducción en la que el flujo sea estacionario, por tanto, un gas que se expande, es decir que disminuye su densidad, debe acelerarse para mantener el valor del flujo másico. 
La ecuación del flujo a través de un orifico en un fluido compresible es la misma que la de un fluido incompresible solo que se tiene en cuenta la densidad del fluido en el interior del conducto al tiempo que se corrige la ecuación debido a los efectos de la compresibilidad mediante el factor de expansión Y. El factor de expansión está relacionado con el cambio de densidad de un fluido a medida que éste pasa del interior de la válvula a la vena contracta y con el cambio del área de la vena contracta a medida que la caída de presión cambia.

El principal inconveniente a la hora de utilizar la fórmula para fluido compresible que propone la norma ISA es la recopilación de datos experimentales requeridos para determinar los factores de capacidad ya que dichos ensayos son más complejos y caros que los procedimientos habituales.

\subsubsection{DETERMINACIÓN GRÁFICA DE $C_{V} Y X_{T}$}

La norma ISA S75.02 Control Valve Capacity Test Procedure propone dos métodos para determinar el coeficiente de la válvula $C_{v}$ y el factor de presión crítico $\mathrm{X}_{\mathrm{T}}$ o factor de presión cuando el caudal es máximo. El primer procedimiento incluye encontrar el valor de flujo máximo $Q_{\max }$ (referido como flujo sónico) de la válvula, y el segundo procedimiento obtiene la información a partir de un ajuste lineal según los resultados de los ensayos. La segunda opción se corresponde con una determinación gráfica de $C_{v}$ y de $\mathrm{X}_{\mathrm{T}}$ a partir de valores conocidos de caudales y presiones en el interior de la tubería.

Tal y como queda expresado en la norma ISA S75.02, el factor de expansión Y es una función lineal del coeficiente de caída de presión X calculado éste último como:

$$
X=\frac{\Delta P}{P_{1}^{*}}
$$

siendo:

$\Delta \mathrm{P}$ el incremento de presión entre el interior y el exterior de la tubería $\mathrm{P}_{1} *$ la presión absoluta en el interior de la tubería

En un tramo fijo el coeficiente $C_{v}$ es constante, pero el factor de expansión $\mathrm{Y}$ cambia con $X$. A medida que $X$ se acerca al valor cero, es decir no hay expansión, $Y$ se aproxima al valor 1 . Con el procedimiento alternativo de la norma ISA, ambos coeficientes $C_{v}$ y $X_{T}$ se determinan ensayando la válvula a un mínimo de cinco valores de $\Delta \mathrm{P}$ diferentes, medidos a una presión constante aguas arriba. De estos datos, los valores de $Y C_{v}$ se calculan según la ecuación: 
$Y C_{v}=\frac{Q}{4.17 \cdot P_{1}^{*}} \cdot \sqrt{\frac{G_{g} \cdot T}{X}}$

Donde:

Q: Caudal en $\mathrm{m}^{3} / \mathrm{h}$

Gg: Gravedad específica de un vapor relativa al aire, $\mathrm{Gg}_{\mathrm{g}}($ aire) $=1$

$\mathrm{T}$ : Temperatura del aire en ${ }^{\circ} \mathrm{K}$

4.17: Factor de conversión de unidades

$\mathrm{P}_{1}$ *: Presión absoluta en el interior de la tubería en $\mathrm{KPa}$

A partir de los datos de los ensayos, se representan en una gráfica los valores de $Y C_{v}$ frente a los de $\mathrm{X}$ y posteriormente se ajustan a una función lineal tal y como se aprecia en la Figura 4.6.

El valor de $C_{v}$ para una muestra de ensayos se obtiene de la intersección de la recta obtenida a partir de la ecuación (Ec 4.7) y que se muestra en la Figura 4.6 con el eje de ordenadas, es decir, cuando $\mathrm{X}=0$ y el factor de expansión $\mathrm{Y}=1$.

Suponiendo que $\mathrm{Y}$ varía linealmente con $\mathrm{X}$, el caudal llega a su valor máximo cuando $\mathrm{Y}=2 / 3=0.667$.

Este valor de $\mathrm{Y}$ se obtiene matemáticamente buscando el valor del caudal máximo. En primer lugar hay que despejar el valor del caudal de la expresión Ec 4.7. Seguidamente se deriva dicha expresión y se iguala a cero para encontrar el valor de $Y$ que hace que dicho caudal sea máximo.

Supóngase que $\mathrm{Y}$ es una función lineal cualquiera que depende del coeficiente de caída de presión $X$, es decir:

$Y=a-b \cdot X$

Sustituyendo este valor en la ecuación (Ec 4.7):

$$
(a-b \cdot X) \cdot C_{v}=\frac{Q}{4.17 \cdot P_{1}} \cdot \sqrt{\frac{G_{g} \cdot T}{X}}
$$

Agrupando los términos constantes de la ecuación anterior bajo la nomenclatura K:

$$
K=\frac{C_{v} \cdot 4.17}{\sqrt{G_{g} \cdot T}}
$$


Haciendo todas las sustituciones oportunas en la ecuación (Ec 4.7) la expresión del caudal queda de la siguiente manera:

$Q=K \cdot(a-b \cdot X) \cdot \sqrt{X}$

El máximo valor del caudal se obtiene igualando la derivada del caudal respecto del factor de caída de presión $X$ a cero:

$\frac{d Q}{d X}=0$

Derivando la expresión de caudal:

$$
\begin{aligned}
& K\left[(-b) \cdot \sqrt{X}+(a-b \cdot X) \cdot \frac{1}{2 \cdot \sqrt{X}}\right]=0 \\
& -2 \cdot b \cdot X+a-b \cdot X=0 \\
& X=\frac{a}{3 \cdot b} \\
& Y=a-b \cdot X=a-b \cdot \frac{a}{3 \cdot b}=\frac{2}{3} \cdot a
\end{aligned}
$$

Conocido el coeficiente $\mathrm{C}_{\mathrm{v}}$, el valor de $\mathrm{X}_{\mathrm{T}}$ se puede despejar de la ecuación $Y C_{v}=0.667 \cdot C_{v}$. Mediante este procedimiento se puede conocer el valor del factor de caída de presión crítico sin tener que llegar al flujo de choque tal y como se describe en la Figura 4.6.

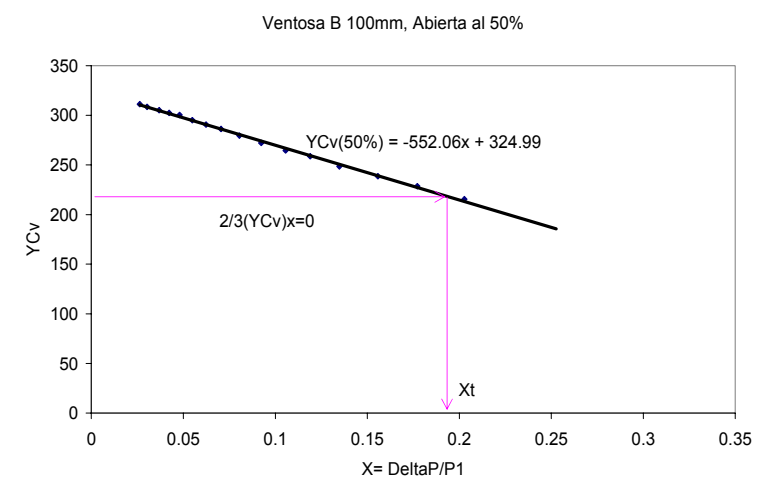

Figura 4.6. Cálculo de $X_{T}$ 
Mediante este procedimiento gráfico para determinar el coeficiente de flujo según la norma ISA S75.02 se obtiene que tomando como ejemplo los datos de los ensayos realizados con la ventosa B abierta un $50 \%$, el coeficiente de la ventosa y la relación crítica de presiones que se puede alcanzar es:

$\mathrm{CV}(50 \%)=324.99$

$\mathrm{X}_{\mathrm{T}}(50 \%)=0.1962$

Se realizan los mismos cálculos con cada apertura de una misma ventosa, 100\%, 50\% o $25 \%$. A modo de ejemplo, se presentan las rectas $Y C_{v}$ obtenidas según el grado de apertura de la ventosa B de DN100:

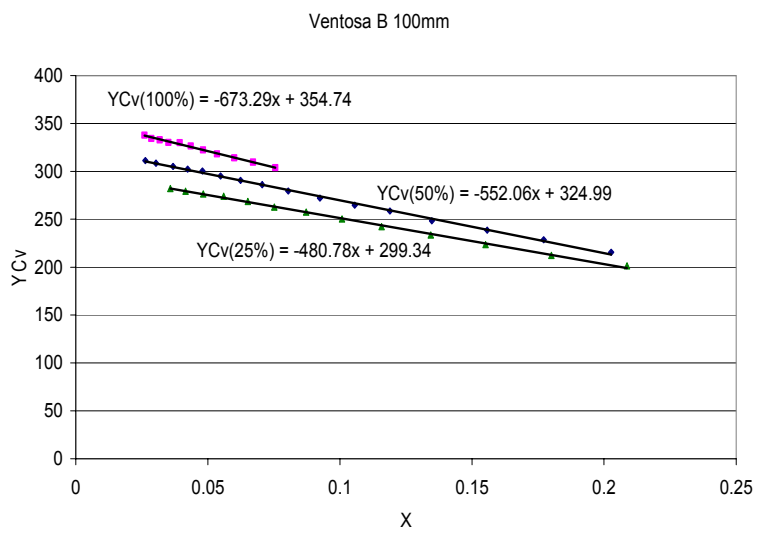

Figura 4.7. Cálculo de $X_{T}$ para diferentes aperturas de la ventosa

Siguiendo el procedimiento explicado anteriormente, los resultados numéricos finales de $C_{V}$ y $X_{T}$ a partir de las rectas obtenidas para la ventosa B de DN100 son:

Tabla 4.2. $C_{v}$ y $X_{T}$ según el grado de apertura de la ventosa

\begin{tabular}{cccc}
\hline Grado de apertura: & $\mathbf{1 0 0 \%}$ & $\mathbf{5 0 \%}$ & $\mathbf{2 5 \%}$ \\
$\mathbf{C}_{\mathbf{v}}$ & 354.74 & 324.99 & 299.34 \\
$\mathbf{X}_{\mathbf{T}}$ & 0.175 & 0.1962 & 0.2075 \\
\hline
\end{tabular}

Se debería proceder de la misma forma con todas las ventosas ensayadas, pero resulta imposible conseguir resultados cuando los valores de la sobrepresión son demasiado pequeños y además no están lo suficientemente espaciados tal y como indica la norma ISA S75.02. Debido a las limitaciones de los equipos de medida y de la instalación no se han podido ensayar las ventosas para un rango de valores de $\mathrm{X}$ suficientemente amplio tal y como se puede comprobar en la gráfica siguiente correspondiente al caso de la ventosa B de $50 \mathrm{~mm}$. 


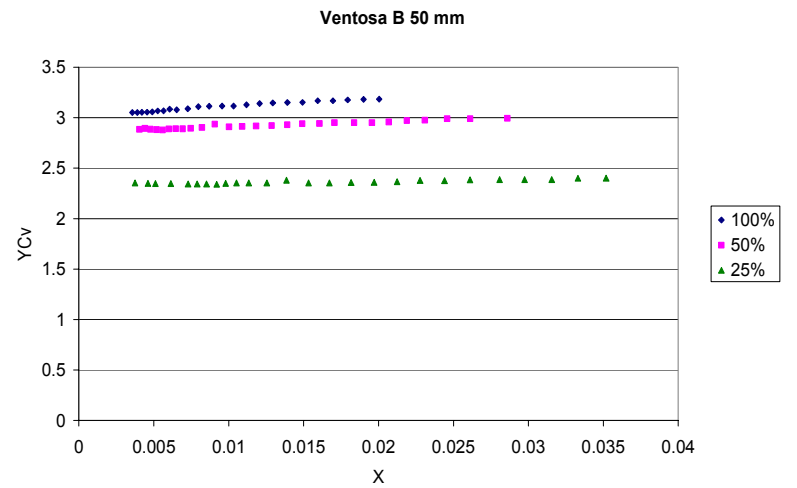

Figura 4.8. Cálculo de $\mathrm{X}_{\mathrm{T}}$. Ventosa B DN50

\subsubsection{DETERMINACIÓN DEL FLUJO MEDIANTE UNA ECUACIÓN PROPORCIONADA POR LA NORMA ISA S75.02}

La ecuación de la norma ISA S75.02 para determinar el coeficiente de flujo de un fluido compresible es función de la relación de presiones $\mathrm{X}$, de la presión absoluta en el interior de la tubería $P^{*}{ }_{1}$, de la temperatura $T$, de la relación crítica de presiones $X_{T}$, de la gravedad específica del gas $\mathrm{G}_{\mathrm{g}}$, del factor de expansión $\mathrm{Y}$, y del caudal:

$Q\left(m^{3} / h\right)=4.17 \cdot C_{v} \cdot P_{1}^{*} \cdot Y \cdot \sqrt{\frac{X}{G_{g} \cdot T}}$

donde:

Gg: Gravedad específica de un vapor relativa al aire, $\mathrm{Gg}_{\mathrm{g}}$ (aire) $=1$

$\mathrm{T}$ : Temperatura del aire en ${ }^{\circ} \mathrm{K}$

4.17: Factor de conversión de unidades

$\mathrm{P} *_{1:}$ Presión en el interior de la tubería en KPa

Por otro lado, el factor de expansión $Y$ se puede expresar en función de la relación de presiones $\mathrm{X}$ y la relación crítica de presiones $\mathrm{X}_{\mathrm{T}}$ como:

$Y=1-\frac{X}{3 \cdot X_{T}} \quad 1 \leq Y \leq 0.667$

El flujo que predice la ecuación anterior llega a un valor máximo cuando $X=X_{T}$, punto en el cual $Y=2 / 3=0.667$ Las condiciones de flujo en las cuales el valor de $X$ supera a $X_{T}$ se conocen como bloqueo sónico. El bloqueo tiene lugar cuando el chorro del fluido en la vena contracta de la válvula alcanza su mayor sección transversal a la velocidad sónica. En este punto el caudal volumétrico ya no puede aumentar más ya que la velocidad del fluido no puede sobrepasar la velocidad del sonido. Así pues, dado que el caudal 
volumétrico no puede ser mayor que el producido en el instante en que se da la relación de presiones crítica, el valor de $\mathrm{Y}$ no puede ser menor que 0.667 . Luego, cuando $\mathrm{X}>\mathrm{X}_{\mathrm{T}}$ :

$$
Q\left(m^{3} / h\right)=4.17 \cdot C_{v} \cdot P_{1} \cdot Y \cdot \sqrt{\frac{X_{T}}{G_{g} \cdot T}}
$$

donde $\mathrm{Y}=0.667$

Seguidamente se representan en un gráfico las curvas de los caudales volumétricos de aire calculados y los medidos previamente en los ensayos frente al incremento de presión, $\Delta \mathrm{P}$, para tres posiciones diferentes del flotador, es decir, con la ventosa totalmente abierta $(100 \%)$ o ventosa parcialmente abierta a un $50 \%$ y a un $25 \%$ respectivamente. Como se puede apreciar en la Figura 4.9, los valores calculados se aproximan a los valores medidos, lo cual viene a corroborar que la fórmula recomendada se puede considerar válida en este caso y que reproduce adecuadamente el comportamiento de la ventosa.

VENTOSA B $100 \mathrm{~mm}$

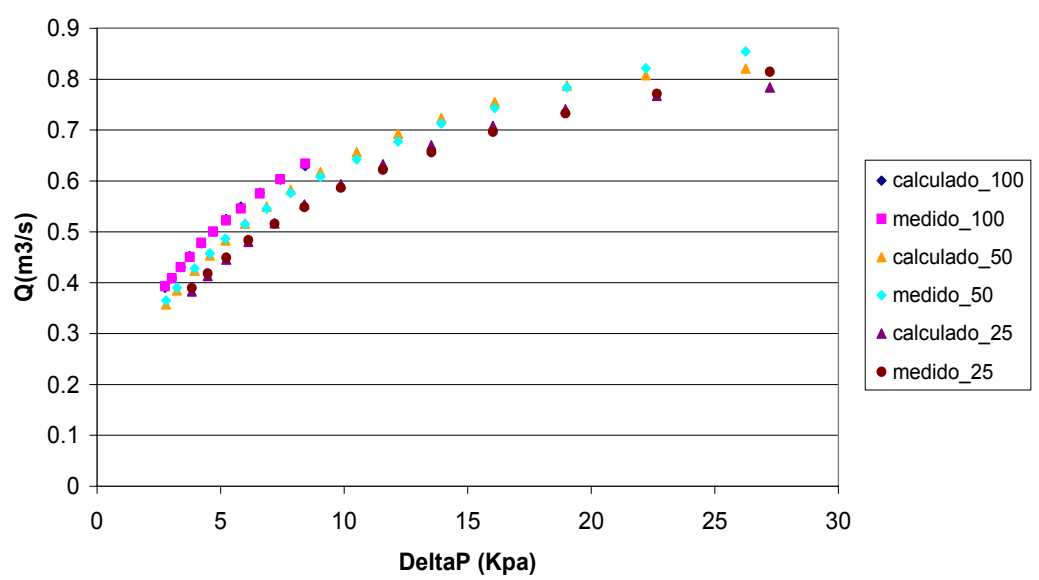

Figura 4.9. Comparación entre caudales calculados y caudales medidos 


\subsection{ENSAYOS DINÁMICOS DE EXPULSIÓN DE AIRE}

Una aproximación para determinar el comportamiento dinámico de las ventosas consiste en medir su respuesta frente a diferentes niveles de aceleración y deceleración del flujo hacia o desde la ventosa. Con estos ensayos se simula el comportamiento de las ventosas en eventos como la puesta en marcha de una instalación.

En este apartado se analiza el comportamiento dinámico de dos ventosas de dos marcas comerciales del mismo diámetro nominal aunque con características constructivas completamente diferentes durante la expulsión de aire de la instalación. Ambas ventosas se probaron en condiciones iniciales similares.

Las ventosas correspondientes a dos marcas comerciales se identifican a lo largo del documento como ventosa A y ventosa B. De cada marca comercial, se estudia una ventosa de diámetro $100 \mathrm{~mm}$ y otra de diámetro $50 \mathrm{~mm}$, con lo cual se ensayan bajo cada supuesto un total de 4 ventosas comerciales.

En todos estos ensayos se parte de una tubería parcialmente llena de agua con una longitud inicial de dicha columna de agua predeterminada. El objetivo del ensayo es la expulsión de aire a través de la ventosa hasta que el agua alcance el flotador de la ventosa y sea capaz de cerrarla. Para conseguir el movimiento de la columna de agua, la conducción está comunicada con un depósito en el cual se almacena agua, tal y como se ha explicado en el Capítulo 3. Desde dicho depósito se ejerce una presión sobre la columna de agua la cual es impulsada hacia la parte superior de la instalación.

Las variables medidas en cada ensayo son la presión en la entrada de la ventosa, la presión en dos puntos de la conducción aguas abajo del depósito de agua, el caudal circulante de agua y la posición del flotador de la ventosa en cada instante de tiempo.

Cada ventosa se ensaya en al menos dos configuraciones diferentes de la instalación. En una de estas disposiciones se mantiene cerrada la válvula de mariposa BV1, situada junto a la ventosa, con lo cual se consigue la expulsión de aire a través de una ventosa situada en el extremo final de la instalación. En la otra configuración se mantiene la válvula de mariposa BV1 abierta de manera que la ventosa queda ubicada en el punto medio de la instalación que es a su vez el punto más elevado de la misma.

Los ensayos para el estudio del comportamiento dinámico de ventosas a través de las cuales se realiza la expulsión de aire de una conducción se han clasificado en ensayos de expulsión de aire a través de una ventosa situada en el punto final de una instalación y ensayos de expulsión en un punto intermedio de la misma. En cada supuesto se ensayan tanto las ventosas de DN100 como las de DN50. 


\subsubsection{EXPULSION DE AIRE AL FINAL DE UNA CONDUCCIÓN. VENTOSAS DN100}

El primer caso de estudio abordado corresponde a los ensayos para analizar el comportamiento dinámico de una ventosa de DN100 durante la expulsión de aire en una instalación de $500 \mathrm{~mm}$ de diámetro con la válvula de mariposa BV1 cerrada, de modo que la ventosa quede situada en el extremo final de la conducción. Dicha instalación se encuentra en el instante inicial parcialmente llena de agua

En la Tabla 4.3 se ofrece un resumen comparativo de los resultados experimentales obtenidos al realizar ensayos dinámicos de expulsión de grandes cantidades de aire con las ventosas A y B, DN100. Cada par de valores hace referencia a dos ensayos realizados bajo condiciones iniciales similares con una longitud inicial de la columna de agua $\mathrm{L}_{0}=1,238 \mathrm{~m}$. En el instante inicial la presión es en todos los casos igual a la presión atmosférica. En la tabla se aporta información del valor de la sobrepresión inicial aplicada a la columna de agua para provocar el movimiento de la misma, de manera que cada par de ensayos comparados tienen una sobrepresión inicial semejante. En la misma tabla se muestra además, los valores de las presiones medidas en tres puntos diferentes de la instalación. Se denomina K3 a la presión medida junto a la ventosa, K2 se refiere a la presión registrada en el tramo inclinado de la instalación mientras que K1 es la presión medida junto al caudalímetro, en el tramo horizontal de la instalación, junto al depósito D1. En la sexta columna aparece el valor de la anchura del pico de presión máxima registrada en la instalación, entendiendo que dicha anchura se refiere a la medida en el pico presión que tiene lugar junto a la ventosa. En la columna siguiente se muestran los valores de la variación de la velocidad entre los instantes de tiempo tc, instante en el cual la ventosa cierra por completo y $t_{z} \mathrm{o}$ instante en el cual se la velocidad del flujo cambia de sentido. Finalmente, se muestra el tiempo que tarda en cerrar la ventosa, es decir, la diferencia entre los instantes de tiempo tc en el cual cierra por completo la ventosa y el instante de tiempo to o instante en el cual la ventosa empieza a cerrar. 
Tabla 4.3. Comparación de los resultados numéricos de algunas variables en ensayos similares de dos ventosas diferentes.

\begin{tabular}{|c|c|c|c|c|c|c|c|c|}
\hline $\begin{array}{l}\text { Número } \\
\text { de test }\end{array}$ & $\begin{array}{l}\Delta \mathrm{P} \\
(\mathrm{m})\end{array}$ & $\begin{array}{c}\text { K3max } \\
\text { (m) }\end{array}$ & $\begin{array}{c}\text { K2max } \\
\text { (m) }\end{array}$ & $\begin{array}{c}\text { K1max } \\
\text { (m) }\end{array}$ & $\begin{array}{c}\text { Anchura } \\
\text { Pico K3 (ms) }\end{array}$ & $\begin{array}{c}d v / d t \_c z \\
\left(m / s^{2}\right)\end{array}$ & $\begin{array}{l}\text { Vmin } \\
(\mathrm{m} / \mathrm{s})\end{array}$ & $\begin{array}{l}\text { tc-to } \\
\text { (ms) }\end{array}$ \\
\hline A17 & \multirow{2}{*}{2,1} & 7,42 & 7,85 & 4,57 & 508 & $-4,38$ & -1.27 & 44 \\
\hline B28 & & 8,76 & 11,10 & 0,55 & 593 & $-3,14$ & -1.28 & 70 \\
\hline A18 & \multirow{2}{*}{2,3} & 16,02 & 13,37 & 7,44 & 380 & $-7,49$ & $-1,24$ & 32 \\
\hline B30 & & 39,73 & 29,90 & 1,25 & 365 & $-8,81$ & $-1,20$ & 37 \\
\hline A19 & \multirow{2}{*}{2,6} & 50,45 & 35,78 & 22,05 & 185 & $-28,80$ & $-1,40$ & 65 \\
\hline B33 & & 125,76 & 86,74 & 34,74 & 199 & $-25,27$ & $-1,33$ & 23 \\
\hline A20 & \multirow{2}{*}{2,5} & 64,76 & 47,96 & 29,10 & 179 & $-32,05$ & $-1,29$ & 43 \\
\hline B31 & & 93,61 & 63,90 & 2,68 & 222 & $-19,05$ & $-1,33$ & 24 \\
\hline A21 & \multirow{2}{*}{2,7} & 81,74 & 55,96 & 36,71 & 159 & $-34,4$ & $-1,12$ & 55 \\
\hline B32 & & 165,06 & 122,21 & 10,75 & 172 & $-34,8$ & $-1,30$ & 24 \\
\hline
\end{tabular}

Los datos mostrados en la tabla anterior ponen de manifiesto que partiendo de condiciones iniciales similares se obtienen resultados diferentes según la ventosa, del mismo diámetro nominal, que se haya utilizado, ventosa A o ventosa B.

Las diferencias entre lo sucedido en cada par de ensayos se hacen más evidentes, al representar gráficamente las curvas de la presión máxima en el cuello de la ventosa medida por el transductor de presión K3 y la velocidad de la columna de agua medida con el caudalímetro en cada instante de tiempo:
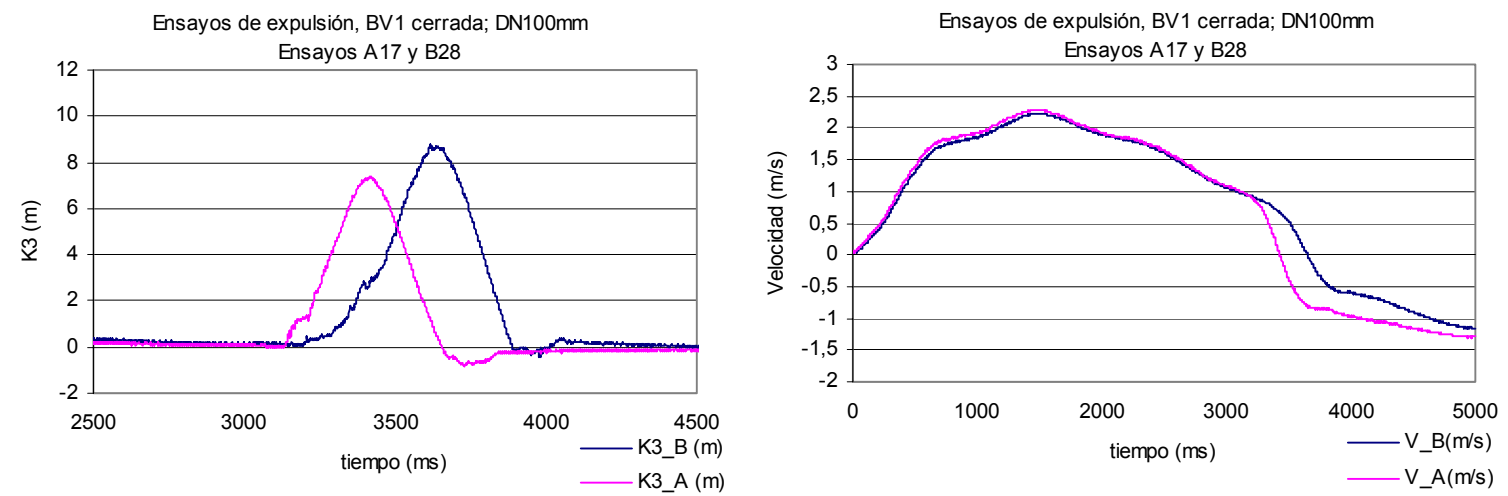

Figura 4.10. Comparación gráfica de dos ensayos de expulsión de aire similares con ventosas

DN100. Ensayos A17 y B28 

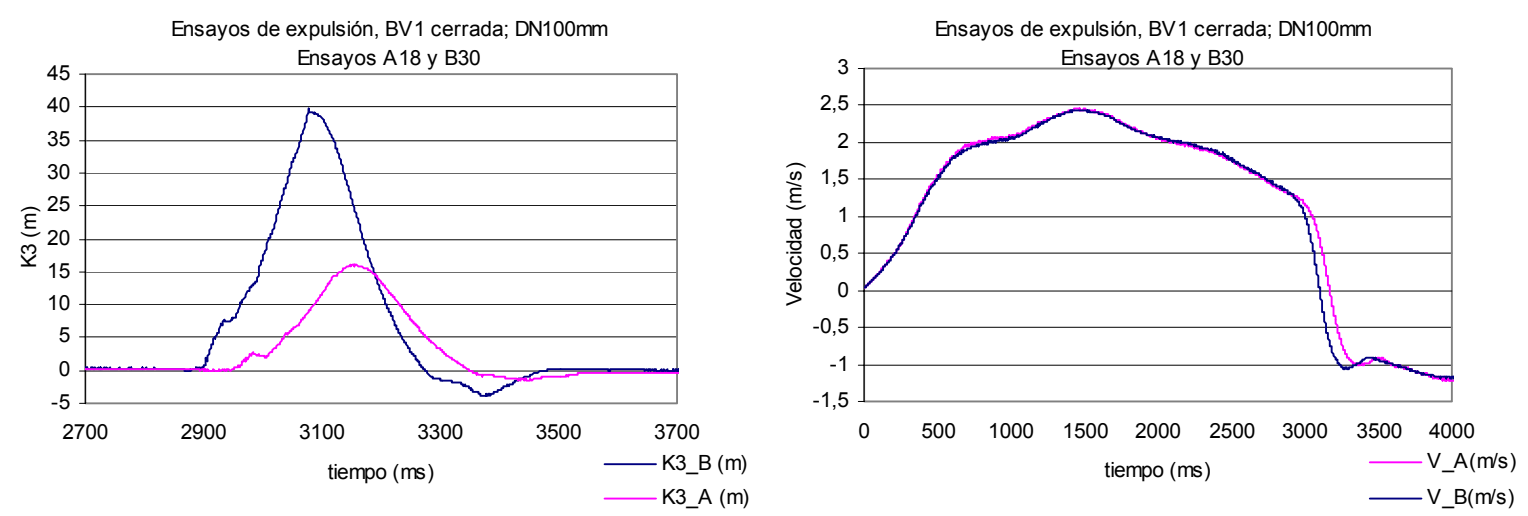

Figura 4.11. Comparación gráfica de dos ensayos de expulsión de aire similares con ventosas DN100. Ensayos A18 y B30
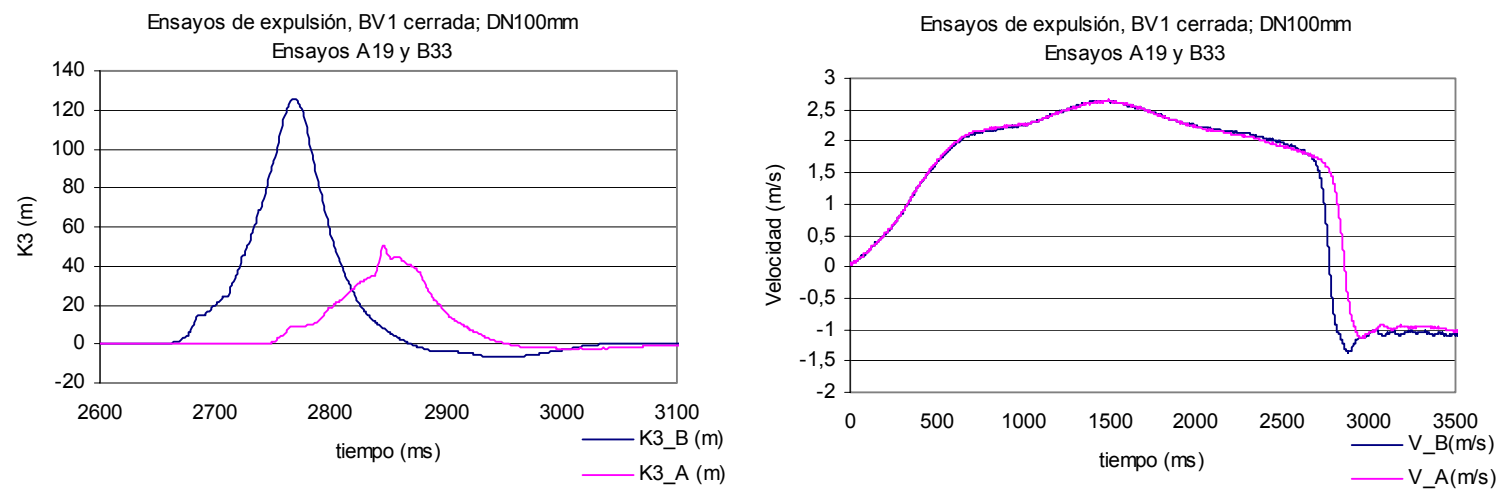

Figura 4.12. Comparación gráfica de dos ensayos de expulsión de aire similares con ventosas

DN100. Ensayos A19 y B33
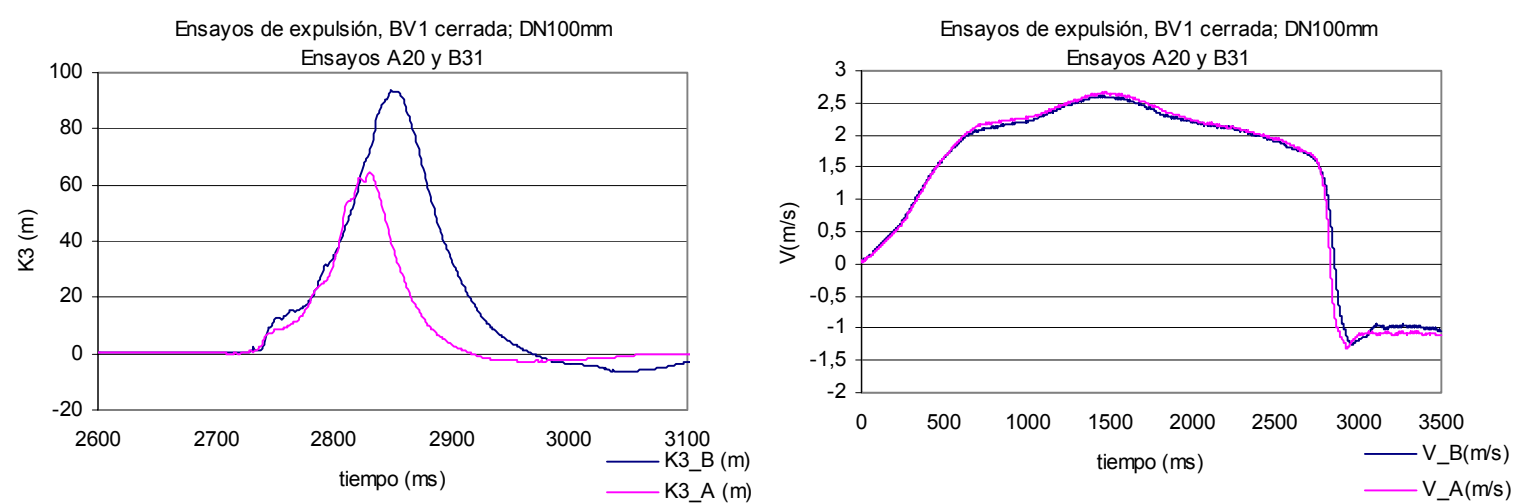

Figura 4.13. Comparación gráfica de dos ensayos de expulsión de aire similares con ventosas

DN100. Ensayos A20 y B31 

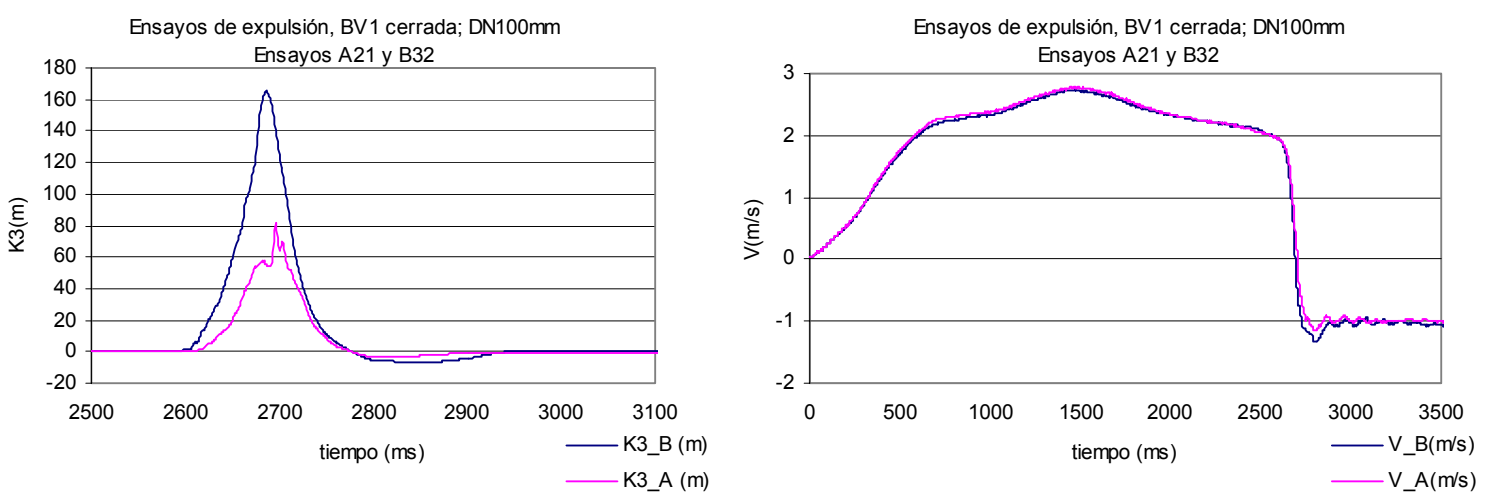

Figura 4.14. Comparación gráfica de dos ensayos de expulsión de aire similares con ventosas DN100. Ensayos A21 y B32

En general, no se observan grandes diferencias en el perfil de la curva de desplazamiento del flotador para cada par de ensayos independientemente de la ventosa utilizada tal y como se puede apreciar en la figura siguiente.
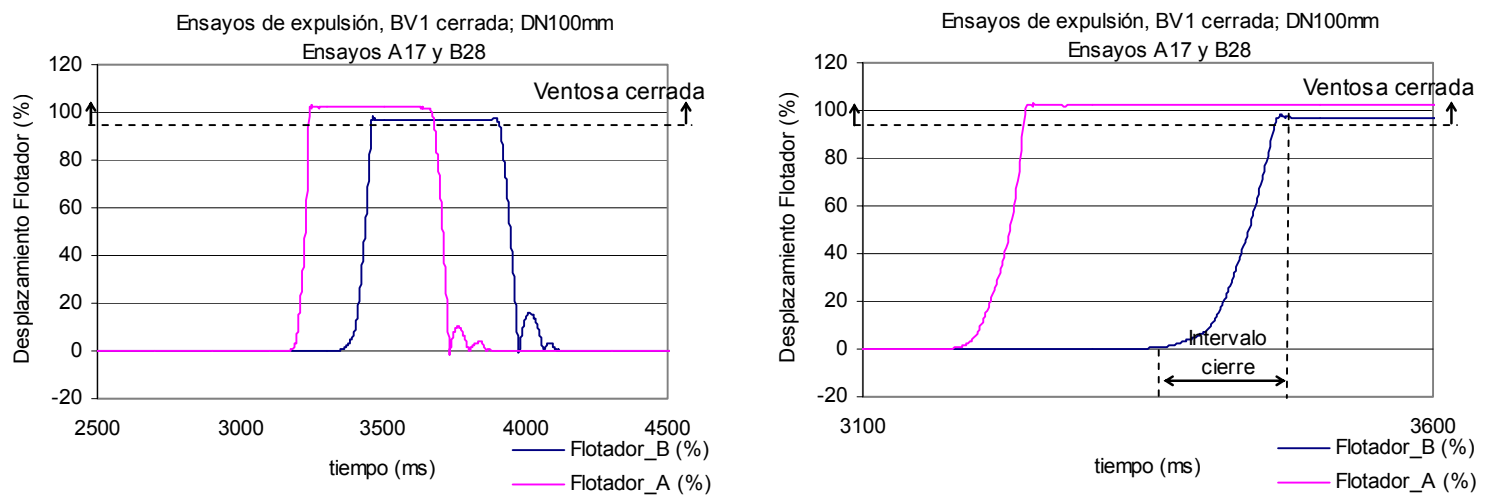

Figura 4.15. Comparación gráfica del cierre del flotador en dos ensayos similares de ventosas

DN100

Con este sencillo análisis previo se pone de manifiesto que existe una diferencia de resultados en cuanto a las presiones y velocidades medidas en un mismo punto de la instalación según la ventosa comercial utilizada para efectuar la expulsión de aire. Por esta razón se desprende la necesidad de establecer un análisis más riguroso que sea capaz de justificar las razones que provocan esta disparidad de resultados.

En principio, el aire que queda atrapado en el sistema tras el cierre de la ventosa y la capacidad efectiva de descarga de la misma son dos posibles causas que afectan tanto a la presión como a la velocidad de la columna de agua. El estudio propuesto en este trabajo consiste en establecer relaciones entre una serie de variables que se recogen directamente de los ensayos de laboratorio o bien se calculan a partir de los mismos de modo que ayuden a entender el fenómeno. De esta forma, se examinan cuales son las posibles causas y las maneras de detectar gráfica o matemáticamente las variaciones de la presión en el sistema estudiado. 
El fenómeno físico que se produce en el interior del sistema objeto de estudio se puede estructurar en diversas fases asociadas, cada una de ellas, a un instante de tiempo determinado. Los instantes de tiempo con sus abreviaturas correspondientes utilizados para identificar cada fase del proceso son:

- Inicio del ensayo: $\mathbf{t}_{i}$, instante en el cual se aplica una sobrepresión al sistema.

- Instante en el que empieza a cambiar la presión de la columna de agua después de aplicarse una sobrepresión al sistema: $\mathbf{t}_{\mathbf{p}}$

- Instante en el que empieza a cerrar la ventosa, es decir, instante en el cual el flotador ha recorrido el $5 \%$ de la carrera total; to

- Instante en el cual se considera que la ventosa está completamente cerrada, o bien instante en el cual el flotador ha recorrido el $95 \%$ del desplazamiento total: $\mathbf{t c}_{\mathbf{c}}$

- Instante en el que se produce la presión máxima registrada por el transductor de presión K3 situado en el cuello de la ventosa: $\mathbf{t}_{\mathbf{m}}$

- Instante en que la presión se anula después de haber alcanzado su pico máximo o instante en el cual finaliza la expansión de la bolsa de aire atrapada: $\mathbf{t}_{\mathbf{p} 0}$

- Instante en el cual la velocidad de la columna de agua se hace cero: $\mathbf{t}_{\mathbf{z}}$

En cada uno de estos instantes de tiempo se dispone de datos de velocidades y presiones en determinados puntos de la instalación, tanto en los ensayos realizados con la ventosa $\mathrm{A}$ como en los realizados con la ventosa B.

La Figura 4.16 muestra la evolución general de la presión medida en el cuello de la ventosa según indica el transductor de presión K3, la velocidad registrada por el caudalímetro electromagnético y la posición del flotador a lo largo del ensayo tras haber aplicado una sobrepresión a la columna de agua en el instante inicial, en un ensayo cualquiera: 


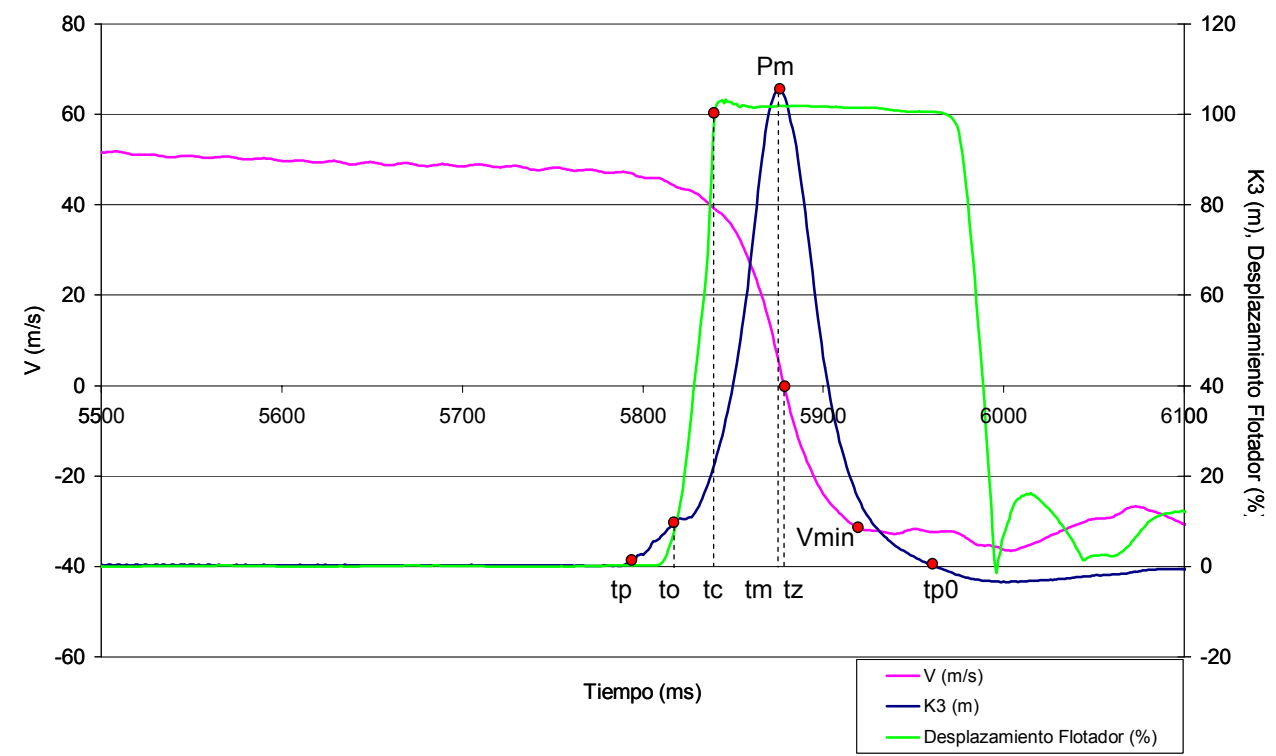

Figura 4.16. Variables principales en un ensayo de expulsión de aire.

En todos estos ensayos siguiendo la evolución de la velocidad de la columna de agua se puede analizar lo que sucede desde el inicio del test. Partiendo de un valor de la velocidad nulo, la columna de agua acelera en cuanto se le aplica una sobrepresión. En el momento en que la ventosa cierra se constata una deceleración brusca hasta que la velocidad alcanza un valor nulo, momento en el cual, aproximadamente, el transductor de presión K3 registra el valor de presión máximo. La deceleración de la columna de agua después del cierre se ha calculado como la variación de la velocidad entre los instantes en que la ventosa cierra completamente tc y el instante en el cual la velocidad de la columna de agua se hace cero tz.

En la Figura 4.17 se detallan gráficamente las diferentes velocidades que ayudarán a analizar el fenómeno ocurrido en la instalación objeto de estudio.

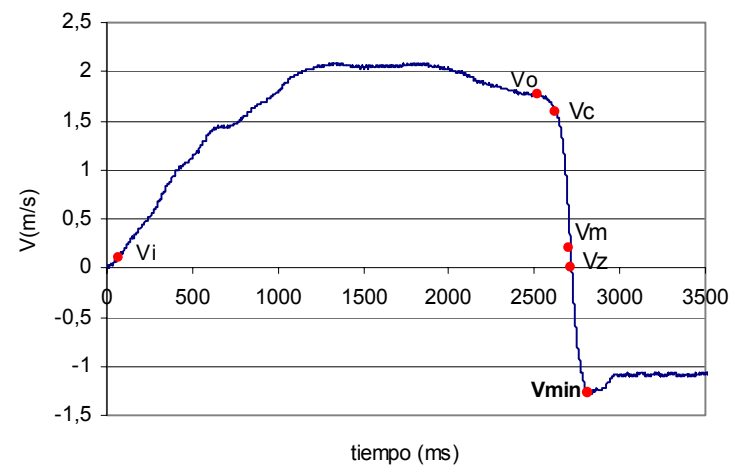

Figura 4.17. Definición de la velocidad del flujo en cada instante de tiempo. 
Donde:

- $\mathbf{V}_{\mathbf{i}}$, Velocidad en el instante $t_{i}$, o velocidad inicial que toma la columna de agua tras verse sometida a una presión desde el depósito que contiene agua.

- $\mathbf{V}_{\mathbf{o}}$, Velocidad en el instante to, la velocidad de la columna de agua cuando alcanza el flotador de la ventosa provocando el movimiento del mismo.

- $\mathbf{V}_{\mathbf{c}}$, Velocidad de la columna de agua en el instante $t_{c}$, o la velocidad cuando la ventosa cierra por completo.

- $\mathbf{V}_{\mathbf{m}}$, Velocidad en el instante $t_{\mathrm{m}}$, cuando se alcanza la presión máxima en el interior del sistema.

- $\quad \mathbf{V}_{\mathbf{z}}$, Velocidad nula. A partir de esta velocidad, la velocidad del flujo cambia de sentido, de manera que la bolsa de aire se expande. Cuando no existe aire atrapado en la instalación $V_{m}$ y $V_{z}$ deberían ser prácticamente iguales.

- V $\mathbf{V}_{\text {min, }}$ Velocidad mínima de retorno que alcanza la columna de agua. Esta velocidad depende no solo de la cantidad de aire que queda atrapado en el sistema sino de la capacidad de admisión de aire de la ventosa, ya que esta velocidad se alcanza después de que tengan lugar los procesos de compresión y expansión de la bolsa de aire atrapado.

Observando los resultados de los ensayos y sin entrar en un análisis profundo de los mismos, se desprende que existe una serie de variables que son decisivas a la hora de determinar el pico de presión que se produce en cada ensayo. Entre dichas variables cabe destacar:

- Velocidad de llegada de la columna de agua al flotador de la ventosa, Vo. Es la velocidad registrada en el instante to. La velocidad de llegada influye en el cierre la ventosa, y en el golpe de ariete que se produce posteriormente debido a la deceleración de la columna de agua.

- Celeridad del fluido. La celeridad del fluido está relacionado con la capacidad de compresión del mismo y del sistema en su conjunto.

- Cantidad de aire que queda atrapado en el sistema tras el cierre de la ventosa

- Duración del cierre de la ventosa, es decir tiempo que transcurre entre que la columna de agua alcanza el flotador y la ventosa cierra por completo, tc-to.

A partir de las mediciones de presión y velocidad efectuadas en cada instante de tiempo, se han calculado otras variables con el objetivo de establecer comparaciones del comportamiento experimentado por cada ventosa. Los cálculos realizados son:

- Deceleración de la columna de agua entre el instante de cierre completo de la ventosa y el instante en el cual el caudal registrado por el caudalímetro electromagnético es cero (dv/dt_cz). 
- Ratios de velocidades: relaciones entre la velocidad en el instante en el cual empieza a cerrar la ventosa $\left(\mathbf{V}_{\mathbf{o}}\right)$, la velocidad cuando la ventosa cierra por completo $\left(\mathbf{V}_{\mathbf{c}}\right)$ y la velocidad mínima a la que llega la columna de agua tras el cierre de la ventosa $\left(\mathbf{V}_{\text {min }}\right)$.

- Suma de los caudales registrados: se trata de realizar una integración de los caudales circulados entre el instante de inicio del ensayo y el instante en el cual el caudal se anula (IntQ_ti_tz). Se propone otra integración de caudales entre el instante de inicio de cierre de la ventosa y el instante de cierre total de la misma (IntQ_tc_to)

- Intervalo de tiempo que tarda en cerrar la ventosa (tc-to): Durante el proceso de cierre de la ventosa entra en juego el comportamiento dinámico de la misma. A priori este parámetro puede interesar ya que puede influir en la cantidad de aire atrapado y en la magnitud del golpe de ariete.

- Presión inicial aplicada sobre la columna de agua. $(\Delta \mathbf{P})$. Es la presión ejercida de forma controlada sobre la columna de agua desde el tanque de agua.

- Presión máxima alcanzada en el cuello de la ventosa $\left(\mathbf{P}_{\max }\right)$. Es el valor máximo de la presión registrada por el transductor de presión K3 situado en el cuello de la ventosa.

- Anchura del pico de presión máxima: Esta anchura de pico se determina sobre la presión identificada en los ensayos como K3 tras comprobar que dicho transductor de presión siempre registraba el mayor valor de presión en el sistema. Dicho transductor se encontraba situado justo en el cuello de la ventosa. El ancho de este pico de presión se ha definido como el tiempo transcurrido entre que la presión $P_{\max }$ empieza a subir $\left(\mathbf{t}_{\mathbf{p}}\right)$ y el instante en el cual tras haber llegado al valor máximo

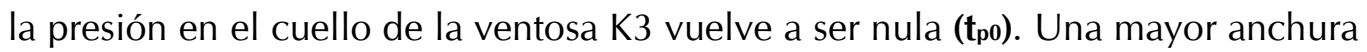
del pico de presión es indicativo de que ha quedado una mayor cantidad de aire atrapado, al ser los procesos de compresión y expansión más lentos.

Dada la gran cantidad de ensayos dinámicos realizados con las ventosas en fase de expulsión de aire al final de una conducción, los datos recogidos se han clasificado atendiendo a las características intrínsecas de cada ensayo, es decir: según la ventosa utilizada (A o B), según el diámetro de la misma (100 mm o $50 \mathrm{~mm}$ ), según el fenómeno estudiado (expulsión, admisión, determinación de la capacidad de descarga....), estado de la válvula de mariposa BV1 (abierta o cerrada), según la longitud inicial de la columna de agua, etc. 
En general en cada disposición de la instalación se ensayaron dos longitudes de columna de agua iniciales diferentes, $L_{0}=1,238 \mathrm{~m}$ y $L_{0}=1,988 \mathrm{~m}$. Cabe decir, que con la ventosa A se ensayó otra longitud inicial de la columna de agua que no se ensayó con la ventosa B, por este motivo, no se incluye dentro de este capítulo en el cual el principal objetivo es comparar el comportamiento de ambas ventosas con el sistema sometido a las mismas condiciones iniciales.

En las gráficas y tablas que se presentan en este capítulo, la longitud de agua ensayada denominada L1, corresponde a una altura inicial de agua medida sobre la vertical del eje longitudinal de la tubería horizontal de 1,238 m. Por otro lado, la longitud inicial de la columna de agua L2, medida de la misma manera, corresponde a una altura en vertical de $1,988 \mathrm{~m}$.

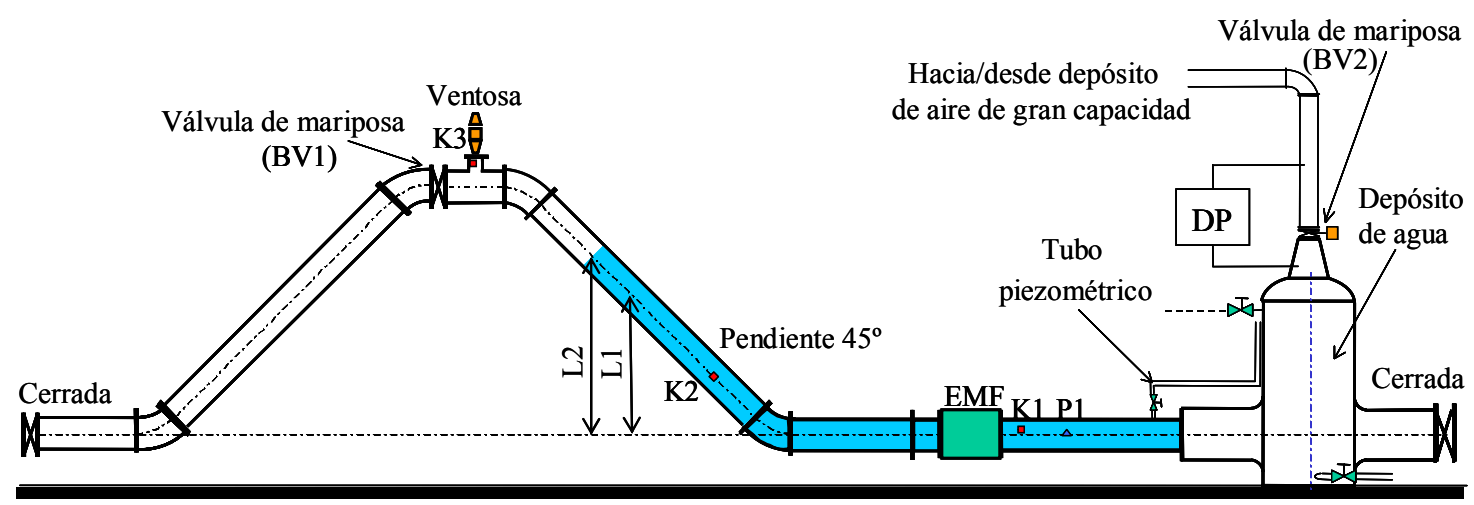

Figura 4.18. Medida de las alturas iniciales de la columna de agua: L1, L2.

\subsubsection{COMPARATIVA PRELIMINAR DEL COMPORTAMIENTO DE DOS VENTOSAS.}

Como queda patente en las figuras del apartado anterior, existe una gran diferencia en los ensayos realizados con dos ventosas de fabricantes diferentes en cuanto a la presión máxima. Esta diferencia puede ser debida a la cantidad de aire atrapado en el sistema tras el cierre de la ventosa en cuestión. Por ello, una vez procesados los resultados de las mediciones, se decide establecer relaciones entre variables como por ejemplo, la cantidad de aire atrapado, la deceleración de la columna de agua, la velocidad de la columna de agua en diversas fases del proceso, la suma de caudales de agua registrados entre dos instantes de tiempo dados y las presiones máximas alcanzadas en el interior de la instalación.

El objetivo final es encontrar relaciones entre los parámetros mencionados que aporten datos coherentes sobre la existencia de mayor o menor cantidad de aire atrapado en la tubería así como sobre la magnitud del pico de presión máxima que se genera. En definitiva se trata de identificar alguna razón que explique la significativa diferencia de comportamiento, al utilizar en un mismo tipo de ensayo ventosas de igual diámetro nominal pero con una estructura interna diferente. 
Para ello, se han elaborado una serie de gráficas que recogen las distintas relaciones entre las principales variables que caracterizan el fenómeno. En dichas gráficas, el eje de abcisas hace referencia a los valores obtenidos con la ventosa $\mathrm{B}$ y el de ordenadas a los medidos con la ventosa $A$. Cada punto representado en este tipo de gráfica contiene información de dos ensayos, uno relativo a la ventosa $A$ y otro relativo a ventosa $B$, efectuados bajo condiciones iniciales similares.

Además, en cada gráfica se ha incluido una línea inclinada $45^{\circ}$ sobre el eje de abcisas a modo de guía la cual facilita la interpretación de los resultados. Así pues, al analizar un parámetro determinado, cuando los puntos quedan aproximadamente sobre la diagonal indica que bajo las mismas condiciones iniciales ambos ensayos se comportan de manera similar. Si los puntos quedan mayoritariamente por debajo de la línea diagonal significa que en los ensayos con la ventosa $B$ se consiguen valores mayores de la variable en cuestión que en los de la ventosa A. Por el contrario, si los puntos quedan por encima de la diagonal supone que en un determinado par de ensayos similares con ventosas distintas los realizados con la ventosa A obtienen valores mayores del parámetro en cuestión.

En las gráficas que se presentan a lo largo de este apartado, aparecen marcados como L1 los puntos pertenecientes a los ensayos con una altura inicial de la lámina libre de agua de 1,238 m medida desde el eje longitudinal de la tubería horizontal. Por otro lado, como L2 se identifican los puntos correspondientes a los ensayos cuya altura inicial de la columna de agua dentro de la tubería es de 1,988 m.

\section{Presión máxima registrada en el sistema}

Del análisis del comportamiento de cada ventosa por separado, bajo condiciones iniciales similares, se observan diferencias en cuanto a la presión máxima registrada en la conexión de la ventosa con la instalación, medición dada por el transductor de presión K3. De hecho bajo las mismas condiciones iniciales los picos de presión alcanzados en la ventosa A son significativamente menores que los medidos en la ventosa B independientemente de la longitud inicial de la columna de agua tal y como se observa en la Figura 4.19. Esta gráfica hace que se plantee ya desde un principio que la diferencia de comportamiento entre las dos ventosas de DN100 puede afectar considerablemente a la magnitud del transitorio hidráulico que se produce en la misma. Las presiones máximas medidas en los ensayos realizados con la ventosa $B, D N 100$, llegan a ser en ocasiones del orden de un $60 \%$ superiores a las obtenidas en los ensayos realizados con la ventosa $A$, bajo condiciones iniciales similares. 


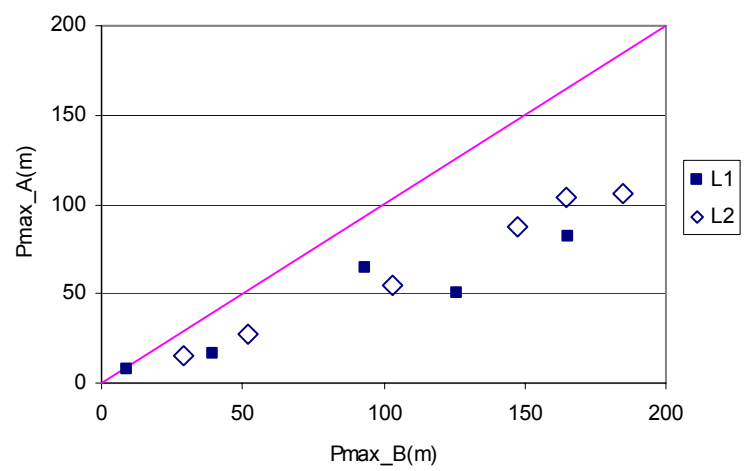

Figura 4.19. Presión máxima en ensayos similares de dos ventosas diferentes

\section{Deceleración de la columna de agua después del cierre}

Cuando la ventosa cierra se produce una pérdida paulatina de velocidad en la columna de agua hasta que dicha velocidad llega a anularse e incluso se invierte el sentido de flujo. La deceleración estudiada entre los instantes $t_{c}$, instante en el cual cierra por completo la ventosa, y $t_{z}$, instante en el cual la velocidad se anula, aporta información sobre la cantidad de aire atrapado después del cierre. Una deceleración mayor significaría que queda menos aire atrapado después del cierre. El caso extremo sería aquel en el cual no quedase aire atrapado con lo que el cambio de velocidad sería prácticamente instantáneo.

De los datos que aporta la Figura 4.20 se concluye que deceleración de la columna de agua entre los instantes $t_{c} y_{t} t_{z}$ son similares en ambas ventosas, o sea, existe una uniformidad aceptable del comportamiento de las ventosas. Según este parámetro la cantidad de aire atrapado en ambas ventosas para un mismo tipo de test sería similar, por lo que habría que buscar explicaciones sobre la diferencia de comportamiento en otros factores.

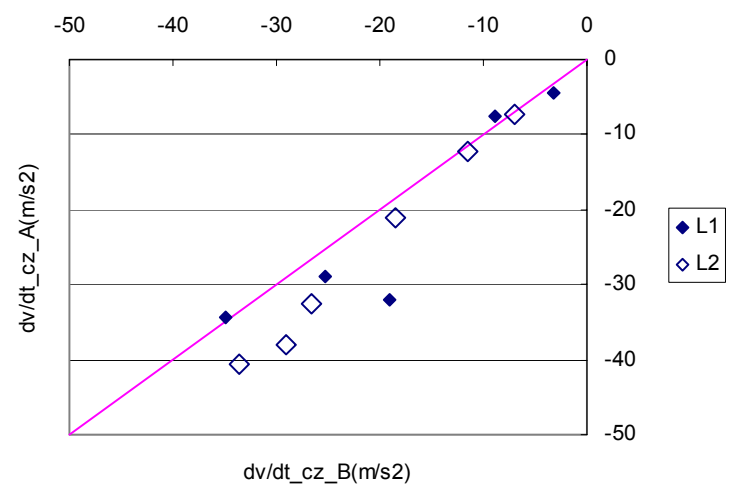

Figura 4.20. Variación de la velocidad del flujo en ensayos similares de dos ventosas diferentes 


\section{Deceleración de la columna de agua durante el cierre}

La deceleración de la columna de agua entre los instantes de tiempo to, instante en el que empieza a cerrar la ventosa, y $t_{c} \mathrm{O}$ instante en el cual la ventosa cierra por completo es mayor en los ensayos realizados utilizando la ventosa A que utilizando la ventosa B bajo condiciones de ensayo similares. Existen tres puntos que se desvían del comportamiento general debido a que la ventosa tarda más en cerrar, con lo cual, cuando cierra $\mathrm{V}_{c}$ es menor que en los otros casos.

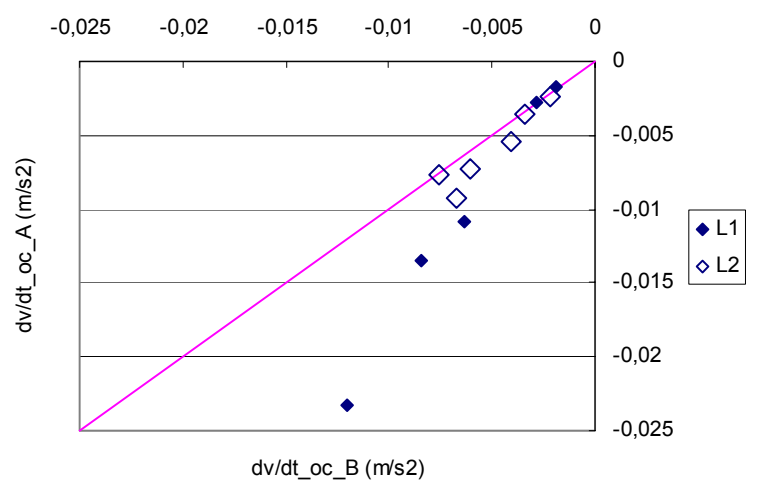

Figura 4.21. Variación de la velocidad del flujo en ensayos similares de dos ventosas diferentes

\section{Volumen de agua circulado entre dos instantes de tiempo}

Cuando se integran los caudales entre el inicio del test ( $\mathrm{t}_{\mathrm{i}}$ ) y el instante en que las velocidades se hacen cero $\left(\mathrm{t}_{\mathrm{z}}\right)$, se obtiene que los volúmenes registrados de agua circulada durante el ensayo de la ventosa A son mayores que en el de la ventosa B. Esto es debido principalmente a una fuga de agua que tenía lugar frecuentemente a través de la ventosa $A$ después del cierre. El caudal registrado es muy parecido independientemente de la longitud inicial de la columna de agua utilizada según se deduce de la Figura 4.22.

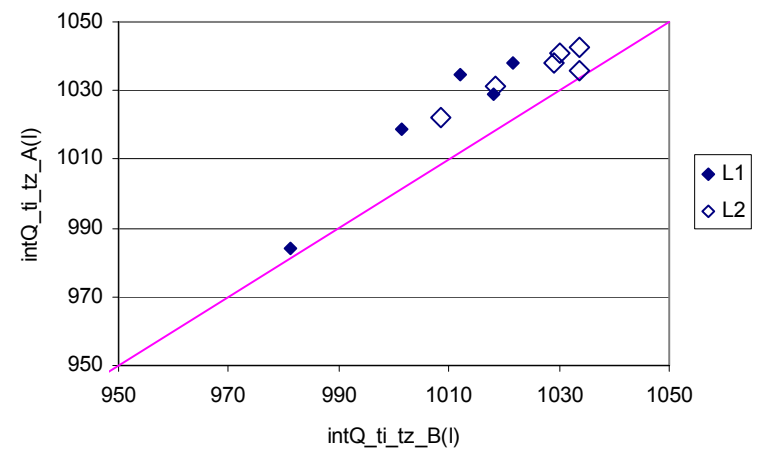

Figura 4.22. Volumen de agua circulado en ensayos similares de ventosas diferentes 


\section{Ratio $V_{\min } / V_{o}$}

La relación entre la velocidad mínima de retorno de la columna de agua $V_{\min }$ y la velocidad de dicha columna de agua cuando llega a la ventosa $V_{o}$, o lo que es lo mismo cuando la ventosa empieza a cerrar está relacionada en cierto modo con la elasticidad del sistema. Es decir, si el sistema no contiene aire atrapado después del cierre de la ventosa, tras llegar la columna de agua al punto más alto de la instalación no se registraría un movimiento de retorno en el caudalímetro electromagnético, ya que dicho caudalímetro no es capaz de registrar el movimiento de las ondas de presión originadas por el golpe de ariete. En este caso se consideraría que la columna de agua, a efectos de medición del caudal, es prácticamente inelástica. Por el contrario, si queda aire atrapado al cerrar la ventosa, el proceso de expansión de esta bolsa de aire hace que la columna de agua retorne hacia el caudalímetro, el cual registra una velocidad en sentido contrario al sentido de la velocidad inicial del ensayo.

La velocidad mínima, $V_{\min }$, hace referencia a la menor velocidad alcanzada en el proceso de deceleración de la columna de agua. En el caso extremo en el cual no haya aire atrapado en el sistema tras el cierre de la ventosa, esta velocidad de retorno sería nula, luego $\mathrm{V}_{\mathrm{min}} / \mathrm{V}_{\mathrm{o}}$ sería igual a cero. Por otra parte, en el caso de una oscilación en masa sin fricción la relación $\mathrm{V}_{\min } / \mathrm{V}_{\text {o }}$ sería igual a la unidad.

Además cabe tener en cuenta, que $\mathrm{V}_{\text {min }}$ depende también, tanto de la rapidez de respuesta de la ventosa ante la aparición de una depresión en el interior del sistema, como de la capacidad de admisión de aire de la ventosa.

En la Figura 4.23 se ha intentado mostrar la relación que existe entre $V_{\min } / V_{o}$ en las dos ventosas pero la dispersión de los resultados obtenidos hace que sea difícil extraer una conclusión clara sobre la influencia de este parámetro.

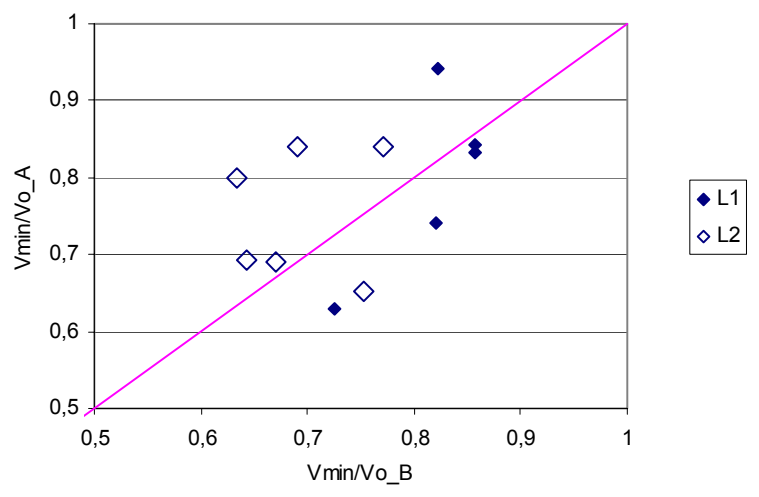

Figura 4.23. Relaciones de velocidades 


\section{Duración del cierre (tc-to)}

La duración del cierre de la ventosa, se define como el tiempo transcurrido desde que la columna de agua llega al flotador de la ventosa ( $\mathrm{t}_{\mathrm{o}}$ ) hasta que el flotador cierra por completo el orificio de salida del aire al exterior (tc). Por tanto, en cada ensayo dinámico de expulsión de aire se calcula como la diferencia entre estos dos valores de tiempo (tc-to). En la Figura 4.24 se observa que la duración del cierre de la ventosa $B$ es muy parecida a la duración del cierre de los ensayos realizados con la ventosa A, exceptuando tres casos particulares de la ventosa $A$. Teniendo en cuenta la escala representada en la figura, se puede concluir que en general la magnitud de la duración del cierre oscila en ambos casos dentro de un rango pequeño de valores.

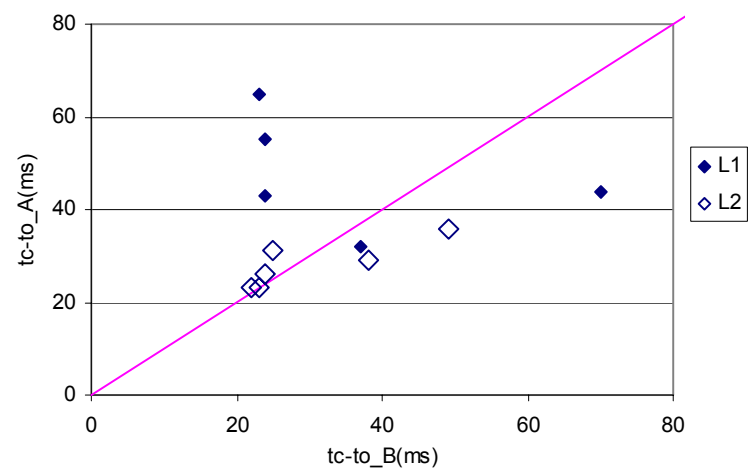

Figura 4.24. Duración del cierre

\section{Tiempo transcurrido entre el cierre completo de la ventosa y el instante de presión máxima $\left(\mathrm{t}_{\mathrm{m}}-\mathrm{t}_{\mathrm{c}}\right)$}

La diferencia entre el instante en el cual se alcanza la presión máxima $\left(\mathrm{t}_{\mathrm{m}}\right)$ en el interior de la instalación y el instante en que la ventosa ha cerrado por completo $\left(\mathrm{t}_{\mathrm{c}}\right)$ se considera un indicador de la existencia de aire atrapado en el sistema. En el caso hipotético en el cual no quedara prácticamente aire atrapado en la instalación $t_{m}$ y $t_{c}$ deberían ser dos valores muy próximos. Cuanto mayor es la cantidad de aire queda atrapado mayor es esta diferencia de tiempos, debido al aumento de la elasticidad del fluido. En la Figura 4.25 se comprueba que bajo las mismas condiciones iniciales estos tiempos son prácticamente iguales para ambas ventosas. Al igual que en la Figura 4.20 se puede concluir que la cantidad de aire que puede quedar atrapado es similar en ambos casos. 


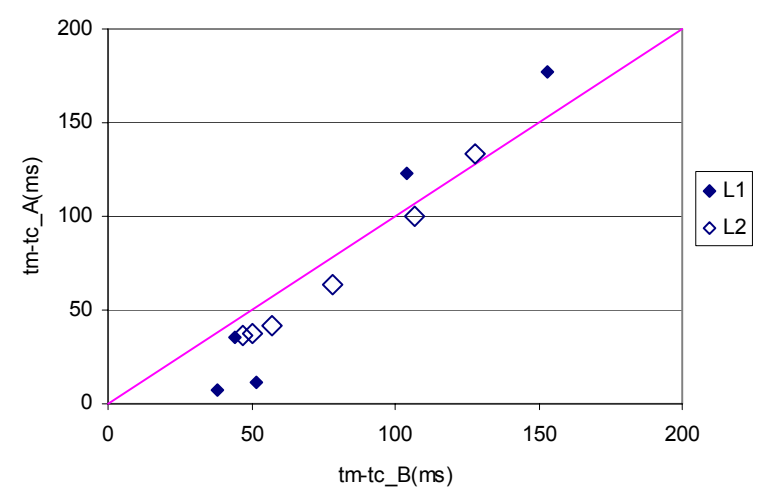

Figura 4.25. Relaciones entre dos instantes de tiempo

Con esta comparación preliminar de ensayos con dos ventosas diferentes de DN100, ha quedado patente que existe una clara diferencia en los resultados del transitorio hidráulico producido. Las presiones obtenidas al ensayar la ventosa B son claramente mayores que las obtenidas al ensayar la ventosa A. Una primera hipótesis podría haber sido que la cantidad de aire atrapo en el sistema tras el cierre de la ventosa es diferente, menor en los ensayos de la ventosa B. Por otro lado, la deceleración del flujo y el tiempo transcurrido entre el cierre completo de la ventosa y el instante de presión máxima es parecida para las dos ventosas, (figuras 4.20 y 4.25 respectivamente). Así pues, cabría pensar que o bien la cantidad de aire atrapado es similar en ambos casos, o bien una mínima diferencia en la cantidad y localización del aire atrapado pueda dar origen a diferencias significativas.

\subsubsection{ESTUDIO DE LAS RELACIONES ENTRE LAS PRINCIPALES VARIABLES DEL TRANSITORIO.}

Una vez realizado el análisis y la comparación entre las variables propuestas con cada una de las ventosas se procede a establecer relaciones entre dichas variables. En los apartados que siguen a continuación se muestra gráficamente la evolución de una variable respecto a otra. En estas figuras además de comparar el comportamiento de dos ventosas bajo las mismas condiciones iniciales se muestran los resultados obtenidos al ensayar dos longitudes de columna de agua iniciales diferentes. En cada figura se representan cuatro series de valores que se identifican como:

- L1A: Ensayos realizados con la ventosa A cuya longitud inicial de la columna de agua tiene un valor $L 1(h=1,238 \mathrm{~m})$

- L1B: Ensayos realizados con la ventosa B cuya longitud inicial de la columna de agua tiene un valor $\mathrm{L} 1$

- L2A: Ensayos realizados con la ventosa A cuya longitud inicial de la columna de agua tiene un valor $L 2(h=1,988 \mathrm{~m})$

- L2B: Ensayos realizados con la ventosa B cuya longitud inicial de la columna de agua tiene un valor $\mathrm{L} 2$ 


\section{Relación dv/dt_cz frente a la presión máxima registrada en el sistema.}

La deceleración de la columna de agua después del cierre de la ventosa muestra una relación bien definida frente a la presión máxima registrada en cada ensayo. Todas las series representadas en la Figura 4.26 siguen una evolución ascendente de la deceleración a medida que se registran también presiones mayores en el transductor de presión K3. Siguiendo las suposiciones hechas hasta el momento, a medida que la deceleración de la columna de agua aumenta, menor es la cantidad de aire atrapado y por tanto debería ser mayor el pico de presión, tal y como se muestra en la figura. En todas las series, la relación entre ambas variables sigue una tendencia marcadamente lineal. Otra característica importante a destacar en la Figura 4.26 es que en general dada una determinada deceleración de la columna de agua, las presiones obtenidas en los ensayos con la ventosa $B$ son significativamente mayores que las registradas en los ensayos con la ventosa A sea cual sea la longitud inicial de la columna de agua utilizada.

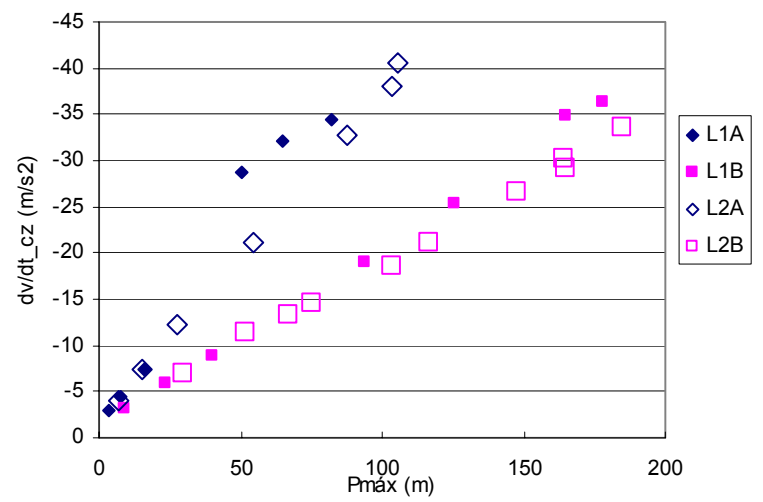

Figura 4.26. Evolución dv/dt_cz con la presión máxima

\section{Relación dv/dt_cz frente a la sobrepresión aplicada}

En la Figura 4.27 se representa la relación entre la deceleración de la columna de agua a partir del instante de inicio del cierre de la ventosa y la presión inicial aplicada a la columna de agua. Todas las series de ensayos representadas muestran una misma tendencia de crecimiento de la deceleración de la columna de agua entre los instantes tc y tz cuando se incrementa la sobrepresión inicial aplicada. En los ensayos con mayor deceleración, la cantidad de aire atrapado en el sistema es menor.

La variación de la deceleración dv/dt_cz con la sobrepresión inicial aplicada, $\Delta \mathrm{P}$, no es lineal. Esto viene reflejado en la Figura 4.27, en la cual se aprecia que con incrementos pequeños de la sobrepresión inicial, el cambio que se produce en la deceleración es mucho mayor. En general, los resultados de los ensayos son semejantes independientemente de la ventosa utilizada. Existen diferencias en este caso, según la longitud de columna inicial de agua utilizada. Para una misma sobrepresión inicial, la 
deceleración es más elevada al considerar una longitud inicial de la columna de agua mayor, L2. Este resultado es lógico ya que al incrementarse la distancia a recorrer por la columna de agua, aumenta la mezcla con el aire quedando por tanto, más aire atrapado después del cierre de la ventosa.

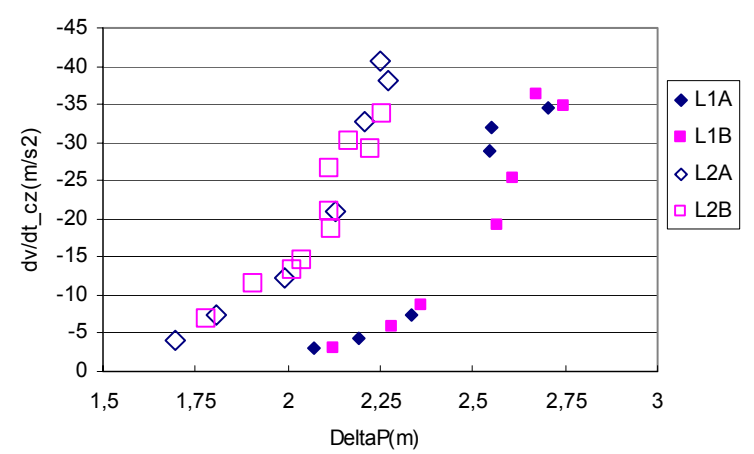

Figura 4.27. Evolución dv/dt_cz con $\Delta \mathrm{P}$

Las velocidades de llegada de la columna de agua a la ventosa son muy similares, por ello, deben existir otra serie de factores que influyan en el incremento de la deceleración de la columna de agua.
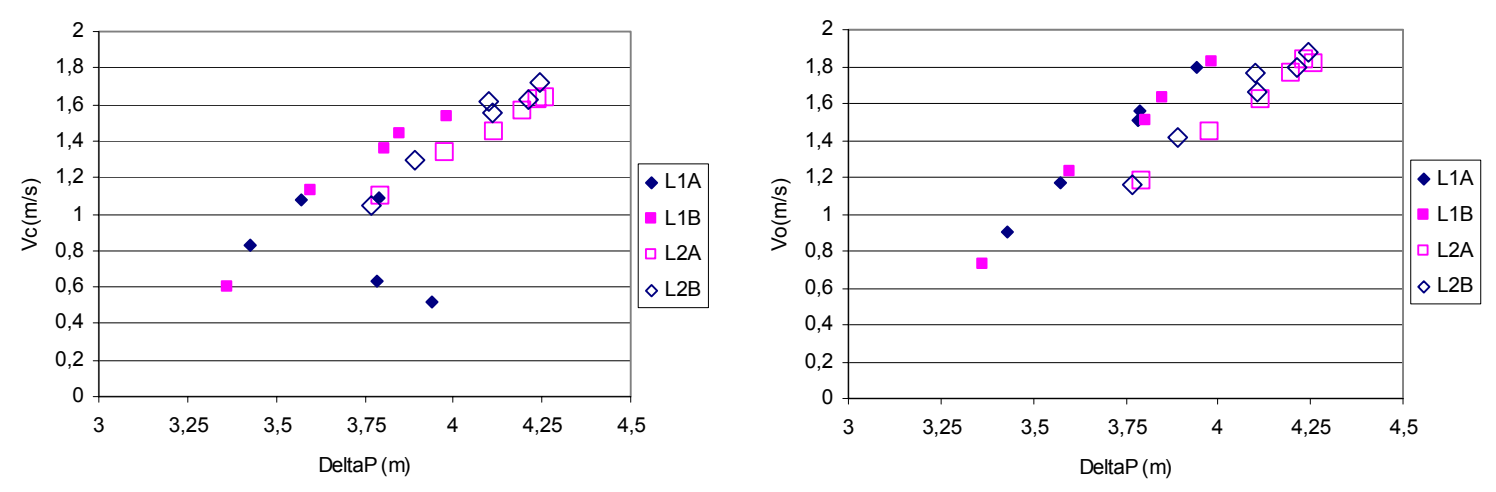

Figura 4.28. Velocidad de llegada de la columna de agua frente a DeltaP

\section{Relación dv/dt_cz frente a la anchura del pico de presión máxima}

Tras analizar la presión medida por el transductor K3 situado en la conexión en T de la ventosa con la instalación en los ensayos de expulsión de aire, se calcula la duración de los procesos de compresión y expansión del pico de presión. La anchura del pico de presión se calcula como la diferencia entre los instantes de tiempo $t_{p}$, o instante de tiempo en el cual la presión empieza a aumentar y tpo o instante en que tras haber llegado al valor máximo la presión vuelve al valor inicial. Se entiende que una mayor duración conjunta de ambos procesos, se debe a la existencia de mayor cantidad de aire atrapado en el sistema tras el cierre de la ventosa. En la Figura 4.29 se observa que todos los cálculos 
realizados en este sentido siguen una misma evolución independientemente de la ventosa ensayada y de la longitud inicial de la columna de agua. De este cálculo en concreto se desprende que a mayor deceleración de la columna de agua entre los instantes $t_{c}$ y $t_{z}$ menor es la anchura del pico de presión. Este resultado es coherente con el punto anterior en el cual se desprendía que con mayor deceleración de la columna de agua, la cantidad de aire atrapado es menor. Por tanto, ambos parámetros servirían como indicadores para estimar la cantidad de aire que queda atrapado, que a su vez está íntimamente relacionado con los picos de presión que se pueden generar durante el transitorio hidráulico. De todos modos, la cantidad de aire atrapado es un parámetro que depende de diversos factores además de la propia ventosa, como por ejemplo la velocidad de llenado, la pendiente de la conducción etc.

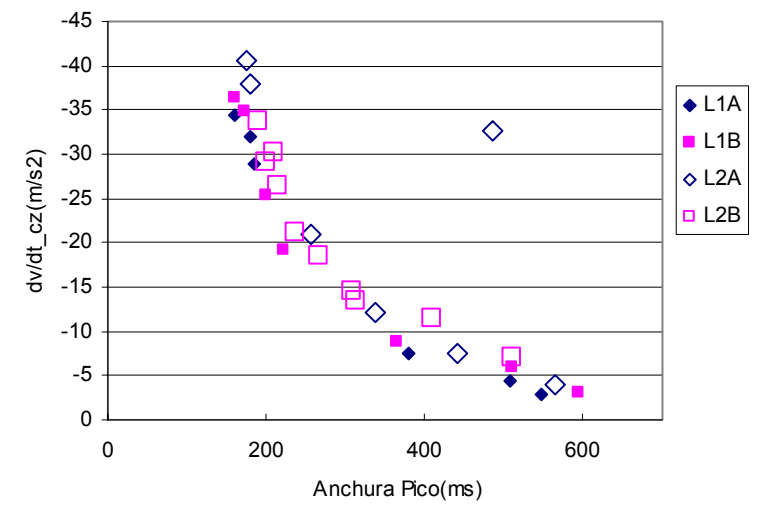

Figura 4.29. Evolución de la deceleración dv/dt_cz con la anchura del pico

\section{Relación dv/dt_cz frente a la duración del cierre,tc-to}

El tiempo que tarda en cerrar cada ventosa es uno de los factores que caracteriza su comportamiento dinámico. Como en general los cierres registrados son rápidos, es importante estudiar su influencia tanto sobre la magnitud del pico de presión alcanzado como sobre la cantidad de aire atrapado en el sistema. Además interesa conocer si este factor se puede relacionar con la capacidad de descarga de las ventosas y si esta capacidad de descarga es diferente según la ventosa utilizada.

En la Figura 4.30 se observa que existe cierta correlación entre la duración del cierre de la ventosa, $t_{c}-t_{0}$, y la deceleración del fluido entre los instantes $t_{c}$ y $t_{z}$. No obstante, se han detectado tres ensayos de la ventosa $A$ que generalmente nunca siguen la tendencia general y en los cuales el tiempo de cierre es significativamente mayor. En los ensayos, independientemente de la ventosa utilizada, se observa una mayor deceleración de la columna de agua, es decir, menor cantidad de aire atrapado cuando la duración del cierre es menor. Según los resultados mostrados en Figura 4.30, no existe apenas diferencia entre lo sucedido al utilizar una ventosa u otra. Tampoco la longitud inicial de la columna de agua tomada influye en estos resultados. 


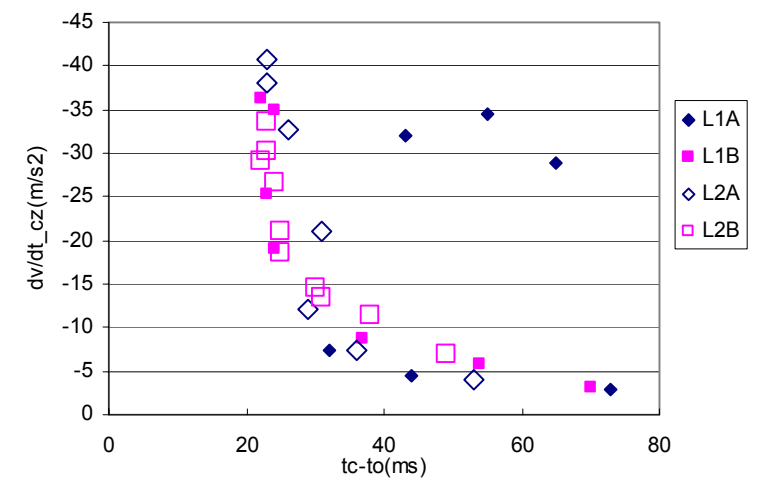

Figura 4.30. Evolución dv/dt_cz con la duración del cierre de la ventosa

\section{Anchura del pico de presión frente a la sobrepresión aplicada}

Como se ha visto en la Figura 4.29, el estudio de la anchura del pico de presión es una variable esencial en cuanto que da una idea de la duración de los procesos de compresión y expansión. Con mayor anchura de este pico de presión se confirmaría que la cantidad de aire atrapado es mayor.

Según la Figura 4.31, existe en todos los ensayos una misma tendencia en la variación de la anchura del pico de presión máxima frente a la sobrepresión aplicada al inicio del test. En general se aprecia que a mayor presión inicial, menor es el ancho del pico de presión máxima. Esto significa que cuanto mayor sea esta presión inicial que se aplica a la columna de agua menos aire queda atrapado tras el cierre de la ventosa. Este resultado es completamente coherente con el de la Figura 4.27.

Al realizar este estudio se llega a la conclusión que con presiones iniciales pequeñas queda más cantidad de aire atrapado en el sistema. La Figura 4.31, también pone de manifiesto que existe una clara diferencia de resultados cuando cambia la longitud inicial de la columna de agua. Para que la anchura del pico de presión máxima sea del mismo valor se necesita una presión inicial $\Delta \mathrm{P}$ mayor, cuando se tiene una longitud inicial de columna de agua menor L1. Como se ha comentado anteriormente, cuanto mayor es la longitud que recorre la columna de agua más tiempo dispone para mezclarse con el aire que arrastra. 


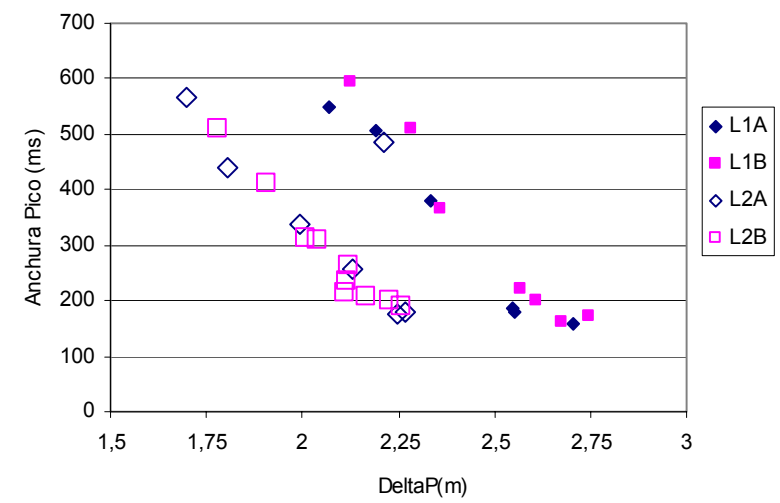

Figura 4.31. Evolución de la anchura del pico de presión con la sobrepresión aplicada

\section{Anchura del pico de presión frente a la duración del cierre de la ventosa}

La anchura del pico de presión crece generalmente al aumentar la duración del cierre de la ventosa independientemente de la ventosa ensayada y de la longitud inicial de la columna de agua, L1 o L2. Cuando el cierre es más lento, la anchura del pico de presión es mayor, es decir, queda más aire atrapado. De nuevo aparecen tres puntos correspondientes a los tests realizados con la ventosa A, ensayada con L1, que presentan un valor semejante de la anchura del pico de presión independientemente del tiempo que tarde en cerrar la ventosa. En reglas generales, se puede concluir que el resultado obtenido es independiente de la ventosa utilizada y de la longitud inicial de la columna de agua.

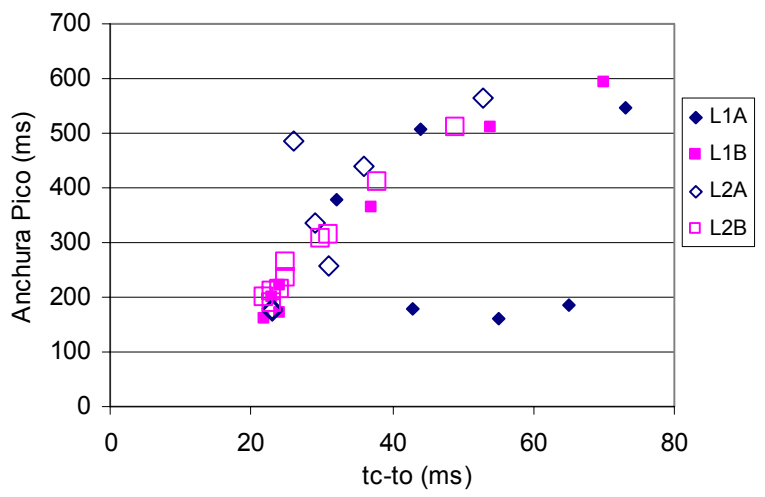

Figura 4.32. Evolución de la anchura del pico de presión con la duración del cierre de la ventosa 


\section{Anchura del pico de presión frente a la presión máxima registrada en el sistema}

La evolución de la anchura del pico de presión frente a la presión máxima que se alcanza en el sistema es independiente de la ventosa ensayada. Tampoco hay grandes diferencias al cambiar la longitud inicial de la columna de agua. Cuando en el sistema queda más aire atrapado, la presión máxima registrada es menor y viceversa, lo cual se refleja claramente en la Figura 4.33. En cualquier caso, existe cierta dispersión en los resultados, lo cual viene a indicar que la presión máxima guarda cierta relación con la anchura del pico pero no es la única variable que le afecta. Es decir, la cantidad de aire que queda atrapado influye en la presión máxima pero existen otras variables, como la velocidad de llegada de la columna de agua a la ventosa, que también influyen sobre el pico de presión máxima.

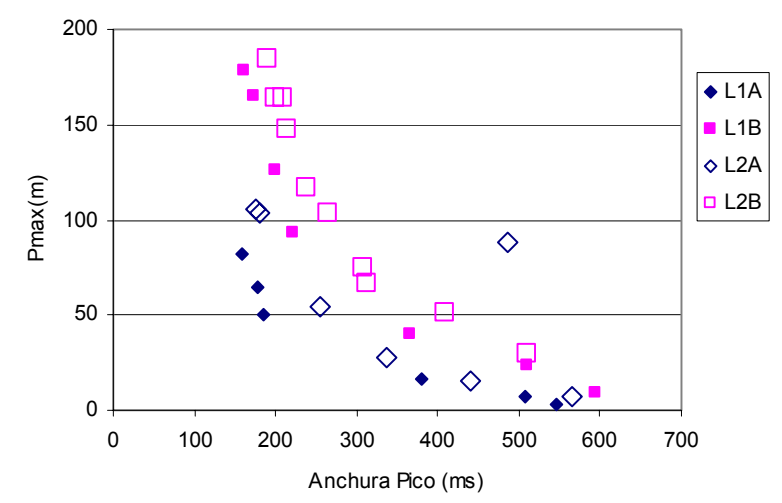

Figura 4.33. Evolución de la presión máxima con la anchura del pico de presión

\section{Anchura del pico de presión frente al volumen de agua circulado entre los instantes $t_{i}$ y $t_{z}$}

En la Figura 4.34 se aprecia una tendencia creciente del volumen de agua circulada desde el inicio del ensayo hasta el instante en el cual se anula la velocidad, $t_{z}$, a medida que disminuye la anchura del pico de presión máxima. Como se ha comentado en apartados anteriores, con una menor anchura del pico de presión la cantidad de aire atrapado es menor. Además, cuanto mayor es el caudal de agua registrado entre los dos instantes de tiempo considerados menor es la cantidad de aire atrapado en el sistema.

Bajo las mismas condiciones iniciales, se constata de nuevo que el volumen de agua circulado en los ensayos de la ventosa $A$ es mayor que en los de la ventosa $B$, tanto con la longitud inicial de la columna de agua L1 como con L2, debido en parte al cierre defectuoso que se producía en la ventosa $\mathrm{A}$. 


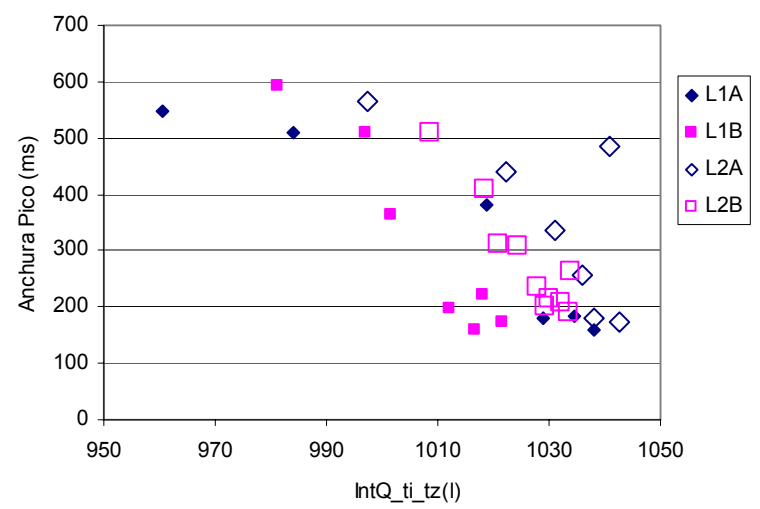

Figura 4.34. Evolución de la anchura del pico de presión con la suma de caudales

\section{Sobrepresión aplicada frente a la presión máxima registrada en el sistema}

En cada ensayo, la variable que hace que se ponga en movimiento la columna de agua y por tanto la causante del transitorio que se genera es la sobrepresión inicial, $\Delta \mathrm{P}$. Manteniendo fijas el resto de condiciones iniciales en un ensayo determinado y variando cada vez la presión inicial aplicada $\Delta \mathrm{P}$ se obtienen diferentes resultados en la magnitud de la presión máxima medida.

En los ensayos de laboratorio se controló la sobrepresión inicial aplicada para que la magnitud del transitorio no excediese de los límites deseados evitando de este modo cualquier daño a la instalación y a sus accesorios. Por esta razón, las sobrepresiones aplicadas se encuentran dentro de un pequeño intervalo de valores.

En la Figura 4.35 se aprecia una uniformidad de los resultados en todas las series analizadas en las cuales se observa perfectamente que la presión máxima registrada en el sistema es mayor cuanto mayor es la sobrepresión aplicada en el instante inicial. Dado un mismo valor de la sobrepresión aplicada para iniciar el ensayo, se obtiene una presión máxima mayor en los ensayos realizados con la ventosa $B$ que en los de la ventosa $A$. Además, con la misma sobrepresión inicial, las presiones máximas son mayores cuando se ensaya la columna de agua inicial mayor, L2. Suponiendo que la cantidad de aire atrapado es similar independientemente de la longitud inicial de columna de agua utilizada en el ensayo, cuando la bolsa de aire atrapado debe frenar una columna de agua con mayor inercia, las presiones que se producen son mayores. 


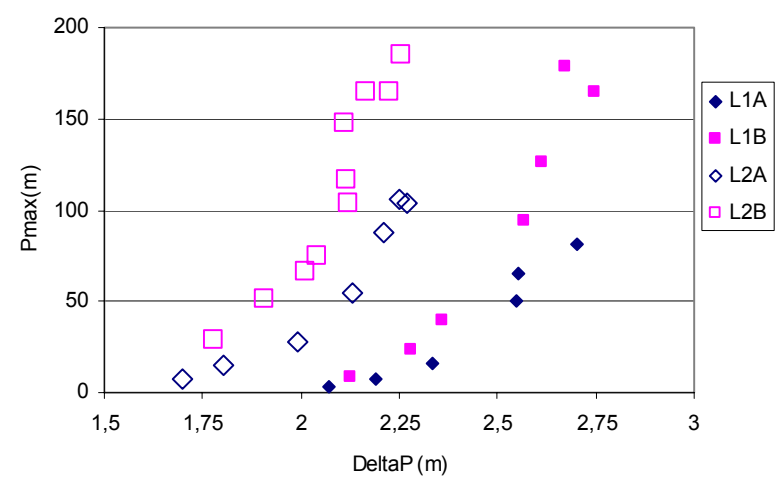

Figura 4.35. Evolución de la presión máxima con la sobrepresión aplicada

\section{Sobrepresión aplicada frente al volumen de agua circulado entre los instantes ti y} $t_{z}$

Según la Figura 4.36, la variación el volumen circulado entre el instante de inicio del ensayo ti y el instante en el cual el flujo cambia de sentido, $t_{z}$, con la presión aplicada en el instante inicial, es similar en los ensayos de ambas ventosas. Se observa que con sobrepresiones iniciales mayores, mayor es el volumen de agua registrado por el caudalímetro. Bajo estas condiciones, con mayores presiones iniciales y mayor suma de caudales registrada, la cantidad de aire atrapado es menor. Estos resultados son coherentes con los representados en la Figura 4.27 y en la Figura 4.31, lo cual es coherente con la idea de que a mayor rapidez del transitorio, menor es la proporción de aire que se mezcla con el agua.

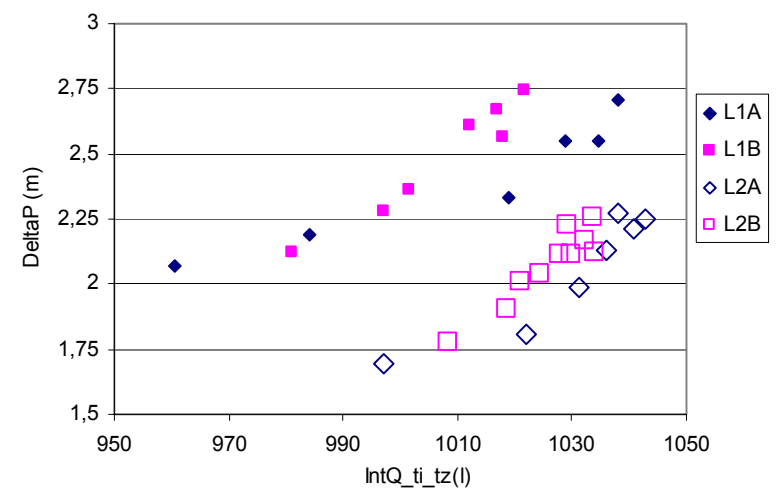

Figura 4.36. Evolución de la suma de caudales con la sobrepresión aplicada 


\section{Volumen de agua circulado entre los instantes $t_{i}$ y $t_{z}$ frente al ratio de velocidades $\mathrm{V}_{\min } / \mathrm{V}_{\mathrm{o}}$}

Como se ha visto en gráficas anteriores en las cuales se ha representado la suma de caudales de agua que ha circulado entre el instante inicial y el instante en el cual se invierte el sentido de la velocidad del flujo, $\mathrm{t}_{\mathrm{z}}$, dicho volumen es mayor siempre en los ensayos realizados con la ventosa $A$ debido al escape de agua que frecuentemente tenía lugar en esta ventosa después del cierre.

La variación del volumen de agua circulado respecto a la relación de velocidades $V_{\min } / V_{\text {o }}$ muestra cierta tendencia, aunque aparece un conjunto de ensayos en los que los resultados están muy agrupados. El volumen de agua medido, disminuye generalmente a medida que la relación $V_{\min } / \mathrm{V}_{\text {o }}$ aumenta.

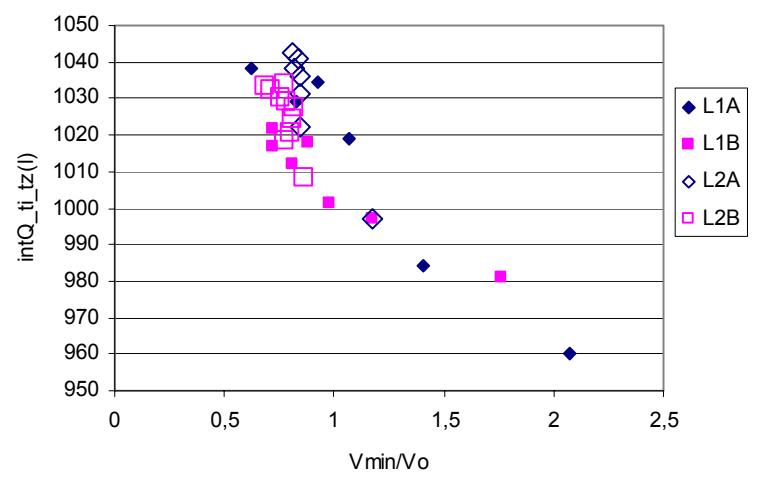

Figura 4.37. Evolución de la suma de caudales con $\mathrm{V}_{\min } / \mathrm{V}_{\mathrm{o}}$

\section{Volumen de agua circulado entre los instantes $t_{i}$ y $t_{z}$ frente a la presión máxima registrada en el sistema.}

En todas las series, el volumen circulado entre los instantes de tiempo ti (instante inicial) y $t_{z}$ (instante en el cual cambia el sentido de la velocidad de la columna de agua) frente a la presión máxima alcanzada en el ensayo muestran una relación creciente y bien definida. Para un mismo valor de volumen, las presiones registradas son mayores en los ensayos de la ventosa $B$ que en los de la ventosa $A$. En principio cuanto mayor sea el volumen registrado, menor es la cantidad de aire atrapado y mayor la presión medida. 


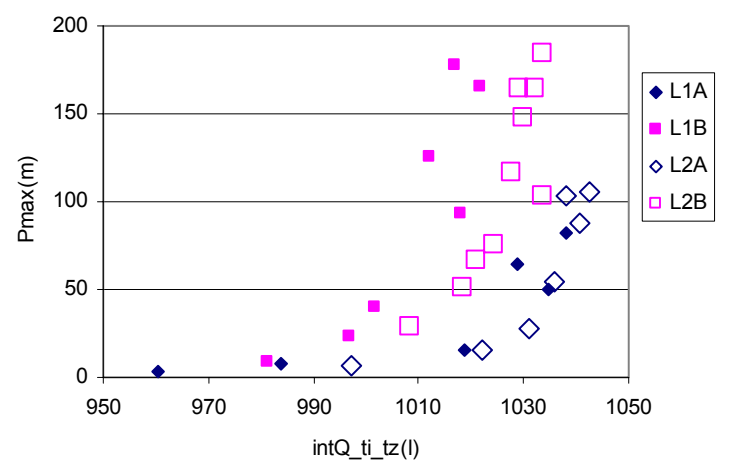

Figura 4.38. Evolución de la presión máxima con la suma de caudales

\section{Presión máxima en función de la velocidad de llegada de la columna de agua a la ventosa}

Finalmente se ha representado la variación de la presión máxima frente a la velocidad de Ilegada de la columna de agua a la ventosa. A mayor velocidad de llegada al flotador de la ventosa mayor es la presión máxima medida. En la Figura 4.39, se compara los valores de presión máxima obtenidos en el transitorio bifásico con la sobrepresión de Allievi. La sobrepresión de Allievi se ha calculado suponiendo una celeridad de la onda de presión de $1.000 \mathrm{~m} / \mathrm{s}$. Las presiones alcanzadas durante el transitorio bifásico son, en este caso de estudio concreto, menores que la sobrepresión de Allievi.

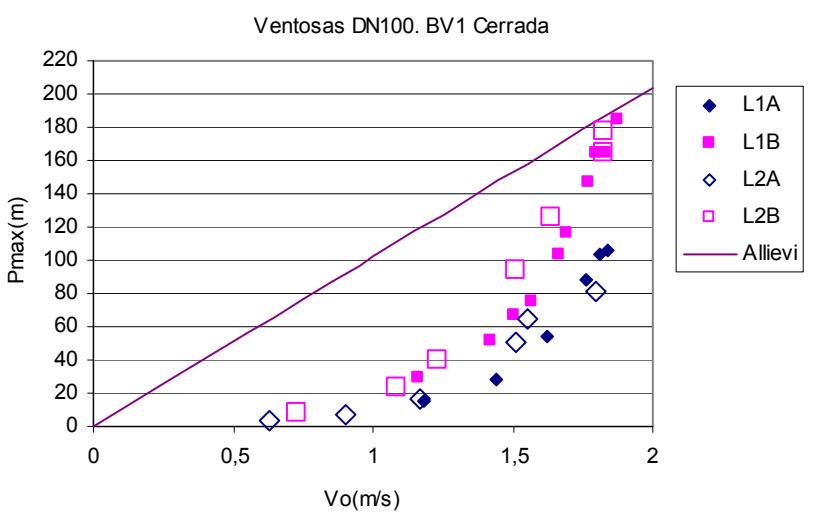

Figura 4.39. Presión máxima según velocidad de llegada a la ventosa 


\subsubsection{EXPULSIÓN DE AIRE EN UN PUNTO INTERMEDIO DE LA CONDUCCIÓN. VENTOSAS DN100}

Otra configuración de la instalación consiste en situar la ventosa en un punto intermedio de la instalación con el objetivo de estudiar su comportamiento así como el transitorio hidráulico generado. De este modo, en este apartado se analizan las diferencias entre los ensayos realizados con la ventosa A y los efectuados con la ventosa B de DN100, en los ensayos dinámicos de expulsión de aire del sistema, cuando la válvula de mariposa BV1 situada junto a la ventosa, se mantiene abierta. Con esta válvula abierta, se permite estudiar la expulsión de aire a través de una ventosa situada en el punto intermedio y más elevado de la instalación, tal y como se explicó en el Capítulo 3.

En el instante inicial, en un ensayo cualquiera de este tipo el depósito D1 se encuentra a presión atmosférica y la ventosa abierta. La tubería está parcialmente Ilena de agua en ambas partes de la instalación, tanto aguas arriba de la ventosa como aguas abajo. La columna de agua situada junto al depósito se mueve hacia la ventosa mientras que la otra columna de agua permanece durante todo el ensayo inmóvil.

Aplicando una sobrepresión desde el tanque, la columna de agua se pone en movimiento hacia la ventosa. Cuando el agua alcanza el flotador, la ventosa empieza a cerrar. En este tipo de ensayos la columna de agua una vez ha llegado al punto más alto de la instalación inicia el descenso hacia la otra parte de la instalación. A su vez, el aire empujado por columna de agua una vez llega a la parte superior puede salir al exterior a través de la ventosa o ser arrastrado por la columna de agua hacia el lado opuesto, tal y como se muestra en la Figura 4.30 del Capítulo 3. Con esta nueva configuración se generan aleatoriamente bolsas de aire en varios puntos de la instalación, con lo cual los resultados obtenidos son totalmente diferentes y más dispersos que los recogidos con BV1 cerrada.

Al estudiar los datos de presiones y caudales recogidos con esta nueva configuración se aprecia una considerable dispersión en los resultados finales. En este apartado se exponen las diferentes casuísticas encontradas, se muestra la evolución de las principales variables y se comparan los resultados con los obtenidos en los ensayos con la válvula de mariposa BV1 cerrada. 


\subsubsection{VARIABLES CARACTERÍSTICAS}

Como se ha comentado, en los ensayos realizados con la válvula BV1 abierta aparece cierta dispersión en los resultados y un comportamiento diferente según se considere una ventosa u otra, lo cual dificulta el análisis de la influencia de las ventosas en la evolución del transitorio hidráulico. Una de las principales diferencias de estos ensayos es que se detectan varios cierres consecutivos del flotador en un mismo ensayo, contabilizándose en ocasiones hasta seis cierres. En ciertos ensayos, los picos de presión máxima no se producen en el primer cierre de la ventosa sino en alguno de los cierres posteriores. Otra característica encontrada en este tipo de ensayos es que la curva de presión presenta, a menudo, un perfil irregular al contrario de lo que sucedía en los ensayos en los cuales se mantuvo la válvula de mariposa BV1 cerrada. Por todas estas razones resulta difícil realizar un análisis de las variables tan exhaustivo como se ha hecho con los ensayos en los que se mantenía la válvula de mariposa BV1 cerrada.

Pese a esta aleatoriedad de resultados, es fundamental observar las características más relevantes de esta serie de ensayos como la presión máxima alcanzada y la velocidad mínima de retorno de la columna de agua.

\section{Presión máxima registrada en el sistema}

Los valores de la presión máxima en los ensayos efectuados con la válvula de mariposa BV1 abierta son aproximadamente del mismo orden de magnitud independientemente de la ventosa utilizada en el ensayo. Tampoco aparece una diferencia significativa en las presiones máximas alcanzadas al cambiar la longitud inicial de la columna de agua que sirve de bloqueo aguas abajo de la ventosa.

Sí que es significativa por otra parte, la diferencia entre los picos de presión medidos con la configuración del sistema manteniendo la válvula de mariposa BV1 abierta frente a la disposición en la cual válvula BV1 se mantuvo cerrada para una misma perturbación inicial. En el primer caso, las presiones máximas registradas son menores debido a la gran cantidad de aire que queda atrapado en el sistema. La presión máxima alcanza valores de hasta 60 m cuando la válvula de mariposa BV1 se encuentra abierta mientras que cuando dicha válvula está cerrada se registran presiones de hasta $165 \mathrm{~m}$ considerando que se trabaja bajo condiciones iniciales similares.

Como se ha comentado en ocasiones anteriores, la mayor cantidad de aire atrapado hace de colchón y minimiza el impacto producido al cerrar la ventosa. En la siguiente figura se comparan los resultados que se han obtenido en los ensayos de expulsión de aire manteniendo la válvula de mariposa BV1 abierta con los ya presentados con la válvula de mariposa BV1 cerrada: 


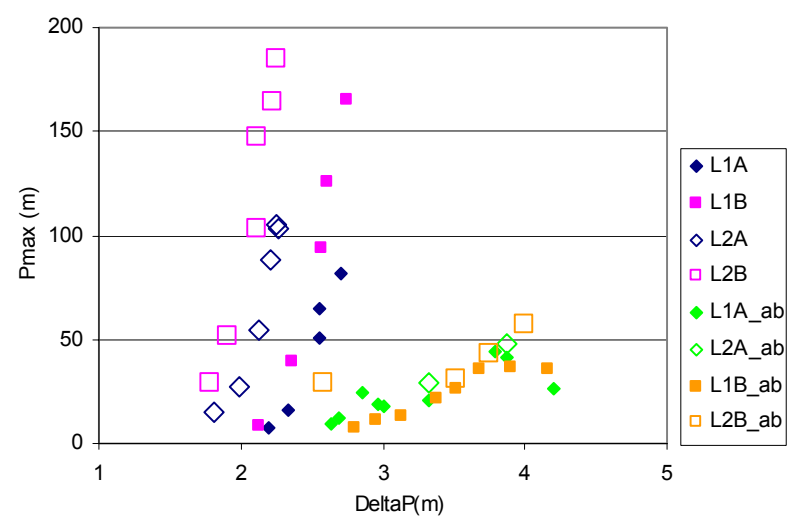

Figura 4.40. Evolución de la presión máxima con la sobrepresión aplicada

En todos los ensayos, tanto en los de la ventosa A como en los de la ventosa B, la altura inicial de la columna de agua sobre el eje de la tubería horizontal que se empuja desde el depósito D1 es de 2,018 m. Sin embargo, la altura de la columna de agua que se mantiene inmóvil y que sirve de bloqueo, medida sobre el eje longitudinal de la tubería horizontal, cambia según el ensayo. La ventosa $A$ se ensaya con dos alturas de columna de agua de bloqueo diferentes, $L 1 A \_a b=2,89 \mathrm{~m}$ y $L 2 A \_a b=3,78 \mathrm{~m}$. Por su parte, la ventosa $B$ se ensaya con las alturas de la columna de agua de bloqueo $L 1 B \_a b=2,73 \mathrm{~m}$ y L2B_ab $=3,78 \mathrm{~m}$

\section{Velocidad mínima registrada por el caudalímetro}

Con la válvula de mariposa BV1 abierta, la velocidad mínima de retorno es mayor en valor absoluto que la medida en los ensayos con válvula cerrada como se observa en la Figura 4.41. Hay que tener en cuenta que la expansión de la bolsa de aire juega un papel importante en la determinación de la velocidad mínima de la columna de agua y en esta nueva configuración, la cantidad de aire atrapado es substancialmente mayor que en la configuración en la cual se mantenía la válvula de mariposa BV1 cerrada. 


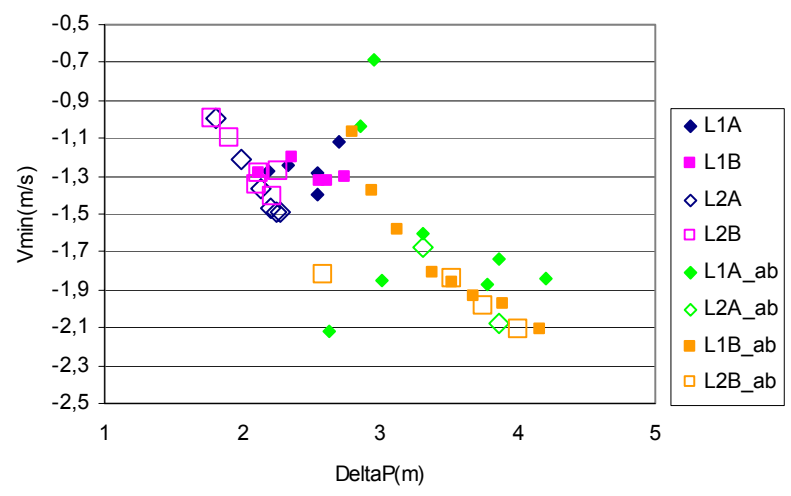

Figura 4.41. Evolución de la velocidad mínima con la sobrepresión aplicada

La velocidad mínima de retorno de la columna de agua mantiene también en este caso una relación con la presión máxima alcanzada en cada ensayo. En los ensayos con la válvula de mariposa BV1 cerrada llega un momento en que con pequeñas diferencias en la velocidad mínima, la presión máxima se incrementa exponencialmente mientras que en los ensayos con la válvula de mariposa BV1 abierta, la relación entre presión máxima y la velocidad mínima presenta una pendiente mucho más suave. De todos modos, los resultados en este último caso son más dispersos.

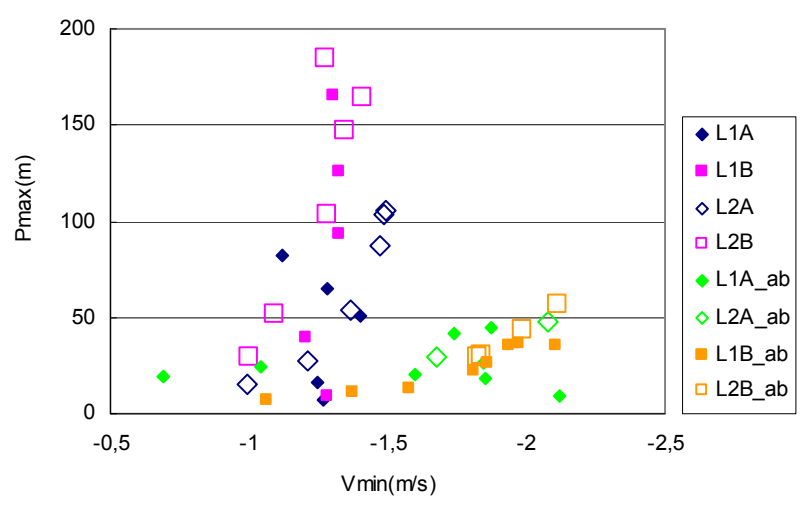

Figura 4.42. Evolución de la presión máxima con la velocidad mínima

\section{Presión máxima en función de la velocidad de llegada de la columna de agua a la ventosa}

En general, la presión máxima medida es mayor cuanto mayor es la velocidad de llegada de la columna de agua a la ventosa. Aunque se sigue una misma tendencia en los resultados referentes a dos ventosas distintas, las velocidades de llegada medidas son en general mayores en el caso de los ensayos realizados con la ventosa B. 


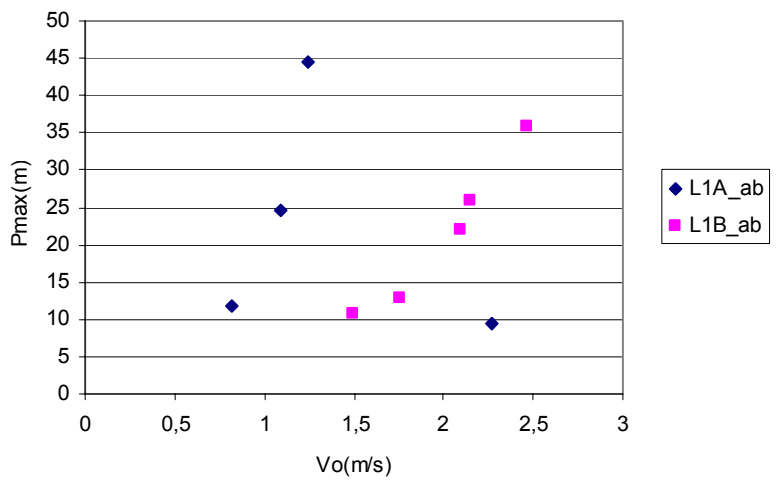

Figura 4.43. Presión máxima según la velocidad de llegada a la ventosa

\subsubsection{CASUÍSTICAS DETECTADAS}

El análisis de los resultados confirma que no existe una uniformidad en cuanto a aperturas y cierres de las ventosas en este tipo de ensayos lo cual se puede atribuir al diseño de la configuración de la instalación. En algunos tests se producen diversas aperturas y cierres consecutivos del flotador durante el transcurso del ensayo. Al mismo tiempo se detecta que la curva de presión máxima dada por el transductor de presión K3 presenta una serie de oscilaciones rápidas y que el pico de presión máxima no se produce en el primer cierre de la ventosa.

En estos ensayos, al no quedar bien definidas las condiciones de contorno aguas abajo de la columna de agua en movimiento, la dispersión de resultados es muy elevada. Por ello, la finalidad de este apartado es ofrecer una visión global del fenómeno ocurrido en los diferentes ensayos.

\section{Particularidades de los Ensayos con la Ventosa A}

Un fenómeno que se repite en numerosos ensayos realizados con la ventosa $A$ es una oscilación en la curva de presión tal y como se desprende de los datos del transductor de presión K3. Hay que añadir que también en este tipo de ensayos se produce una salida incontrolada de agua por la ventosa tal y como se observa en la fotografía de la Figura 4.44, de manera más pronunciada que en los ensayos con la válvula de mariposa BV1 cerrada. 


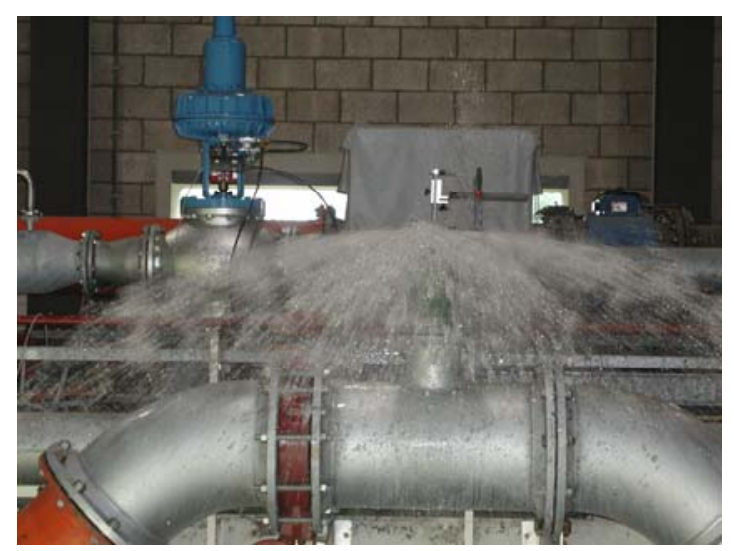

Figura 4.44. Fuga de agua a través de la ventosa

En la Figura 4.45 se muestra un ejemplo de la oscilación producida sobre el perfil de la curva de presión máxima. La figura corresponde a un ensayo de la ventosa A con la válvula de mariposa BV1 abierta, con una altura del agua en el interior del depósito D1 de $2,018 \mathrm{~m}$, un nivel de la columna de agua que hace de bloqueo de 2,89 $\mathrm{m}$ y una sobrepresión inicial aplicada de 3,32 m.c.a.

La gráfica de la izquierda de la Figura 4.45 ofrece una visión general de la evolución de la velocidad de la columna de agua, la presión medida en la unión en T de la ventosa con la instalación y la posición del flotador desde el inicio del ensayo. Como principales características de este ensayo cabe remarcar una oscilación del flotador de la ventosa después del cierre, y una serie de oscilaciones en el perfil general de la curva de presión registrada por el transductor de presión K3 producidas al cerrar la ventosa. Dichas oscilaciones se muestran con detalle en la Figura 4.46
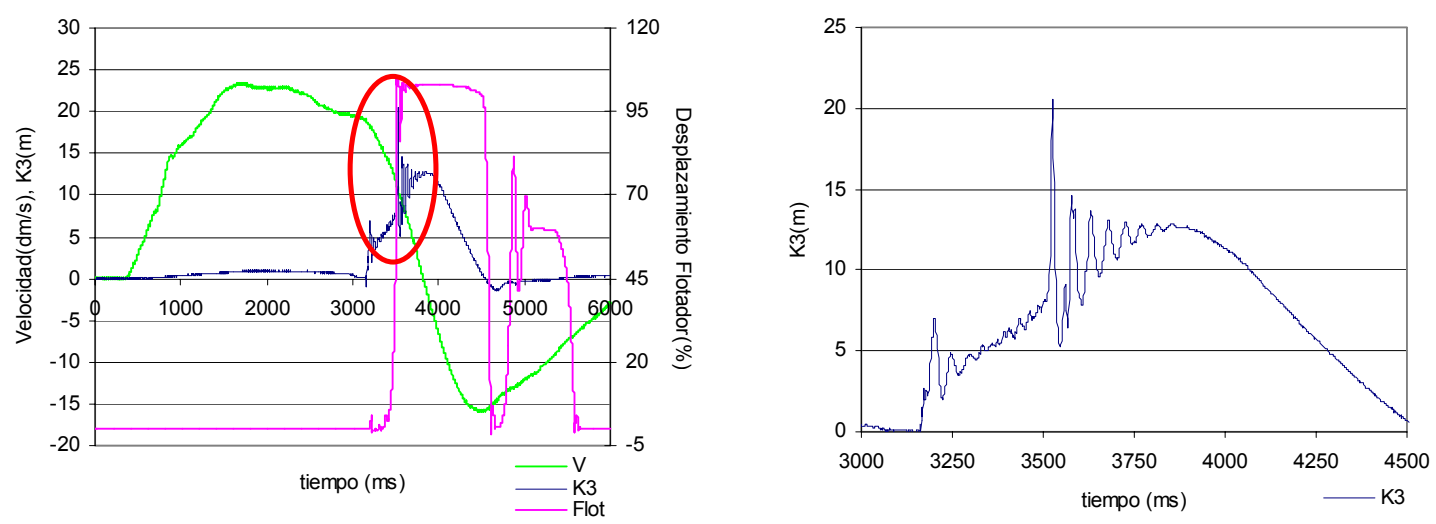

Figura 4.45. Ensayo de la ventosa A. Oscilaciones en el pico de presión. 


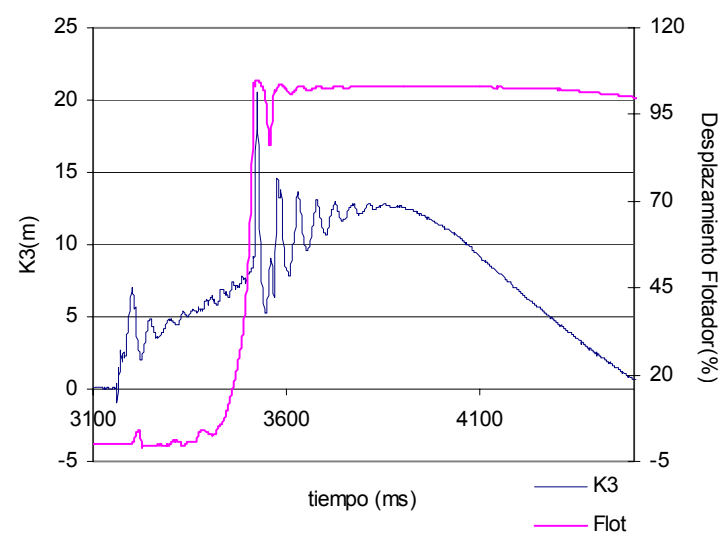

Figura 4.46. Oscilaciones en la curva de presión y desplazamiento del flotador.

No obstante, no todos los ensayos de la ventosa $A$ situada en un punto intermedio de la instalación presentan las características comentadas anteriormente.

En la Figura 4.47 se muestra un ensayo en el cual las longitudes de las columnas de agua fueron las mismas que las del ensayo anterior pero en el que la sobrepresión inicial tomó un valor de 3,86 m (frente a los 3,32 $\mathrm{m}$ del ensayo anterior). Las condiciones iniciales de estos dos ensayos son muy parecidas, sin embargo en este segundo caso la ventosa experimenta cuatro cierres y es en el segundo de estos cierres cuando se produce la presión máxima del ensayo. Se aprecian también en este caso oscilaciones sobre la curva de presión máxima.
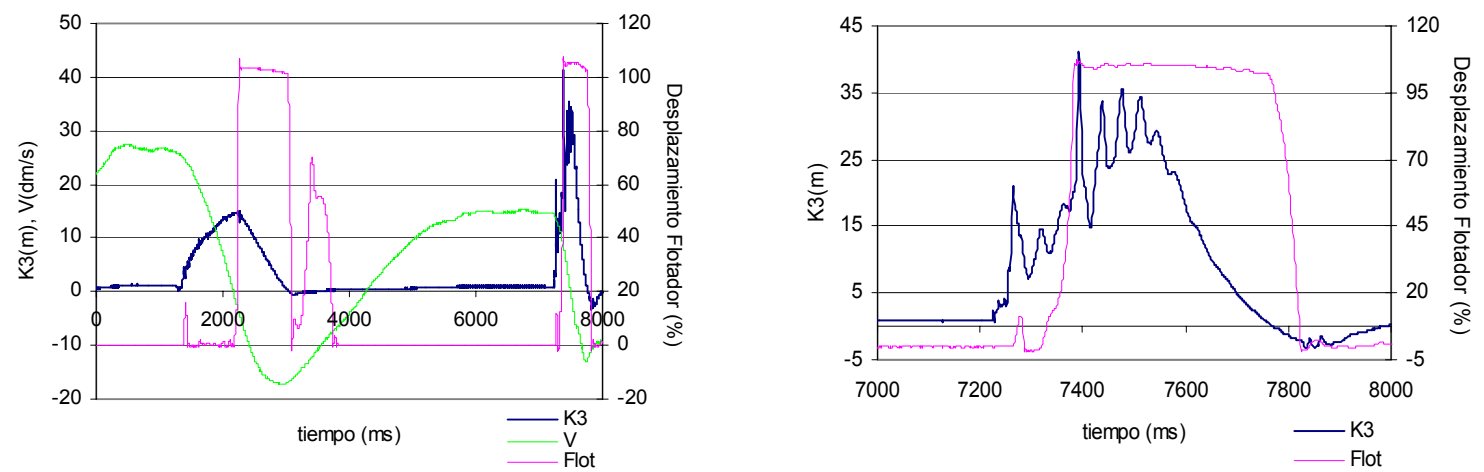

Figura 4.47. Ensayo de la ventosa A. Rebote del flotador y oscilaciones en la presión

\section{Particularidades de los Ensayos con la Ventosa B}

La particularidad esencial de los ensayos de la ventosa B situada en un punto intermedio de la instalación está relacionada con el instante en el cual se produce el pico de presión máximo. En la práctica totalidad de estos ensayos, existe más de un cierre y es en el segundo cierre de la ventosa cuando se produce el pico de presión máxima y no en el primer impacto del flotador. 
En la Figura 4.48 se muestra un ensayo en el que se puede apreciar este fenómeno. En dicho ensayo el nivel inicial de la columna de agua que se mueve, medida sobre el eje longitudinal de la tubería horizontal fue de 2,018 m. Por otra parte, la altura de la columna de agua de bloqueo sobre el eje longitudinal de la tubería horizontal fue de $3,78 \mathrm{~m}$.

Como se puede comprobar en la parte izquierda de la Figura 4.47, aparecen varios cierres consecutivos de la ventosa. En el primer cierre, la presión alcanzada es de unos $22 \mathrm{~m}$ mientras que en el segundo cierre la presión obtenida es de unos $57 \mathrm{~m}$. Si se observa con atención este segundo pico de presión, se advierte tal y como sucedía con la ventosa A, que la curva de presión presenta una serie de oscilaciones sobre su perfil. Es decir, la compresión del aire atrapado no se produce de manera uniforme.

El motivo por el cual el pico de presión no se produce en el primer cierre podría deberse a que tras este primer cierre permanece en el sistema una gran cantidad de aire atrapado que mitiga la magnitud del pico. Después la ventosa abre, se expulsa aire y tras el segundo cierre, el colchón de aire que atenúa el pico de presión es significativamente menor que el anterior. Por ello, aún con una velocidad de llegada de la columna de agua al flotador menor durante el segundo cierre, se genera un pico de presión mayor.
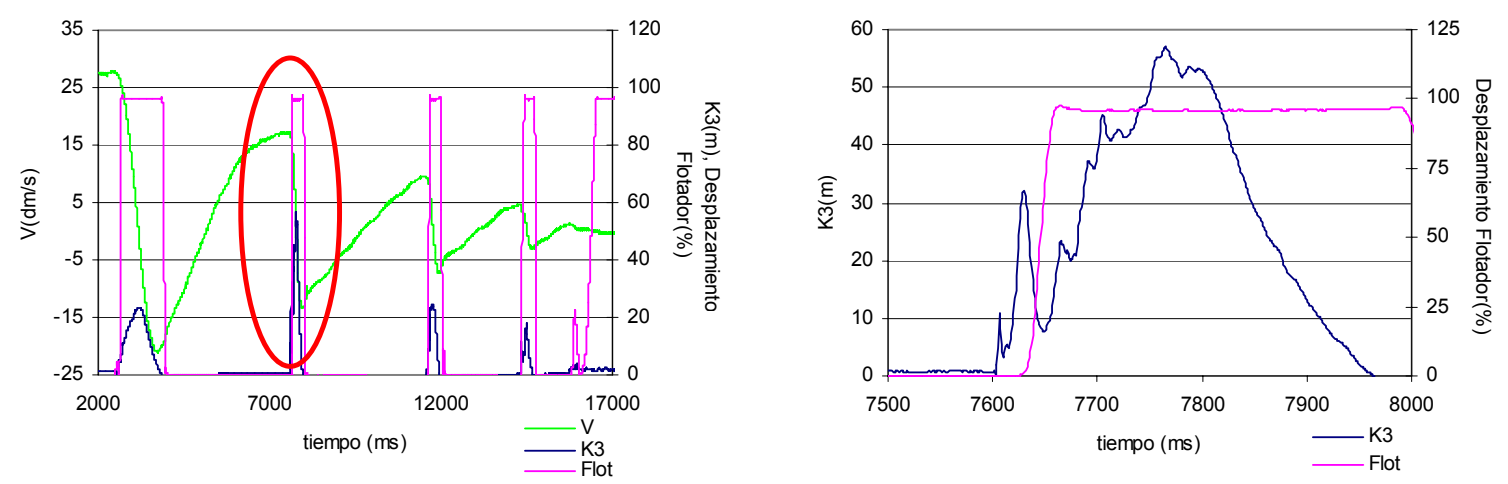

Figura 4.48. Evolución general de un ensayo de la ventosa B. Presión máxima.

En todos estos ensayos, la columna de agua tiene una doble posibilidad de circulación una vez cerrada la ventosa. Es decir, la columna de agua en movimiento puede retornar por la misma conducción por la que llega a la parte superior de la instalación o bien puede seguir hacia el otro lado de la instalación. De este modo, se genera mayor dispersión de las bolsas de aire dentro de la tubería y la turbulencia de los fluidos es mayor. Si en los casos en los cuales se mantenía la válvula de mariposa BV1 cerrada, la posibilidad de simular en un modelo matemático el movimiento de la columna de agua como flujo pistón podría cuestionarse, en esta configuración hay que descartar esta posibilidad por completo. 


\subsubsection{EXPULSIÓN DE AIRE AL FINAL DE UNA CONDUCCIÓN. VENTOSAS DN50}

Con la finalidad de completar el estudio del fenómeno transitorio ocurrido en una instalación que cuenta con la presencia de una ventosa para efectuar la expulsión de aire de una tubería, se estudian dos ventosas de menor diámetro nominal pero de las mismas características internas y de las mismas marcas comerciales que las de $100 \mathrm{~mm}$ de diámetro.

Las ventosas A y B de diámetro nominal $50 \mathrm{~mm}$ se analizan en un sistema de estructura idéntica al de las ventosas de $100 \mathrm{~mm}$ pero de dimensiones menores. El diámetro del tubo en este caso es de $200 \mathrm{~mm}$. Las principales magnitudes medidas siguen siendo las mismas, es decir, presión en el punto más alto de la instalación, posición del flotador de la ventosa y caudal en el tramo horizontal de la instalación a la salida del depósito D1 en cada instante de tiempo del ensayo.

No obstante, la respuesta en frecuencia del caudalímetro de $200 \mathrm{~mm}$ de diámetro instalado en este tipo de ensayos resultó ser demasiado baja y como consecuencia, el caudalímetro no fue capaz de registrar correctamente las variaciones bruscas de caudal por lo que esta magnitud como tal no puede tenerse en cuenta.

A diferencia de las ventosas DN100, en los ensayos de expulsión de aire con ventosas de DN50 se han considerado tres configuraciones diferentes de la instalación Dos de estas configuraciones no se han probado con las ventosas de DN100. La principal diferencia de estas nuevas configuraciones de la instalación reside en la posición de la ventosa. Aunque se modifique la configuración del sistema, la ventosa siempre se sitúa en el punto extremo de la instalación, en el punto más alto. Además de montar la ventosa directamente sobre la T de la conducción, la ventosa se colocó en lo alto de un carrete vertical. Los carretes verticales utilizados tenían una longitud de $1.185 \mathrm{~mm}$ en un caso, y de $2.185 \mathrm{~mm}$ de longitud en el otro caso, tal y como muestra el esquema de la Figura 4.49. Este carrete vertical se sitúa en el punto más alto de la instalación de manera que la columna de agua debe recorrer un tramo mayor hasta llegar a la ventosa. La probabilidad de que quede aire atrapado en zonas intermedias con estas configuraciones se reduce significativamente. 


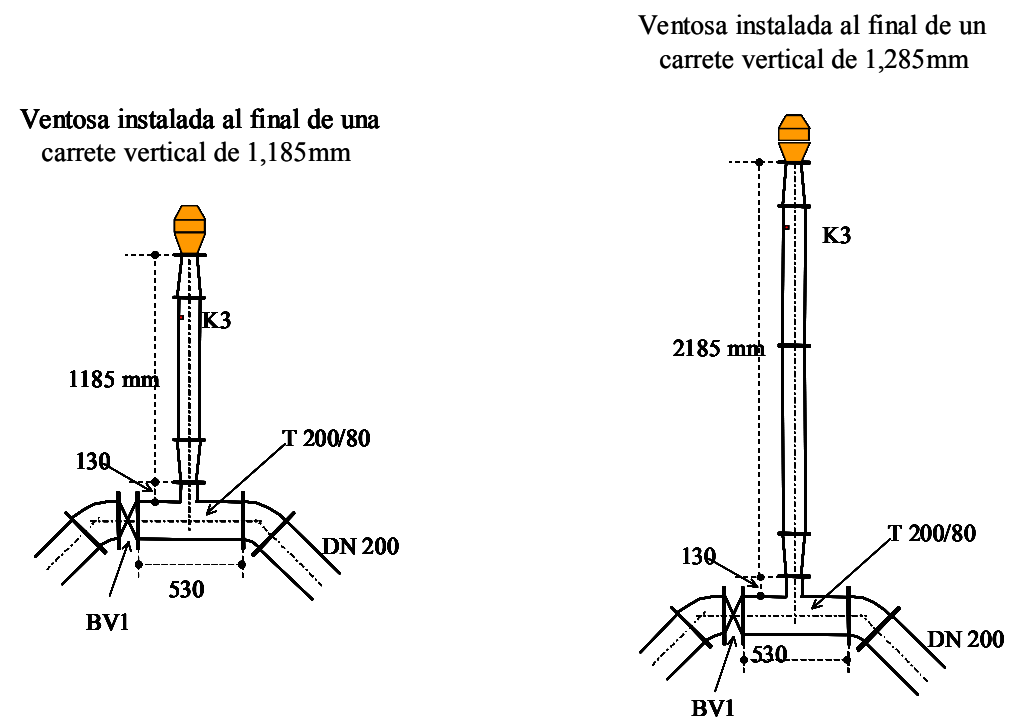

Figura 4.49. Detalle de la ventosa sobre carrete vertical.

\subsubsection{VENTOSA SOBRE LA CONDUCCIÓN}

Este tipo de ensayo es análogo al efectuado con las ventosas de DN100 con la válvula de mariposa BV1 cerrada. Inicialmente la ventosa se encuentra abierta así como también se encuentra abierta la válvula de bola que comunica el depósito D1 con el exterior. Así pues, en el instante inicial la presión en el interior del sistema es igual a la atmosférica. La columna de agua se impulsa mediante una sobrepresión controlada desde el tanque de agua hacia la ventosa. Cuando la columna de agua alcanza el flotador de la ventosa, ésta empieza a cerrar.

Estos ensayos se clasifican en dos grupos según la longitud inicial de la columna de agua utilizada en cada caso. Existen ensayos realizados con una altura de agua sobre el eje longitudinal de la tubería horizontal de $0,805 \mathrm{~m}$ y ensayos cuya altura inicial de agua sobre el eje longitudinal de la tubería horizontal es de 1,38 m, de modo análogo al representado en la Figura 4.18.

\section{Presión máxima de los ensayos con ventosa sobre la conducción}

Los resultados de las mediciones de la presión en los ensayos realizados utilizando la ventosa A o la ventosa B de $50 \mathrm{~mm}$ de diámetro, con cualquiera de las dos longitudes iniciales de columna de agua, se reflejan en la Figura 4.50. En esta figura se aprecia un claro aumento de la presión máxima registrada por el transductor de presión situado en el cuello de la ventosa cuando se incrementa la presión aplicada en el instante inicial tal y como sucedía con las ventosas de mayor calibre, DN100. En cualquier caso, la dispersión de resultados es mucho mayor que la obtenida en el caso de las ventosas DN100. En numerosas ocasiones, en los ensayos de la ventosa A DN50, el flotador de la ventosa no 
recorre el total de la carrera, si no que recorre simplemente $40 \%$. En el caso de la ventosa B DN50, en muchos ensayos el pico de presión máxima se produce en el segundo cierre de la ventosa. No todos los ensayos presentan una misma evolución, y por ello, aparece una elevada distorsión en los resultados finales.
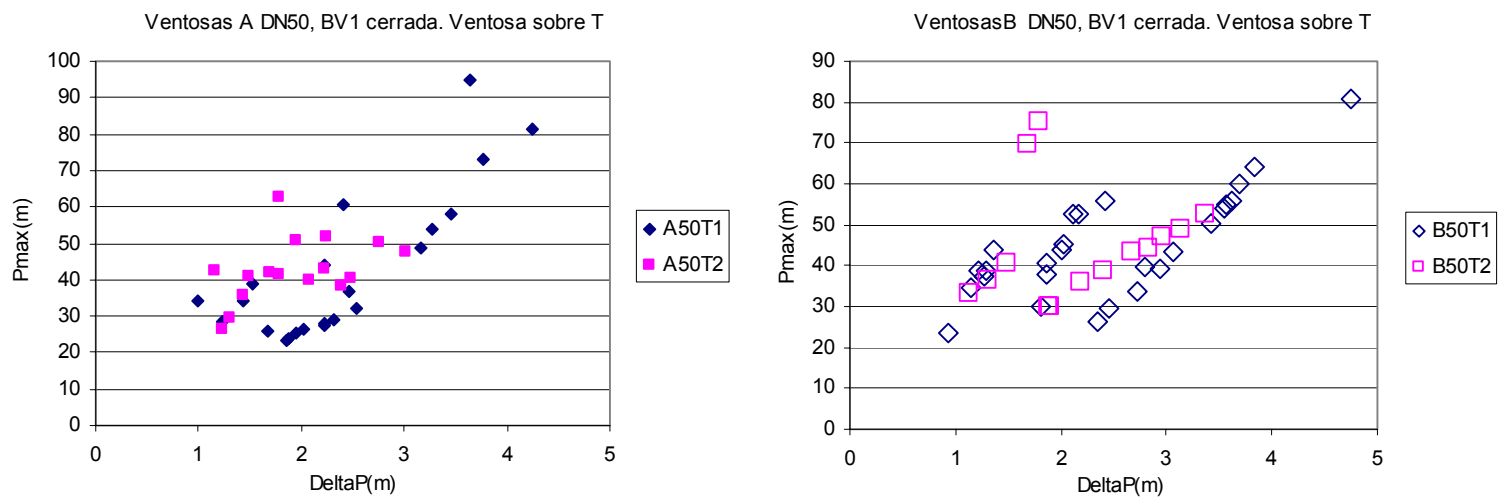

Figura 4.50. Presiones máximas según la sobrepresión inicial.

En estas gráficas:

A50T1: Corresponde a los ensayos realizados con la ventosa A de DN50, situada directamente sobre la T de la instalación. La altura inicial de columna de agua es de $0,805 \mathrm{~m}$.

A50T2: Corresponde a los ensayos realizados con la ventosa A de DN50, situada directamente sobre la $\mathrm{T}$ de la instalación. La altura inicial de columna de agua es de $1,38 \mathrm{~m}$.

B50T1: Corresponde a los ensayos realizados con la ventosa B de DN50, situada directamente sobre la $\mathrm{T}$ de la instalación. La altura inicial de columna es e agua de $0,805 \mathrm{~m}$.

B50T2: Corresponde a los ensayos realizados con la ventosa B de DN50, situada directamente sobre la $\mathrm{T}$ de la instalación. La altura inicial de columna de agua es de $1,38 \mathrm{~m}$.

Con esta nomenclatura, se presenta la gráfica que muestra los resultados de la anchura del pico de presión máxima obtenida en los ensayos de expulsión de aire de las ventosas de DN50 con la válvula de mariposa BV1 cerrada, frente a la presión máxima alcanzada en cada ensayo.

En este caso, también se sigue una misma tendencia de decrecimiento de la presión máxima detectada en el sistema a medida que el ancho de este pico de presión es mayor tal y como sucedía con las ventosas DN100. 
BV1 cerrada. Ventosa A sobre T

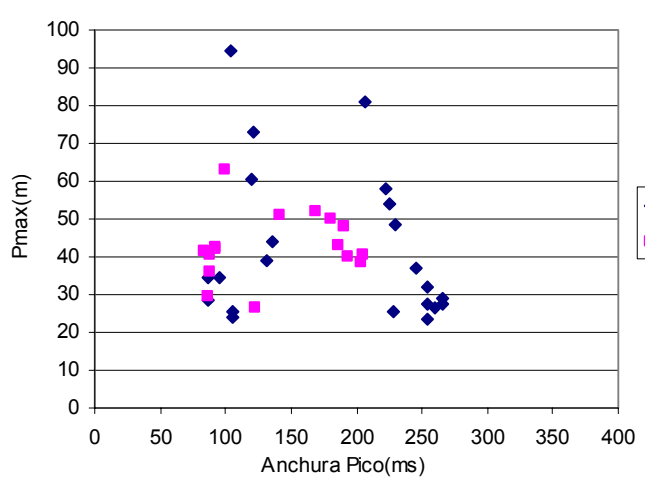

BV1 cerrada. Ventosa B sobre T

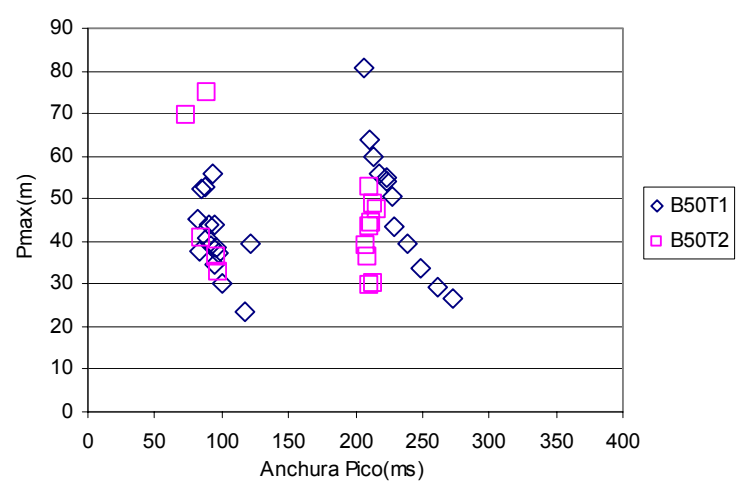

Figura 4.51. Relación entre la presión máxima y la anchura del pico de presión máxima.

En ambas gráficas, dentro de un mismo tipo de ensayos se aprecia cierta dispersión de los resultados. Por esta razón se presenta a continuación un análisis exhaustivo de las particularidades del fenómeno ocurrido en la instalación.

\section{Particularidades de los ensayos con ventosa sobre la conducción}

No todos los ensayos incluidos dentro de un mismo grupo, es decir ensayos realizados con una misma ventosa y con las mismas condiciones iniciales exceptuando la sobrepresión inicial, presentan resultados semejantes.

En este apartado se intenta analizar paso a paso cada una de los comportamientos detectados, estableciendo clasificaciones incluso dentro de un mismo tipo de ensayo, es decir, entre ensayos con una misma ventosa y misma altura inicial de columna de agua.

Si se atiende a los resultados obtenidos al ensayar la ventosa A situada en el punto más alto de la conducción, se observa una evolución de la presión máxima creciente cuanto mayor es la sobrepresión inicial que se aplica y ligeramente decreciente cuando aumenta el ancho de este pico de presión máxima.
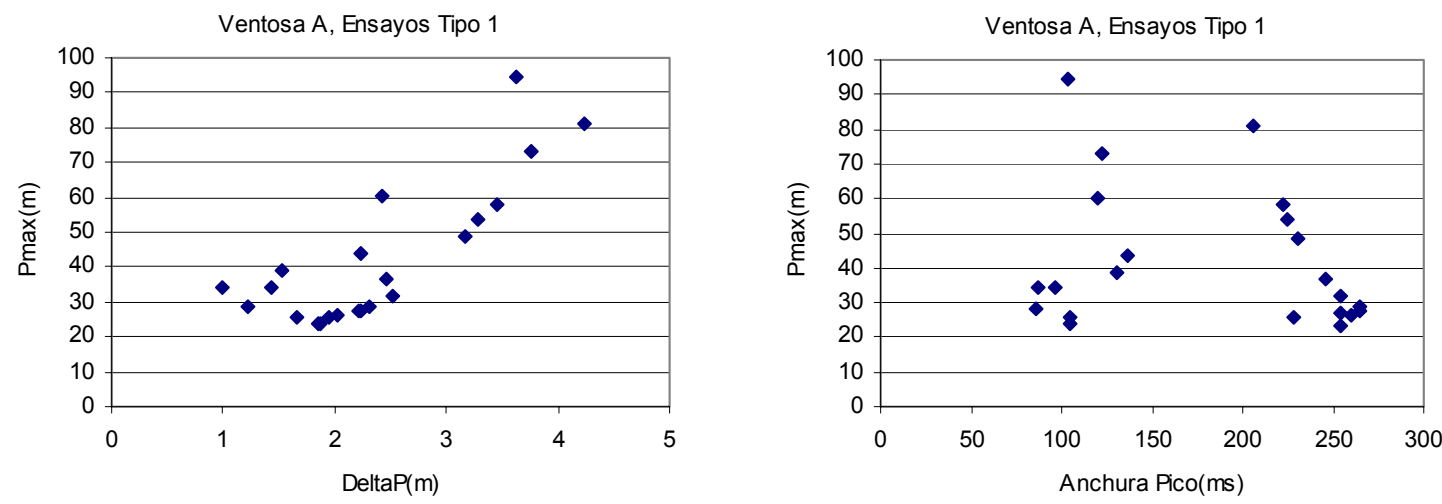

Figura 4.52. Presión máxima cuando la ventosa está sobre la conducción. 
En los ensayos de la Figura 4.52, aunque se detectan comportamientos diferentes se observa que la tendencia de crecimiento o de decrecimiento de una serie de puntos es la misma.

En las figuras que siguen a continuación, se detalla la evolución de la presión máxima a lo largo del ensayo y además se representa el caudal ya que en algunos casos ayuda a entender mejor el evento, no obstante hay que tener en cuenta que no se puede considerar una medida correcta en cuanto a magnitud porque como se ha mencionado anteriormente la respuesta en frecuencia del caudalímetro de diámetro $200 \mathrm{~mm}$ no era la adecuada.

Los ensayos en los cuales la sobrepresión inicial aplicada es pequeña, menor de 1,6 mca experimentan inicialmente un cierre parcial de la ventosa debido a que dicha sobrepresión está por debajo del umbral de presión necesaria para que la columna de agua alcance el flotador y sea capaz de cerrar la ventosa. En cambio, posteriormente, en una segunda oscilación, el agua llega a la ventosa con suficiente fuerza como para cerrarla tal y como se observa en la Figura 4.53.
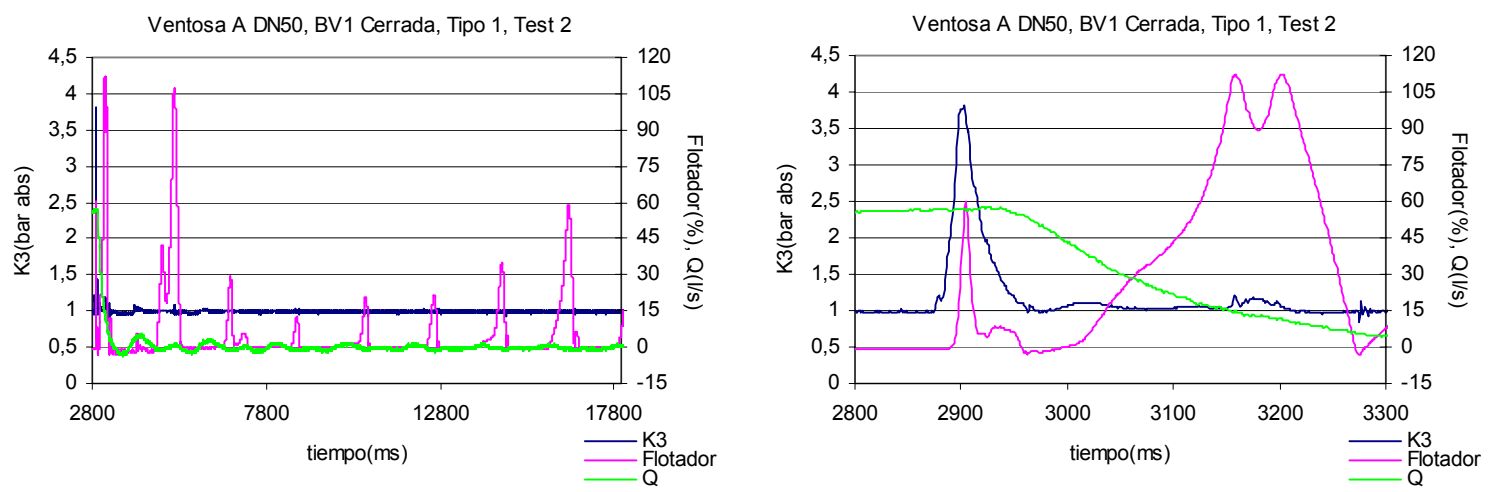

Figura 4.53. Secuencia de cierres de la ventosa.

Por otro lado, en la Figura 4.54 se muestra un ensayo en el que también se observan varios cierres de la ventosa. En dicho ensayo se produce una perturbación de la presión de mayor magnitud que en el caso anterior. De este modo, la secuencia de cierres de la ventosa se debe tanto a la presencia de bolsas de aire atrapado en el interior de la tubería, las cuales se expanden y contraen, como a la oscilación en masa que experimenta el agua dentro de la conducción debida a la sobrepresión generada desde el depósito. El tiempo transcurrido entre dos cierres consecutivos disminuye progresivamente a lo largo del ensayo porque cada vez existe menos cantidad de aire atrapado en el sistema.

El pico de presión máxima aparece habitualmente en el segundo cierre de la ventosa. Esto puede deberse, en parte, a que la velocidad de llegada de la columna de agua al flotador de la ventosa es considerable y a que tras el primer cierre queda menos cantidad de aire en el interior del sistema que durante el primer cierre. 

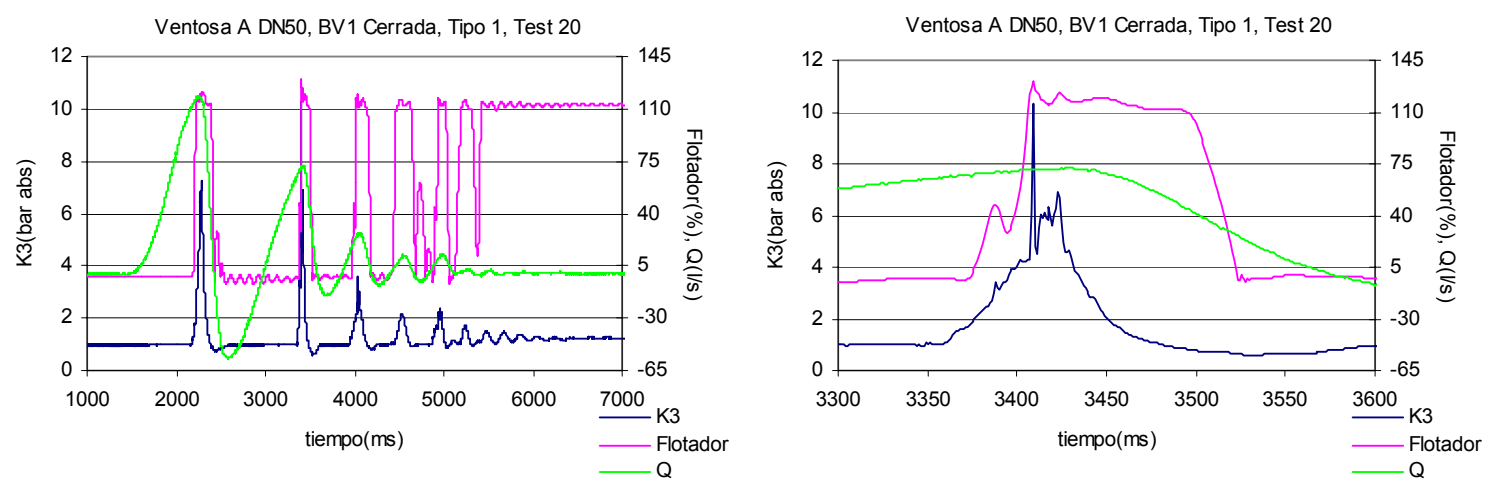

Figura 4.54. Presión máxima en segundo cierre.

Por último, aparece un tercer grupo de ensayos similar al anterior en los cuales tras aplicar una sobrepresión inicial, el pico de presión máxima del evento se produce siempre en el primer cierre de la ventosa. Al igual que en la figura anterior, la presencia de aire atrapado a lo largo del ensayo se pone de manifiesto en las sucesivas oscilaciones que presenta la onda de presión cada vez que se produce un cierre de la ventosa. La frecuencia de cierres de la ventosa disminuye en cada oscilación, ya que la cantidad de aire atrapado en el sistema es cada vez menor.
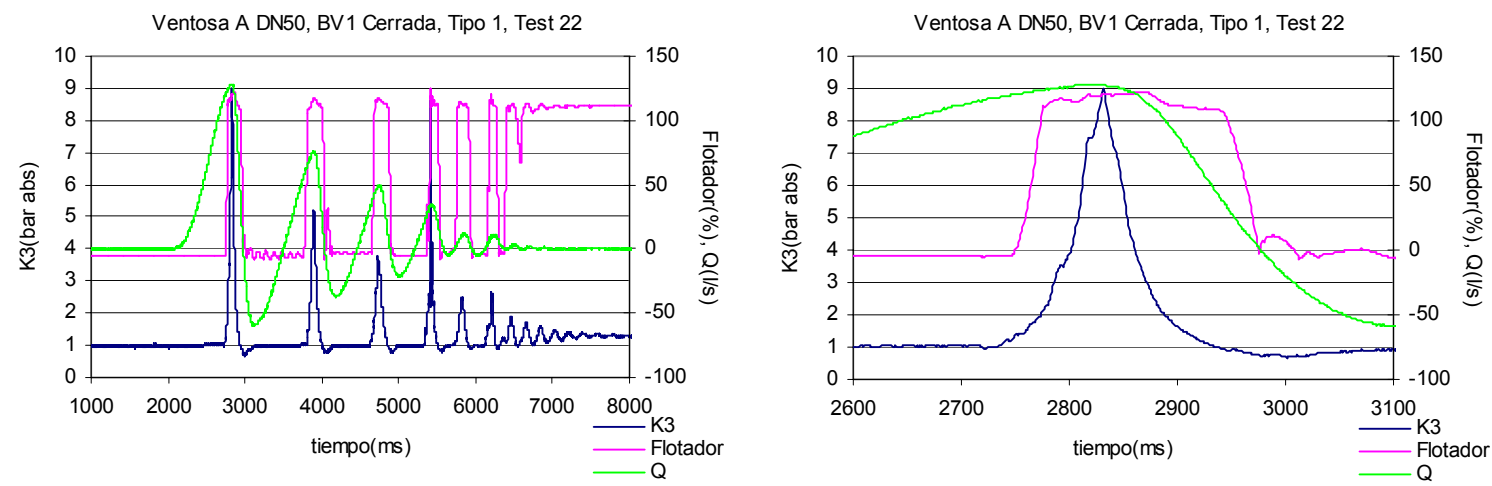

Figura 4.55. Oscilaciones de la presión en múltiples cierres.

En los ensayos de la ventosa A de DN50, situada directamente sobre la T de la instalación y con una altura inicial de columna de agua de $1,38 \mathrm{~m}$, aparecen dos tipos de comportamiento lo cual se detecta en la representación general de la presión máxima medida frente a la anchura de este pico de presión máxima: 

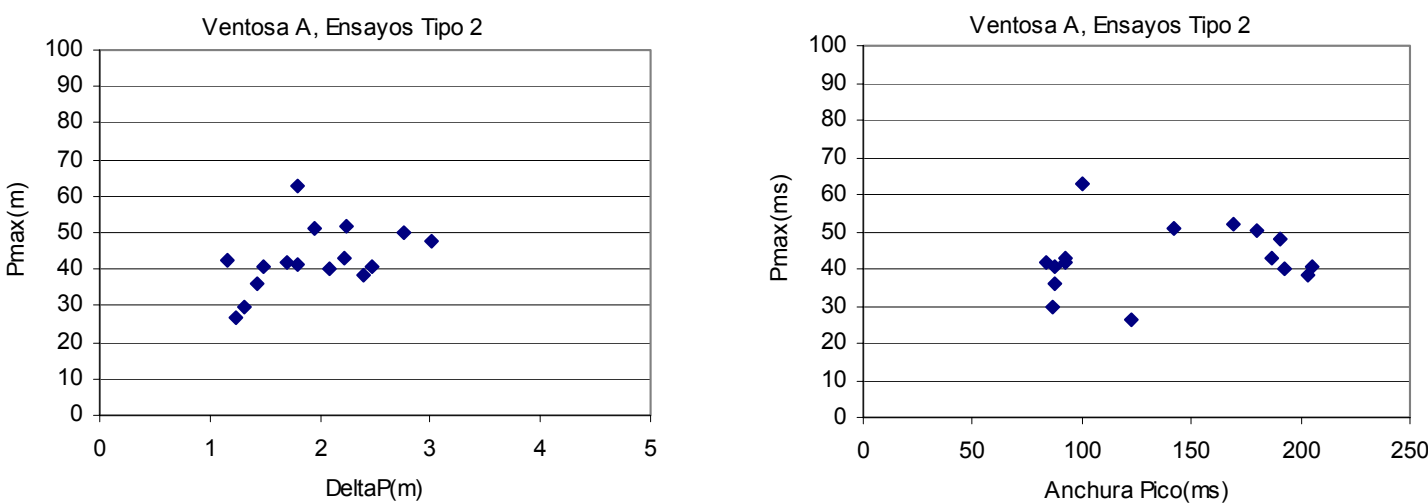

Figura 4.56. Presión máxima en ventosa A, DN50.

En este caso se han detectado una serie de ensayos en los cuales la ventosa experimenta inicialmente un cierre parcial, es decir, el flotador únicamente recorre, aproximadamente, el $40 \%$ del total de la carrera y vuelve a la posición inicial.

Después de este movimiento del flotador se produce el pico de presión que resulta ser el máximo, similar al que se produce en el resto de ensayos que experimentan un cierre total. Posteriormente al cierre parcial, la ventosa cierra por completo aunque con oscilaciones en la posición del flotador. En todos los ensayos que se comportan de este modo, la sobrepresión inicial aplicada desde el depósito D1 es inferior a 1,8 mca, sobrepresiones que se consideran pequeñas si se comparan con las del resto de ensayos que oscilan entre los 2 m.c.a y los 3 m.c.a. Este es un comportamiento similar al ya visto con los ensayos de esta misma ventosa mostrados en la Figura 4.53.
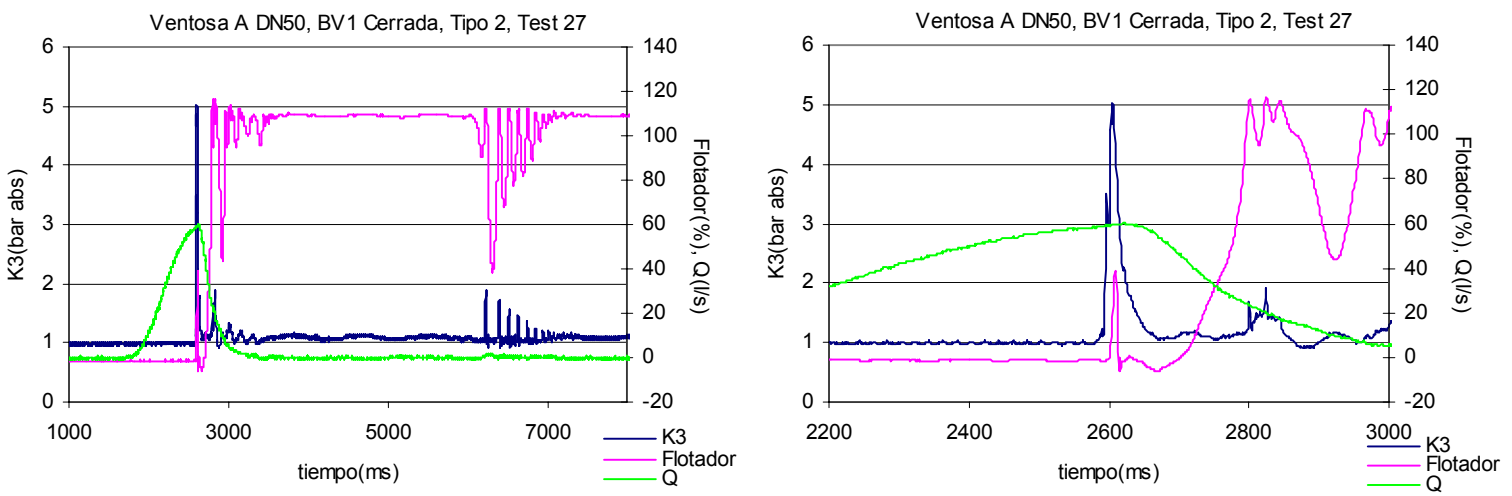

Figura 4.57. Evolución del ensayo

El resto de los ensayos no presenta aparentemente ninguna alteración. Se aprecia que queda aire atrapado en el sistema tras el primer cierre debido a las oscilaciones de la onda de presión asociadas a cada uno de los cierres posteriores de la ventosa. El pico máximo se produce cuando la ventosa cierra por primera vez tal y como se muestra en la Figura 4.58 . 

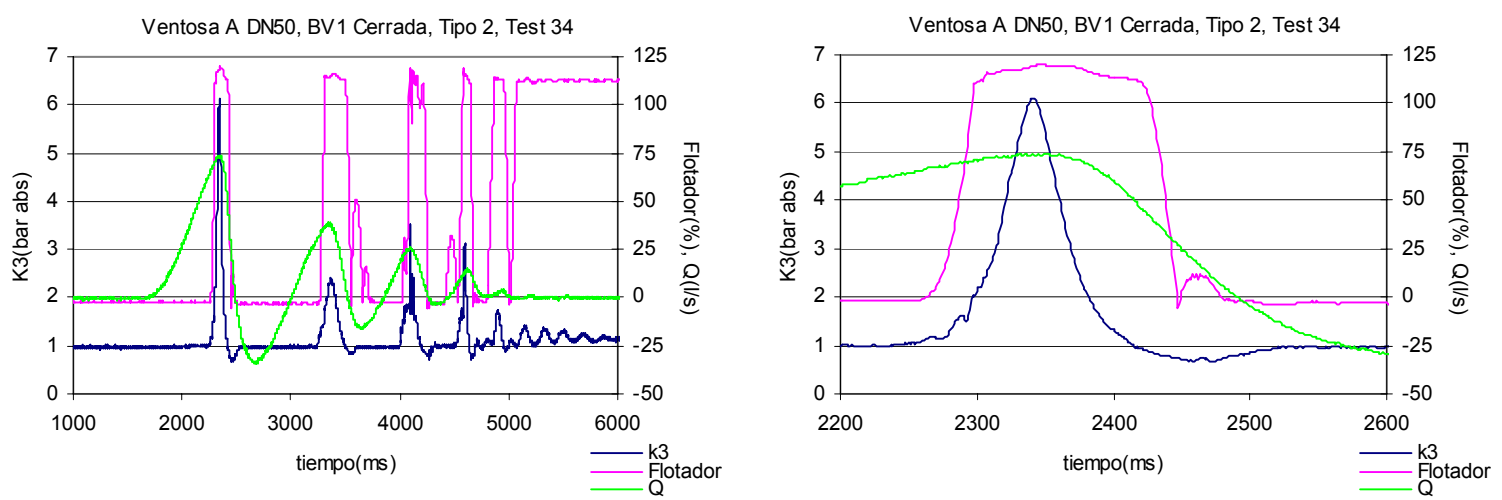

Figura 4.58. Evolución general del ensayo

Los ensayos realizados con la ventosa B de DN50 bajo condiciones de contorno similares a los efectuados con la ventosa A y con la misma configuración de la instalación, también muestran diferentes tendencias en el comportamiento como se presenta en la Figura 4.59. En dicha figura aparecen tres series de puntos de la presión máxima medida frente a la sobrepresión inicial aplicada para un mismo tipo de ensayos.
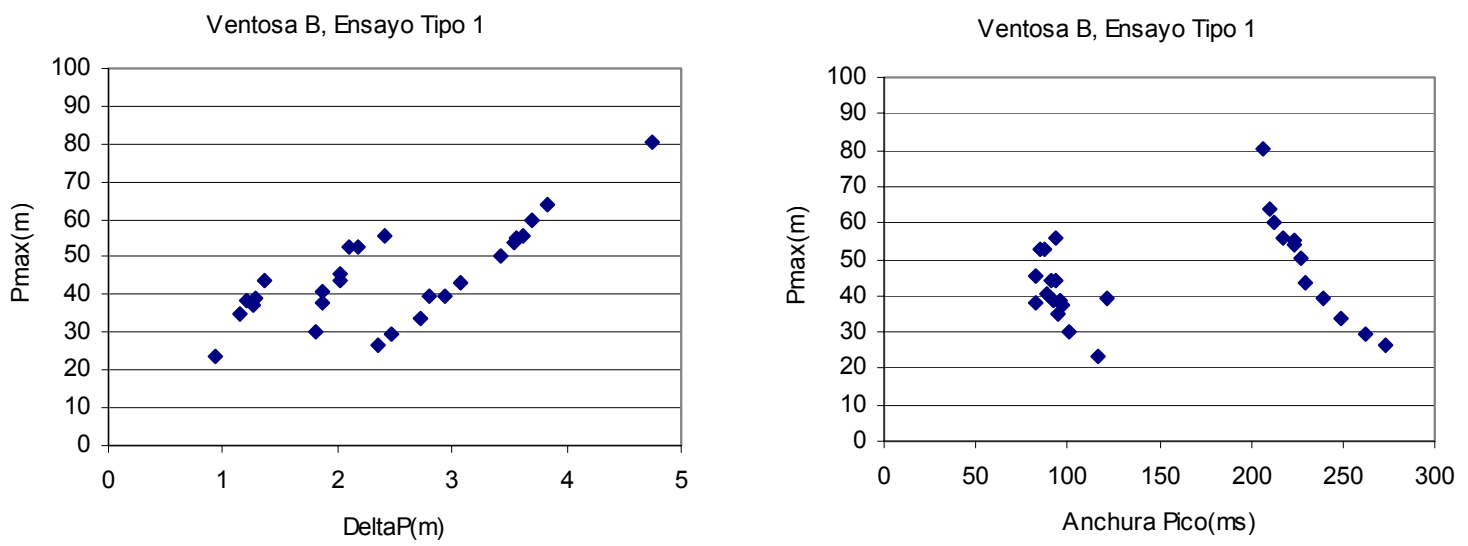

Figura 4.59. Presión máxima en ensayos de la ventosa B en el punto más elevado de la conducción.

Los ensayos realizados con la ventosa B DN50, situada directamente sobre la T de la instalación y con una altura inicial de columna de agua de 0,805 m presentan, al igual que los ensayos con la ventosa $\mathrm{A}$ de las mismas características, diferentes comportamientos.

En primer lugar, se encuentran los ensayos en los cuales la ventosa experimenta una sucesión de cierres y aperturas, produciéndose el mayor pico de presión en el primer cierre de la misma. La mayor parte del aire en estos ensayos es expulsado antes de este primer cierre de la ventosa. Por este motivo en los sucesivos cierres detectados, debidos a la reducida oscilación en masa de la columna de agua, la onda de presión medida por el transductor de presión K3 no muestra variaciones apreciables. En estos casos la ventosa queda abierta al finalizar el ensayo. 

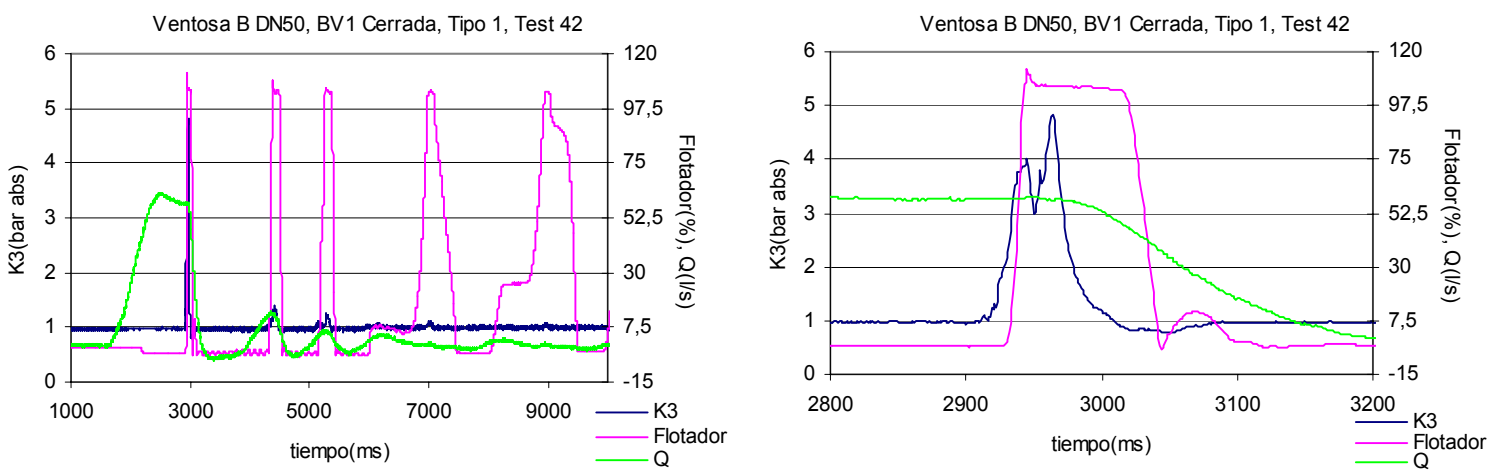

Figura 4.60. Sucesión de cierres de la ventosa y presión máxima.

En los ensayos que aparecen en la Figura 4.59 con un valor de $\Delta \mathrm{P}$ intermedio, se registran diversos cierres de la ventosa a lo largo del evento. Sin embargo, en contrapartida a lo visto en el caso anterior, en cada cierre de la ventosa se detecta un cambio considerable en la onda de presión. Esto indica que tras el primer cierre de la ventosa queda mayor cantidad de aire atrapado en la instalación que en el caso expuesto anteriormente. Como se puede ver en la Figura 4.61 el tiempo transcurrido entre dos cierres consecutivos disminuye a lo largo del ensayo debido a que se expulsa el aire progresivamente. Se aprecia además un aumento de la frecuencia de la oscilación. Un indicio más de que en este grupo de ensayos queda gran cantidad de aire atrapado en la instalación se deduce de la Figura 4.59, en la cual se aprecia como estos ensayos muestran una anchura del pico de presión máxima mucho mayor que los otros.
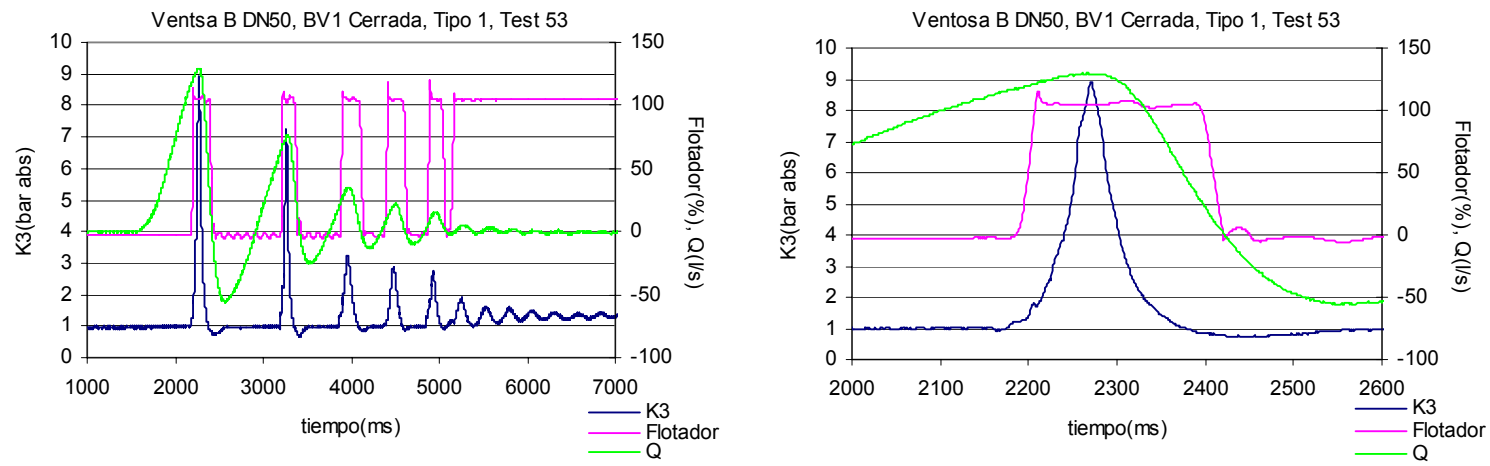

Figura 4.61. Oscilaciones de presión y cierres de la ventosa DN50 con valores de sobrepresión intermedios

Finalmente, es interesante hacer referencia a un conjunto de ensayos en los cuales el pico de presión máxima se produce siempre en el segundo cierre de la ventosa. Se trata de los ensayos a los que se le aplicó una sobrepresión mayor, tal y como muestra la Figura 4.59.

El denominador común encontrado en estos casos es que cuando se produce el segundo cierre de la ventosa, existe menos aire atrapado en el interior de la instalación y la velocidad de la columna de agua que Ilega al flotador de la ventosa es elevada. La unión 
de estos dos factores hace que se den ciertas condiciones que hacen que el pico de presión máximo se produzca en este segundo cierre
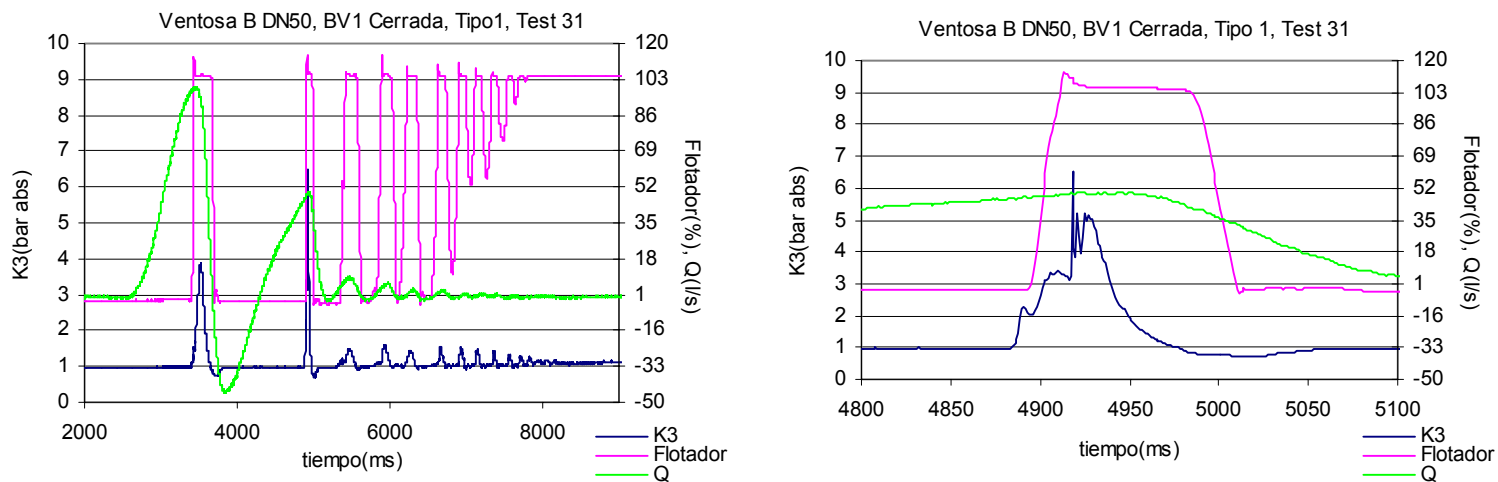

Figura 4.62. Presión máxima en el segundo cierre de la ventosa

En cuanto a los ensayos de la ventosa B de diámetro $50 \mathrm{~mm}$, situada directamente sobre la T de la instalación y con una altura inicial de columna de agua de 1,38 m, se detectan según muestra la Figura 4.63 dos tipos de comportamiento. Por un lado aparecen ensayos que presentan anchos de pico menor (entre $70 \mathrm{~ms}$ y $100 \mathrm{~ms}$ ). En dichos ensayos se produce una irregularidad en el pico de presión máxima aunque el cierre de la ventosa no presenta ningún efecto extraño tal y como se observa en la Figura 4.64.

Por otro lado se encuentran los ensayos con anchos de pico mayor (entre $200 \mathrm{~ms}$ y $220 \mathrm{~ms}$ ) cuya curva de presión dada por el transductor de presión K3, no presenta ninguna irregularidad, es decir, que mantiene perfectamente su perfil en forma de campana como se demuestra en la Figura 4.65.
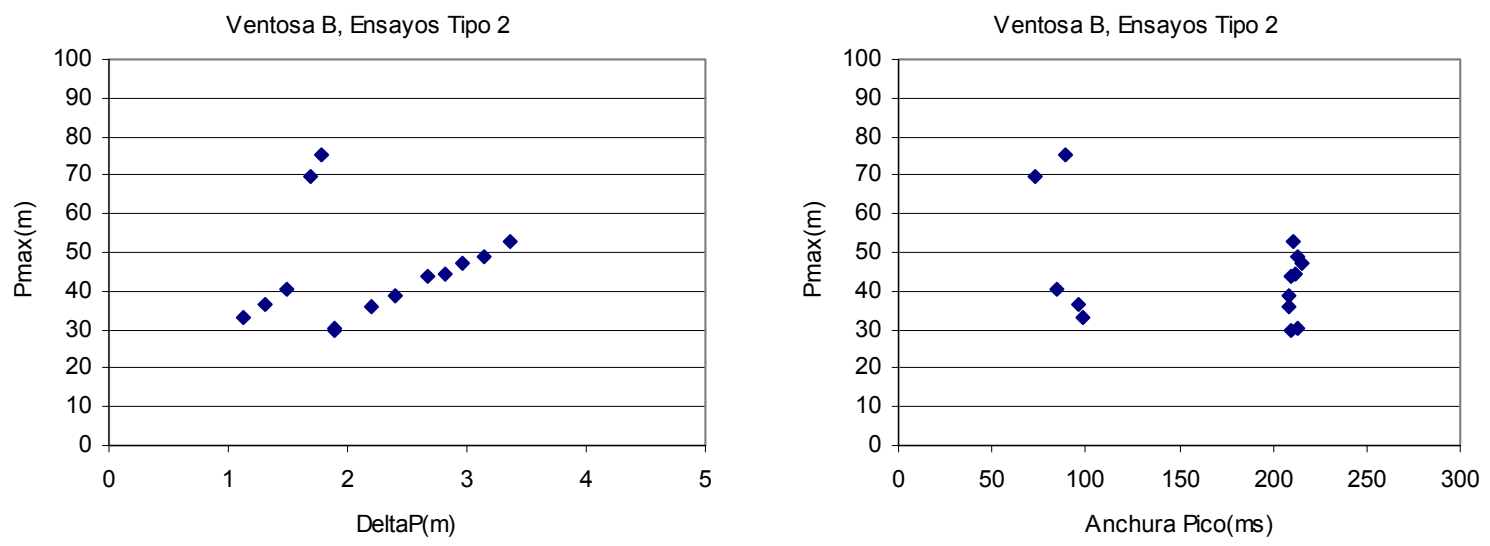

Figura 4.63. Presión máxima. Ventosa B

Los ensayos en los cuales tras el primer cierre de la ventosa no queda prácticamente aire atrapado se distinguen ya que el pico de presión máxima es más estrecho, con lo cual, en los cierres posteriores no se aprecia una variación en el perfil de la presión medida con el transductor de presión K3. En la Figura 4.64 se puede observar que después del primer 
cierre queda una cantidad de aire atrapado mínima porque la curva de presión apenas muestra oscilaciones significativas.
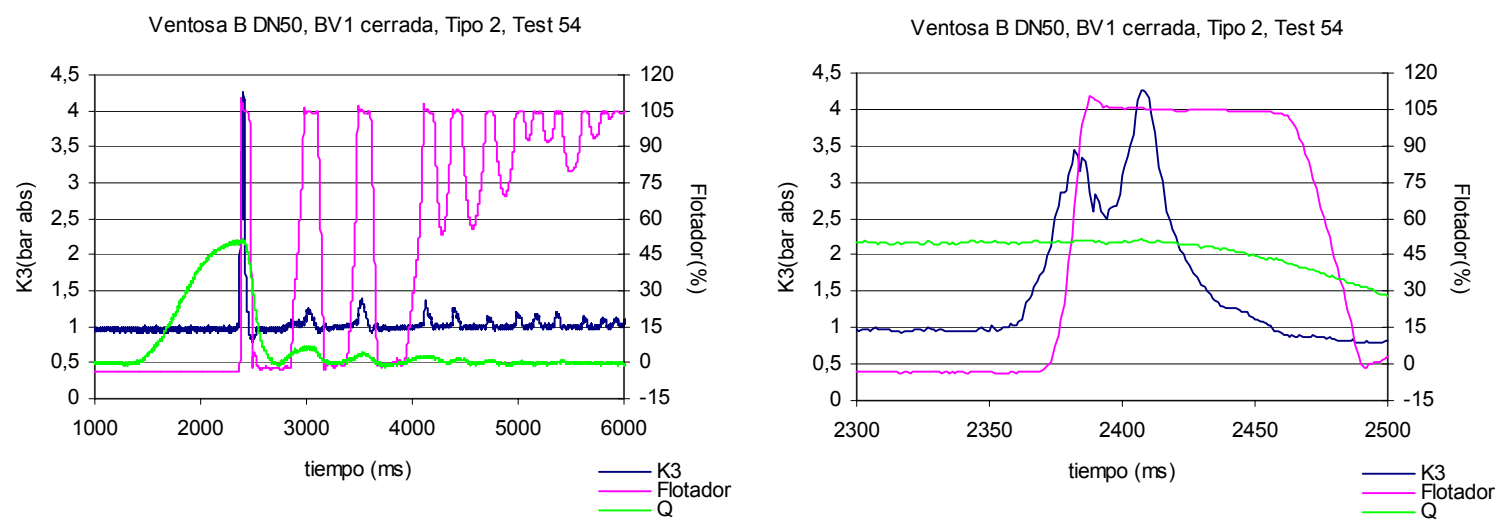

Figura 4.64. Relación entre la frecuencia de cierres y la oscilación de la presión en ensayos con ventosa DN50

En cambio, los ensayos que reflejan una mayor anchura del pico de presión máxima, se comportan tal y como se observa en la Figura 4.65. Después del primer cierre de la ventosa, queda gran cantidad de aire atrapado en el sistema, lo cual se demuestra en la oscilación de la onda de presión máxima en los diversos cierres y aperturas del flotador. Cada vez el tiempo transcurrido entre dos cierres consecutivos es menor debido a que en cada oscilación se reduce el volumen de aire atrapado en la instalación.
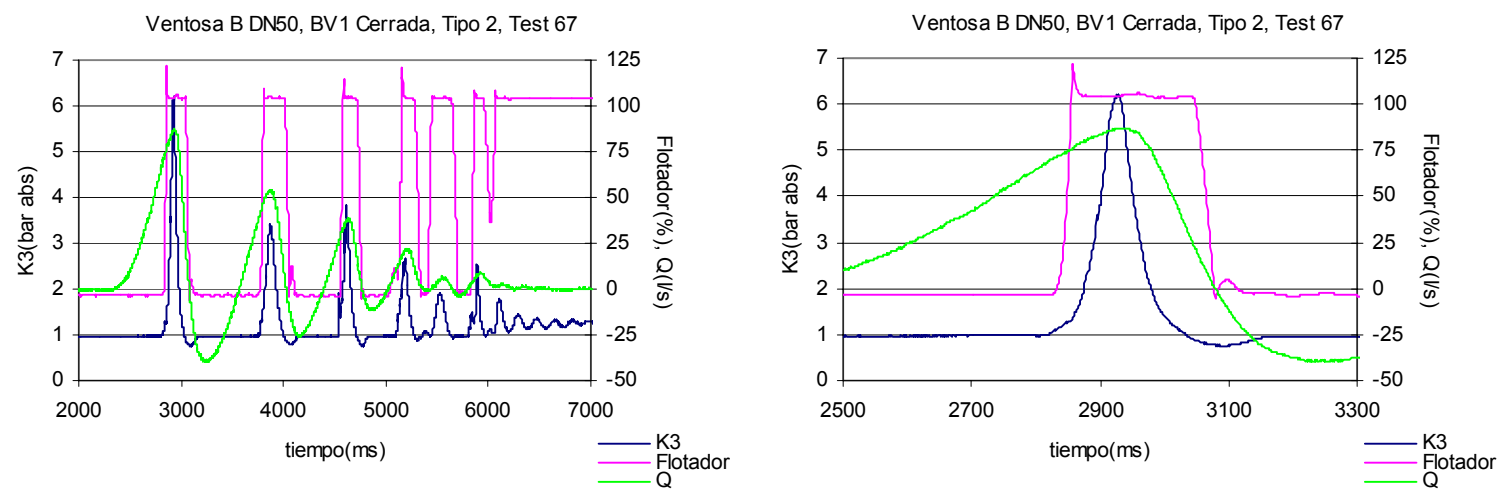

Figura 4.65. Relación entre la frecuencia de cierres y la oscilación de la presión

\subsubsection{VENTOSA SOBRE CARRETE VERTICAL DE LONGITUD 1,185 m}

Con las ventosas de DN50 se realizaron ensayos de expulsión de aire al final de una conducción pero con una configuración de la instalación especial. Dicha configuración consiste en colocar una tubería vertical de diámetro DN80 y longitud 1,185 m en el punto más alto de la instalación. Al final de dicha conducción se sitúa la ventosa DN50. El procedimiento del ensayo de expulsión de aire es exactamente igual que en el caso anterior. 
Cada ventosa se ensayó con dos longitudes iniciales de columna de agua diferentes. Se realizaron ensayos con una altura inicial de la columna de agua medida sobre el eje longitudinal de la tubería horizontal de la instalación de 1,38 m y ensayos con una altura inicial de la columna de agua sobre el eje de la tubería horizontal de 0,81 m.

\section{Presión máxima en los ensayos con ventosa sobre un carrete vertical de 1,185 m de longitud}

En la Figura 4.66 se muestran los resultados en cuanto a la presión máxima registrada dada una sobrepresión inicial a la columna de agua de los ensayos efectuados situando la ventosa sobre un carrete vertical de 1,185 m de longitud.
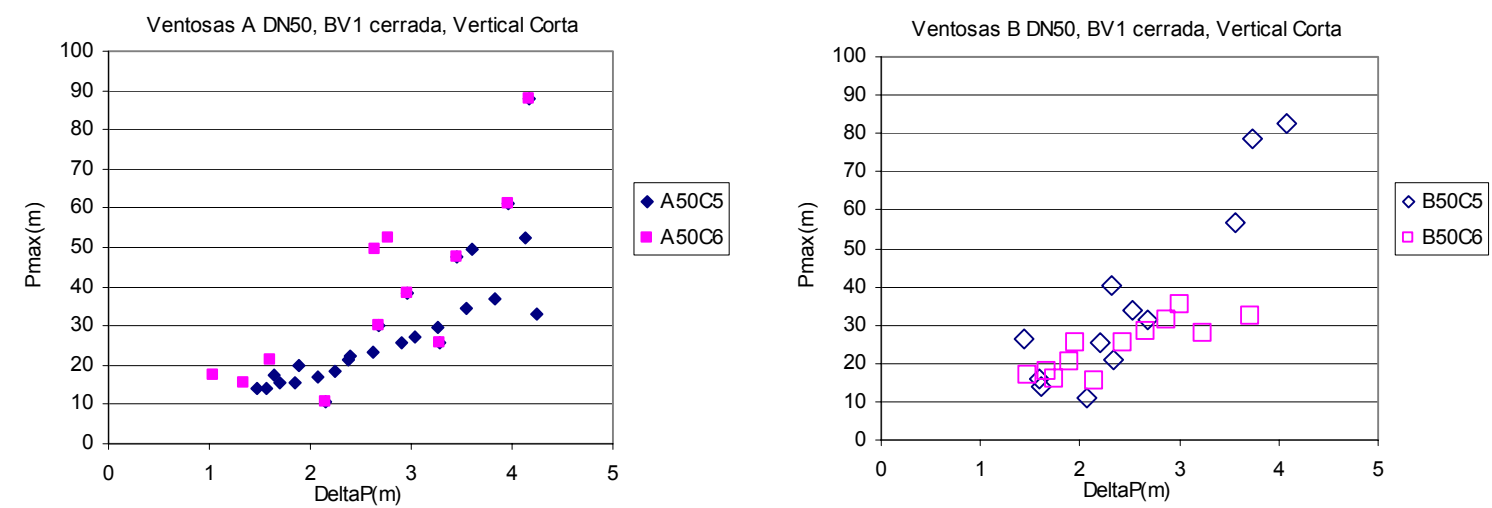

Figura 4.66. Presión máxima en ensayos con ventosa sobre carrete vertical corto.

En esta figura:

A50C5: Corresponde a los ensayos realizados con la ventosa A de DN50, situada sobre una tubería vertical corta. Altura inicial de columna de agua de 1,38 m.

A50C6: Corresponde a los ensayos realizados con la ventosa A de DN50, situada sobre una tubería vertical corta. Altura inicial de columna de agua de 0,81 m.

B50C5: Corresponde a los ensayos longitud realizados con la ventosa B de DN50, situada sobre una tubería vertical corta. Altura inicial de columna de agua de 1,38 m.

B50C6: Corresponde a los ensayos realizados con la ventosa B de DN50, situada sobre una tubería vertical corta. Altura inicial de columna de agua de 0,81 m.

Cabe remarcar, que en esta configuración, bajo condiciones iniciales similares, con una misma sobrepresión inicial, se debe elevar la columna de agua a una cota mayor que en el caso de situar la ventosa directamente sobre la T de la instalación. Por ello, para una misma sobrepresión inicial aplicada, la magnitud del transitorio esperado es menor. 
En general, todas las series mostradas en la Figura 4.66 siguen una misma tendencia. Además, no existe tanta dispersión de resultados como en el caso de los ensayos de la ventosa situada directamente sobre la $\mathrm{T}$.

En cuanto a la anchura del pico de presión máxima obtenida en este caso, los resultados obtenidos se sitúan dentro de una franja estrecha de valores según muestra la Figura 4.67.
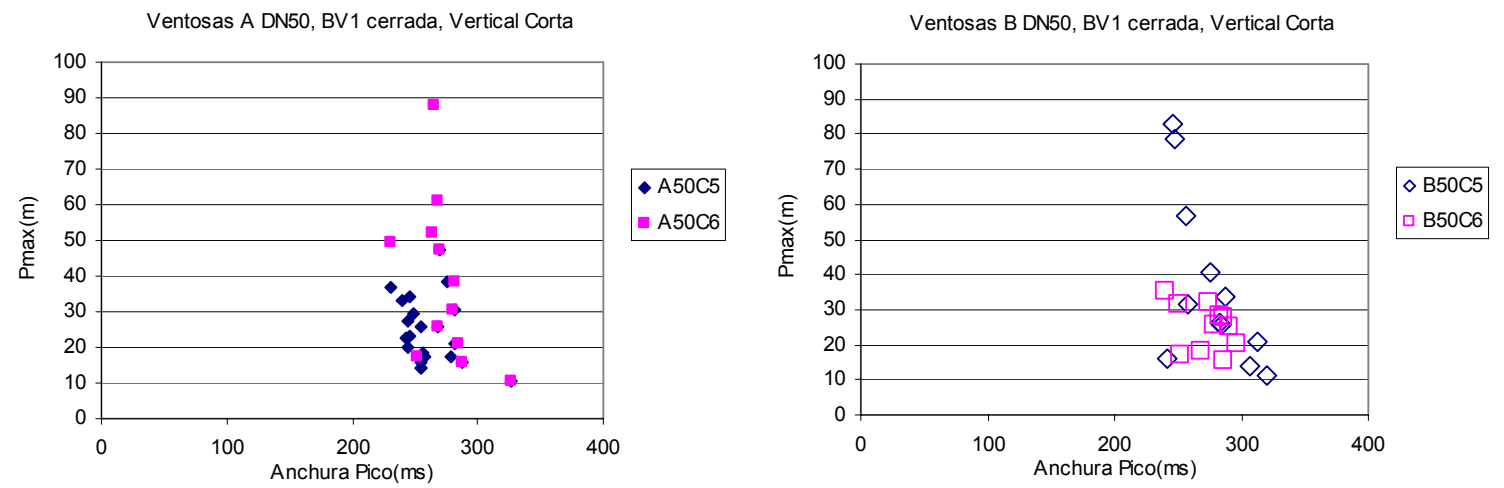

Figura 4.67. Presión máxima y anchura del pico de presión en ensayos con ventosa sobre carrete vertical corto.

Con la ventosa al final de la tubería vertical de 1,185 m, aunque sí se han apreciado irregularidades en la forma del perfil del pico de presión de algunos ensayos, se mantiene una uniformidad en cuanto a la anchura del pico de presión que oscila entre $200 \mathrm{~ms}$ y $350 \mathrm{~ms}$.

\section{Particularidades de los ensayos con ventosa sobre carrete vertical de 1,185 m de longitud.}

En muchos de estos ensayos, tanto los realizados con la ventosa A como los de la ventosa $B$, se ha detectado que los perfiles de la curva de presión máxima, medida por el transductor de presión K3, y la curva del desplazamiento del flotador, dada por el transductor de posición, tienen unas formas características.

Las condiciones iniciales bajo las cuales se lleva a cabo un ensayo son en principio las mismas salvo la sobrepresión inicial que hace que el fluido se ponga en movimiento.

Tanto la Figura 4.68 como la Figura 4.69, son un ejemplo de lo que suele ocurrir en general en estos ensayos realizados con la ventosa A de DN50, situada sobre una tubería vertical corta y con una altura inicial de columna de agua de 1,38 m. Las sobrepresiones iniciales son similares en los ensayos mostrados en estas figuras, en el caso del test 22 la sobrepresión inicial tiene un valor de 3,46 m.c.a. mientras que en el test 13 dicha sobrepresión inicial es de 3,83 m. 

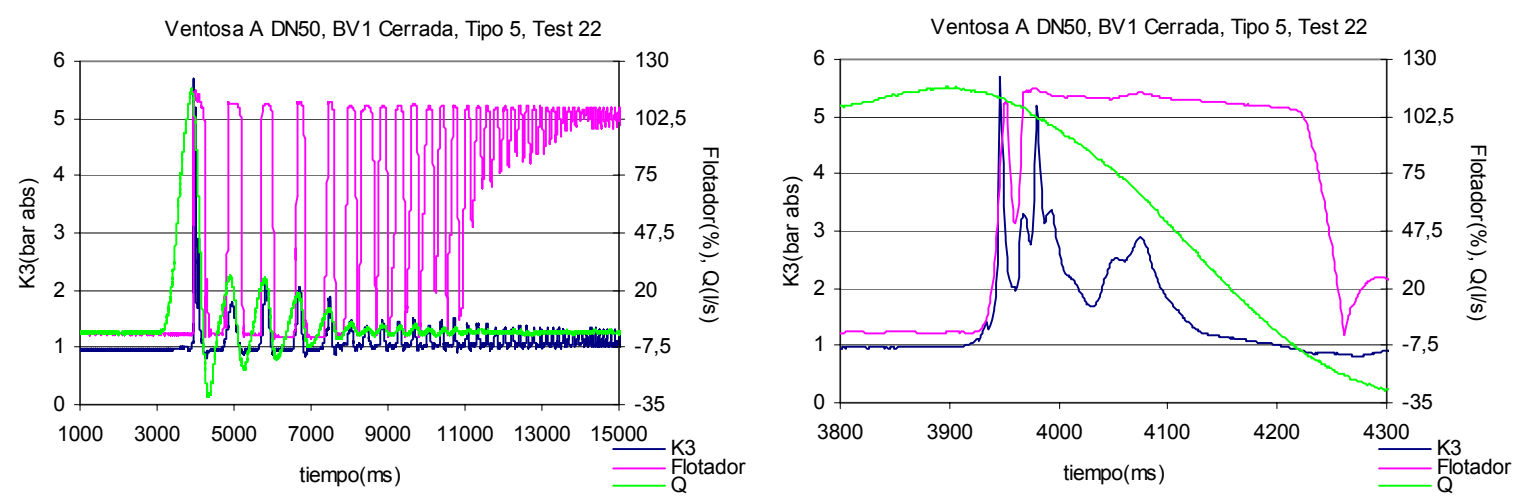

Figura 4.68. Evolución general de un ensayo con ventosa A DN50 sobre carrete vertical corto

En la Figura 4.69, existen menos rebotes del flotador y el pico de presión asociado a cada rebote es mayor que en el ensayo mostrado por la Figura 4.68. La velocidad de Ilegada de la columna de agua al flotador es ligeramente mayor en el caso del ensayo 22, que a su vez es el que registra una presión mayor.
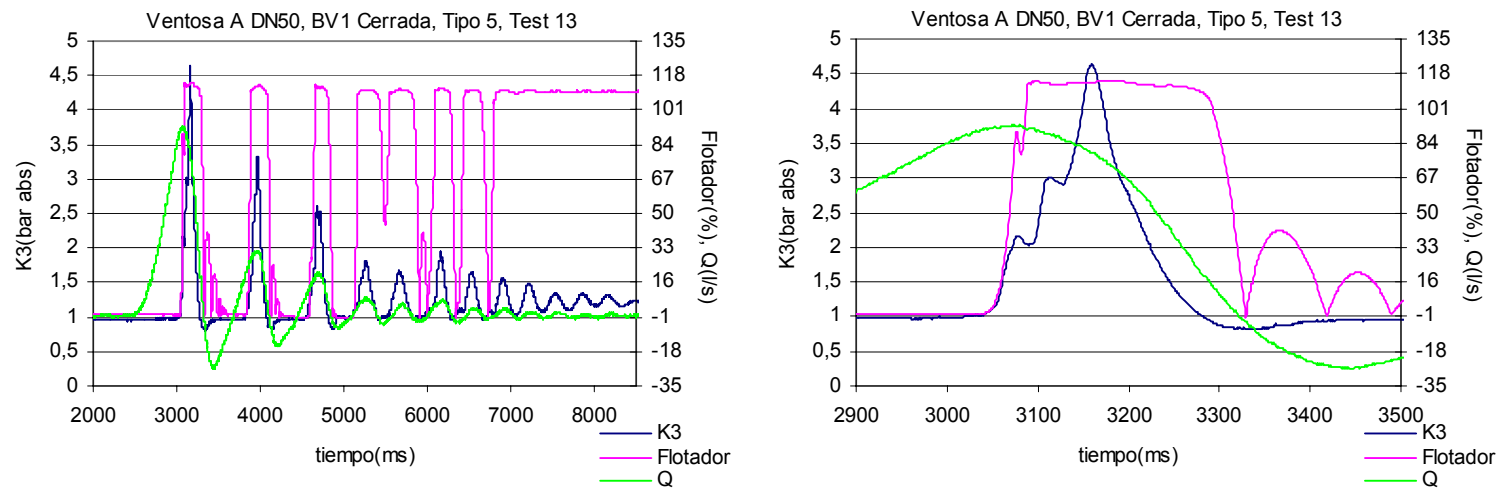

Figura 4.69. Evolución general de un ensayo con ventosa A DN50 sobre carrete vertical corto con una velocidad de llegada menor

En general hay bastante uniformidad en los resultados obtenidos al ensayar la ventosa $B$ DN50 sobre el carrete vertical de 1,185 m de longitud. La mayor parte de los ensayos presenta un comportamiento similar al representado en la Figura 4.70. En dicha figura aparecen varios rebotes del flotador y diversas oscilaciones de la onda de presión. El pico irregular de la onda de presión podría deberse a la compresión del flujo bifásico que contiene una cantidad de aire considerable. Este flujo bifásico se redistribuye irregularmente en el proceso de expansión. 

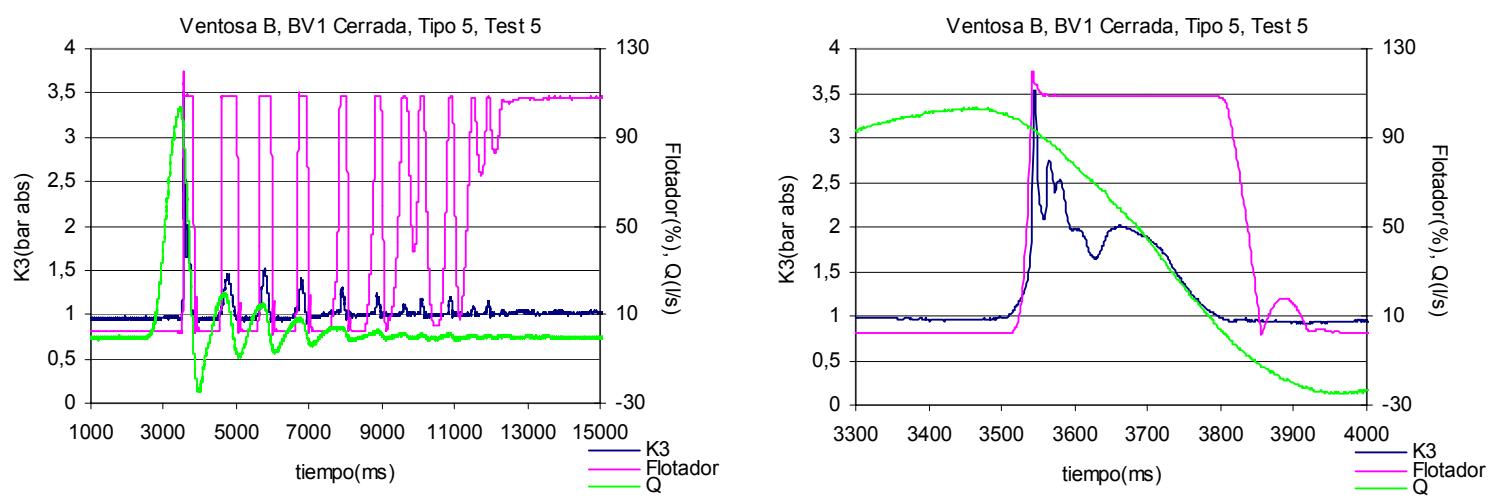

Figura 4.70. Evolución general de un ensayo con ventosa B sobre carrete vertical corto

Siguiendo con la misma configuración de la instalación, en los ensayos de la Ventosa B DN50, cuya altura inicial de columna de agua es de 0,81 m, también existe uniformidad de resultados, que se pueden resumir en dos comportamientos tal y como muestran las figuras siguientes.

La primera de ellas, Figura 4.71, es un ejemplo de aplicación de una sobrepresión inicial inferior a 2 m.c.a. sobre la columna de agua. La presión máxima alcanzada en el ensayo es relativamente pequeña así como la velocidad de llegada de la columna de agua al flotador. Aparecen diversas aperturas y cierres de la ventosa con una presión asociada a cada rebote relativamente pequeña como resultado de que la sobrepresión inicial no es suficientemente elevada para que la columna de agua cierre ventosa.
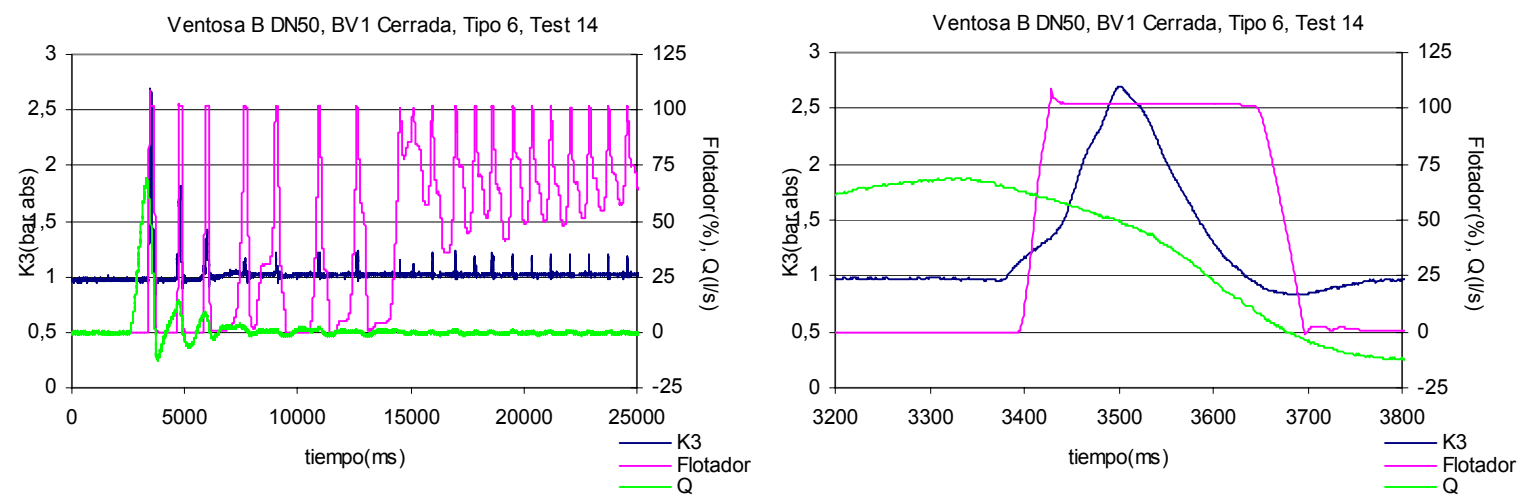

Figura 4.71. Ensayo con la ventosa B sobre carrete vertical corto con sobrepresión inicial menor de 2 m.c.a.

El otro modelo de comportamiento en este tipo de ensayos, es el que corresponde a los ensayos con una sobrepresión mayor a 2 m.c.a. En estos casos aparece un número menor de cierres porque la columna de agua llega al flotador con más fuerza y el ensayo finaliza con la ventosa cerrada. La sobrepresión inicial es suficiente para elevar la columna de fluido hasta la parte superior donde se encuentra la ventosa. 

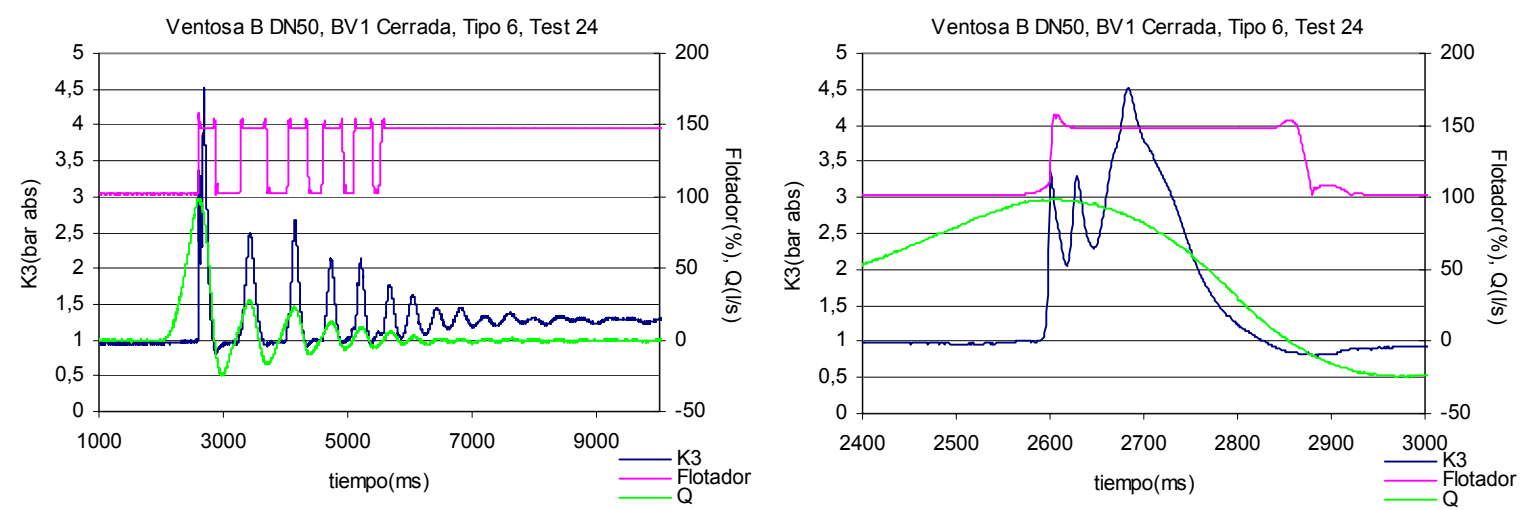

Figura 4.72. Ensayo con la ventosa B sobre carrete vertical corto con sobrepresión inicial mayor de 2 m.c.a.

\subsubsection{VENTOSA SOBRE CARRETE VERTICAL DE LONGITUD 2,185 m}

Finalmente, para concluir la tanda de ensayos de expulsión de aire realizados con las ventosas de DN50 con la válvula de mariposa BV1 cerrada, se instaló la ventosa en el extremo de una tubería vertical de mayor longitud, concretamente de 2,185 m. A su vez esta tubería, como en el caso del apartado anterior, se situó en el punto más alto de la instalación.

Se ensayó en primer lugar, una altura inicial de la columna de agua con un valor de 1,85 m medido sobre el eje longitudinal de la tubería horizontal. Realizados los ensayos previstos con estas características iniciales, se realizan otros ensayos similares en los cuales se aumentó la altura inicial de la columna de agua en 1,12 m a partir de la brida de la T.

\section{Presión máxima en los ensayos de la ventosa sobre un carrete vertical de 2,185 m de longitud.}

La presión máxima medida en estos ensayos se relaciona también con la sobrepresión inicial aplicada sobre la columna de agua para ponerla en movimiento y con la anchura del pico de presión máxima. A continuación se presentan los resultados obtenidos con cada ventosa en una misma figura. 


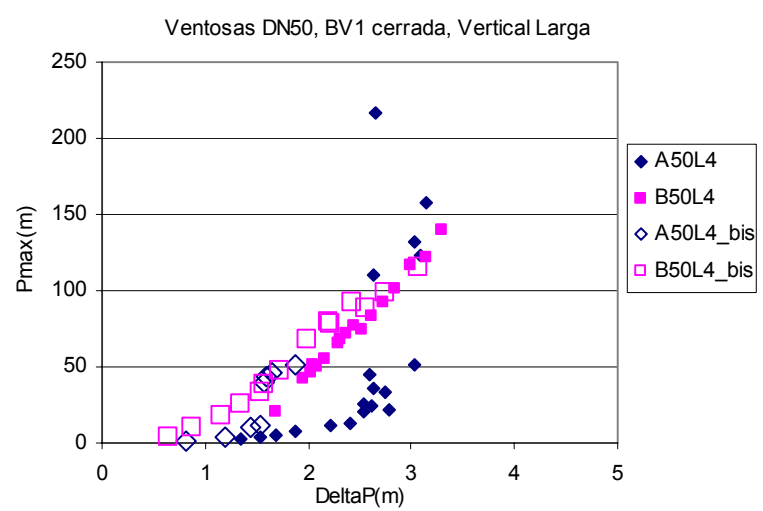

Figura 4.73. Presión máxima en ensayos con ventosas sobre carrete vertical largo

Donde:

A50L4: Corresponde a los ensayos realizados con la ventosa A de DN50, situada sobre una tubería vertical larga. La altura inicial de columna de agua es de 1,85 m.

B50L4: Corresponde a los ensayos realizados con la ventosa B de DN50, situada sobre una tubería vertical larga. La altura inicial de columna de agua es de 1,85 m.

A50L4_bis: Corresponde a los ensayos que se realizan con la ventosa A de DN50, situada sobre una tubería vertical larga. La altura inicial de columna es de agua de 2,97 m.

B50L4_bis: Corresponde a los ensayos que se realizan con la ventosa B de DN50, situada sobre una tubería vertical larga. La altura inicial de columna de agua es de 2,97 m.

Dado que la tubería vertical es más larga, se expulsa mayor cantidad de aire que en los casos anteriores, es decir, en los casos en los cuales se colocaba la ventosa sobre una tubería vertical corta o bien se colocaba la ventosa directamente sobre la $\mathrm{T}$ en el punto más alto de la instalación. Esta conclusión referente a la cantidad de aire atrapado finalmente en el sistema, se refleja en las presiones máximas medidas por el transductor de presión $\mathrm{K} 3$.
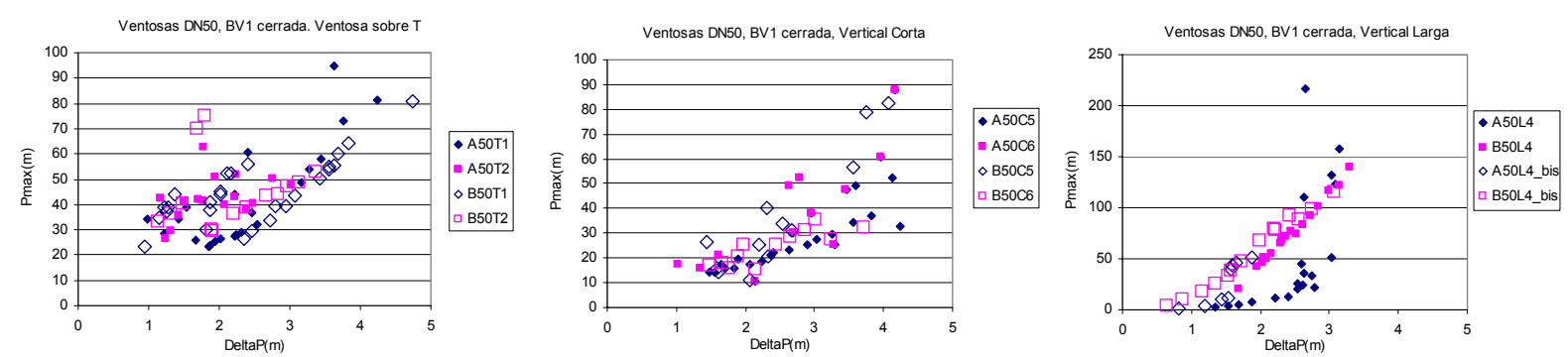

Figura 4.74. Comparación de resultados entre los tres tipos de ensayos de expulsión de aire al final de la conducción con ventosa DN50

Con una misma sobrepresión inicial, $\Delta \mathrm{P}, \mathrm{y}$ teniendo en cuenta que la longitud que debe vencer la columna de agua es mayor, las presiones alcanzadas son de un orden de magnitud superior. 
Atendiendo a la longitud inicial de la columna de agua, no existe prácticamente diferencia de resultados entre las dos series de puntos de una misma ventosa cuando consideran columnas de agua iniciales diferentes tal y como se aprecia en la Figura 4.75. En esta misma figura se aprecian dos tendencias diferentes de resultados obtenidos con la ventosa A DN50 con una altura inicial de la columna de agua de 1,85 m. Los ensayos que en la figura siguiente presentan una anchura del pico de presión mucho menor que el resto, corresponden a ensayos en los cuales se produce el pico de presión máxima en cierres parciales de la ventosa. En general, en los ensayos de las ventosas sobre el carrete de mayor longitud los resultados son más repetitivos porque la condición de contorno queda más definida.

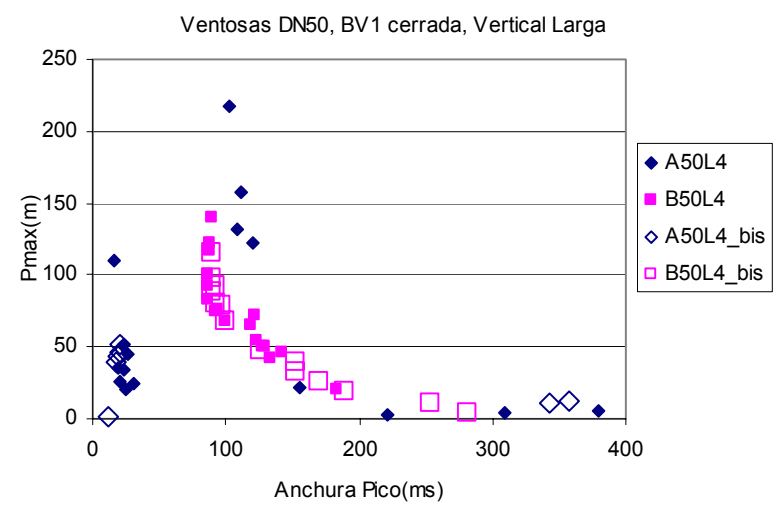

Figura 4.75. Presión máxima frente a la anchura del pico de presión en ventosas sobre carrete vertical largo

\section{Particularidades de los ensayos de la ventosa sobre carrete vertical de 2,185 m de longitud.}

En estos ensayos, cuya condición de contorno está perfectamente definida, también se han detectado situaciones particulares que evidencian la difícil tarea de ordenar y extraer conclusiones para una determinada serie de ensayos llevada a cabo bajo condiciones iniciales similares.

En primer lugar, comentar que la ventosa A presenta mayor dispersión de resultados debido a que la ventosa quedaba parcialmente abierta al final del ensayo. Con la columna de agua de altura 1,85 m medida sobre el eje longitudinal de la tubería horizontal se distinguen tres tipos de comportamientos.

Hay muchos ensayos de la ventosa A en los cuales, con una sobrepresión inicial aplicada inferior a 2,4 m.c.a., no se consigue que la ventosa cierre completamente, tal y como muestra el ejemplo de la Figura 4.76. Las presiones máximas alcanzadas en estos ensayos son también pequeñas, entre 2 m.c.a. y 12 m.c.a., en comparación con el resto de 
ensayos y los anchos del pico de presión máxima toman valores elevados, que llegan a alcanzar los 700 ms y por esta razón no aparecen en la Figura 4.75
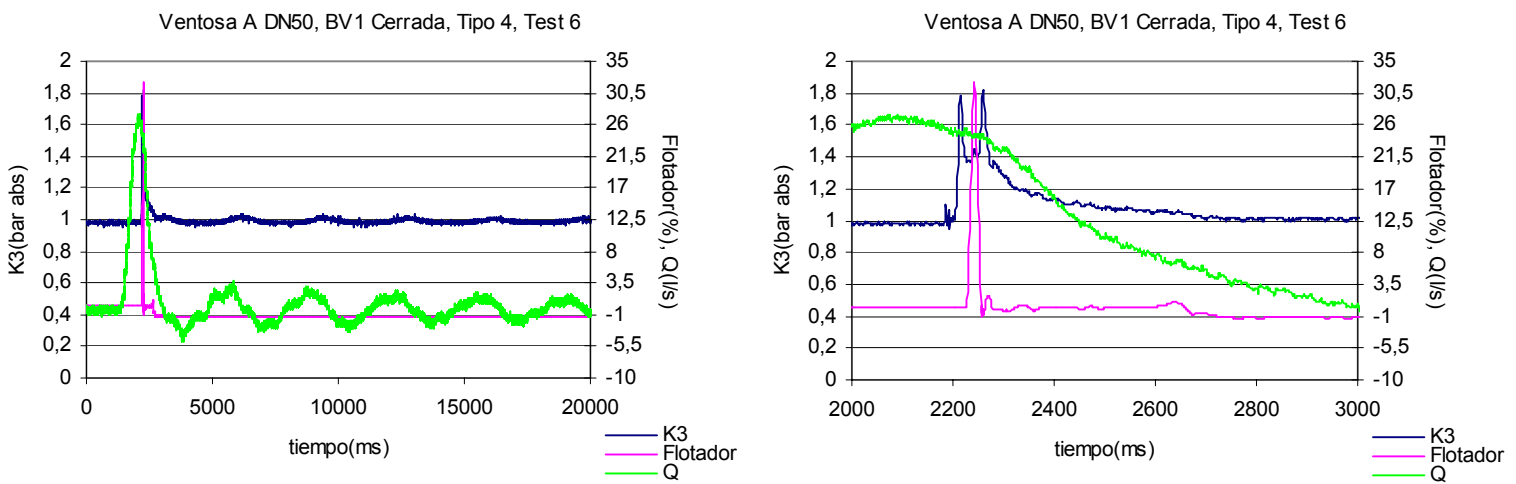

Figura 4.76. Evolución general de un ensayo con la ventosa A montada sobre un carrete vertical largo. Sobrepresion inicial $=1,9$ m.c.a

Existe otra serie de ensayos en los cuales con sobrepresiones iniciales entre 2,5 m.c.a. y 3 m.c.a. se alcanzan presiones máximas entre 20 m.c.a. y 60 m.c.a., y con anchuras del pico máximo de presión de 100 ms y 150 ms. El perfil general de la curva de presión y el perfil del desplazamiento del flotador son normalmente similares a los que se representan en la Figura 4.77
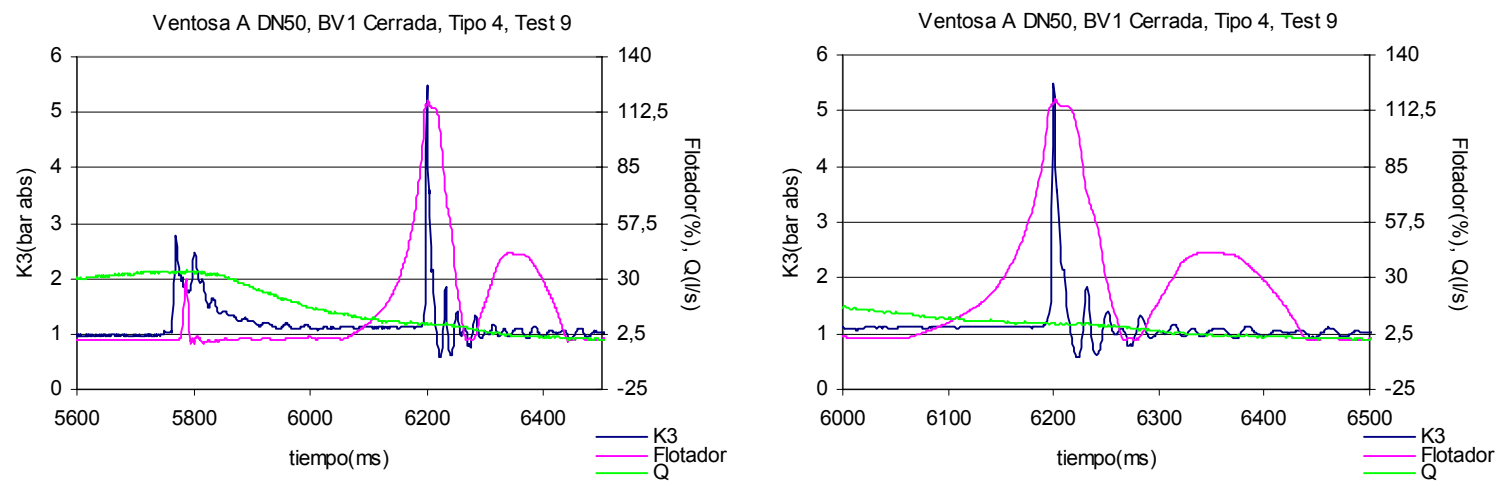

Figura 4.77. Evolución de un ensayo con la ventosa A montada sobre un carrete vertical largo.

Sobrepresion inicial $=2,6$ m.c.a.

Un tercer tipo de comportamiento de las diferentes variables, la presentan una serie de ensayos en los cuales tras aplicarles sobrepresiones iniciales entre 2,5 m.c.a. y 3 m.c.a., surgen presiones máximas de hasta 200 m.c.a. 

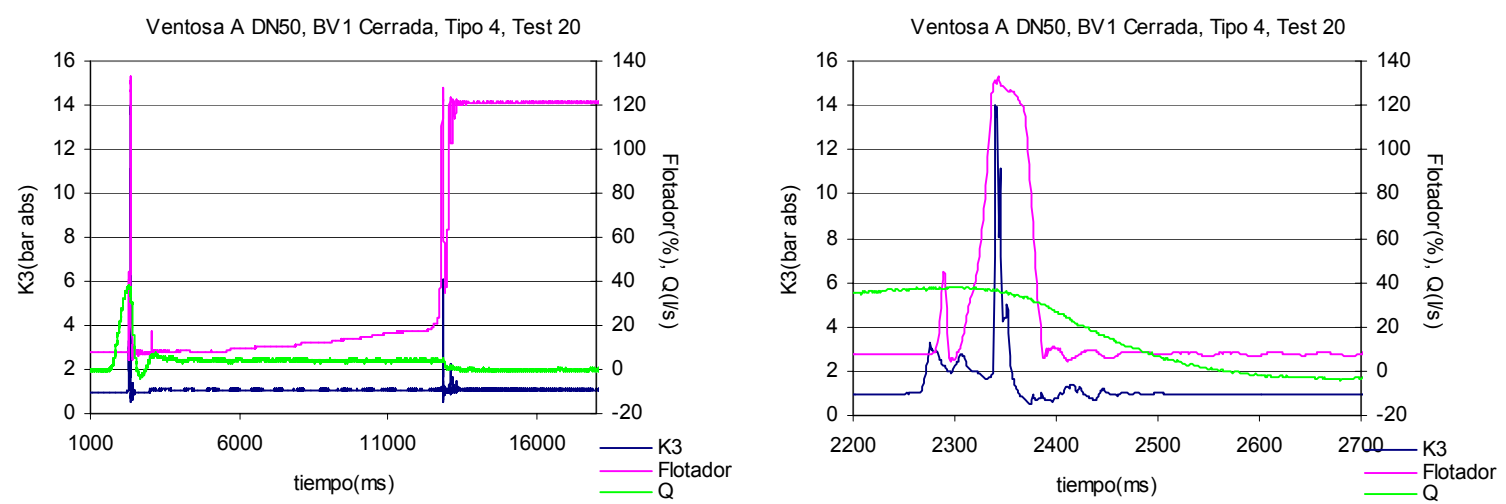

Figura 4.78. Evolución de un ensayo con la ventosa A montada sobre un carrete vertical largo.

Sobrepresion inicial = 3,03 m.c.a.

Como muestra de la gran diversidad de comportamientos producidos hay que comentar que en otros casos, se ha observado que la ventosa realiza en primer lugar un cierre parcial, el flotador llega a recorrer solo el 30\% del total de su recorrido, y posteriormente vuelve a cerrar por completo. La peculiaridad de este caso, es que el pico de presión máxima se produce con este cierre parcial como se observa en la Figura 4.79.
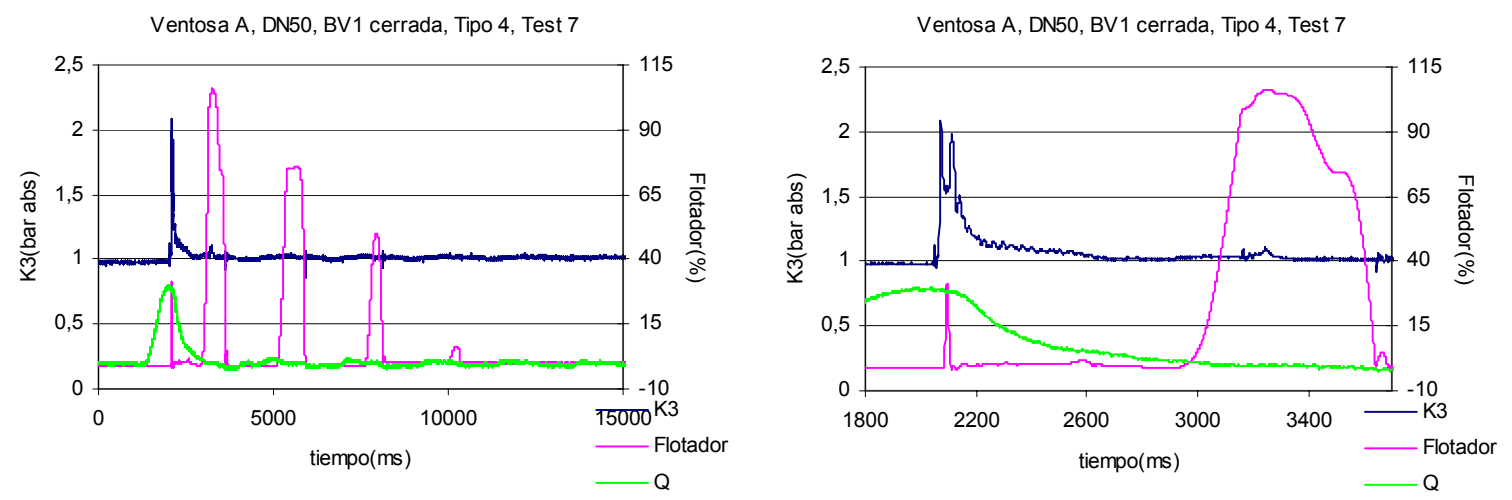

Figura 4.79. Evolución de un ensayo con la ventosa A montada sobre un carrete vertical largo. Sobrepresion inicial $=2,22$ m.c.a.

Todos estos fenómenos, caracterizados por la falta de uniformidad en la secuencia de cierres y en el perfil de la curva de presión máxima, hacen difícil establecer relaciones entre variables como se ha realizado con los ensayos de expulsión de aire efectuados con ventosas de DN100. 

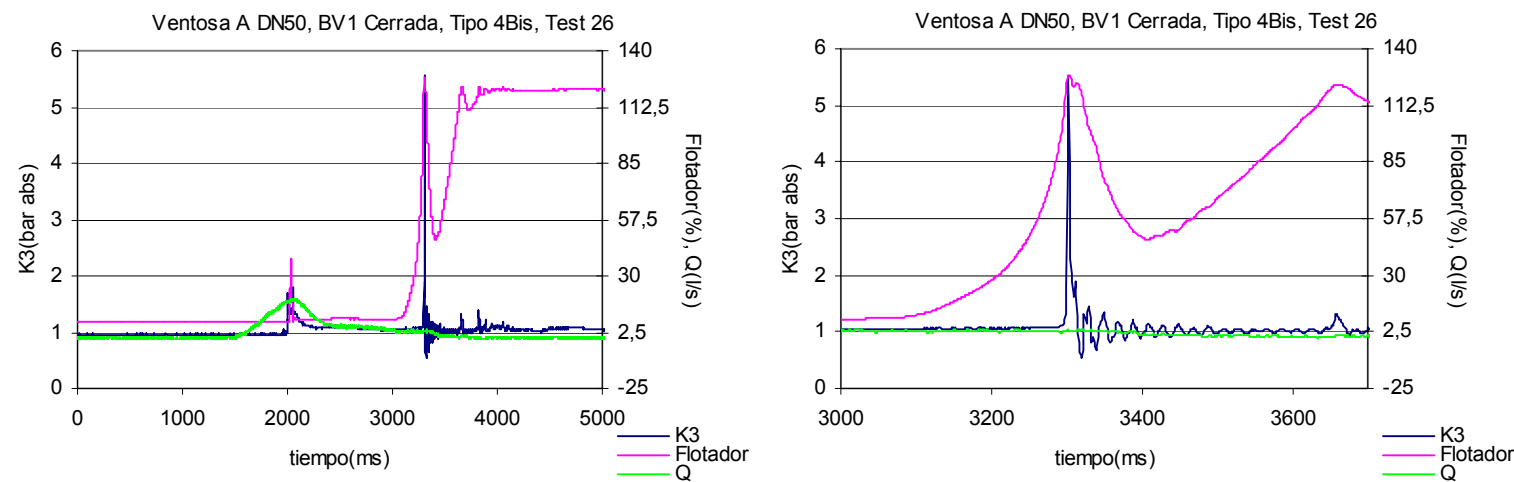

Figura 4.80. Evolución de un ensayo con la ventosa A montada sobre un carrete vertical largo.

Sobrepresion inicial $=1,65$ m.c.a.

Los ensayos realizados con la ventosa A cuando se aumenta la altura inicial de la columna de agua a 1,12 m medidos sobre el eje longitudinal de la tubería horizontal siguen una evolución similar a la mostrada en la Figura 4.81 .
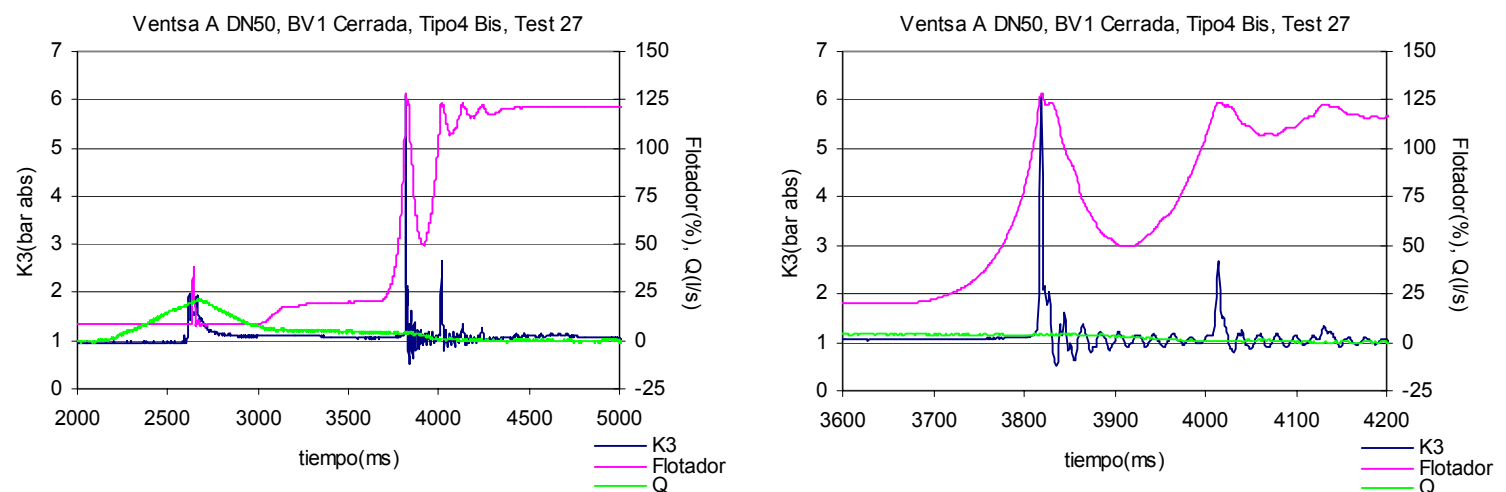

Figura 4.81. Evolución de un ensayo con la ventosa A montada sobre un carrete vertical largo.

Sobrepresion inicial $=1,87$ m.c.a.

Por lo que respecta a la ventosa B DN50 ensayada bajo estas últimas condiciones, cabe remarcar que presenta un comportamiento más uniforme, según se deduce de la Figura 4.73 y de la Figura 4.75.

En la Figura 4.82 y en la Figura 4.83 se muestran ejemplos de dos ensayos de esta ventosa ejecutados bajo condiciones iniciales similares pero con una altura inicial de la columna de agua diferente. En el primer caso la longitud inicial de la columna de agua es de 1,285 m mientras que en el segundo caso es de 2,97 m. 

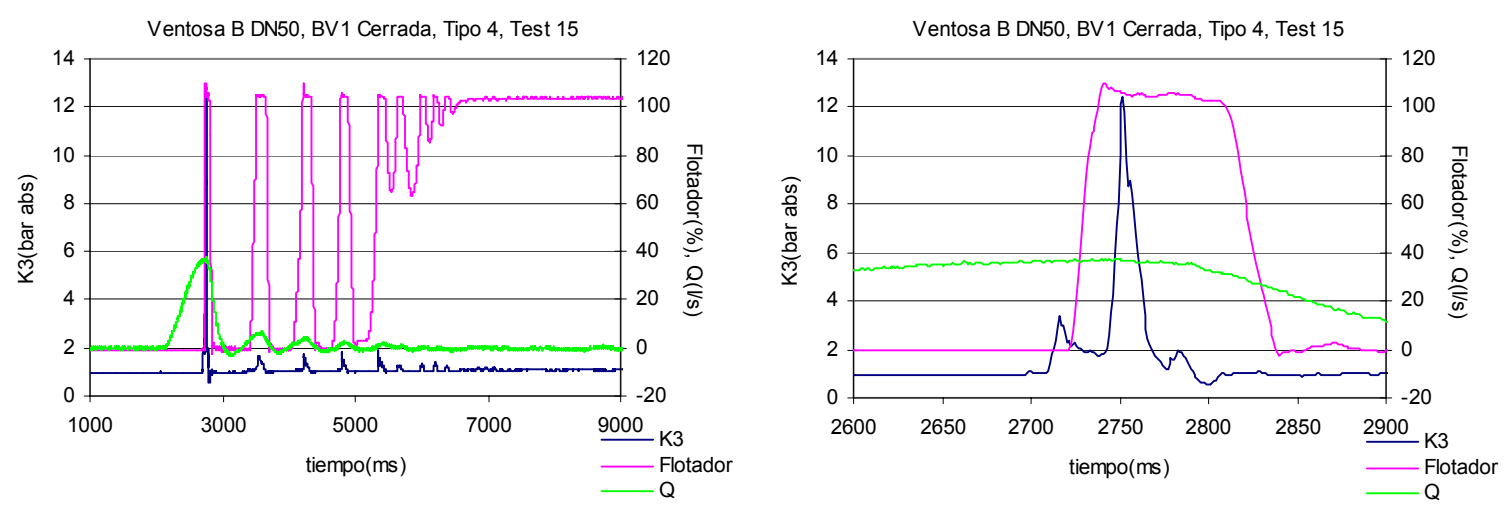

Figura 4.82. Evolución de un ensayo con la ventosa B montada sobre un carrete vertical largo.

Sobrepresion inicial =2,99 m.c.a.
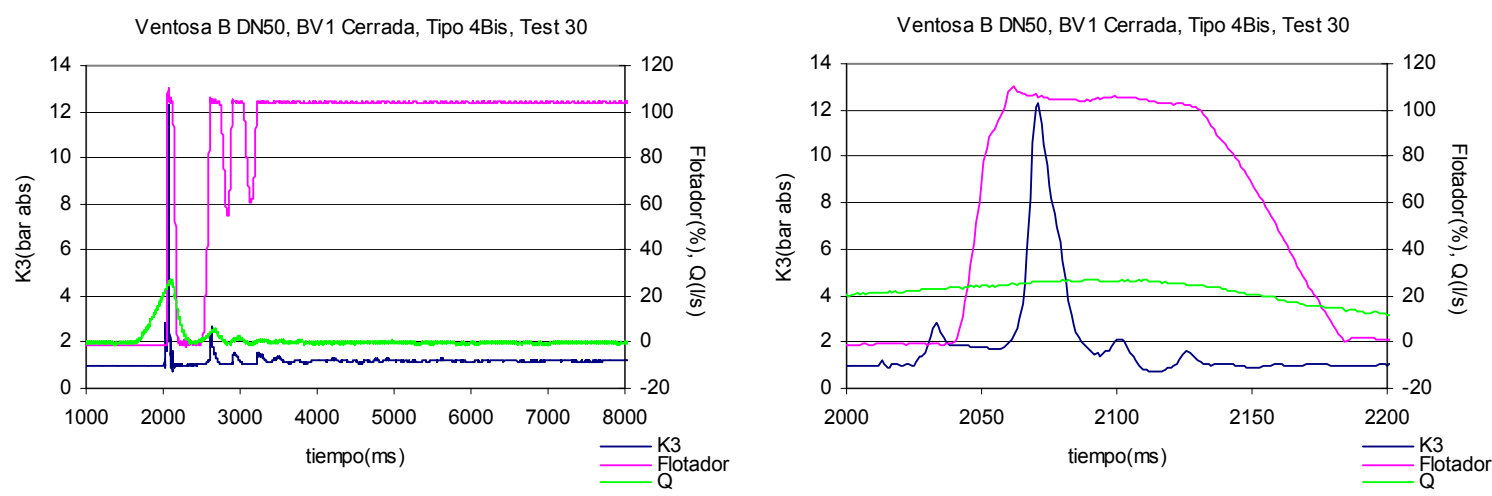

Figura 4.83. Evolución de un ensayo con la ventosa B montada sobre un carrete vertical largo.

Sobrepresion inicial $=3,07$ m.c.a..

Con en esta última disposición de la ventosa B DN50, se pone de manifiesto que se ha expulsado gran cantidad de aire antes del primer cierre, como se aprecia en las dos figuras anteriores. En estas figuras la presión máxima medida es elevada y la onda de presión después de llegar a su valor máximo no experimenta apenas variaciones. 


\subsubsection{ENSAYOS DE EXPULSIÓN DE AIRE EN UN PUNTO INTERMEDIO DE LA CONDUCCIÓN. VENTOSAS DN50}

En este apartado se engloban los ensayos de expulsión de aire realizados con las ventosas A y B de DN50 en el supuesto de dejar la válvula de mariposa BV1 situada junto a la ventosa, abierta. Al igual que en los anteriores ensayos de las ventosas DN50 el caudalímetro correspondiente no presentó una respuesta en frecuencia adecuada, por lo que la medida del caudal no se puede utilizar en los análisis del comportamiento de las ventosas. Con esta disposición, la ventosa objeto de estudio se ensayó en dos ubicaciones diferentes, directamente sobre el punto más elevado de la instalación, o montada sobre un carrete vertical de longitud 1,185 m situado a su vez en dicho punto.

Al estar la válvula de mariposa BV1 abierta, la ventosa queda en un punto intermedio de la instalación de manera que intervienen en el proceso las dos partes de la instalación. Es decir, el bloqueo de la columna de agua en movimiento se produce por la presencia de una columna de agua inmóvil existente en el lado opuesto de la válvula de mariposa BV1 y no lo produce únicamente la válvula BV1 como en el caso de estar dicha válvula cerrada.

De este modo, como ya se ha visto en los ensayos con las ventosas de DN100, la columna de agua en movimiento una vez llegado al punto más alto de la instalación cierra la ventosa y puede continuar su camino arrastrando en su movimiento parte del aire que no se expulsa por la ventosa. La cantidad de agua capaz de mover el flotador de la ventosa es en principio menor que si la válvula de mariposa BV1 estuviera cerrada ya que parte del agua que continuaría su camino por la conducción principal.

\subsubsection{VENTOSA SOBRE LA CONDUCCIÓN}

Tanto en los ensayos con la ventosa A como con los de la ventosa B de DN50, con esta disposición de la instalación se dividen en dos tipos de ensayo. Los que se realizan con una columna de bloqueo situada a $0,2 \mathrm{~m}$ del punto más alto de la instalación y los realizados con la columna de agua de bloqueo situada a 1,33 m del punto más alto. La longitud inicial de la columna de agua en movimiento tiene en todos los casos un valor de 2,315 m medida desde el eje de la tubería horizontal. 


\section{Presión máxima en los ensayos de la ventosa sobre la conducción}

Una de las pocas relaciones gráficas entre variables de la cuales se pueden obtener conclusiones, dado que solo se pueden aprovechar los datos de presión, es la de la presión máxima obtenida mediante el transductor de presión situado en el la conexión en T de la ventosa a la instalación frente a las sobrepresiones iniciales aplicadas desde el depósito de agua que hacen posible el movimiento de la columna de agua.

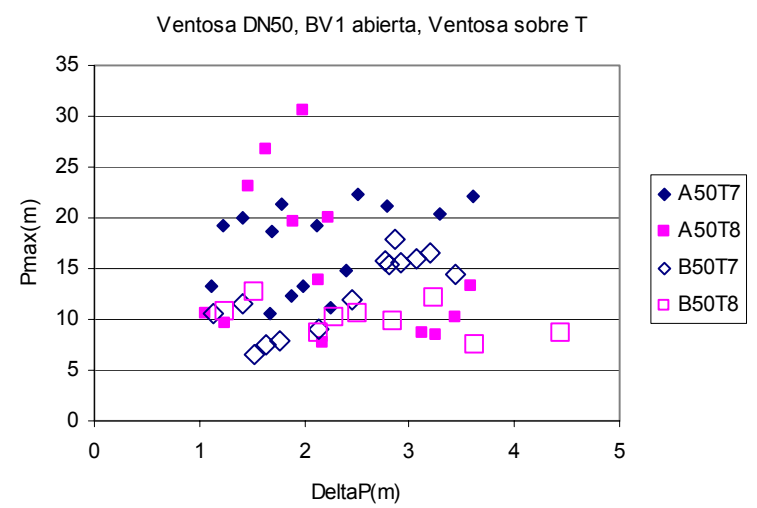

Figura 4.84. Presión máxima en ensayos de expulsión de aire un punto intermedio instalación.

Ventosas DN50

En la figura anterior:

A50T7: Representa los ensayos realizados con la ventosa A de DN50, situada directamente sobre la $\mathrm{T}$ de la instalación. La altura inicial de la columna de agua medida sobre el eje longitudinal de la tubería horizontal es de $2,315 \mathrm{~m}$ y la distancia entre el punto más alto de la instalación y la columna de agua de bloqueo es de 0,2 m.

A50T8: Representa los ensayos realizados con la ventosa A de DN50, situada directamente sobre la $\mathrm{T}$ de la instalación. La altura inicial de columna de agua medida sobre el eje longitudinal de la tubería horizontal es de 2,315 m y la distancia entre el punto más alto de la instalación y la columna de agua de bloqueo es de 1,33 m.

B50T7: Representa los ensayos realizados con la ventosa B de DN50, situada directamente sobre la $\mathrm{T}$ de la instalación. La altura inicial de columna de agua medida sobre el eje longitudinal de la tubería horizontal es de 2,315 m y la distancia entre el punto más alto de la instalación y la columna de agua de bloqueo es de 0,2 m.

B50T8: Representa los ensayos realizados con la ventosa B de DN50, situada directamente sobre la $\mathrm{T}$ de la instalación. La altura inicial de columna de agua medida sobre el eje longitudinal de la tubería horizontal es de $2,315 \mathrm{~m}$ y la distancia entre el punto más alto de la instalación y la columna de agua de bloqueo es de 1,33 m.

De la gráfica anterior se concluye que las presiones máximas registradas por el transductor de presión $\mathrm{K} 3$, se mantienen prácticamente constantes independientemente de la presión inicial aplicada, o en cualquier caso la correlación existente entre ambas variables es muy 
baja, próxima a cero. Además, comparadas con las obtenidas con los ensayos a válvula cerrada, estas presiones son considerablemente menores, ya que la cantidad de aire atrapado es mayor cuando la válvula de mariposa BV1 está abierta. Con esta nueva disposición de la instalación existe una determinada cantidad de aire que en lugar de ser expulsada es arrastrada por el flujo de agua hacia el otro lado de la instalación. El aire atrapado ejerce una función de colchón y atenúa el pico de presión.

En cuanto a la anchura del pico de presión máxima, hay que hacer algunos incisos dados los siguientes resultados:

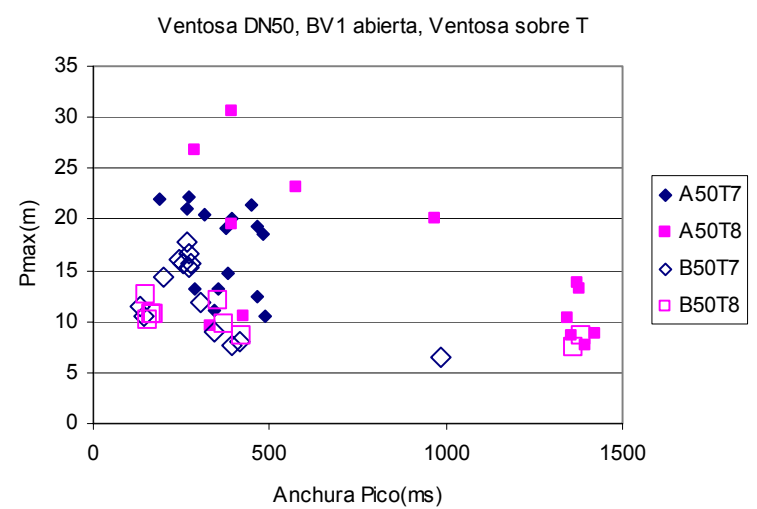

Figura 4.85. Presión máxima frente a la anchura del pico de presión en ensayos de expulsión de aire en un punto intermedio instalación. Ventosas DN50

En todas las series de la figura anterior, los valores menores del ancho de pico se producen en ensayos en los cuales el pico máximo no se da en el primer cierre de la ventosa si no en cierres posteriores (segundo, tercero incluso cuarto cierre según el ensayo)

En las series de puntos A50T8 y B50T8, aparecen anchuras de pico superiores a $1.000 \mathrm{~ms}$. Esto es debido a que tiene lugar una compresión de la bolsa de aire en la cual se llega al valor máximo de presión en el sistema. Seguidamente, sin que esta presión baje a la atmosférica, se da otra compresión. Todo ello sucede mientras la ventosa está cerrada.

En general, la anchura del pico de presión es superior a la de los ensayos de las mismas características realizados con BV1 cerrada.

\section{Particularidades de los ensayos de la ventosa sobre la conducción}

Del estudio de cada ensayo por separado, se detectan ciertas particularidades en cuanto a la evolución general del ensayo se refiere. En numerosos ensayos la ventosa experimenta varios cierres y la presión máxima del evento no se produce en el primero de ellos. Es decir, en algunos casos se produce en el segundo cierre, pero hay ensayos en los cuales el 
pico de presión máxima se ha producido en el tercero, cuarto, quinto e incluso sexto cierre. Este fenómeno se produce en ensayos de cualquiera de los tipos mencionados anteriormente, tanto en ensayos realizados con la ventosa $\mathrm{A}$ como en ensayos realizados con la ventosa $B$.

En la Figura 4.86 se muestra un caso en el cual el pico máximo de presión se produce en el sexto cierre de la ventosa. A lo largo del ensayo se observa una cierta repetibilidad en cuanto al perfil de la presión y al movimiento del flotador.
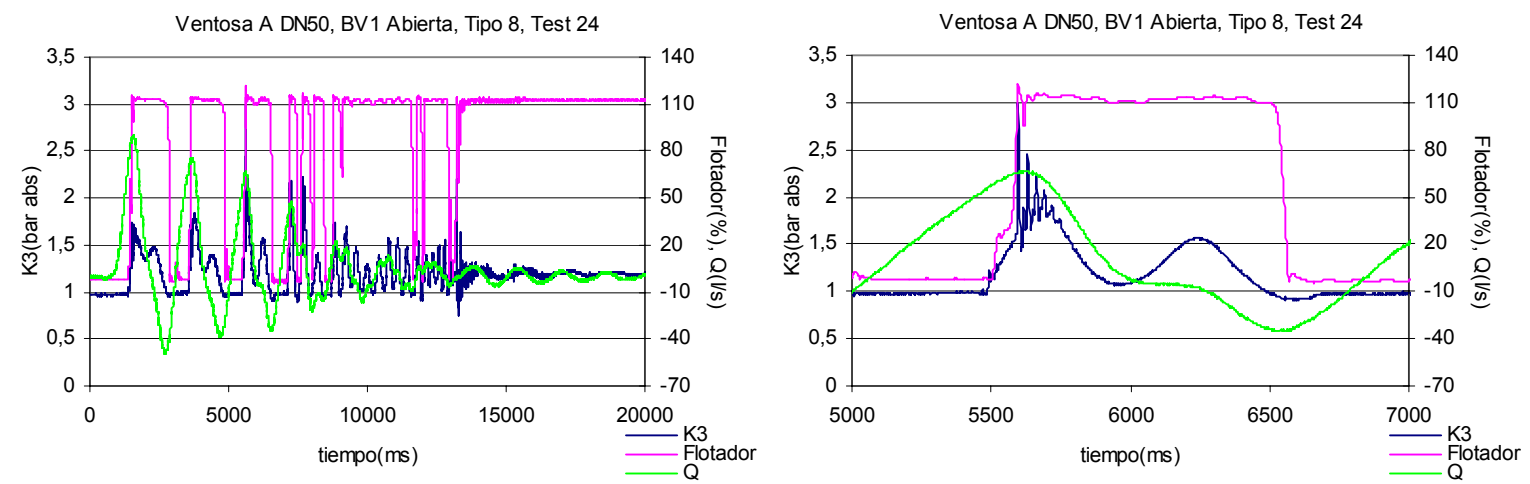

Figura 4.86. Evolución general de un ensayo de la ventosa A sobre conducción y en punto intermedio de la instalación. Sobrepresión inicial=2,23 m.c.a.

En los ensayos realizados con la ventosa B de DN50, aparece el mismo fenómeno que en los de la ventosa A de DN 50. Seguidamente se muestra uno de los casos extremos, en el cual el pico de presión se produce también en el sexto cierre de la ventosa.
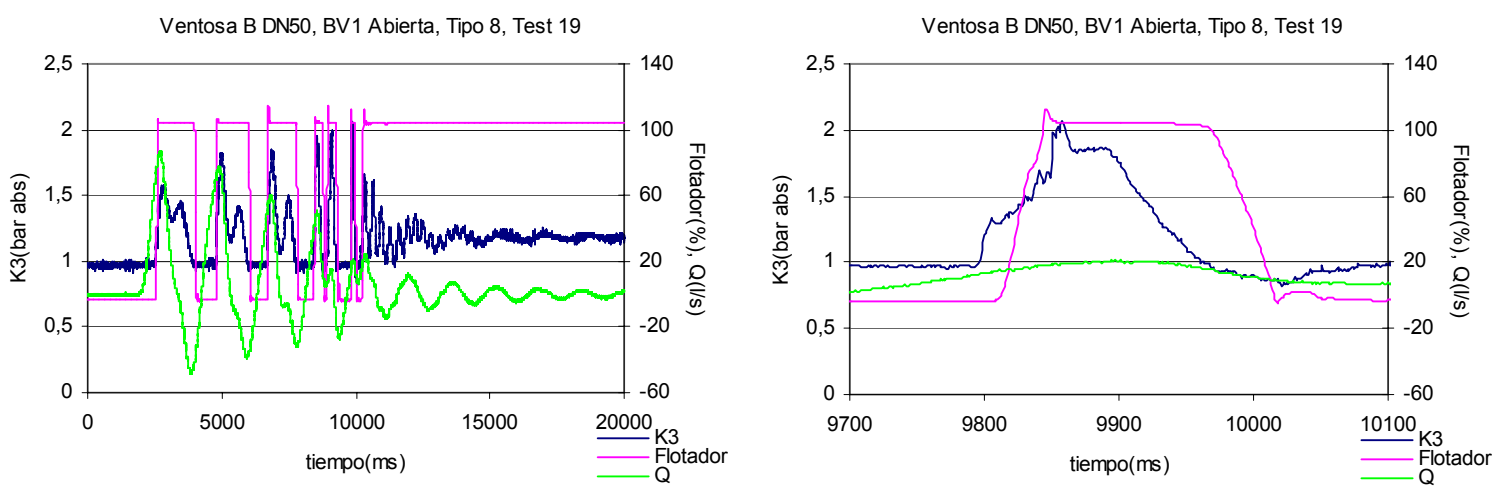

Figura 4.87. Evolución general de un ensayo de la ventosa B sobre conducción y en punto intermedio de la instalación. Sobrepresión inicial =2,51 m.c.a

Durante todo el ensayo se mantiene atrapada una cantidad de aire apreciable lo cual se deduce a partir de las oscilaciones de la presión medida por el transductor de presión K3. Cada vez que abre la ventosa se expulsa aire con lo cual, cada vez que cierra la ventosa existe menos cantidad de aire atrapado. 
Este tipo de evolución es frecuente pero no se repite sistemáticamente en todos los ensayos, es decir, existen ensayos en los cuales solo aparece un cierre de la ventosa y es simultáneamente a este cierre cuando se produce el pico de presión máxima.

Las bolsas de aire atrapado dispuestas de manera dispersa en el interior del sistema que se contraen y expanden, son posiblemente las causantes de que la ventosa abra y cierre varias veces ya que con su movimiento impulsan el agua hacia el flotador.

Toda esta aleatoriedad del fenómeno dificulta una vez más la tarea de intentar establecer las pautas del comportamiento de las ventosas bajo unas condiciones dadas o intentar predecir cual puede ser la presión máxima en el sistema durante el transitorio.

\subsubsection{VENTOSA SOBRE UN CARRETE VERTICAL DE LONGITUD 1.185 m}

La segunda configuración ensayada con las ventosas de DN50 en un punto intermedio de la instalación consiste en montar la ventosa en el extremo superior de una tubería vertical de 1,185 m de longitud quedando situada en el punto más alto de la instalación.

\section{Presión máxima de los ensayos de la ventosa sobre carrete vertical de 1,185 m de longitud}

El análisis de los ensayos efectuados con esta disposición lleva a la obtención de los resultados que se muestran en la figura siguiente:

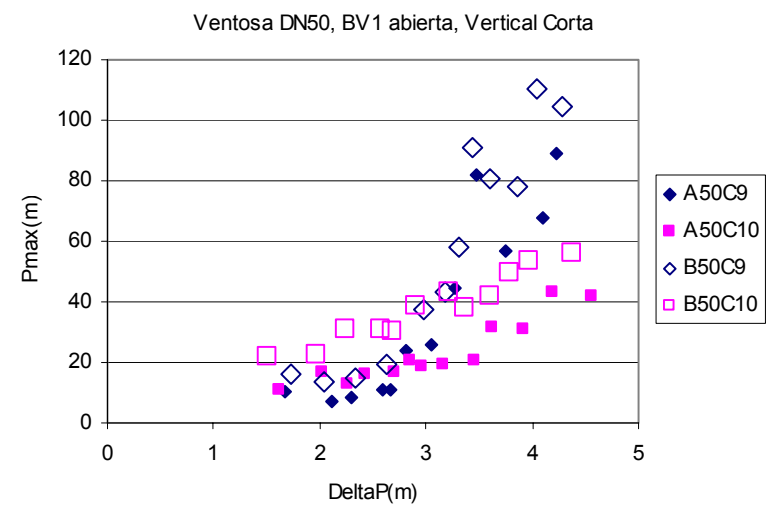

Figura 4.88. Relación entre la presión máxima y la sobrepresión aplicada. 
Donde:

A50C9: Representa los ensayos realizados con la ventosa A de DN50, situada sobre la tubería vertical. La altura inicial de la columna de agua es de $2,315 \mathrm{~m}$ y la distancia entre el punto más alto de la instalación y la columna de agua de bloqueo es de 0,2 m.

A50C10: Representa los ensayos realizados con la ventosa A de DN50, situada sobre la tubería vertical. La altura inicial de columna de agua es de 2,315 m y la distancia entre el punto más alto de la instalación y la columna de agua de bloqueo es de 1,33 m.

B50C9: Representa los ensayos realizados con la ventosa B de DN50, situada sobre la tubería vertical. La altura inicial de la columna de agua es de 2,315 m y la distancia entre el punto más alto de la instalación y la columna de agua de bloqueo es de 0,2 $\mathrm{m}$.

B50C10: Representa los ensayos realizados con la ventosa B de DN50, situada sobre la tubería vertical. La altura inicial de la columna es de agua $2,315 \mathrm{~m}$ y la distancia entre el punto más alto de la instalación y la columna de agua de bloqueo es de 1,33 m.

De la Figura 4.88 se deduce que cuando las sobrepresiones aplicadas son mayores, se obtienen picos de presión más elevados en el transitorio. Una vez más se pone de manifiesto que con la disposición de la ventosa al final de una tubería vertical, se favorece la expulsión de aire, lo cual comporta que se obtengan picos de presiones más elevados tal y como se observa de la comparación de las gráficas de la Figura 4.89.
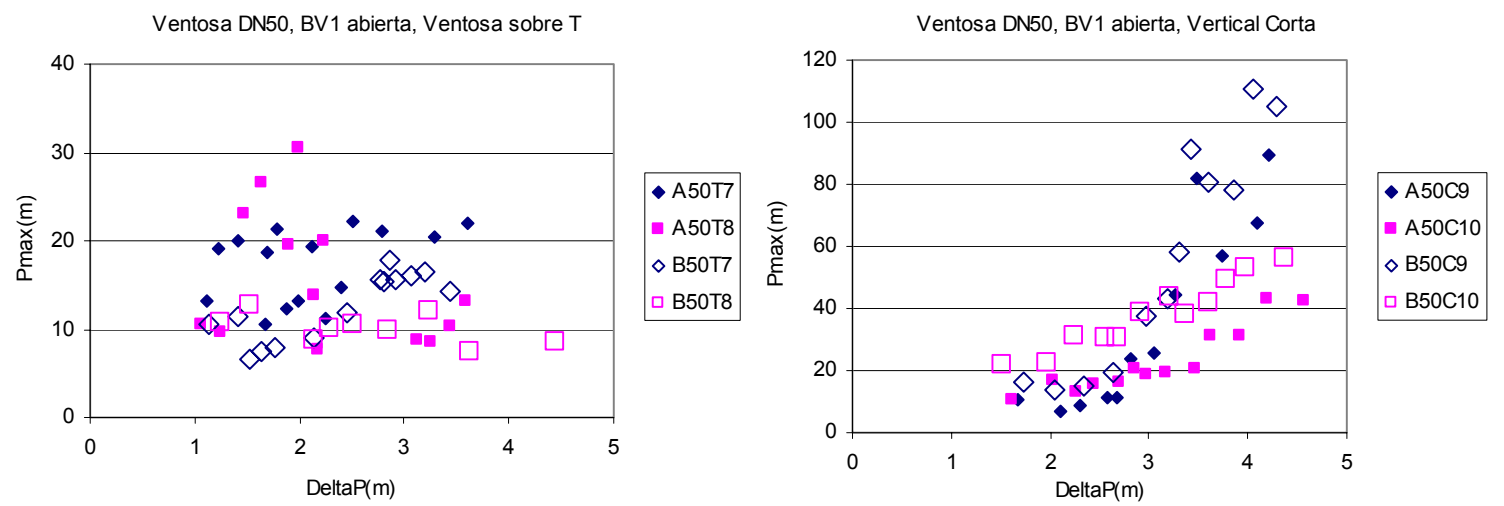

Figura 4.89. Comparación entre las presiones máximas obtenidas en ensayos de expulsión de aire a través de una ventosa situada sobre la T o al final de un carrete vertical corto.

También se deduce de la misma figura que cuando la columna de agua de bloqueo es más corta, distancia desde la $\mathrm{T}$ hasta la columna de agua de bloqueo igual a 1,33 m, las presiones máximas que se registran son menores ya que en este caso hay mayor posibilidad de que quede aire atrapado.

En este caso, al igual que en los anteriores, también se evalúa el ancho del pico de la presión máxima obteniendo el siguiente resultado: 


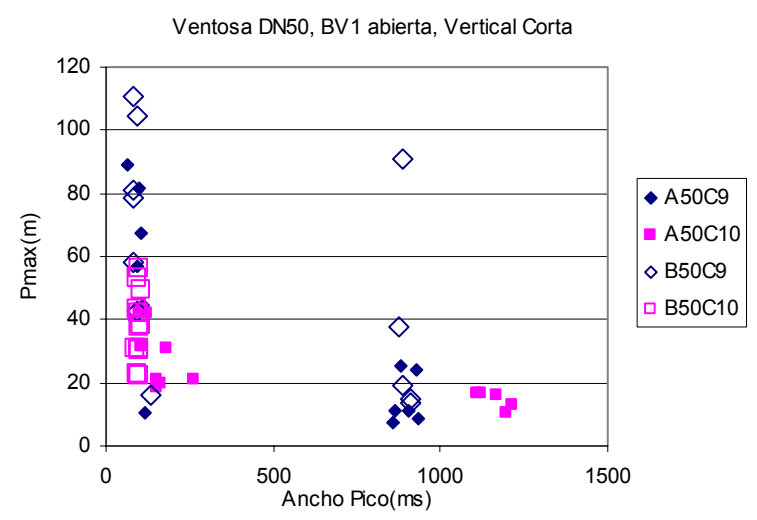

Figura 4.90. Relación entre la presión máxima y la anchura del pico de presión en expulsión de aire en un punto intermedio de la instalación con ventosa sobre carrete vertical corto.

En la Figura 4.90 los resultados aparecen claramente divididos en dos grupos. Los valores más altos del ancho de pico que aparece en la Figura 4.90, hacen referencia en este caso a los ensayos que alcanzan la presión máxima cuando inicialmente el flotador de la ventosa solo llega a recorrer el $60 \%$ de su recorrido total y posteriormente vuelve a abrir. En este caso la cantidad de aire expulsado es mínima. La gran cantidad de aire que queda atrapado en estos ensayos en la instalación queda reflejado en este elevado valor de la anchura del pico de presión, mayor que 800 ms.

El resto de ensayos mantienen un mismo orden de magnitud en cuanto a anchura del pico de presión se refiere.

\section{Particularidades de los ensayos de la ventosa sobre carrete vertical de 1,185 m de longitud}

La mayor parte de situaciones anómalas se producen en ensayos realizados con la ventosa A. En muchos de ellos, independientemente de la altura de la columna de agua de bloqueo, el pico máximo de presión se produce en un primer intento de cierre de la ventosa en el cual el flotador solo llega a alcanzar aproximadamente un $30 \%$ del recorrido total. 


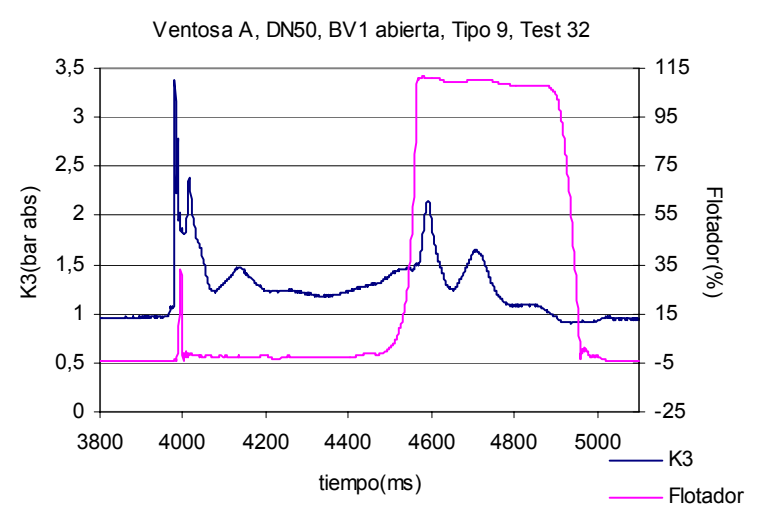

Figura 4.91. Cierre parcial de la ventosa y pico de presión.

Con la ampliación de la figura anterior se observa más detenidamente los dos instantes en los cuales aparecen cambios en el perfil de las curvas de presión y desplazamiento del flotador:
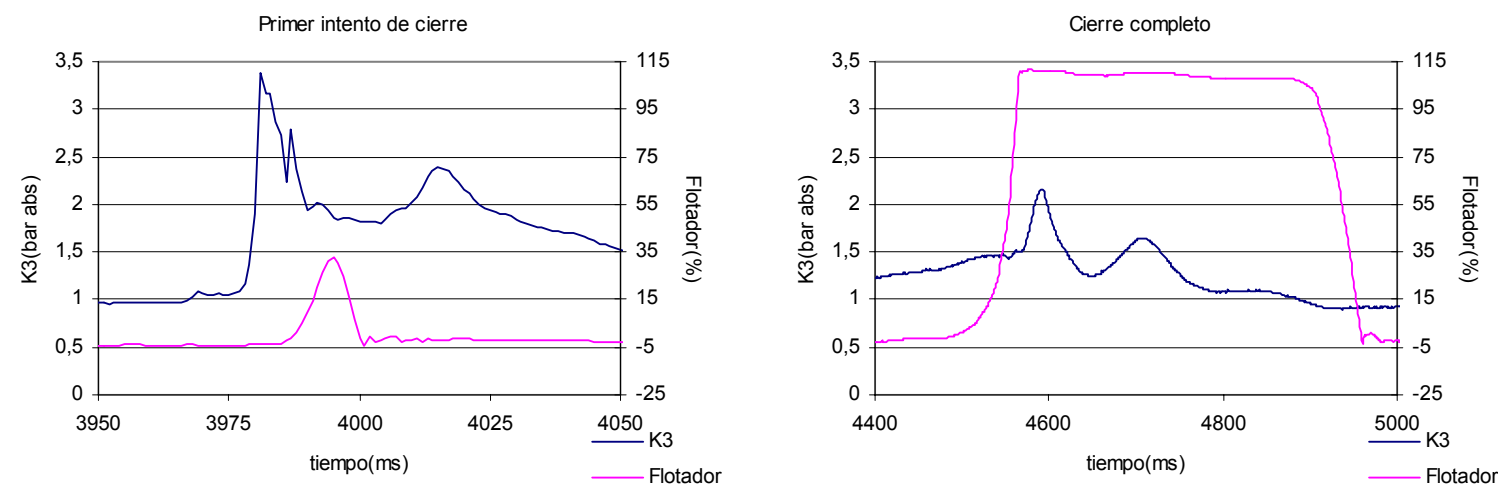

Figura 4.92. Movimiento del flotador de la ventosa A DN50 y presión medida.

En el primer caso, el movimiento del flotador se ha registrado después del pico de presión, lo cual puede ser debido a la existencia de aire atrapado en algún punto de la tubería relativamente lejos de la ventosa. En cambio, posteriormente se produce el cierre completo de la ventosa que provoca un ligero cambio en el perfil de la curva de presión.

También se han encontrado casos similares al anterior pero en esta ocasión la presión máxima se produce cuando la ventosa cierra por completo. En cualquier caso se comprueba la irregularidad de la onda de presión causada por la presencia de aire distribuido por toda la conducción. 


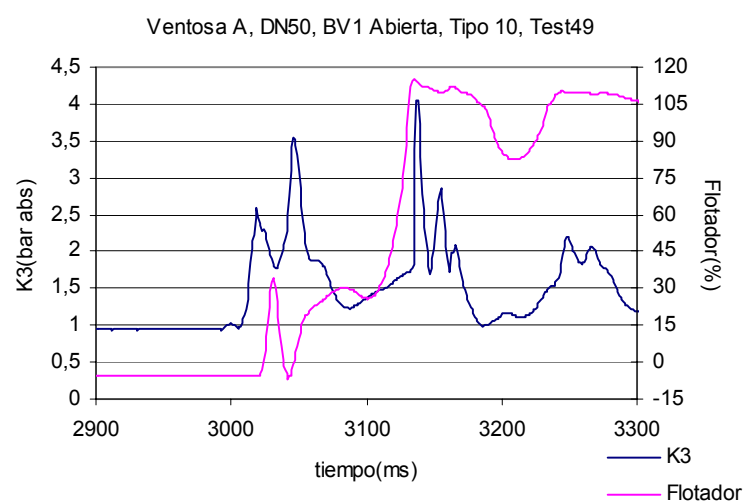

Figura 4.93. Movimiento del flotador de la ventosa A DN50 y presión medida

Un ejemplo de lo que es el comportamiento general de los ensayos realizados con la ventosa B de DN50 con la válvula de mariposa BV1 abierta, independientemente de la altura de la columna de agua de bloqueo utilizada en cada ensayo, se muestra en la Figura 4.94 .

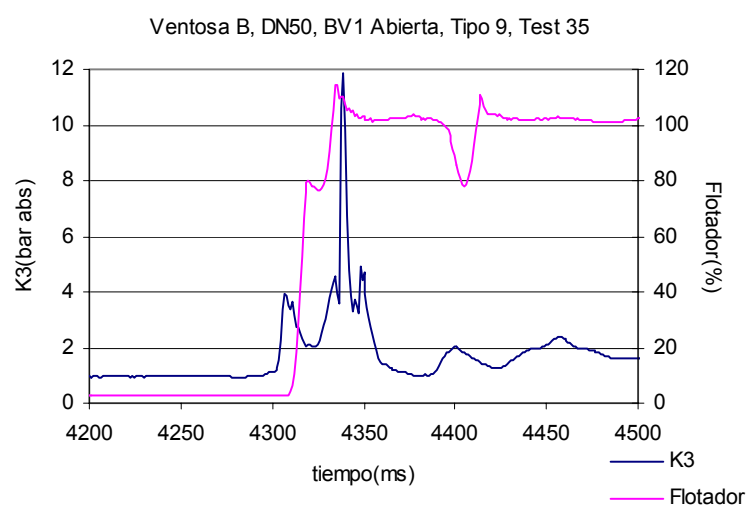

Figura 4.94. Presión en el cuello la ventosa

Antes de que el flotador inicie el ascenso por la guía de la ventosa, ya aparece un aumento significativo de la presión, registrado por el transductor K3. Una vez cierra la ventosa por completo se detecta el pico máximo de presión de este ensayo.

Por último, hay que señalar que han existido otros ensayos en los cuales tras alcanzar la presión máxima, la curva de presión no desciende hasta la presión atmosférica si no que experimenta otra subida ligera, todo ello con la ventosa cerrada tal y como se muestra en la Figura 4.95. Esto se debe a la presencia del aire atrapado en forma de bolsas en el tramo descendente de la instalación, lo cual provoca una ligera oscilación de la columna de agua. 


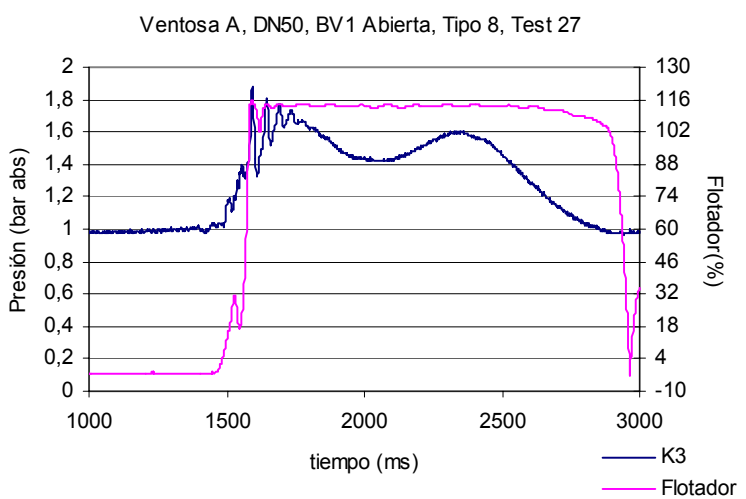

Figura 4.95. Ondulaciones en el perfil de la onda de presión. 


\subsubsection{COMPARACIÓN DEL COMPORTAMIENTO DE VENTOSAS, DN100 Y DN50, EN ENSAYOS DE EXPULSIÓN DE AIRE AL FINAL DE LA CONDUCCIÓN.}

Los ensayos dinámicos de expulsión de aire a través de una ventosa situada al final de una conducción se han llevado a cabo del mismo modo con todas las ventosas independientemente de su diámetro nominal. Aunque el diámetro de la instalación en la cual se han Ilevado a cabo los ensayo de las ventosas DN100 y DN50, son diferentes, es decir, $500 \mathrm{~mm}$ en un caso y $200 \mathrm{~mm}$ en el otro, se considera interesante establecer una comparación entre los resultados obtenidos en ambos casos. Por este motivo se presentan pares de gráficas en las cuales aparecen representadas las mismas variables obtenidas al ensayar las ventosas DN100 y las ventosas DN50.

En general, cabe destacar, que para una misma magnitud del transitorio, medida bien como sobrepresión aplicada en el instante inicial o bien como velocidad en el instante en el cual empieza a aumentar la presión, la presión máxima alcanzada es mayor en la instalación de mayor tamaño.
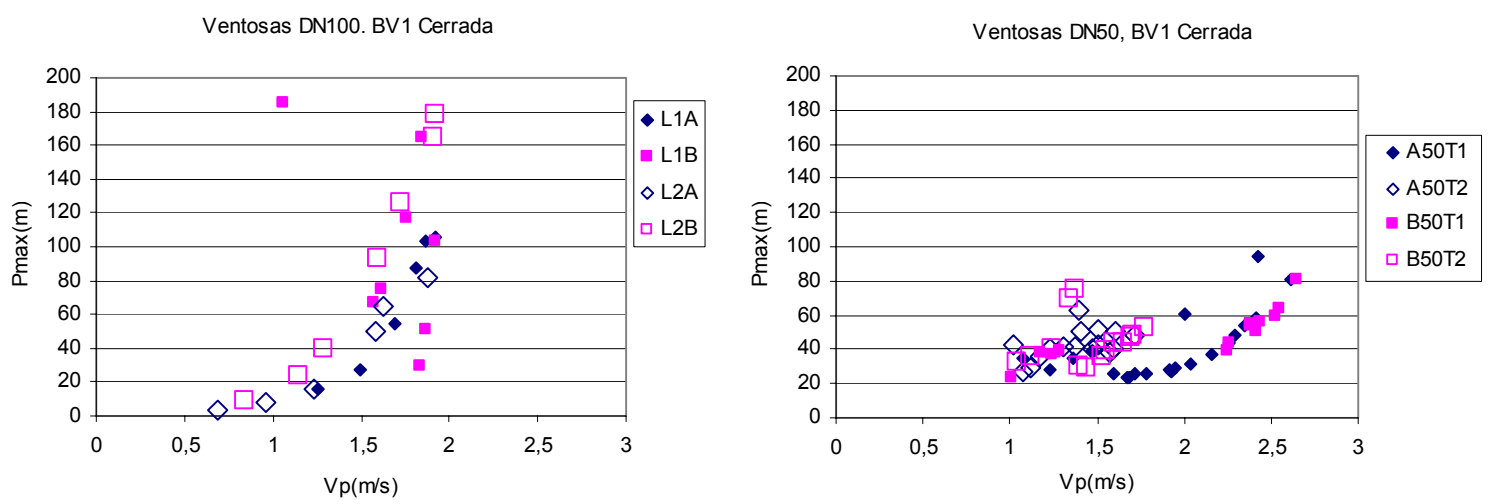

Figura 4.96. Presión máxima frente a la velocidad en el instante que aumenta la presión.

La velocidad de la columna de agua cuando empieza a aumentar la presión en el sistema sigue la misma tendencia creciente respecto al aumento de la sobrepresión inicial aplicada en todos los casos. 

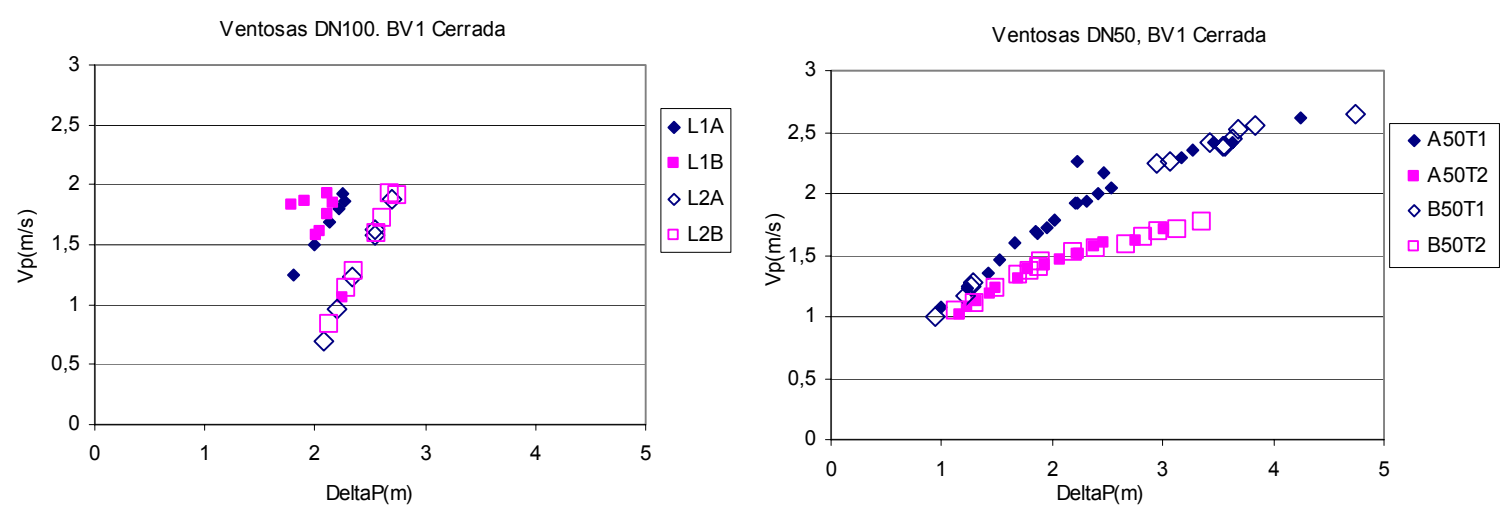

Figura 4.97. Velocidad cuando aumenta la presión frente a la sobrepresión inicial.
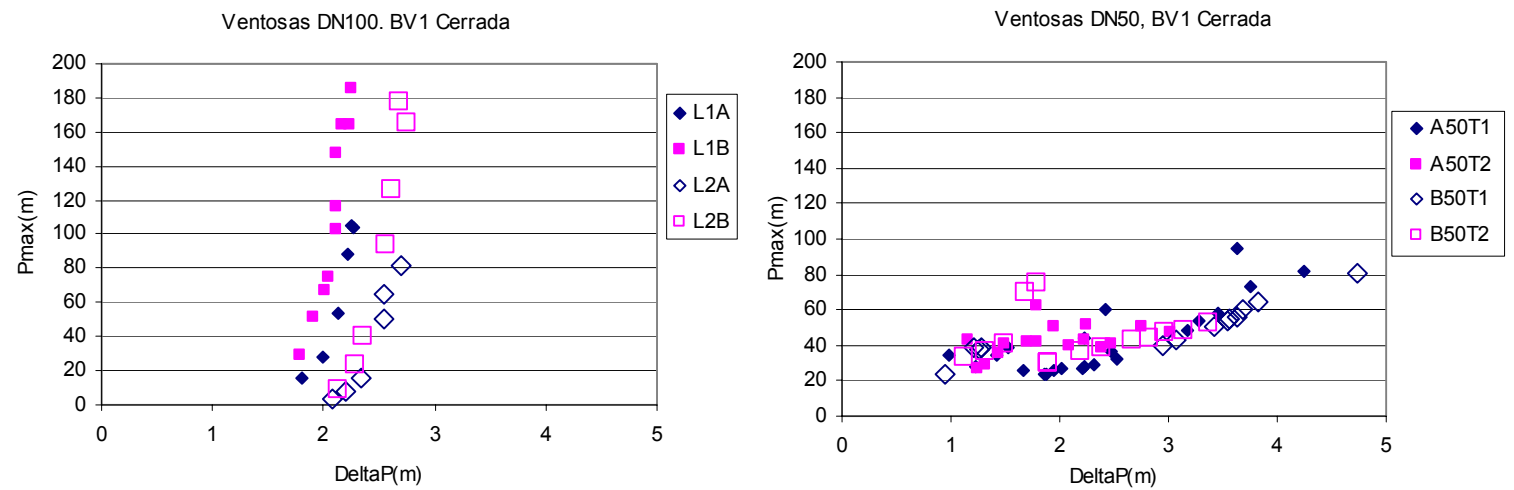

Figura 4.98. Presión máxima frente a la sobrepresión inicial.

\subsection{ENSAYOS DINÁMICOS DE ADMISIÓN DE AIRE}

Las ventosas ensayadas además de expulsar aire son capaces de admitir aire en grandes cantidades cuando cae la presión en el interior de la tubería por debajo de la atmosférica. De todos los posibles casos en los cuales puede tener lugar un proceso de admisión de aire en una instalación de agua a presión a través de una ventosa se analizan dos situaciones.

En primer lugar, se estudia la diferencia de comportamiento del flujo ante una situación en la que se produce una separación de la columna de agua debida al cierre de una válvula de retención. Este fenómeno se estudia bajo dos supuestos, es decir, en el supuesto en el cual la instalación cuente con una ventosa en el lugar donde se produce dicha separación y en el supuesto en el cual la instalación no cuente con ventosa. De este modo se pretende deducir si la ventosa es capaz de mitigar la depresión que aparece durante el transitorio. 
El resto de ensayos pretenden estudiar el fenómeno ocurrido cuando se procede al drenaje de una tubería, es decir, simulan el fenómeno que se produce cuando se vacía una tubería que inicialmente está completamente llena de agua.

Además, los ensayos se han llevado a cabo en dos instalaciones con la misma configuración pero de diámetro diferente. En unos casos la conducción tenía un diámetro de $500 \mathrm{~mm}$ y otros casos la conducción tenía un diámetro de $200 \mathrm{~mm}$. Las ventosas ensayadas de diámetro nominal DN100 se instalaron sobre la conducción de $500 \mathrm{~mm}$ de diámetro mientras que las ventosas DN50 se ensayaron sobre la conducción de 200 m de diámetro.

\subsubsection{ADMISIÓN DE AIRE CON SEPARACIÓN DE LA COLUMNA DE AGUA}

El fenómeno de la separación de la columna de agua se consiguió simular forzando el cambio del sentido de circulación del flujo. Dicho cambio de sentido provocaba el cierre de una válvula de retención. De este modo después del cierre de la válvula, aparecían sobrepresiones en un lado de la válvula mientras que el otro lado estaba sometido a depresiones. En el lado de la válvula en el cual se generaban depresiones, se producía la separación de la columna de agua ya que se alcanzaban presiones inferiores a la atmosférica.

En este tipo de ensayos se pretende averiguar si una ventosa situada aguas arriba de la válvula de retención, justo en el lado donde se generan bajas presiones debido al cierre de la válvula ante un flujo inverso, es capaz de mitigar dicho fenómeno admitiendo aire en la conducción con suficiente rapidez.

Por esta razón, se repite el mismo ensayo con ventosa y sin ventosa, comparando de esta manera la influencia de este elemento de protección. La ventosa utilizada para este estudio ha sido en todos los casos la ventosa $B$, de diámetro $50 \mathrm{~mm}$ o $100 \mathrm{~mm}$ según las dimensiones de la instalación, cuyas especificaciones vienen definidas en el Capítulo 3.

Las variables consideradas más significativas a la hora de analizar este tipo de ensayo son:

- Instante inicial ti en el cual empieza a descender la velocidad

- Caudal inicial, Qini, o caudal a partir del cual se inicia un descenso brusco del caudal y se inicia el flujo inverso.

- Caudal mínimo Qmin, caudal mínimo registrado por el caudalímetro electromagnético y Velocidad mínima $\mathrm{V}_{\text {min }}$

- La variación de velocidad entre los instantes tQini y tomin

- La duración de la depresión que tiene lugar cuando cierra la válvula de retención 


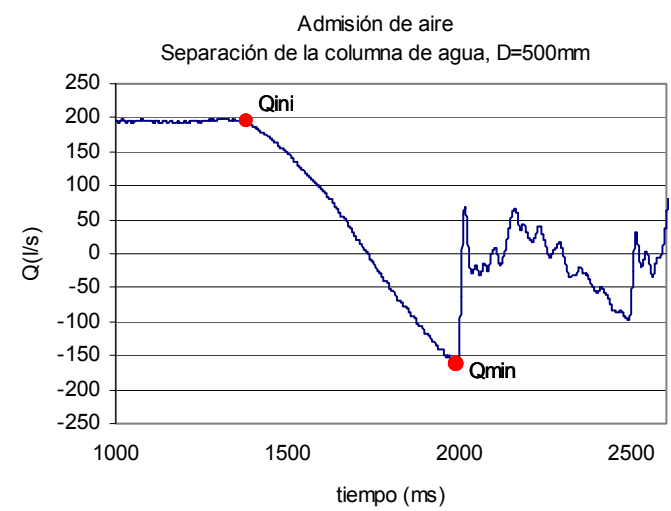

Figura 4.99. Variación de la velocidad de la columna de agua en ensayo de admisión de aire a través de una ventosa debido al cierre de una válvula.

La deceleración del flujo se calcula entre el instante en el cual la velocidad empieza a disminuir desde un valor inicial constante y el instante en que la velocidad registra su valor mínimo tal y como se representa en la figura anterior.

Así pues la deceleración del flujo entre estos instantes dados se ha calculado como:

$$
\frac{d v}{d t}=\left|\frac{Q_{i n i}-Q_{\min }}{t_{\text {Qini }}-t_{\text {Qmin }}}\right| \cdot \frac{1}{A}
$$

Siendo:

$Q_{\text {ini }}$ : Caudal inicial $\left(\mathrm{m}^{3} / \mathrm{s}\right)$

Qmin : Caudal mínimo $\left(\mathrm{m}^{3} / \mathrm{s}\right)$

tQini : Instante inicial (s)

tQmin : Instante en el que el caudal es mínimo (s)

A: sección transversal de la tubería $\left(\mathrm{m}^{2}\right)$

Los ensayos realizados bajo estos supuestos se pueden clasificar como:

- Ensayos de admisión de aire con separación de columna de agua en la instalación de diámetro $500 \mathrm{~mm}$ sin ventosa.

- Ensayos de admisión de aire con separación de columna de agua en la instalación de diámetro 500 mm con una ventosa de DN100.

- Ensayos de admisión de aire con separación de columna de agua en la instalación de diámetro $200 \mathrm{~mm}$ sin ventosa.

- Ensayos de admisión de aire con separación de columna de agua en la instalación de diámetro 200 mm con una ventosa de DN50

La descripción más detallada del procedimiento de este tipo de ensayos se encuentra en el Capítulo 3 de este trabajo. 
En la Figura 4.100 se presenta la evolución general de las presiones aguas arriba y aguas abajo de la válvula de retención en la instalación de diámetro $500 \mathrm{~mm}$, medidas por los transductores de presión K2 y K3 respectivamente, así como el desplazamiento del flotador de la ventosa.

En líneas generales, se aprecia como en dos situaciones con condiciones iniciales similares, en las cuales la sobrepresión inicial aplicada, que provoca la inversión del flujo, es del orden de 1,2 bar, y con presiones máximas en ambos casos en el lado aguas abajo de la ventosa del orden de 13 bar, la duración de la depresión medida con el transductor de presión $\mathrm{K} 2$ es menor, en cuanto a magnitud y en cuanto a duración, cuando se instala una ventosa junto a la válvula de retención. La ventosa es capaz de aliviar, en parte, la depresión producida al cerrar la válvula de retención aunque presenta cierto retraso en abrir una vez producida la depresión y no es capaz de eliminarla en su totalidad.
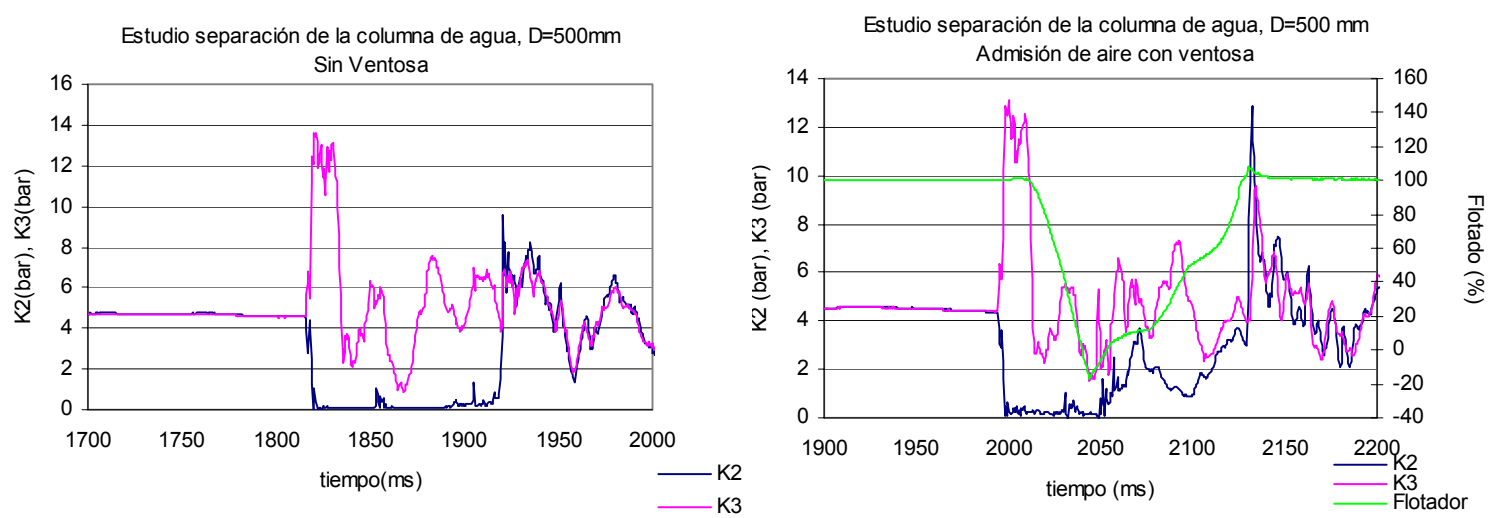

Figura 4.100. Separación columna de agua. Ensayo sin y con ventosa.

\subsubsection{SEPARACIÓN DE LA COLUMNA DE AIRE EN LA CONDUCCIÓN DE $\mathrm{D}=\mathbf{5 0 0} \mathrm{mm}$}

Además de distinguir gráficamente el efecto producido con y sin ventosa, se analizan seguidamente ciertas relaciones entre las variables características medidas en este tipo de ensayos. En cada gráfica se comparan los resultados obtenidos al efectuar el ensayo sin ventosa y al llevarlo a cabo con una ventosa situada junto a la válvula de retención, en el lado en el cual se producen las bajas presiones.

Las gráficas siguientes muestran que la magnitud de la sobrepresión que se produce aguas arriba de la válvula de retención es similar independientemente de si se ha utilizado o no una ventosa en el ensayo. Esto es lógico, ya que la ventosa se sitúa en el lado aguas debajo de la válvula de retención, donde tienen lugar las depresiones. 

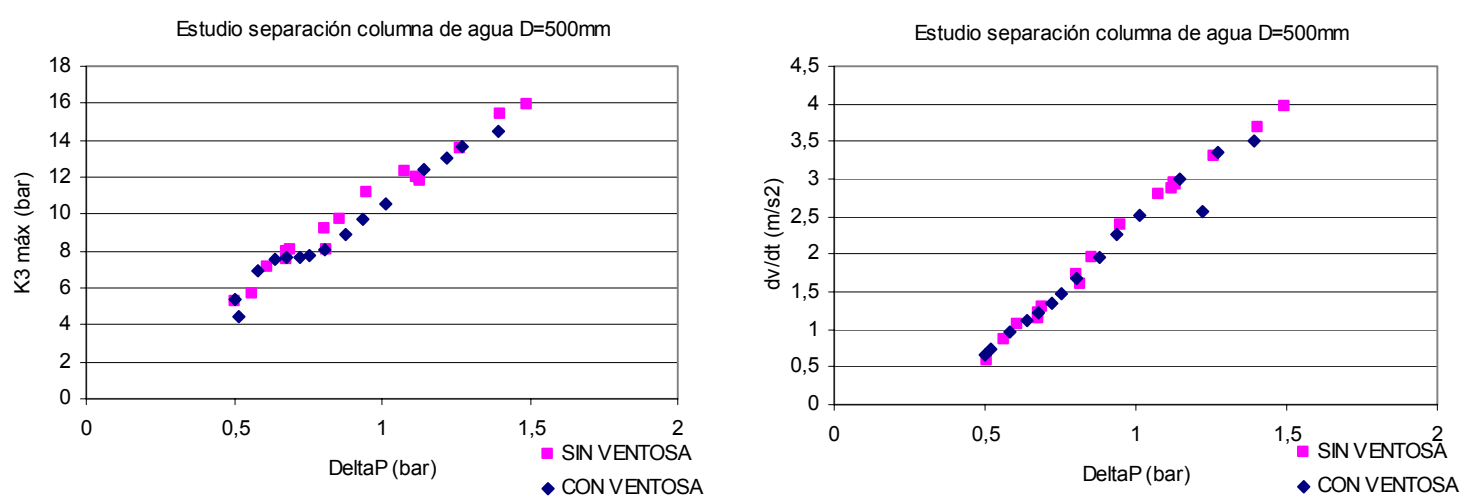

Figura 4.101. Presiones máximas y deceleración del flujo en ensayos de cierre de válvula de retención por inversión del flujo.

Dada una sobrepresión inicial aplicada a la columna de agua, la velocidad mínima que dicha columna alcanza durante un ensayo es similar tanto si se utiliza ventosa como si no se utiliza ventosa.
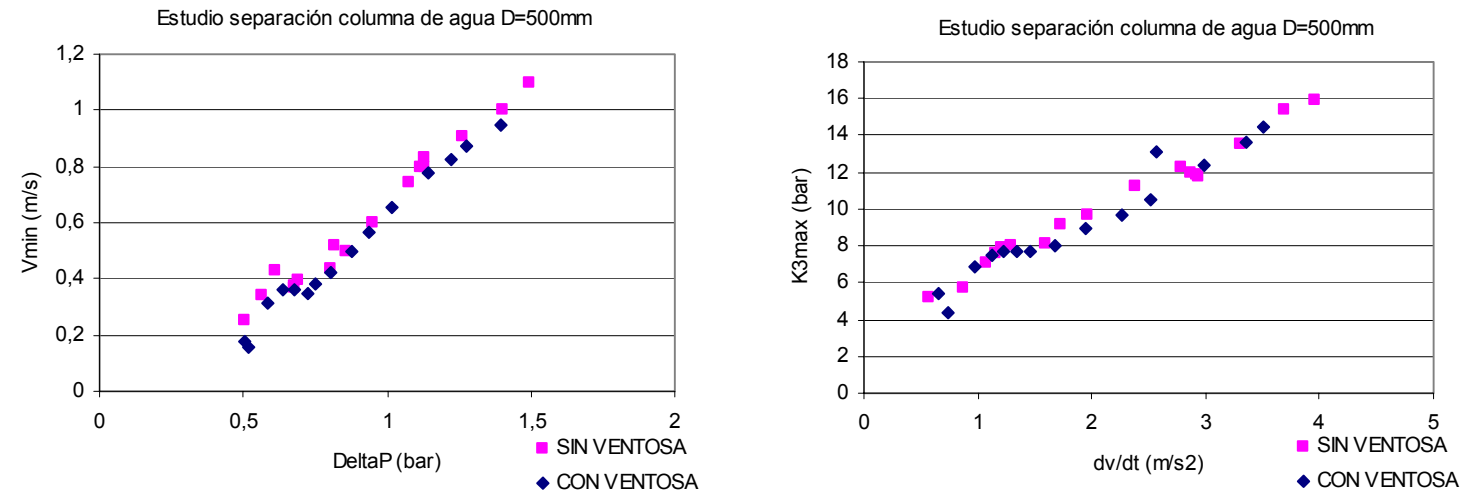

Figura 4.102. Velocidad mínima y Presión máxima en ensayos de cierre de válvula de retención por inversión del flujo
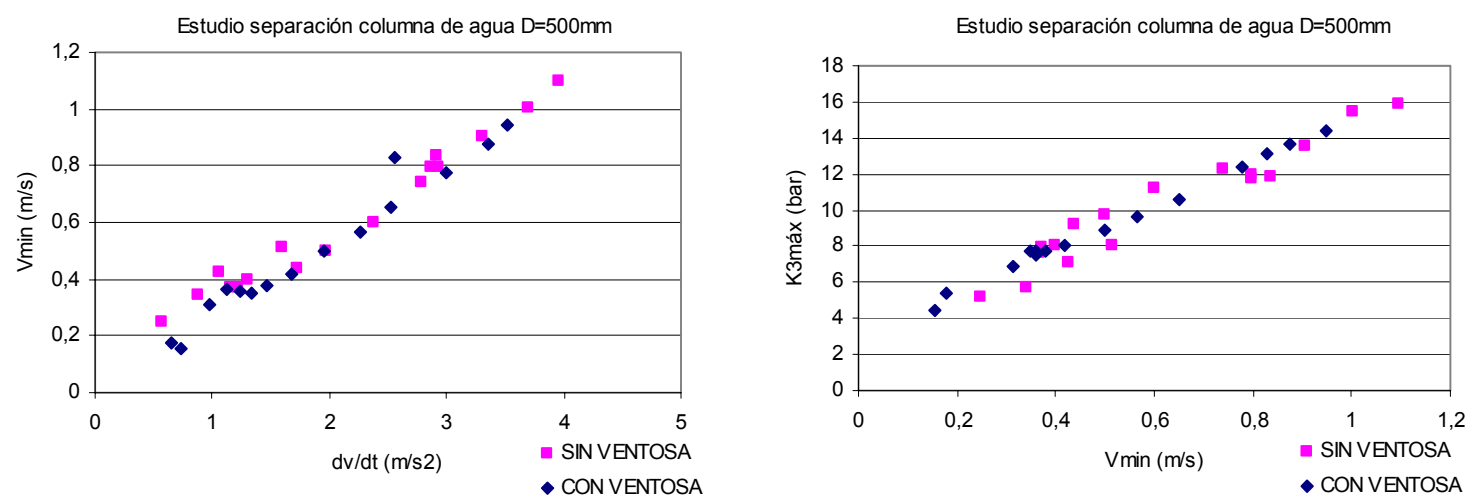

Figura 4.103. Velocidad mínima y presión máxima en ensayos de cierre de válvula de retención por inversión del flujo

El efecto más significativo conseguido con la presencia de la ventosa como se puede comprobar en la Figura 4.104 ha sido disminuir la duración de la depresión que se 
produce al cerrar la válvula de retención. La magnitud de la depresión producida es ligeramente más pronunciada en el ensayo sin ventosa. Además, la duración de la depresión se ve reducida a unos 60 ms cuando se sitúa una ventosa junto a la válvula de retención. Por tanto la ventosa contribuye en este caso positivamente a la disminución de la depresión.
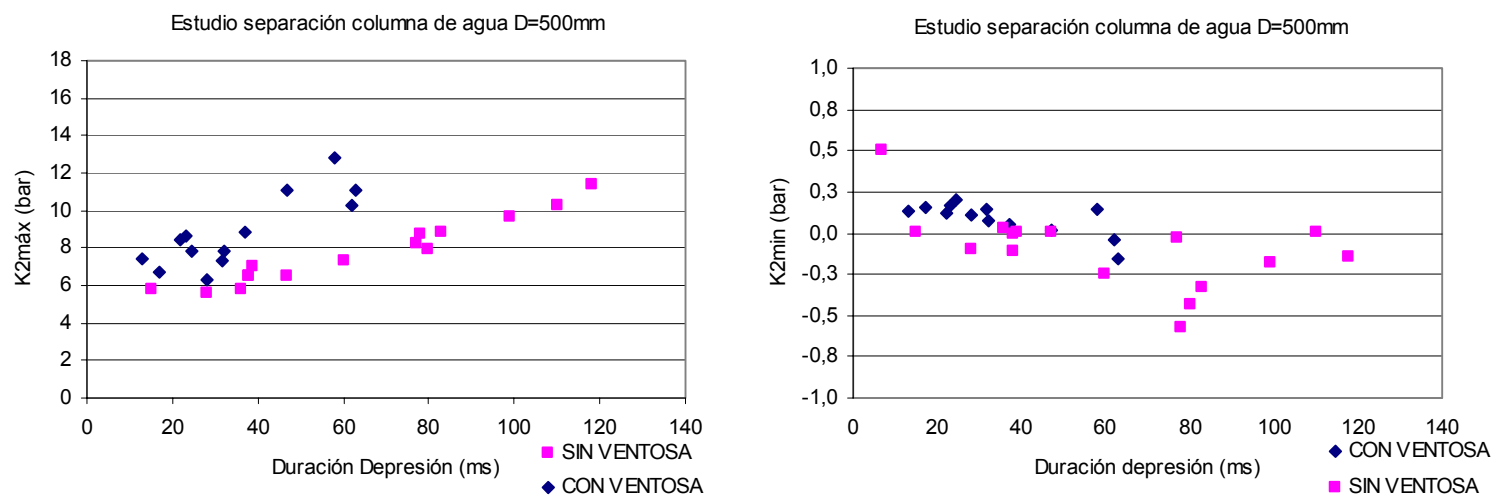

Figura 4.104. Relación entre la presión máxima y la duración de la depresión
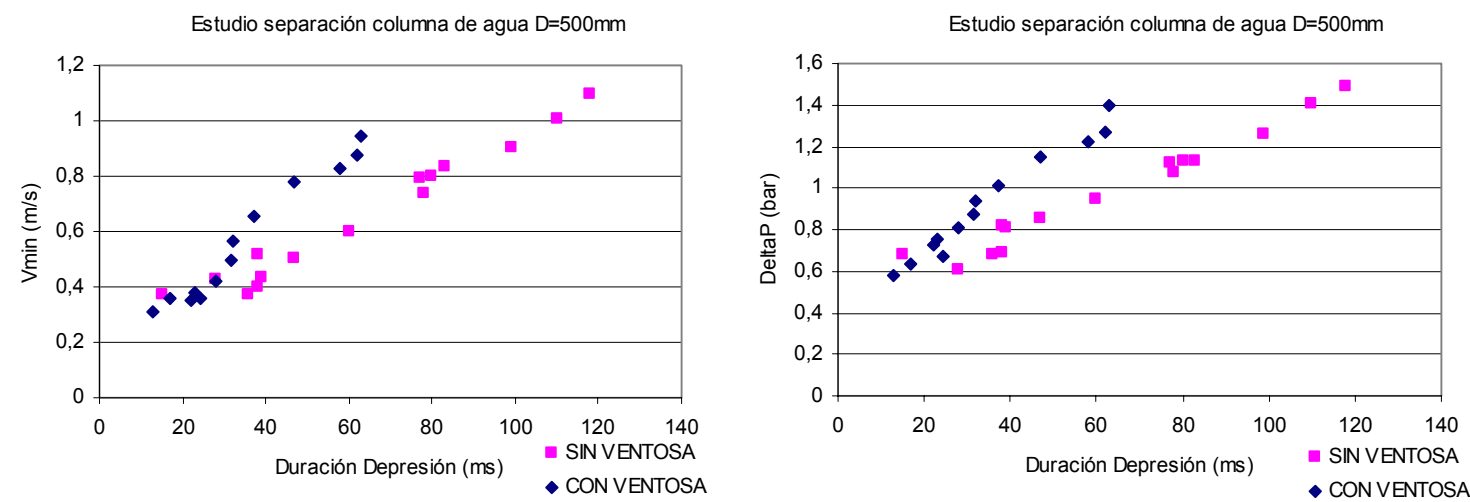

Figura 4.105. Relación entre la velocidad mínima, la duración de la depresión y la sobrepresión inicial aplicada en ensayos con y sin ventosa

\subsubsection{SEPARACIÓN DE LA COLUMNA DE AIRE EN LA CONDUCCIÓN DE $\mathrm{D}=200 \mathrm{~mm}$}

En este apartado el número de variables a analizar es menor ya que no se dispone de medidas de caudal fiables. Así pues, teniendo en cuenta que existen otras variables equivalentes, en cuanto a la predicción de resultados, a la velocidad mínima alcanzada por la columna de agua, $V_{\min }$, se ha procedido a analizar las medidas de presión aguas arriba y aguas abajo de la válvula de retención.

Las presiones máximas que se alcanzan a ambos lados de la válvula de retención son similares a las obtenidas al ensayar las ventosas de mayor tamaño sobre la conducción de $500 \mathrm{~mm}$ de diámetro. 

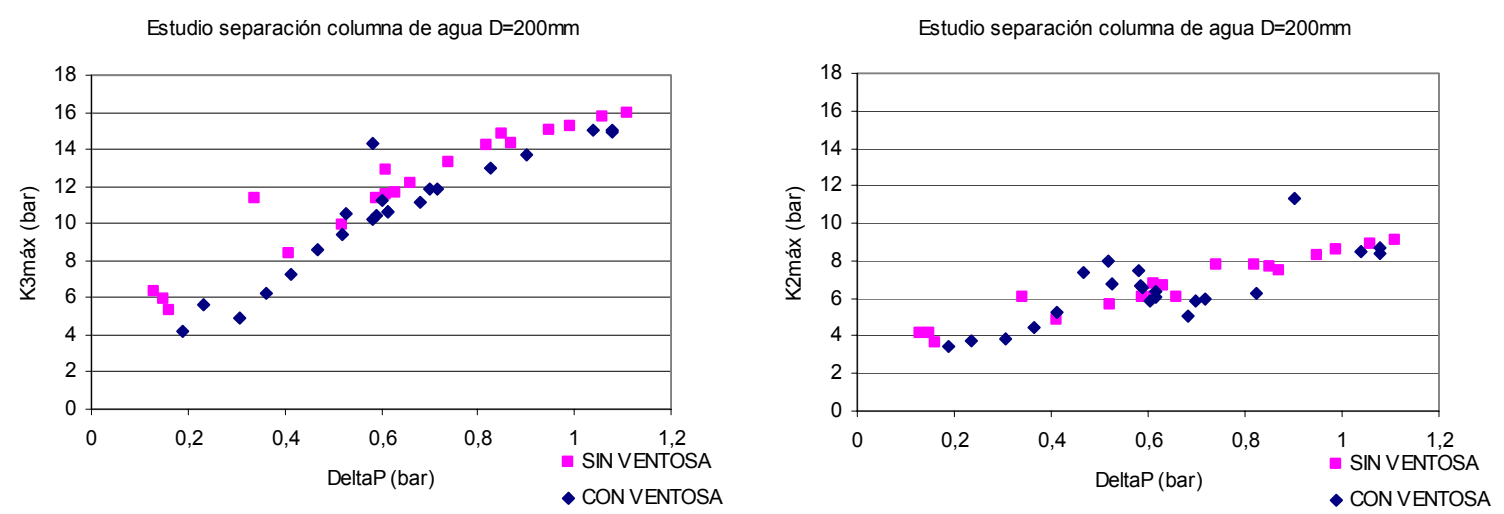

Figura 4.106. Presión aguas arriba y aguas abajo de la válvula de retención

Al instalar la ventosa se comprueba que la duración de la depresión producida junto a la válvula de retención se reduce, limitándose a un valor de unos $30 \mathrm{~ms}$, mientras que el valor absoluto de dicha depresión es prácticamente del mismo orden de magnitud tal y como se puede comprobar en la Figura 4.107
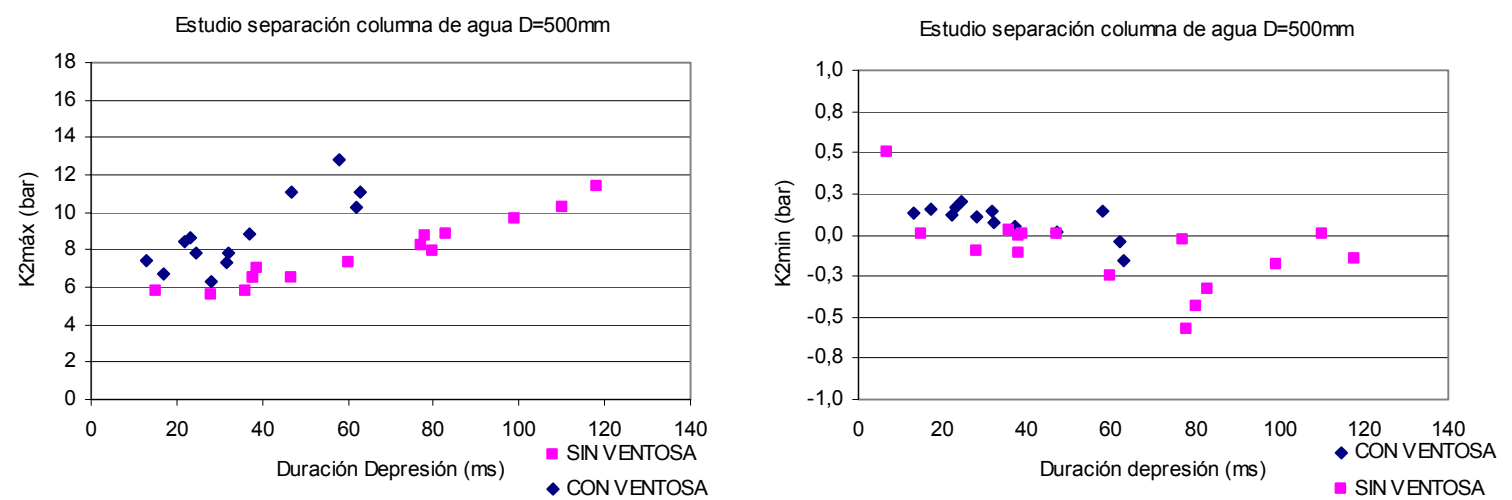

Figura 4.107. Medida de la presión en el lado de las bajas presiones.

Dado un mismo valor de la sobrepresión inicial aplicada a la columna de agua, como ya se ha comentado anteriormente, la duración de la depresión ocasionada es mayor en el caso de no utilizar una ventosa. 


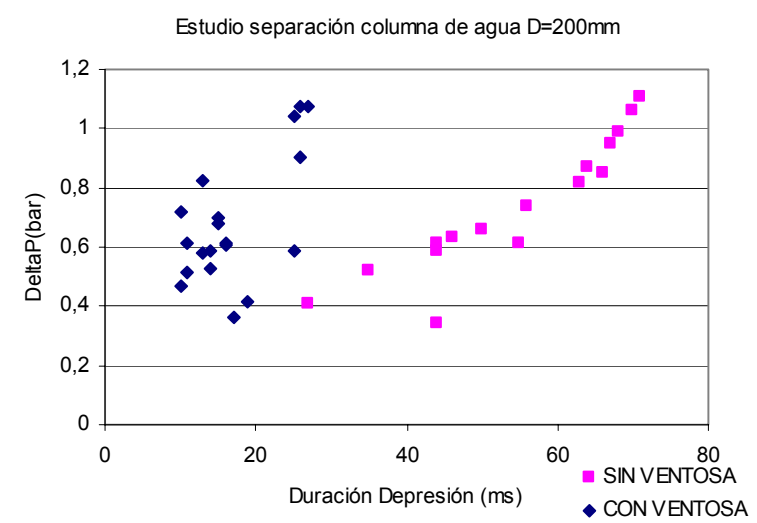

Figura 4.108. Duración de la depresión frente a la sobrepresión que invierte el flujo

\subsubsection{ADMISIÓN DE AIRE DURANTE EL VACIADO DE UNA CONDUCCIÓN}

En las instalaciones de Delft Hydraulics se realizaron con las mismas ventosas ensayos que simulan la admisión de aire a través de una ventosa situada en el punto más alto de la instalación cuando se procede al vaciado de una tubería. Se disponen de datos de caudal, medido en la tubería horizontal, presión en varios puntos de la instalación, tanto en la conexión en $\mathrm{T}$ de la ventosa con la instalación como a lo largo de la tubería, así como datos de temperatura y de desplazamiento del flotador en cada instante de tiempo. El procedimiento de ejecución de estos ensayos se detalla en el Capítulo 3 del presente trabajo.

Se ensayaron las ventosas A y B de diámetros $50 \mathrm{~mm}$ y $100 \mathrm{~mm}$ cada una. Como en el resto de casos las ventosas de DN50 se ensayan en la instalación de diámetro 200 mm y las de DN100 en la instalación de diámetro 500 mm. Luego en definitiva se dispone de datos de:

- Admisión de aire al final de una conducción mediante una ventosa de DN100

- Admisión de aire al final de una conducción mediante una ventosa de DN50

La tubería se conectaba al depósito D1 que contenía agua y que se encontraba presurizado. Dicho depósito estaba a su vez conectado con un depósito D2 que contenía aire el cual se encontraba a una presión menor. Como respuesta a la disminución de presión, la columna de agua se mueve en dirección al depósito de agua, con lo cual, deja de estar en contacto con el flotador de la ventosa generándose una depresión. En este instante, la ventosa abría y empezaba a admitir aire en el sistema. En la Figura 4.109 se muestra la evolución general de las principales variables medidas en los diferentes ensayos. Es decir, la presión junto a la ventosa medida con el transductor de presión K3, el caudal circulante por la conducción durante el transitorio y la posición del flotador de la ventosa. 


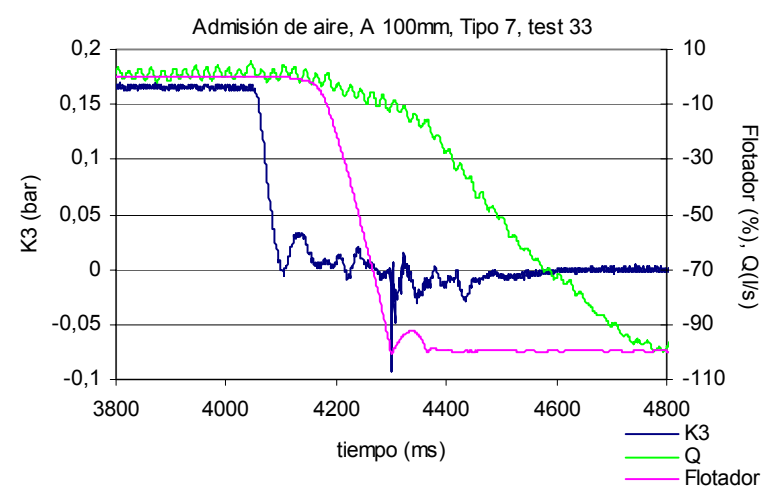

Figura 4.109. Evolución de un ensayo de admisión de aire a través de una ventosa

\subsubsection{ANÁLISIS DE LA PRESIÓN Y EL CAUDAL EN LOS ENSAYOS DE ADMISIÓN DE AIRE}

El número de ensayos de admisión de aire mediante una ventosa situada al final de una conducción es mucho menor que el resto de ensayos expuestos a lo largo de este capítulo. Con esta pequeña muestra, se representan los valores de las variables características de este tipo de ensayos, es decir, la presión mínima alcanzada en la instalación y el caudal mínimo. El valor del caudal de los ensayos realizados con ventosas de DN50 es orientativo debido, una vez más, a la lenta respuesta en frecuencia del caudalímetro de DN200.

Las presiones mínimas alcanzadas en el cuello de la ventosa son mucho más pequeñas en la ventosa B de DN100 que en la A del mismo tamaño. Esto puede ser debido a que el flotador de la ventosa B tiene un peso mayor, tal y como se muestra en las tablas de especificaciones de las ventosas sometidas a ensayo mostradas en el Capítulo 3 y por tanto mayor inercia. La ventosa $B$, en general, no es capaz de mitigar las depresiones con la misma eficacia que la ventosa $\mathrm{A}$.
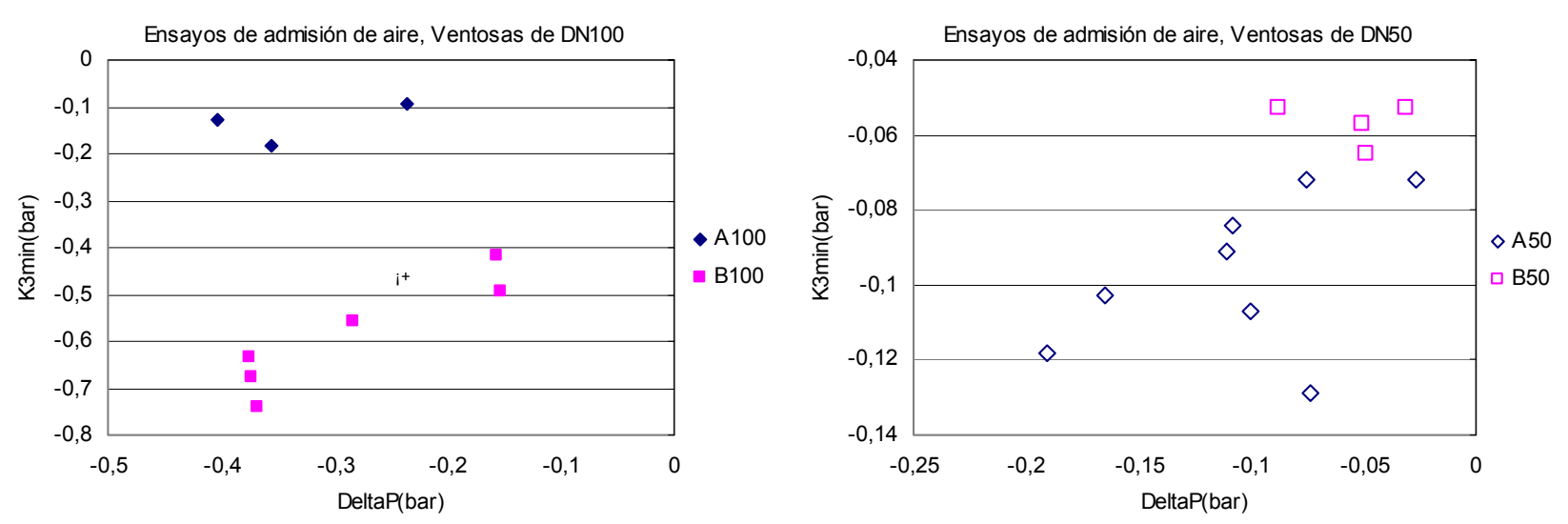

Figura 4.110. Presión mínima medida junto a la ventosa. 
Los caudales mínimos, que representan la magnitud del transitorio generado, son del mismo orden para las dos ventosas. De todos modos cabría ampliar el número de ensayos de las muestras para establecer conclusiones más firmes.
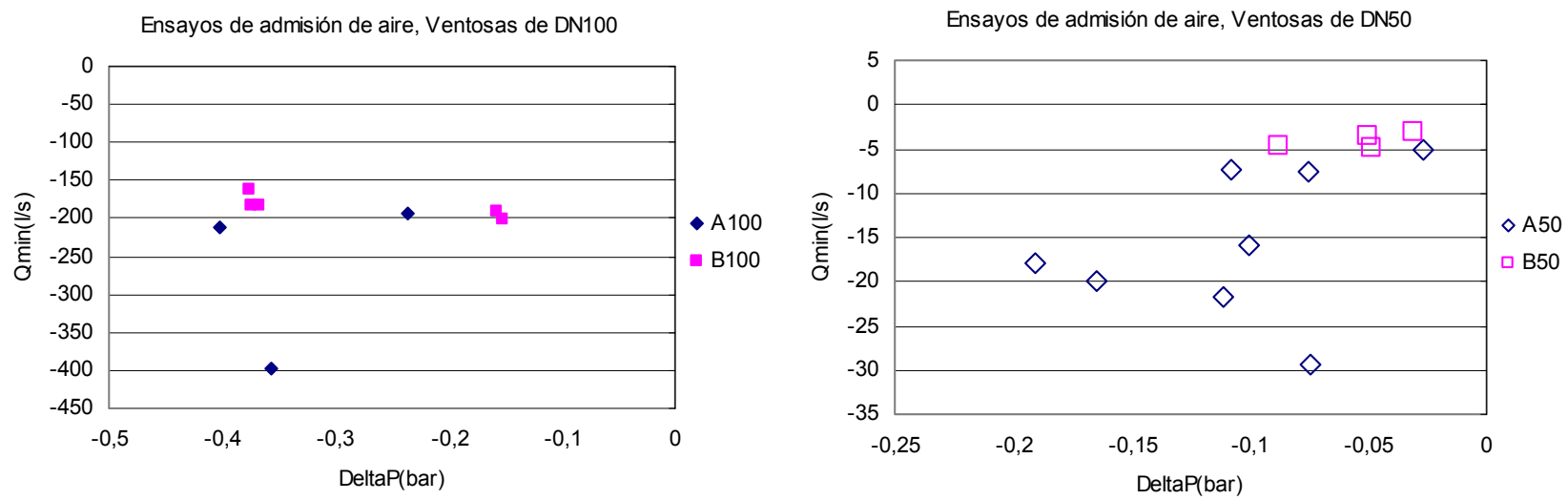

Figura 4.111. Caudales mínimos registrados durante los ensayos.

En general todos los ensayos presentan un comportamiento similar al mostrado en la Figura 4.109. Únicamente en un ensayo de la ventosa A de DN100 aparece una doble apertura de la ventosa debido a la oscilación en masa que hace que la columna de agua vuelva a la ventosa y la cierre, tal y como se muestra en la figura siguiente.

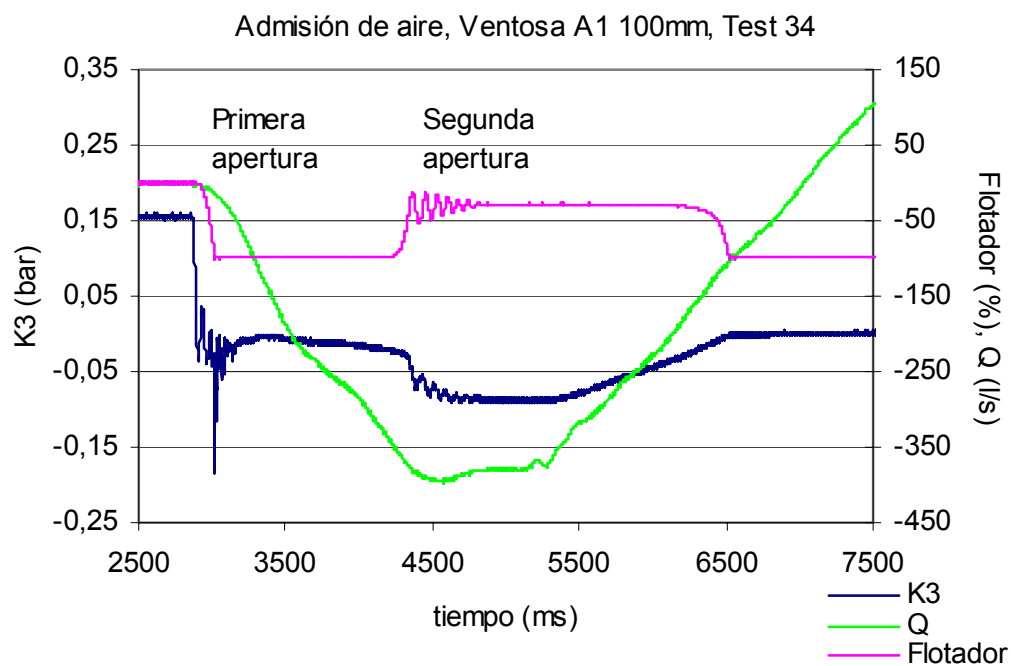

Figura 4.112. Evolución general de un ensayo de admisión de aire. 


CAPÍTULO 5. MODELACIÓN MATEMÁTICA DEL TRANSITORIO AGUA-AIRE 



\subsection{INTRODUCCIÓN}

Los resultados experimentales expuestos en el Capítulo 4, en el cual se analizan detalladamente cada uno de los tipos de ensayos realizados en las instalaciones de W.L.|Delft Hydraulics, ponen de manifiesto que bajo las mismas condiciones iniciales y de contorno, las presiones y velocidades difieren según la ventosa que se haya utilizado.

Uno de los principales objetivos de este trabajo consiste en elaborar un modelo matemático que sea capaz de reproducir el transitorio que se produce cuando partiendo de una instalación parcialmente llena de agua se procede a su llenado completo. El modelo que se pretende confeccionar debe considerar la expulsión de aire a través de una ventosa situada al final de la instalación que a su vez es el punto más elevado de la misma. Por ello, el modelo debe contener y enlazar las ecuaciones correspondientes a los dos fluidos que intervienen en el proceso, es decir, aire y agua.

Los diferentes resultados teóricos que aporte el modelo podrán ser contrastados posteriormente con los resultados de los experimentos realizados en las instalaciones de W.L.|Delft Hydraulics y que se han presentado en el capítulo cuatro. Estos resultados experimentales resultan de gran ayuda a la hora de determinar si realmente se pueden asumir las distintas suposiciones que simplifican el modelo.

La mayoría de los investigadores que han estudiado los transitorios hidráulicos con aire atrapado se han decantado por el uso del modelo rígido frente al modelo elástico. La razón fundamental es que con el modelo rígido se establecen importantes simplificaciones a nivel computacional. La respuesta ante la decisión de qué modelo utilizar no es inmediata y generalmente la cuestión de cuantificar la frontera entre el modelo elástico y 
el modelo rígido depende de cada sistema hidráulico tal y como concluyen Abreu et al. (1991).

Gracias a los avances tanto computacionales como a los avances en métodos numéricos hoy en día se pueden realizar simulaciones con condiciones críticas relativas a efectos que anteriormente se ignoraban resolviendo el transitorio mediante el modelo elástico sin que esto suponga un esfuerzo adicional de cálculo importante.

Martin C.S. (1976), aplicó el modelo rígido al caso de una apertura rápida de una válvula situada aguas arriba de una tubería que unía dos depósitos y que contenía una o más bolsas de aire atrapado localizado en los puntos más altos de la tubería. En su análisis consideró constante la longitud de la columna de agua.

Thorley y Main (1990) presentaron un análisis de un sistema representativo similar a una tubería que transporta un combustible líquido el cual explotó al ponerse en marcha la bomba. Los autores pusieron especial atención en sistemas relativamente cortos y compactos como los que se pueden encontrar en sistemas que transportan aceite sometidos a altas presiones. Los autores compararon los resultados experimentales con las predicciones teóricas tanto del modelo rígido como del elástico. Al final ambos investigadores concluyen que el modelo elástico proporciona resultados más exactos.

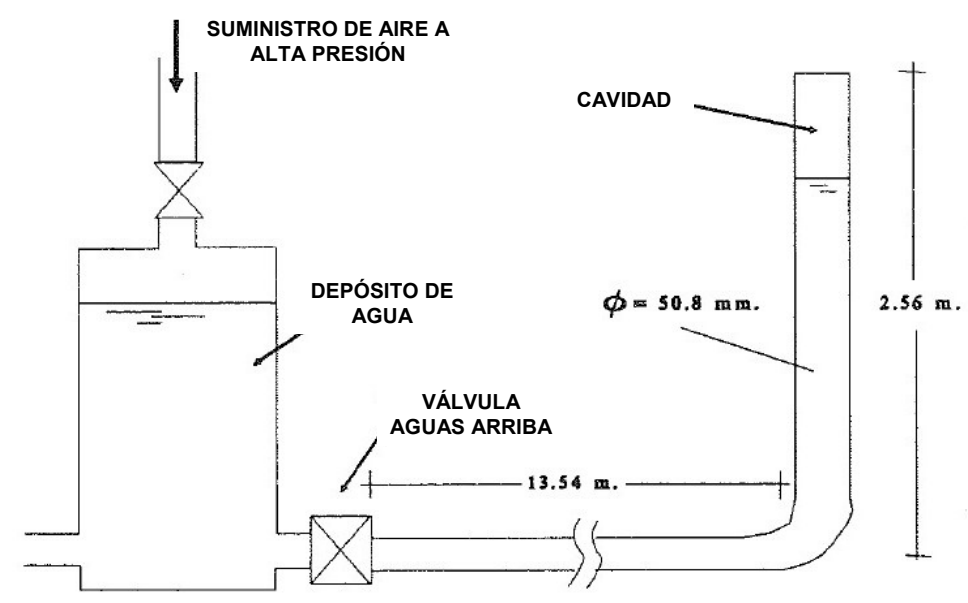

Figura 5.1. Experimento de Thorley y Spurret (1990)

En 1985 Jönsson presentó medidas realizadas en una estación de bombeo de un sistema de saneamiento que dispone de una válvula de retención. Cuando el nivel de agua en el calderín de la bomba era bajo entraba aire en la línea de succión de la bomba.

Los picos de presión eran considerablemente mayores que en el caso en el cual el nivel de agua fuera elevado. Para analizar este sistema usó ambos tipos de modelos de 
transitorios y concluyó que las propiedades elásticas de la columna de agua y de la tubería son muy importantes cuando el volumen de aire atrapado es pequeño.

\subsection{MODELO NUMÉRICO PARA SIMULAR LA EXPULSIÓN DE AIRE AL FINAL DE UNA TUBERÍA}

Los estudios anteriores presentan algunos puntos en común. En todos ellos existe una tubería parcialmente Ilena de agua la cual contiene una bolsa de aire. Una fuente de alimentación situada en un extremo del sistema proporciona la suficiente energía para acelerar la columna líquida y causar la compresión de la bolsa de aire. De este modo, la principal diferencia de todos estos estudios con el fenómeno tratado en este trabajo es que en este caso se incorpora una ventosa en el extremo final de la tubería, con lo cual se permite la salida automática de aire al exterior.

Al plantear el sistema de ecuaciones que describe el comportamiento de los dos fluidos (agua y aire) que se encuentran en el interior de la tubería se deben tener en cuenta:

- Las ecuaciones de conservación de la masa y de la cantidad de movimiento que rigen el comportamiento de la columna de agua.

- Las ecuaciones que describen el comportamiento de la bolsa de aire en cuanto a la compresión y expansión del mismo.

- Las condiciones iniciales que señalan el punto de partida para la evolución del transitorio.

- Las condiciones de contorno que describen el comportamiento de los elementos activos.

El esquema general seguido a la hora de resolver el transitorio hidráulico se compone de cinco etapas fundamentales, tal y como se muestra en la Figura 5.2:

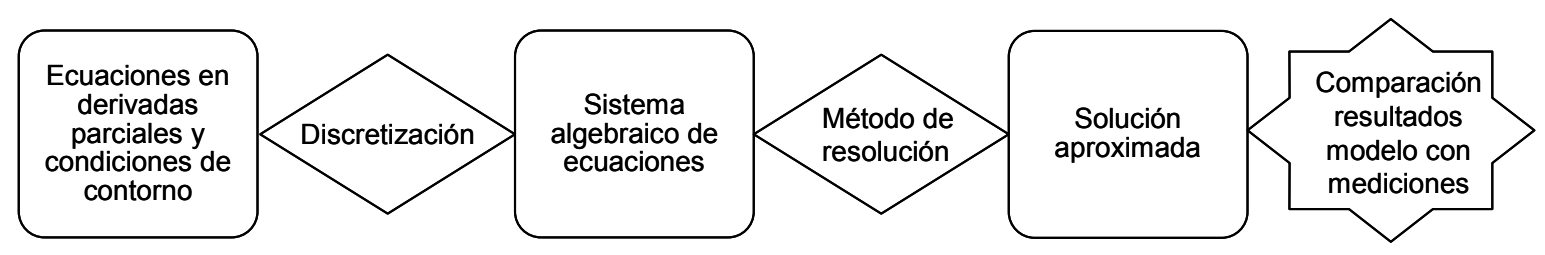

Figura 5.2. Fases en la resolución del transitorio. 


\subsubsection{ECUACIONES DEL MODELO}

Gracias a los avances tecnológicos en materia de computación se ha creído oportuno simular el transitorio con el modelo elástico. En los transitorios hidráulicos la elasticidad la aporta tanto el fluido, a través de la capacidad de almacenar energía elástica, como la tubería mediante posibles deformaciones en su diámetro.

Además de considerar elásticos los fluidos implicados en el fenómeno transitorio, también se tiene en cuenta la disminución de aire en el interior del sistema que se expulsa a través de la ventosa y la variación paulatina de la longitud columna de agua que avanza hacia la ventosa con el tiempo.

En el modelo teórico propuesto se establecen una serie de suposiciones básicas de partida, es decir:

- El movimiento de la columna de agua se calcula como si no hubiera aire disuelto en ella de manera que la columna de agua empuja la bolsa de aire situada aguas abajo de la misma.

- Tanto la columna de agua como la bolsa de aire ocupan toda la sección transversal de la tubería.

- La interfase aire-agua es en todo instante perpendicular al eje longitudinal de la tubería. Esta interfase se considera que permanece perfectamente definida.

- El aire se considera gas perfecto y su evolución es politrópica.

- El factor de fricción calculado como si se tratase de flujo estacionario es aplicable a las condiciones de flujo transitorio.

- La celeridad del fluido es constante a lo largo del tiempo y del espacio. Se suponen uniformes las características del agua y del aire (cada una por separado) en toda la longitud.

- Se considera una evolución lineal del coeficiente de descarga de la ventosa con el grado de apertura de la misma durante el intervalo de tiempo que dura el cierre. Dicha suposición se puede considerar válida tras los resultados obtenidos en el análisis de los ensayos experimentales.

\subsubsection{BALANCE DIFERENCIAL DE MASA: ECUACIÓN DE CONTINUIDAD.}

Las dos expresiones básicas de los transitorios hidráulicos elásticos pueden ser elaboradas a partir de las ecuaciones de continuidad y de la conservación de la cantidad de movimiento. El objetivo fundamental es obtener los valores de la presión y la velocidad a lo largo del espacio y del tiempo a partir del instante en el cual se genera la perturbación que hace abandonar el estado estacionario, esto es:

$$
p=p(x, t) \quad ; \quad V=V(x, t)
$$




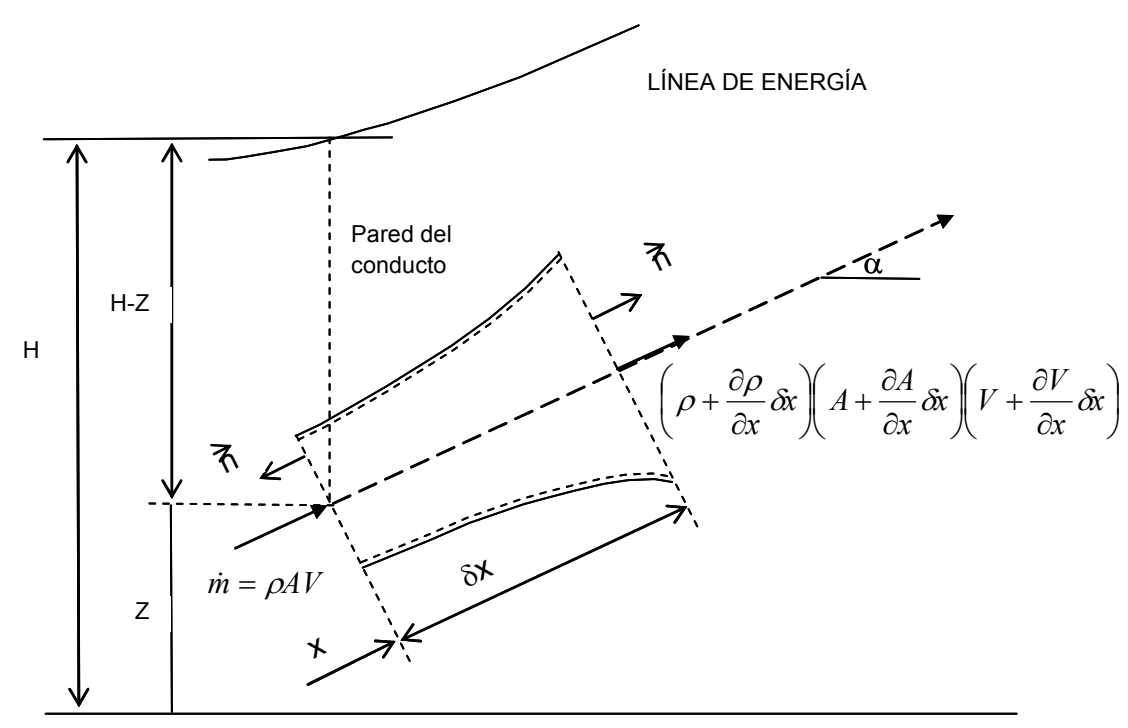

Figura 5.3. Balance de masa

La ecuación de continuidad aplicada a un volumen diferencial como el representado en la Figura 5.3 plantea básicamente que la masa que entra en este volumen de control más la variación temporal de la masa encerrada en el mismo es igual a cero. Esto se puede expresar matemáticamente como:

$\frac{\partial}{\partial t} \int_{V C} \rho \cdot \delta \forall+\int_{S C} \rho \cdot \vec{V} d \vec{A}=0$

Obviando el carácter vectorial de la ecuación anterior ya que se considera flujo unidimensional, el flujo másico neto se puede expresar como:

$$
\int_{S C} \rho V d A=-\rho A V+\left(\rho+\frac{\partial \rho}{\partial x} \delta x\right)\left(A+\frac{\partial A}{\partial x} \delta x\right)\left(V+\frac{\partial V}{\partial x} \delta x\right)
$$

Luego la ecuación (Ec. 5.1) puede escribirse de la siguiente forma:

$$
-\rho A V+\left(\rho+\frac{\partial \rho}{\partial x} \delta x\right)\left(A+\frac{\partial A}{\partial x} \delta x\right)\left(V+\frac{\partial V}{\partial x} \delta x\right)+\frac{\partial}{\partial t}(\rho A \delta x)=0
$$

Realizando las oportunas transformaciones algebraicas, despreciando los términos en $(\delta x)^{2}$ y dividiendo todos los términos por $\rho A \delta x$ se obtiene:

$\frac{1}{\rho} \cdot \frac{\partial \rho}{\partial t}+\frac{V}{\rho} \cdot \frac{\partial \rho}{\partial x}+\frac{1}{A} \cdot \frac{\partial A}{\partial t}+\frac{V}{A} \cdot \frac{\partial A}{\partial x}+\frac{1}{\delta x} \cdot \frac{\partial(\delta x)}{\partial t}+\frac{\partial V}{\partial x}=0$ 
La derivada total de una función puede escribirse como la suma de la derivada local más la derivada convectiva del siguiente modo:

$\frac{d G}{d t}=V \frac{\partial G}{\partial x}+\frac{\partial G}{\partial t}$

y sabiendo que para el volumen de control permaneciendo fijo $\partial\left(\frac{\delta x}{\partial t}\right)=0$ la ecuación (Ec. 5.4) queda como:

$\frac{1}{\rho} \frac{d \rho}{d t}+\frac{1}{A} \frac{d A}{d t}+\frac{\partial V}{\partial x}=0$

La ecuación (Ec. 5.6) es la ecuación de continuidad válida para un conducto cualquiera de sección A, ya sea rígido o flexible, el cual transporta un fluido homogéneo. En dicha expresión aparecen como incógnitas la densidad del fluido, $\rho$, la sección del conducto A, y la velocidad del fluido $V$. Generalmente se trabaja en función de las variables más significativas, presión y velocidad, lo cual supone relacionar los efectos elásticos (variaciones de densidad y sección) con la causa que los genera, es decir, las variaciones de presión. Aplicando las transformaciones adecuadas se obtiene una expresión de la ecuación de continuidad que relaciona la altura piezómetrica con la velocidad del siguiente modo:

$\frac{g}{a^{2}} \frac{d H}{d t}+\frac{\partial V}{\partial x}+\frac{g}{a} V \operatorname{sen} \alpha=0$

Siendo la celeridad:

$a=\frac{\sqrt{\frac{K}{\rho}}}{\sqrt{1+\frac{K}{E} \frac{D}{e}}}$

Donde:

K, módulo de compresibilidad del fluido

E, módulo de Young del material de la tubería

$\mathrm{D}$, diámetro de la tubería

e, espesor de la tubería

$\rho$, densidad del fluido 
En la Figura 5.4 aparece la gráfica aportada por Kobori et al. en la cual se muestra la variación de la celeridad de un fluido, calculada tanto teórica como experimentalmente, en función de la cantidad de aire disuelto en el agua

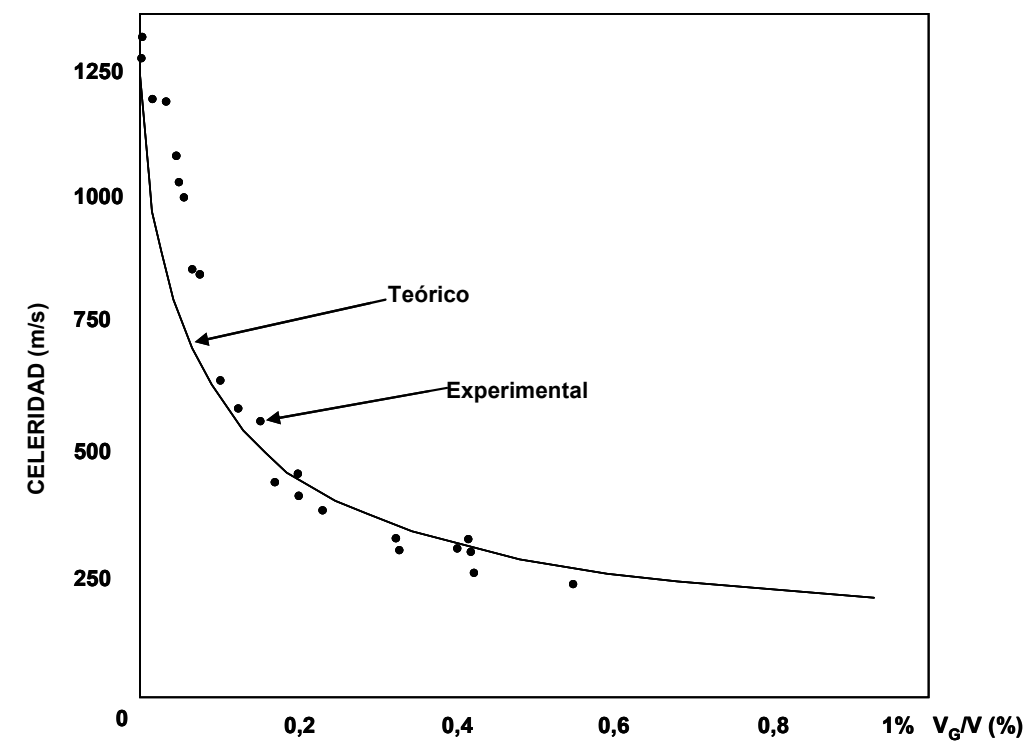

Figura 5.4. Celeridad del fluido según la proporción de gas y líquido

\subsubsection{BALANCE DIFERENCIAL DE FUERZAS: ECUACIÓN DE LA CANTIDAD DE MOVIMIENTO.}

Para efectuar el balance de fuerzas en un instante de tiempo dado cuando la tubería está deformada se utiliza un volumen de control como el representado en la Figura 5.5. Las fuerzas actuantes sobre la región de control son las fuerzas de presión que actúan en las secciones transversales del volumen de control, las fuerzas de rozamiento que actúan sobre las paredes del conducto y la fuerza gravitatoria. Se supone que el flujo es unidimensional y la fuerza de rozamiento entre secciones de fluido se calcula como si se tratara de un flujo en régimen estacionario. 


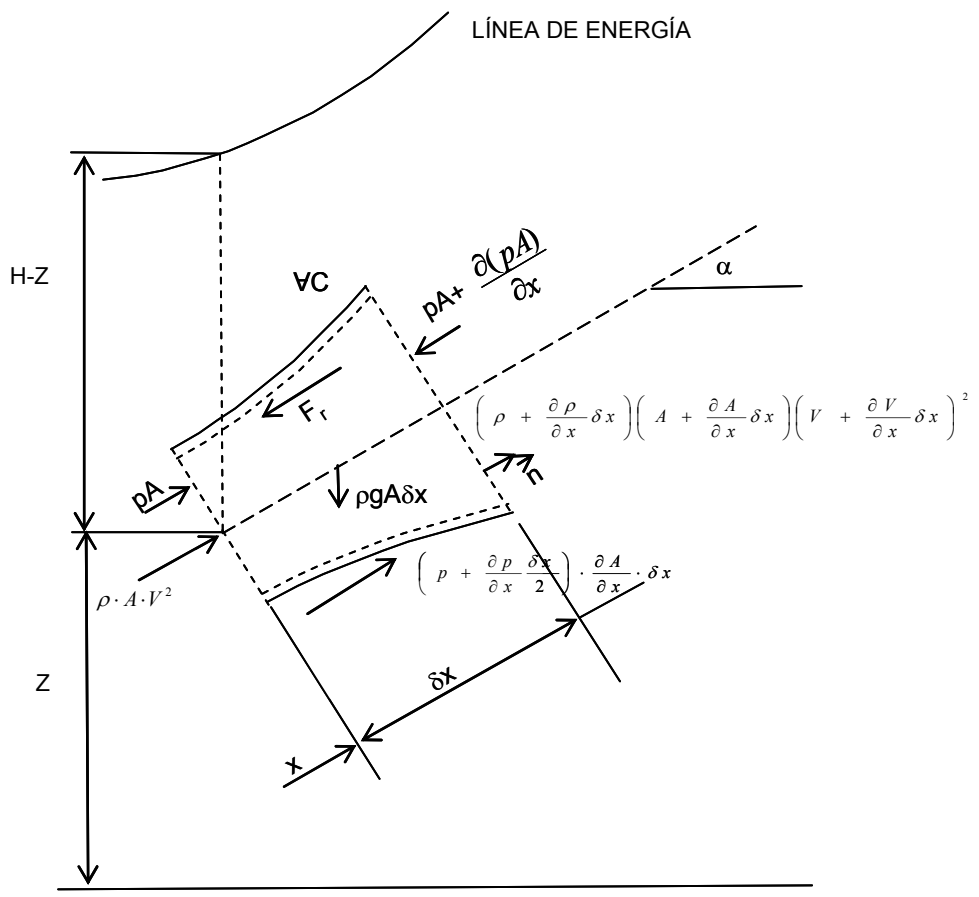

Figura 5.5. Balance de fuerzas

La fuerza gravitatoria volumétrica coincide con el peso del elemento de volumen que proyectada en la dirección del movimiento queda como:

$\delta W_{X}=\rho \cdot g \cdot A \cdot \delta x \cdot \operatorname{sen} \alpha$

La fuerza de rozamiento, supuesto el régimen estacionario, se obtiene aplicando la expresión de Darcy-Weisbach:

$\delta F_{r}=A \cdot \gamma \cdot h_{f}=\rho \cdot g \cdot f \cdot \frac{\delta x}{D} \cdot \frac{V^{2}}{2 g} \cdot A$

siendo f el coeficiente de fricción y $\gamma$ el peso específico del fluido $(\gamma=\rho \cdot \mathrm{g})$

Como la fuerza de rozamiento es contraria al movimiento hay que modificar el término cuadrático $\mathrm{V}^{2}$ para que refleje correctamente el sentido de la fuerza, así pues la fuerza de rozamiento se puede expresar como:

$\delta F_{r}=\rho \cdot g \cdot f \cdot \frac{\delta x}{D} \cdot \frac{V \cdot|V|}{2 g} \cdot A$ 
El balance de las fuerzas de presión que actúan sobre todo el contorno es:

$$
p A-\left(p+\frac{\partial p}{\partial x} \delta x\right) \cdot\left(A+\frac{\partial A}{\partial x} \delta x\right)+\left(p+\frac{\partial p}{\partial x} \frac{\delta x}{2}\right) \cdot\left(\frac{\partial A}{\partial x} \delta x\right)
$$

Eliminando los términos en $(\delta x)^{2}$ y realizando las simplificaciones oportunas, el balance de fuerzas queda de la siguiente forma:

$$
\sum F=-A \cdot \frac{\partial p}{\partial x} \cdot \delta x-\rho \cdot f \cdot \frac{A \cdot \delta x \cdot V \cdot|V|}{2 D}+\rho \cdot g \cdot A \cdot \delta x \cdot \operatorname{sen} \alpha \cong \rho \cdot A \cdot \delta x \cdot \frac{d V}{d t}(\text { Ec. 5.13) }
$$

Dividiendo ambos términos por $\rho \cdot A \cdot \delta x$, resulta la ecuación:

$$
\frac{d V}{d t}+f \cdot \frac{V \cdot|V|}{2 D}+\frac{1}{\rho} \cdot \frac{\partial p}{\partial x}-g \cdot \operatorname{sen} \alpha=0
$$

Como en el caso de la ecuación de conservación de la masa, es interesante expresar la ecuación anterior en función de las variables significativas, altura piezómetrica y velocidad, $\mathrm{H}$ y V. Para ello hay que considerar que $\operatorname{sen} \alpha=-\frac{\partial z}{\partial x}$ con lo que la ecuación del balance de fuerzas queda expresada como:

$\frac{d V}{d t}+f \cdot \frac{V \cdot|V|}{2 D}+g \cdot \frac{\partial H}{\partial x}=0$

Finalmente, se llega a la conclusión que para simular el comportamiento de la columna de agua se dispone del siguiente sistema de ecuaciones diferenciales:

$$
\left\{\begin{array}{c}
\frac{d V}{d t}+f \cdot \frac{V \cdot|V|}{2 D}+g \cdot \frac{\partial H}{\partial x}=0 \\
\frac{g}{a^{2}} \cdot \frac{d H}{d t}+\frac{\partial V}{\partial x}+\frac{g}{a} \cdot V \cdot \operatorname{sen} \alpha=0
\end{array}\right.
$$

La transición del sistema elástico al modelo rígido (fluido incompresible y tubería rígida) resulta sencilla a partir del concepto de celeridad de la onda de presión expresado anteriormente. Cuando dicha celeridad tiende a infinito $(a \rightarrow \infty)$ por ser el sistema rígido, o la variación local de la altura piezométrica $\mathrm{H}$ tiende a cero $(\partial H / \partial t \rightarrow 0)$ por cambiar las condiciones del flujo muy lentamente en el tiempo, la primera ecuación del sistema de ecuaciones diferenciales deducido anteriormente se convierte en: 


$$
\frac{\partial V}{\partial x}=0
$$

Con lo cual la velocidad del flujo pasa a depender únicamente del tiempo, es decir, $\mathrm{V}=\mathrm{V}(\mathrm{t})$ mientras que la segunda ecuación del sistema de ecuaciones diferenciales se convierte en:

$$
\frac{1}{g} \cdot \frac{d V}{d t}+\frac{d H}{d x}+\frac{f}{D} \cdot \frac{V \cdot|V|}{2 g}=0
$$

Las ecuaciones diferenciales que componen el sistema del modelo rígido queda de este modo como:

$$
\left\{\begin{array}{l}
\frac{\partial V}{\partial x}=0 \\
\frac{1}{g} \cdot \frac{d V}{d t}+\frac{d H}{d x}+\frac{f}{D} \cdot \frac{V \cdot|V|}{2 g}=0
\end{array}\right.
$$

\subsubsection{ECUACIONES DE LA BOLSA DE AIRE}

El movimiento de la bolsa de aire se determina básicamente a partir del modelo teórico desarrollado por Martin (1976) para calcular la oscilación de la presión de una bolsa de aire atrapada en una tubería sujeta a aperturas instantáneas de una válvula.

$\frac{d H^{*}}{d t}=-k \cdot \frac{H^{*}}{\forall_{a}} \cdot \frac{d \forall_{a}}{d t}-k \cdot \frac{H^{*}}{\forall_{a}} \cdot Q_{a}$

En la expresión anterior la altura de presión de la bolsa de aire viene dada en términos de presión absoluta. Por otro lado, $\mathrm{Q}_{\mathrm{a}}$ es el caudal volumétrico de aire que es expulsado a través del orificio de la ventosa. El área del orificio de salida se representa como $A_{0}$ mientras que $k$ es el coeficiente politrópico.

Por otro lado la variación del volumen de la bolsa de aire está relacionada con la velocidad de la columna de agua del siguiente modo:

$\frac{d \forall_{a}}{d t}=-A \cdot V$ 
Siendo A, el área de la sección transversal de la tubería de diámetro D.

El caudal de aire que se expulsa a través de la ventosa se puede obtener mediante las siguientes expresiones en función del carácter del flujo de aire:

En condiciones subsónicas, es decir, si $H^{*} / H_{0}^{*}<1,89$, el caudal de aire se calcula como:

$Q_{a}=C_{d} \cdot A_{0} \cdot Y \cdot \sqrt{2 \cdot g \frac{\rho}{\rho_{a}} \cdot\left(H^{*}-H_{0}^{*}\right)}$

Y el factor de expansión se puede expresar según Martin (1976) como:

$Y=\sqrt{\frac{k}{k-1} \cdot\left(\frac{H_{0}^{*}}{H^{*}}\right)^{2 / k} \cdot \frac{1-\left(\frac{H_{0}^{*}}{H^{*}}\right)^{(k-1) / k}}{1-\frac{H_{0}^{*}}{H^{*}}}}$

Sin embargo, en condiciones de flujo supersónicas, es decir, si $H^{*} / H_{0}^{*}>1,89$, la velocidad del aire en el cuello de la ventosa es constante, bloqueándose el caudal volumétrico expulsado:

$Q_{a}=C_{d} \cdot A_{0} \cdot \sqrt{\left(g \cdot \frac{\rho}{\rho_{a}} \cdot H^{*}\right) \cdot\left[k \cdot\left(\frac{2}{k+1}\right)^{\frac{k+1}{k-1}}\right]}$

En este caso, el coeficiente de expansión Y adopta un valor de 0.684

En las expresiones anteriores, $\mathrm{H}_{0}$ * es la altura de presión del aire en el instante inicial, que en este caso es igual a la presión atmosférica en términos absolutos. $C_{d}$ es el coeficiente de descarga de la ventosa, el cual se puede determinar bien a partir de unas tablas hidráulicas convencionales para flujos compresibles a través de orificios o toberas o bien a partir de las recomendaciones de la American Gas Association (1978).

La norma ISO Standard 5167-1 (ISO 1998) no considera un valor constante para el $\mathrm{C}_{d}$ sino que propone seguir la ecuación de Reader-Harris/Gallagher la cual establece diferentes valores según la relación entre el diámetro del orificio de salida y el diámetro de la tubería $d / D$. Los valores del coeficiente de descarga según esta norma son menores que los propuestos por la American Gas Association. 
En el modelo planteado en este estudio, se opta por utilizar los coeficientes de descarga calculados a partir de los ensayos de flujo en régimen permanente para la determinación de la capacidad de expulsión de aire de cada ventosa efectuados en las instalaciones de W.L.|Delft Hydraulics, tal y como se expone en el capítulo 4. El coeficiente de descarga calculado de este modo resulta sensiblemente mayor que el valor propuesto por la American Gas Association igual a 0,65.

\subsubsection{RESOLUCIÓN DE LAS ECUACIONES MEDIANTE EL MÉTODO DE LAS CARACTERÍSTICAS}

La resolución del transitorio, considerando el modelo elástico, se realiza mediante métodos numéricos ya que el sistema de ecuaciones diferenciales no se puede resolver analíticamente. El método numérico de resolución adoptado ha sido el método de las características que consiste fundamentalmente en una discretización de las ecuaciones en derivadas parciales.

La discretización para definir el esquema en diferencias se efectúa en el plano $(x, t)$ para cada variable dependiente velocidad, $\mathrm{V}(\mathrm{x}, \mathrm{t})$ y altura piezométrica, $\mathrm{H}(\mathrm{x}, \mathrm{t})$. La solución numérica se obtiene de una forma progresiva, para cada instante de tiempo $(0<t<\infty)$ y cada punto del sistema en $0<x<L$ a partir de unos valores iniciales conocidos $V(x, 0)$, $\mathrm{H}(\mathrm{x}, 0)$ y de las condiciones de contorno.

El esquema del procedimiento empleado para la resolución del sistema de ecuaciones es el siguiente:

- En primer lugar se procede a la preparación de las ecuaciones de la columna de agua y de la bolsa de aire para su posterior discretización en el plano $(x, t)$.

- Seguidamente se discretizan las ecuaciones que describen el comportamiento de la columna de agua y de la bolsa de aire.

- Finalmente se acoplan las ecuaciones complementarias de la columna de agua, las de la bolsa de aire, las ecuaciones que dan información de las condiciones iniciales y las condiciones de contorno siguiendo un esquema determinado.

A partir del sistema de ecuaciones:

$$
\left\{\begin{array}{c}
\frac{g}{a^{2}} \cdot \frac{d H}{d t}+\frac{\partial V}{\partial x}+\frac{g}{a} \cdot V \cdot \operatorname{sen} \alpha=0 \\
\frac{d V}{d t}+f \cdot \frac{V \cdot|V|}{2 D}+g \cdot \frac{\partial H}{\partial x}=0
\end{array}\right.
$$


Y teniendo en cuenta las derivadas totales:

$$
\begin{aligned}
& \frac{d V}{d t}=\frac{\partial V}{\partial t}+V \cdot \frac{\partial V}{\partial x} \\
& \frac{d H}{d t}=\frac{\partial H}{\partial t}+H \cdot \frac{\partial H}{\partial x}
\end{aligned}
$$

Se puede escribir el sistema de ecuaciones como:

$$
\begin{aligned}
& L_{1}: \frac{g}{a^{2}} \cdot\left(\frac{\partial H}{\partial t}+H \cdot \frac{\partial H}{\partial x}\right)+\frac{\partial V}{\partial x}+\frac{g}{a} \cdot V \cdot \operatorname{sen} \alpha=0 \\
& L_{2}: \frac{\partial V}{\partial t}+V \cdot \frac{\partial V}{\partial x}+f \cdot \frac{V \cdot|V|}{2 D}+g \cdot \frac{\partial H}{\partial x}=0
\end{aligned}
$$

Combinando linealmente las ecuaciones $L_{1}$ y $L_{2}$ se obtiene una nueva ecuación de modo que:

$$
\begin{aligned}
& L_{1}+\lambda \cdot L_{2}=0 \\
& {\left[\frac{\partial H}{\partial t}+\frac{\partial H}{\partial x} \cdot(\lambda g+V)\right]+\lambda \cdot\left[\frac{\partial V}{\partial t}+\frac{\partial V}{\partial x} \cdot\left(\frac{a^{2}}{g \cdot \lambda}\right)+V\right]+\lambda \cdot f \cdot \frac{V|V|}{2 D}+V \operatorname{sen} \alpha=0}
\end{aligned}
$$

Si se cumple que el multiplicador $\lambda$ es de tal forma que se verifica la ecuación:

$$
\frac{d x}{d t}=\lambda \cdot g+V=\frac{a^{2}}{\lambda \cdot g}+V
$$

Entonces la ecuación anterior puede escribirse como:

$$
\frac{d H}{d t}+\lambda \cdot \frac{d V}{d t}+\lambda \cdot f \cdot \frac{V \cdot|V|}{2 D}+V \operatorname{sen} \alpha=0
$$

Esta ecuación en derivadas totales es fácilmente integrable, el problema reside en que solo es válida para los valores $\lambda$ que cumplen:

$$
\lambda \cdot g+V=\frac{a^{2}}{\lambda \cdot g}+V \rightarrow \lambda^{2}=\frac{a^{2}}{g^{2}} \rightarrow \lambda= \pm \frac{a}{g}
$$

Luego, el valor de la variación de $x$ con el tiempo, $d x / d t$, también varía dependiendo del valor de $\lambda$ adoptado: 


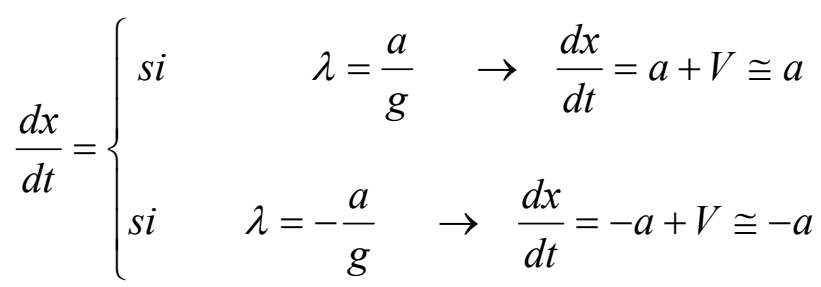

En las expresiones anteriores se puede despreciar la velocidad del fluido, que es de unos pocos metros por segundo, teniendo en cuenta que la celeridad de la onda de presión es del orden de $1.000 \mathrm{~m} / \mathrm{s}$.

Finalmente, el sistema de ecuaciones en derivadas totales se compone por las dos ecuaciones siguientes:

$$
\begin{array}{ll}
\frac{d H}{d t}+\frac{a}{g} \cdot \frac{d V}{d t}+\frac{a}{g} \cdot f \cdot \frac{V \cdot|V|}{2 D}+V \cdot \operatorname{sen} \alpha=0 & \rightarrow \frac{d x}{d t}=+a \\
\frac{d H}{d t}+\frac{a}{g} \cdot \frac{d V}{d t}-\frac{a}{g} \cdot f \cdot \frac{V \cdot|V|}{2 D}+V \cdot \operatorname{sen} \alpha=0 & \rightarrow \frac{d x}{d t}=-a
\end{array}
$$

Con la integración de estas dos ecuaciones se pretende determinar los valores de la altura piezométrica $\mathrm{H}\left(\mathrm{x}_{\mathrm{i}}, \mathrm{t}_{\mathrm{i}}\right)$ y la velocidad $\mathrm{V}\left(\mathrm{x}_{\mathrm{i}}, \mathrm{t}_{\mathrm{i}}\right)$ en un punto e instante dado $\mathrm{P}$. Estos valores se obtienen a partir de los valores de altura piezométrica $\mathrm{H}$ y velocidad $\mathrm{V}$ de los puntos anterior $\mathrm{H}\left(\mathrm{x}_{\mathrm{i}-1}, \mathrm{t}_{\mathrm{i}-1}\right)$ y $\mathrm{V}\left(\mathrm{x}_{\mathrm{i}-1}, \mathrm{t}_{\mathrm{i}-1}\right)$ y posterior $\mathrm{H}\left(\mathrm{x}_{\mathrm{i}+1}, \mathrm{t}_{\mathrm{i}-1}\right)$ y $\mathrm{V}\left(\mathrm{x}_{\mathrm{i}+1}, \mathrm{t}_{\mathrm{i}-1}\right)$ en el instante anterior, $\mathrm{A}$ y $B$, respectivamente tal y como se muestra en el esquema de la figura siguiente:

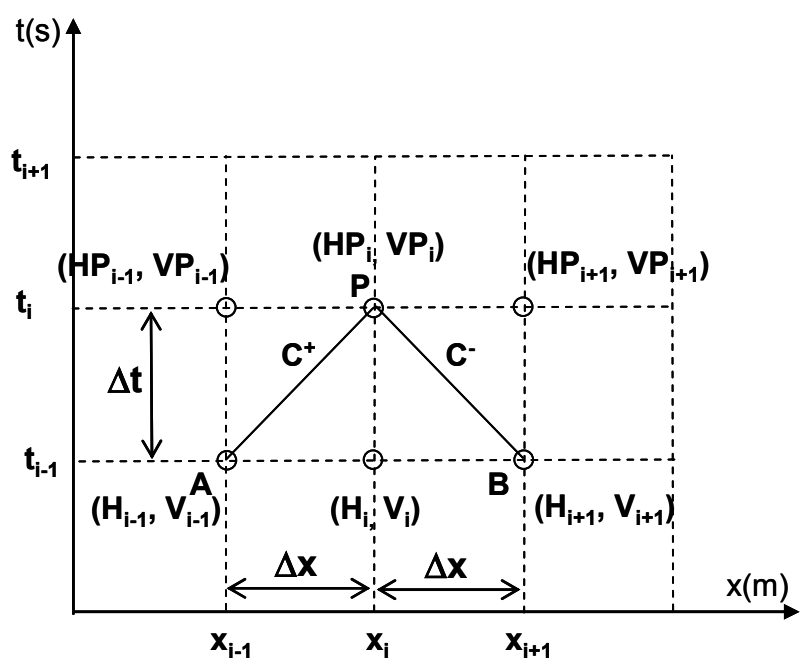

Figura 5.6. Esquema del método de las características 
En el desarrollo del esquema numérico se utiliza la notación $\mathrm{H}^{\mathrm{P}} \mathrm{o} \mathrm{V}^{\mathrm{P}}$ para designar los valores de las funciones en el instante $(\mathrm{t})$ mientras que las notaciones sin referencia al punto $\mathrm{P}$ indican el valor de las funciones en el instante anterior $(\mathrm{t}-\Delta \mathrm{t})$.

La integración de la primera de las dos últimas ecuaciones da lugar a la recta característica positiva $\mathrm{C}^{+}$. Por otro lado, la recta característica negativa $\mathrm{C}^{-}$de la figura anterior se obtiene de la integración de la segunda ecuación.

La recta característica positiva $\mathrm{C}^{+}$resulta:

$$
\begin{aligned}
& H^{P}(i)=H(i-1)-\frac{a}{g} \cdot\left[V^{P}(i)-V(i-1)\right]- \\
& -\frac{a}{g} \cdot f \cdot \frac{V(i-1) \cdot|V(i-1)|}{2 D} \cdot \Delta t-\cdot \operatorname{sen} \alpha \cdot \Delta t \cdot V(i-1)
\end{aligned}
$$

Mientras que la recta característica negativa C:

$$
\begin{aligned}
& H^{P}(i)=H(i+1)+\frac{a}{g} \cdot\left[V^{P}(i)-V(i+1)\right]+ \\
& +\frac{a}{g} \cdot f \cdot \frac{V(i+1) \cdot|V(i+1)|}{2 D} \cdot \Delta t-\cdot \operatorname{sen} \alpha \cdot \Delta t \cdot V(i+1)
\end{aligned}
$$

Finalmente se consigue llegar a dos ecuaciones cuyas incógnitas a despejar son $\mathrm{H}^{\mathrm{P}}$ (i) y $\mathrm{V}^{\mathrm{P}}(\mathrm{i})$ que representan los valores de presión y velocidad en un instante de tiempo de los puntos interiores de la columna de agua.

El valor de la velocidad en el punto $\mathrm{P}, \mathrm{V}^{\mathrm{P}}(\mathrm{i})$, se obtiene despejando esta variable de la resta de las ecuaciones $\mathrm{C}^{+}-\mathrm{C}^{-}$, con lo cual queda:

$$
\begin{aligned}
& V^{P}(i)=\frac{g}{2 \cdot a} \cdot[H(i-1)-H(i+1)]+\frac{1}{2} \cdot[V(i+1)+V(i-1)]- \\
& -\frac{f \cdot \Delta t}{4 \cdot D} \cdot[V(i+1) \cdot|V(i+1)|+V(i-1) \cdot|V(i-1)|]- \\
& -\frac{g \cdot \Delta t}{2 \cdot a} \cdot \operatorname{sen} \alpha \cdot[V(i+1)-V(i-1)]
\end{aligned}
$$


Y el valor de $\mathrm{H}^{\mathrm{P}}(\mathrm{i})$ se obtiene al sustituir este valor de la velocidad en la ecuación $\mathrm{C}^{+}$:

$$
H^{P}(i)=H(i-1)-\frac{a}{g}[V(i)-V(i-1)]-
$$

$$
-\frac{a \cdot f \cdot \Delta t}{2 \cdot g \cdot D} \cdot[V(i-1) \cdot|V(i-1)|]-\Delta t \cdot \operatorname{sen} \alpha \cdot V(i-1)
$$

En estas condiciones, falta por definir el número de puntos de cálculo en los que se divide el sistema en los cuales se aplican cada una de las ecuaciones, así como el paso de tiempo.

En la instalación estudiada, se divide la columna de agua en un total de $\mathrm{N}=15$ tramos de la columna de agua, cada uno con una longitud $\Delta x$ metros. En cada instante de tiempo se calcula la presión y la velocidad en todos los puntos en los que ha quedado dividida la columna de agua, desde $i=0$ hasta $i=15$. Una vez fijados el número de puntos de cálculo se determinan los saltos de longitud y de tiempo, $\Delta \mathrm{x}$ y $\Delta \mathrm{t}$, del siguiente modo:

$$
\Delta x=\frac{L(t)}{N}
$$

$$
\Delta t=\frac{\Delta x}{a}
$$

Como la longitud de la columna de agua cambia con el tiempo, es decir, en cada instante de tiempo aumenta la longitud total de la columna de agua en su avance hacia la ventosa, también varían el incremento de espacio y consecuentemente el de tiempo. Por otro lado, se mantiene siempre el mismo número de puntos de cálculo independientemente de la longitud de la columna de agua.

Siguiendo con la misma notación que la utilizada con la velocidad y la presión, la evolución de la longitud de la columna de agua se calcula en el modelo como:

$$
L^{P}(i)=L(i)+\Delta t \cdot V(i)
$$

\subsubsection{CONDICIONES INICIALES Y CONDICIONES DE CONTORNO}

En los apartados anteriores se han presentado las ecuaciones que describen el movimiento de los dos fluidos que intervienen en el proceso. Pero el movimiento de ambos fluidos está relacionado entre sí ya que a medida que avanza la columna de agua, el volumen de aire se reduce porque es expulsado a través de la ventosa. Consecuentemente, también varían con el tiempo la presión, la masa y la densidad de la bolsa de aire. Todas estas 
variables, al igual que la velocidad, se calculan en cada instante de tiempo en función del valor de la variable en cuestión en el instante de tiempo anterior, siguiendo el procedimiento explicado anteriormente.

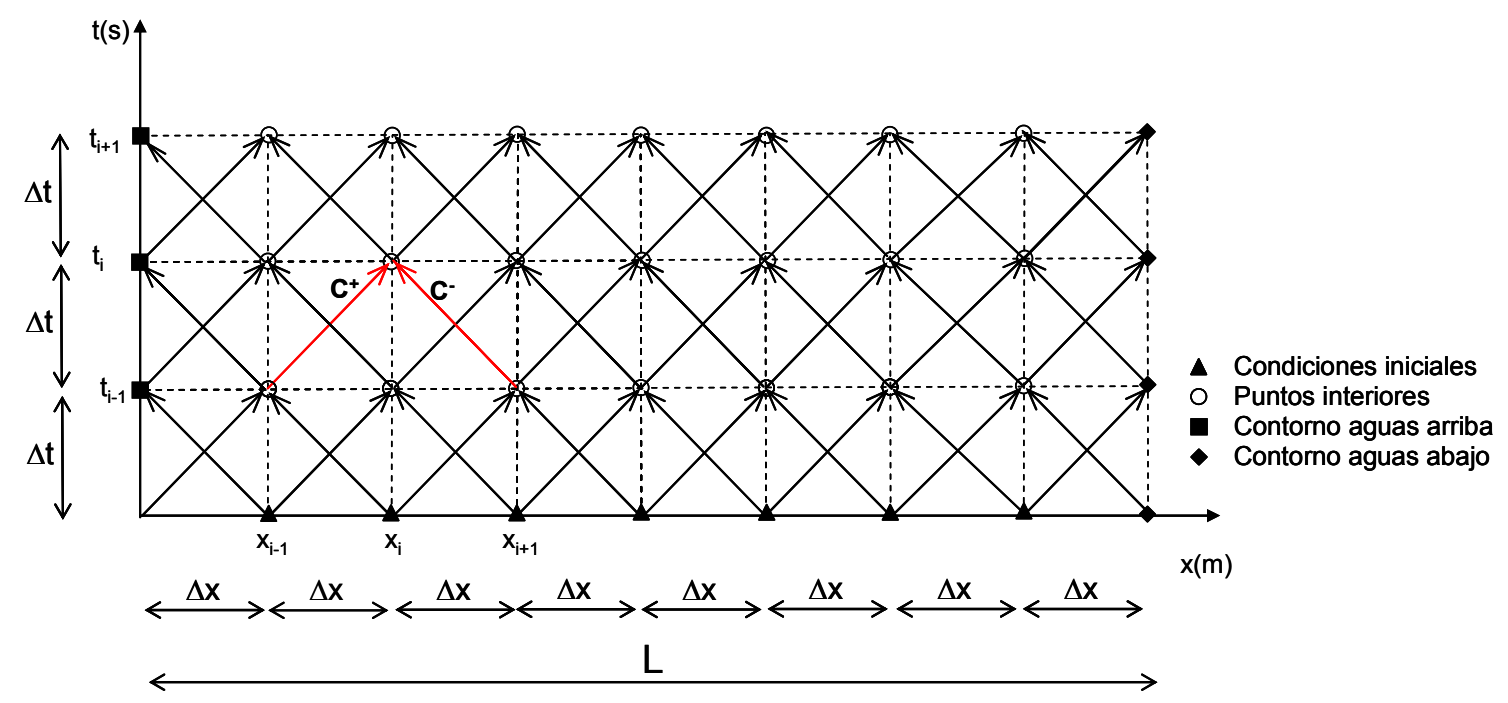

Figura 5.7. Esquema del método de las características

En la figura anterior se muestra, a modo de esquema, el planteamiento de la resolución de las ecuaciones del sistema numérico. En ella se puede apreciar los puntos en los cuales se aplican cada una de las condiciones a las que está sometido el sistema, las condiciones iniciales y las condiciones de contorno. Se observa además, cómo se divide en tramos de longitud $\Delta x$ la longitud total de la columna de agua y cómo se avanza en el cálculo desde un instante de tiempo dado al siguiente. Hay que señalar que dicha figura se ha introducido a modo de ejemplo orientativo de lo que sería el esquema de cálculo pero no representa la situación real. En la realidad la longitud de la columna de agua aumenta en cada paso de tiempo.

\section{Condiciones iniciales del transitorio}

Otras ecuaciones a tener en cuenta en el modelo son las condiciones iniciales y las condiciones de contorno del sistema. Inicialmente el fluido se encuentra en reposo, la ventosa se encuentran abierta y el depósito de agua se encuentra comunicado al exterior, por lo que la presión inicial del sistema es igual a la presión atmosférica.

Se considera que en el instante inicial, $\mathrm{t}=0$, en la instalación objeto de estudio se dan las siguientes condiciones:

La longitud de la columna de agua:

$L(i, t)=L_{0}(\mathrm{~m})$ 
La columna de agua se divide en una serie de tramos para proceder a la discretización de las ecuaciones $\Delta \mathrm{x}$ :

$$
\Delta x_{0}=\frac{L_{0}}{N}
$$

Se supone un valor de la presión atmosférica:

$$
\text { Patm }=101320 \mathrm{~Pa}
$$

En el instante inicial la velocidad de la columna de agua es nula:

$$
V(i, t)=0(m / s)
$$

también lo es por tanto el caudal de agua, $\mathrm{Q}=\mathrm{V}(\mathrm{i}, \mathrm{t}) /$ Area:

$$
Q_{a}(i, t)=0\left(m^{3} / s\right)
$$

La altura piezómetrica inicial de la columna de agua es igual a la altura de agua que hay en el depósito:

$$
H(i, t)=H \operatorname{dep}(m)
$$

La densidad del aire se calcula como si de un gas perfecto se tratara $\left(\rho=\frac{P a t m}{R \cdot T}\right)$, con una presión igual a la atmosférica y una temperatura $T=293^{\circ} \mathrm{K}$, y la constante de la ley de los gases perfectos. En el caso concreto del aire esta constante toma el valor $287 \mathrm{~Pa} \cdot \mathrm{m}^{3} / \mathrm{mol}^{\circ}{ }^{\circ} \mathrm{K}$

$$
\rho_{a}(i, t)=1,205\left(\mathrm{Kg} / \mathrm{m}^{3}\right)
$$

El volumen de aire que se encuentra inicialmente en la instalación es:

$$
\forall_{a}(i, t)=A \cdot\left(L_{t u b}-L_{0}\right)\left(m^{3}\right)
$$

A partir de la densidad y del volumen se puede conocer la masa de aire que existe en el instante inicial en la instalación:

$$
m_{a}(i, t)=\rho_{a}(i, t) \cdot \forall_{a}(i, t)(K g)
$$


Ecuaciones en el extremo aguas arriba de la columna de agua, $i=0$ :

Cuando desde el depósito de aire se comunica una determinada presión al depósito de agua, está presión hace que la columna de agua se ponga en movimiento. Esto implica que en el punto $\mathrm{i}=0$ de la columna de agua la presión es:

$H^{P}(i)=H d e p+\Delta P$

La sobrepresión $\Delta \mathrm{P}$ aplicada varía de un ensayo a otro y viene expresada en metros de columna de agua.

La velocidad para cada instante de tiempo de este primer punto de la columna de agua se calcula como indica el esquema de la Figura 5.7 a partir de la característica negativa, C:

$$
\begin{aligned}
& V^{P}(i)=V(i+1)+\frac{g}{a} \cdot[(H d e p+\Delta P)-H(i+1)]- \\
& -\frac{f \cdot \Delta t}{2 \cdot D}[V(i+1) \cdot \mid V(i+1)]+\frac{g \cdot \Delta t}{a} \cdot \operatorname{sen} \alpha \cdot V(i+1)
\end{aligned}
$$

En el modelo se considera que en la interfase agua-aire existe igualdad de velocidades y presiones como se indica en la Figura 5.8. En cada instante de tiempo, el modelo calcula mediante el método de las características, las velocidades y presiones en cada punto de la columna de agua. Al llegar a la interfase entre ambos fluidos el modelo iguala las condiciones y prosigue realizando los cálculos con las ecuaciones relativas a la fase gas.

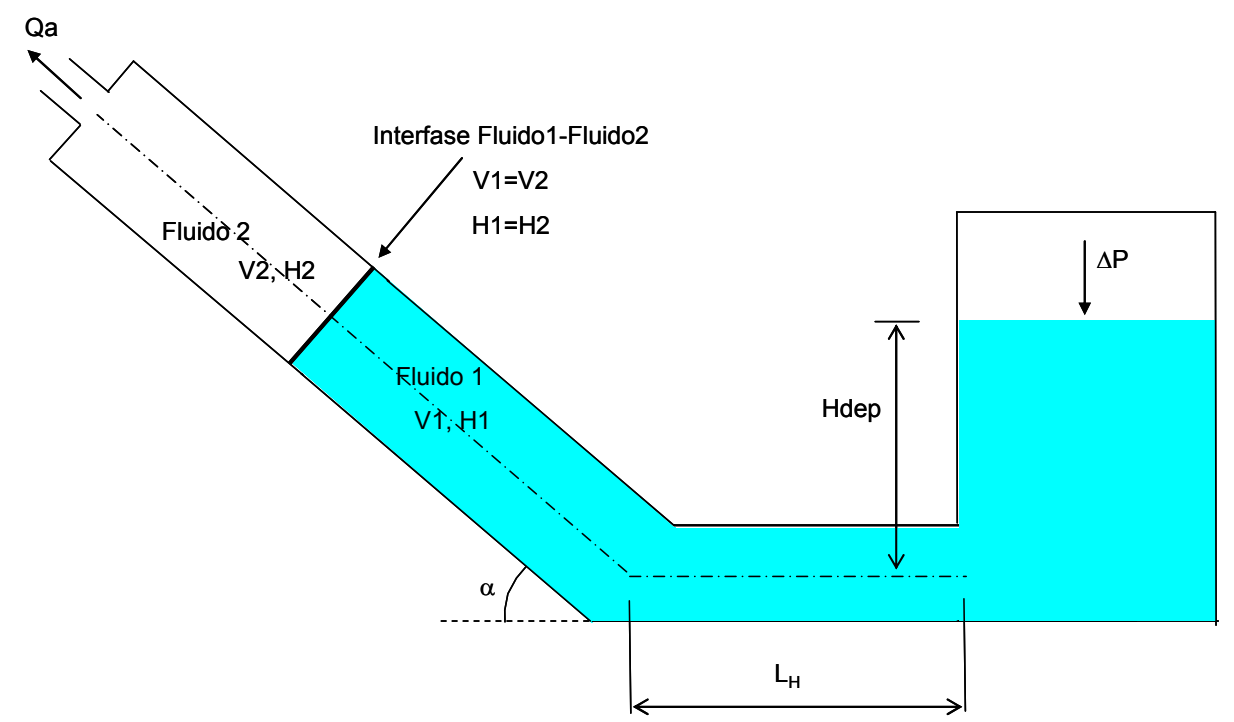

Figura 5.8. Esquema de la instalación introducida en el modelo 
Ecuaciones en el último punto de la columna de agua, $\mathrm{i}=15$ :

Las ecuaciones utilizadas para calcular la velocidad y la presión en el último punto de la columna de agua, el cual se encuentra en contacto con la bolsa de aire son, siguiendo el esquema de cálculo de la Figura 5.7, la ecuación de la característica positiva, $\mathrm{C}^{+}$, las ecuaciones relativas a la bolsa de aire y una serie de ecuaciones complementarias.

Hay que tener en cuenta en todo momento que las presiones de las ecuaciones de la bolsa de aire se expresan en términos absolutos. En este último punto de la columna de agua se sigue la notación utilizada hasta ahora. En dicha notación, el superíndice $\mathrm{P}$ hace referencia al valor de la magnitud en el punto dado en el instante de cálculo, mientras que si no aparece la notación $\mathrm{P}$ se considera que se refiere al valor de la variable en el instante anterior.

La cota de un punto cualquiera de la columna de agua para un instante P se calcula como:

$$
Z^{P}(i)=\left(i \cdot \Delta x-L_{H}\right) \cdot \operatorname{sen} \alpha
$$

La longitud del tramo horizontal de tubería situado junto al depósito de agua en la instalación de mayor calibre, DN500 es $L_{H}=6,85 \mathrm{~m}$. Se ha supuesto que esta longitud incluye hasta la mitad del codo inferior de la instalación, mientras que la otra mitad del codo, extremo superior, y el pequeño tramo horizontal de la $T$ donde se ubica la ventosa se incluyen como longitud adicional del tramo inclinado. La longitud total de la instalación de diámetro $500 \mathrm{~mm}$ еs Lтот $=13,85 \mathrm{~m}$.

Retomando las ecuaciones de la bolsa de aire, se prosigue calculando la masa de aire, el volumen de aire y la densidad del aire como:

$$
\operatorname{masa}_{\operatorname{aire}}^{P}(i)=\text { masa aire }(i)-Q_{a} \cdot \rho(i) \cdot \Delta t
$$

Volumen aire $^{P}(i)=$ Volumen aire $(i)-V(i) \cdot \Delta t \cdot A$

$$
\rho^{P}(i)=\frac{\text { masa aire }^{P}(i)}{\text { Volumen }_{\text {aire }}^{P}(i)}
$$

La presión de este último punto de la columna de agua se calcula a partir de la ecuación (Ec. 5.20) como:

$$
\operatorname{Paire~}^{P}(i)=\frac{\text { Paire }(i) \cdot \text { Volumen }_{\text {aire }}^{P}(i)}{\text { Volumen aire }^{P}(i)+k\left(\text { Volumen }_{\text {aire }}^{P}(i)-\text { Volumen aire }(i)\right)+k \cdot \text { Qaire }(i) \cdot \Delta t}
$$


(Ec. 5.59)

La altura piezométrica del punto se calcula con este valor de presión y con la cota del punto en cuestión:

$H^{P}(i)=$ Paire $^{P}(i)-$ Patm $+Z^{P}(i)$

Finalmente la velocidad de este punto se extrae de la ecuación de la característica positiva $\mathrm{C}^{+}$:

$V^{P}(i)=V(i-1)+\frac{g}{a} \cdot\left[H(i-1)-H^{P}(i)\right]-\frac{f \cdot \Delta t}{2 \cdot D}[V(i-1) \cdot|V(i-1)|]-\frac{g}{a} \cdot \Delta t \cdot \operatorname{sen} \alpha \cdot V(i-1)$

(Ec. 5.61)

\section{Modelación del comportamiento de la ventosa}

El modelo simula el comportamiento del fenómeno transitorio que se produce en una instalación parcialmente llena de agua en la cual se procede a la descarga de aire a través de una ventosa situada en su extremo final.

En los ensayos, la ventosa empieza a cerrar cuando el agua llega al flotador de la misma. En el modelo, se ha supuesto que el inicio del cierre de la ventosa empieza cuando la longitud de la columna de agua es igual a la longitud de la tubería. El cierre completo se traduce en el modelo añadiendo una condición sobre el volumen de aire atrapado, especificando que éste sea menor de una cantidad predefinida. El valor de este volumen de aire crítico que queda atrapado es un valor cercano a los valores de aire atrapado resultantes en los ensayos de laboratorio.

Volumen de aire crítico $<0,04 \mathrm{~m}^{3}$

Se ha supuesto que el coeficiente de descarga de la ventosa evoluciona de manera lineal con la posición del flotador en cada instante de tiempo, suposición válida una vez contrastados los resultados de las mediciones ofrecidas por transductor de posición del flotador.

El cierre de la ventosa se representa en el modelo de manera que a partir de un determinado instante to el coeficiente de descarga $C_{d}$ empieza a disminuir linealmente del siguiente modo:

$C_{d}(t)=C_{\text {dini }}\left(\frac{t_{c}-t}{t_{c}-t_{o}}\right) \quad t_{o} \leq t \leq t_{c}$ 
Donde:

$C_{\text {dini }}$ es el valor del coeficiente de descarga inicial, mientras la ventosa permanece completamente abierta.

$t_{o}$, es el instante en el cual la ventosa empieza a cerrar y $C_{d}(t)=C_{d i n i}$

$t_{c}$, es el instante en el cual la ventosa cierra por completo, en el cual $C_{d}(t)=0$

En los ensayos para la determinación de la capacidad de expulsión de aire de las ventosas se determinaron los valores de $C_{d}$ para la ventosa $A$ y para la ventosa B completamente abiertas, de dichos ensayos se desprende:

$C_{\text {dini }}(A)=0,8$

$C_{\text {dini }}(B)=0,79$

\subsection{APLICACIONES DEL MODELO NUMÉRICO}

El modelo numérico se ha programado en un entorno Windows mediante el programa Visual Basic. Cabe remarcar que el modelo numérico aquí presentado no pretende ser un modelo predictivo dada la gran variedad de factores que se deben tener en cuenta en el estudio de los transitorios hidráulicos con aire atrapado y la dificultad requiere el obtener un calculo preciso. La función fundamental del modelo presentado es ofrecer una visión general de la influencia de cada uno de los parámetros que intervienen en el transitorio, en los resultados numéricos finales.

El modelo utilizado es capaz de:

- Calcular el campo de presiones y velocidades del transitorio, tomando las condiciones de partida de un ensayo de expulsión de aire al final de una conducción de los experimentos llevados a cabo en las instalaciones de W.L.|Delft Hydraulics.

- Existen una serie de coeficientes de los cuales no se sabe a priori su valor. Es el caso de la celeridad (a), el factor de fricción (f), el coeficiente politrópico ( $k$ ) y el volumen de aire atrapado en el sistema (Vol aire). Uno de los objetivos de este modelo es efectuar un análisis de sensibilidad en el cual se demuestre el efecto de todos y cada uno de los parámetros anteriores sobre la presión máxima en el sistema y la velocidad de la columna de agua. Además se pretende obtener una aproximación al valor numérico de cada uno de ellos que hace que el error de cálculo del modelo sea el menor posible. El modelo calcula la combinación óptima de estos factores con la cual se logra mínimo error de cálculo. 


\subsubsection{ANÁLISIS DE SENSIBILIDAD DEL FENÓMENO TRANSITORIO FRENTE A DIFERENTES FACTORES.}

Como se ha comentado anteriormente, en el modelo existen una serie de parámetros difíciles de cuantificar y que pueden ser decisivos a la hora de resolver el transitorio. Dichos parámetros no se pueden determinar con aparatos de medida convencionales en el laboratorio con lo cual, en la mayoría de los modelos consultados, se opta por asignarles valores empíricos que se extraen de la bibliografía existente.

Estos parámetros dependen de multitud de factores y además pueden ser variables con el tiempo o incluso pueden variar dentro de la misma sección de la tubería con lo cual deben ser estudiados con detenimiento para lograr una buena simulación. Analizar la evolución de cada uno de estos coeficientes a lo largo del transitorio necesitaría de un estudio amplio y detallado que queda fuera de los objetivos de la presente tesis doctoral.

En este trabajo se plantea un análisis de sensibilidad que sea capaz de aportar detalles de la influencia de los distintos parámetros que intervienen en el transitorio sobre el resultado final del mismo.

Uno de estos parámetros, es el coeficiente politrópico k el cual determina el tipo de evolución del aire en los procesos de compresión y expansión. Este coeficiente determina si la evolución del aire ha sido isoterma, adiabática o politrópica.

Otro parámetro, no menos importante y que ha despertado un gran interés en el estudio de los transitorios hidráulicos, es la celeridad de la onda de presión, la cual depende tanto del tipo de fluido como del material de la tubería. El flujo bifásico hace que se replantee el otorgar un valor de $1.000 \mathrm{~m} / \mathrm{s}$ a la celeridad como si solo existiera agua en la instalación. La celeridad depende de la proporción de gas en el seno del fluido, lo cual se desconoce en este caso, al igual que se desconoce la distribución de la mezcla agua-aire a lo largo de la conducción y del tiempo.

Muchos de los estudios realizados para calcular la celeridad de la onda de presión en sistemas bifásicos hacen referencia al aire que se desprende del líquido debido a la aparición de bajas presiones durante el transitorio. La velocidad de la onda de presión se ve significativamente reducida cuando existe una mezcla gas-líquido. Autores como W Zielke y H. Perko (1985) desarrollaron métodos que describen la cantidad de expulsión de gas del líquido.

El flujo transitorio de una mezcla gas-líquido homogénea con una fracción de gas pequeña y con una densidad de masa de líquido determinadas se puede describir mediante las ecuaciones clásicas del golpe de ariete en las cuales la velocidad de la onda se puede sustituir por una expresión de la celeridad de la mezcla am que depende de la presión (E.B. Wylie, 1984): 


$$
a_{m}=\sqrt{\frac{a^{2}}{1+\frac{\alpha_{g} \cdot a^{2}}{g \cdot\left(H-z-h_{v}\right)}}}
$$

En esta expresión:

$$
\begin{aligned}
& \text { a es la celeridad del golpe de ariete } \\
& \alpha_{\mathrm{g}} \text { es la fracción de gas } \\
& \mathrm{H} \text { es la altura piezómetrica } \\
& \text { z es la cota } \\
& \text { h}_{v} \text { es la presión de vapor } \\
& \text { g es la aceleración de la gravedad }
\end{aligned}
$$

Otro factor que condiciona los resultados de cualquier transitorio es el factor de fricción. El parámetro de fricción o coeficiente de resistencia de Darcy- Weisbach ( $f$ ) es un parámetro adimensional que depende del número de Reynolds $(R e)$ y de la rugosidad relativa $(K)$ :

$$
f=f\left(\operatorname{Re}, \frac{K}{D}\right)
$$

Pero la influencia de estos dos parámetros sobre el coeficiente de fricción es cuantitativamente distinta según las características del flujo. En régimen laminar se demuestra que el factor de fricción, $f$, es independiente de la rugosidad relativa mientras que el cálculo de f en régimen turbulento es mucho más complicado y requiere hacer un estudio minucioso del flujo existente en el conducto.

Tradicionalmente los algoritmos del golpe de ariete estándar incorporan términos del factor de fricción estacionario o cuasi-estacionario. Esta suposición es satisfactoria en transitorios lentos en los cuales el esfuerzo de fricción con las paredes tiene un comportamiento estable en el tiempo. La validación experimental de modelos de fricción cuasi-estáticos en transitorios rápidos muestra discrepancias en cuanto a la atenuación y al desfase del perfil de la onda de presión al comparar los resultados computacionales con los resultados medidos. La magnitud de estas discrepancias está gobernada por las condiciones del flujo (laminar o turbulento) y las propiedades del líquido (viscosidad).

Las imprecisiones de los resultados del modelo numérico pueden dar lugar a una predicción errónea de fenómenos como la cavitación o la separación de la columna de agua Bergant A. et al. (2001). Estos autores afirman que para reducir la incertidumbre se deben excluir las influencias de la estructura del fluido y la expulsión de aire en los experimentos de validación del factor de fricción no estacionario. 
Según Zielke (1968) el término de fricción puede ser considerado como la suma de una componente del régimen estable y una componente del régimen transitorio. Un modelo propuesto por Vardy et al. (1992) sigue las hipótesis formuladas por Zielke para el régimen laminar de flujo. En este modelo los autores consideran que un anillo de flujo laminar envuelve un núcleo de flujo uniforme, teoría anteriormente propuesta por Funk y Wood (1974).

A partir de diversos estudios realizados hasta el momento se puede decir que los términos de fricción variable se clasifican fundamentalmente en seis grupos, Bergant et al., (2001):

1. El factor de fricción depende de la velocidad instantánea media del flujo, V. Hino et al (1977), Brekke H. (1984, Cocchi G. (1998)

2. El factor de fricción depende de la velocidad instantánea media, V, y de la aceleración instantánea local $\partial V / \partial t$, Daily et al (1956), Carstens y Soller (1959), Safwat y Van der Polder (1973), Kurokawa y Morikawa (1986), Golia U.M. (1990), Kompare B. (1995)

3. El factor de fricción depende de la velocidad instantánea media, V, de la aceleración instantánea local $\partial V / \partial t$ y de la aceleración instantánea convectiva. Brunone et al. (1991), Bughazem M.B. y Anderson A. (1996)

4. El factor de fricción depende de la velocidad instantánea media, $V$ y de la difusión $\partial^{2} V / \partial x^{2}$ Vennatro B. (1996), Svingen B. (1997)

5. El factor de fricción depende de la velocidad instantánea media, $\mathrm{V}$, y de una función de peso $W(\tau)$ que tiene en consideración la aceleración local en una sección del conducto para cualquier intervalo de tiempo de cálculo. Zielke W. (1968), Trikha A.K. (1975, Achard J.L.y Lespinard G.M. (1981), Arlt H. (1983), Kagawa T. et al. (1983), Brown F.T. (1984), Yiang C. y Jing-Chao (1984), Suzuki K. et al. (1991), Schohl G. (1993), Vardy A. (1992), Vardy A. et al. (1993), Shuy E. (1995), Zarzycki Z. (1997)

6. El término de fricción se basa en la distribución de la velocidad del flujo instantáneo en la sección transversal del tubo. Word y Funk (1974)

Dada la gran complejidad que conlleva la determinación del factor de fricción como variable y debido a las incertidumbres del comportamiento de los fluidos, el modelo utilizado en este trabajo considera un factor de fricción constante a lo largo del tiempo y de la sección de la tubería.

Finalmente, en el análisis de sensibilidad llevado a cabo se analizan parámetros como la duración del cierre de la ventosa del cual se disponen mediciones, el volumen de aire que queda atrapado en el sistema y el coeficiente de descarga de la ventosa.

En este trabajo, se dispone de un orden de magnitud de la duración del tiempo de cierre de la ventosa, gracias a los datos aportados por el del transductor de posición situado en 
el flotador de la misma. Este transductor de posición facilitaba información sobre la posición del flotador en cada instante de tiempo.

Por otro lado, hay que decir que la tarea de predecir el volumen de aire que queda atrapado en el sistema al cerrar la ventosa es complicada debido a la turbulencia del flujo entre otras cosas.

Mediante el uso combinado del presente modelo y de los datos extraídos a partir de los ensayos dinámicos de expulsión de aire a través de una ventosa situada en el extremo final de la instalación, se consigue establecer un orden de magnitud aproximado del volumen de aire atrapado en la instalación.

El coeficiente de descarga se determina en principio a partir de los ensayos de laboratorio tal y como se ha presentado en el capítulo 4 . No obstante, como se verá más adelante el valor de este coeficiente adimensional es clave a la hora de ajustar correctamente el modelo teórico.

El análisis de sensibilidad Ilevado a cabo ha sido un proceso largo y complicado que se ha sido modificado paulatinamente a medida que se han extraído conclusiones razonadas. Se podría decir que dicho análisis se ha llevado a cabo siguiendo una serie de etapas en las cuales se han depurado los resultados.

Los primeros cálculos realizados en el análisis de sensibilidad se efectuaron asignando a cada parámetro cinco valores numéricos diferentes, de manera que con cada combinación de parámetros se resolvía un transitorio diferente. Con este método, la cantidad de transitorios calculados con unas determinadas condiciones iniciales era de unos 5.000 transitorios.

La selección de los valores numéricos de cada parámetro que proporcionen unos resultados que se ajusten a los resultados teóricos se basa principalmente en la definición de una función de error. Esta función calcula el error como la diferencia entre los valores calculados por el modelo y los valore medidos en los ensayos entre dos instantes de tiempo dados. Dichos instantes de tiempo son $t_{p}$ y $t_{p 0}$, siendo $t_{p}$ el instante en el cual empieza la compresión de la bolsa de aire y tpo el instante de tiempo en el cual se anula presión después de llegar a su valor máximo.

Error Presión $=\sum_{t=t p}^{t=t p 0}(\text { Presión calculada }- \text { Presión medida })^{2}$

Error Velocidad $=\sum_{t=t p}^{t=t p 0}(\text { Velocidad calculada }- \text { Velocidad medida })^{2}$ 
Después de una serie de cálculos, en el análisis de sensibilidad se descartan progresivamente diferentes valores asociados a cada parámetro. A continuación se detalla y razona los valores adoptados finalmente en dicho análisis:

- Como resultado de cada una de estas etapas se desprende que con una celeridad de la onda de presión igual a $1.000 \mathrm{~m} / \mathrm{s}$ se obtienen resultados satisfactorios, no siendo así con valores mucho menores como $600 \mathrm{~m} / \mathrm{s}$ o $500 \mathrm{~m} / \mathrm{s}$. Esto podría ser debido a que realmente no existe una mezcla apreciable de los dos fluidos que intervienen en el proceso sino que el aire avanza empujado por la columna de agua como una bolsa compacta. También podría ser debido a que el aire disuelto en el agua, en una cantidad apreciable, se modele mejor a través de la inclusión de una bolsa de aire aislada al final de la conducción.

- Del mismo modo, se establece un valor del coeficiente politrópico $k=1,2$ lo cual significa que se trata de un fenómeno politrópico. Los valores de $k$ que hacen referencia a una evolución isoterma $\mathrm{k}=1$ se descartan porque se trata de un fenómeno rápido y por tanto no isotermo. La diferencia de resultados al adoptar un coeficiente $k=1,4$ no es realmente significativa, si bien más adelante se mostrará cómo afecta el uso de un valor u otro del coeficiente $k$ en el transitorio.

- En casi todos los ensayos, el tiempo que tarda en cerrar la ventosa según las mediciones se encuentra en torno a los 0,04 s. El análisis de sensibilidad se realiza con dos valores diferentes de la duración del cierre, concretamente se efectúan cálculos con los tiempos de cierre 0,03 s y $0,04 \mathrm{~s}$.

- En cuanto al coeficiente de descarga $C_{d}$, se han realizado dos tipos de simulaciones. En un primer instante se consideró el valor del coeficiente de descarga $C_{d}$ calculado a partir de los ensayos de expulsión de aire en condiciones de flujo permanente. El problema de utilizar este dato es que la capacidad de descarga en los ensayos dinámicos no coincide con la capacidad de descarga de los ensayos de flujo permanente. De este modo, al utilizar el coeficientes $\mathrm{C}_{d}$ calculado con flujo permanente, el modelo no logra ajustar la curva de presión entre el instante inicial ( $\mathrm{t}_{i}$ ) y el instante en el cual empieza la compresión ( $\mathrm{t}_{\mathrm{p}}$ ). Por este motivo se buscó mediante el análisis de sensibilidad un coeficiente de descarga que ajustara mejor los resultados del transitorio en cuestión.

- El modelo se muestra especialmente sensible al factor de fricción. El factor de fricción está relacionado con la disipación de energía de la columna de agua y consecuentemente con la velocidad de llegada de la columna de agua a la ventosa. De este modo, al aumentar el factor de fricción, aumenta dicha disipación de energía y disminuye la velocidad con la que la columna de agua Ilega a la ventosa. Por otro lado cabe decir, que en las simulaciones se obtienen valores del factor de fricción excesivamente elevados, lo cual se debe a que en el 
modelo no se han tenido en cuenta las pérdidas menores de la instalación. Cabe destacar que dicha instalación presenta dos codos de $45^{\circ}$, el primero cerca del depósito de agua y el segundo antes de llegar a la ventosa. En principio se introducen dos valores para el factor de fricción, bastante diferentes 0,03 y 0,07. En general, los valores del coeficiente de fricción utilizados son ligeramente más elevados de lo que es habitual en este tipo de modelos para tener en cuenta las pérdidas menores y a que se trata de un régimen no permanente.

Se ha detectado que cualquier cambio efectuado sobre la longitud de la tubería influye directamente sobre la velocidad de llegada de la columna de agua y en consecuencia sobre el pico de presión que se produce. Un pequeño cambio en la longitud de la conducción, del orden de escasos centímetros, repercute de manera directa en los resultados del modelo en cuanto al instante en el cual se produce el pico de presión, lo cual se corrige cambiando el volumen de aire atrapado. Tanto la longitud de la tubería como el volumen de aire atrapado, son sin lugar a dudas los dos factores que más influyen en el ajuste del modelo, tanto en cuanto al pico de presión máximo como a la anchura del mismo y a la derivada de la velocidad. Esto es debido a que ambos factores están íntimamente ligados de uno u otro modo con la cantidad de aire atrapado.

- En la longitud total de la instalación se refleja una parte importante de las pérdidas. De hecho, en muchos ensayos la capacidad de reflejar todas las pérdidas que se deben considerar en el modelo recae sobre la longitud. En este modelo de sensibilidad se evalúan cuatro valores diferentes de la longitud total de la tubería: $13,7 \mathrm{~m}, 13,8 \mathrm{~m}, 13,9 \mathrm{~m}$ y $14 \mathrm{~m}$.

- Se dispone de un orden de magnitud aproximado del volumen de aire atrapado gracias a los ensayos de laboratorio. En el análisis de sensibilidad se fijan un total de nueve valores: $0,02 \mathrm{~m}^{3}, 0,025 \mathrm{~m}^{3}, 0,03 \mathrm{~m}^{3}, 0,035 \mathrm{~m}^{3}, 0,04 \mathrm{~m}^{3}, 0,045 \mathrm{~m}^{3}$, $0,05 \mathrm{~m}^{3}, 0,055 \mathrm{~m}^{3}$ y $0,06 \mathrm{~m}^{3}$.

Estudiado paso a paso cada ensayo, es decir, realizando primero el análisis de sensibilidad y posteriormente corrigiendo cada uno de los parámetros para cada ejemplo concreto se presentan los resultados de los transitorios obtenidos con la ventosa $A$ y con la $B$, ambas de DN100.

\section{Ensayos de expulsión de aire a través de la ventosa A, DN100, situada al final de la conducción.}

Como se ha comentado anteriormente, después de realizar el análisis de sensibilidad a cada ensayo, se deciden los valores de los parámetros que mejor ajustan la presión y velocidad calculadas y medidas, mediante las funciones de error definidas previamente en las ecuaciones Ec. 5.66 y Ec. 5.67. 
Seguidamente se presentan pares de gráficos referidos a un mismo ensayo, en los cuales se indican los valores finales de cada parámetro. En el primer gráfico se representa el transitorio desde el inicio del mismo, $\mathrm{t}_{\mathrm{i}}$, hasta el instante en el cual se anula la presión después de haber alcanzado su valor máximo, tpo. En este mismo gráfico se muestran los valores de los parámetros que logran el mejor ajuste entre las variables calculadas y las medidas. Como Pdepo se entiende la suma de la altura inicial de la columna de agua sobre el eje de la tubería y la sobrepresión inicial que se aplica en cada caso. Además se ha indicado, solo en la primera figura, la curva de la velocidad de la columna de agua (V) y la curva de presión (P).

El segundo gráfico muestra con más detalle la diferencia entre los valores de presión y velocidad calculados y los medidos cuando se produce la compresión y expansión de la bolsa de aire atrapado.
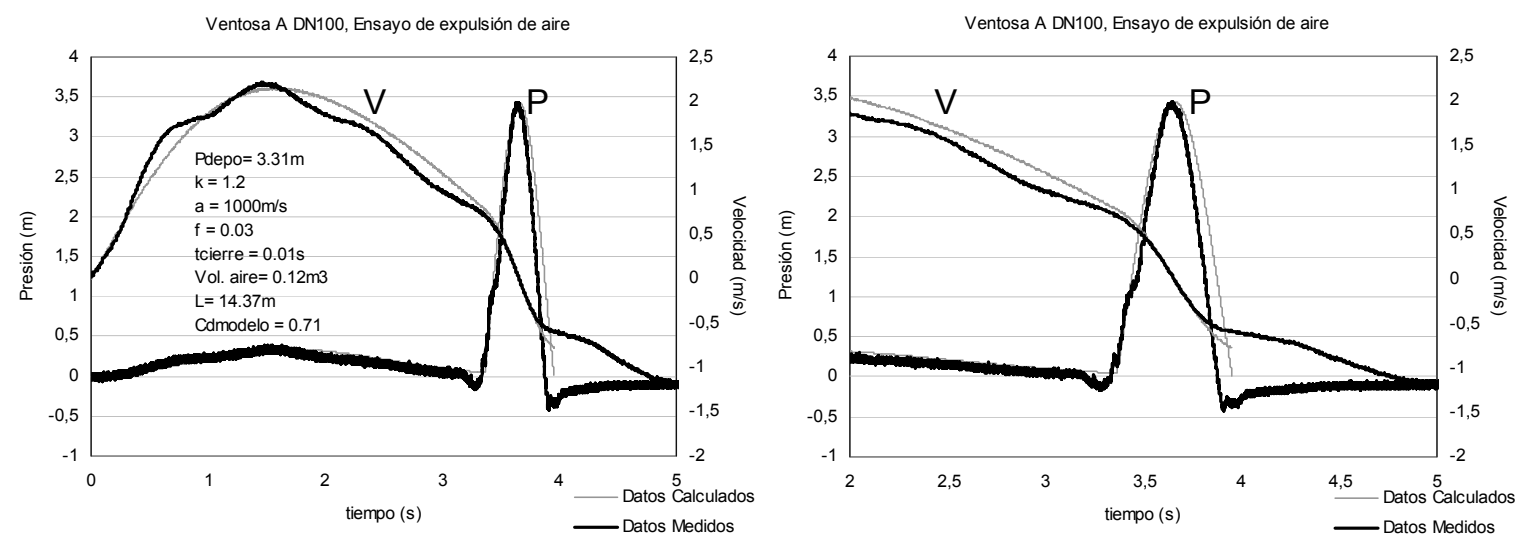

Figura 5.9. Expulsión de aire con ventosa A DN100, DeltaP $=3,31 \mathrm{~m}$
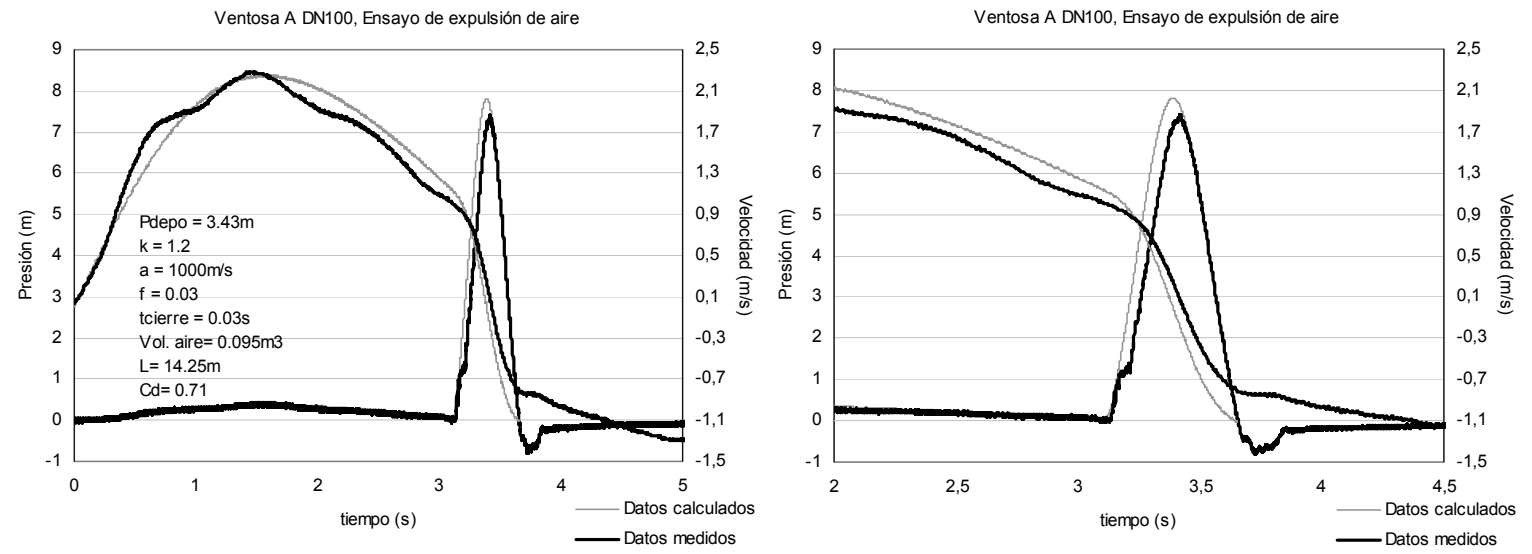

Figura 5.10. Expulsión de aire con ventosa A DN100, DeltaP=3,43 m 

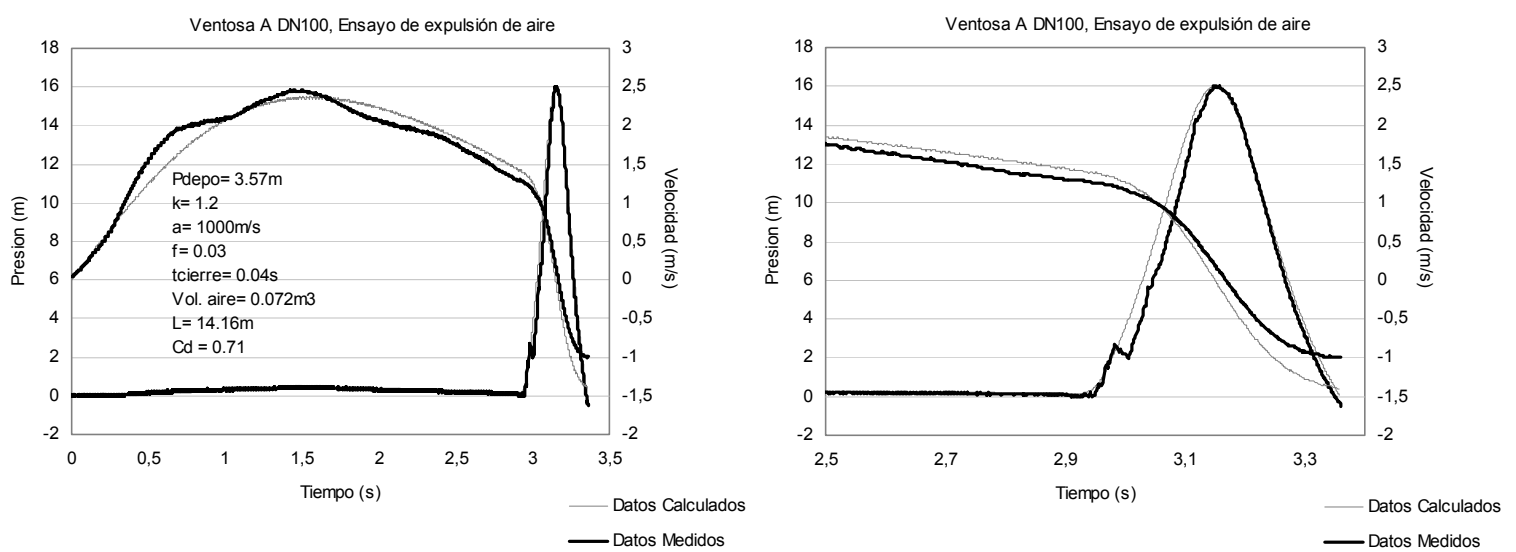

Figura 5.11. Expulsión de aire con ventosa A DN100, DeltaP =3,57 m
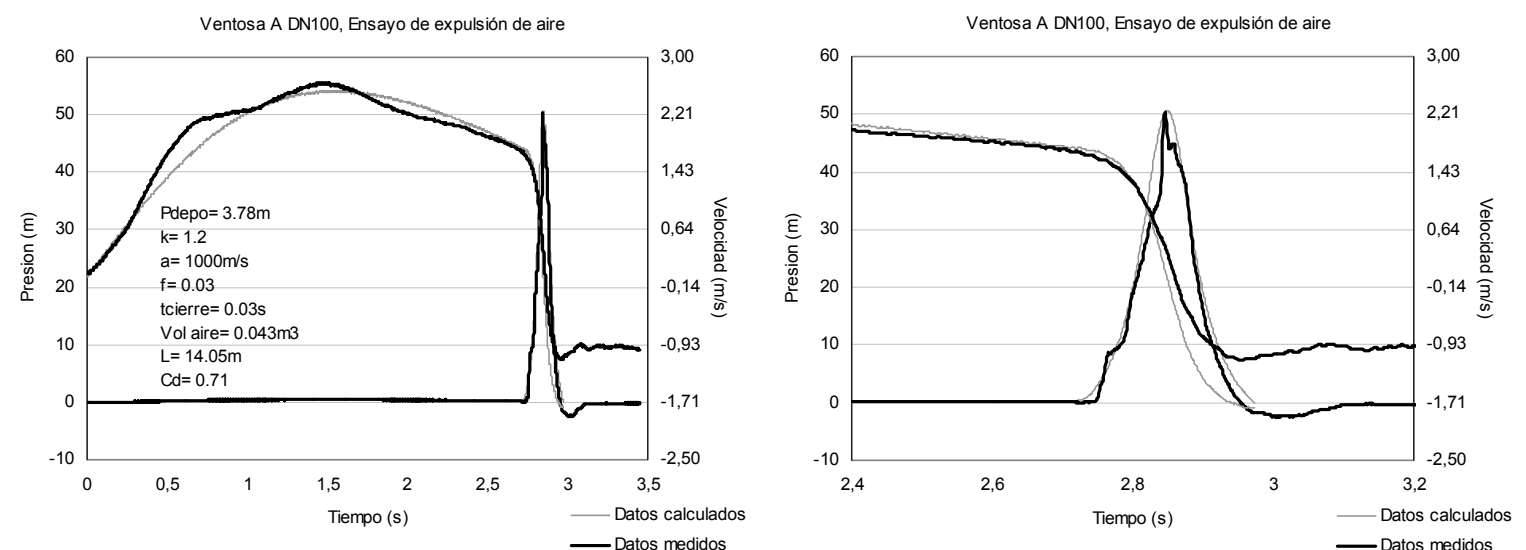

Figura 5.12. Expulsión de aire con ventosa A DN100, DeltaP $=3,78 \mathrm{~m}$
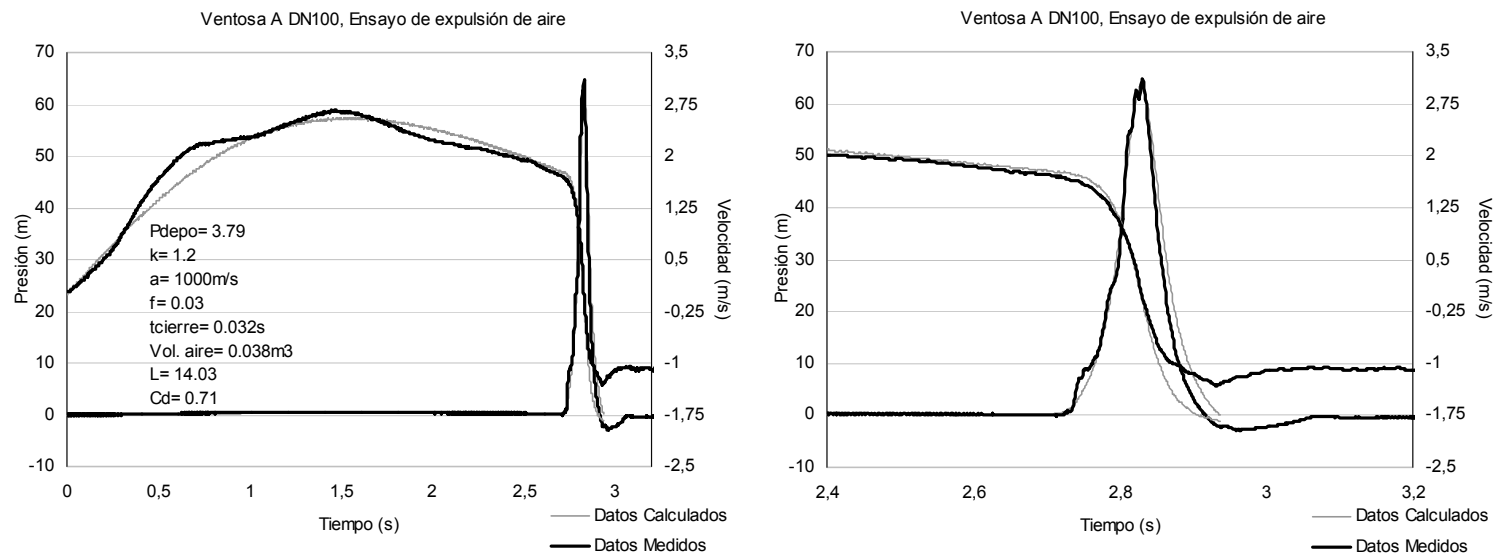

Figura 5.13. Expulsión de aire con ventosa A DN100, DeltaP $=3,79 \mathrm{~m}$ 

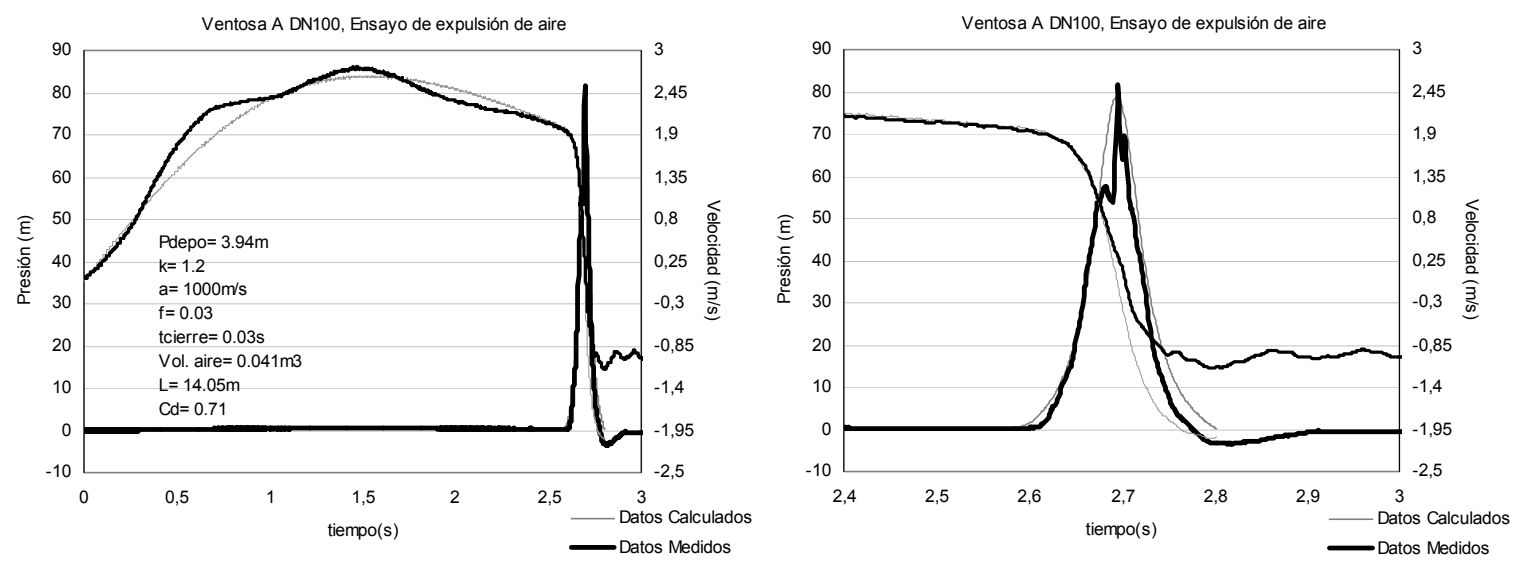

Figura 5.14. Expulsión de aire con ventosa A DN100, DeltaP=3,94 m

\section{Ensayos de expulsión de aire a través de la ventosa B, DN100, situada al final de la} conducción

Análogamente al estudio que se ha realizado con los ensayos de la ventosa $\mathrm{A}$ de diámetro nominal $100 \mathrm{~mm}$, se representan un par de gráficos de cada ensayo de la ventosa $B$, del mismo diámetro nominal. En este caso, no se pueden ajustar al mismo tiempo la amplitud del pico de presión $\left(t_{p 0}-t_{p}\right)$, la deceleración de la velocidad $(\mathrm{dv} / \mathrm{dt})$, variables relacionadas con la cantidad de aire atrapado, y la magnitud del pico de presión máxima.

Se ha considerado conveniente definir la cantidad de aire atrapado en el sistema y buscar las razones por las cuales no es posible en este caso establecer una concordancia total de las magnitudes de las distintas variables que definen el fenómeno transitorio.
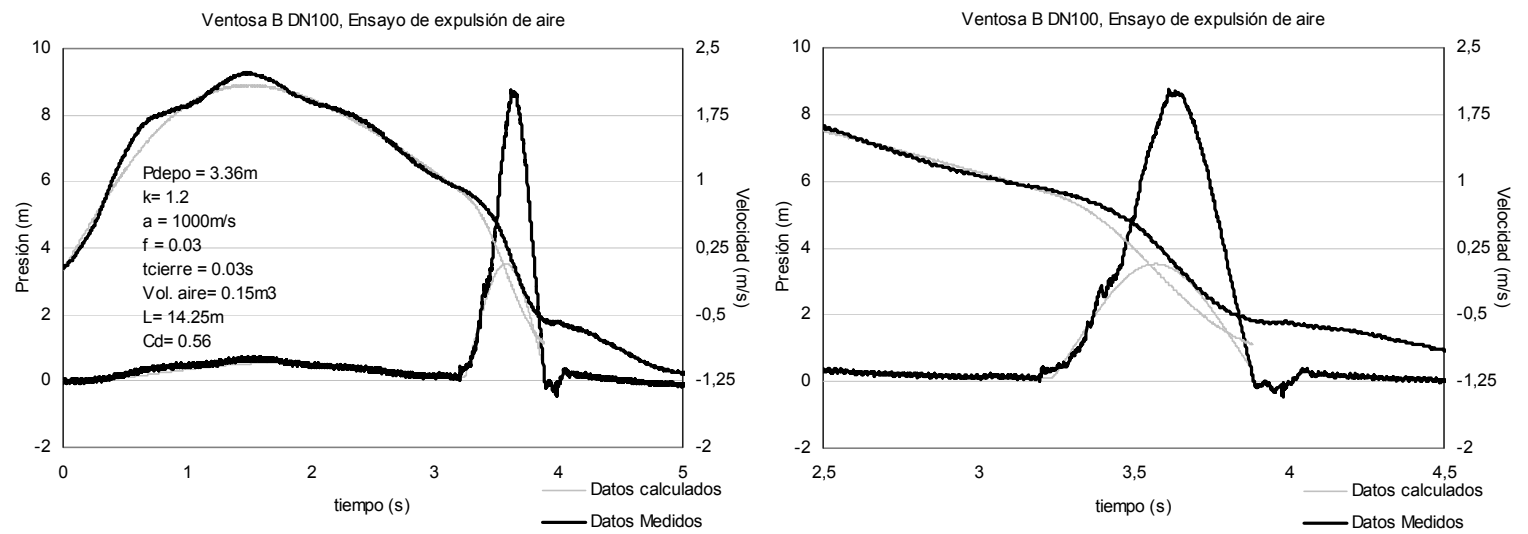

Figura 5.15. Expulsión de aire con ventosa B DN100, DeltaP =3,36 m 

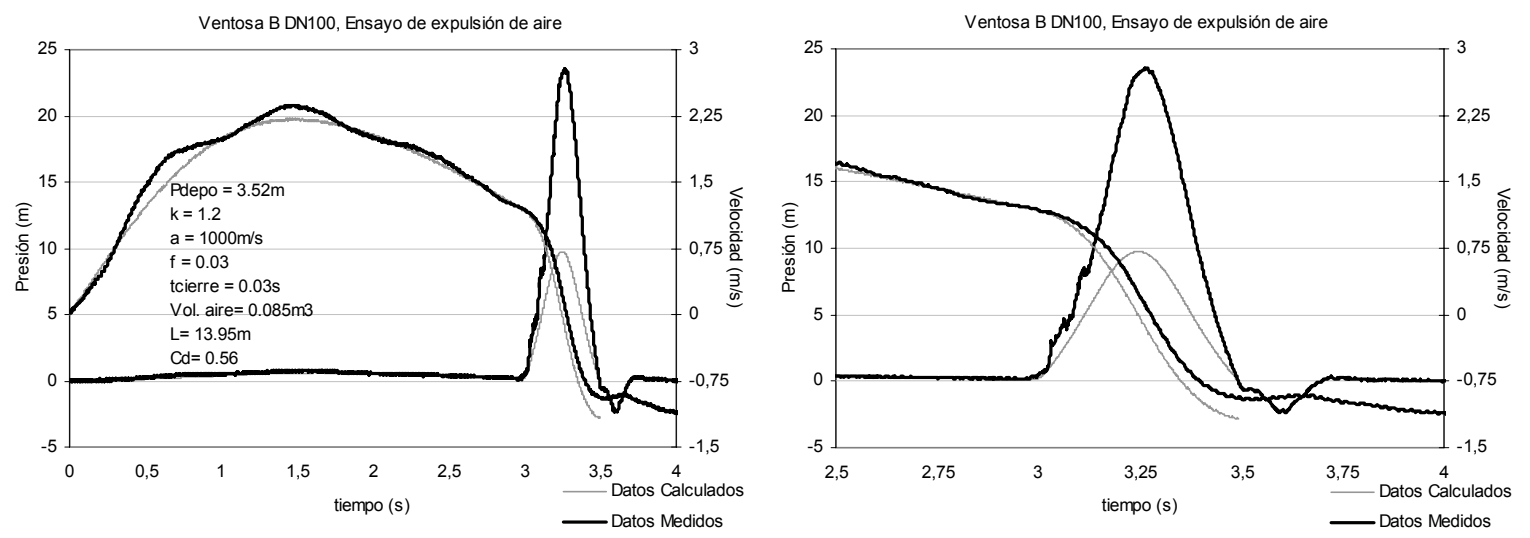

Figura 5.16. Expulsión de aire con ventosa B DN100, DeltaP $=3,52 \mathrm{~m}$
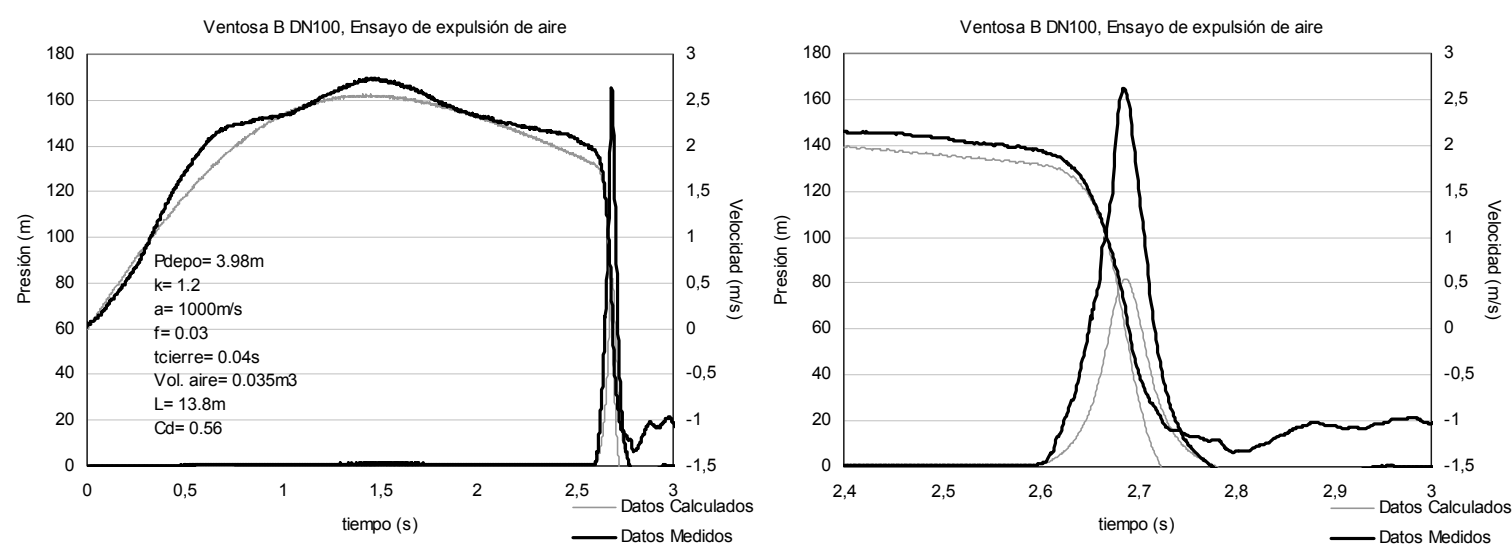

Figura 5.17. Expulsión de aire con ventosa B DN100, DeltaP=3,98 m
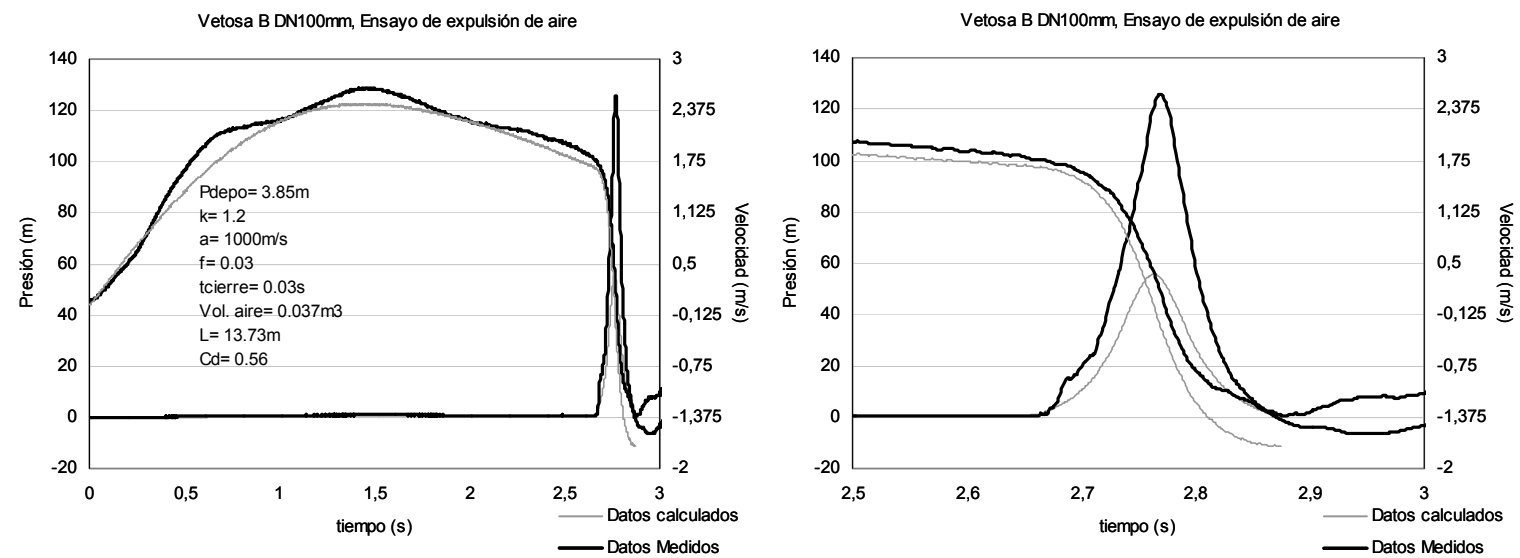

Figura 5.18. Expulsión de aire con ventosa B DN100, DeltaP=3,85 m 

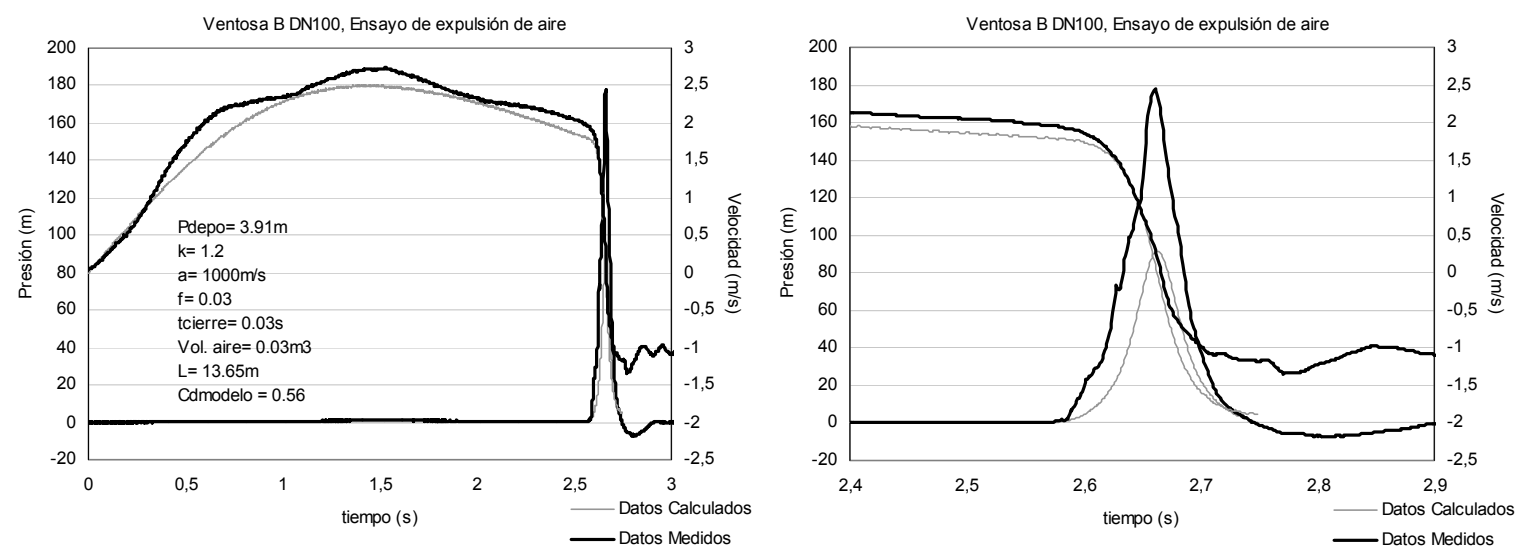

Figura 5.19. Expulsión de aire con ventosa B DN100, DeltaP=3,91 m

Como se puede comprobar tras comparar la velocidad y la presión medida con la calculada, se observa que se consiguen ajustar mejor los ensayos realizados con la ventosa $A$ que los realizados con la ventosa B. Mientras que en la ventosa $A$, los ajustes son aceptables, en la ventosa $B$ no se ha conseguido ninguna combinación de valores para los diferentes parámetros que reproduzca los resultados de las mediciones.

\subsubsection{INFLUENCIA DE DIFERENTES PARÁMETROS EN EL FENÓMENO TRANSITORIO}

El proceso seguido hasta llegar a minimizar el error de cálculo en las simulaciones anteriores ha servido entre otras cosas para determinar el modo en que cada parámetro afecta a este fenómeno transitorio para un sistema determinado. La variación de los parámetros afecta generalmente de forma similar en la mayor parte de los casos analizados, cualquiera que sea la ventosa utilizada y cualquiera que sea la presión inicial aplicada a la columna de agua desde el depósito. Así pues, para mostrar la influencia de cada uno de ellos sobre el fenómeno, se toma un ensayo en el cual ajusten perfectamente tanto el pico de presión máxima, como la anchura de dicho pico de presión ( $\mathrm{t}_{\mathrm{p} 0}-\mathrm{t}_{\mathrm{p}}$ ) y la deceleración de la velocidad de la columna de agua entre el instante de tiempo en el cual cierra la ventosa $\left(t_{c}\right)$, y el instante en el cual la velocidad cambia de sentido $\left(t_{z}\right),\left(d v / d t \_c z\right)$. En dicho ensayo se va modificando cada vez el valor de un solo parámetro.

Se ha tomado como base para realizar el estudio de cada parámetro el ensayo de la ventosa A, DN100, el cual se llevó a cabo con una presión inicial desde el depósito D1 de 3,79 m.c.a., este valor incluye la altura de la columna de agua y la sobrepresión inicial aplicada a la misma. El ajuste óptimo obtenido con el análisis de sensibilidad considera los siguientes parámetros: 


$$
\begin{aligned}
& \mathrm{k}=1,2 \\
& \mathrm{a}=1.000 \mathrm{~m} / \mathrm{s} \\
& \mathrm{f}=0,03 \\
& \text { tcierre }=0,032 \mathrm{~s} \\
& \text { Vol. Aire }=0,038 \mathrm{~m}^{3} \\
& C_{d}=0,71
\end{aligned}
$$

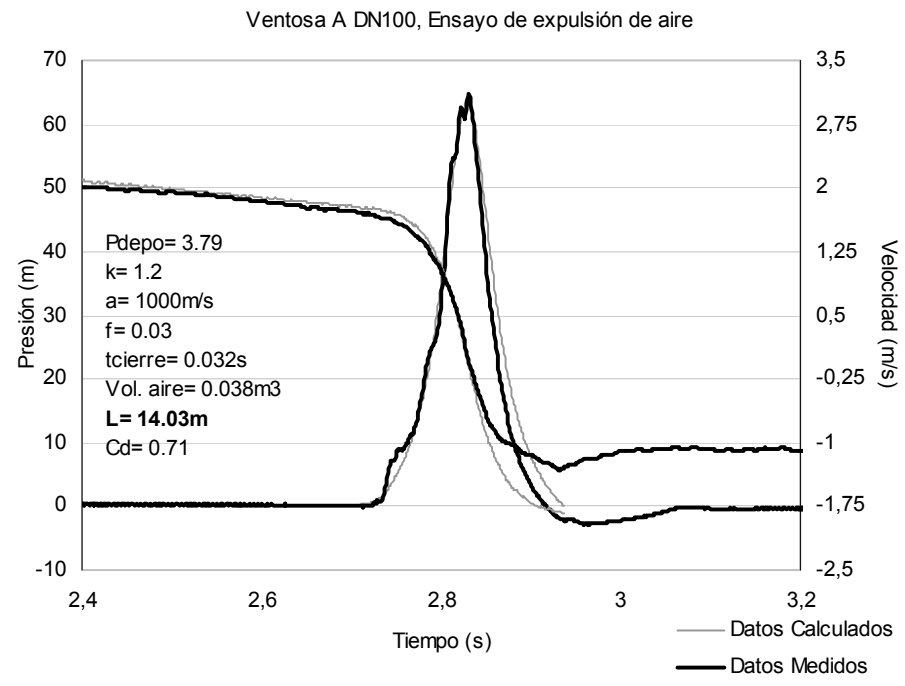

Figura 5.20. Expulsión de aire con ventosa A DN100. Datos de partida

El análisis siguiente tiene por objetivo mostrar cómo afecta la variación de un sólo parámetro al transitorio. Con este fin, se representa gráficamente el mismo ensayo cambiando en cada paso únicamente un parámetro dejando el resto con el valor del mejor ajuste. Se prueban dos valores de cada parámetro, uno menor y otro mayor que el considerando en la Figura 5.20.

\section{Influencia del coeficiente politrópico.}

El coeficiente politrópico $k$ determina el tipo de evolución que sigue el aire en su proceso de compresión y expansión. El coeficiente politrópico utilizado en el ajuste óptimo anterior ha sido $k=1,2$. Por tanto cabe analizar lo que sucede al considerar la evolución del aire isoterma $k=1$ o bien adiabática $k=1,4$ : 

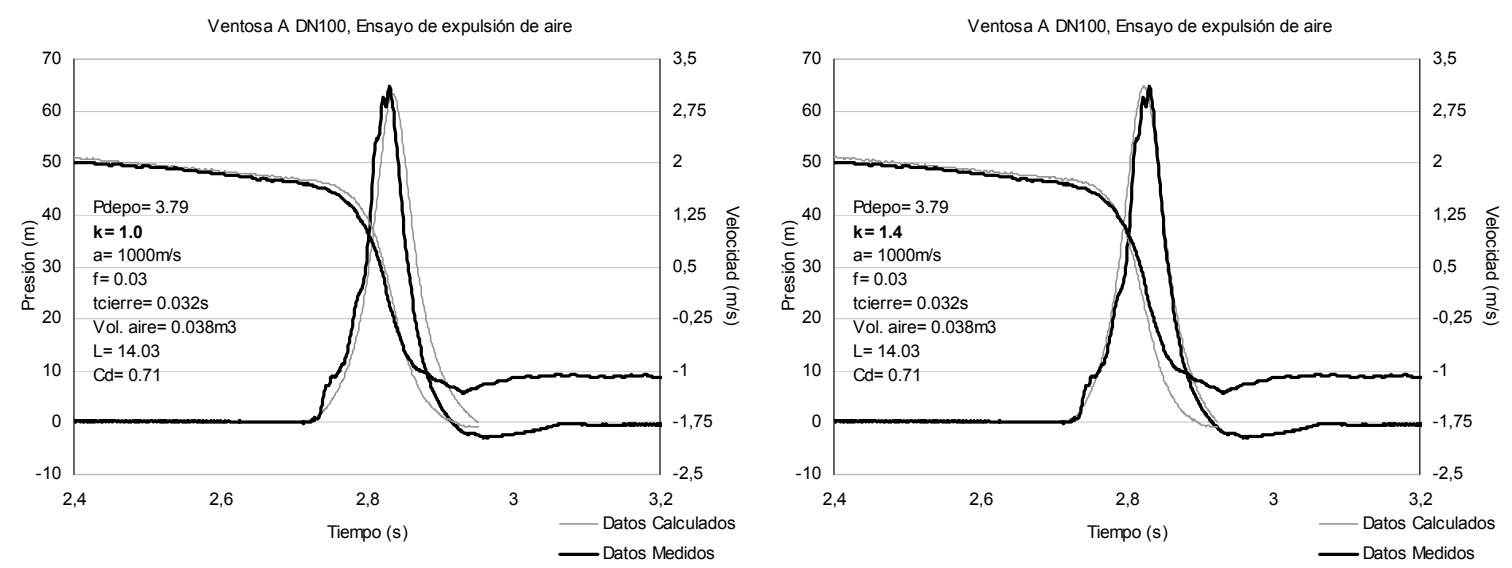

Figura 5.21. Efectos sobre el transitorio al modificar $\mathrm{k}$

Al considerar $\mathrm{k}=1$, el fenómeno se retrasa ligeramente en el tiempo mientras que con $k=1,4$ el fenómeno se adelanta. Si se tiene en cuenta que la escala de tiempos es del orden de milisegundos, realmente la diferencia de resultados entre ambos supuestos es mínima en cuanto a tiempos. Tampoco son considerables los cambios experimentados por el pico máximo de presión si bien con la evolución isoterma, $\mathrm{k}=1$, la presión máxima calculada es ligeramente menor que la presión máxima medida. Por otro lado, el ancho del pico de presión, tpo-tp es algo mayor. Así pues, al considerar un coeficiente politrópico, $k=1$, habría que reducir el volumen de aire atrapado para lograr un mejor ajuste del pico máximo de presión así como de la anchura de este pico.

Por otro lado, considerando una evolución del aire adiabática, $k=1,4$, las diferencias respecto a utilizar $\mathrm{k}=1,2$ son menores. $\mathrm{Al}$ comparar con los resultados medidos, hay una gran similitud en cuanto al pico de presión máxima y en cuanto a la anchura de dicho pico.

\section{Influencia del tiempo de cierre de la ventosa}

Se ha optado en este caso por comprobar lo que ocurre con dos tiempos de cierre $t_{\text {cierre }}=0,02 \mathrm{~s}$ y $t_{\text {cierre }}=0,06 \mathrm{~s}$, bastante alejados del tiempo de cierre utilizado en un principio en el ajuste óptimo de la Figura 5.20, tcierre $=0,032 \mathrm{~s}$.

Con un tiempo de cierre de la ventosa más rápido tcierre $=0,02 \mathrm{~s}$, queda más aire atrapado en el interior de la conducción, lo cual se refleja en una mayor anchura del pico de presión $\left(t_{p o}-t_{p}\right)$. Se considera que el aire atrapado ejerce un efecto colchón y por lo tanto, disminuye la magnitud del pico de presión máxima.

Al considerar un tiempo de cierre de la ventosa más lento, tcierre $=0,06 \mathrm{~s}$, se expulsa más cantidad de aire a través de la ventosa. Esto se traduce en que queda menor cantidad de aire atrapado en la instalación, lo cual afecta tanto a la magnitud del pico de presión máxima que es más elevado, como a la anchura del pico de presión que disminuye. Del 
mismo modo se observa que la deceleración de la columna de agua aumenta como consecuencia de quedar menos aire atrapado en el sistema.

Estos resultados vienen condicionados en cierta medida por el modo en el cual ha sido programado el modelo. El modelo propuesto considera que la ventosa empieza a cerrar cuando aire atrapado en la instalación es inferior a $40 \mathrm{I}$. De este modo, si se imponen cierres lentos, el aire atrapado en la instalación después del cierre de la ventosa será inferior a si se el cierre impuesto es un cierre rápido.
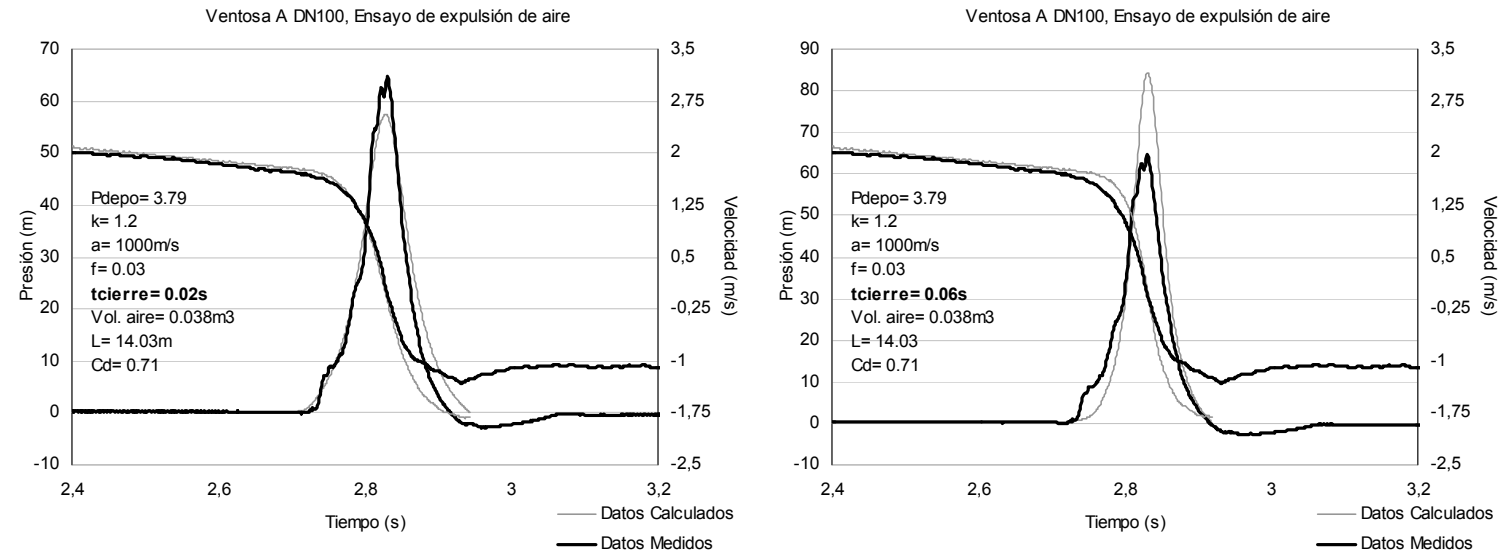

Figura 5.22. Efectos sobre el transitorio al modificar tcierre

\section{Influencia del coeficiente de descarga de la ventosa.}

El tramo de la curva de presión donde realmente se aprecia la influencia del coeficiente de descarga de la ventosa es el tramo comprendido entre el instante inicial, $\mathrm{t}_{\mathrm{i}}$, y el instante en el cual empieza a subir realmente la presión $t_{p}$. En la Figura 5.23, se muestra la variación de la presión entre estos dos instantes de tiempo como consecuencia del cierre de la ventosa cuando se considera un coeficiente de descarga $C_{d}=0,71$, coeficiente tomado finalmente en el mejor ajuste del modelo. 


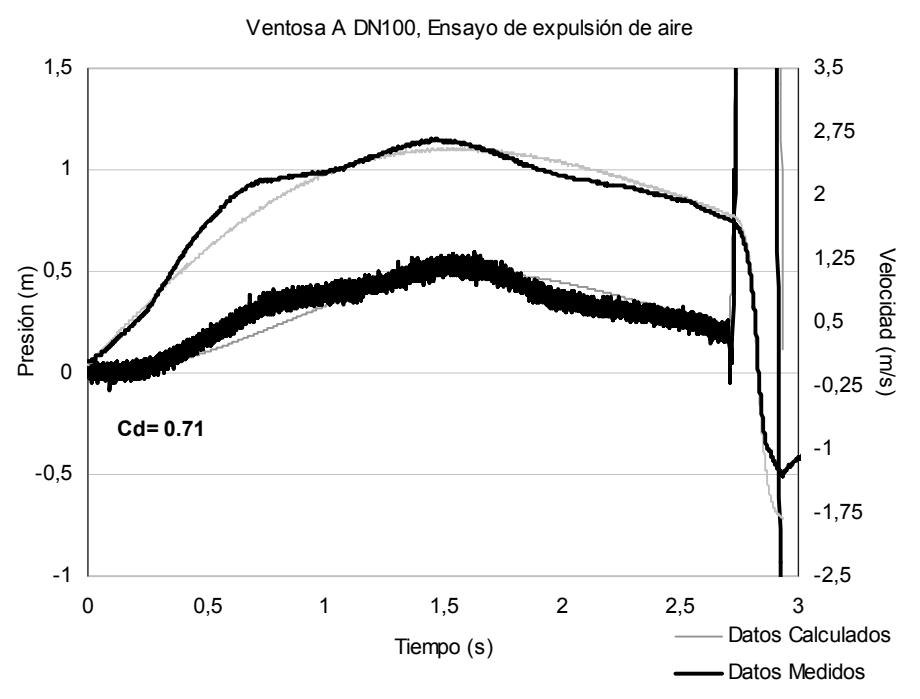

Figura 5.23. Efectos sobre el transitorio del $C_{d}$

Aplicando un coeficiente de descarga menor $C_{d}=0,61$, la presión en dicho tramo aumenta como consecuencia de haber atribuido a la ventosa menor capacidad de descarga de aire. Además la llegada de agua a la ventosa se retrasa. Por otra parte, con un coeficiente de descarga mayor, $C_{d}=0,81$, coeficiente de descarga calculado a partir de los ensayos específicos para la determinación del coeficiente de descarga de aire de esta ventosa, la presión entre los instantes inicial y de inicio del aumento de la presión, $t_{i}, y t_{p}$ disminuye debido a que aumenta la capacidad para expulsar aire. Con este coeficiente sucede el fenómeno contrario respecto a la llegada de la columna de agua a la ventosa que en el caso anterior, es decir, se adelanta la llegada de la misma.
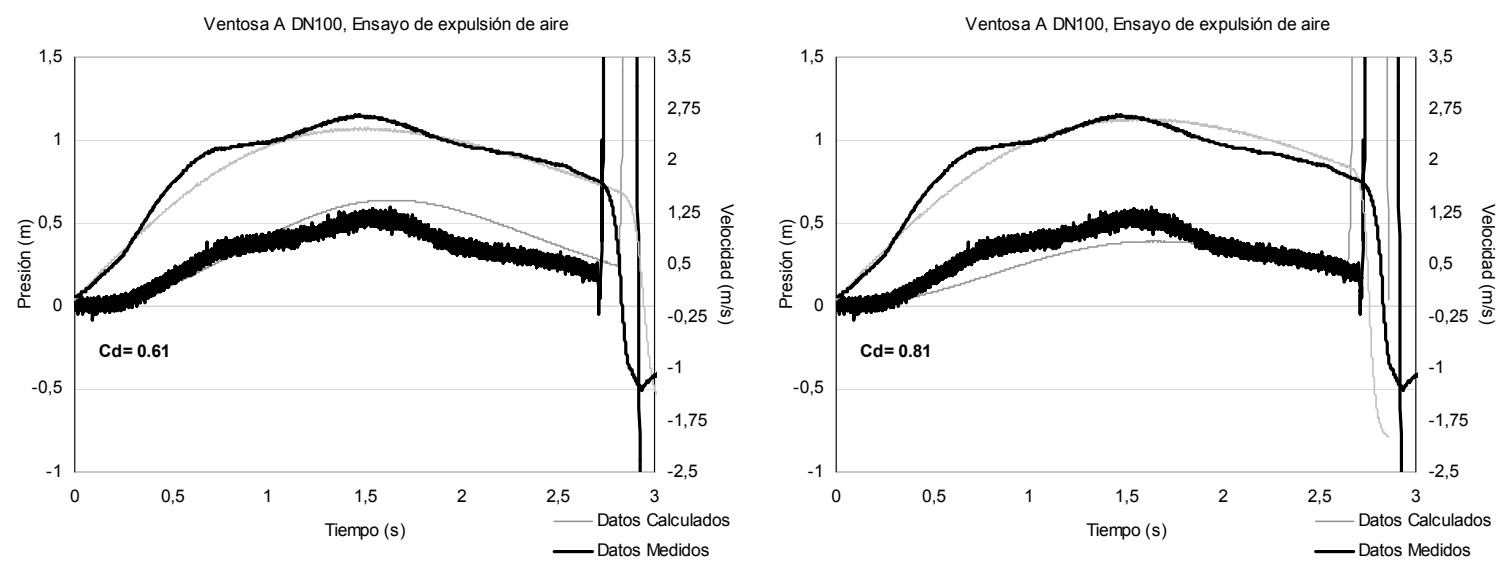

Figura 5.24. Efectos sobre el transitorio al modificar $\mathrm{C}_{d}$ 


\section{Influencia del factor de fricción.}

El factor de fricción de la tubería, tanto su valor como su posible evolución a lo largo de la sección de la tubería y del tiempo, es difícil de determinar en cualquier transitorio hidráulico, y especialmente en este caso en el cual existe un flujo bifásico. En cualquier caso, en el presente trabajo el factor de fricción se ha considerado constante ya que su estudio se escapa de los objetivos previstos. Simplemente se procura ofrecer una visión bastante amplia de la influencia de dicho factor en este transitorio. De este modo se resuelve el transitorio con dos valores diferentes del coeficiente de fricción $f=0,02$ y $\mathrm{f}=0,07$. Aunque este último valor no sea físicamente correcto, se ha considerado de manera que se permita observar la evolución de los resultados obtenidos y establecer comparaciones. Además, se entiende que de este modo se incluyen las pérdidas menores de la instalación.
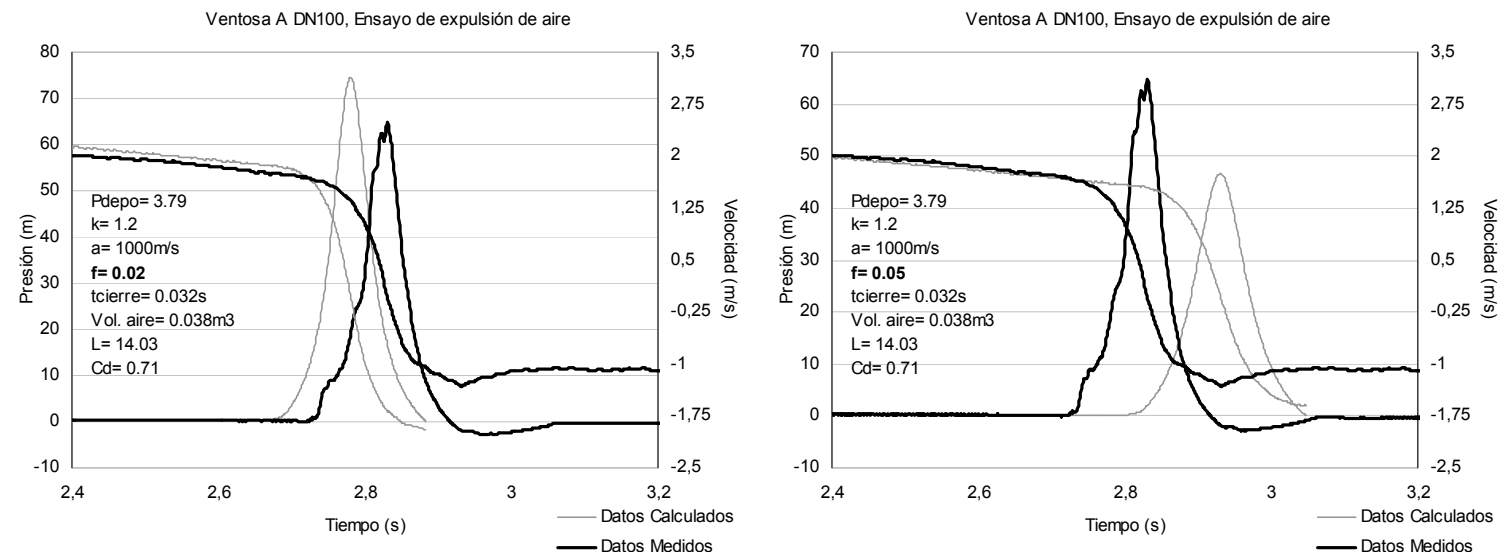

Figura 5.25. Efectos sobre el transitorio al modificar $f$

El factor de fricción menor $\mathrm{f}=0,02$, adelanta el instante de cierre de la ventosa ya que la columna de agua Ilega antes al flotador que en los ensayos prácticos. Por otro lado, al considerar un factor de fricción mayor $\mathrm{f}=0,07$ el instante de cierre de la ventosa se retrasa.

La única variable que experimenta un cambio considerable en el análisis anterior es la presión máxima registrada y el tiempo de llegada de la columna de agua a la ventosa. No se observa un cambio importante ni en la anchura del pico de presión ni en la deceleración de la columna de agua. Con un coeficiente de fricción $\mathrm{f}=0,02$, el valor de la presión máxima es mayor que la medida mientras que cuando se supone $f=0,07$, la presión máxima disminuye, ya que la velocidad de llegada de la columna de agua al flotador en este último caso es menor. 


\section{Influencia de la longitud total de la tubería}

La longitud total que debe recorrer la columna de agua es uno de los factores más influyentes en el ajuste de los resultados calculados por el modelo a los resultados de las mediciones obtenidas en los ensayos de laboratorio en cuanto al posicionamiento del pico de presión se refiere. Este modelo se ha mostrado especialmente sensible a cualquier cambio en longitud total de la tubería, por pequeño que éste fuera.

Para mostrar el efecto que provoca la variación de la misma gráficamente, se han tomado dos valores de la longitud de la tubería: $L=13,85 \mathrm{~m}$, que en principio, y si no hubieran errores de cálculo sería la medida real de la tubería y $L=14,0 \mathrm{~m}$.
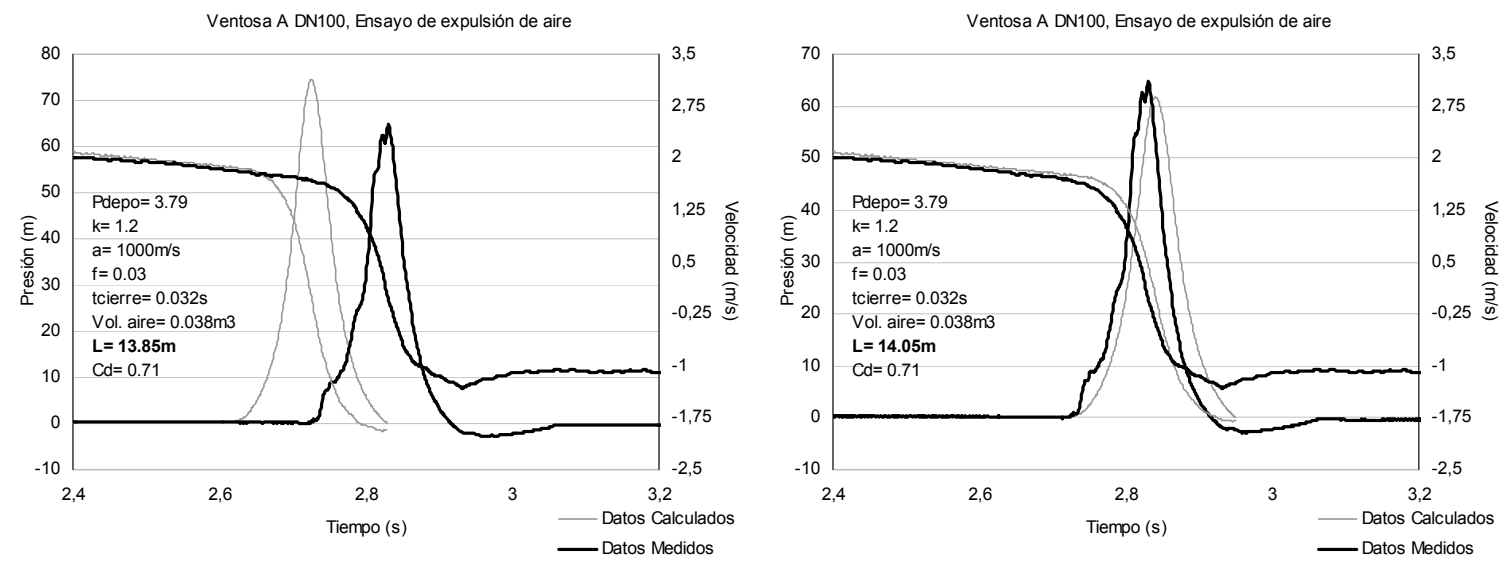

Figura 5.26. Efectos sobre el transitorio al modificar la longitud del tubo, L

Al tener en cuenta el primer valor, $L=13,85 \mathrm{~m}$, se observa que tanto el perfil de la curva de presión como el perfil de la curva de velocidad avanzan considerablemente en el tiempo. La magnitud más afectada en este caso ha sido el instante de cierre de la ventosa, ya que con una longitud de tubería mayor, como se desprende de considerar una longitud $\mathrm{L}=14, \mathrm{o} 5 \mathrm{~m}$, la columna de agua tarda más en alcanza el flotador de la ventosa, y lo hace a una velocidad menor, con lo cual el pico de presión es menor.

En la instalación aparecen dos codos de $45^{\circ}$ de inclinación sobre la horizontal cuya medida puede conducir a errores. Además, el estar considerando en estos dos casos un factor de fricción de 0,03 hace que las pérdidas menores de la instalación recaigan en mayor medida sobre la longitud total de la tubería.

\section{Influencia del volumen de aire atrapado.}

En un transitorio en el cual aparecen dos fluidos, en este caso aire y agua, es fundamental la cantidad de aire que queda atrapado en el sistema a la hora de determinar la magnitud de la presión máxima. Este factor junto con la longitud han sido altamente decisivos a la 
hora de ajustar completamente los datos calculados por el modelo con las mediciones de los ensayos.

Cualquier cambio en el volumen de aire atrapado altera completamente los resultados de la simulación. Para mostrar los efectos del volumen de aire atrapado se presentan dos simulaciones realizadas con dos volúmenes de aire atrapado distintos: Vol. Aire $=0,02 \mathrm{~m}^{3}$ y $\operatorname{Vol}$. Aire $=0,048 \mathrm{~m}^{3}$. Con el primer valor disminuye la anchura del pico de presión calculado respecto del medido mientras que la presión máxima y la deceleración de la columna de agua aumentan.

Por otro lado, al considerar más cantidad de aire atrapado, aumenta el ancho del pico de presión y disminuyen la presión máxima y la deceleración de la columna de agua. Simplemente efectuando variaciones de $0,01 \mathrm{~m}^{3}$ de aire atrapado respecto al transitorio representado en la Figura 5.20, las alteraciones en los resultados finales aportados por el modelo teórico son evidentes.
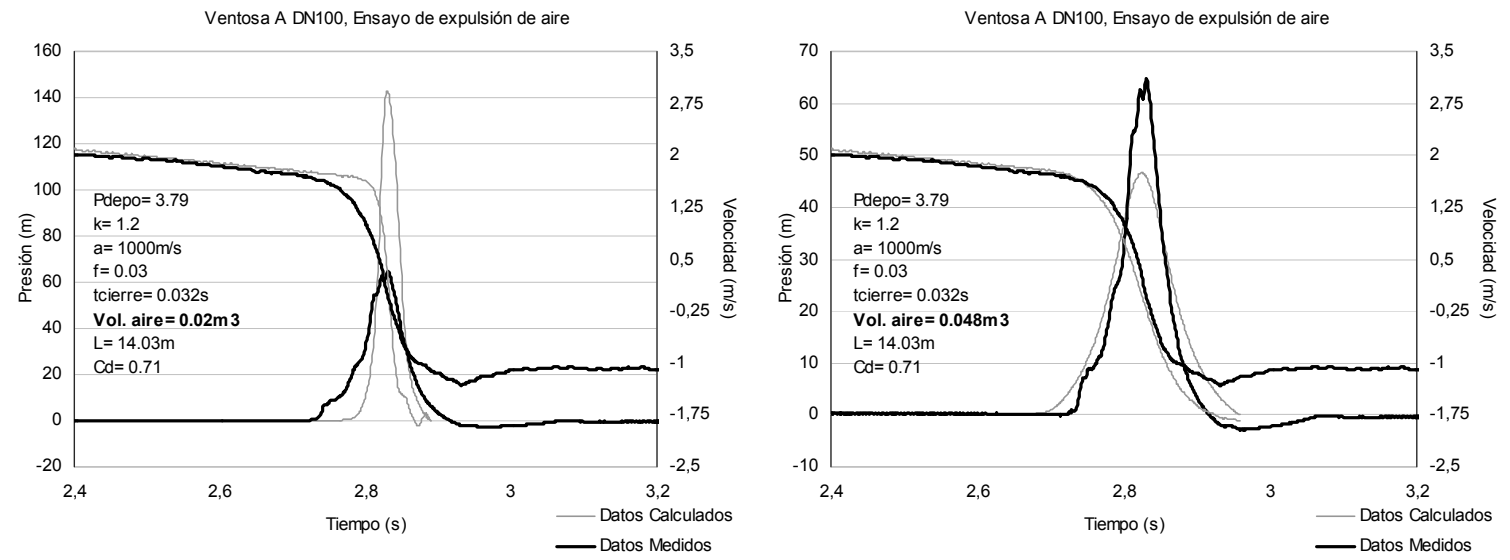

Figura 5.27. Efectos sobre el transitorio al modificar el volumen de aire

Gracias al análisis de sensibilidad de los parámetros que intervienen en el evento estudiado, se ha establecido el rango de variación de cada uno de ellos en un transitorio concreto al tiempo que se analiza la influencia de los mismos en el resultado final. Todos los parámetros analizados modifican en cierta medida el resultado final del transitorio.

Del análisis individual de cada parámetro se observa en líneas generales que mientras unos valores inciden básicamente en la magnitud del pico máximo de presión, como es el caso del volumen de aire atrapado al final del evento o del tiempo que tarda en cerrar la ventosa, otros en cambio inciden en el avance o retraso del instante en el cual se produce este pico de presión máxima como es el caso de la longitud total de la tubería o el factor de fricción.

Por otro lado el coeficiente de descarga influye en la mayor o menor compresión de la bolsa de aire mientras la ventosa se encuentra abierta. El uso de un valor u otro del 
coeficiente politrópico no afecta en gran medida el resultado, si bien parece claro que no se trata de un fenómeno isotermo. Finalmente, en este transitorio se ha optado por mantener un valor constante de la celeridad de la onda, fijándolo igual a la del agua ya que dicho valor es el que ha proporcionado el mejor ajuste. Esto podría ser debido a que en este caso es correcto suponer que no existe apenas mezcla de aire y agua, quedando el aire atrapado en una bolsa al final de la columna con lo cual la modelación del evento como flujo pistón se puede considerar aproximada para modelar adecuadamente el transitorio.

Aunque estas conclusiones sobre el modo la influencia de los diferentes parámetros son ciertas y de gran ayuda para analizar el fenómeno ocurrido, cabe decir, que el resultado final de los valores de presión y velocidad son fruto de una combinación de la influencia de todos ellos.

\subsubsection{SIMULACIÓN DEL TRANSITORIO CON LA VENTOSA DE DN50.}

La simulación del fenómeno transitorio de ensayos de expulsión de aire al final de una tubería de DN200 a través de una ventosa de diámetro nominal $50 \mathrm{~mm}$ se lleva a cabo con el mismo programa de cálculo con el cual se analizan los ensayos de la instalación de mayor calibre. Es importante remarcar nuevamente que con esta instalación de menor tamaño se dispone de menos variables a la hora de validar el modelo ya que el caudalímetro electromagnético utilizado en los ensayos no presentó una respuesta en frecuencia adecuada. De todos modos, aún disponiendo de menos variables, se ha intentado ajustar al menos la curva de la presión producida en el cuello de la ventosa.

Después de efectuar un análisis de sensibilidad el coeficiente politrópico, la celeridad de la onda de presión y el factor de fricción se fijan con el mismo valor que el tomado en la instalación de mayor tamaño. Por otro lado, el tiempo de cierre de la ventosa se fija con el valor medido en los ensayos mediante el transductor de posición instalado en el flotador de la ventosa. Finalmente, el volumen de la bolsa de aire que queda atrapado al final de la instalación y la longitud total de la instalación son las dos magnitudes que se han variado en un rango de valores.

Concretamente, al volumen de aire atrapado se le han asignado valores entre 0,01 $\mathrm{m}^{3} \mathrm{y}$ $0,02 \mathrm{~m}^{3}$ y a la longitud total de la instalación se le asignan valores entre $7,5 \mathrm{~m}$ y $8 \mathrm{~m}$. Finalmente como coeficiente de descarga se ha utilizado el coeficiente calculado a partir de los ensayos para la determinación de la capacidad de expulsión de las ventosas DN50, cuyo valor es 0,8 para la ventosa A y 0,78 para la ventosa B. La variación de cada uno de estos parámetros influye del mismo modo en la presión y la velocidad que el presentado en el análisis anterior para la instalación de 500 mm de diámetro. 
Se ha optado, ante las diferencias evidentes entre los cálculos y las mediciones ajustar el ancho del pico de presión, el cual hace referencia a la cantidad de aire atrapado. En general, los resultados obtenidos en este apartado muestran que el mismo programa de cálculo proporciona para estos ensayos en cuestión, valores de la presión calculada superiores a los valores de presión obtenidos mediante las mediciones en el laboratorio

Esta sobreestimación de la presión máxima se cumple tanto en las validaciones realizadas usando los valores medidos en los ensayos de la ventosa $A$ de diámetro nominal $50 \mathrm{~mm}$, como las efectuadas utilizando los valores medidos en los ensayos de la ventosa B del mismo diámetro, justo al contrario de lo que ocurría con la ventosa B DN100. En esta ventosa tampoco se conseguía un ajuste perfecto al intentar ajustar los cálculos teóricos a los medidos pero al igualar el ancho del pico de presión, el valor máximo calculado de dicha presión era inferior al medido.

En las figuras siguientes aparecen las condiciones iniciales y de contorno de cada ensayo así como los valores de los parámetros característicos que logran el mejor ajuste del transitorio en cada caso para determinado valor de sobrepresión inicial. 

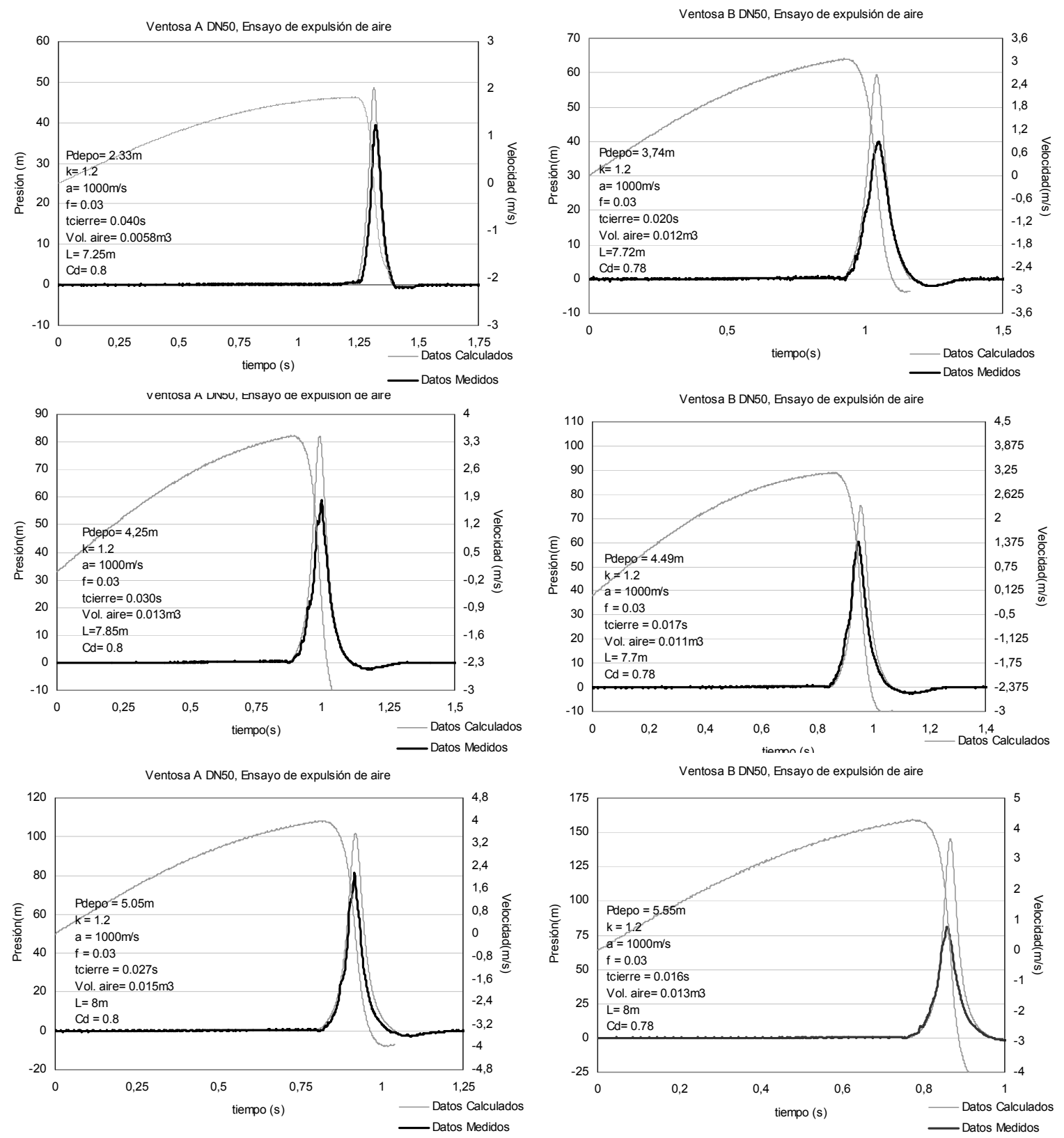

Figura 5.28. Presión medida y calculada en ventosas a y B, DN50

En estas gráficas no se aprecia una elevación de presión entre el instante inicial y el instante en el cual la columna de agua llega a la ventosa, $t_{c}$, tal y como se apreciaba en la instalación de mayor diámetro. Esto es debido a que posiblemente la ventosa DN50 instalada en la conducción de diámetro $200 \mathrm{~mm}$ es excesivamente grande en comparación con la ventosa DN100 sobre la instalación de 500 mm de diámetro y por ello no se detectan los ligeros aumentos de presión anteriores al pico de presión máxima.

En este apartado no se han simulado con el modelo propuesto las otras configuraciones ensayadas en el laboratorio con las ventosas DN50 debido a la complejidad añadida que introducen los diversos cambios de sección y la configuración con carrete vertical. 


\subsection{PROGRAMAS COMERCIALES DE DIMENSIONADO E INSTALACIÓN DE VENTOSAS}

Hoy en día se pueden encontrar en el mercado dos tipos de programas informáticos relacionados con el estudio de sistemas hidráulicos que incluyen la presencia de agua y aire. Por un lado se encuentran los programas informáticos que algunos fabricantes de ventosas incluyen entre sus productos y que ayudan a decidir el tipo de ventosa a utilizar de entre las disponibles en sus catálogos así como la ubicación óptima de las mismas. Este tipo de programas informáticos necesitan datos referentes a las dimensiones y materiales de la instalación, tipo y velocidad del fluido y la presión máxima que es capaz de soportar el sistema. Generalmente se trata de programas descriptivos los cuales se centran en la elección de la ventosa adecuada en cuanto a la función que debe desempeñar al tiempo que recomiendan un determinado tamaño de la misma.

Por otro lado, se encuentran los programas informáticos destinados al estudio de la evolución del transitorio que se genera en la instalación. En ellos es posible introducir todos los elementos presentes en el sistema y realizar simulaciones considerando los diferentes dispositivos de control. Calculan las presiones y las velocidades del flujo en cada instante de tiempo para cualquier punto de la instalación pero no indican la ubicación óptima de los elementos de control, entre ellos las ventosas.

Seguidamente se ofrece una pequeña muestra de estos dos tipos de programas disponibles en el mercado actual. En este apartado se detallan programas como los que ofrecen las casas comerciales ARI VALVES, VENT-O-MAT y APCO-VALVES, los cuales sitúan las ventosas de sus catálogos que mejor se ajustan a las necesidades de la instalación sobre el perfil de la misma. Como ejemplos de programas de cálculo de transitorios introduciendo elementos de control se presentan los programas HAMMER (Bentley) y WANDA (Delft Hydraulics)

\subsubsection{ARI VALVES}

El programa de elección del tipo de ventosa y su ubicación en la instalación de ARI VALVES, permite elegir en primer lugar entre el tipo de agua que circula por la instalación, es decir, agua limpia o agua residual. En cuanto al material de la tubería, el programa ofrece una lista de seis posibles materiales: acero, hierro fundido, plástico, GRP (plástico reforzado con fibra de vidrio), hormigón, cemento con amianto. El programa asocia un determinado coeficiente de rugosidad de Hazen-Williams (constante) según el material de tubería introducido. 


\begin{tabular}{|c|c|}
\hline \multicolumn{2}{|c|}{ VALORES DE HAZEN WILLIAMS } \\
\hline MATERIAL DE LA TUBERÍA & HAZEN WILLIAMS (VALOR C) \\
\hline Acero & 120 \\
\hline Hierro fundido & 100 \\
\hline Plástico & 140 \\
\hline GRP & 140 \\
\hline Hormigón & 120 \\
\hline Cemento con amianto & 120 \\
\hline
\end{tabular}

Figura 5.29 Coeficiente de Hazen Williams según el material de la tubería

En este programa, como en la gran mayoría, se puede trabajar tanto con unidades del sistema internacional como con unidades del sistema Americano.

Para evitar picos de presión no deseados y por tanto daños en la instalación se recomienda limitar la velocidad inicial de llenado de la instalación. Por esta razón el programa establece como velocidad inicial de llenado un valor por defecto igual a $0,5 \mathrm{~m} / \mathrm{s}$. Si en algún momento la velocidad del flujo supera el valor de $1 \mathrm{~m} / \mathrm{s}$ el programa advierte que se está superando el valor recomendado pero se puede seguir trabajando con el valor de velocidad introducido.

Se debe introducir en el programa la presión nominal de la ventosa de entre cinco presiones nominales disponibles: PN10, PN16, PN25, PN40 y PN64. Este dato sirve de ayuda al programa para elegir la ventosa adecuada del catálogo de fabricante. En algunos casos, es posible seleccionar también el material del cuerpo de la ventosa: hierro dúctil o acero fundido.

En la pantalla de selección se recuerda el tipo de fluido a utilizar y además se introduce el dato de presión mínima con lo cual se determina el límite de presión diferencial subatmosférica que el usuario permite al sistema que se produzca. Esta presión es la presión mínima esperada en función de la ventosa y el diámetro de la tubería. El programa tiene establecida por defecto una presión subatmosférica de 0,4 bar a la cual la ventosa debe empezar a admitir aire y es la mayor diferencia de presión que admite. Por otro lado, ARI Plan determina la presión diferencial positiva a la cual la ventosa empieza a descargar aire en 0,6 bar.

En los tramos de tubería en los cuales no existan puntos elevados o cambios de sección, el usuario puede limitar la distancia entre ventosas. La distancia por defecto que toma el programa es de $500 \mathrm{~m}$ pero puede ser modificada por el usuario. Si la presión nominal es igual o superior a 40 bar, se puede elegir entre dos tipos de material para el cuerpo de la ventosa: hierro dúctil o acero fundido.

La tabla de datos del perfil de la instalación es el componente más importante del plan que propone ARI ya que el análisis que se realiza se basa en la información que aparece en la misma. En esta tabla aparecen las distintas longitudes de las secciones, las alturas de 
los puntos elevados, y el diámetro de cada tramo de tubería. Los puntos singulares se identifican como una estación con un determinado identificador (ID). El valor de las longitudes se puede introducir como longitudes por tramos o como longitudes acumuladas. De este modo, las longitudes seccionales o por tramos son las distancias entre dos puntos identificados (ID). Por su lado, la longitud acumulada se calcula de modo que en el primer punto de la instalación es cero mientras que en el último punto es la longitud total de la instalación. En la Figura 5.30 se muestra un ejemplo de cómo se introducen las longitudes de los diferentes tramos, ya sea entre dos puntos o por longitudes acumuladas.

En la tabla de datos del perfil de la instalación también se introducen en forma de códigos aquellos elementos que contribuyen a la alteración del flujo y que son útiles a la hora de representar las diferentes situaciones a las cuales se puede ver sometida la instalación como por ejemplo un punto de rotura, un punto de drenaje etc.

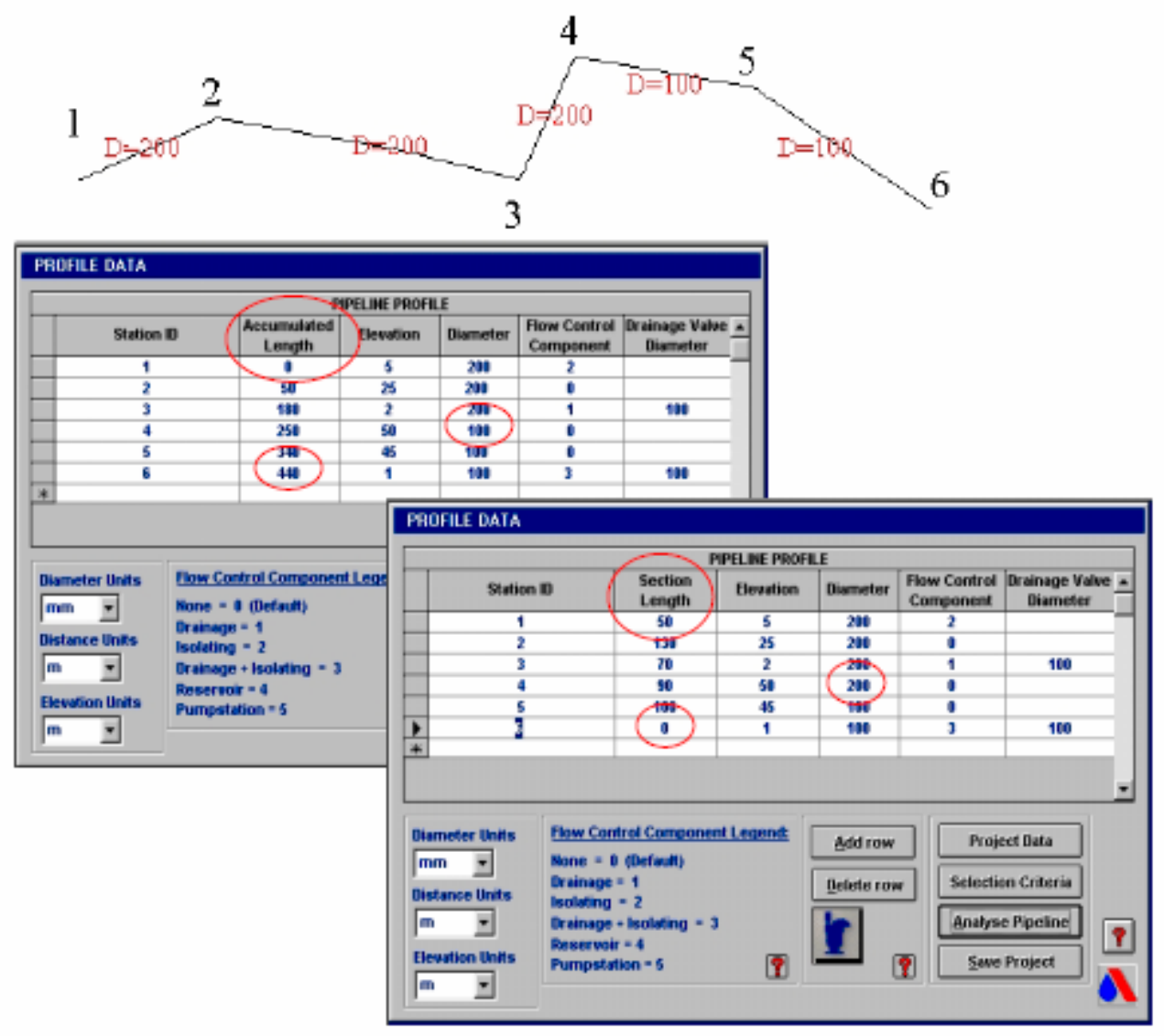

Figura 5.30. Entrada de datos del perfil de la instalación 
Este programa puede realizar tres tipos de análisis diferentes:

- Análisis de rotura en algún punto de la instalación.

- Análisis de drenaje de la instalación.

- Análisis de llenado de la instalación.

\section{Análisis de rotura}

En el análisis de rotura se supone un diámetro de rotura de la instalación o diámetro del orificio por el cual sale agua al exterior. Para evitar que se produzcan bajas presiones se debe admitir aire a través de una ventosa por encima del punto de rotura a una velocidad igual a la de salida del agua por el orificio de rotura. El programa calcula la capacidad de Ilenado para cada sección a partir de la ecuación de Hazen Williams:

$Q_{\text {rotura }}=\sqrt[1.852]{\frac{s \cdot D^{4.87} \cdot C^{1.852}}{10.69}}$

Donde:

Qrotura es la capacidad de llenado requerida en $\mathrm{m}^{3} / \mathrm{s}$.

s es la pendiente de la tubería $(\mathrm{m} / \mathrm{m})$.

D el diámetro de la tubería (m).

C es la constante de Hazen Williams.

El análisis de rotura no tiene en cuenta la diferencia de cota entre puntos de tal modo que incluso cuando los cambios de pendiente son suaves se requiere una alta capacidad de admisión de aire. Aunque el programa comprueba los cambios de pendiente entre secciones, en este análisis no sitúa una ventosa en cada punto donde se produce dicho cambio. En lugar de esto, el programa evalúa las velocidades del flujo en las dos secciones que confluyen en el punto de cambio de pendiente y calcula la diferencia de la altura piezométrica en base a la diferencia de velocidades:

$$
\Delta h_{v}=\frac{v_{2}^{2}}{2 g}-\frac{v_{1}^{2}}{2 g}
$$

Si este valor es menor que $1,5 \mathrm{~m}$ el programa no sitúa ninguna ventosa en el punto de cambio de pendiente. Por el contrario la altura piezométrica es igual o mayor que 1,5 m, entonces sitúa una ventosa que cumpla la función de admisión de aire en el punto de cambio de pendiente. 


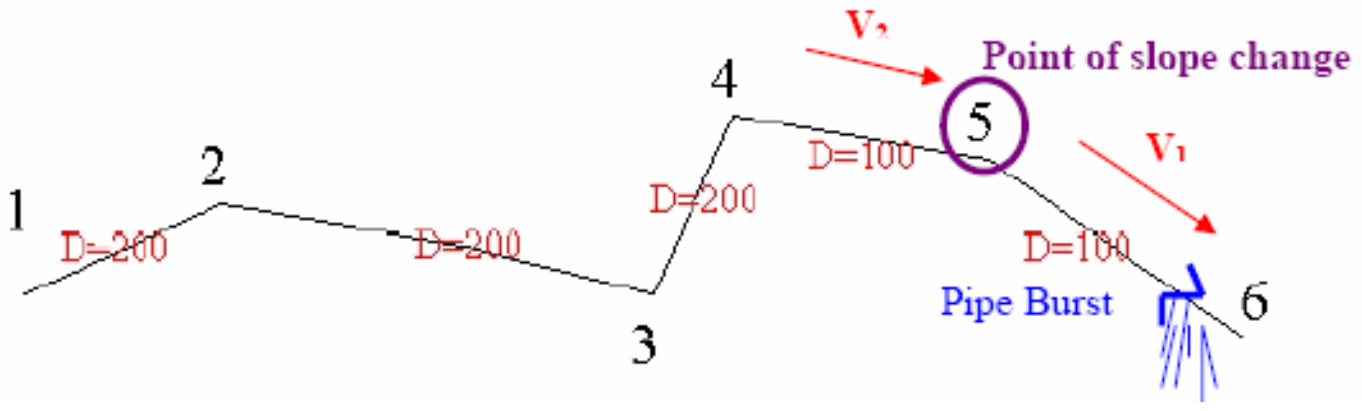

Figura 5.31 Punto de rotura

\section{Análisis del drenaje de la instalación}

El programa realiza el análisis drenaje de una instalación basándose en la fórmula de salida de agua por un orificio:

$Q_{\text {drenaje }}=C d \cdot \sqrt{2 \cdot g \cdot \Delta h} \cdot \pi \cdot\left(\frac{D}{2}\right)^{2}$

Donde:

D es el diámetro de la válvula de drenaje $(\mathrm{m})$.

$\mathrm{C}_{\mathrm{d}}$ es el coeficiente de descarga. El programa toma un valor de 0,6 por defecto.

$\mathrm{G}$ es la aceleración de la gravedad $(9,81 \mathrm{~m} / \mathrm{s})$.

$\Delta \mathrm{h}$ es la diferencia de alturas entre los dos puntos entre los cuales se efectúa el drenaje (m).

En este análisis no se tienen en cuenta los cambios de pendiente entre las secciones ni las pérdidas de carga en la instalación. Se supone que la tubería se comporta como un depósito el cual tiene un orificio en la parte inferior por el que sale el agua y cuyo diámetro es igual al diámetro de la válvula de drenaje. Por otro lado, para cada válvula de drenaje se revisa toda la instalación y el efecto de cada sección sobre el resto y de cada ventosa sobre las demás.

\section{Análisis de llenado de la instalación}

Es el único análisis basado en la capacidad de expulsión de aire de la instalación a través de una ventosa. Asume que el caudal de salida del aire es igual a la velocidad del agua en el sistema que se haya especificado como dato de entrada.

Además de estos tres análisis, se pueden realizar combinaciones de dichos análisis siendo la opción más conservativa aquella que tenga en cuenta los tres análisis al mismo tiempo. Se recomienda que en cualquier combinación de análisis se tenga siempre en cuenta el 
análisis de llenado de la conducción. En tuberías muy largas con diferencias de alturas entre el punto más alto de la instalación y el punto más bajo de drenaje $(\Delta h)$ elevadas, el análisis de drenaje es el más conservativo de modo que se proponen las ventosas más grandes. Si las diferencias de alturas $(\Delta \mathrm{h})$ en la instalación son moderadas pero las pendientes son pronunciadas se utiliza el análisis de rotura. Finalmente si la tubería es relativamente plana, con pendientes suaves, el análisis de llenado es el más conservativo.

Una vez completada la entrada de datos aparece una pantalla que muestra gráficamente los resultados de toda la instalación. En dicha pantalla, se puede obtener toda la información relativa a un punto concreto, o bien información sobre el tipo de ventosa utilizada etc. tal y como muestran dos figuras siguientes:

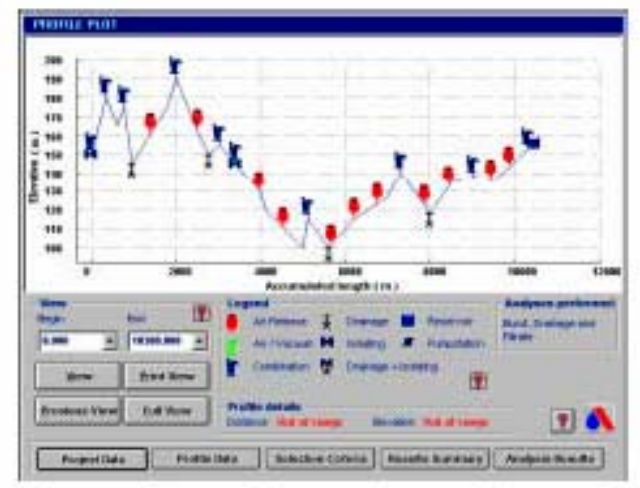

Figura 5.32. Perfil de la instalación

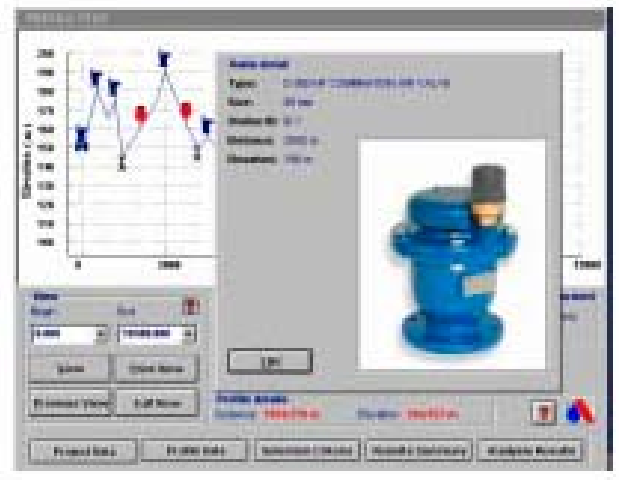

Figura 5.33. Selección de la ventosa

La principal característica de la pantalla de resultados de los análisis es una tabla en la cual se listan todos los puntos de la instalación con toda la información relativa a cada uno de ellos: identificador, longitud acumulada, altura, tipo de válvula (modelo, descripción etc), velocidad del flujo, tamaño de la ventosa. 


\subsubsection{VENT-O-MAT}

El programa para la selección de ventosas que aporta la casa VENT-O-MAT es similar al propuesto por ARI Valves en cuanto a los datos de entrada que necesita el programa y el tipo de cálculos que realiza. En primer lugar, hay que establecer el tipo de sistema a analizar, es decir si se trata de un sistema sometido a un bombeo o es un sistema que funciona por gravedad.

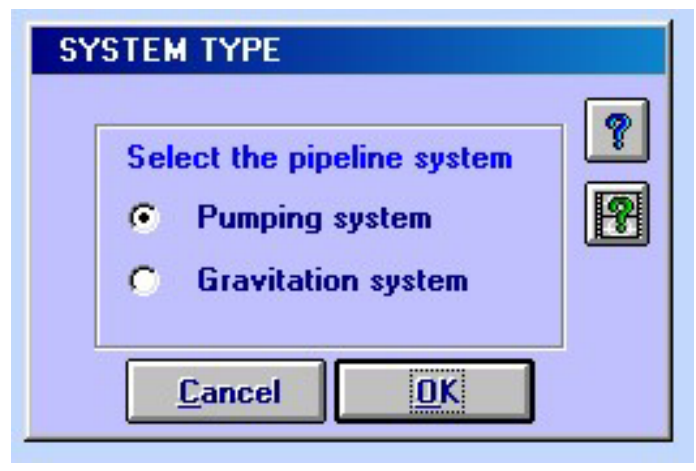

Figura 5.34. Selección del tipo de sistema

\section{Entrada de datos}

La entrada de datos al programa se realiza en tres etapas diferenciadas: datos generales, datos del perfil de la instalación y datos de asesoramiento económico. Los datos generales engloban los datos referentes a las características del flujo, las características de las tuberías y el criterio de selección de las ventosas.

Dentro de las características del flujo es posible realizar una descripción general del proyecto que puede servir posteriormente como recordatorio de los objetivos del mismo. Además el programa necesita conocer el tipo de fluido a utilizar (agua limpia o agua residual), la velocidad de operación del flujo, la velocidad de llenado, la temperatura (para calcular la presión de vacío) y la elevación con la que se calcula la presión de vacío, todo ello en las unidades deseadas.

En la tabla de características de la tubería, hay que definir el tipo de material de las mismas, la ruptura estimada de la tubería y la rugosidad absoluta $\left(\mathrm{k}_{\mathrm{s}}\right)$ Los materiales de la tubería disponibles en este programa son: HDPE (polietileno de alta densidad), LDPE, (polietileno de baja densidad), uPVC, fibrocemento, GRP (glass reinforced polyester), recubrimiento de caucho, acero nuevo, hierro dúctil, hierro fundido y acero corroído. La selección del material de la tubería sirve para establecer la máxima diferencia de presión negativa permitida a través de la ventosa. Se recomienda una presión negativa de $20 \mathrm{KPa}$ para el HDPE, LDPE, uPVC (PVC orientado) y GRP y una presión negativa de $35 \mathrm{KPa}$ para el fibrocemento, el hierro y los aceros. 
El tamaño estimado de la ruptura se introduce como un porcentaje del diámetro de la tubería. Cada material tiene unas características de ruptura diferentes, por ello, el programa establece unos porcentajes según el material adoptado. Así pues para HDPE, LDPE, uPVC GRP, hierro y acero se establece que el tamaño de ruptura es un $15 \%$ del diámetro de la tubería mientras que para el fibrocemento es de un $50 \%$.

El programa recomienda una serie de valores de la rugosidad de la tubería según el material de la misma. Dicha rugosidad se utiliza para definir la línea de alturas piezométricas. Los valores de la rugosidad que el programa introduce por defecto son:

Tabla 5.1. Tabla de rugosidades del material

\begin{tabular}{l|l} 
HDPE, LDPE, uPVC y fibrocemento & $0,03 \mathrm{~mm}$ \\
\hline GRP & $0,04 \mathrm{~mm}$ \\
\hline Recubrimiento de caucho & $0,05 \mathrm{~mm}$ \\
\hline Acero nuevo & $0,06 \mathrm{~mm}$ \\
\hline Hierro dúctil & $0,15 \mathrm{~mm}$ \\
\hline Hierro fundido y acero medio & $0,30 \mathrm{~mm}$ \\
\hline Acero corroído & $3 \mathrm{~mm}$
\end{tabular}

Al definir el criterio de selección de ventosas, se debe especificar las presiones negativas permitidas, el espacio entre ventosas, el tamaño y tipo de ventosa. Se debe introducir el valor de la diferencia de presión negativa permitida siguiendo las indicaciones del fabricante de la tubería. Las condiciones de flujo críticas empiezan aproximadamente a presiones diferenciales de 0,35 bar bajo condiciones de vacío.

El programa recomienda establecer una distancia de 600 m entre ventosas de expulsión de aire en un tramo largo de tubería que no presente cambios de pendiente apreciables. De todos modos, el usuario puede cambiar este valor y decidir si prefiere instalar las ventosas a mayor o menor distancia entre ellas. El programa indica los puntos en los cuales se produce una velocidad del flujo crítica, es decir, los puntos en los cuales no se puede transportar aire y en donde debe haber un suficiente número de ventosas. El usuario puede introducir un tamaño específico de ventosa si lo considera oportuno así como el tipo de ventosa o bien dejar que el programa realice estos cálculos automáticamente.

El segundo grupo de datos a introducir en el programa son los relativos al perfil de la tubería. En este apartado hay que describir el perfil de la instalación y las unidades en las que se quiere trabajar. 
Para definir perfectamente el perfil de la tubería hay que describir cada uno de los puntos. Se debe introducir la longitud acumulada de la tubería en un punto dado tal y como se ha explicado en el programa que ofrece ARI Valves, la elevación de cada punto singular y el diámetro de cada sección de la tubería. Una vez hecho esto, se procede a introducir el tipo de punto de control, el cual se puede elegir entre las siguientes opciones sin necesidad de introducir nada cuando no hay ninguna función de control en el punto.

- Drenaje: Punto por el cual se puede drenar la tubería. Se debe introducir el diámetro de la válvula de desagüe.

- Aislamiento: Punto en el cual se puede cerrar la tubería

- Aislamiento y drenaje: Es una combinación de las dos situaciones anteriores.

- Antiretorno: Punto en el cual se limita el sentido del flujo en una dirección.

- Salida: Puntos de salida o extracción de caudal a lo largo de la tubería. En este caso hay que introducir la cantidad de agua que se está descargando a otro sistema.

- Depósito: Depósito que puede estar al principio o al final de la instalación. El programa necesita conocer el nivel de agua en el depósito. Dicho nivel se utiliza para calcular la línea de alturas piezométricas. Además cuando se procede al drenaje de la instalación se supone que el depósito no se vacía, se mantiene como aislado del resto del sistema.

- Estación de bombeo: Si hay una estación de bombeo en el punto inicial del sistema.

Una novedad que introduce este programa es la evaluación económica resultado de haber realizado una adecuada expulsión de aire. Es necesario establecer el período durante el cual se quiere realizar dicha evaluación en años. Con este módulo se pretende comparar el coste energético entre un sistema en el cual se ha expulsado el aire eficientemente y un sistema en el cual no se haya expulsado aire. Si la instalación posee un sistema de bombeo hay que introducir la curva de la bomba, el tiempo durante el cual se está bombeando cada día y un promedio del coste energético del bombeo por hora. Si se trata de un sistema que actúa por gravedad hay que introducir un beneficio promedio en la venta de agua. El descenso de la capacidad de transporte del sistema debido a una ineficaz expulsión de aire puede hacer que se reduzcan las posibles entradas.

\section{Análisis que realiza el programa}

Este programa realiza el mismo tipo de análisis que el programa presentado por ARI Valves, es decir, análisis de rotura, análisis del drenaje de la tubería y análisis de Ilenado de agua de la instalación. Se puede realizar solo uno de estos análisis o bien una combinación de los mismos existiendo así mismo la posibilidad de realizar en cada caso un análisis económico. El programa determina la capacidad de cada ventosa y determina las secciones de la tubería que se deben proteger porque sean susceptibles de sufrir condiciones de vacío durante una simulación de una rotura o durante el vaciado o 
drenaje de la instalación. El programa indica a su vez como actúan las ventosas durante el llenado de la instalación (descarga de aire) y la capacidad de expulsión de aire de la instalación en condiciones de operación normales.

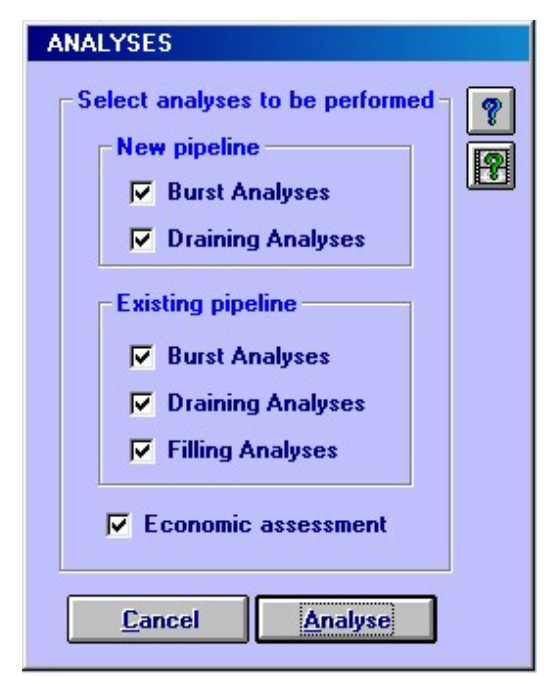

Figura 5.35. Análisis que efectúa el programa Ventomat

\section{Resultados del programa}

Los resultados se presentan en forma de tablas o gráficos. El gráfico del perfil de la instalación muestra las ventosas escogidas del catálogo de esta marca comercial y su ubicación en la misma.

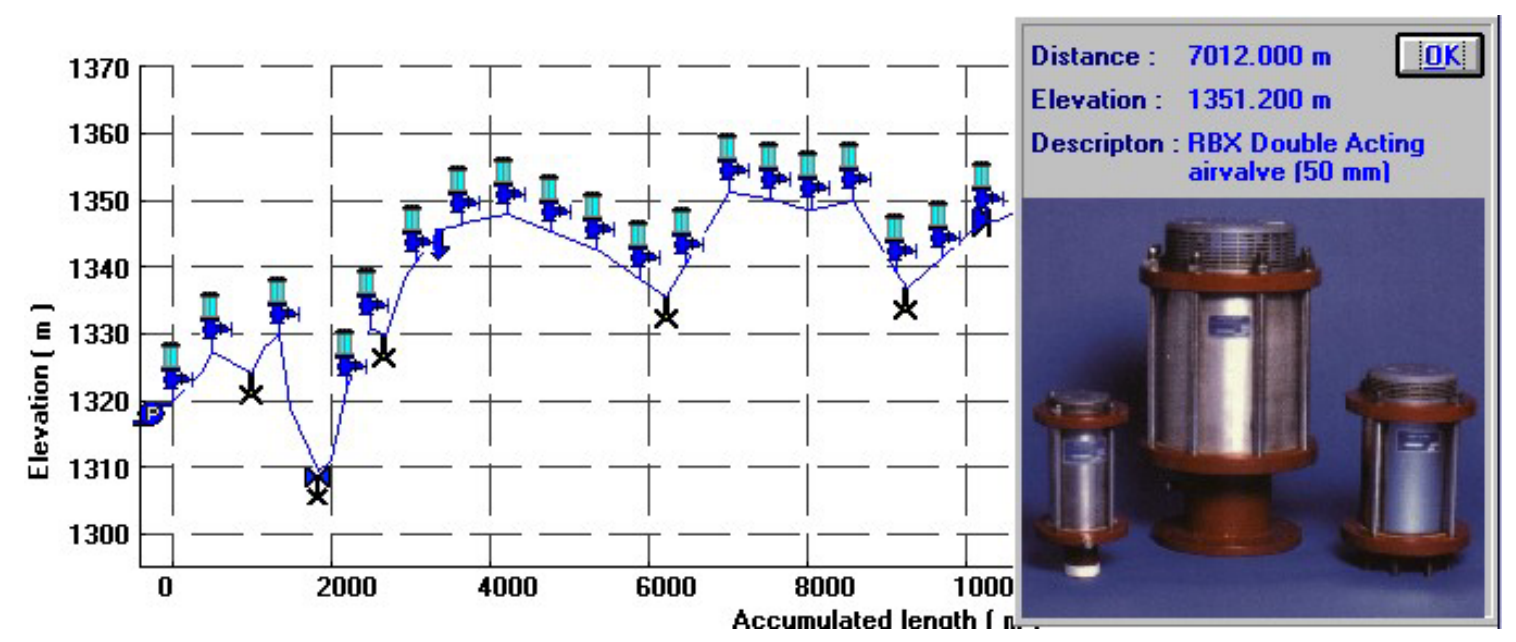

Figura 5.36. Pantalla de resultados 
En la tabla de resultados aparecen los resultados de forma numérica tal y como muestra la Figura 5.37:

\begin{tabular}{|c|c|c|c|c|c|c|c|c|}
\hline Nr & Point description & \begin{tabular}{|c|} 
Accumulated \\
length
\end{tabular} & Elevation & Air valve & Size & Valve class & Model number & $\Delta$ \\
\hline 1 & First point & 0.000 & 1320.000 & RBX Double Acting airvalve & $50 \mathrm{~mm}$ & 25 Bar & 050RB $\times 251$ & \\
\hline 2 & Point 2 & 369.000 & 1324.000 & No airvalve required & - & - & - & \\
\hline 3 & Point 3 & 500.000 & 1327.500 & RBX Double Acting airvalve & $80 \mathrm{~mm}$ & $16 \mathrm{Bar}$ & 080RB $\times 161$ & \\
\hline 4 & Point 4 & 985.500 & 1324.000 & No airvalve required & - & - & - & \\
\hline 5 & Point 5 & 1143.200 & 1328.000 & No airvalve required & - & - & - & \\
\hline 6 & Point 6 & 1245.000 & 1328.800 & No airvalve required & - & - & - & \\
\hline 7 & Point 7 & 1345.000 & 1329.900 & RBX Double Acting airvalve & 100 mm & 16 Bar & 100RBX16 1 & \\
\hline 8 & Point 8 & 1490.300 & 1319.000 & No airvalve required & - & - & - & \\
\hline 9 & Point 9 & 1846.100 & 1309.300 & No airvalve required & - & - & - & \\
\hline 10 & Point 10 & 2006.300 & 1311.200 & No airvalve required & - & - & - & $\nabla$ \\
\hline \begin{tabular}{|l|l|}
4 & \\
\end{tabular} & & & & & & & & \\
\hline
\end{tabular}

Figura 5.37. Tabla de resultados

$\mathrm{Si}$ adicionalmente se realizado un estudio económico el programa muestra de modo gráfico y numérico la comparación de expulsar el aire de forma eficaz o ineficazmente.
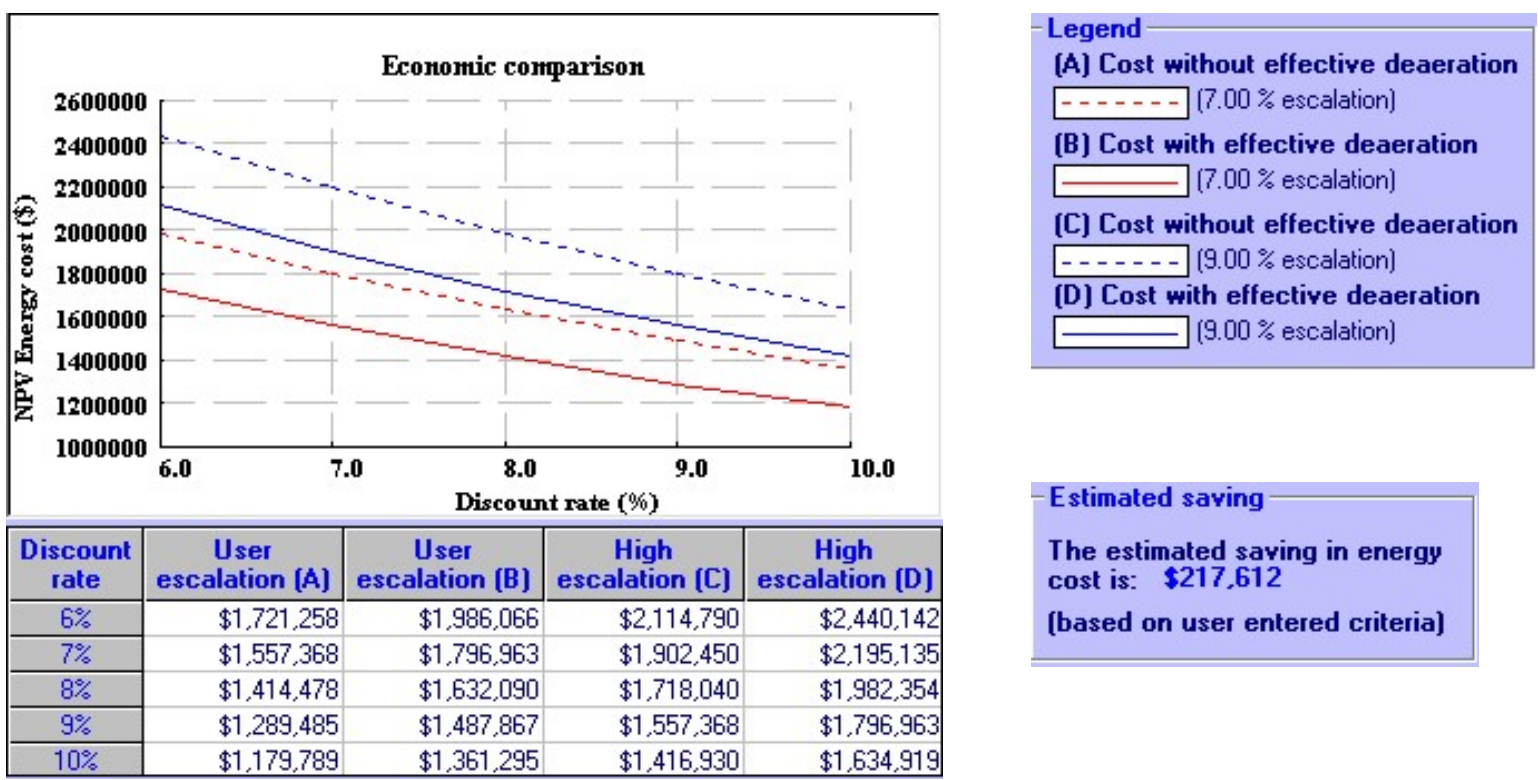

Figura 5.38. Pantalla de resultados del estudio económico

Estimated saving
The estimated saving in energy
cost is: $\$ 217,612$
[based on user entered criteria]




\subsubsection{APCO VALVES}

Los fabricantes de válvulas Apco-Valves presentan tres módulos en formato Excel de los cuales dos de ellos APSLIDE y APSPEC están relacionados con el dimensionado y ubicación de ventosas en una instalación. Estos dos módulos permiten obtener los requerimientos de tamaño de ventosa necesarios para una aplicación dada y las especificaciones de la ventosa seleccionada de su catálogo.

En primer lugar, el usuario debe introducir los datos en el módulo APSPEC. Este módulo consta de un menú principal desde el cual se puede acceder a cada una de las diferentes pantallas de entrada de datos hasta completar los requerimientos del programa.

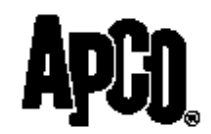

Apco Valve and Primer Corporation

Air and Vacuum Valve Sizing Program for Pipelines

\begin{tabular}{|c|c|c|}
\hline \multicolumn{2}{|c|}{ FUnстіон } & Click Her \\
\hline 1 & Select appropriate units andior utilize velocity calculator & F1 \\
\hline 2 & Enter system information for $\mathrm{AV} V$ design & F2 \\
\hline 3 & Enter or review pipe profile data & F3 \\
\hline 4 & Start AVV design at a specific pipe high point & F4 \\
\hline 5 & View schematic of pipe high point & F5 \\
\hline 6 & Calculate pipe collapse pressure & F6 \\
\hline 7 & Design air release valve orifice size & F7 \\
\hline 8 & Size AV for air intake and air exhaust & F8 \\
\hline 9 & Review AVV design summary for each high point & F9 \\
\hline 10 & Valve Models and Specifications & F10 \\
\hline Reset & Design Summary Table (F9) & Help \\
\hline
\end{tabular}

Figura 5.39. Pantalla inicial del programa

La primera operación a efectuar en el módulo de selección de ventosas APSLIDE es introducir las unidades con las que se quiere trabajar. El usuario puede elegir entre la opción de trabajar con unidades del sistema inglés o del sistema métrico internacional. Además en esta misma ventana se especifica el diámetro interior de la tubería y el caudal circulante por la misma. 


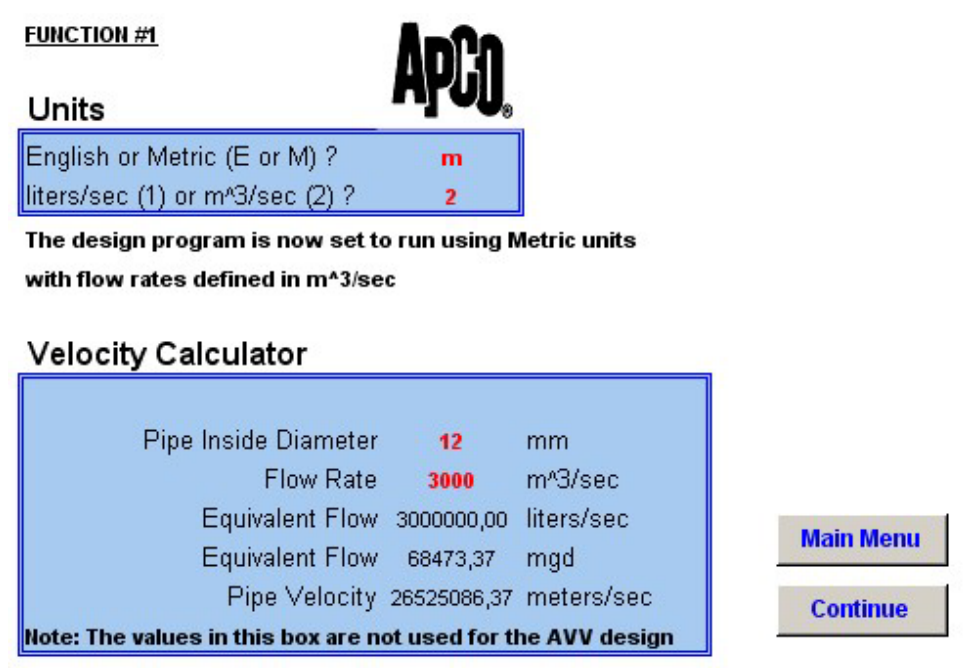

Figura 5.40. Datos iniciales

En la segunda ventana de este módulo se define el tipo de fluido que circula por el sistema, agua limpia o agua residual y el material de tubería disponible (acero o PVC). Además hay que especificar el valor de descarga de diseño máxima, la presión suministrada, la velocidad de llenado máxima y el diámetro de la tubería.

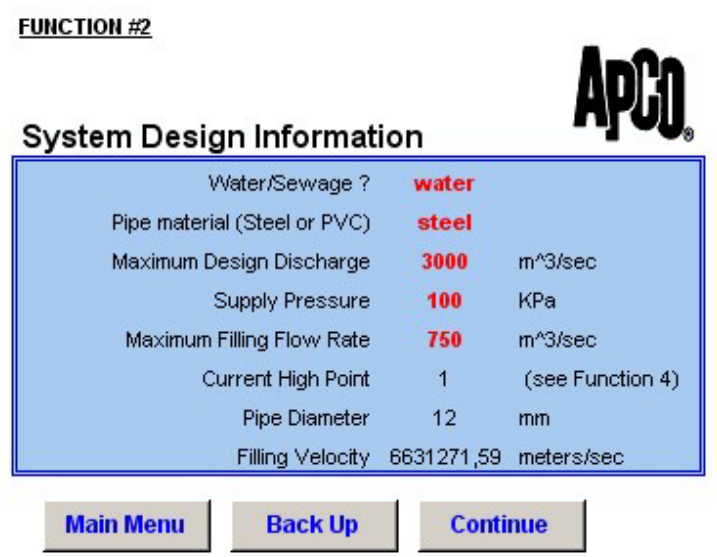

Figura 5.41. Información de diseño del sistema

Una vez introducidos todos estos datos de partida se debe rellenar la tabla de entrada de datos del perfil de la instalación. Dicha tabla recoge la identificación de los puntos en los cuales hay cambio de pendiente y en ella se describe la pendiente ascendente y la pendiente descendente que confluyen en dicho punto. 


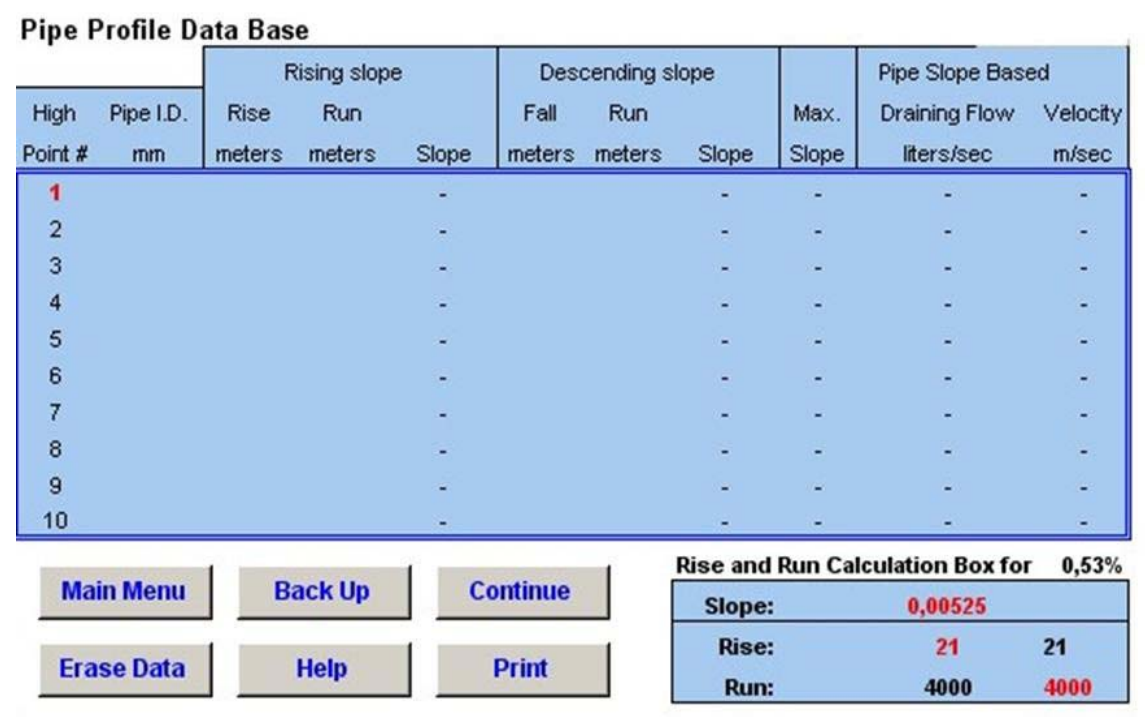

Figura 5.42. Datos del perfil de la instalación

La presión de colapso es la presión negativa que es capaz de soportar la tubería y se calcula en función del material y del espesor de la misma. El programa ofrece la posibilidad de introducir incluso un factor de seguridad para determinar el valor de la presión por debajo de la cual se puede producir la rotura de la tubería.

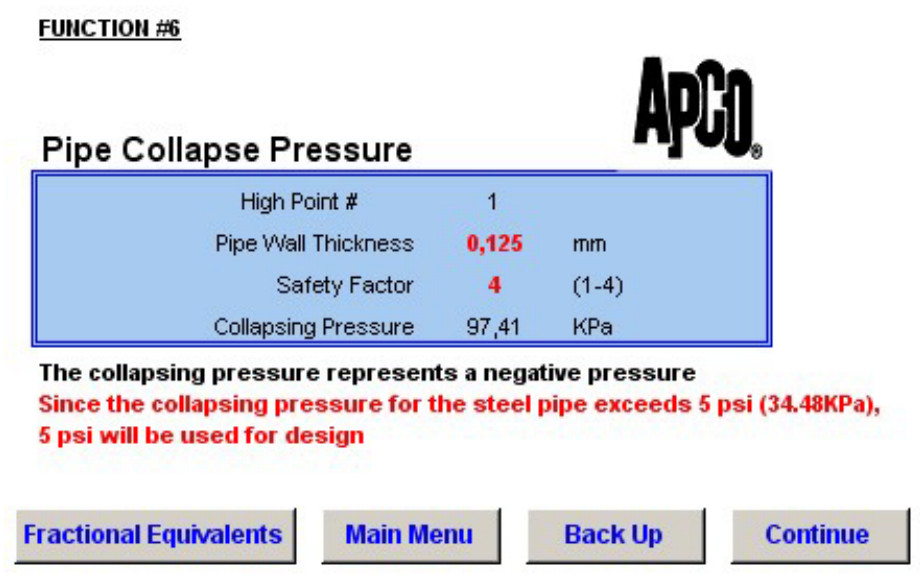

Figura 5.43. Elección de la presión de colapso

En el siguiente paso, se calcula el tamaño del orificio que debe tener la ventosa de expulsión de aire. El tamaño de la ventosa se determina a partir de la presión en el punto elevado donde se va a realizar la expulsión de aire. El programa dispone solamente de 14 diámetros preestablecidos. 
FUNCTION $\#$ T

Air Release Orifice Size Selection

Available Orifice Sizes

\begin{tabular}{|rcc||}
\hline High Point \# & 1 & \\
Operating Pressure at High Point & 80 & $\mathrm{KPa}$ \\
Orifice I.D. Number & 4 & \\
Orifice Diameter & 3,175 & $\mathrm{~mm}$ \\
Venting Capacity of ARV & & \\
$2 \%$ of design discharge & 3,65 & CFM \\
\hline
\end{tabular}

\begin{tabular}{||lccc||}
\hline 1 & 0,79 & 9 & 7,94 \\
2 & 1,59 & 10 & 9,53 \\
3 & 2,38 & 11 & 11,11 \\
4 & 3,18 & 12 & 12,7 \\
5 & 3,97 & 13 & 19,05 \\
6 & 4,76 & 14 & 25,4 \\
7 & 5,56 & 15 & No Size Sufficient \\
8 & 6,35 & Units in (mm) \\
\hline
\end{tabular}

\begin{tabular}{c|c|c|c|} 
Help & Main Menu & Back Up & Continue \\
\cline { 1 - 1 } Available Orifice Sizes & Size Air Release Orifice \\
\hline
\end{tabular}

Note: Available orifice sizes listed with an I.D. number.

Air Release Valve Models and Pressure Ratings

\begin{tabular}{|c|c|c|c|c|c|c|c|c|c|c|c|c|c|c|}
\hline \multirow[b]{2}{*}{ Model } & \multirow{2}{*}{$\begin{array}{l}\text { Inlet } \\
\text { Size }\end{array}$} & \multicolumn{13}{|c|}{ MAXIMUM ORIFICE SIZES TO BE USED WITH FOLLOWING PRESSURES } \\
\hline & & 10 & 25 & 50 & 75 & 100 & 125 & 150 & 200 & 250 & 300 & 500 & 800 & 1500 \\
\hline 50 & $1 / 2 ", 3 / 4 ", 1 "$ & 3/32 & 3/32 & $3 / 32$ & $3 / 32$ & $3 / 32$ & $3 / 32$ & 3/32 & 1/16 & 1/16 & 1/16 & & & \\
\hline 55 & 1/2" & $3 / 32$ & $3 / 32$ & $3 / 32$ & $3 / 32$ & $3 / 32$ & $3 / 32$ & $3 / 32$ & & & & & & \\
\hline 65 & 3/4" & $7 / 32$ & $7 / 32$ & $7 / 32$ & $7 / 32$ & $1 / 8$ & $1 / 8$ & $1 / 8$ & & & & & & \\
\hline $200 A$ & 1", 2" & $5 / 16$ & $5 / 16$ & $5 / 16$ & $1 / 4$ & $3 / 16$ & 3/16 & 3/16 & $5 / 32$ & $5 / 32$ & $5 / 32$ & & & \\
\hline 200 & 2" & $1 / 2$ & $1 / 2$ & $1 / 2$ & $1 / 2$ & $3 / 8$ & $3 / 8$ & $3 / 8$ & $7 / 32$ & $7 / 32$ & $7 / 32$ & & & \\
\hline 205 & 2" & & & & & $1 / 2$ & $3 / 8$ & $3 / 8$ & $7 / 32$ & $7 / 32$ & $7 / 32$ & $7 / 32$ & $1 / 8$ & \\
\hline 206 & 2" & & & & & & & & & & & & & $3 / 32$ \\
\hline 207 & 6" & 1 & 1 & 1 & 1 & 1 & 1 & 1 & $3 / 4$ & $3 / 4$ & $3 / 4$ & & & \\
\hline 400 & 2", 3", 4" & $5 / 16$ & $5 / 16$ & $5 / 16$ & $1 / 4$ & $1 / 4$ & $1 / 4$ & $1 / 4$ & $3 / 16$ & $5 / 32$ & $5 / 32$ & & & \\
\hline 450 & 2", 3", 4" & $1 / 2$ & $1 / 2$ & $1 / 2$ & $1 / 2$ & $1 / 2$ & $1 / 2$ & $1 / 2$ & $7 / 16$ & $7 / 16$ & $7 / 16$ & & & \\
\hline
\end{tabular}

Figura 5.44. Elección del orificio de salida de la ventosa

Una vez realizado el cálculo correspondiente a la expulsión de aire, se procede al cálculo del diámetro necesario para la admisión de aire de manera que se impida que se produzcan condiciones de vacío:

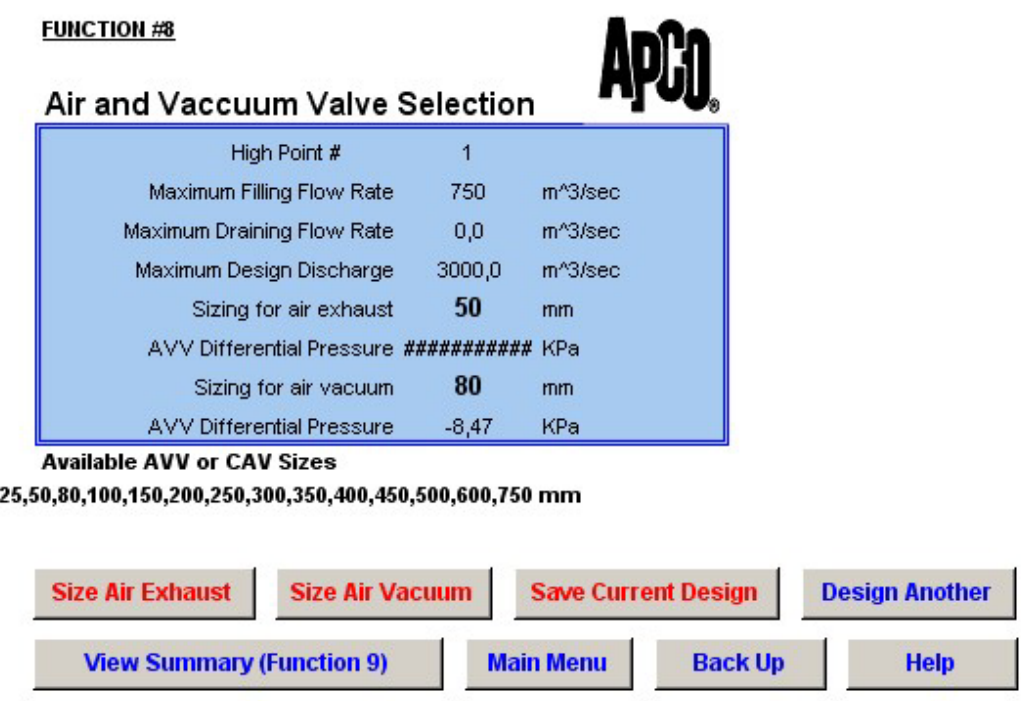

Figura 5.45. Elección del tamaño del orificio de entrada de aire 
El módulo de especificaciones APCOSPEC, es una especie de catálogo en el cual el usuario puede consultar las características de las ventosas que han sido recomendadas al final del análisis de la instalación mediante el módulo APSLIDE. Así pues, se pueden consultar las especificaciones de ventosas de expulsión de aire, ventosas para la eliminación de situaciones de vacío, ventosas combinadas, y ventosas para sistemas de saneamiento.

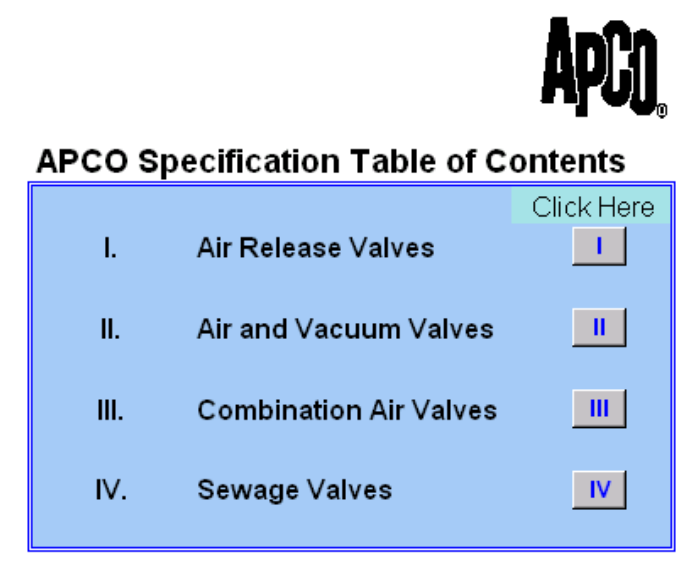

Specifications are for standard materials -

for other optional materials please contact the factory

Figura 5.46. Tabla de las ventosas disponibles en el catálogo de APCO

\subsubsection{HAMMER}

El programa Hammer es un programa dedicado fundamentalmente a resolver transitorios con golpe de ariete. Este programa identifica, gestiona y mitiga los riesgos asociados a los transitorios hidráulicos. Tiene una interfase directa con Epanet y otros modelos hidráulicos de manera que se puede interrelacionar con otros programas informáticos sin que sea necesario construir el modelo de nuevo.

Las ecuaciones del transitorio se resuelven mediante el método de las características, que es el método más utilizado por su rigurosidad y robustez. Con este método se calculan velocidades y presiones a lo largo de todo el sistema.

El programa Hammer ofrece la posibilidad de introducir dispositivos de protección de entre los 20 disponibles de manera que se pueden representar un gran número de situaciones. De este modo el usuario puede elegir la estrategia más adecuada para mitigar las presiones en su sistema concreto. Entre los elementos de protección destacan los depósitos (abiertos, unidireccionales, de vejiga, de área variable etc.), los tanques de aire, las válvulas de retención, y el control mecánico o eléctrico. En caso que el programa no disponga de un elemento determinado que se quiera representar el usuario puede definir un nuevo elemento que se adapte a sus necesidades. Además de los dispositivos de 
control, el programa cuenta con los elementos habituales de una red de tuberías para definir el sistema por completo.

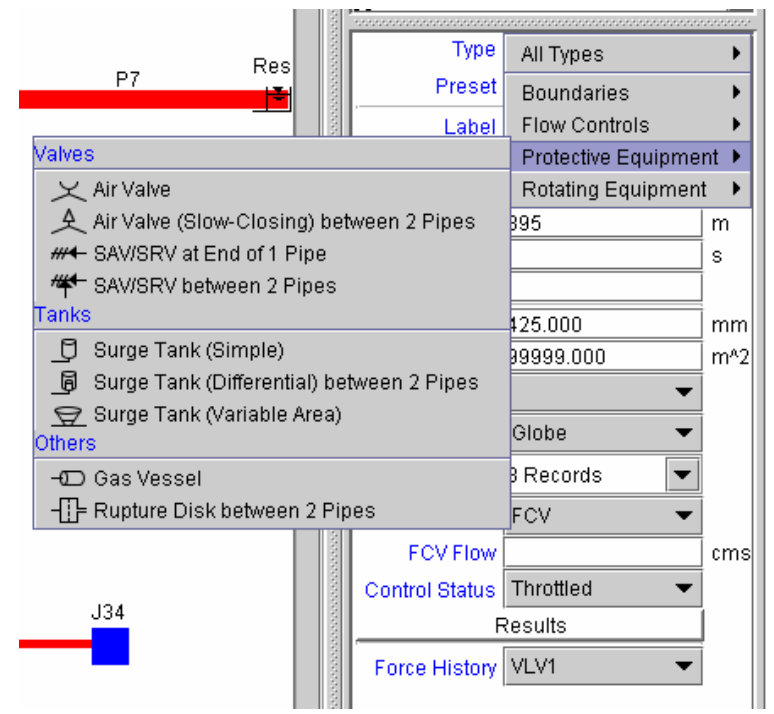

Figura 5.47. Dispositivos de control disponibles

Dentro de los fenómenos transitorios, este programa incluye la simulación de los fenómenos de cavitación y separación de la columna de agua. Además incorpora un algoritmo para calcular la formación de las cavidades de vapor, su movimiento y colapso. El modelo numérico enlaza la oscilación en masa de la columna rígida con el modelo elástico.

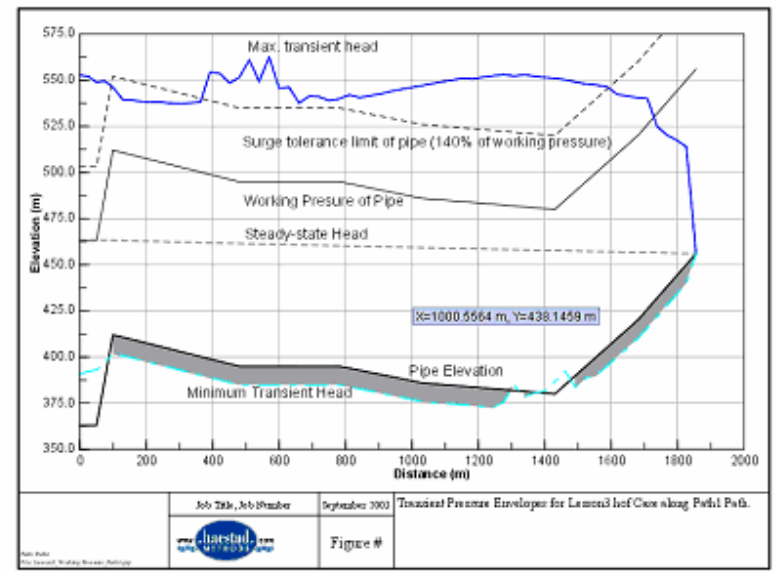

Figura 5.48. Representación gráfica del transitorio 
Se puede definir el paso de tiempo a utilizar en el cálculo del transitorio o utilizar el que recomienda el programa por defecto. Los datos de entrada de la instalación se introducen de forma ordenada mediante tablas lo cual facilita la revisión de los resultados. Existe la posibilidad de introducir librerías propias que incluyan datos de bombas, líquidos y válvulas. También es posible introducir las curvas de las bombas que se desee o utilizar las que ofrece el programa por defecto.

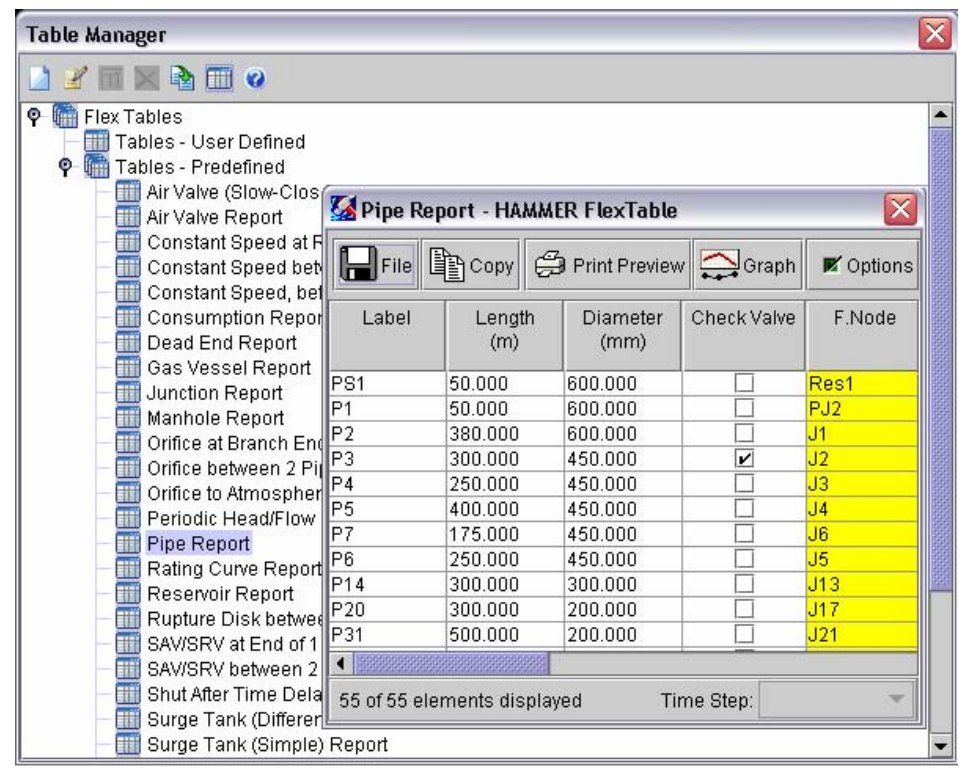

Figura 5.49. Tabla de resultados

El programa calcula la magnitud y dirección de las fuerzas del transitorio en cada paso de tiempo y analiza los resultados de forma gráfica y en forma de tablas. Los resultados se pueden exportar a otros programas de análisis estructural.

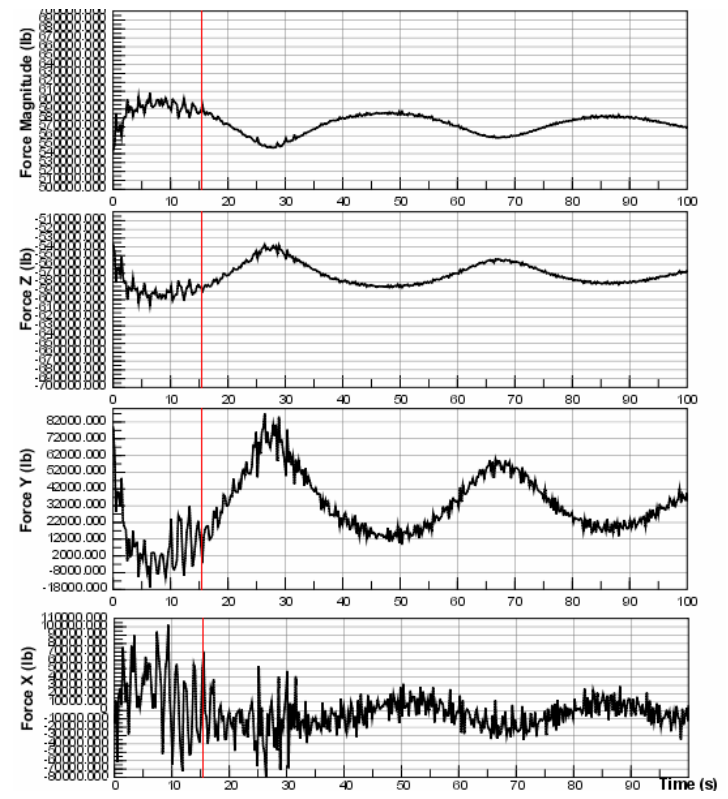

Figura 5.50. Resultados gráficos 
Los resultados se presentan además en forma de mapas de colores, animaciones y gráficas y perfiles flexibles. En los mapas de colores se detecta de una forma clara las áreas problemáticas. Estos mapas muestran las alturas máximas y mínimas, las presiones, el flujo o el volumen de aire o de vapor. El programa marca las zonas con presiones negativas que pueden ser la causa de la entrada de partículas contaminantes en la instalación. Además, proporciona mapas de roturas en los cuales se visualiza correctamente las zonas de presiones elevadas. Las animaciones se pueden empezar o parar en cualquier instante de tiempo. Finalmente el programa puede dibujar la evolución del transitorio en cualquier punto de la instalación.

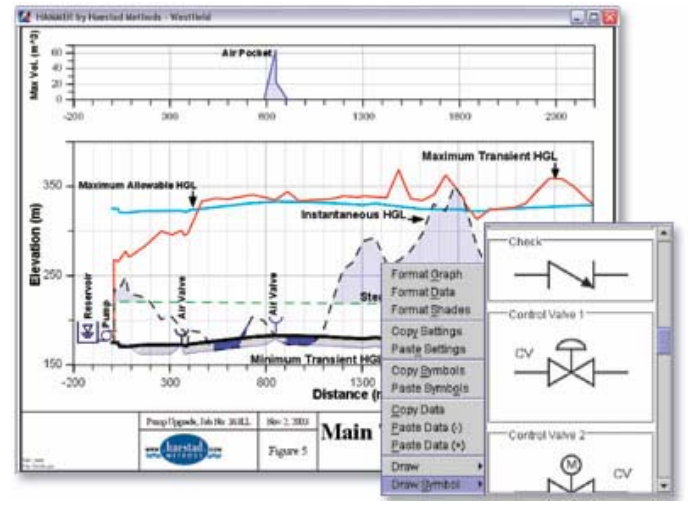

Figura 5.51. Gráficas de resultados

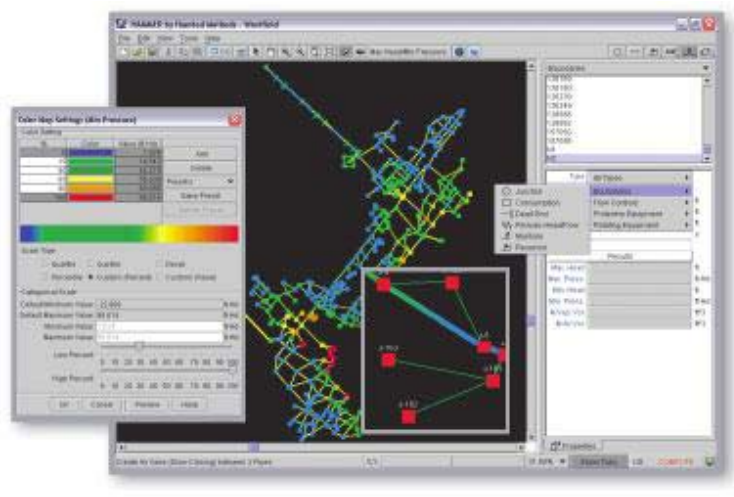

Figura 5.52. Mapas de colores

\subsubsection{WANDA}

El instituto de investigación y consultoría especializada $W L \mid$ Delft Hydraulics que proporciona asistencia técnica en el campo de la ingeniería hidráulica ha desarrollado una serie de herramientas de simulación de diseños hidráulicos.

El software de golpe de ariete que ofrecen se denomina Wanda. Dicho programa es un paquete de simulación validado que permite planificar el diseño hidráulico de una 
instalación determinada. El programa evalúa y optimiza la velocidad y capacidad del flujo, la distribución del flujo, el patrón de presiones, la selección de válvulas de control y sistema de bombeo y los principios de control.

El programa de simulación Wanda se utiliza en todo tipo de sistemas como por ejemplo largas líneas de transporte, sistemas antiincendios, sistemas de saneamiento, redes de distribución de agua, plantas desalinizadoras, plantas hidroeléctricas, plantas químicas y sistemas hidráulicos de coches y aviones.

El programa realiza cálculos de velocidades y presiones, e incluye las características del sistema, curvas de bombas combinadas junto con un diseño del control operacional.

Dicho programa consta de tres módulos:

- Wanda Engineering para el cálculo del estado estático y de balances de flujos.

- Wanda Transient para el análisis de la evolución de las presiones en el sistema y posibles mediciones.

- Wanda Control que sirve para evaluar y optimizar las operaciones de control.

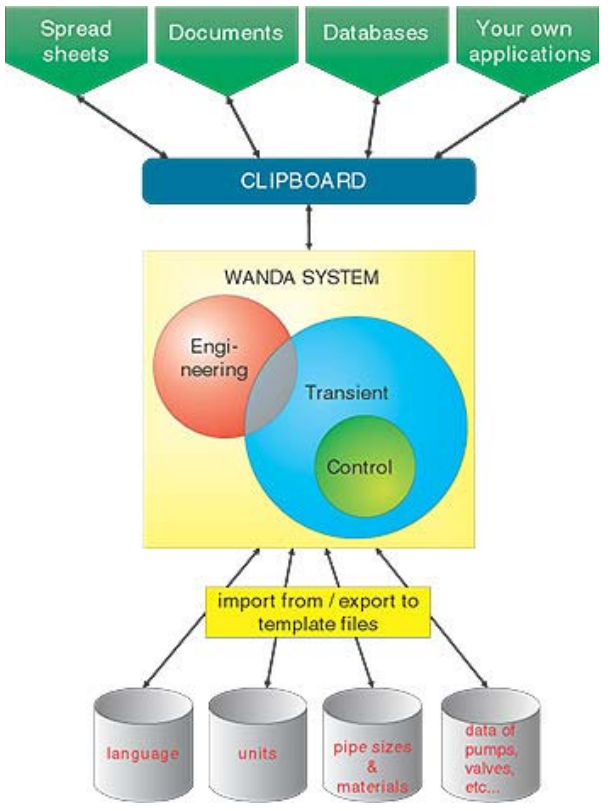

Figura 5.53. Módulos de los que consta el programa

El programa WANDA proporciona soluciones de una forma rápida e introduce opciones de copiar y pegar así como opciones de entrada y salida de datos. Además facilita tanto la investigación de flujos en lámina libre con mezcla de flujos como las operaciones de llenado y drenaje de un sistema. 
Los diferentes módulos permiten al usuario desarrollar modelos de bombeo que incluyan variadores de frecuencia. El programa realiza conversiones de esquemas de Epanet, permite elegir las unidades y el idioma, y crea ficheros AVI para presentar los resultados de forma interactiva.

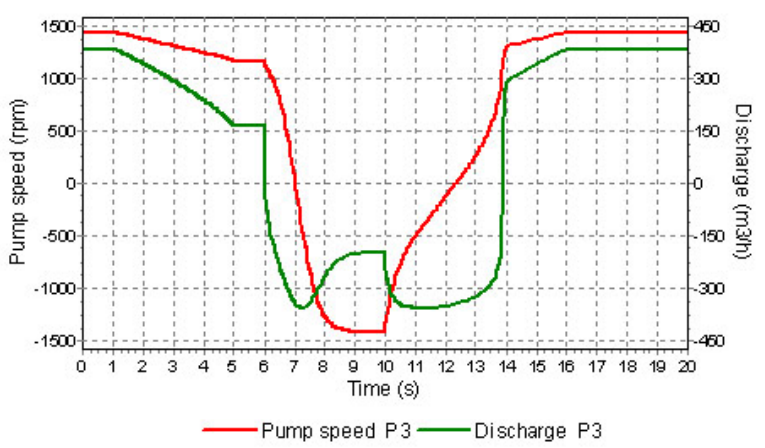

Figura 5.54. Curvas de la bomba

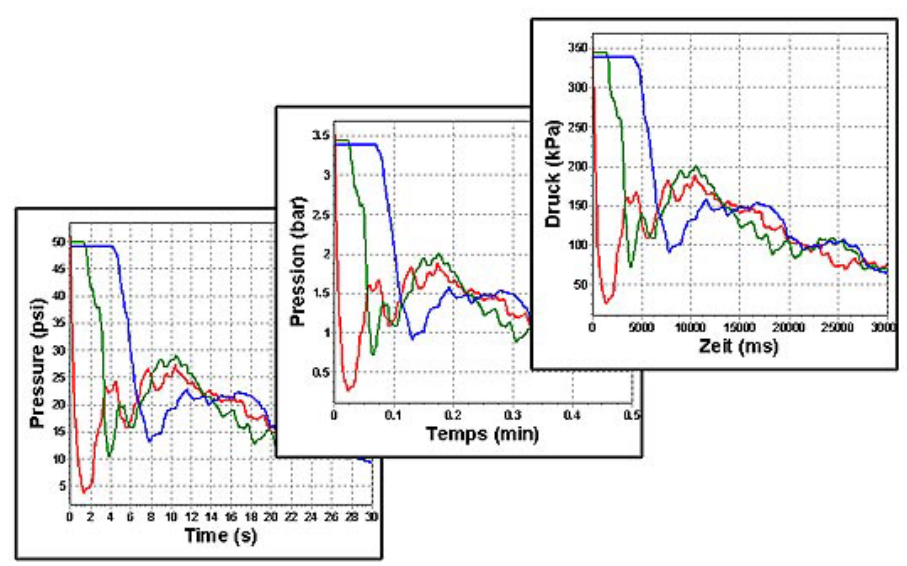

Figura 5.55. Salida de datos en diferentes idiomas 


CAPÍTULO 6. CONCLUSIONES 

En el presente capítulo se resume el contenido de esta tesis al tiempo que se presentan las conclusiones más relevantes obtenidas a lo largo del desarrollo de la misma.

\section{CAPÍTULO 1}

Las ventosas son dispositivos de protección utilizados en las redes de distribución de agua que permiten eliminar, durante la operación normal del sistema, el aire desprendido por el agua que se acumula en el interior de las tuberías así como los grandes volúmenes de aire que deben expulsarse durante el Ilenado de las conducciones. Además, el diseño de las mismas permite la admisión de aire en caso de aparición de presiones negativas en la instalación. Por ello, una de las primeras tareas realizadas en el capítulo $\mathbf{1}$ del presente trabajo ha consistido en revisar y analizar diferentes situaciones en las cuales puede aparecer aire atrapado en las conducciones de agua, ya sea en forma de grandes bolsas o de pequeñas burbujas distribuidas a lo largo de la conducción. En este sentido, se ha comprobado que entre las causas más frecuentes de la existencia de aire atrapado en una instalación destacan un diseño inadecuado del trazado de las conducciones, especialmente cuando la orografía del terreno es irregular con desniveles importantes, los Ilenados o vaciados del sistema realizados de manera incorrecta, o simplemente los cambios de presión que hacen que el aire disuelto se desprenda del agua en circulación.

\section{CAPÍTULO 2}

El siguiente paso, tal y como se recoge en el capítulo 2, ha sido recopilar información sobre los diferentes métodos utilizados para prevenir y mitigar los efectos perjudiciales que puede tener dicho aire atrapado. El trabajo se ha centrado en el análisis funcional de las ventosas y su capacidad para prevenir posibles sobrepresiones o depresiones que pudiesen dañar el sistema. La finalidad de esta revisión, principalmente bibliográfica a través de artículos, catálogos y recomendaciones facilitadas por los fabricantes, ha sido la 
de obtener información en cuanto a diferentes tipos de ventosas, diseños especiales de las mismas (para aplicaciones singulares como la de eliminación del aire aguas arriba de un contador de agua o, incluso, en sistemas de transporte de aguas residuales). Además se han revisado diferentes métodos utilizados en la actualidad de selección y dimensionado de ventosas así como la correcta ubicación de las mismas.

Dada la relevante función que pueden desempeñar las ventosas durante un transitorio hidráulico con aire atrapado, especialmente en lo que se refiere a su velocidad de obturación y capacidad de descarga y admisión en condiciones de flujo no permanente, se ha prestado una especial atención a los diseños de los fabricantes relacionados con el control del movimiento del flotador con el fin de reducir las deceleraciones que puede sufrir la columna de agua en movimiento por el cierre de la ventosa. A este tipo de ventosas, de uso no generalizado, se las denomina de cierre progresivo. Al respecto conviene decir que, para estas ventosas, según el fabricante consultado y la disposición de los flotadores, se ha detectado una gran variedad de diseños. En cualquier caso, hay que subrayar que no se ha encontrado estudio alguno relativo al funcionamiento de las mismas en las que se demuestre cuantitativamente el beneficio que introduce el control del cierre del flotador durante un transitorio en función de las características de dicho cierre y de la propia instalación.

Además de las ventosas propiamente dichas, existen otros dispositivos, que de uno u otro modo incorporan la función de una ventosa, y que por ello son capaces de proteger las instalaciones de los efectos perjudiciales que pueden generar las bolsas de aire atrapado. En el presente trabajo se han recogido las características de estos ingenios entre los cuales destacan las ventosas que incorporan en su interior una válvula de retención. También las ventosas controladas hidráulicamente, las ventosas antirretorno o los calderines que incluyen una ventosa en su parte superior son dispositivos utilizados en la práctica. En general, todos estos mecanismos son más voluminosos y caros que las ventosas convencionales por lo que su uso se suele restringir a situaciones e instalaciones con unas características muy específicas.

La selección, dimensionado, y ubicación de las ventosas en una red de agua viene detallada en el manual de la American Water Works Association "Air release, air/vacuum, and combination air valves", AWWA Manual M51, $1^{\text {st }}$ Edition, American Water Works Association, Denver (USA), 2001. Las directrices en él incluidas no tiene carácter de normativa, son más bien una guía que atribuye al usuario la última decisión sobre prestaciones y lugares de montaje de las ventosas en función de las características específicas de la instalación. Cabe decir, que las recomendaciones que realiza la AWWA sobre selección, dimensionado y ubicación de las ventosas son muy generales lo cual puede inducir a confusión durante la toma de decisiones. La AWWA recomienda, por ejemplo, en cuanto a la ubicación de las ventosas en tramos largos de tubería con pendiente ascendente, descendente o en tramos largos de tuberías horizontales, instalarlas con una separación comprendida entre 400 m y 800 m de longitud, sin concretar la 
longitud óptima. En cuanto al cálculo del diámetro del orificio de la ventosa, se utilizan ecuaciones simplificadas que no tienen en cuenta la evolución de la presión y la velocidad de la columna de agua en el tiempo.

Por otro lado, los efectos perjudiciales asociados a la presencia de aire atrapado en una instalación por la que circula un líquido han motivado el estudio de las características del flujo bifásico aire-agua. Se ha encontrado un número importante de referencias bibliográficas sobre patrones de flujo bifásico líquido-gas en una conducción. Sin embargo, estos trabajos están principalmente orientados al estudio de la capacidad de transporte de las conducciones por las que discurren este tipo de flujos. La clasificación del flujo bifásico en patrones y mapas se realiza básicamente atendiendo a la disposición de la tubería (horizontal, vertical o inclinada) así como a la proporción y velocidad del flujo de aire en el seno del fluido líquido. Dichos estudios hacen referencia normalmente a conducciones por las que circulan líquidos viscosos como aceites, fuel, etc., mientras que en lo referente a patrones de flujo bifásico agua-aire la bibliografía al respecto es más bien escasa. En cualquier caso, dada la complejidad que supone la determinación de mapas para determinar la capacidad de transporte de una conducción ante un flujo bifásico agua-aire, el presente trabajo no aborda este aspecto.

La búsqueda de antecedentes ha puesto de manifiesto que existe una gran escasez de documentación técnica sobre el comportamiento de las ventosas ante regimenes de flujo no estacionarios tanto por lo que se refiere a su capacidad de descarga como a la admisión de aire. Esta falta de documentación respecto a ensayos en laboratorio se debe principalmente a la falta de instalaciones adecuadas para llevarlos a cabo. Dichas instalaciones, además de las elevadas exigencias de espacio, son muy costosas por las grandes dimensiones de los elementos que las constituyen, de tal modo que la inversión necesaria para el montaje y mantenimiento de las mismas es considerable. En la actualidad existen muy pocas instalaciones en el mundo con medios necesarios para generar transitorios hidráulicos en conducciones de 500 mm diámetro o más.

Precisamente, para analizar el comportamiento de las ventosas durante un transitorio hidráulico se concibió el proyecto "Dynamic behaviour of air valves" enmarcado dentro del programa "Transnational Access to Major Research Infraestructure (MRI)" de la Comisión Europea y que Bruselas aprobó en 2001.

El objetivo del mencionado proyecto era, fundamentalmente, poner a disposición de diversos grupos investigación instalaciones, a las cuales es difícil acceder de otro modo, y que reúnan las características necesarias tanto para realizar ensayos de capacidad de descarga de aire a través de ventosas como para provocar transitorios hidráulicos controlados en una instalación con aire atrapado. En la programación y realización de este proyecto colaboraron, liderados por los directores de esta tesis, investigadores pertenecientes a cinco grupos de investigación europeos de prestigio. Esta tesis, es por 
tanto, uno de los resultados de dicho proyecto de investigación en la cual se utilizan los ensayos realizados durante el mismo.

\section{CAPÍTULO 3}

En el capítulo 3, se detallan los diferentes tipos de ensayos llevados a cabo durante el desarrollo del proyecto de investigación así como las instalaciones en las cuales se han realizado.

Tal y como se explica en este capítulo, mediante los ensayos de laboratorio se ha podido determinar la capacidad de descarga y admisión de aire de ventosas en régimen permanente, así como su influencia en los transitorios hidráulicos tanto en el proceso de descarga de grandes volúmenes de aire como en la eliminación puntual de bajas presiones en la instalación. En estos casos se ha realizado un análisis pormenorizado del transitorio hidráulico producido. El trabajo de laboratorio ha proporcionado una gran cantidad de datos numéricos referentes a presiones, velocidades del agua y desplazamiento del flotador de la ventosa para cada instante de tiempo. La labor de ordenación y análisis de estos resultados experimentales representa una parte significativa del presente trabajo. Del análisis de los datos recopilados en el laboratorio se han podido establecer comparaciones entre el comportamiento de dos ventosas del mismo tamaño nominal instaladas en el mismo punto y ensayadas bajo condiciones iniciales y de contorno similares.

La flexibilidad de la instalación permitió llevar a cabo ensayos con diferentes configuraciones del sistema, las cuales se adecuaron al tipo de estudio a realizar, de manera que fue posible analizar la influencia de las ventosas en la evolución de la presión durante diferentes transitorios hidráulicos con aire atrapado. Entre los ensayos más relevantes destacan el estudio de la determinación de la capacidad de descarga y admisión de aire de las ventosas en régimen permanente para diferentes grados de apertura, el estudio del comportamiento dinámico de las mismas tanto para la expulsión como para la admisión de aire y, en fin, el estudio de la admisión de aire como respuesta a las bajas presiones ocasionadas debido al cierre rápido de una válvula de retención. Además, se han podido añadir a los montajes elementos adicionales (como carretes de tubería de diferentes longitudes entre la conducción y la ventosa o una válvula de retención junto a la ventosa) estudiando el efecto que introducían dichos elementos en las presiones generadas durante el transitorio.

\section{CAPÍTULO 4}

En el capítulo 4, se han analizado los resultados obtenidos en los ensayos de laboratorio al tiempo que se ha intentado relacionar las diferentes variables que caracterizan cada proceso. 
Los ensayos para establecer la capacidad de descarga en régimen permanente con flujo de aire se realizaron manteniendo fijo el flotador de la ventosa en tres aperturas diferentes. Con ello, se ha conseguido calcular el coeficiente de descarga de aire de cada ventosa para las posiciones mencionadas. Se ha comprobado que la capacidad de descarga de dos ventosas con el mismo diámetro nominal difiere sensiblemente dependiendo de las características constructivas. Además, los valores calculados del coeficiente de descarga $C_{d}$ cuando la ventosa se encuentra completamente abierta son en general superiores al valor recomendado por la American Gas Association (1978), para flujo compresible a través de orificios y toberas, es decir, $C_{d}=0,65$. Concretamente, se ha obtenido un valor del coeficiente de descarga en una ventosa de DN100 de 0,81, mientras que en la otra ventosa del mismo diámetro nominal se ha obtenido un valor del coeficiente de descarga de 0,79 .

Para determinar la capacidad de descarga de una ventosa ante el paso de aire en condiciones de flujo compresible se ha propuesto la aplicación de los métodos descritos en la norma ISA75.01 referente al dimensionado de válvulas industriales. Los resultados obtenidos con dichos métodos pueden considerarse satisfactorios. El principal inconveniente que aparece, y no debido a este método en particular sino a la determinación de la capacidad de descarga de las ventosas en general, es que a menudo no se disponen de medios para efectuar los ensayos oportunos, especialmente por lo que respecta a la consecución de determinados flujos de aire. Este es el motivo por el cual muy pocos fabricantes de ventosas aportan esta información, y hasta en ocasiones, los valores suministrados por los fabricantes no coinciden con la capacidad real de las ventosas, lo que puede dar lugar a una elección errónea de una ventosa, pudiendo provocar graves daños a la instalación durante un transitorio.

Respecto a los ensayos para determinar el comportamiento dinámico de las ventosas conviene comentar que se han testado un total de cuatro ventosas de dos marcas comerciales diferentes. Concretamente, se han ensayado dos ventosas de diámetro DN100 en una instalación de $500 \mathrm{~mm}$ de diámetro y otras dos ventosas de DN50 en una instalación de 200 mm de diámetro.

En el capítulo 3 se detallan las características constructivas de cada configuración de la instalación, las características de las ventosas utilizadas y de los aparatos de medición empleados durante los ensayos de laboratorio, describiéndose los pasos de cada uno de ellos. Es importante remarcar que las dos ventosas comerciales comparadas en cada ensayo poseen el mismo diámetro nominal pero tanto su estructura interna como el tamaño, forma y peso del flotador y área del orificio de salida o entrada del aire son diferentes.

Gracias a las medidas de presión y caudal registradas en los tests se han establecido comparaciones entre los transitorios producidos, bajo las mismas condiciones de contorno, con cada ventosa. 
De estas comparaciones se desprende que en los ensayos dinámicos de expulsión de aire los valores de presión máxima y velocidad de la columna de agua alcanzada difieren significativamente según la ventosa utilizada, teniendo en cuenta que ambas ventosas se han ensayado en la misma instalación y bajo condiciones similares.

Para proceder al estudio de la influencia de las ventosas en este tipo de transitorios hidráulicos se ha dividido el fenómeno en una serie de etapas cuyos instantes de inicio y final se fijan en función del valor alcanzado por una determinada variable (presión, velocidad del flujo de agua, posición del flotador, etc.). De este modo el transitorio queda perfectamente definido y estructurado pudiéndose comparar los resultados y mediciones de diferentes ensayos.

Posteriormente, se procedió al estudio pormenorizado de algunas variables consideradas de especial relevancia. La finalidad de este análisis era observar las posibles relaciones entre dichas variables y analizar en los diferentes ensayos cómo su evolución puede justificar las discrepancias encontradas, especialmente en lo referente a las presiones máximas. Como variables a analizar se han tomado la presión máxima alcanzada en el transitorio, la duración del pico de presión provocado por la compresión del aire, la deceleración de la columna de agua después del cierre de la ventosa y el volumen de agua total registrado por el caudalímetro entre el instante inicial y el instante en el que se produce la inversión del flujo.

Se ha encontrado que la magnitud del pico de presión tiene relación tanto con la velocidad de llegada del agua a la ventosa, como con la cantidad de aire atrapado en el sistema (ya que éste puede actuar como colchón o por el contrario puede acentuar las sobrepresiones generadas) así como con la longitud total de la conducción.

En los ensayos la longitud de la conducción estaba limitada por las posibilidades de espacio en el laboratorio y, por ello, superaba escasamente los $10 \mathrm{~m}$. En este caso, el período de una onda de presión estaba cercano a los $20 \mathrm{~ms}$, por lo que todos los cierres de las ventosas que se producen en los ensayos pueden considerarse como cierres lentos ya que el tiempo de cierre de las ventosas superaba dicho valor (entre $25 \mathrm{~ms}$ y $60 \mathrm{~ms}$ aproximadamente). En cualquier caso, las condiciones definidas por la longitud de la conducción son exactamente las mismas para las dos ventosas. Gracias a las mediciones que se realizaron sobre la posición del flotador, se demostró que los tiempos de cierre eran similares en ambas ventosas bajo las mismas condiciones de ensayo, por lo que las discrepancias de presiones máximas, en este caso concreto, no tienen su origen en los tiempos de cierre de las ventosas.

Por otro lado, queda claro que la cantidad de aire que puede quedar atrapado en el sistema tras el cierre va a adoptar un papel crítico en los valores de presión máxima que se alcancen durante el transitorio. Se requiere, por tanto, utilizar variables o medidas 
indirectas que permitan conocer en cada caso la cantidad de aire que no es expulsada por las ventosas durante los transitorios. Entre las variables auxiliares utilizadas para este fin se encuentran la anchura (duración) del pico de presión que está condicionada por la compresión del aire, la deceleración de la columna de agua una vez se ha producido el cierre de la ventosa y la velocidad de retorno máxima del agua durante la expansión de la bolsa de aire.

En los diferentes ensayos se ha demostrado que la deceleración de la columna de agua, la anchura del pico de presión máxima así como la sobrepresión aplicada para generar el transitorio guardan una estrecha relación entre sí. Además, estas tres variables son indicativas de la cantidad de aire atrapado que queda en la instalación tras el cierre de la ventosa.

Analizando en primer lugar la deceleración sufrida por la columna de agua después del cierre de la ventosa, se comprueba que dicha deceleración, para unas condiciones de contorno similares, son semejantes para ambas ventosas (figura 4.20, capítulo 4). No obstante, es cierto que se aprecia que para una misma deceleración la presión máxima alcanzada en los ensayos con la ventosa del fabricante B es superior que en los de la ventosa del fabricante A (figura 4.26, capítulo 4). En ambos casos, la deceleración de la columna de agua después del cierre de la ventosa muestra una relación creciente con la presión máxima registrada en cada ensayo.

Cuando se analiza la relación entre la deceleración de la columna de agua respecto a la sobrepresión aplicada al inicio del ensayo se establece que las diferencias del comportamiento vienen marcadas por la longitud inicial de la columna de agua del ensayo (figura 4.27, capítulo 4). La deceleración sufrida, para una misma sobrepresión inicial aplicada, es muy inferior en el caso en el que la columna de agua existente al inicio del ensayo tiene menor longitud. Esto a pesar de que las diferencias de masas de agua en ambos casos no son excesivamente importantes.

Finalmente se ha verificado que la deceleración de la columna de agua es inversamente proporcional a la anchura del pico de presión máxima (figura 4.28, capítulo 4) o el tiempo de cierre de la ventosa (figura 4.29, capítulo 4), independientemente de la ventosa o la longitud inicial de la columna de agua utilizada. Este resultado es perfectamente coherente con lo esperado, ya que una mayor duración del pico de presión es indicativa de una mayor cantidad de aire atrapado. Al contrario, una deceleración más alta implica menor cantidad de aire atrapado.

Por otro lado, conviene comentar que la presión máxima registrada en cualquier ensayo, en el que la expulsión de aire se producía en el final de la conducción, es menor que la sobrepresión de Allievi.. En cualquier caso, como cabría suponer, dicha presión máxima es mayor cuanto más elevada es la velocidad de llegada de la columna de agua al flotador de la ventosa. No obstante, la relación entre ambas variables no es lineal (figura 4.38, 
capítulo 4) Cabe comentar que este resultado se hubiera podido ver modificado si se hubiera forzado el sistema aplicando sobrepresiones iniciales mayores en el mismo.

En los ensayos en los que se trató de simular la expulsión de aire en un punto medio elevado de una instalación se registraron presiones máximas menores que cuando la expulsión se producía en el extremo final de la instalación. En este caso, en el que la ventosa se encuentra instalada en un punto intermedio, la cantidad de aire atrapado después del cierre de la misma es significativamente mayor, lo cual justifica este descenso de las presiones máximas. Con esta configuración de la instalación existe menor uniformidad en cuanto a la evolución general del evento y las relaciones entre las diferentes variables comentadas anteriormente son más difusas. Aumenta, con ello, la complejidad a la hora de interpretar los resultados finales de presión y velocidad e identificar los parámetros que condicionan tanto la magnitud de las presiones como su evolución en el tiempo.

En general, se ha encontrado que la secuencia de cierres que se experimenta durante un ensayo concreto es diferente según la ventosa utilizada. Incluso empleando la misma ventosa, la secuencia de cierres cambia aleatoriamente dada la compleja parametrización del fenómeno. Cuando se ensayan las ventosas en un punto intermedio de la instalación se observa una serie de cierres consecutivos de manera que el pico de presión máxima no se produce generalmente en el primero de estos cierres. Esto es debido a que tras el primer cierre queda gran cantidad de aire atrapado en la instalación, lo cual amortigua el transitorio haciendo que las presiones sean menores. Al expulsar aire paulatinamente, el pico tiende a producirse tras otros cierres, cuando la cantidad de aire atrapado es menor. No obstante, en un sistema más largo podría darse el caso de que el pico de presión sea mayor que la sobrepresión de Allievi en función de la cantidad de aire que queda atrapado y de la masa de agua en movimiento.

De manera análoga, la evolución de la presión medida en el cuello de la ventosa difiere según la ventosa montada en el ensayo. Se puede afirmar que debido a la configuración de la conducción, aumenta la aleatoriedad en la evolución del transitorio, lo que dificulta enormemente la unificación de modelos de conducta.

En general, se puede afirmar que las bolsas de aire atrapado dispuestas de manera dispersa en el interior del sistema que se contraen y expanden, son las causantes de que la ventosa abra y cierre varias veces ya que con su movimiento impulsan el agua hacia el flotador.

Los ensayos dinámicos para estudiar el efecto de las ventosas durante un transitorio hidráulico con aire atrapado también se realizaron con ventosas de DN50 montadas en una conducción de $200 \mathrm{~mm}$ de diámetro. Las proporciones de longitudes y diámetros se trataron de mantener lo más fielmente posible con respecto a la instalación preparada anteriormente para las ventosas de DN100. Además, gracias al menor tamaño de la 
instalación fue posible la ejecución de ensayos con un mayor número de configuraciones del sistema.

No obstante, debido a la reducida respuesta en frecuencia del caudalímetro electromagnético empleado para medir el flujo de agua durante el transitorio, se dispone de una menor cantidad de datos para realizar un análisis exhaustivo de estos ensayos, tanto los que simulan la expulsión de aire en el extremo de la conducción como en un punto intermedio. Por otro lado, se ha encontrado que la casuística de comportamientos es mucho más variada en este caso. El valor de presión máxima no siempre se encontraba en la primera llegada del agua a la ventosa por lo que las tendencias y correlaciones entre diferentes variables se tornan extremadamente complejas.

En primer lugar, debido a la influencia que en la magnitud del pico de presión que demostró tener durante los ensayos de las ventosas DN100 el aire atrapado en el interior de la conducción, se evaluaron, igual que para las ventosa de diámetro nominal $100 \mathrm{~mm}$, las variables que indirectamente facilitan un orden de magnitud de este parámetro

En concreto, se ha comprobado que el valor de la presión máxima desciende a medida que aumenta la duración de este pico, lo cual pone de manifiesto, una vez más, que el aire atrapado en la instalación actúa a modo de colchón (figura 4.50, capítulo 4). No obstante, se observa en dicha gráfica que la longitud de la columna de agua, o lo que es lo mismo, la inercia de la columna de agua que tiene que frenar la bolsa de aire durante la compresión, tiene una importancia considerable en el pico de presión que se puede alcanzar. Una misma cantidad de aire atrapado, dependiendo de la masa de agua que se aproxime a la ventosa y que tenga que frenar, provocará un pico de presión u otro. Por ello, resulta imposible a priori predecir la magnitud del pico de presión únicamente conociendo la cantidad de aire que pueda quedar en el interior de las tuberías.

Por otro lado, se ha observado que no todos los ensayos de ventosas DN50 siguen la misma evolución en cuanto al número de cierres de la ventosa y al instante en el cual se registra la presión máxima del evento. La evolución del desplazamiento del flotador y de la presión medida en el cuello de la ventosa se explican atendiendo al aire atrapado en la instalación y a la oscilación en masa de la columna de agua que tiene lugar en el sistema.

Los ensayos de las ventosas DN50, situadas en el extremo de un carrete vertical muestran presiones máximas superiores a las registradas cuando dicha ventosa se sitúa directamente sobre la T de la instalación ya que mediante esta disposición se favorece la expulsión de aire de la instalación. En el análisis de las medidas aparecen en esta configuración sucesivos cierres y aperturas del flotador, produciéndose en ocasiones el pico de presión máxima hasta en el sexto cierre. Esto es debido a que la magnitud de dicho pico de presión depende de una combinación entre la velocidad de llegada del agua a la ventosa y de la cantidad de aire que permanece en la conducción. 
Precisamente por ello, se ratifica la idea de que las ventosas de cierre controlado pueden reducir significativamente los picos de presión que se producen en el sistema después del cierre de la misma, aunque ello origine dos efectos en sentido contrario. Por un lado, al haberse expulsado todo el aire el pico de presión tiende a ser mayor que cuando queda aire atrapado y, por otro, al disminuirse controladamente la deceleración de la columna de agua, el pulso de presión tiende a reducirse.

También dentro del capítulo 4 se detallan los resultados obtenidos en los ensayos de admisión de aire en una conducción a través de una ventosa. Una parte de dichos ensayos se han realizado para determinar la capacidad de la ventosa para eliminar la depresión que se produce al cerrarse una válvula de retención. Comparando dichos ensayos con otros realizados en condiciones similares pero sin ventosa se concluye que este elemento de protección es sólo capaz de aliviar en parte la depresión producida, (figura 4.100, capítulo 4) Además, en esta figura se comprueba el ligero retraso en la apertura de la ventosa una vez producida la depresión, lo que limita su capacidad para reducir las depresiones que se puedan originar. No obstante, si que se observa una disminución de la duración de la depresión cuando se incorpora una ventosa como elemento de protección (figura 4.104, capítulo 4). De estos ensayos cabe concluir que las ventosas utilizadas no han sido capaces de reducir significativamente las depresiones que se producen en este tipo de eventos.

Adicionalmente, se realizaron otro tipo de ensayos de admisión de aire cuya finalidad era la de intentar reproducir el comportamiento de las ventosas durante el vaciado de una tubería. En este caso, el experimento se limitó a establecer diferencias, en cuanto a capacidad de eliminación de depresiones, entre los dos modelos comerciales disponibles. En dichos ensayos, las depresiones alcanzadas en la conexión de la ventosa con la tubería son mayores cuando se ensaya la ventosa del fabricante B de DN100 que cuando se ensaya la ventosa del fabricante A del mismo tamaño. Esto es debido al mayor peso del flotador de la ventosa B, que le confiere mayor inercia $y$, por tanto, velocidades de actuación más lentas. En cualquier caso, debido a las dimensiones de las ventosas en relación con el diámetro de la tubería, se observó que una vez abierta la ventosa, se eliminaba completamente la depresión. Sin embargo, en los casos en los que la capacidad de admisión de aire de las ventosas hubiesen resultado demasiado ajustadas para el diámetro de la conducción, las diferencias en cuanto a depresiones alcanzadas entre las dos hubiesen sido significativas y habrían estado condicionadas por las discrepancias entre las capacidades de admisión de una y otra ventosa.

\section{CAPÍTULO 5}

Como complemento al estudio experimental sobre la influencia de las ventosas durante los transitorios hidráulicos con aire atrapado se ha propuesto en el capítulo 5 un modelo matemático que intenta reproducir el comportamiento de un sistema con una ventosa montada en el extremo final de la conducción durante el fenómeno transitorio. 
El modelo matemático unidimensional propuesto es capaz de representar el transitorio que se produce cuando partiendo de una instalación parcialmente llena de agua se procede a su llenado completo con la consecuente expulsión de aire a través de la ventosa situada al final de la conducción. Para la validación del modelo se han simulado los ensayos correspondientes a la expulsión de aire en condiciones teóricas iguales o similares a las de los experimentos realizados en laboratorio, comparando los resultados de la presión y caudal en ambos casos. El modelo teórico se ha planteado utilizando las ecuaciones del modelo elástico, ya que se considera que los ordenadores actuales disponen de suficiente capacidad de cálculo como para resolver el mismo rápidamente. La resolución del sistema de ecuaciones se ha llevado a cabo mediante el método de las características.

Las principales hipótesis adoptadas para confeccionar el modelo, han sido las siguientes:

- Consideración del aire como gas perfecto cuya evolución es politrópica.

- Cierre lineal de la ventosa, considerando que el coeficiente de descarga evoluciona linealmente con la posición del flotador.

- Factor de fricción constante calculado como si se tratase de un flujo estacionario.

- Movimiento de la columna de agua como si no hubiera aire disuelto en ella.

- La interfase aire-agua es en todo instante perpendicular al eje longitudinal de la tubería. Esta interfase se considera que permanece perfectamente definida ya que la columna de agua avanza como si tratara de un pistón. Además se supone que tanto la columna de agua como la bolsa de aire ocupan toda la sección transversal de la tubería

- Finalmente se admite que la celeridad del agua es constante en el tiempo y el espacio.

Los resultados de presión máxima en la instalación y velocidad de la columna de agua que proporciona el modelo se ajustan perfectamente a las mediciones obtenidas en los ensayos de expulsión de aire a través de la ventosa A de DN100. Sin embargo, no ha sido posible ajustar presión y velocidad a los datos medidos en los ensayos del mismo tipo con la ventosa B de DN100 ni con las ventosas DN50. En estos casos, el modelo predice valores claramente inferiores del pico de presión en el caso de la ventosa B de DN100 mientras que en el caso de las ventosas DN50, los valores de la presión máxima calculados con el modelo teórico son mayores que los realmente medidos en los ensayos.

En el capítulo 5 se ha demostrado que el modelo elástico presentado, con las oportunas simplificaciones, es válido solamente en algunos casos para calcular la evolución de las presiones y velocidades del transitorio producido cuando se procede al llenado de una conducción en la que la ventosa se ha montado en su extremo final. A pesar del gran número de simulaciones realizadas, no ha sido posible establecer las causas de las discrepancias entre el modelo teórico propuesto y las mediciones. 
El modelo matemático aportado además de permitir la resolución del transitorio hidráulico generado durante la expulsión de aire a través de una ventosa, es capaz de realizar un análisis de sensibilidad de una manera sistemática. Con el modelo teórico y las mediciones de caudal y presión de los ensayos en laboratorio se ha podido realizar un análisis de sensibilidad, mediante el cual, se ha identificado la influencia de los factores más influyentes sobre el resultado final del transitorio. Los principales parámetros analizados han sido el coeficiente politrópico, la celeridad de la onda de presión, el coeficiente de fricción, la duración del cierre de la ventosa, el coeficiente de descarga, el volumen de aire atrapado en la instalación y la longitud total de la instalación.

De dicho análisis de sensibilidad se ha desprendido que para el caso de estudio es válido considerar un valor de la celeridad constante igual a la del agua en una conducción de acero. El grado de ajuste conseguido con este valor de la celeridad es satisfactorio e incluso mejor que el obtenido con otros valores menores que tienen en cuenta una proporción más elevada de aire en el seno del agua. Por otra parte, la evolución del aire durante el transitorio se ha considerado finalmente como una evolución politrópica, con un valor del coeficiente politrópico igual a 1,2. Con este parámetro se reproduce de forma más ajustada a la realidad la evolución de la presión del aire durante la compresión, una vez cierra la ventosa, y la de la velocidad del agua en su aproximación hacia la misma, (Figura 5.20)

Debido al modo en que se ha simulado el comportamiento de la ventosa durante el cierre, el análisis de sensibilidad muestra que el aumento del tiempo de cierre hace que disminuya la cantidad de aire atrapado al alargarse el proceso de expulsión de aire. Una menor cantidad de aire atrapado, con la misma velocidad de llegada de la columna de agua, origina un pico de presión máxima superior, (Figura 5.22). Por ello, en el modelo propuesto, a mayores tiempos de cierre les corresponden valores de presión máxima más altos.

Por otra parte, el coeficiente de descarga de la ventosa afecta a la evolución de la presión en un primer momento, es decir, desde el instante inicial del transitorio hasta el instante en el cual el agua llega a la ventosa. Una mayor capacidad de descarga de la ventosa, reduce el tiempo de llegada de la columna de agua, modificando asimismo la velocidad de Ilegada del agua a la ventosa, (Figura 5.24). En el caso concreto que se ha simulado, debido a la configuración del sistema, una capacidad de descarga más elevada aumenta la velocidad de la columna de agua que impacta finalmente contra la ventosa, generándose transitorios de mayor intensidad.

Un incremento en el factor de fricción produce justamente el efecto contrario, retrasándose el instante de cierre de la ventosa y disminuyéndose la velocidad de llegada del agua. En consecuencia, la presión máxima alcanzada durante el transitorio en estas circunstancias también desciende, (Figura 5.25). 
La longitud total de la instalación ha sido otro de los parámetros analizados mediante el análisis de sensibilidad. El modelo, para este caso particular, se ha mostrado especialmente sensible a cualquier alteración de este parámetro. Con la disminución de la longitud de la instalación, la columna de agua llega en un tiempo menor al flotador y, como se ha comentado antes, por las características específicas del sistema analizado, aumenta la velocidad de impacto del agua sobre la ventosa. Por este motivo, con una longitud de conducción inferior se experimenta una presión máxima más elevada, (Figura 5.26).

Finalmente, se llevó a cabo un análisis de sensibilidad con un parámetro especialmente importante: la cantidad de aire que permanece en el sistema después del cierre de la ventosa. En concreto, se comprueba que un mayor volumen de aire atrapado en el interior de la conducción hace que aumente la duración del pico de presión y disminuya la magnitud de la presión máxima que se alcanza durante la compresión de dicho aire. Se comprueba en este caso que el aire ejerce un efecto colchón que amortigua el valor de la presión máxima. No obstante, tal y como se ha comentado anteriormente, a medida que se reduce la masa de aire atrapado con respecto a la masa de agua que debe frenar, los valores de presión alcanzados puede superar sobradamente los valores predichos por la fórmula de Allievi, (Figura 5.27).

En este mismo capítulo, además de aportar un modelo propio para analizar los transitorios hidráulicos con aire atrapado, se ha efectuado una revisión de los programas informáticos que ofrecen actualmente algunos fabricantes de ventosas. De esta revisión se desprende que existen fundamentalmente dos tipos de programas. Por un lado, existen los de carácter meramente descriptivo, en los cuales el usuario puede elegir la ventosa más adecuada en cuanto a la función que debe desempeñar, así como el tamaño recomendado. Estos programas ofrecen la posibilidad de indicar la ubicación idónea de la ventosa en el sistema de distribución de agua para que desempeñe del modo más conveniente su cometido. Por otro lado, se ofertan otro tipo de programas destinados al estudio de la evolución del transitorio con aire atrapado que se puede producir en las instalaciones de agua. Estos programas de cálculo resuelven las ecuaciones del modelo rígido mediante el método de las características y con ellos es posible simular la evolución de la presión y de la velocidad de la columna de agua introduciendo cualquier dispositivo de control adicional existente en la instalación.

Cabe decir que los programas descriptivos no calculan el transitorio producido utilizando ecuaciones para el cálculo de la presión y del caudal sencillas, que simplifican excesivamente fenómeno. Por otro lado los programas que calculan el transitorio, optan por las ecuaciones del modelo rígido, las cuales no tienen en cuenta la elasticidad del flujo y de la tubería, y no por las del modelo elástico, más completas, como en el caso propuesto en este trabajo. En estos programas se puede introducir cualquier elemento de la instalación, sin embargo no son capaces de realizar un análisis de sensibilidad que determine el mejor rango de valores de los parámetros característicos del evento. 


\section{DESARROLLOS FUTUROS}

A la vista de los resultados aportados por el presente trabajo, y una vez finalizado el análisis de los resultados obtenidos en el laboratorio y el estudio del transitorio hidráulico se propone diversas alternativas como investigaciones futuras.

En primer lugar, en cualquier investigación, se debe tener presente que antes de iniciar cualquier ensayo de laboratorio hay que asegurarse de que se dispone de los medios necesarios. Es fundamental contar con una buena instrumentación, con aparatos precisos y perfectamente calibrados. Uno de los problemas que ha impedido el completo análisis de las ventosas de diámetro nominal $50 \mathrm{~mm}$ ha sido precisamente la limitación en cuanto a respuesta en frecuencia del caudalímetro de 200 mm de diámetro.

La propuesta prioritaria para desarrollos futuros consiste en ensayar una ventosa con un diámetro determinado en dos instalaciones de las mismas características pero de diámetro diferente. El objetivo de tal propuesta es estudiar cómo afecta el tamaño en de la ventosa en los resultados finales del transitorio que se produce. Por ejemplo, concretando sobre el caso de estudio presentado en este trabajo hubiera sido interesante ensayar la ventosa de DN50 sobre la tubería de $500 \mathrm{~mm}$ de diámetro. Esta propuesta pretende completar el abanico de ensayos realizados durante este trabajo y que finalmente no fue posible llevar a cabo.

Siguiendo con la posibilidad de realizar cambios en la configuración de la instalación se propone estudiar una instalación que considere como mínimo dos puntos elevados, e instalar en ellos ventosas del mismo o de diferente diámetro nominal. Además, en el caso de disponer de suficiente espacio, se podría incluso instalar alguna ventosa en un punto intermedio de los tramos ascendentes o descendentes. Si los tramos ascendentes son de una longitud considerable, cabría entonces realizar un estudio de la separación idónea entre ventosas en dichos tramos y comprobar experimentalmente que las recomendaciones de la AWWA, indicadas en capítulos anteriores, son correctas.

Uno de los principales usos para los que se destinan las ventosas es para eliminar el aire que se puede introducir en la instalación debido al bombeo de la columna de agua. Las ventosas se sitúan en estos casos junto a las bombas, en las salidas de pozos o depósitos etc. Quedan pues por analizar diferentes situaciones de usos de ventosas que no se han tenido en cuenta en el presente trabajo.

Asimismo, sería positivo ensayar las ventosas en instalaciones reales con altos niveles de control de los ensayos que eviten posibles daños en la instalación y en los accesorios de la misma. 
Finalmente, en cuanto a ensayos prácticos se refiere, se propone realizar ensayos en instalaciones cuyas conducciones tengan la longitud suficiente para que se pueda considerar el cierre de la ventosa como un cierre rápido.

En cuanto al modelo teórico, es evidente que el modelo aquí presentado tiene ciertas limitaciones debido fundamentalmente a las hipótesis establecidas. Así pues, el modelo podría ser más complejo y tener en cuenta más factores y variables. Una posible mejora sería adoptar menos restricciones como el mantener un factor de fricción constante a lo largo de la tubería y del tiempo. El incluir en el modelo un factor de fricción variable a lo largo de la sección y del tiempo requiere un análisis complejo y detallado. El modelo podría ampliarse introduciendo algunas mejoras como la búsqueda del valor de ciertos parámetros, difíciles de determinar en la práctica, mediante la ayuda de otras técnicas conocidas, disponibles y aplicadas en distintos ámbitos de la ingeniería como los algoritmos genéticos o las redes neuronales. De este modo, se completaría y mejoraría el análisis de sensibilidad. 

CAPÍTULO 7. REFERENCIAS 

Abreu J., Cabrera E., García Serra J., Izquierdo J. Boundary between elastic and inelastic models in hydraulic transints analysis with entrapped air pockets.

Abreu J. De Almeida B. (2000) Pressure transient dissipative effects: a contribution for their computacional prediction. Proceedings $8^{\text {th }}$ Internacional conference on pressure surges-Safe design and operation of industrial pipe systems. pp 499-517.

Achard J.L., Lespinard J.M. (1981) Structure of the transient wall-law in one-dimensional models of laminar pipe flows. Journal of fluid mechanics. 113. pp 283-298.

Acosta A., (1999) Aire atrapado en tuberías. Consideraciones sobre el volumen crítico. $5^{\text {a }}$ Reunión Grupo de trabajo sobre hidromecánica. IAHR. IMFIA. Montevideo (Uruguay).

American water works association (2001) Air release, air/vacuum, and combination air valves. Manual of water supply practices M51. First edition.

Arlt H. (1983) Experimentelle untersuchungen ubre des instationäre, turbulente Reibungs verhalten bei aufgeprägten Druckimpulsen in einer rohrleitung mit kreisquerschnitt. Mitteilungsheft. No102, Institut für wasserbau und wasserwirtschaft, technische universität Berlin. Germany.

Arregui F., García-Serra J., Kruisbrink A.C.H., Cabrera E., Fuertes V., Palau V., Gascón L. Air valve dynamic behaviour. Pumps, electromechanical devices and systems applied to urban water management. ISBN 90-5809-560-6. Vol 2. pp 623-632. 
Baker P., Ramos H. (2000) Selection of transient analysis software for pipeline designtowards an European standard. Proceedings $8^{\text {th }}$ Internacional conference on pressure surges-Safe design and operation of industrial pipe systems. pp249-259.

Balutto A. (1996) The application of controlled air transfer technology to new and existing pipeline systems. www.ventomat.com

Barnea D., Shoham O., Taitel Y. (1980) Flow pattern transition for gas-liquid flow in horizontal and inclined pipes. International journal of multiphase flow. Pergamon press. Vol. 6. pp 217-225.

Bergant A., Simpson A., Vitkovsky J. Developments in unsteady pipe flow friction modelling. (2001) Journal of hydraulic research, Vol 39, No 3, pp 249-257.

Bergant A., Tijsseling A. (2001) Parameters affecting water hammer wave attenuation, shape and timing. $10^{\text {th }}$ International meeting of the work group on the behaviour of hydraulic machinery under steady oscillatory conditions IAHR.

Bergant A., Tijsseling A., Vitkovsky J., Covas D., Simpson A., Lambert M. Further investigations of parameters affecting water hammer wave attenuation, shape and timing. Part 1: Mathematical tools. Trodheim, Norway.

Bergant A., Arregui F., Kruisbrink A. (2004) Column separation measurements in a largescale experimental apparatus. $9^{\text {th }}$ International conference on pressure surges. BHRG. Chester. England. ISBN 1855980517

Betamio de Almeida A., Koelle E. (1992) Fluid transients in pipe networks. Computational mechanics publications. Elsevier applied science. Southampton. United Kingdom. ISBN 1 562520962.

Borga A., Ramos H., Covas D., Dudlick A., Neuhaus N. (2004) Dynamic effects of transients flows with cavitation in pipe systems. Proceedings of the $9^{\text {th }}$ International conference on pressure surges. BHRG. Chester. England. pp 605-617.

Brekke H. (1984) A stability study on hydropower plant governing including the influence from a quasi-nonlinear damping of oscillatory flow and from the turbine characteristics. PhD Thesis. NTH Trodheim, Norway.

Brown F.T. (1984) On weighting functions for the simulation of unsteady turbulent flow. Forum on unsteady flow. ASME. New Orleans. USA. FED-Vol. 15. pp 26-28. 
Brunone B., Golia U.M., Greco M. (1991) Some remarks on the momentum equation for fast transients. International meeting on hydraulic transients with column separation, $9^{\text {th }}$ Round table. IAHR Valencia. Spain pp 140-148.

Bughazem M.B., Anderson A. (1996) Problems with simple models for damping in unsteady flow. International conference on pressure surges and fluid transients BHR Group, Harrogate, England. pp 537-548.

Burrows R., Qiu D. (1995) Effects of air pockets on pipeline surge pressure. Proceedings of the institution of civil engineers. Journal of water, maritime and energy. Vol. 112. Paper 10859. pp 349-361.

Cabrera E., Abreu J., Pérez R., Vela A. (1992) Influence of liquid length variation in hydraulic transients. Journal of hydraulic engineering. ASCE. pp 1639-1650.

Cabrera E., Fuertes V.S., García-Serra J., Iglesias P., Izquierdo J. (1997) Ilenado de tubería con aire atrapado. Ingeniería del agua. Vol. 4.

Cabrera E., Fuertes V.S., García-Serra J., Arregui F., Gascón L., Palau V. (2003) Reviewing air valve selection, IAHR-IWA Pumps electronic devices and systems conference.

Campbell A. (1983) The effect of air valves on surge in pipelines. International conference on pressure surges. University of Bath, England.

Carstens M.R., Roller J.E. (1959) Boundary shear stress in unsteady turbulent pipe flow. Journal of hydraulics division. ASCE 85(HY2) pp 67-81.

Cocchi G. (1988) Esperimeto sulla resistenza al deflusso con moto vario in un tubo. Atti della Academia delle Scienze dell' Instituto di Bologna. Bologna. Italia. 14(5) pp 203-210.

Covas D., Graham N., Maksimovic C., Kapelan Z., Savic D., Walters G. (2003) An assessment of the application of inverse transient analysis for leak detection: Part IICollection and application of experimental data, proceedings of computer control for water industry (CCWI), advances in water suplí management. London (U.K.) pp 79-87.

Daily W.L., Hankey W.L., Olive R.W., Jordaan J.M. (1956) Resistance coefficients for accelerated and decelerated flows through smooth tubes and orifices. Transactions of ASME, 78. pp 1071-1077. 
Dawson P., Fox J. (1983) Surge analysis and supresión techniques for a water supply scheme - a case study. Transactions of the institute of measurement and control. Vol. 5. Issue 4. pp 134-142.

De Martino G., Fontana N., Giugni M. (2003) Pressure surges in water systems caused by air venting. Pumps, electromechanical devices and systems applied to urban water management. ISBN 90-5809-560-6. Vol 2. pp 641-668.

Duckler A., Taitel Y. (1977) Flow regime transitions for vertical upward gas liquid flow: A preliminary approach through physical modelling. Progress report No. 1. University of Houston. NUREG-0162.

Driskell L. (1969) Hydrocarbon Processes. p131.

Eichinger P., Lein G. (1992) The influence of friction on unsteady pipe flow. Proceedings International conference on unsteady flow and fluid transients. Durham. England. pp 4150.

Falk K., Gudmundsson J. (2000) Waterhammer in high-pressure multi-phase flow. Proceedings $8^{\text {th }}$ Internacional conference on pressure surges - Safe design an operation of industrial pipe systems. pp 41-54.

Falvey H.T. (1980) Air-water flow in hydraulic systems. Bureau of reclamation. Engineering monograph No. 41.

Fuertes V.S., Arregui F., Cabrera E., Iglesias P.L. (2000) Experimental setup of entrapped air pockets model validation. $8^{\text {th }}$ International conference on pressure surges-safe design and operation of industrial pipe systems. pp 635-644.

Fuertes V.S. (2001) Transitorios hidráulicos con aire atrapado. Tesis doctoral. Universidad politécnica de Valencia.

Fujii T., Akagawa K. (2000) A study of water hammer phenomena in a one-componenet two-phase bubbly flow. JSME. Internacional journal series B-fluids and termal engineering. Vol. 43. Pt 3. pp 386-392.

Funk J.E., Wood D.J. (1970) A boundary-layer theory for transient viscous losses in turbulent flow. Journal of basic engineering. ASME 92(4) pp 865-873.

Golia U.M. (1990) Sulla valutazione delle forze resistente nel colpo d'ariete. Report n. 639. University of Naples. Italy. 
Hansen E. (1986) Two phase flows in pipelines and risers. Series paper 40. Institute of hydrodynamics and hydraulic engineering. Technical university of Denmark.

Hino M., Sawamoto M., Takasu S. (1977) Study on the transition to turbulence and frictional coefficient in an oscillatory pipe flow. Transactions of JSCE, 9, pp 282-284.

Huygens M., Verhoeven R., Van Pocke L. (1998) Air entrainment in water hammer phenomena. Advances in fluid mechanics II. Vol. 21. pp 273-282.

Iglesias P.L., Fuertes V., Andreu M. (1995) Sistemas de protección indirecta. Transitorios y oscilaciones en sistemas hidráulicos a presión. $1^{\text {a }}$ Edición. ISBN 84-600-9146-5. Capítulo 11.

ISA Transactions (1970) Vol. 9, № 4.

Ishii M., Mishima K. (1980) Study of two-liquid model and interfacial area. Argonne national laboratory. ANL-80-111. NUREG/CR-1873.

Jonsson L. (1985) Maximum transient pressures in a conduit with check valve and air entrainment. International conference on the hydraulic of pumping stations. Manchester. pp 55-76.

Kagawa T., Lee I., Kitagawa A., Takenaka T. (1983) High speed and accurate computing method of frequency-dependent friction in laminar pipe flow for characteristics method. Transactions of JSME, 49 (447) pp 2638-2644.

Kompare B. (1995) The use of artificial intelligence in ecological modelling. PhD Thesis University of Ljubljana, Slovenia.

Kruisbrink A.C.H., Arregui F., Carlos M., Bergant A. (2004) Dynamic performance characterisation of air valves. $9^{\text {th }}$ International conference on pressure surges. Chester. England. ISBN 1855980517

Kurokawa J., Morikawa M. (1986) Accelerated and decelerated flows in a circular pipe. Bulletin of JSME, 29 (249) pp 758-765.

Lauchlan C.S:, Escarameia M., May R.W.P., Burrows R., Gahan (2005) Air in pipelines. A literatura review. C. Report S R 649, Rev 2.0. HR Wallingford 
Lee T. (1994) Numerical modelling and computation of fluid pressure transients with air entrainment in pumping installations. Proceedings of the Internacional journal for numerical methods in fluids. Vol 19. Issue 2. pp 89-103.

Lee T., Low H., Weidong H. (2003) The influence o fair entrainment on the fluid pressure transients in a pumping installation. Internacional journal of computacional fluid dynamics. Vol. 17. Pt5. pp 387-403.

Leow L.C., Lee T.S. (1998) Effects of air valve on pressure surges during pumping trip in pumping station. Proceedings of the XIX IAHR Symposium on hydraulic machinery and cavitation. Vol 1, Vol. 2. pp 556-563.

Lescovich J.E. (1972) Locating and sizing air release valves. J. AWWA. 64(7) pp 457-461.

Low H.T., Lee T.S. (1998) Fluid pressure transients with air entrainment. Proceedings of the XIX IAHR Symposium on hydraulic machinery and cavitation. pp 656-664.

Martin C.S. (1976) Entrapped air in pipelines. BHRA. Proc $2^{\text {nd }}$ International conference on pressure surges. Bedford, England.

Nalluri C., Featherstone R. (2001) Civil engineering hydraulics. $4^{\text {th }}$ Edition. Blackwell science. United Kingdom.

Ohmi M, Kyomen S., Usuy T. (1985) Numerical analysis of transient turbulent flow in a liquid line. Bulletin of JSME, 28(239) pp 799-806.

Parmakian J. (1955) Waterhammer analysis. Prentice Hall Inc. Englewood Cliffs, N.J.

Pezzinga G. (1999) Quasi-2D model for unsteady flow in pipe networks. Journal of hydraulic engineering. ASCE 125(7) pp 676-685.

Prado A., Larreteguy A:E. (2002) A transient shear stress model for the analysis of laminar water-hammer problems. Journal of hydraulic research. Vol. 40.

Pyng Liou C., Hunt W.A. (1996) Filling of pipelines with undulating elevation profiles. Journal of hydraulic engineering. Vol. 122. No. 10, pp 534-539.

Reader R.A., Kennard M.F., Hay J. (1997) Valves, pipework and associated equipment in dams-guide to condition assessment. CIRIA Report 170. CIRIA. Pp160.

Rocha M., Andrade J., Luvizotto E. (1999) El factor de fricción en el transitorio. $5^{\text {a }}$ Reunión Grupo de trabajo sobre hidromecánica. IAHR. IMFIA. Montevideo (Uruguay) 
Rouhani S.,Sohal M. (1983) Two-phase flow patterns: a review of research results. Progress in nuclear energy. Vol 11. No 3. pp 219-259.

Safwat H.H., Van der Polder J. (1973) Friction-frequency dependence for oscillatory flows in circular pipes. Journal of the hydraulics division. ASCE 99. (HY11) pp1933-1945.

Scholh G.A. (1993) Improved approximate method for simulating frequency-dependent friction in laminar liquid pipe flow. Journal of fluids engineering. ASME. 113(4) pp420424.

Sheldon T. (1998) Air management in water distributions systems. Clear Water Legacy, Burlington, Ontario, Canada

Shuli W., Zhuo L., (2003) Water hammer phenomena in gas-water two-phase bubbly flow through a 90-degree bend tube. Journal of fluids engineering. Vol. 125, pp 736-739.

Shuy E. (1995) Approximate wall shear equation for unsteady laminar pipe flows. Journal of hydraulic research. IAHR 33(4) pp 457-469.

Silva-Araya W., Chaudry M. (1997) Computation of energy dissipation in transient flow. Journal of hydraulic engineering. ASCE 123(2) pp 108-115.

Stephenson D., (1997) Effects of air valves and pipework on water hammer pressures. Journal of transportation engineering Vol. 123, No. 2, pp 101-106.

Stewardson D., Brunone, Ferrante M. (2000) Using experimental design to determine transient pressure behaviour. Proceedings $8^{\text {th }}$ International conference on pressure surgesSafe design and operation of industrial pipe systems. Pp 611-623.

Suzuki K., Taketomi K., Sato S. (1991) Improving Zielke's method of simulating frequencydependent friction in laminar liquid pipe flow. Journal of fluids engineering. ASME 113(4) pp 569-573.

Svingen B. (1997) Rayleigh damping as an approximate model for transient hydraulic pipe friction. Proceedings $8^{\text {th }}$ International meeting on the behaviour of hydraulic machinery under steady oscillatory conditions. IAHR Chatou. France. Paper F-2.

Taitel Y., Duckler A. (1976) A model for predicting flow regime transition in horizontal and near horizontal liquid flow. AIChE, Journal. Vol. 22. No 1. pp 47-55. 
Thorley A.R:D., Main B.G. (1986) Spontaneous combustion in vapour cavities subjected to fluid transients in pipelines. $5^{\text {th }}$ BHRA International conference on pressure surges. Hannover. pp 139-149.

Thorley A.R:D., Enever K. (1979) Control and suppression of pressure surges in pipelines and tunnels. CIRIA Report 84. CIRIA United Kingdom.

Thorley A.R:D., Spurret R.P. (1990) Cavity dynamics and the risk of explosive combustion in pipelines. $6^{\text {th }}$ BHRA International conference on pressure surges. Cambridge. pp 139149.

Thorley A.R:D. (1991) Fluid transients in pipeline systems. D and L George. United Kingdom.

Trikha A.K. (1975) An efficient method for simulating frequency-dependent friction in transient liquid flows. Journal of fluid engineering. ASME 97(1) pp 97-105.

Van Vuuren S.J. (2001) The importance of the correct sizing and location of air valves. Pump and valve summit.

Vardy A. (1992) Approximating unsteady friction at high Reynolds numbers. Proceedings International conference on unsteady flow and fluid transients. Durham. England. pp 2129.

Vardy A., Hwang K. (1991) A characteristics model of transient friction in pipes. Journal of hydraulic research. IAHR. 29(5) 669-684.

Vardy A., Hwang K., Brown J. (1993) A weighting function model of transient turbulent pipe flow. Journal of hydraulic research. IAHR 31(4) pp 533-548.

Vennatro B. (1996) Unsteady friction in pipelines. Proceedings XVIII IAHR Symposium on hydraulic machinery and cavitation. Valencia. Spain. Vol 2. pp 819-826.

Vennatro B. (1998) Oscillating flow in pipelines. Proceedings XIX. IAHR Symposium on hydraulic machinery and cavitation. Singapore. Vol. 2. pp 694-702.

Whiteman K., Pearsall I. (1959) Reflux valve and surge tests at Kingston pumping station. BHRA. National engineering laboratory. Glasgow. Joint repport 1.

Whiteman K., Pearsall I. (1962) Reflux valve and surge tests at a station. Fluid handling. XIII. pp 248-250. pp 282-286. 
Willis J. (1990) Design and positioning of air valves. South African institution of civil engineers.

Wood D., Funk J., (1970) A boundary-layer theory for transient viscous losses in turbulent flow. Journal of basic engineering. ASME. 92(4) pp 865-873.

Wylie E., Streeter V. (1978) Fluid transients. McGraw-Hill International book. company. New Cork. Pp 384.

Wylie E. (1984) Simulation of vaporous and gaseous cavitation. Journal of fluid engineering. ASME. 106(3) pp 307-311.

Yigang C., jing-Chao S. (1989) An efficient approximate expression for transient flow or high viscous fluid in hydraulic pipelines. Proceedings $6^{\text {th }}$ International conference on pressure surges. BHRA Cranfield, England. pp 349-356.

Zarzycki Z. (1997) Hydraulic resistance of unsteady turbulent liquid flow in pipelines. Proceedings $3^{\text {rd }}$ International conference on water pipeline systems. BHR Group. The Hague. The Netherlands. Pp 163-178.

Zhou F. (2000) Effects of trapped air on flow transients in rapidly filling sewers. PhD thesis, Water Resources Engineering. Department of civil and environmental engineering. University of Alberta. Canada.

Zhou F., Hicks F., Steffler P. (2002) Observations of air-water interaction in a rapidly filling horizontal pipe. Journal of hydraulic engineering. Vol.128, No. 6, pp 635-639.

Zhou F., Hicks F., Steffler P. (2004) Analysis of effects of air pocket on hydraulic failure of urban drainage infrastructure. NRC Research press web site http://cjce.nrc.ca. Canadian journal of civil engineering, 31, pp 83-94.

Zielke W. (1968) Frequency-dependent friction in transient pipe flow. Journal of basic engineering. Transactions of ASME.90(1) pp 109-115.

Zielke W., Perko H. (1985) Unterdruckerscheinungen und druckstoberechnung. 3R international 24(7). pp 348-355. 
http://www.arivalves.com/

http://www.apcovalves.com/

http://www.bentley.com/en-US/Products/HAMMER/

http://www.charlatte.com/

http://cjce.nrc.ca

http://www.gavalves.co.uk/

http://www.glenfield.co.uk

http://www.irua.es/

http://www.ventomat.com/

http://www.wldelft.nl/ 

